\title{
DEPOLITICIZING AND HUMANIZING CLIMATE CHANGE THROUGH A PUBLIC HEALTH FRAME \\ A CASE STUDY OF ONTARIO'S CLIMATE CHANGE POLICY DISCOURSE
}

By

\author{
Luckrezia Awuor, \\ BASc. Ryerson University, 2014 \\ A Dissertation \\ presented to Ryerson University \\ in partial fulfillment of the \\ requirements for the degree of \\ Doctor of Philosophy \\ in the program of \\ Environmental Applied Science and Management
}

Toronto, Ontario, Canada, 2020

Ryerson University

(C) Luckrezia Awuor, 2020 


\section{AUTHOR'S DECLARATION}

I hereby declare that I am the sole author of this dissertation. This is a true copy of the dissertation, including any required final revisions, as accepted by my examiners.

I authorize Ryerson University to lend this dissertation to other institutions or individuals for the purpose of scholarly research.

I further authorize Ryerson University to reproduce this dissertation by photocopying or by other means, in total or in part, at the request of other institutions or individuals for the purpose of scholarly research.

I understand that my dissertation may be made electronically available to the public. 


\section{DEPOLITICIZING AND HUMANIZING CLIMATE CHANGE THROUGH A PUBLIC HEALTH FRAME: A CASE STUDY OF ONTARIO'S CLIMATE CHANGE POLICY DISCOURSE}

\section{Doctor of Philosophy - Environmental Applied Science and Management}

Luckrezia Awuor; June 2020

The relevance of a public health frame in supporting the climate change impact awareness and consensus on actions is well recognized but largely underutilized. Overall, supporting public health's capacity in climate change has focused on projecting and highlighting public health impacts due to climate change, identifying public health policy responses, and emphasizing public health role. The integration of the public health perspective in the discussion and communication of climate change ideas has remained elusive.

Climate change is also a complex social problem whose construction of meaning and actions is rooted in institutionalized language, discourse, and human interactions. Thus, understanding of the construction of the relevance of public health in climate change discourse is central to understanding the impediments of the public health frame application. Unfortunately, this has been a neglected area of research, and the dissertation responded to that gap.

To delineate the impediments of the public health frame, the study used the case study of the context of climate change policy discourse in the Province of Ontario (Canada) to examine the construction of public health relevance, the extent of public health frame application, and the systematic influences in the discourse.

The analysis of policy documents and key informant interviews revealed that the public health frame remained isolated from the primary focus of Ontario's climate change policy discourse. Instead, Ontario's historically and socially constructed climate change as an economic and political issue solved through market strategies and technological innovations forwarded by political, bureaucratic, and technological elites. The focus substantiated the types of structures and processes of policies and decisions, the relevant actors and knowledge, and the values supporting the discursive, normative, and strategic practices. Ontario's focus also limited the utilization of the public health frame and the supporting capacities through the misalignment between public health and the provincial strategic actions, the lack of recognition and integration 
of public health roles, mandate and structures, and limited public health capacity building initiatives.

Therefore, public health framing as an endpoint of climate change discourse requires legitimation of public health in the underlying institutional structures for, and governance of, climate change. 


\section{ACKNOWLEDGEMENTS}

The completion of this dissertation would not have been possible without the personal and professional support of so many people.

First, I wish to express my sincere appreciation to my supervisors, Dr. Richard Meldrum and Dr. Eric Liberda, who guided and mentored me to be the professional I am today. Your expertise, input, wisdom, and relentless determination to support my studies and research are reflected in both my academics and profession. May every student you mentor have the luxury to experience your leadership and professionalism. I am forever grateful!

I wish to acknowledge and recognize my dissertation committee, Dr. Chris Gore, Dr. Jordan Tustin, Dr. Andrew Papadopoulos and Dr. Dancun McLelland, for the significant insights and feedback on the dissertation. To Dr. Gore, without the countless consultations you have accorded me through years, the design and the policy needs of this dissertation would not have been the same. Most importantly, thank you for introducing to public policy. To Dr. Tustin and Dr. Papadopoulos, thank you for providing the public health and methodological insight relevant to this study. To Dr. McLelland, thank you for providing the policy and political understandings of my dissertation.

I truly appreciated Ryerson University, Yeates School of Graduate Studies, the Environmental Applied Science and Management Program, and the School of Occupational and Public Health for providing the physical, technical and financial contribution for supporting my graduate studies goals.

To all the participants across Ontario's ministries and the public health sector, thank you for taking me on an incredible journey of learning. Your knowledge, insights, and time are greatly appreciated.

I would also like to acknowledge the enormous assistance and encouragement provided by Dr. Melles, Dr. Pushchak, Rhonda, and Fatima. Thank you all for your support.

Finally, I wish to express my deepest gratitude and acknowledge the support and great love of my family, specifically my husband Calvin and my son CJ. Calvin, you cheered me every step of the way even when I was giving up. You believed in me more than I believed in myself. May the sacrifices you made for my success be your future rewards! CJ, you are always my source of inspiration. Mama is done now, and yes, you can now call me Dr. Mama! Let's design that STU rocket now! 


\section{DEDICATION}

To my Habibi Calvin and CJ, for your unconditional love, support, and belief in my dream. Our journey continues!

In Memory of my mum, Francesca, you inspired me to live a purpose-driven life and your passion for us to succeed has been my foundation. I wish you were here to witness the accomplishments, but I know you are watching from above! 


\section{Table of Content}

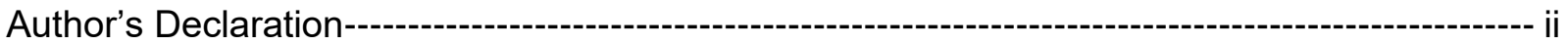

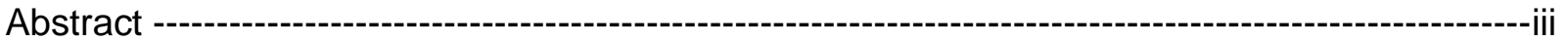

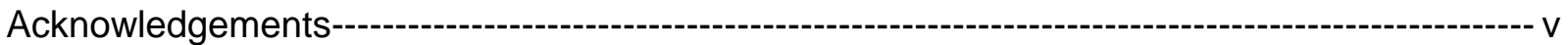

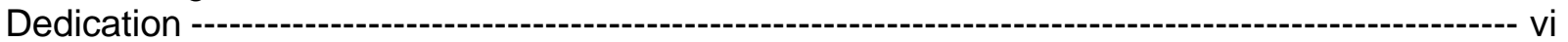

List of Tables-------

List of Figures-----

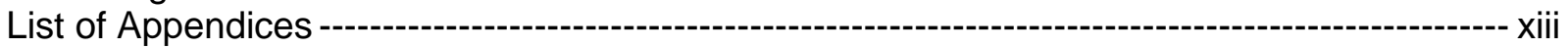

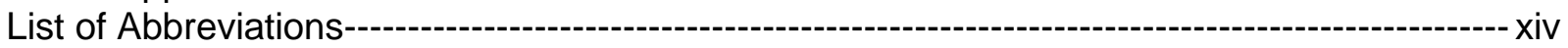

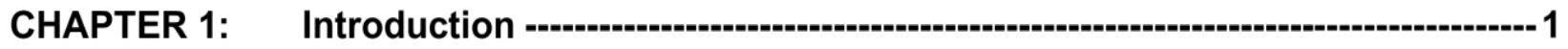

1.1 Context of the Study----- 1

1.1.1 A Call for Public Health Engagement and Leadership --

1.1.2 The Need for the Study ---:-

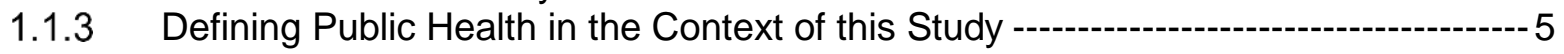

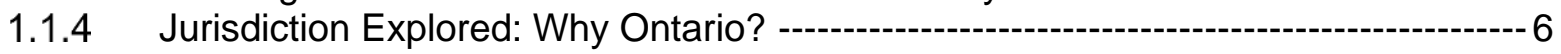

1.2 Aims and Objectives --- 9

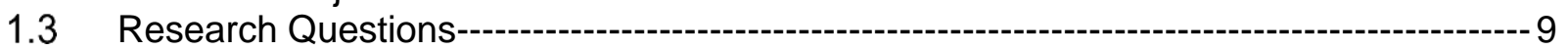

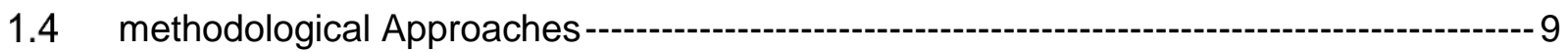

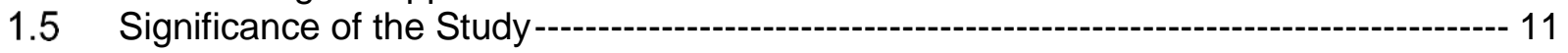

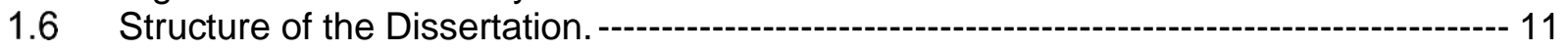

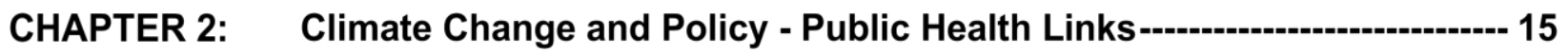

Introduction----

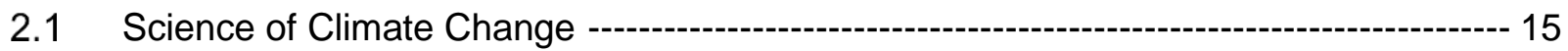

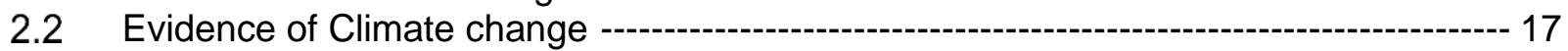

2.2.1 Evidence of Climate change in Ontario ---

2.2.2 Human Health Impacts and Vulnerabilities in Ontario------------------------- 19

2.3 Public Policy and the Climate Change Policy Responses------------------------------- 27

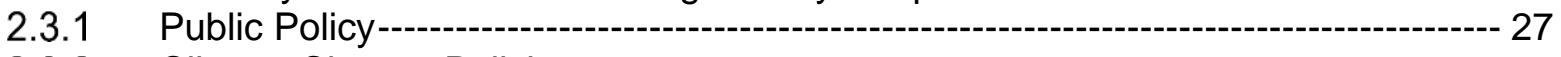

2.3.2 Climate Change Policies ---

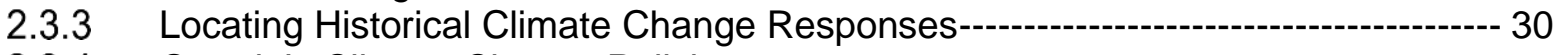

2.3.4 Ontario's Climate Change Policies-----.----- 31

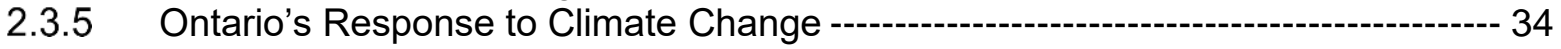

2.4 Summary--- 40

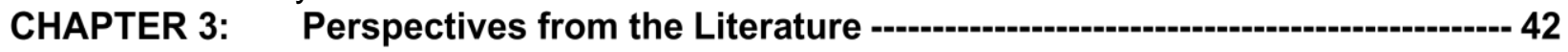

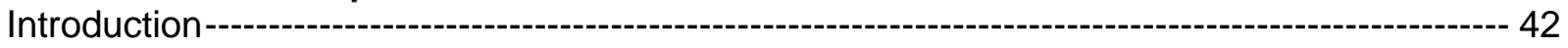

3.1 Deliberating on Climate Change Impacts and Policies ------------------------ 43

3.1.1 Framing-------- 44

3.1.2 Climate Change Frames ------

3.2 Literature Exploring The Relevance of a Public Health Framed Climate Change Policy 47

3.2.1 Risk Perceptions -- 47

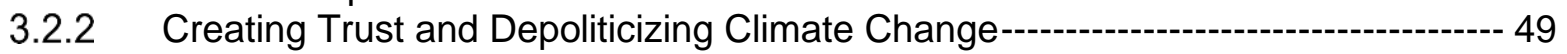

3.2.3 Moral Justification for Action --:--:--- 51

3.2.4 Highlighting Health Co-benefits of Actions------ 52

3.3 Literature on Discursive Formation, Social Construction, and Social Meanings ------- 53

3.3.1 Discursive Strategies for Understanding the Influence of Language on Public

Health Framed Climate Change Policy discourse ------------------------------------ 55

3.3.2 Philosophical Paradigms for Exploring Climate Change Discourse------------------ 59

3.3.3 Theoretical Perspectives of the Social Construction of Climate Change ---------- 62 


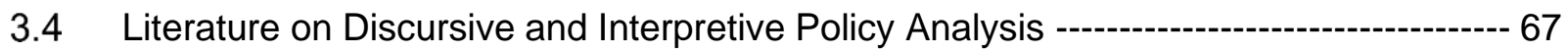

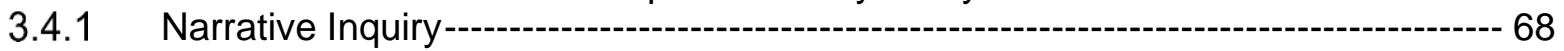

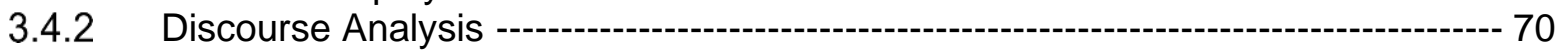

3.4.3 Analyzing Institutional Context Shaping Meanings and Discourses --------------- 73

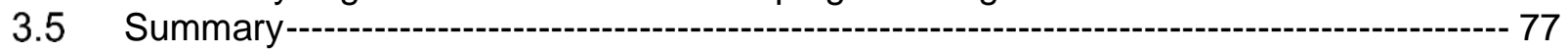

CHAPTER 4: Research Methodology - 79

Introduction------.-- 79

4.1 Research Design------- 79

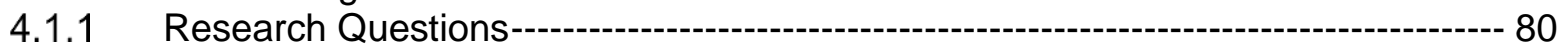

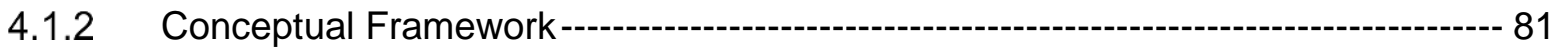

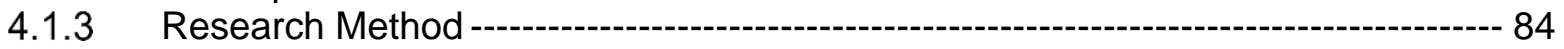

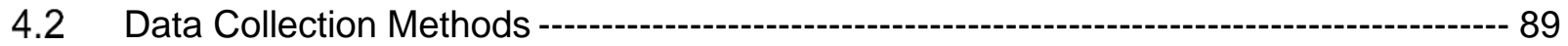

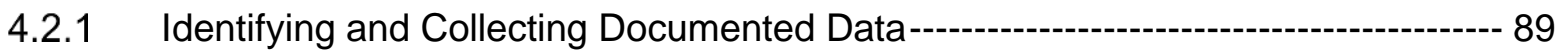

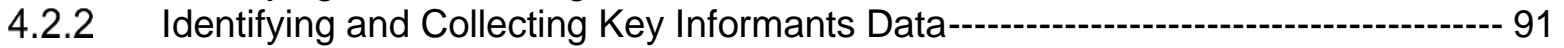

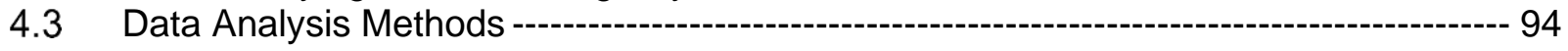

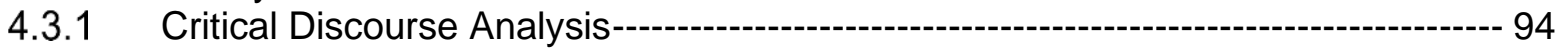

4.3.2 Thematic Analysis ------- 98

4.4 Summary-------

CHAPTER 5: features of the Policy Document and Key Informant Interviews --------101

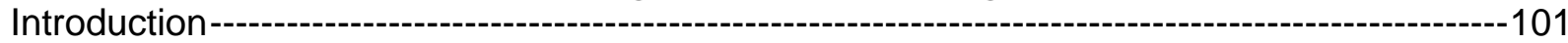

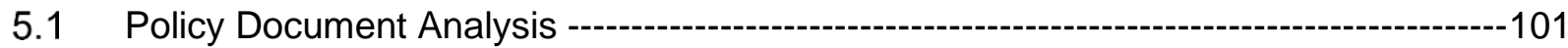

5.2 Key Informants ------on

5.3 Cluster Analysis -----on

5.4 Coding of Themes ---on

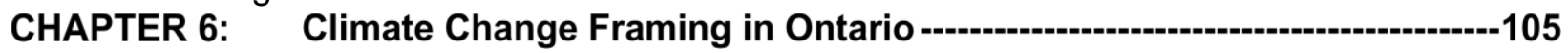

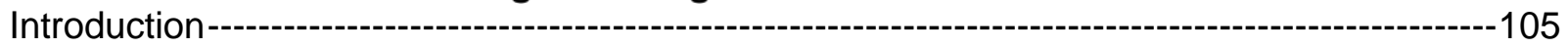

6.1 Framing of Climate Change In Ontario ----

6.2 Historical and Systematic Context of Climate Change Frames ------------------106

6.3 Discursive Strategies Advancing the Climate Change Frames ------------------107

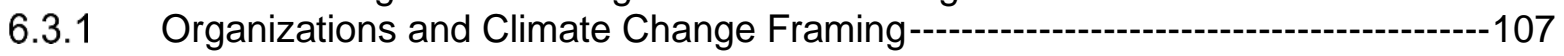

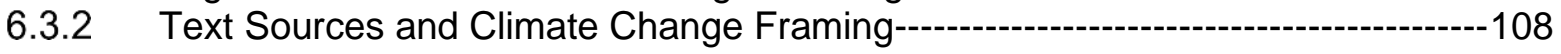

6.3.3 The Ambiguity of the Public Health Framing -----on

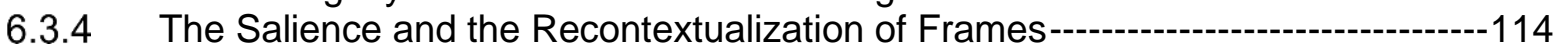

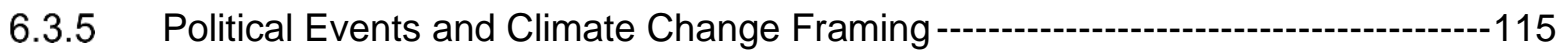

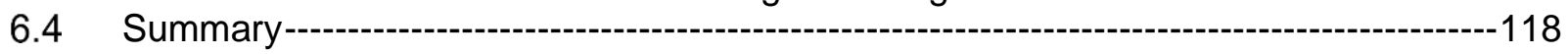

CHAPTER 7: Institutional Arrangements at the Provincial Level----:-a-------120

Introduction----------------120

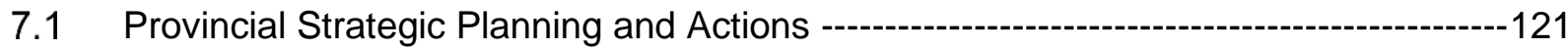

7.2 Agency on Climate----

7.2.1 Mandate on Climate Change----------ons

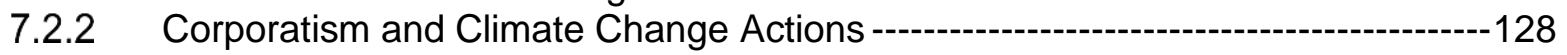

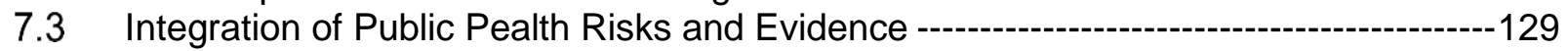

7.3.1 Health Impacts Identified ---

7.3.2 Agencies' Consideration of Public Health Evidence -------------------------130

7.4 Influence of the Constitution Powers ---_ed

7.5 Summary----------139

CHAPTER 8: Public Health-Specific Institutional Arrangements -----:--:-------141

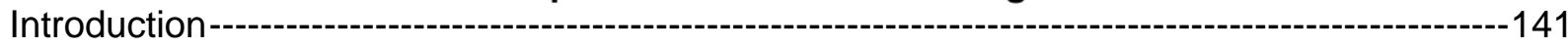

8.1 Public Health Strategic Approach to Climate Change-------------------------141

8.1.1 A Focus on Adaptation ---

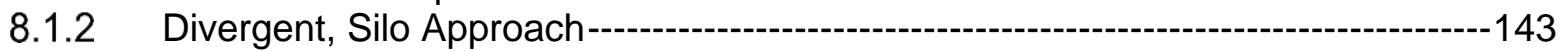




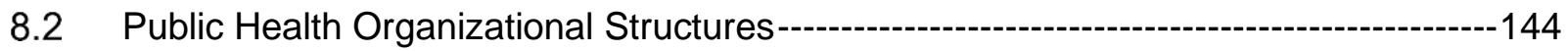

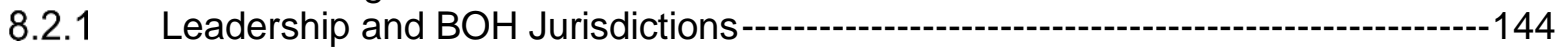

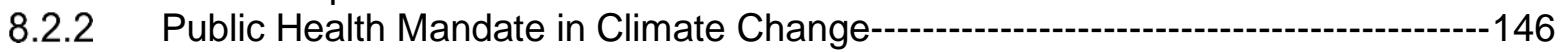

8.3 Public Health Resources ---

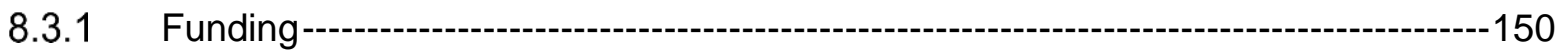

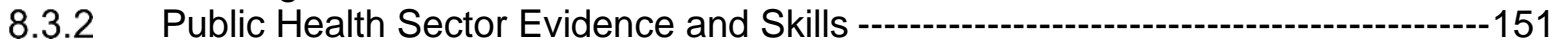

8.3.3 Surveillance as an Approach to Gathering and Disseminating Evidence----------157

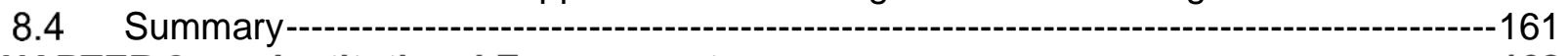

CHAPTER 9: Institutional Engagements---162

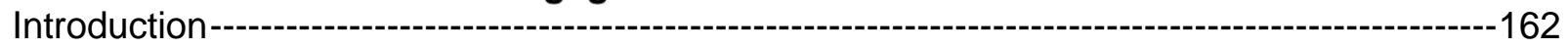

9.1 Fostering Institutional Engagements ------------on

9.2 Influences on Institutional Engagements ---

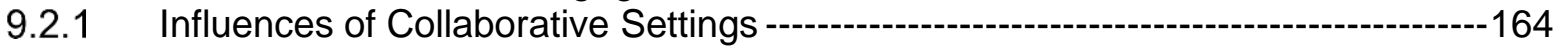

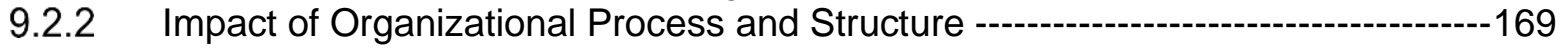

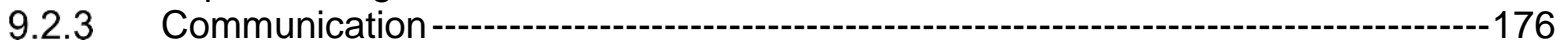

9.3 Effects of Interorganizational Engagements on Institutional Capacities -----------180

9.4 Summary-----on-

CHAPTER 10: Perspectives on the Climate Change-Public Health Nexus ----------186

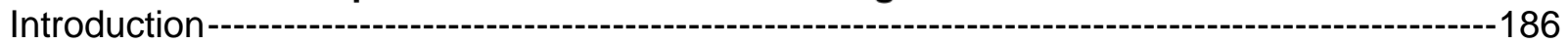

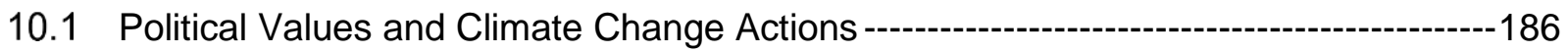

10.1.1 Convergence and Divergence of Political and Partisan Norms ---------------186

10.1.2 Participant's Perspectives on Ontario's Political Approaches to Climate Change

and Public Health Prioritization -----------------------------------------------189

10.2 Perceptions on Public Health's Role, leadership and Inclusion-----------------------192

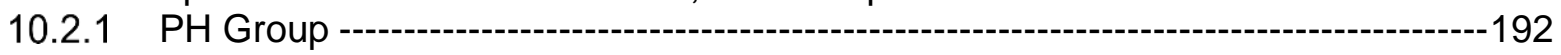

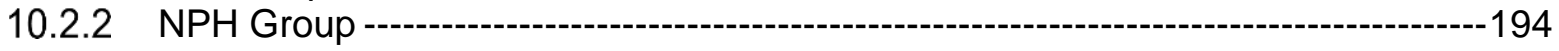

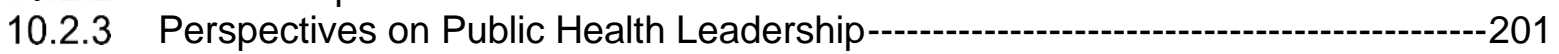

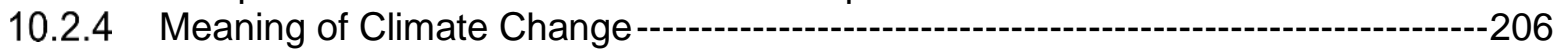

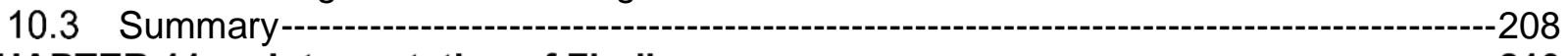

CHAPTER 11: Interpretation of Findings --.

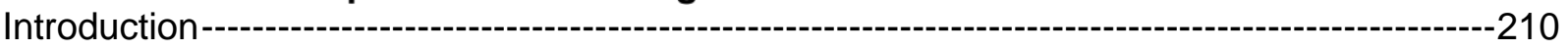

11.1 Ontario's Climate Change Framing, Strategic Influences, and Social Contexts -------210

11.1.1 Discourse --------------------------------------------------------213

11.1.2 Strategic and Communicative Discourses --------------------------------216

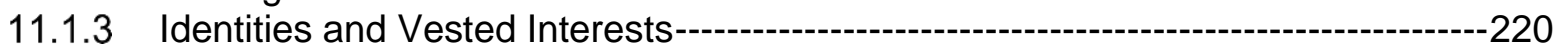

11.2 Systemic Factors Influencing Public Health Capacities in the Discourse--------------223

11.2.1 Contexts of Political Power and its Impediments on Public Health Framing ------224

11.2.2 Lack of Integration of Public Health Needs and Knowledge in Climate Change

Decisionmaking Processes--------------------------------------------------227

11.2.3 Institutional Engagement Practices and Barriers to Public Health Capacity in

Advancing Public Health Framed Policy Discourse--------on

11.3 Addressing Criticisms and Limitations of the Study--------------------------235

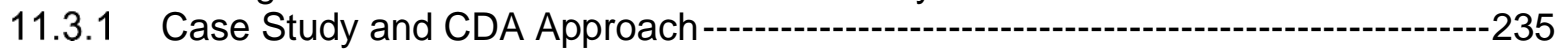

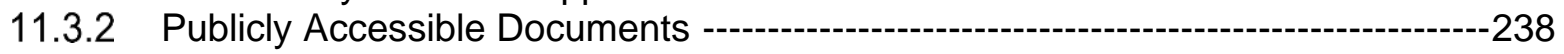

11.3.3 Research Participation-----------------------------------------239

11.3.4 Challenges of Discourse Analysis--------------------------------239

11.3.5 Structure of Public Health in Ontario and Analytical Generalizability -------------240

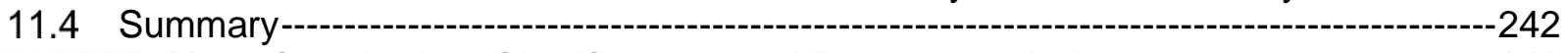

CHAPTER 12: Conclusion, Significance, and Recommendations ---:--:--:------243

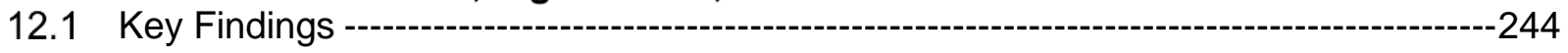

12.2 Significance, Contributions, and Future Directions --- 
12.2.1 A Framework for Public Health Framed Climate Change Policy Discourse-------245

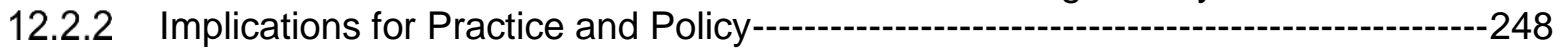

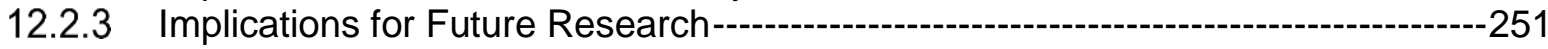

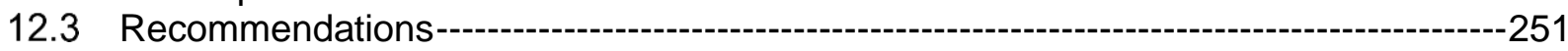

12.3.1 Recommendation 1: Incorporate democratic climate change policy approaches engagements that support the inclusion of public health inclusion----------------------251

12.3.2 Recommendation 2: Advance public health leadership and advocacy in climate change policy discourse-------------

12.3.3 Recommendation 3: Advance a health-in-all-policy approach ----------------------253

12.3.4 Recommendation 4: Support public health capacity and mandates with access to

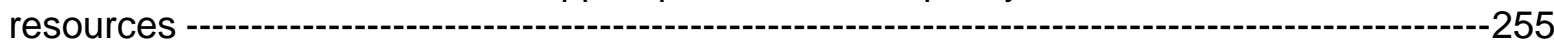

12.3.5 Recommendation 5: Create public health governance structures that promote equitable access to resources and capacity to act on climate change---------------257 12.3.6 Recommendation 6: Develop communication resources for advancing public health's role in climate change awareness and education -------------------258

12.3.7 Feasibility and Limitations of Recommendations---

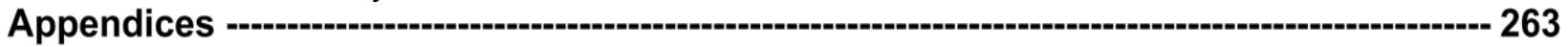

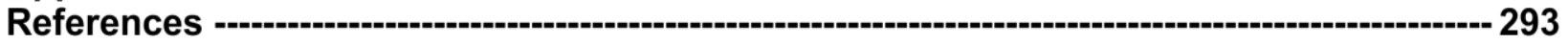




\section{LIST OF TABLES}

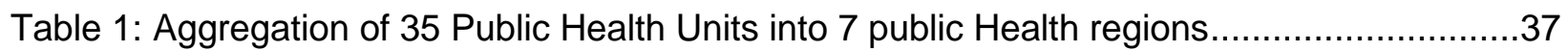

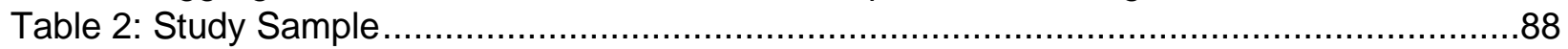

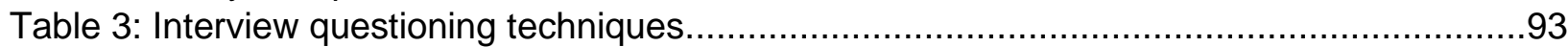

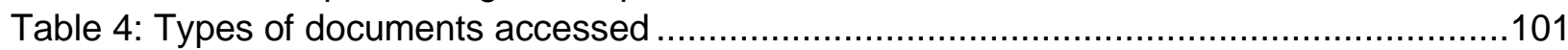

Table 5: Characteristics of data sources by organization ...............................................102

Table 6: Participation solicitation, response and retention ...........................................103

Table 7: Ambiguity of terms................................................................................ 112

Table 8: The strategic positioning of climate change frames in policy texts .........................117

Table 9: Sources of evidence informing climate change decisions at the provincial level ........131

Table 10: Ministries' use of decision support tools, as described by NPH participants ...........135

Table 11: Sources of evidence for climate change decisions within public health..................151

Table 12: Barriers to public health evidence generation .................................................152

Table 13: Public health capacities and boundary processes ..........................................156

Table 14: Summary of stakeholder collaboration reported ............................................163

Table 15: Structures for stakeholder identification ......................................................... 165

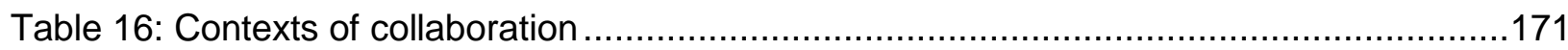

Table 17: Impacts of engagements on public health's capacities ....................................182

Table 18: Why public health does not have a role in mitigation .........................................193

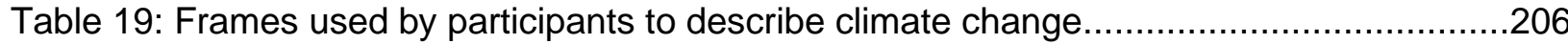

Table 20: influences of power on public health role and framing .....................................225

Table 21: Summary of the application of reliability and validity in the research process ..........236 


\section{LIST OF FIGURES}

Figure 1: Public health's unique position in addressing climate change health impacts ............ 6

Figure 2: Map of Canada depicting the 10 provinces and 3 territories ................................... 7

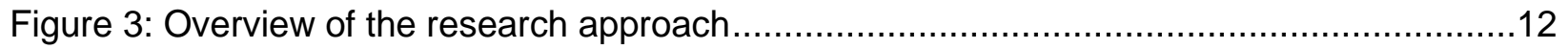

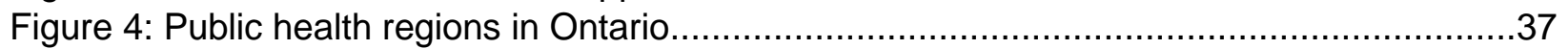

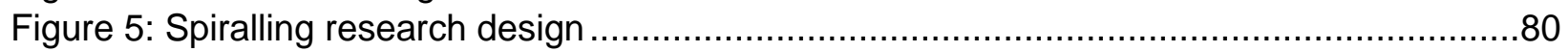

Figure 6: Logic model of the relevance of public health framing in climate change..................82

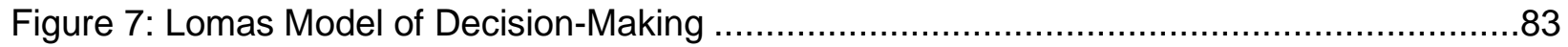

Figure 8: Philosophical and theoretical underpinnings and assumptions guiding the study .......85

Figure 9: Conceptual framework for critical discourse analysis ..........................................95

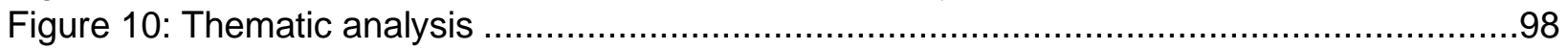

Figure 11: Dendrogram comparing word similarities between PH and NPH groups ...............104

Figure 12: Framing of climate change in Ontario .............................................................

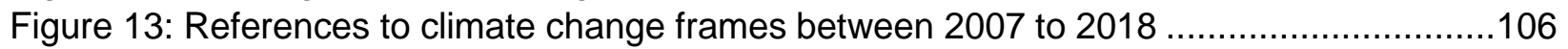

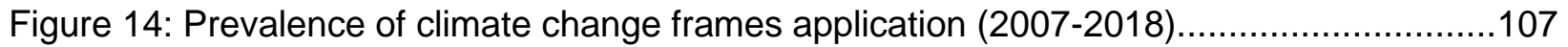

Figure 15: A comparison of climate change frame across ministries ...................................108

Figure 16: Salience of frames within ministries............................................................. 109

Figure 17: A comparison of climate change frames across sources ..................................110

Figure 18: A comparison of climate change frames within sources ...................................111

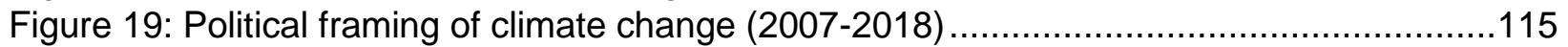

Figure 20: Climate change frames and historical political actions $(2007-2018) \ldots \ldots \ldots \ldots \ldots \ldots \ldots . . . . . .116$

Figure 21: Health risks reported in climate change policy documents ................................130

Figure 22: Health related extreme events reported in documents ...................................130

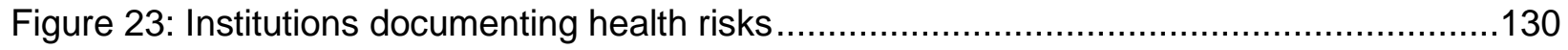

Figure 24: Achieving collaborative governance in Ontario ............................................231

Figure 25: Governance and institutional approaches for legitimizing the public health frame: a

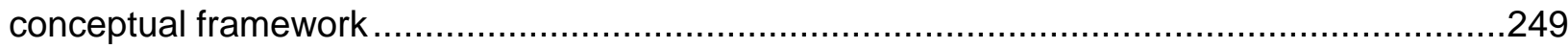




\section{LIST OF APPENDICES}

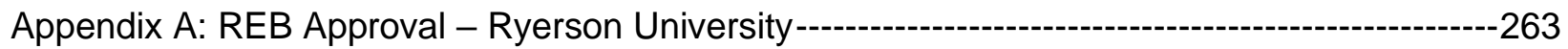

Appendix B: REB Approval - Participant Requested Ethics Review ------------------------264

Appendix C: Renewal Ryerson University -----on

Appendix D: Renewal - Participant Requested Ethics Review --------------------------267

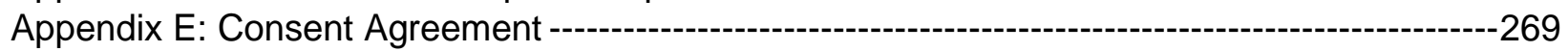

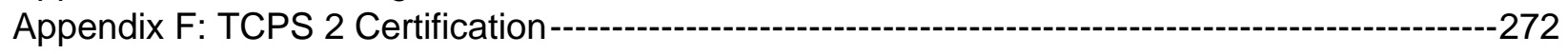

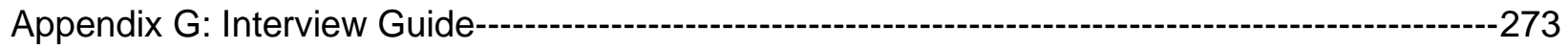

Appendix H: Interview Questions Guiding Themes-------------------------------------276

Appendix I: Main Issues Analyzed in Textual Analysis and Discursive Practices ----------------278

Appendix J: A Guide for Coding the a Priori Thematic Frames and Sample Text---------------280

Appendix K: Chronology of Ontario's Climate Change Activities and Responses ----------------284

Appendix L: Systematic Search of Records as Guided by PRISMA-------------------------288

Appendix M: Integration of Public Health in the Provincial Climate Change Frameworks-------289

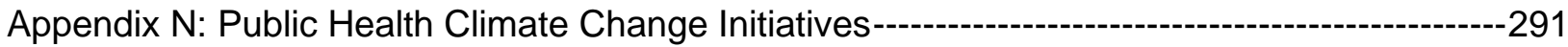




\begin{tabular}{|c|c|}
\hline ALPHA & Association of Local Public Health Agencies \\
\hline APHEO & Association of Public Health Epidemiologists of Ontario \\
\hline ASPHIO & Association of Supervisors of Public Health Inspectors of Ontario \\
\hline $\mathrm{BOH}$ & Boards of Health \\
\hline CANUE & Canadian Urban Environmental Health Research Consortium \\
\hline CAPE & Canadian Association of Physians for the Environment \\
\hline CBA & Cost Benefit Analysis \\
\hline CDA & Critical Discourse Analysis \\
\hline CIPHI & Canadian Institute of Public Health Inspectors \\
\hline $\mathrm{CPHA}$ & Canadian Public Health Association \\
\hline CPR & Common-Pool Resources \\
\hline EBR & Environmental Bill Of Rights \\
\hline EPCCA & Expert Panel on Climate Change Adaptation \\
\hline GDP & Gross Domestic Product \\
\hline $\mathrm{GHG}$ & Greenhous Gas \\
\hline GO & Government of Ontario \\
\hline HIA & Health Impact Assessment \\
\hline HiAP & Health in All Policies \\
\hline HPPA & Health Protection and Promotion Act \\
\hline IAD & Instituional Analysis and Development \\
\hline IPCC & Intergovernmental Panel on Climate Change \\
\hline IR & Indigenous Relations \\
\hline MECP & Ministry of Environment, Conservation and Parks \\
\hline MEDJCT & Ministry of Economic Development, Job Creation and Trade \\
\hline MIA & Ministry of Indigenous Affairs \\
\hline $\mathrm{MMAH}$ & Ministry of Municipal Affairs and Housing \\
\hline MNR & Ministry of Natural Resources \\
\hline MOE & Ministry of Energy, Northern Development and Mines \\
\hline $\mathrm{MOH}$ & Medical Officer of Health \\
\hline MOHLTC & Ministry of Health and Long-Term Care \\
\hline MOT & Ministry of Transportation \\
\hline MRIS & Ministry of Research, Innovation and Science \\
\hline NASA & National Aeronautics and Space Administration \\
\hline NDP & New Democratic Party \\
\hline NOAA & National Oceanic and Atmospheric Administration \\
\hline $\mathrm{NPH}$ & Non-Public Health \\
\hline $\mathrm{NRC}$ & Natural Resources Canada \\
\hline OCCIAR & Ontario Centre for Climate Change Impacts and Adaptation Resources \\
\hline OMAFRA & Ontario Ministry of Agriculture, Food and Rural Affairs \\
\hline OPHA & Ontario Public Health Association \\
\hline OPHS & Ontario Public Health Standards \\
\hline $\mathrm{PC}$ & Progressive Conservative Party of Ontario \\
\hline $\mathrm{PH}$ & Public Health \\
\hline PHAC & Public Health Agency of Canada \\
\hline $\mathrm{PHO}$ & Public Health Ontario \\
\hline $\mathrm{PHU}$ & Public Health Unit \\
\hline $\mathrm{RHA}$ & Regional Health Authority \\
\hline
\end{tabular}


$\mathrm{SDOH} \quad$ Social Determinants of Health

TCPS Ethical Conduct for Research Involving Humans

UN United Nations

UNFCCC United Nations Framework Convention on Climate Change

$\mathrm{V}$ and $\mathrm{A} \quad$ Vulnerability and Adaptation

WCl Western Climate Initiative

WHO World Health Organization

WMO World Meteorological Organization

WNV West Nile Virus 


\section{CHAPTER 1: INTRODUCTION}

\subsection{CONTEXT OF THE STUDY}

\subsubsection{A Call for Public Health Engagement and Leadership}

Climate change is projected to impact ecological, social, political, and economic structures that humans depend on for survival, leading to adverse direct and indirect health outcomes (Berry, 2008; Watts et al., 2015, 2017, 2018). Specifically, there are mortalities and morbidity arising from direct impacts of extreme events such as heat, floods, and storms; the indirect effects are due to changes in the quality of air, food and water, the transmission of infectious disease, socioeconomic impacts, and exposure to ultraviolet radiation (Berry, 2008; Ebi, Anderson, Berry, Paterson, \& Anna Yusa, 2016; Watts et al., 2015, 2017). The World Health Organization [WHO] (2018) estimates that between the years 2030 to 2050, climate change will result in approximately 250,000 deaths annually; many of these deaths will be attributed to heat exposure, undernutrition, gastrointestinal, and vector-borne illnesses. While some health impacts are acknowledged, many are poorly understood (Akerlof et al., 2010; Cardwell \& Elliott, 2013a; Berry, Kaila-Lea, Pajot, 2011). The impacts are also likely to be worsened in the future by the 'dangerous climate change' which is likely to cause grave damage to the environment (Intergovernmental Panel on Climate Change [IPCC], 2013b, 2014b; Thompson, 2010; Watts et al., 2018). This dangerous climate, identified as a $2^{\circ}$ Celsius $(\mathrm{C})$ increase in global surface temperatures, has become the foundation for climate change actions policies and set a massive discourse on global action (Costello et al., 2009; Lorenzoni, Pidgeon, \& O’Connor, 2005; United Nations Framework Convention on Climate Change [UNFCCC], 2016, 2017).

Against this backdrop, much has happened across the globe. Scientists, media, politicians, environmental and societal groups, and policymakers each forward discursive construction of climate change needs (Fleming, Vanclay, Hiller, \& Wilson, 2014). Such groups have influenced the prioritization, advancement, negotiation, proposition, and opposition of climate change needs which have then been reported or promoted by the media, shaping the comprehension and discussion of climate change across social settings (Cadman, 2013; Dryzek, 2013; Dryzek, Norgaard, \& Schlosberg, 2012; Fleming et al., 2014; Taylor, 2013). International agreements, such as the Paris Agreement, have led to the ambitious targets for greenhouse gas (GHG) reduction (UNFCCC, 2016, 2017; World Meteorological Organization [WMO], 2009). Despite remarkable progress, a meaningful reduction of GHG concentrations is lagging (IPCC, 
2014b; Stocker et al., 2013). The GHGs continue to rise at record concentrations; their ability to trap heat in the earth's atmosphere has increased by 41\% between 1990 to 2017 (WMO, 2018). As GHG levels rise, the disproportionate effects of climate change continue to impact various parts of the world (Berry, Clarke, Fleury, \& Parker, 2014; Gough, Anderson, \& Herod, 2016; C. Howard, Rose, \& Rivers, 2018; IPCC, 2014d). The problem is not that people have not been given facts on climate change; the information has not been provided in the right way; this is called framing (Hulme, 2009; Maibach, Nisbet, Baldwin, Akerlof, \& Diao, 2010; Nisbet, 2009; Pralle \& Boscarino, 2011). Frames emerge from discourses, and discourse the use of language in the verbal or written communication or exchange of ideas (Fletcher, 2009; Walter, 2013).

Climate change impacts, debates and decisions or actions can be framed in several ways. The frame can emphasize environmental impacts (Dervin \& Rudolph, 2015; Maibach et al., 2010), economic opportunities or drawbacks of actions (Fletcher, 2009), or the effects of climate change on national security and political systems (Dervin \& Rudolph, 2015). A frame can also stress the human health impacts (Dervin \& Rudolph, 2015; Maibach et al., 2010) or technological solutions (Wang \& Horton, 2015); it can focus on scientific knowledge generation and communication (Dervin \& Rudolph, 2015; Fleming et al., 2014; Sarewitz, 2004); highlight social and environmental disparities, inequalities, and injustices (Markandya, 2011; Popke, Curtis, \& Gamble, 2016; Valles, 2015); or entirely challenges the science, presence or impact of climate change (Cann, 2015; Dearden \& Mitchell, 2016; Jang \& Hart, 2015).

Empirical evidence now suggests that a health framed climate change discourse can steer climate change impact awareness and build consensus on actions (Maibach et al., 2010; Myers, Nisbet, Maibach, \& Leiserowitz, 2012). The health frame achieves this in several ways. First, the frame provides a broader audience with relatable health risks as opposed to the complicated jargons of climate change - e.g. carbon pricing - through social marketing, risk and health communication (Akerlof et al., 2010; Maibach et al., 2010; Myers et al., 2012; Wang \& Horton, 2015). As Wang and Horton (2015) argue, framing climate change as a health issue "rather than purely as an environmental, economic, or technological challenge" puts a face to the somewhat distant threat, resonates with the public, and supports political will. Second, lateral public health supports collaborative and democratic platforms for stakeholder engagement; this depoliticizes and democratizes the issue by offering bipartisan solutions that integrate broader institution and citizen participation and deliberation (Fischer, 2012a; Semenza, 2011). The health promotion and disease prevention competencies of public health can address the many health impacts posed, highlight the health co-benefits of actions and provide the health evidence necessary for mainstreaming and linking the health agenda to climate change initiatives (Maibach et al., 2010; 
Neville \& Weinthal, 2016; Nilsson, Evengård, Sauerborn, \& Byass, 2012). Third, the incomprehension of climate change health impacts dictates a moral obligation for public health action as prescribed in public health principles (Canadian Public Health Association [CPHA], 2017). In other words, a critical role of a public health framed climate change policy is a clear call for public health engagement and leadership. This call has been reinforced by the various scientists and commissions, including the Lancet Countdown, an international multidisciplinary research collaboration that tracks climate change response and resulting health benefits across the globe (Watts et al., 2015, 2017, 2018a, 2018b).

The public health sector can play three roles. They can advance the awareness of climate impacts and consensus on actions required by embedding the public health frame in the climate change discourse. The public health sector can enhance their health promotion and disease prevention functions directly under the sector's mandate and provide leadership and guidance on national policies, plans, and programs that target the various $\mathrm{SDOH}$ and mitigation needs (Frumkin, Hess, Luber, Malilay, \& McGeehin, 2008; Ganesh \& Smith, 2017; Watts et al., 2015).

\subsubsection{The Need for the Study}

The concept of public health's importance in climate change discourse has generated optimism. Optimism has come from those who argue that public health inclusion in climate change discourse provides a compelling vision for supporting holistic approaches to democratic policies and supporting climate change awareness and actions (e.g. (Akerlof et al., 2010; Maibach et al., 2010; Myers et al., 2012; Semenza, 2011; Wang \& Horton, 2015). That, the negative health outcomes of climate change present public health with opportunities for addressing the various health needs; that the health co-benefits of actions provide strategic opportunities for intersectoral collaborations and linking public health to non-health sector policies (Dora, Fletcher, Pfeiffer, \& Adair-Rohan, 2014; WHO, 2014). Viewing climate change as the "greatest global health opportunity of the 21 st century," "greatest health opportunity," or "biggest global health threat of the 21st century" (Costello et al., 2009; Howard et al., 2018; Watts et al., 2015) also provide optimism for public health inclusion and leadership in climate change discourse (Frumkin \& McMichael, 2008; Watts et al., 2015, 2017).

Despite the growing relevance of public health framed climate change policy, the various stakeholders working to educate the public and influence climate change actions have often presented biased perspectives on climate change needs (Rowson, 2013; Schäfer \& O'Neill, 2017). Political power has dominated the response to climate change; divergence between scientific evidence and economic power continue to define actions (Dearden \& Mitchell, 2016; 
Lynch \& Duke, 2004; Rowson, 2013; Spence \& Pidgeon, 2010). There are competing interests between "scientists, industry, policymakers, and non-governmental organizations," each forwarding subjective perspectives on the issue (Schäfer \& O'Neill, 2017). Little attention has been paid to public health, a sector that still struggles for a place in the climate change discourse both locally and internationally (Austin et al., 2016, 2015; Aylett, 2015; Lesnikowski et al., 2011; Public Health Agency of Canada [PHAC], 2013; Workman, Blashki, Bowen, Karoly, \& Wiseman, 2018).

In attempts to support public health's capacity in climate change issues, empirical studies, social scientists, and various commissions on public health and climate change have investigated the relevance of framing climate change in health terms; they have also presented the necessary tools and suggested policy option for supporting public health's leadership in climate change. Such approaches have not significantly influenced public health's role in climate change; the sector still struggles for a dominant position in the discourse. This highlights several gaps and questions.

1. Why is climate change discourse out of tune with the empirical evidence?

2. Why is a public health framed climate change not dominant or emphasized?

3. Are there jurisdictions excelling at integrating public health leadership and frame?

4. Are policymakers and public health community aware of the relevance of public health?

5. How can public health overcome competing interests and heed the call to lead and actively engage in climate change actions?

Climate change can be understood as a scientific phenomenon where science provides evidence and predictions for addressing and adapting to the changes (IPCC, 2007a; IPCC, 2013). However, climate change is also a complex, social problem whose construction of meaning and actions needed are rooted in institutionalized language, discourse, structures, values, practices and ideas (Dearden \& Mitchell, 2016; Kreuter, De Rosa, Howze, \& Baldwin, 2004; Pettenger, 2007b; van Woezik, Braakman-Jansen, Kulyk, Siemons, \& van Gemert-Pijnen, 2016). Social meanings, interactions and values define politics and policymaking (Fischer, 2012c). Meaning that the understanding of the construction of the relevance of public health in climate change within social interactions and political contexts is central to understanding the impediments of public health framed policy discourse. Such meanings, constructs, and social interactions must be elucidated, and, the rationale, influences, and barriers exposed if utilization of public health framed and led climate change policy is anticipated. Unfortunately, this has been a neglected area of research that has attempted to build public health's capacity in climate change actions 
and debates. This dissertation responds to this need by examining climate change language and discourse and their discursive influence on decision- and policy-making contexts of climate change framing and actions. The study aims to explore and explain the diversity of discursive, social, and political contexts impeding public health framing and the resulting barriers to public health engagements.

\subsubsection{Defining Public Health in the Context of this Study}

The WHO (2019) defines public health as "the art and science of preventing disease, prolonging life and promoting health through the organized efforts of society." The PHAC (2008) definition goes further to include the characteristics and the population approach to public health. That is, the PHAC defines the term as "an organized activity of society to promote, protect, improve, and when necessary, restore the health of individuals, specified groups, or the entire population. It is a combination of sciences, skills, and values that function through collective societal activities and involve programs, services, and institutions aimed at protecting and improving the health of all people." The Government of Ontario (2013) definition further highlights public health's role in public policies. That is, as "the organized efforts of society to prevent illnesses, disease and injury through a sustained combination of approaches including one-onone health services, health promotion, health protection and healthy public policies.

Common to all the definitions above is the inclusion of the word 'health'. Health is both the absence of disease and a complete state of physical, mental and social wellbeing, including quality and average year of life lived (Awuor \& Melles, 2019; Parrish, 2010; WHO, 1946). Health disparities and subsequent risk of illnesses, quality of life or premature mortality can result from lifestyle choices or socioeconomic, cultural, biological and environmental factors (Government of Canada, 2013; Mikkonen \& Raphael, 2010). These structures hinder people from achieving good health and are collectively referred to as the social determinants of health (SDOH) (Marmot, M. G. \& Wilkinson, 2006). SDOH independently and collectively influence health outcomes and portray both individual and place characteristics (Government of Canada, 2013; Pearce et al. 2007). Resulting inequalities can have three dimensions; individual, demographic, and socioeconomic disparities and spatially-related groups (Pearce, Witten, Hiscock, \& Blakely, 2007). Public health provides a holistic approach to preventing ill-health and advancing the SDOH to support positive health outcomes. The sector achieves this through its unique position to advance $\mathrm{SDOH}$ within both the health and non-health sector, as illustrated in Figure 1: Public health's unique position in addressing climate change health impacts. 


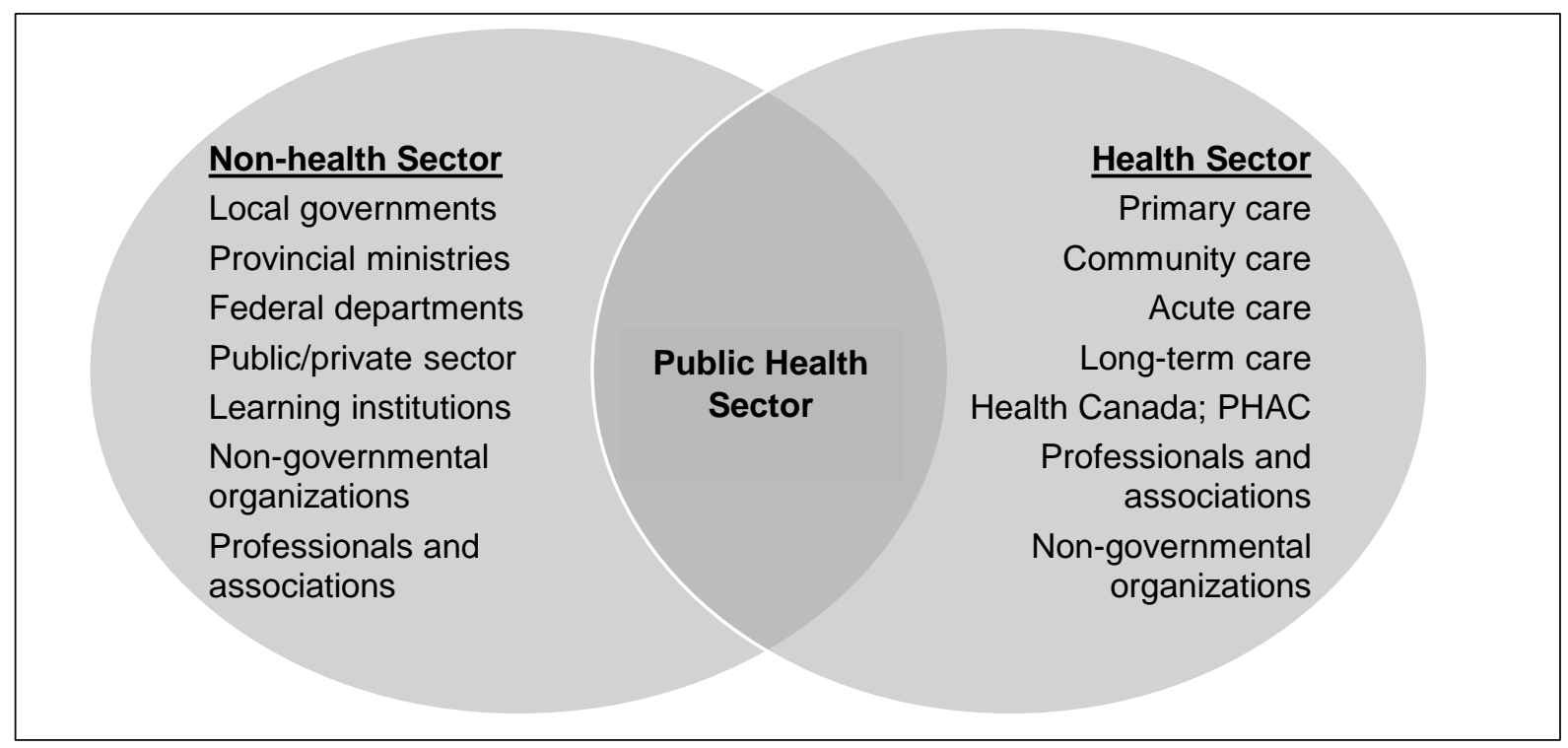

Figure 1: Public health's unique position in addressing climate change health impacts Source: Modified from Government of Ontario (2013)

For instance, investing in public health leads to reduced health care costs and sectoral initiative costs through public health's upstream disease prevention strategies (Government of Ontario, 2013). In the context of climate change, public health advances the SDOH through its core competencies (related to health promotion, health protection, and disease and injury prevention) and by partnering with health and non-health sectors to minimize population impacts from the direct and indirect climate change impacts (Maibach et al., 2010; Neville \& Weinthal, 2016; Nilsson et al., 2012; Semenza, 2011). Therefore, the study visions and defines public health as an institution, a sector, a way of thinking, and as a domain and collection of practitioners with the combination of skills, expertise, and practices all aimed at advancing healthy populations and public policies (Government of Ontario, 2013; PHAC, 2008; WHO, 2019).

\subsubsection{Jurisdiction Explored: Why Ontario?}

Climate change is characterized by unique geographical features that present unique risks, vulnerabilities and impacts and require geographically specific actions (IPCC, 2014d; Patz, Grabow, \& Limaye, 2014). Addressing climate change also requires exclusive institutional setups, culture, norms, and policy instruments (Cadman, 2013; Oulo, 2015; Willems \& Baumert, 2003). Within these governance structures, policy discourses are constructed by many including scientist, media, politics, environmental, and societal groups, each forwarding a specific discursive construction of the issue as influenced by social interactions and contexts (Fleming et 
al., 2014). Therefore, the study focuses on a particular jurisdiction - the province of Ontario context - as an outset for understanding climate change framing and decision-making processes, and their influences on public health framed climate change. Several characteristics make Ontario ideal for the study.

Ontario is one of the ten provinces of Canada (Figure 2: Map of Canada depicting the 10 provinces and 3 territories).

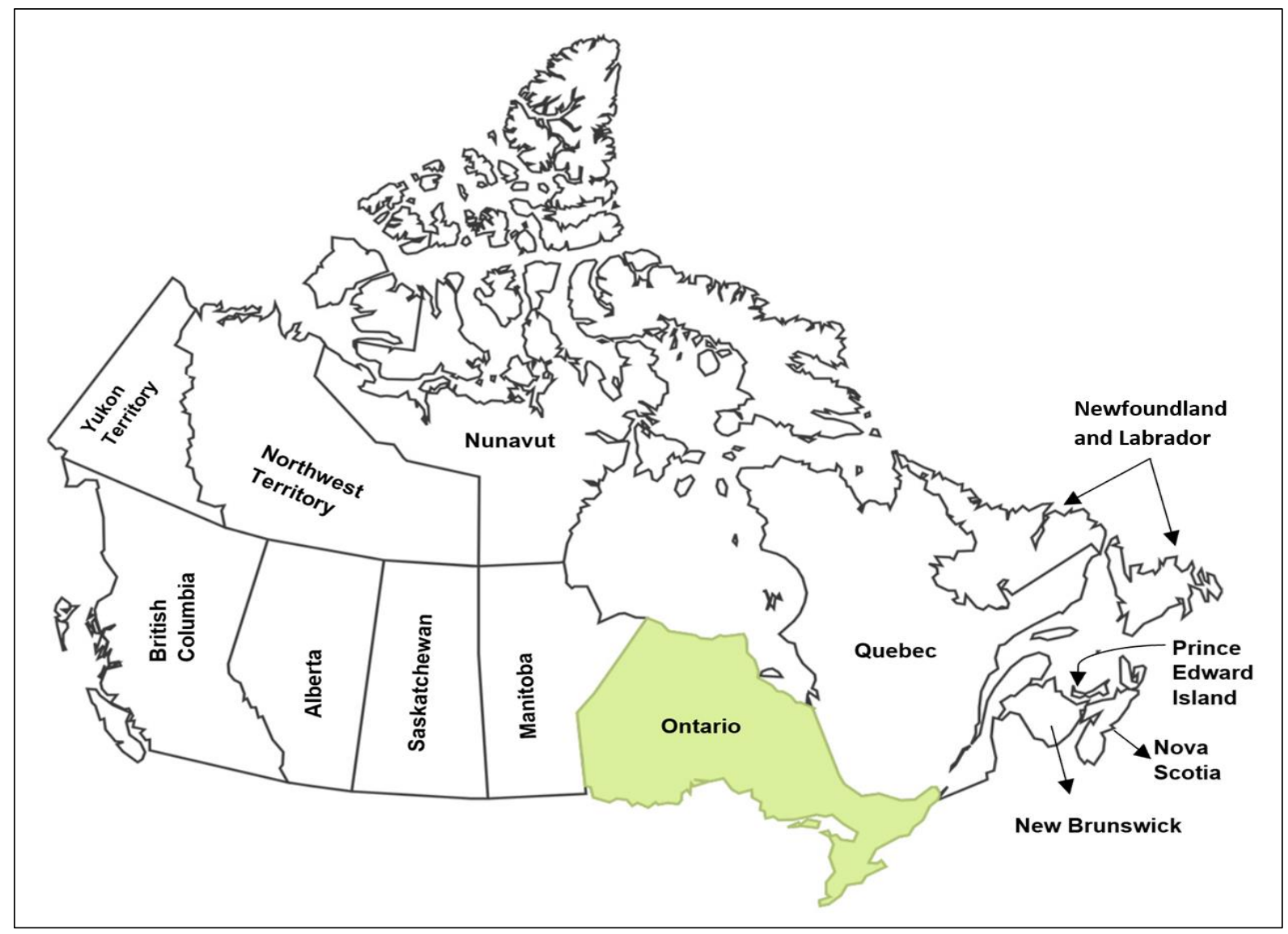

Figure 2: Map of Canada depicting the 10 provinces and 3 territories Modified from: Polese (2018)

As one of the largest, economically vibrant and most populous province in Canada, Ontario has led and aggressively engaged in climate change policies since 2007 (Government of Canada, 2019c; Government of Ontario, 2007c; Ontario Ministry of Environment, Conservation and Parks [MECP], 2014, 2015; Polese, 2018; Statistics Canada, 2018). Such engagements preceded or proceeded strategic action plans and policy decisions that have gradually evolved over the years (MECP, 2014, 2015). Within these years, Ontario's climate change framing or discourse has never been evaluated. These evolutions and engagements have produced over ten years of documented evidence relevant for analyzing frames or discourses, decision-making 
processes, strategic actions, institutional arrangements, dominant actors, and knowledge guiding actions as well as successes and challenges encountered. Since 2007, Ontario's climate change policies have been dominated by politics, partisan divisions and by specific ministries and sectors (MECP, 2016). The province has also actively engaged in international debates and discourses on climate change and was one of the first provinces in Canada to be involved in both domestic and international climate change agreements such as the Western Climate Change Initiative (WCI) (MECP, 2016). The province's climate change policies have evolved through the years producing some documented evidence and transformative climate change actions relevant for studying climate change discourse and policymaking. Such activities are relevant in understanding the institutional arrangements, governance structures, values, subjective perceptions, and knowledge that set political agendas and guide climate change discourse and decision processes.

There is evidence of climate change in Ontario. The changes have resulted in both direct and indirect health impacts arising from climate change-related events such as increases in temperatures, altered precipitation patterns, drought, tornadoes, wildfires and winter storms (Gough et al., 2016; Ebi, Anderson, Berry, Paterson, \& Anna Yusa, 2016; Berry, Clarke, Fleury, \& Parker, 2014). The diversity across Ontario's population, coupled with the unique vulnerabilities and population health needs, ideally require unique attention and approach. In Canada, public health is mainly the responsibility of each province or territory; each has a role in planning and implementing public health initiatives with a significant emphasis on core public health competencies (Government of Ontario, 2013; Miljan \& Brooks, 2018). Ontario's public health system is adequately developed with mandates that address the various SDOH. According to the Government of Ontario (2013), public health can provide evidence, advocate for climate change actions and collaborate with partners for the development and implementation of interventions addressing health. The delivery of public health initiatives is decentralized to local health agencies through geographical designations known as Public Health Units (PHUs) (MOHLTC, 2012, 2013). The guiding legislation, standards and protocols also provide a mandate to local public health in addressing climate change, making the public health sector ideally situated to advance climate change needs (MOHLTC, 2012, 2013). The governance structures and the various public health competencies were relevant for exploring public health capacities, engagements and experiences in the climate change discourse.

Overall, the characteristics provide opportunities for examining climate change discourse, decision-making processes, structures, institutions, governance, and perceptions and their 
influences on public health framing and engagement. These also provide avenues for developing a framework for public health inclusion in the discourse.

\section{$1.2 \quad$ AIMS AND OBJECTIVES}

The purpose of this research is to use the context of climate change policy discourse in the province of Ontario (Canada) to examine how public health needs are socially constructed in the discourse and the sociopolitical contexts advancing or impeding the public health framed climate change policy discourse. The specific objectives of the study are three-fold. The study aimed to examine:

1. The extent of the public health frame application in the province's climate change discourse.

2. The systematic factors influencing the public health frame and needs in the discourse.

3. How public health framed climate change policies can be advanced in the climate change language, discourse, and institutions.

\subsection{RESEARCH QUESTIONS}

To support the study objectives, the dissertation is structured around the following questions.

1. How does the province of Ontario frame its climate change discourse?

2. What discursive and systematic contexts have influenced the framing of climate change?

3. How have the contexts influenced the public health frame and capacity in the climate change discourse?

\section{$1.4 \quad$ METHODOLOGICAL APPROACHES}

The study assumes that climate change policies and decision-making processes are socially constructed through language and discourse (Dearden \& Mitchell, 2016; Kreuter et al., 2004; van Woezik et al., 2016). The construction structures social and political actions by shaping views and social interactions, supplying institutions and their actors with symbolic meanings, norms, ideas, and values that influence governance structures for climate change decisionmaking, knowledge considerations and relevant actors in the decision processes (Barkan, 2013; Brinkmann, Jacobsen, \& Kristiansen, 2015; Carter \& Fuller, 2015; Mills, Durepos, \& Wiebe, 2010; Moon \& Blackman, 2014; Pettenger, 2007b). The social construction of the research problem also means that the multiple realities exist between individuals and groups within a local or cultural context, space, and time; the view of knowledge and its sources are subjective, value-laden and 
rely on human experiences (Baghramian \& Carter, 2018; Brown, 2003; Fischer, 2012c; Kolkman, Veen, \& Geurts, 2007; Moon \& Blackman, 2014; Palys \& Atchison, 2014).

As a result, to address the research goals, objectives and questions, the study is grounded in constructionism theory which explores the social construction of knowledge (Baghramian \& Carter, 2018; Fischer, 2012c; Gould \& Lewis, 2009; Moon \& Blackman, 2014; Palys \& Atchison, 2014). It is guided by the constructivism theory which explores how meanings are created as a result of how an individual constructs reality (Palys \& Atchison, 2014; Yin, 2014) and interpretivism - a philosophical principle that reveals the social construction of reality, human experiences and the relevance of meanings in knowledge generation (Brinkmann et al., 2015; Yanow, 2007) through a combination of three theories. First, symbolic interactionism that explores the influence of language and interactions between individuals within social settings (Aksan, Kısac, Aydın, \& Demirbuken, 2009; Brinkmann et al., 2015; Spencer, Pryce, \& Walsh, 2015). Second, hermeneutics which delineates why people act in a certain way at a particular time by exposing the existing underlying individual or collective human interpretations of a phenomenon (Brinkmann et al., 2015; Moon \& Blackman, 2014; Yanow, 2007). Last, phenomenology which considers the fundamental relevance of understanding a phenomenon through people's perspectives within their social and historical contexts (Bazeley, 2013; Brinkmann et al., 2015; Moon \& Blackman, 2014; Walter, 2013; Yanow, 2007).

Social actions cluster around, and are embedded in, institutions (Cadman, 2013; Cairney, 2012; Dryzek, 2013; Fairclough, 2013; Gould \& Lewis, 2009). The Lomas Model of Decision Making is used to identify the broader contextual factors for understanding policy-making influences and decisions and to reveal the effect of knowledge, institutional structures, and values on climate change policies and discourse (Brehaut \& Juzwishin, 2005; Lomas, 2000; Rosella et al., 2013).

Based on the research questions and the need to examine real-life social contexts to generate theory (Baxter \& Jack, 2008; Berg \& Lune, 2016; Whetten, 2016; Yin, 2014), a single, embedded case study approach was the most useful for the needs of the study.

A systematic review of policy documents representing 11 government agencies in Ontario (10 ministries and the Office of the Premier) is used to identify dominant frames in Ontario's climate change discourse. Policy documents and transcripts from in-depth interviews, directed at public health policy experts from 11 PHUs and 13 policy experts from 11 government agencies in Ontario, are used to explore the contexts influencing climate change framing and discourse. Focusing on language and discourse, critical discourse analysis (CDA) and thematic analysis is used to analyze the study data. Institutional analysis and analysis of narratives supplement the 
CDA to account for social contexts influencing discourse and to overcome CDA shortfalls. The emerging themes explored include: 1) the frames and discourses driving Ontario's climate change actions and the discursive strategies used to describe and inform such frames and discourses; 2) the construction of the relevance of public health framed climate change policies as well as the structures, processes, and contexts motivating or obscuring public health's framing and needs in the discourse - including how norms define agency and how shared meanings influence social and political contexts; 3) how climate change construction and meanings are projected in texts (written and spoken), participant experiences, accounts or narratives, social events, and interactions across institutions; and 4) influences on public health framing of and engagement in climate change. The themes that emerge from the analysis are then aggregated and reported in specific chapters (Chapters 6 to 10), reflecting all the major themes and the subsequent subthemes. The results are integrated into the interpretation phase (Chapter 11). The research approach and methodology are summarized in Figure 3: Overview of the research approach (next page).

\subsection{SIGNIFICANCE OF THE STUDY}

An exploration of the frames applied in Ontario will extend existing knowledge and theories on how various institutions and policy actors conceptualize, develop, and link policies and interventions addressing climate change, and how these elements intersect to influence actions and public health needs.

Examining construction, perspectives and attitudes towards public health inclusion in the climate change discourse will clarify why specific frames dominate; it will also reveal the gridlocks to public health framing, capacity, and the relevance of public health in advancing socially inclusive discourse. Overall, the study aims to support knowledge translation in Ontario's government and across other governments by mobilizing policy actors to promote resilient climate change strategies relatable to a broader audience.

\subsection{STRUCTURE OF THE DISSERTATION.}

This dissertation consists of 12 chapters, including the Introduction (Chapter 1), which summarizes the contexts, scope, purpose, and significance of the study.

- Chapter 2: Climate Change, Impacts, and Responses provides background on the connections between climate change and public health and connects them to the contexts of climate change policies broadly and specific to the province of Ontario while locating Ontario's policies and public health position in the discourse. 


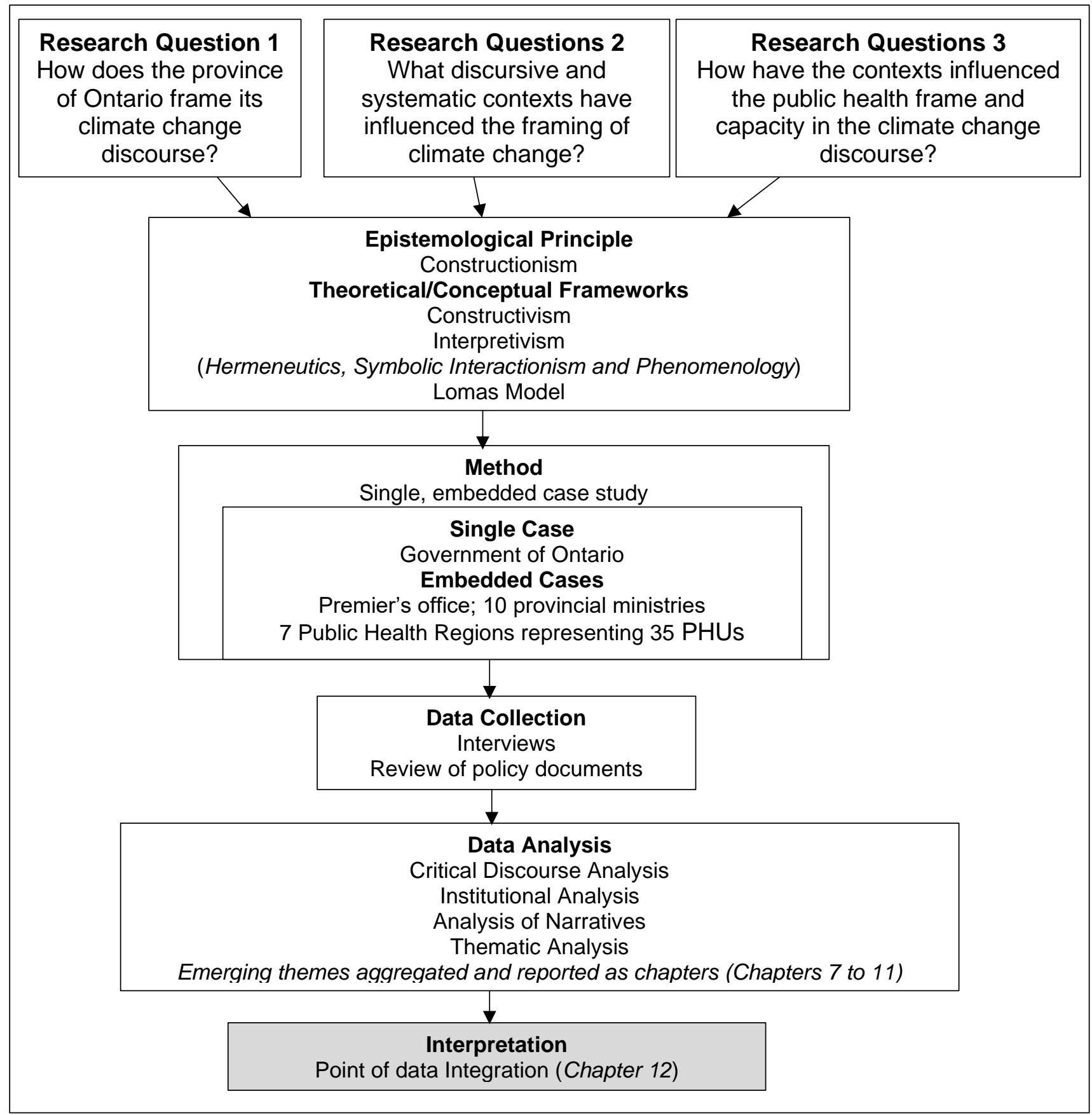

Figure 3: Overview of the research approach

- Chapter 3: Perspectives from the Literature locates the research within the context of other empirical studies through summary and synthesis that supports the understanding of the research issue, how the problem has been addressed, and gaps that exist. It specifically presents the discursive formations and the social construction of climate 
change, and the discursive and interpretive approaches for exploring climate change framing and the relevance of public health in climate change.

- Chapter 4: Research Methodology describes the actions undertaken to investigate the research problem and answer the research questions as well as the rationale for applying the chosen research technique. It expands on the theoretical and conceptual framework, research design, data collection - including the cases and evidence (from documents and key informants) considered - and the methods of analysis, interpretation and reporting of findings.

- Chapter 5: Results summarize the documents and participants' characteristics and coded themes that inform the study; it also briefly describes the emerging themes. However, the chapter does not detail the findings. The proceeding chapters (6-10) state the findings arranged in a logical sequence based on themes and subthemes from the analysis.

- Chapter 6: Climate Change Framing in Ontario provides the study results on the framing of climate change in Ontario, including the dominant, ambiguous and suppressed frames and the discursive, social, and historical contexts that have defined such frames.

- Chapter 7: Institutional Arrangements at the Provincial Level presents the results of the influences of framing and public health engagements within the ministries (excluding the MOHLTC) and Premier's office. The results discussed include the influence of policy goals and objectives, convergence and divergence of frames, policy fragmentation, institutional arrangements and evidence supporting climate change policies.

- Chapter 8: Public Health-Specific Institutional Arrangements introduces the results from a public health-specific context (PHUs and MOHLTC) on the influences and barriers to public health framing and engagement. The results discussed include the effects of public health's organizational structure, resources, programs and services.

- Chapter 9: Institutional Engagements focuses on the influences of partnerships and collaboration in the deliberation and participation in climate change policies. The results include how the organizations have accessed and engaged with stakeholders and the various contexts that have impacted engagement, including influences of issue definition, collaborative settings, organizational processes and structures and communication. It concludes with how such collaborations have impacted public health's capacity in climate change.

- Chapter 10: Sociological Perspectives on the Climate Change-Public Health Nexus focuses on the political and policy actors' values (ideologies, beliefs and interests) and 
perspectives on Ontario's actions and public health roles in climate change (including perspectives on a public health frame, leadership and inclusion).

- Chapter 11: Interpretation of Findings, Conclusion, Recommendations, and Study Limitations interprets the study results by connecting the findings with the research questions. The chapter explains the framing of climate change in Ontario and strategic or systematic influences. It connects the framing to the effects and roles of discourses, strategic and communicative actions, and identities in the construction of climate change. The chapter also connects the influence of climate change framing in Ontario to the governance structures and processes, and institutional arrangements, within and outside public health, which either facilitated or impeded the public health frame and capacity in climate change policy discourse. There is a particular focus on the impediments of knowledge integration, institutional engagements, and contexts of power. Finally, the chapter addresses the characteristics of the methodology or study design likely to impact the interpretation of the study findings and how such limitations were overcome or addressed.

- Chapter 12: Conclusion, Significance, and Recommendations concludes the study by summarizing the key findings, the significance, implications, and future directions of the study, and recommendations for advancing public health needs in the discourse, including the feasibility and limitations of the recommendations. 


\section{CHAPTER 2: CLIMATE CHANGE AND POLICY - PUBLIC HEALTH LINKS}

\section{INTRODUCTION}

Climate change presents a diverse and eminent collection of risks. It is projected to impact the environment, human activities and health, policies, and feasibility of resources and economies. Minimizing the impacts require identification of health impacts, vulnerabilities and the development of policies to target such impacts at the local and international levels. The purpose of this chapter is to summarize the critical facts on climate change, connect the phenomenon to public health and policy contexts. The chapter also provides the contexts that are relevant for connecting Ontario to the aims and objectives of the study in a manner that grounds the research approaches applied to answer the research questions.

Section 2.1 provides an overview of the scientific basis of climate change, including natural and human-induced changes and the observed climate change evidence.

Section 2.2 discusses an overview of climate change evidence, impacts, vulnerabilities and perceptions.

Section 2.3 defines public policy and locates the various climate change policies and responses internationally and within the province of Ontario. It also contextualizes the public health-climate change-policy connections and public health-specific responses. The section also discusses the characteristics that make Ontario an ideal case for exploring the research problem. Contexts presented include the socioeconomic factors (including urbanization, demography and economy), political culture, constitution influences, and the unique public health features in Ontario.

\subsection{SCIENCE OF CLIMATE CHANGE}

Climate change is defined as "any significant long-term changes in current normal climate conditions, such as temperature, precipitation, extreme weather events, snow cover and sea-level rise" (PHAC, 2015). The changes describe average weather patterns over an extended period, likely over 30 years (NASA, 2015).

The climatic changes can be attributed to natural and human activities (IPCC, 2013; Public Health Agency of Canada, 2015; The Expert Panel on Climate Change Adaptation [EPCCA], 2009; Watts et al., 2015, 2018). Natural climate can result from the changes in the shape of the 
earth's orbit which changes from nearly circular to oval every 100,000 years (eccentricity), the variation of the earth's tilt between 22.1 to 24.5 , every 41,000 years (obliquity), and the rotation of the earth's surface every 25,000 years (precision) (Masters \& Ela, 2008). Natural changes can also be caused by the earth's reflectivity (albedo) (IPCC, 2007c; Masters \& Ela, 2008). Human activities result in climate change through the unprecedented release of anthropogenically emitted GHGs which trap heat in the earth's atmosphere (Haines, Kovats, Campbel-Lendrum and Corvalan, 2006; 2015; IPCC, 2013; PHAC, 2015; NASA, 2019; NOAA, 2014; US EPA, n.d.-b).

Records of the earth's changing climate have been traced back from hundreds to millions of years. Scientists have studied the changes by analyzing various indirect measures. These have included ice cores (Petit et al., 1999), tree rings (Marcott et al., 2013), flora and fauna deposits (Petit et al., 1999), marine sediments, glacial lengths, pollen deposits, and the variation in earth's orbit around the sun (IPCC, 2013); Antarctic temperatures to levels of Carbon dioxide $\left(\mathrm{CO}_{2}\right)$ in the atmosphere (Barnola et al.,1987; Chappellaz et al., (1990). The analyses have shown variation in climate systems over time, dating back to the pre-industrial period. Before the industrial revolution in the 1700s, changes in the earth's climate were within stable ranges and resulted from natural factors (Petit et al., 1999). However, recent changes in climate, specifically in the $20^{\text {th }}$ century, cannot be attributed to nature (IPCC, 2013).

The current changes in climate have been characterized by increasing surface temperatures, rising sea levels, warming oceans, loss and decrease in snow and ice cover, and extreme weather events such as heat, flooding, among others (IPCC, 2007a; IPCC, 2013; Mimura, 2013; Nuccitelli et al., 2012; Stocker et al., 2013; Vermeer \& Rahmstorf, 2009). Based on the analysis of the Vostok ice core in Antarctica, Petit et al. (1999) concluded that GHG emissions, and not orbital variations, have significantly contributed to the warming of the earth. For instance, pre-7000 years ago, $\mathrm{CO}_{2}$ levels were between 200 parts per million (ppm) during ice ages and 280 ppm in warmer interglacial periods (NASA, 2019). The levels are now higher than ever, surpassing 400 ppm in 2013 (NASA, 2019). As of July 2019, the $\mathrm{CO}_{2}$ levels had reached $411 \mathrm{ppm}$, with the highest concentrations being experienced from the 1950s onwards (NASA \& NOAA, 2019). The concentrations of methane nearly doubled from just above 1ppm (the 1950s) to almost 2 ppm (2015). Nitrous oxide has increased by about 17\% between the 1950s to 2015 (NASA \& NOAA, 2019). These concentrations have been attributed to the use of fossil fuels and agricultural activities (Watts et al., 2015).

The significant rise GHG concentrations on the earth's atmosphere and the resultant feedback mechanisms have impacted and will continue to affect the energy balance and warming of the various climate systems in the future (Watts et al., 2017, 2015; Portier et al., 2010a). The 
continuing rise of the level of GHG atmospheric concentrations and the resultant feedback mechanisms result in a myriad of climate and health outcomes (Watts et al., 2017, 2015; Portier et al., 2010a).

\section{$2.2 \quad$ EVIDENCE OF CLIMATE CHANGE}

Warming of the earth's systems is unequivocal" (IPCC, 2013a). There is evidence of rising global average temperatures and sea levels and declining snow cover in the northern hemisphere (IPCC, 2007a). Specifically, there is a linear association between the levels of anthropogenic emitted CO2 and global surface temperatures (IPCC, 2014d). Anthropogenic GHG emissions will continue to be key drivers of future climate (IPCC, 2014d). IPCC projects future impacts based on scenarios that simulate anthropogenic forcing using the demographic development, socioeconomic development, and technological change; these specifically include population size, economic activity, lifestyle, energy use, land use patterns, technology and climate policy (IPCC, 2007c, 2013a, 2014d).

Since 1900 , global temperatures have increased by $0.74^{\circ} \mathrm{C}$ and are expected to increase by approximately $1.1^{\circ} \mathrm{C}$ by 2100 (IPCC, 2007b; EPCCA, 2009; Zhang et al., 2010). Between 1990 to 2015 , global temperatures increased by $0.150 \mathrm{C}$ to $0.3^{\circ} \mathrm{C}$ per decade; a "warming of $0.2^{\circ} \mathrm{C}$ per decade" is expected over the next two decades (IPCC, 2007a). IPCC has also established that since 1850, the last three decades have been successfully warmer than the previous decades (IPCC, 2014d). In 2010, the UNFCC established that an average increase of global surface temperatures above $2^{\circ} \mathrm{C}$ is detrimental to the various socioeconomic systems and will significantly impact the earth and human systems (IPCC, 2007; Rijsberman \& Swart, 1990). Recent studies reveal that global temperatures are likely to increase by over $2^{\circ} \mathrm{C}$ by the end of the century (Raftery, Zimmer, Frierson, Startz, \& Liu, 2017; Thorsten \& Pincus, 2017). Raftery et al. (2017) project a $95 \%$ chance of surpassing the $2^{\circ} \mathrm{C}$ increase; the study projects an increase of $2^{\circ}$ to $4.9^{\circ} \mathrm{C}$ by 2100 .

The most significant impact of temperature increase is on sea levels (Mimura, 2013; Vermeer \& Rahmstorf, 2009). As the earth's temperature increases, most of the heat is absorbed by the oceans. The absorbed heat increases the ocean's heat content; this heat moves from the surface to the deep levels of the sea. Between 1971 t0 2010, over $90 \%$ of the heat gained by the earth has been absorbed by the oceans (IPCC, 2013b). Nuccitelli et al. (2012) analyzed the distribution of heat between land, ice, atmosphere and ocean between the years 1961 to 2008 . The analysis demonstrated that total heat content in oceans has continued to increase significantly with the highest increase experienced in the top layers ( 0 to 700 metres); the deeper 
layer (700 to 2000 metres) accounts for about $30 \%$ of the ocean heat content. $60 \%$ of the earth's energy is stored in the upper 700 layers (Nuccitelli et al., 2012; Stocker et al., 2013). A significant trend in warming for the layer between 2000 to 2000 has not been observed (IPCC, 2013b).

Warm water expands; this expansion raises the levels of seawater (Levitus et al., 2012). A significant increase in sea level rise was experienced since the mid-19 $9^{\text {th }}$ century with 1901 to 2010 accounting form 1.7 millimetres per year and 1971 to 2010 accounted for approximately 2 millimetres per year. Furthermore, the temperature increase has been accompanied by changes in ice and snow cover. IPCC (2013b) reported that both Greenland and Antarctic have lost ice sheet mass while the glaciers around the world have been shrinking significantly; the Northern hemisphere continues to experience reduced snow cover (IPCC, 2013b). Similarly, as temperatures rise, it impacts the earth's water cycle due to increased evaporation; this results in precipitation and storms in some areas and drought in other areas. Changes in precipitation can result in intense rainfalls, storms or drought (Government of Canada, 2019; NASA, 2017; Levitus et al., 2012). These changes and the continuing rise of the level of GHG atmospheric concentrations and the resultant feedback mechanisms result in a myriad of health outcomes(Watts et al., 2017, 2015; Portier et al., 2010a).

\subsubsection{Evidence of Climate change in Ontario}

The northern hemisphere is warmer than it has been in a 1000 years (EPCCA, 2009). The period between the years 1983-2012 was the warmest over the last 1400 years (IPCC, 2014d). There have been significant increases in mean air temperatures across most regions of Canada between 1950 to 2007 (Zhang et al., 2010). Overall, mean annual temperatures increased by $1.4^{\circ}$ C (Zhang et al., 2010). However, western and northwest Canada experienced the strongest warming at more than $1.5^{\circ} \mathrm{C}$. Eastern Canada demonstrated slower warming of less than $0.5^{\circ} \mathrm{C}$. Warming in the rest of the regions ranged from an increase of $1^{\circ} \mathrm{C}$ to $2^{\circ} \mathrm{C}$ accompanied by significantly warmer winters and springs in western Canada, cooler falls in northern Canada and warmer summers in southern Canada. Temperatures in the eastern regions have remained cool due to the ocean circulations from the northwest Atlantic Ocean. However, temperatures in the northwest region have increased by more than $2.5^{\circ} \mathrm{C}$ (Zhang et al., 2010; EPCCA, 2009). Equally, precipitation has risen considerably since 1950 (Zhang et al., 2010; Government of Canada, 2015). More warming in Northern Canada with an insignificant or possibly decreased impacts in Southern Canada has been reported by Zhang et al. (2010) and Natural Resources Canada [NRC] (2015a, 2015b). In addition, Arctic sea ice has declined by $8 \%$ since 1979; snow cover has decreased by 20 days in most northern regions, and permafrost continues to thaw in most areas 
(Government of Canada, 2015a). Shifts in the summer warming have also led to drier conditions, specifically in Western Canada (Zhang et al., 2010). These trends are anticipated to increase in the future, intensifying in some regions than others.

In Ontario, annual and seasonal temperatures have been increasing and are projected to increase even further over the years, with the most striking changes anticipated in the far North (EPCCA, 2009). The EPCCA (2009) reported that the average temperatures have increased by $1.3^{\circ} \mathrm{C}$ over the past 60 years; McDermid et al. (2015) reports a $1.6^{\circ} \mathrm{C}$ increase over the past 63 years. Temperature trends estimated by Vincent et al. (2012) demonstrated that the average temperatures in the province increased by $0.5^{\circ} \mathrm{C}$ to $1.5^{\circ} \mathrm{C}$ between 1950 to 2010 . Within this 61 year period, significant temperature increase occurred in southern Ontario, within variabilities in northern Ontario (McDermid, Fera, \& Hogg, 2015; Vincent et al., 2012). By 2050s, the projected temperature increase in the southern and northern regions will range from $2.3^{\circ} \mathrm{C}$ to $3^{\circ} \mathrm{C}$, and, $3.2^{\circ} \mathrm{C}$ to $4^{\circ} \mathrm{C}$, respectively. Most prominent are the projected winter temperatures increase in the far north, ranging from approximately $3^{\circ} \mathrm{C}$ to $5^{\circ} \mathrm{C}$. Colombo, McKenney, Lawrence, and Gray (2007) have also projected future climatic deviations from 1971 to 2000 across two climate scenarios. By 2100 , temperatures in the southern regions of the province are anticipated to increase by $3^{\circ} \mathrm{C}$ to $5^{\circ} \mathrm{C}$ in the summer and $4^{\circ} \mathrm{C}$ to $6^{\circ} \mathrm{C}$ in the winter. In the northern regions, summer temperature increases will range from $3^{\circ} \mathrm{C}$ to $6^{\circ} \mathrm{C}$, while winter temperatures are anticipated to increase by $4^{\circ} \mathrm{C}$ to $10^{\circ} \mathrm{C}$ (Colombo et al., 2007).

The increasing temperatures are accompanied by seasons of short ice cover and continuous melting of permafrost (EPCCA, 2009). Far North will experience precipitation increase of up to $15 \%$ in the winter and up to $20 \%$ in the spring. Little to no changes in summer precipitation is projected in the province (EPCCA, 2009). Variability in precipitation is anticipated through the years and across the climate scenarios. Overall, precipitation is expected to increase by $240 \mathrm{~m}$ per year by 2080, above the 1971 to 2000 baseline (McDermid et al., 2015). However, a 10-20\% reduction in precipitation is anticipated between October to March in Southern Ontario and a 20\% reduction in the winter seasons in Northern Ontario.

The current and anticipated changes in Ontario's climate pose significant risks and challenges to human health.

\subsubsection{Human Health Impacts and Vulnerabilities in Ontario}

The observed and anticipated climate change impacts have both direct and indirect impacts on human health. Changes in weather patterns that lead to storms, drought, flood and heatwave have direct effects (Watts et al., 2017, 2015, 2018). The direct implications include heat 
strokes and heat exhaustion from heat events, and traumatic injuries and death resulting from disasters and extreme events (Greenough et al., 2001; Ontario Centre for Climate Change Impacts and Adaptation Resources [OCCIAR], 2015; Public Health Ontario, 2014). Of the effects, the indirect impacts may pose the most significant health threats (Health Canada, 2008; Watts et al., 2017, 2018). Indirect impacts represent a complex interaction between ecological, physical, economic, and social systems to impact health (Haines et al., 2006; Portier et al., 2010; Health Canada, 2008). Indirect health outcomes are well documented in the literature (Frumkin et al., 2008; Portier et al., 2010; Gough et al., 2016; Health Canada, 2008; Public Health Ontario, 2014; WHO \& WMO, 2012).

The IPCC's fifth assessment of climate change presented climate change impacts as reported in 8 regions between 2001 to 2010 (IPCC, 2014d). These regions included Polar regions (Arctic and Antarctic) North America, Europe, Central and South America, Africa, Asia, Australia and small islands. In North America, IPCC (2014) reported a variety of impacts that have been observed based on various studies from 2001 to 2010. Physical system impacts include reduced glacial, snow, ice and permafrost cover, changes in levels and quality of water in rivers and lakes, floods, and wildfire. Impacts on biological systems were associated with effects on terrestrial and marine ecosystems. Human impacts reported included impacts on livelihood, economy and health. IPCC (2014) also identified climate change risks related to damages from wildfires, heatrelated mortalities and increased risks of urban and coastal flooding.

In Ontario, the province is vulnerable to health impacts associated with several climate change hazards. Morbidity and mortality will result from extreme weather events, air pollution, food and waterborne diseases resulting from inadequate food and water quality and quantity, increase in the transmission and seasonality of vector-borne diseases, and exposure to ultraviolet rays resulting in cancers, skin and eye effects, and immune disorders (Gough et al., 2016; Ebi, Anderson, Berry, Paterson, \& Anna Yusa, 2016; Berry, Clarke, Fleury, \& Parker, 2014).

\subsubsection{Extreme weather events}

Changes in temperature and precipitation results in extended periods of heatwaves, reduced incidences of cold waves, extreme events such as heavy precipitation, flooding, drought and intense storms with both direct and indirect health consequences (Berry et al., 2014; Watts et al., 2015). The 2009 report by the EPCCA indicated that the frequency of extreme events had not yet been observed in Ontario by the time of the reporting, but, the panel acknowledged that the province was vulnerable to these events. However, Gough et al. (2016) and the Ontario MOECC (2011) report that Ontario continues to experience increased frequencies of heat waves, 
torrential rain and wind storms, and drought. Ontario MOECC (2015) also reports that Ontario has already experienced some of the extreme weather effects resulting from ice storms, severe flooding, and compensations from damaged infrastructure. Between 2003-2012, Ontario experienced nine floods, two winter storms, four severe storms and thunderstorms, four tornadoes and four wildfires (PHO, 2014b). During the same period, emergency visits due to natural heat increased from 600 (2003) to 1400 (2012), an increase of over 130\%. This was countered by a $57 \%$ decrease in emergency visits due to the natural cold. By 2009, extreme events resulted in 2003 deaths in Ontario; these mortality figures do not account for those related to extreme heat events (Ontario Centre for Climate Change Impacts and Adaptation Resources - OCCIAR, 2015).

Cheng, Auld, Li, \& $\mathrm{Li}$ (2012) projects up to a $50 \%$ increase in days with over $25 \mathrm{~mm}$ of rainfall by late this century and up to $55 \%$ increase in freezing rains by 2100 in Ontario. Extreme weather events resulting from unprecedented changes in precipitation and temperatures have direct and indirect impacts on human health (Greenough et al., 2001). Severe heat events are anticipated to be more severe in southern Ontario; severe heat events $\left(>32^{\circ} \mathrm{C}\right)$ is likely to increase incidences of mortality in those over 65 years (Smoyer, Rainham, \& Hewko, 2000). By 2015, Toronto experienced approximately 20 days with extreme heat $\left(>30^{\circ} \mathrm{C}\right) ; 46$ additional days of extreme heat are anticipated by 2049 (Toronto Public Health [TPH], 2015). In Southwest Ontario, the number of mean daily temperatures above $18^{\circ} \mathrm{C}$ has consistently increased, as illustrated by the temperature increases in Chatham Ontario (Berrang-Ford, MacLean, Gyorkos, Ford, \& Ogden, 2009; Berry et al., 2014).

The province also continues to experience the impact of severe weather on both private and public infrastructures (MOECC, 2012). In 2005, a storm damaged public and private properties in Toronto, washing away part of a major road, breaking two gas mains and flooding over 4200 basements. The total damage was estimated at over $\$ 590$ million. Between 2009 and 2010 , tornados and windstorms resulted in over $\$ 306$ million of losses, disrupted infrastructure (electricity and gas) and caused personal injuries. The 2009 tornado event in Vaughan Ontario led to over $\$ 76$ million of losses (Ontario MOECC, 2011). In 2011, a lightning storm in Northwestern Ontario resulted in forest fires that lasted for two weeks, evacuated of 3292 people from communities nearby, and let to individual losses resulting from power outages, including lack of food storage and shortage (Ebi et al., 2016). Overall, extreme weather events resulted in over 700,000 utility disruption and over 10,000 evacuations between 2003 to 2012 (PHO, 2014a). Between 1900 to 2005, floods in Ontario accounted for many of at least 170 floods recorded in Canada; out of the 52 fires recorded between 1900 to 2005, about 31\% (16) occurred in Ontario (Health Canada, 2008). 


\subsubsection{Air quality}

Pollutants associated with climate change have the potential to impact air quality and health. Temperature increases and other meteorological activities related to climate change affect air quality by influencing the concentrations of the various chemicals present in the air (Berry et al., 2014; Hassan, Hashim, \& Hashim, 2016). Climate variables such as temperature, wind, humidity, and precipitation influence the chemical and biological pathways of pollutants, determining their transformations and deposition (Kelly, Makar, \& Plummer, 2012). Pollutants such as ozone, sulphur dioxide, nitrogen oxide, carbon monoxide, and particulate matter (PM) have all been associated with premature mortality (Ontario Medical Association [OMA], 2005). Biological contaminants and allergens have also been associated with climate change-related air quality health impacts (Berry et al., 2014; Schenck, Ahmed, Bracker, Debernardo, \& Cih, 2010). Also, there is a direct association between an increase in temperature and an increase in groundlevel ozone, which causes smog (Ontario College of Family Physicians, n.d.). Kelly et al. (2012) projected air quality in North America using a ten-year (1997 to 2006) period and two climate scenarios (2040 and 2050). The study demonstrates an overall increase in levels of ozone, up to 10 parts per billion by volume (ppbv) and an increase in the levels of particulate matter by 0.5 micrograms per meters cubed $(\mu \mathrm{g} / \mathrm{m} 3)$ to $1 \mu \mathrm{g} / \mathrm{m} 3$. While the changes in Canada are slightly lower than United States, an overall reduction in key pollutants is anticipated in Ontario, including a reduction in the levels of ozone, PM, nitrogen, and sulfur. However, according to (Berry et al., 2014), levels of ozone are anticipated to increase by 4 to 5 ppbv in Ontario. Great Lake regions in Ontario are particularly vulnerable to ozone and PM air pollution; southern Ontario is also susceptible to ragweed and fungal pathogenic air contamination (Berry et al., 2014). Even with the projected decrease in air pollution in Ontario, the anticipated increase in most areas of North America compromises the health of Ontarians due to the ability of such pollutants to disperse to longer distances.

Ontario is also vulnerable to air quality impacts of air pollution resulting from increasing amounts of fires in the province. Compared to the 10-year average of 855 fires, the province saw an increase in forest fires, recording 1324 fires in 2018 and 537 in 2019 (Government of Ontario, 2020).

Air pollution has been linked to respiratory, cardiovascular and cancer outcomes and reduced physical activities (OCCIAR, 2015; WHO, 2014b). Overall, WHO has attributed 7 million deaths a year to pollution (WHO, 2014). In Ontario, the OMA estimates the impacts of smogrelated pollution in the province to be approximately 5800 deaths each year (OMA, 2005). Such statistics are accompanied by a steady rise in hospital emergency service visits and admissions, 
mostly from cardiovascular complications and some respiratory issues. Over 16,000 hospital admissions and more than 60,000 emergency visits were associated with air pollution in 2015; these are anticipated to rise by almost 10,000 and 20,000, respectively, by 2026 (OMA, 2005). Cheng et al. (2012) project that deaths attributed to air pollution is likely to increase by up to $50 \%$ by the end of this century compared to the historical year of 1954 to 2000 . In the city of Toronto, poor air quality results in about "1,300 premature deaths and 3,550 hospitalizations" every year (TPH, 2015).

\subsubsection{Foodborne and waterborne illnesses}

Changes in temperature, precipitation and the weakening of infrastructure are likely to increase incidences of infectious diseases by influencing the replication and persistence of pathogens, and the seasonality and distribution of food-, water- and vector-borne diseases (Crabbé \& Robin, 2006; K. M. Thomas et al., 2006). While there are limited studies addressing the prevalence of water- and waterborne diseases in Ontario, studies in other parts of Canada have demonstrated the significant influence of climate on such diseases. A cross-sectional study in Quebec found a positive association between acute gastroenteritis and levels of precipitation (Febriani et al., 2010). Fleury, Charron, Holt, Allen, \& Maarouf (2006) correlated three reported pathogenic foodborne illness and ambient temperature in two Canadian provinces. The analysis demonstrated a positive association between temperature and the reported cases of Campylobacter, Salmonella, and enterotoxigenic Escherichia coli (E. coli). Ravel et al. (2010) found a positive relationship between ambient temperatures and Salmonellosis. Thomas et al. (2006) analyzed the relationship between extreme weather events and incidences of waterborne outbreaks. The study revealed a positive association between increased temperature and rainfall and waterborne disease outbreaks in Canada. Crabbe et al. (2006) circumstantially connect the impacts of climate and waterborne disease using the 2000 Walkerton outbreak that led to 7 deaths in Ontario. While drinking water operation negligence played a role in the outbreak, climate variables exposed the vulnerability of drinking water systems contamination from changes in precipitation. In the Walkerton outbreak, high amounts of rainfall following a dry season flooded agricultural lands, contaminating the drinking water system with deadly $E$. coli $0157: H 7$ and $C$. jejuni among other contaminants (Crabbé \& Robin, 2006; O'Connor, 2002a, 2002b).

Warm weather favours the proliferation of algae (Pilotto et al., 1997). Over the past 15 years, increased blooms of blue-green algae (Cyanobacteria) have been observed in Ontario's surface water systems (Berry et al., 2014; Orihel et al., 2012). Since 1994, there has been a significant increase in an algal bloom in Ontario. Although a substantial increase is experienced 
along the Canadian Shield, algal blooms are now reported even in the late fall seasons compared to the 1990s (Winter et al., 2011). The occurrence of cyanotoxins in water systems poses a significant health concern. Cyanobacteria produce toxins that can contaminate drinking and recreational water, air, and seafood; these toxins can be consumed, inhaled or absorbed by the skin (Berry et al., 2014; Health Canada, 2016; Orihel et al., 2012). The toxin can poison the liver, nerve tissues, cells and gastrointestinal system and cause skin irritation (Funari \& Testai, 2008).

\subsubsection{Vector-borne disease infections}

Long-lasting shifts in weather patterns influence the transmission dynamics and geographical distribution of vector-borne disease (Berry et al., 2014; Brown et al., 2015; Chen et al., 2013; Hongoh, Berrang-Ford, Scott, \& Lindsay, 2012; Ogden, 2016; Ogden et al., 2008; Githeko, Lindsay, Confalonieri, \& Patz, 2000). The disease vectors, such as ticks and mosquitoes, and the pathogens they transmit respond independently to a diverse range of climate factors including mean temperatures, precipitation, and humidity (Githeko et al., 2000; Ogden, 2016; Sutherst, 2004; WHO, 2014a; Wu, Lu, Zhou, Chen, \& Xu, 2016; PHO, 2016).

Warmer seasons, altered precipitation patterns with drier springs and wetter falls, declining thicknesses of ice and snow, and melting permafrost characterize Canadian climatic changes (NRC, 2015a, 2015b; EPCCA, 2009; Zhang et al., 2010). The current and projected patterns are likely to influence the epidemiology of vector-borne diseases, supporting the expanded distribution and the emergence of invasive diseases vectors and the infections they transmit across Canada. Currently, West Nile virus (WNV) and Lyme disease, spread by mosquitos and black-legged ticks, respectively, are the primary vectors of concern in Ontario and across Canada. Climate variables, especially temperature, have played a substantial role in the prevalence of the two vector-borne diseases in Canada, and particularly in Ontario. Ontario's susceptibility to impacts of vector-borne disease due to climate change is well documented; favourable climate conditions have played a significant role in driving ecology and epidemiology of the two vector-borne diseases. Since reporting of WNV and Lyme disease commenced in 2002 and 2009 respectively, surveillance data show that Canada has reported 5414 and 3999 cases by 2016 (Government of Canada, 2015; PHAC, 2017). However, between 2009 to 20016, Lyme disease was the most reported (3999 cases compared to 867 for WNV). Most of the incidences occurred in Ontario (Government of Canada, 2015; Habegger, 2014). Between 2009 to 2016, Ontario accounted for over $22 \%$ of WNV cases in Canada; the number of Ontario cases increased from 39 reported infections in 2009 to 323 cases in 2015 (Government of Canada, 2015). Equally, since the identification of WNV in 2001 in Ontario, the virus has expanded northward to previously 
non-endemic areas due to the changing climate (PHO, 2014b, 2015; Zheng, Drebot, \& Coulthart, 2014). In 2002 and 2012, Ontario recorded the highest number of human WNV cases and positive mosquito pools (PHO, 2016a; PHAC, 2017). These years also marked above-average summer temperatures. Conversely, 2014, 2009, and 2004 recorded low prevalences that corresponded to some of the coolest summer temperatures recorded. By 2100, WNV and Lyme disease are expected to be endemic in most, if not all, parts of Ontario (Hongoh et al., 2012; Ogden et al., 2008). Climate change is currently supporting the spread of Eastern Equine Encephalitis, a mosquito-borne disease currently reported in horses across Canada (Berry et al., 2014; OCCIAR, 2015; PHO, 2014a)

Ontario's vulnerability to exotic mosquito-borne infections such as Dengue, Zika, Malaria, Chikungunya, among others, is evident (Awuor \& Melles, 2019). Mosquito vectors such as the Aedes aegypti that transmit Dengue fever and $A$. albopictus that transmit Zika and chikungunya are now present in Ontario (PHO, 2015a, 2016b; Windsor-Essex Country health Unit, 2016). Temperatures in Ontario are now becoming suitable for Malaria disease vector, Anopheles mosquito (Berry et al., 2014). A threshold temperature of $18^{\circ} \mathrm{C}$ determines the transmission of the malaria parasite (Berrang-Ford et al., 2009). The number of days above this reference temperature has continued to rise in Ontario over the years; these increases are likely to support the survival transmission of malaria. While the transmission is likely to occur when there are competent mosquito vectors, travel and trade and immigration are likely to increase Ontario's vulnerability to infections (Petersen et al., 2016; Reisen, 2013; WHO, 2014a; Health Canada and PHAC, 2010; Petersen et al., 2016; Sutherst, 2004; Abelsohn, Rachilis, Rosen, \& Kasperski, 2008). Unfortunately, many Canadians do not perceive themselves to be at risk of vector-borne diseases; only $16 \%$ have some knowledge of their vulnerability to WNV, the currently endemic mosquito-borne disease in Canada (Berry et al., 2011).

\subsubsection{Psychological, social, and economic impacts}

Areas exposed to climate change hazards are the most likely to experience socioeconomic impacts that with directly or indirectly impact on health and wellbeing of individuals and communities (Portier et al., 2010a). Increased morbidity and mortality associated with climate change impacts from infectious diseases, water, air and food pollution, and extreme events can put unplanned pressure on health protection and disease prevention system leading to increased demand in services (Campbell-Lendrum, Corvalán, \& Neira, 2007). Extreme events such as floods and tornadoes are likely to cause damage to critical infrastructures that support the production of food, energy, and potable water, and the management of waste, storm and 
wastewater, sanitary conditions; such events can also cause stress and trauma associated with relocations, loss of loved ones and economic losses from damaged properties (Hamlet, Lee, Mickelson, \& Elsner, 2010; Liu et al., 2013; Parry, Rosenzweig, Iglesias, Livermore, \& Fischer, 2004; Patz, Campbell-Lendrum, Foley, \& Holloway, 2005). For instance, in Ontario, the impacts of climate change are likely to influence the economic significance of the province's natural resources such as forestry, mining, and energy. Specifically, Ontario is likely to have financial consequences from reduced quality and quantity of timber (OCCIAR, n.d.). There is a likely 30$40 \%$ drop in lake trout (cold-water species) by the end of the century due to warming water (Minns, 2009). A $10-20 \%$ reduction on the number of skiers to ski resorts has been experienced between 2000 to 2010 in Ontario (Warren \& Lemmen, 2014). Climate change is also likely to negatively impact Ontario's competitive advantage in trade and manufacturing (OCCIAR, n.d.).

In short, climate change risks can be summarized as diverse; the potential impacts are irreversible and inequitable (Campbell-Lendrum et al., 2007).

\subsubsection{The conception of health impacts}

Given the diverse impacts, climate change is a significant public health threat (Maibach \& Nisbett, 2011; Watts et al., 2015; USGRP, 2016). Yet, a common conception is that the health impact is poorly understood (Akerlof et al., 2010; Berry, Clarke, \& Pajot, 2011). For instance, while many people do not understand the scientific basis of climate change and its consequences (Lorenzoni et al., 2005), studies prominently show that human health impacts of climate change are poorly understood by the public, health professionals, and even the elected politicians who play a significant role in climate change policies (Akerlof et al., 2010; Debono, Vincenti, \& Calleja, 2012; Howe, Mildenberger, Marlon, \& Leiserowitz, 2015; Maibach et al., 2010). Many people do not rank climate change as a major health risk or see themselves vulnerable to climate change (Akerlof et al., 2010; Berry et al., 2011).

To illustrate, Akerlof et al. (2010) compared perceptions of health consequences of climate change in Canada, the United States and Malta. The study revealed that the health impacts of climate change lacked prominence and were poorly understood by many in all three countries.

Berry et al. (2011) also found that many Canadians are not aware of the health impacts of climate change. Incomprehension of health impacts reveals the failure of climate change communication processes and the attitudes towards climate change knowledge. Specifically, over $50 \%$ of Canadians do not view climate change as a future risk; only $32 \%$ rank it as a major health risk; despite being at greater risks, over $75 \%$ of seniors do not think they are vulnerable to the health impacts (Akerlof et al., 2010; Berry et al., 2011). 
McFarland \& Huffman (2017) surveyed 401 residents of Owen Sounds Ontario to gather their knowledge of climate change awareness and perceived impacts, concerns, and beliefs. The study revealed that most people were aware $(95 \%)$ or concerned $(86 \%)$ of climate change. While over $92 \%$ of the respondents believed vehicle emissions contribute to climate change, only $61 \%$ believed in the impacts of home energy; $28 \%$ believe home energy does not contribute to climate change. More than half believed climate change would impact extreme events $(66 \%)$, frequent heat waves $(79 \%)$, and air quality $(62 \%)$. Climate change air quality impacts varied by gender; more women (67\%) than men (55\%) believed climate change would negatively impact air quality. Overall, $30 \%$ of respondents believed climate change negatively impacts health, $12 \%$ thought it positively impacts health, $16 \%$ thought climate change poses both positive and negative health impacts, $6 \%$ believed there are no health impacts while $37 \%$ did not know.

Such studies reveal the varied perceptions people hold regarding climate change and the influences of people's values on knowledge and policies on climate change. However, CampbellLendrum et al. (2007) also acknowledge that many of these health impacts can be prevented or avoided through short- and long-term interventions within public health and across sectors whose activities or policies have direct and indirect health impacts. Furthermore, the continued emission of anthropogenic GHGs is likely to result in dangerous climate, identified as a $2^{\circ}$ Celsius (C) increase in global surface temperatures (Costello et al., 2009; IPCC, 2007c; Lorenzoni et al., 2005; Rijsberman \& Swart, 1990; UNFCCC, 2016, 2017). This temperature threshold has become the foundation for climate change actions, setting a massive discourse on global climate policies (Costello et al., 2009; Lorenzoni et al., 2005; UNFCCC, 2016, 2017)

\subsection{PUBLIC POLICY AND THE CLIMATE CHANGE POLICY RESPONSES}

\subsubsection{Public Policy}

Public policy, although very common in political science and often used in governance discussions, encompasses different definitions from different perspectives of a policy process (Cairney, 2012c). An examination of public policy must begin with an understanding of the terms "public" and "policy" (Parsons, 1995). The "public" nature of policies relate to the analogy of viewing an issue as an aspect of human activity that requires regulation through societal or government interventions (Parsons, 1995). According to the Canadian Encyclopedia of Public Policy, a "policy" can relate to two meanings: as rules and procedures or as actions of a government (Historica Canada, 2019). That is, how a government does things administratively or substantively to define or formulate actions. In turn, public policy portrays both the purpose of 
government actions and means of achieving the objectives of specified actions. Parsons (1995) further signifies that "policy" as a term is "an expression of political rationality." That policy portrays rational reasoning about an understanding of the issue and how to solve the issue. Therefore, a commonly cited definition of "policy" is what a government does or fails to do (Miljan \& Brooks, 2018). That is, "public policy" portrays a claim of the legitimate role of the state and politics in the process and outcome. It recognizes the role of government in administrative policies and policy instruments and the influence of politics on public policy processes, where politicians choose policies based on their preferences (Cairney, 2012c; Historica Canada, 2019; Miljan \& Brooks, 2018; Parsons, 1995).

Several interpretations and characteristics of public policy exist. Public policy can refer to "an aim, a decision or an outcome," or an intention (Cairney, 2012c). The processes and outcomes vary by issue, region, types of stakeholders involved, historical influences, and policy area, and, it is characterized by a government's action or inaction which is unlikely to be distinguished from administration; and can lead to visible and invisible outcomes (Cairney, 2012c; Goodin, Rein, \& Moran, 2008; Hogwood \& Gunn, 1984). Cairney (2012) characterizes the ten various types of public policy. These include an understanding of public policy as a field of study, an expression of intent, a specific proposal, a program, a package of legislation, staffing and funding, intermediate and ultimate outputs, outcomes of what is actually achieved, a process, or a series of decisions designed to respond to an issue.

\subsubsection{Climate Change Policies}

Tackling climate change relies on two broad categories of policies: mitigation and adaptation strategies. Mitigation strategies aim to reduce or minimize the amount of GHGs, primarily carbon dioxide, methane, and nitrous oxide, and enhance carbon sinks (Frumkin et al., 2008a; Haines et al., 2006; IPCC, 2014b). Reducing the amounts of GHG can include a range of actions such as the use of renewable energy (IPCC, 2007c, 2014b; Sathaye et al., 2011), sustainable transportation (IPCC, 2007, 2014a; WHO, 2011), land use planning and adaptive building designs (Flowerdew, Manley, \& Sabel, 2008; O'Campo et al., 2015; Roux \& Mair, 2010; Watts et al., 2017). Mitigation can involve converting agricultural waste to biofuels and manure, capturing methane from landfills, and waste management practices can reduce soil, air, and water pollution and the deposition of waste to landfills (WHO, 2011; Dora et al., 2015; IPCC, 2007b; IPCC, 2014; OMAFRA, 2017). Mitigation can be supported through the sustainable production of agricultural foods and supporting the consumption of fruits and vegetables (WHO, 2011). Several 
sectors have been identified to be relevant in GHG reduction. These sectors include energy, agriculture and forestry, buildings and residential housing, industry (IPCC, 2014a; WHO, 2014a).

Adaptation strategies are measures taken to cope with the impacts of climate change (IPCC, 2007, 2014; Watts, et al., 2015, 2018; Stocker et al., 2013). Adaptation targets climate change through actions that reduce or manage the risks resulting from climate change impacts and build resilience within communities and various systems (political, economic, social and environmental). There are several strategies for adapting to, and building resilience for, climate change impacts. However, many options are informed by the unique and diverse array of geographical risks, vulnerabilities, and impacts (IPCC, 2014b). Actions can include ecosystem protection (e.g. protecting plant and animal habitats on land and water), preserving wetlands and biodiversity, maintaining water quality (e.g. storm-water management, source protection, and the construction, maintenance of water and food security infrastructures (EPA, 2019; Watts et al., 2015, 2017, 2018; WHO, 2014b). Adaptation and resilience actions can target direct and indirect health outcomes by acting on the SDOH that determine climate-sensitive diseases (WHO, 2014; Watts et al., 2017, 2015, 2018). Actions associated with direct health impacts can include approaches for managing extreme event impacts such as early warning systems for extreme events or actions to reduce the burden of heatwaves, for example (Watts et al., 2017, 2015, 2018). Actions targeting storms and floods are two-fold: structural (e.g. dams or dykes to keep floodwater away from people and infrastructure) and non-structural (e.g. zoning bylaws prohibiting the construction of infrastructure along floodways; floodproofing) (Watts et al., 2017, 2015, 2018).

Adapting to the indirect health impacts is challenging due to the complexities of, and the difficulty in, predicting such outcomes (Costello et al., 2009; Watts et al., 2015). However, actions can include enhancing water infrastructure as well as promoting food security through agriculture, aquaculture and fisheries. Adaptation can also be supported through the availability of coping mechanisms and livelihood that minimize migration of people from climate-affected areas; these actions can include both institutional and humanitarian policies and responses (Costello et al., 2009; Watts et al., 2015, 2018). Responses can include land degradation and water management policies, provision of services and economic investments (Watts et al., 2015). Other actions include strengthening the disease surveillance and monitoring initiatives that allow for the collection of data for analyzing trends, vulnerabilities and risks; investing in public health or building resilient public health systems (e.g. sustainable infrastructures and programs; availability of financial, technological, and human resources) that enhance public health's capacity to deal with the health impacts, and, linking the health needs to the broader government policies (Costello et al., 2009; Watts et al., 2015). 


\subsubsection{Locating Historical Climate Change Responses}

Policies on climate change began with the formation of the World Climate Conference in 1979 (UNFCCC, 2017). The conference supported the use and improvement of existing knowledge for understanding the climate change phenomenon and reducing anthropogenic input (UNFCCC, 2017). Over the years, several progressive achievements have followed. First, the Intergovernmental Panel on Climate Change (IPCC) set up in 1988, continues to provide scientific, technical, and socioeconomic information on climate change (UNFCCC, 2017). The first IPCC report in 1990 expressed concerns that launched international negotiations and the formation of UNFCCC, an intergovernmental treaty for addressing climate change. Second, UNFCCC established the objectives for limiting GHGs and set up the decision-making body, Conference of Parties (COP) (UNFCCC, 2017). Third, the COP, convened in 1995, have served as formal meetings for discussing and to negotiate climate policy since 2005 (UNFCCC, 2017). The negotiations have led to several climate policies across countries. For instance, the Paris Agreement negotiated at COP21 and entered into force in 2016, saw 175 out of 197 parties to the United Nations (UN) embark on ambitious goals to mitigate and adapt to climate change (UNFCCC, 2016, 2017; WMO, 2009). Over 88\% of the convention members agreed to minimize global temperature rise "below 2 degrees Celsius above pre-industrial levels and to pursue efforts to limit the temperature increase even further to 1.5 degrees Celsius" (UNFCCC, 2016). As a result, climate policies have dominated policy discourses across various governments throughout the world.

Currently, signatories to the UNFCC have agreed on both mitigation and adaptation policies and information for influencing actions (Dearden \& Mitchell, 2016; Shaw, 2017). Achieving such ambitious goals requires technology, investment, and behaviour change that target the diverse cultural, social, economic, and political setting (Watts et al., 2015). Currently, a meaningful reduction of GHG concentrations and concrete adaptation strategies are lagging. GHGs continue to rise at record concentrations, trapping nearly $41 \%$ of heat in the earth's atmosphere between 1990 to 2017 (WMO, 2018). While climate change actions dominate international and national policy agendas, actions have not resulted in a meaningful reduction of GHGs (IPCC, 2014; Thompson, 2010; Watts et al., 2018; WMO, 2018). Besides, there is often less engagement at the local levels (Romsdahl, Blue, \& Kirilenko, 2018). Minimizing global temperature increases below $2^{\circ} \mathrm{C}$ by 2100 is unlikely(Raftery et al., 2017) and is likely to result in a dangerous climate in the next two to three decades (IPCC, 2013b, 2014b; Thompson, 2010; Watts et al., 2018). 


\subsubsection{Ontario's Climate Change Policies}

The contexts of climate change policy decision in Ontario are influenced by various factors, specifically, its social and economic characteristics, the political culture, and constitution (Miljan \& Brooks, 2018); these characteristics have been identified to influence both climate change decisionmaking and actions (IPCC, 2007b, 2007c; Stocker et al., 2013).

\subsubsection{Geography, demographics, urbanization, and economy}

Ontario is one of the ten provinces of Canada located in East-Central Canada (Figure 2: Map of Canada depicting the $\mathbf{1 0}$ provinces and $\mathbf{3}$ territories). Ontario is also Canada's most populous province, with a population of approximately 13.4 million as per the 2016 Canadian Census Profile (Statistics Canada, 2016). This population occupies a land area of 908,669.33 square kilometres with a population density of 14.8 per square kilometre [km²] (Statistics Canada, 2016). In 2006, the rural areas accounted for $14.9 \%$ of the population (Ontario Ministry of Finance, 2010). Population and urbanization are important determinants of GHG emissions and have been used by IPCC to project future GHG scenarios (IPCC, 2007b, 2007c; Stocker et al., 2013). Population density is associated with different consumption and lifestyle patterns that are likely to influence individual carbon footprints. For instance, population density has also been correlated with on-road vehicle fleets, a significant factor for GHG emissions. A 2008 survey conducted by NRC revealed that Ontario's vehicle fleet accounted for over $36 \%$ of Canada's on-road vehicle fleet (Government of Canada, 2010). Given the low population density per $\mathrm{km}^{2}$, many will drive longer distances for leisure and to access services. In 2008, the average annual distance travelled by vehicles in Ontario was 16,000 and 21,400 km per year for lightweight vehicles and trucks, respectively (Government of Canada, 2010). During the operations, the light vehicles consumed gasoline at approximately 11 litres per 100kilometre $(\mathrm{L} / 100 \mathrm{~km})$; medium and heavy trucks consumed diesel at 23 and $35 \mathrm{~L} / 100 \mathrm{~km}$, respectively. GHG emissions from these vehicles have a significant impact on both public health and climate change policies. Also, higher populations mean that public health will have to address various vulnerabilities and risks to climate change impacts.

The province's economy has been defined by major sectors such as agriculture, manufacturing and industries, energy production and transportation (Government of Ontario, 2007c; (Government of Canada, 2019b; Polese, 2018; Statistics Canada, 2018). These have been linked to GHG emissions. And, like population growth, economies have substantial impacts on GHG emissions (IPCC, 2007b, 2007c; Stocker et al., 2013). The distinctive economies, as well 
as the social aspects, drive politics (McKenzie, 2001; Miljan \& Brooks, 2018) can define the direction of climate change policies through norms defined by political and partisan ideologies.

\subsubsection{The Constitution and the political culture}

The province of Ontario's roles in climate change policies is likely to be influenced by governance structures defined by the system of government in Canada (Miljan \& Brooks, 2018). Canada is a federal state (Jackson \& Jackson, 2006; Miljan \& Brooks, 2018). Federalism refers to a form of government where jurisdiction and authority are shared amongst two or more levels of government (Jackson \& Jackson, 2006). In the Canadian Federalism, two levels of autonomous governments are recognized: the federal and provincial governments (comprising ten provinces). However, two additional forms of government exist; these include territorial and local governance structures (Miljan \& Brooks, 2018). The provincial and territorial governments are already depicted in Figure 2: Map of Canada depicting the 10 provinces and 3 territories. Responsibilities and the distribution of power and authority between the governments are determined by the Constitution.

\subsection{The Constitution and climate change policies in Ontario}

Constitution refers to "a set of fundamental laws that determine the central institutions and offices, and powers and duties of the state" (Cairney, 2012). The constitutional influence is particularly important because Canada's Constitution (Constitution Act (1867)) sets formal rules that govern the separation of power that influencing policymaking styles in the country's federal system (Field \& Olewiler, 2011; McKenzie, 2001; Miljan \& Brooks, 2018). The Canadian Constitution, only recognizes the federal and provincial governments (Government of Canada, 2019b; Miljan \& Brooks, 2018). The territories and local governments fall under the jurisdiction of the federal and provincial governments correspondingly (Jackson \& Jackson, 2006). The constitutional powers and authority that guide the federal and provincial governments are specified in Sections 91 and 92 of the Constitution respectively (Field \& Olewiler, 2011; Gall \& McLellan, 2017; McKenzie, 2001). The federal government enacts and implements laws that govern the whole of Canada while the provincial governments each enacts and implements laws governing their respective jurisdictions (Government of Canada, 2019b). However, included in Section 91 is the clause of Peace Order and Good Government that provides the federal government with additional powers over provinces (Gall \& McLellan, 2017; Government of Canada, 2019b). The broad and vague scope of federal power has been interpreted to mean that the federal government has powers over provinces in matters not described in Section 91 and 92 of the Constitution. These include emergency and national concerns and where there is overlap 
between laws of the two levels of government (Gall \& McLellan, 2017). Historically, the overlapping roles have led to contradictory, and sometimes lack of, action on environmental issues. McKenzie (2001) provides examples such as the laxity in pollution and air quality regulations between the two levels of government. Overall, the division of power can have a significant influence on Ontario's climate change policies.

In the Constitution, there is no direct mention of the environment. However, as an environmental issue, climate change touches the various aspects of the environments specified in the Constitution. These include land, water, air, and natural resources (Field \& Olewiler, 2011; Gall \& McLellan, 2017; Government of Canada, 2019b; McKenzie, 2001). Each level of government has a role in climate change policies. There are also some overlapping jurisdictions in relation to air quality (McKenzie, 2001). However, provinces lead environmental policies in Canada as many environmental aspects such as land and natural resources are located within the provincial jurisdictions (Field \& Olewiler, 2011; Gall \& McLellan, 2017; Government of Canada, 2019b; McKenzie, 2001; Miljan \& Brooks, 2018). Such contexts are influenced by political and institutional arrangements for governing environmental issues.

In Ontario, the environmental rights are also embedded in the Environmental Bill of Rights (1993). The Bill gives Ontarians formal and formal rights to participate in environmental decisionmaking processes. Through the Environmental Bill of Rights (1993), Ontario has provided a website, Environmental Registry, where the government's environmental decisions, proposals, policy notices, including those related to climate change, are posted for public comments.

\subsection{Politics culture and institutional arrangements}

Ontario, like other provinces and the federal government, practices a cabinet government consisting of the legislative assembly and the lieutenant-governor (Ruff, 2015). The LieutenantGovernor, appointed by the federal cabinet, represents the crown, modelled under the British parliamentary system. The legislative assembly consists of those democratically elected by the people to represent them and pass laws (Legislative Assembly of Ontario, 2019; Ruff, 2015). The legislative assembly is headed by the Premier of the political party in power (Ruff, 2015). In Ontario, the political parties include the Progressive Conservative Party of Ontario (PC), Ontario Liberal Party (Liberals), National Democratic Party (NDP) and the Ontario Green Party. The Premier, then selects cabinets, from within the party, who hold ministerial appointments for various areas of provincial policy areas representing the 24 ministries in Ontario. Some of the ministries include health, environment, transportation, energy, infrastructure, agriculture, and natural resources, among others. In theory, lawmaking in the province is defined by the legislative 
assembly and the Lieutenant-Governor. However, within the legislative assembly, policymaking has been controlled by the selected cabinet members (Ruff, 2015). Actions in the legislature are mainly influenced by party loyalty by the members of the assembly and the domination (Ruff, 2015). As a result, the legislature is mainly dominated by the Premier and the Cabinet due to political party loyalty, power of party leadership and their control of the assembly. This has significantly influenced the lawmaking powers of the cabinet members and ministers who head the various ministries formed to shape the operation and administration of government's needs. These features are especially relevant because the provincial governments have authority over various environmental functions and regulations operated and legislated by its various ministries and municipalities - local governments as created and legislated by the provinces. Such power can significantly influence the politics of climate change polity in Ontario.

For instance, each political party and the resultant cabinets or ministers can have divergent views and culture on public policy (and specifically, climate change policies). Since the issues of climate change began to dominate Ontario's agenda in 2008, two parties have governed Ontario: Liberals (2003 to May 2018, with a minority government between 2011 to 2014) and PC (June 2018 to current). Between the two parties, there has been a divergence of values and policies on climate change. To illustrate, while the Liberals had diverse climate change policies, including a cap-and-trade program, the PC cancelled many climate change policies, including the cap-and-trade program, that were developed by its predecessor.

\subsubsection{Ontario's Response to Climate Change}

Ontario's response to climate change can be classified into two: province-wide strategic responses and public health response.

\subsubsection{Province-wide Action on Climate Change}

The province of Ontario is already advancing strategic action on climate change (MOECC, 2014, 2015). The national strategies have mainly been under the leadership of the MECP, formerly the Ministry of Environment and Climate Change (MOECC). The effort to target climate change began with the signing of the 2007 memorandum of understanding between Ontario and California with collaborative effort on GHG reduction and energy efficiency promotion. This was followed by the introduction of the province's first action plan, the Go Green: Ontario's Action Plan (2007) set out the GHG reduction target for 2014, 2020 and 2050, then by the formation of an EPCC in 2007 to guide Ontario's adaptive capacity to climate change (Government of Ontario, n.d.; EPCCA, 2009). The panel advised the province on how to plan and prepare for impacts of 
climate change through its report "Adapting to Climate Change in Ontario," released in 2009 (EPCCA, 2009). The report focused on four broad areas: environment, infrastructure, economy and public health. It provided 59 recommendations to the province. The weight of focus on each area varied considerably but mainly focused on the environment and infrastructure. In 2008, the province identified climate change as a priority issue during the Federation Forum on Climate Change Adaptation Summit in 2008 (EPCCA, 2009). Ontario's response to the recommendations of the experts was the Climate Ready - Adaptation Strategy and Action Plan: 2011 to 2014 (Ontario MOECC, 2011). The plan included 30 action areas that created frameworks for sectoral actions. Consequently, Ontario made significant commitments to facilitate the reduction of GHG emissions and adapt to the impact of climate change within the province. All coal power plants in Ontario closed by 2014 (Ontario MOECC, 2014). The Green Energy Act enacted in 2009 promotes the production and use of clean, renewable energy sources and the transition to clean energy technologies (Ontario MOECC, 2014, 2015). The province introduced the cap and trade system for $\mathrm{CO} 2$ emissions reduction and outlined key actions and legislation to support the proposed cap-and-trade scheme and the capacity for clean and renewable energy (Government of Canada, 2016s).

Ontario's Five-year Climate Change Action Plan: 2016-2020 plan set a foundation for the short- and long-term climate change mitigation and adaptation programs and policies in the province (Government of Ontario, 2016). The plan focused on Ontario's five-year mitigation and adaptation strategies in eight action areas: transportation, buildings and homes, land-use planning, industries and businesses, collaborations with indigenous communities, research and development that support low carbon economies and innovations, government, agriculture, and, forest and land. The plan outlines environmental measures for reducing GHG emissions and transitioning to a low carbon economy in its major economic sector and by major GHG emitters (Ontario MOECC, 2015). The province also proposes to raise public awareness on the impacts of climate change and the public's role in climate change mitigation and adaptation (Government of Ontario, 2015). The plan defined the public's role in climate change actions: reducing their GHG emission footprints through personal practices and choices (Government of Ontario, 2015).

Upon taking office in late 2018, the new government (PC) made drastic changes to climate change policies. The government developed a new climate action plan disregarding the previous government's actions and activities. The Made-in Ontario Environmental Plan (2018) aimed at protecting land, air and water, addressing litter and reducing waste, reducing Ontario's share of GHG and preparing for climate change impacts (MECP, 2018). The new government's actions also included the elimination of cap and trade scheme, the Environmental Commissioner's office, 
the word 'climate change' from the ministry of environment and replacing it with 'conservation and parks' green rebate programs, and reduction in funding to ministries on climate change issues.

\subsubsection{Public Health in Ontario and the Climate Change Response}

\subsection{Structure of the public health system}

In Canada, provinces have autonomy over public health policies. In Ontario, the public health sector is divided into provincial and municipal levels (Government of Ontario, 2013). Each level takes a range of activities to promote health and prevent diseases at the population level. At the provincial level, the MOHLTC develops legislation, standards, and protocols guiding public health practice at the provincial and local levels; the ministry oversees public health funding and sets accountability indicators; it also coordinates emergency response and coordinates with the federal government on health matters (Government of Ontario, 2013; Wilson, 2004).

At the municipal level, Boards of Health $(\mathrm{BOH})$ govern public health within specific geographical jurisdictions - known as Public Health Units (PHUs) - in Ontario under the authority of the Health Protection and Promotion Act (HPPA). There are three types of BOH in Ontario: 25 autonomous, 4 semi-autonomous (or single-tier) and 6 regional $\mathrm{BOH}$ (Association of Local Public Health Agencies, 2018). The majority of $\mathrm{BOH}$ are autonomous where administrative structures of the board are independent of those of municipalities; such boards have multiple representations of municipalities, citizens and the province. Regional $\mathrm{BOH}$ operate under the structure of regional governments; these $\mathrm{BOH}$ have no citizen or public representation. In single-tier structure, the municipal council serves as the $\mathrm{BOH}$ with staff operating under the municipal governance structure. A subset to the Single-tier is the semi-autonomous where municipalities retain budgeting and staff administration but appoint members to a separate $\mathrm{BOH}$. These $\mathrm{BOH}$ have no provincial representation, and citizen representation may be possible in the semi-autonomous structure (Association of Local Public Health Agencies [ALPHA], 2018; Region of Waterloo, 2019).

Within the $\mathrm{BOH}$, the PHUs deliver the provincially mandated health interventions within their jurisdictions; they also develop additional programs based on local needs. PHUs are geographically distinct regions distributed across the province, each governed by a Board of Health (BOH), as illustrated in Figure 4: Public health regions in Ontario (MOHLTC, 2012, 2013). There are 35 PHUs in Ontario; these are further aggregated into 7 distinct regions based on population characteristics and not on decisionmaking abilities, as highlighted in Table 1: Aggregation of 35 Public Health Units into 7 public Health regions (ALPHA, 2019). 


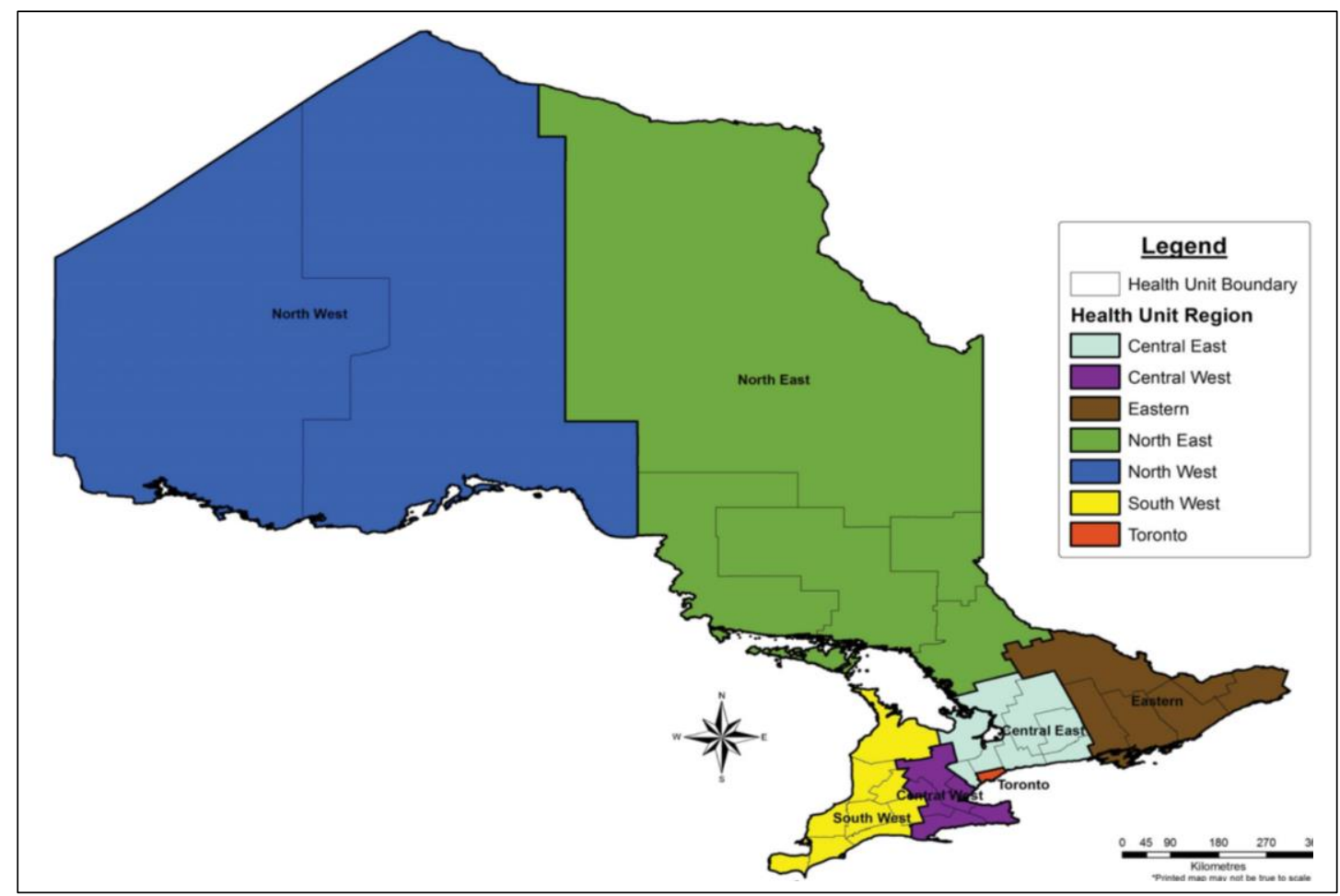

Figure 4: Public health regions in Ontario

Source: Bolotin et al. (2018)

Table 1: Aggregation of 35 Public Health Units into 7 public Health regions

\begin{tabular}{|l|l|}
\hline Region & Public Health Unit \\
\hline North West & Northwestern, Thunder Bay \\
\hline North East & Porcupine, Algoma, Sudbury, Timiskaming, North Bay Parry Sound \\
\hline East & $\begin{array}{l}\text { Ottawa, Eastern Ontario, Leeds-Grenville, Renfrew, Hastings-Prince } \\
\text { Edward, Kingston, Frontenac and Lennox and Addington (KFL\&A) }\end{array}$ \\
\hline Central East & $\begin{array}{l}\text { Haliburton-Kawartha Pine Ridge, Peterborough, Simcoe Muskoka, } \\
\text { Durham, York, Peel }\end{array}$ \\
\hline Toronto & Toronto \\
\hline Central West & $\begin{array}{l}\text { Wellington-Dufferin-Guelph, Waterloo, Halton, Hamilton, Brant, Niagara, } \\
\text { Haldimand-Norfolk }\end{array}$ \\
\hline South West & $\begin{array}{l}\text { Grey Bruce, Huron, Perth, Middlesex-London, Lambton, Southwester, } \\
\text { Chatham-Kent, Windsor Essex }\end{array}$ \\
\hline
\end{tabular}

Source: ALPHA, (2019)

The PHUs vary in size and populations served. Smallest PHU serves less than 35,000 people geographically dispersed over more than 640,000 square kilometres $\left(\mathrm{km}^{2}\right)$; the largest serves over 2.7 million people within $630 \mathrm{~km}^{2}$ (Expert Panel on Public Health - EPPH, 2017). A $\mathrm{BOH}$ governs each health unit under the leadership of a Medical Officer of Health; $\mathrm{BOH}$ mainly consists of elected local municipal representatives (EPPH, 2017; MOHLTC, 2014). 
To meet public health needs in Ontario, PHUs are guided by the Health Protection and Promotion Act (HPPA) and the Ontario Public Health Standards (OPHS) developed by the MOHLTC to establish the minimum mandatory requirements and expectations for implementation and delivery of public health programs and services, including those related to climate change. The programs and services are meant to protect and promote health, prevent diseases and injuries, and reduce health inequities within the populations living in Ontario (MOHLTC, 2018). The public health requirements are informed by five core functions: assessment and surveillance, health promotion and policy development, health protection, disease prevention, and emergency management (MOHLTC, 2018). The functions focus on four domains: $\mathrm{SDOH}$, healthy behaviours and communities, and population health assessment; these also form the objectives of the public health program and service delivery. The public health functions are also grounded on four principles: need, impact, capacity, and, partnership, collaboration and engagement. That is, assessing and tailoring the programs and services according to the needs of the population (need); considering evidence, effectiveness, barriers and performance measurements of programs and services (impact); making the best use of resources to meet the needs of the population (capacity); and, engaging with multiple partners across sectors, communities and priority populations including the Indigenous communities (MOHLTC, 2018). To achieve the goals, domains and the principles of Ontario's public health practice, nine program standards guide public health's work: Chronic disease prevention and wellbeing; food safety; healthy environments; healthy growth and development; immunization; infectious and communicable disease prevention and control; safe water; school health; and substance use and injury prevention (MOHLTC, 2018).

The public health's mandate on climate change is mainly guided by the HPPA which requires PHUs to identify, minimize and mitigate health hazards within their jurisdictions and the Healthy Environments Standards whose goal is to "to reduce exposure to health hazards and promote the development of healthy built and natural environments that support health and mitigate existing and emerging risks, including the impacts of a changing climate" (MOHLTC, 2018). Specifically, the $\mathrm{BOH}$ are required to assess the impacts of climate change and develop effective strategies through collaborations and partnerships (MOHLTC, 2018). Public health acquired this mandate very recently (in 2018). For instance, the previous OPHA (2008) did not have a specific mandate for climate change, but the standards required PHUs to be aware of the risk factors of climate change. 


\subsection{Public health climate change response}

The EPCCA (2009) recommended three public health-specific actions. The experts suggested the province assess and expand public health capacity, tools, and resources to enhance public health emergency response to risks relating to climate change, and to complete an assessment of vulnerability and adaptive capabilities within the province's health regions. In 2013, the MOHLTC's Make No Little Plan laid out the vision, mission, strategic goals, and the public health focus areas (Government of Ontario, 2013). The plan provided a foundation for the Environmental Health Climate Change Framework for Action in a manner that builds public health capacity and resilience. The framework was "designed to support an adaptive and resilient public health system" (Ebi et al., 2016). The framework focuses on promoting healthy environments and strengthening public health capacity, infrastructure and preparedness through system integration, prioritization and program delivery, and enhancing public health capacity and scientific evidence (Ebi et al., 2016; Gough et al., 2016).

To assist the PHU in implementing Environmental Health Climate Change Framework for Action, the MOHLTC developed the Ontario Climate Change and Health Toolkits, which includes two complementary tools for addressing the health-related climate change challenges in Ontario (MOHLTC, 2016). The Climate Change and Health Vulnerability and Adaptation Assessment Guidelines allow PHUs to identify vulnerabilities and implement mitigation and adaptation strategies within their jurisdictions (Ebi et al., 2016; MOHLTC, 2016). The Climate Change and Health Modelling Study provides area-specific health impact assessment guidelines (Gough et al., 2016; MOHLTC, 2016). In addition to the frameworks, two pieces of guidelines laid out the climate change legislative mandate for PHUs prior to 2018. The Health Hazard Prevention and Management Standard mandated the PHU to "increase public awareness of the health risks associated with" health hazards, including climate change (MOHLTC, 2010; PHO, 2008). The Identification, Investigation, and Management of Health Hazard Protocol offered best practices for the development of policies that target the surveillance, investigation, risk assessment, control measures, and timely response to the identified health hazard (MOHLTC, 2008). In 2018, the modernization of OPHS led to a specific mandate for public health in climate change. The MOHLTC also developed two frameworks: the Healthy Environments Standards and the Healthy Environments and Climate Change Guideline. The Healthy Environments Standards aimed to reduce health hazards and develop healthy built and natural environments to minimize risks and impacts of climate change. The Healthy Environments and Climate Change Guideline assist PHUs in identifying and managing climate change health risks through assessments and collaborations with other sectors, partners, and communities. 


\section{$2.4 \quad$ SUMMARY}

Climate change presents a diverse and eminent collection of risks. It is projected to impact the environment, human activities and health, policies, and feasibility of resources and economies. As these structures are impacted, long-term public health consequences are anticipated. And, like the rest of the world, Ontario is not immune to the impacts of climate change. Such impacts and their magnitudes are anticipated to increase.

On the other hand, tackling climate change health impacts relies on reducing greenhouse gases and building resilience to cope with the impacts of climate change. To respond to climate change, Ontario has developed strategies and participated in activities within the province, with other provinces and internationally, to address climate change. Ontario has also identified public health's role and supportive actions on climate change. However, the chapter has also demonstrated that climate change features and their impacts vary by regions and populations. Hence, policies addressing climate change are diverse and strategically positioned to impact the needs of specific geographical areas or groups. Like the rest of the world, Ontario is not immune to the impacts of climate change; such impacts and their magnitudes are anticipated to increase. To respond to climate change, Ontario has developed strategies and participated in activities within the province, with other provinces and internationally, to address climate change. Ontario has also identified public health's role and supportive actions on climate change. Through the various strategic plans and activities, Ontario has identified, prioritized, and communicated the province's key climate change needs and action plans. Many considerations are very relevant to the public health sector. Efforts have included promoting sustainable transportation, dense communities, reduced reliance on fossil fuel, tree planting and conservation, waste reduction and resource recovery from waste, improved agricultural practices, and increased uptake of renewable energy. How public health is integrated into the broader climate change actions will directly or indirectly influence future climate change health outcomes and public health engagement.

Despite increased policy activities locally and internationally, meaningful GHG reduction is lagging. Regrettably, the health impacts are also poorly understood by the public, health professionals, and elected politicians, who play a significant role in policymaking. Many researchers have argued that merely having policies do not translate into actions; steering the policy through awareness and discursive stakeholder input legitimizes the policy and promotes awareness and consensus to action (Alaszewski \& Brown, 2012; Fischer, 2012c, 2012a). Awareness and attention on the issue is influenced by the overall policy image as well as the facts, structures, and values that advance that image; that is how decisoinmakers promote or 
minimize the salience of certain aspects of the issue and the structures, values and knowledge that act as individual's frame of reference (Cairney, 2012c; Fischer, 2012c; Pettenger, 2007b). Furthermore, communicating and managing climate change risks is in a manner that impacts awareness and builds consensus involves complex scientific processes and varied perceptions that are dependent on individual judgments (Lorenzoni et al., 2005; Spence \& Pidgeon, 2010). The stakeholder (whether individuals, organizations or agencies) integrate their perspectives or organizational norms with the risk references to judge the magnitude of risk, source, and moral basis of the communication and the need for consensus on the action required (Alaszewski \& Brown, 2012; Covello, Peters, Wojtecki, \& Hyde, 2001). Meaning that the lack of meaningful actions may point to the way climate change has been presented. As a result, there is a need to examine the discussion and presentation of climate change and how the governance of the issue influences discussion and participation in climate policies to impact awareness and consensus on the actions needed. 


\section{CHAPTER 3: PERSPECTIVES FROM THE LITERATURE}

\section{INTRODUCTION}

According to Fischer (2012c), people's comprehension of an issue and the resulting consensus on, and uptake of, proposed actions are shaped by the discursive practices of the political actors supplied by institutions through language, discourse, structures and norms. Therefore, the purpose of this chapter is to examine the literature underpinning the discussion and construction of climate change (in general) and as a public health issue in order to place the research problem within existing literature in a manner that identifies gaps for understanding the impediments to a public health framed climate change. The purpose of this chapter is to outline the scope and boundaries of the study by drawing on several areas of literature including a) framing of climate change, b) the relevance of public health in the framing, c) discursive, philosophical, and theoretical paradigms for understanding the social construction of climate change, and d) the discursive and interpretive inquiry techniques for examing the social construction of climate change. These literature areas also serve as a foundation for building a conceptual framework for understanding and developing the methodology for addressing the problem using theories, frameworks, and approaches emerging from the literature.

Section 3.1 situates climate change discussions broadly as an environmental issue and discusses the literature on understanding the image (frame) assigned to climate change phenomenon, the various types of images and their relevance or influences to climate change discussions

Section 3.2 considers the literature exposing the significance of a public health-focused climate change discussion and the ability of the frame to provide holistic approaches that can influence democratic policies and target perceptions that hinder awareness and actions on climate change.

Section 3.3 is a literature review detailing the discursive formations and their relevance in understanding, investigating, and interpreting social meanings and language guiding climate change policy discourse. It details discursive strategies for framing climate change, the discourse of climate change, how climate change discourses have emerged, and the philosophical and theoretical tenets guiding the construction of climate change (with a specific focus on paradigms guiding this study). 
Section 3.4 elaborates on the methodological approaches and considerations for accessing, generating, and analyzing the data that inform the interpretation of meanings and social construction with a specific focus on discourse, narrative and institutional analyses.

\subsection{DELIBERATING ON CLIMATE CHANGE IMPACTS AND POLICIES}

The atmosphere, forests, and oceans are common resources (sinks) that sequester GHGs emitted from human activities; they also provide resources that sustain humans (e.g. biodiversity, minerals, food, etc.) (Dietz, Ostrom, \& Stern, 2003; Paavola, 2012). The sinks are common, shared resources (also known as common-pool resources - CPR) whose users cannot be excluded from using the resource (Paavola, 2012). It is this common nature that impacts the sustainability of the sinks for GHGs when human's independent behaviours sometimes ignore the costs imposed on others (Dietz et al., 2003; Paavola, 2012). This misuse has been referred to as the "tragedy of the commons", a common and powerful narrative for describing common societal good or problem as first described by Garret Hardin in 1969 (Dietz et al., 2003). The misuse of atmospheric commons has led to the threats of climate change resulting in the formulation and adoption of many policies by governments at the local, national and international levels.

As solutions to the "commons" problems, Hardin suggested two institutional arrangements: the use of centralized (command and rule) government to govern the commons and privatization of the commons (Dietz et al., 2003). However, the approach has been criticized for its top-down approach to resource management; privatization is viewed to imposes a cost when users who inherently depend on the collective use of CPR are excluded (Dietz et al., 2003; Paavola, 2012). Ideally, Dietz et al. (2003) suggest the adaptive governance approach for governing the CPR and mobilizing collective action. The approach focuses on four major areas: provision of information (aggregate and local) and infrastructure (institutional, physical and technological); conflict resolution through resource and user group boundary definition, and a mix of institutional types; embracing change as new knowledge is gathered; and, inducing rule compliance through deliberation, enforcements, and prohibition of specific actions, financial instruments, monitoring and provisions (Dietz et al., 2003; Paavola, 2012). Achieving adaptive governance requires steering climate change policies through platforms that support awareness of impacts and a discussion that incorporates varied perceptions and opinions on appropriate actions; such approaches further legitimizes the policy process and promotes consensus to action (Alaszewski \& Brown, 2012; Fischer, 2012c, 2012a). This can be achieved through effective risk communication, which relays relevant knowledge for informed decision-making, builds or rebuilds stakeholder trust in the decisions, and engages people in meaningful approaches for solving the 
issue (Covello et al., 2001). Irrespective of how the risk is communicated, the structure and content of the messaging influence outcomes (Spence \& Pidgeon, 2010). People's thoughts, attitudes, and beliefs form the basis of the communication strategy (Dervin \& Rudolph, 2015; Dickinson, Crain, Yalowitz, \& Cherry, 2013; Schäfer \& O’Neill, 2017).

\subsubsection{Framing}

Framing provides a structure and context for creating awareness, influencing perceptions and priorities, and building consensus (Alaszewski \& Brown, 2012; Rickards, 2013; Spence \& Pidgeon, 2010). It portrays a policy's image (Cairney, 2012c). According to Rickards (2013), through frames, meanings of subjects are assigned, which emphasize and prioritize certain features of the subject in messages and decisions; such emphasis is done knowingly, unknowingly, explicitly or implicitly. Nisbet (2009) also asserts that framing is inevitable in communication processes or in policies. Olsson and Paglia (2008) portray framing as a political process used to influence the public through contexts that are coherent to reality and unified views. Whether a frame is used intuitively or deliberately, it impacts the communication process by influencing perceptions to action and the amount of attention an action receives (Bardwell, 199). Benford and Snow (2000) indicate that framing provides meaning, mobilizes resources and provides political opportunities for identifying with a specific social approach. According to Nisbet (2009), frames can play several roles. Frames support an understanding and discussion of an issue. It can support the crafting and appeal of news and reports. It can define policymakers' decisions and policy options, or it can simplify technical information. Framing can reveal how language connects actors and institutions to political power (Fletcher, 2009). Framing forms the basis for the deliberation and decisionmaking of policies (Pralle \& Boscarino, 2011). The frame applied to climate change debates is likely to influence the comprehension of impacts, consensus on actions needed, and the availability of participative and deliberative platforms (Akerlof et al., 2010; Gallagher \& Updegraff, 2012; Maibach et al., 2010). Exploring such contexts also exposes how the climate change problem is defined and presented and actions that arise from such definitions (Fischer, 2012c; Gould \& Lewis, 2009; Pettenger, 2007b, Hajer, 1997).

\subsubsection{Climate Change Frames}

Policy discourses are constructed by scientists, media, politicians, and various societal groups and actors (Fleming et al., 2014). How such groups frame information can be located within four fields of framing research: strategic framing, journalistic framing, media content framing, and audience framing (Fleming et al., 2014; Matthes, 2011). Strategic framing focus 
positions an issue in a manner that guides political actions, priorities and guiding structures while connecting the other three framing fields by establishing uptake of the issue by journalists and a discussion of the issue in the media, and between individuals (Alaszewski \& Brown, 2012; Matthes, 2011; Rickards, 2013; Spence \& Pidgeon, 2010). Strategic framing can incorporate persuasive messaging that politicize the issue (politicized framing), highlight the benefits of action (gain-frames), consequences of inaction (loss-frame, also referred to as outcome frame) or distance people from actions (psychologically distancing frame) (Gallagher \& Updegraff, 2012; Schäfer \& O’Neill, 2017; Spence \& Pidgeon, 2010). The framing fields draw upon several framing principles: equivalency, emphasis, generic or issue specific framing (Brugman \& Burgers, 2018; Chong \& Druckman, 2007a, 2007b). That is, the framing can portray two opposing alternatives of the same issue (equivalency), intentionally emphasize specific aspects of an issue (emphasis), focus on presenting as specific issue as opposed to others (issue specific) or be abstract (generic).

According to Maibach et al. (2010), the impacts of climate change and the benefits of action can be framed and communicated in three ways: environmental, national security and public health frames. Fletcher (2009) also presents four frames to climate change; these include the scientific, skepticism, national threat and economic opportunity frames. The environmental frame emphasizes the climate impacts on the environmental components and ecosystems; the national security framing highlights the impacts of climate change on economic and political systems and the stability of a nation (Fletcher, 2009; Maibach et al., 2010). Referencing Ullman (1983, p. 133), Fletcher (2009) defines national security threat "as a drastic event that occurs in a brief span of time, degrades our quality of life and narrows the range of policy choices available; it's an issue that transcends the national boundaries." Fletcher (2009) further argues that national security framing gives attentional to the national threat of an issue and activates the national defence and intelligence mechanisms to counter the issue, attract media attention that highlights the catastrophic impacts of climate change, and attract financial support towards mitigation needs. However, the author states that there is no direct relationship between climate change and a threat to national security or political tension.

A public health framing stresses the impacts of climate change on human health and wellbeing; it is likely to unite the different stakeholders involved in the climate change dialogues by striving to achieve a common goal, that is, sustainable health (Akerlof et al., 2010; Petrovic, Madrigano, \& Zaval, 2014; Watts et al., 2015).

Skeptics frame challenges the presence or science of climate change and promotes skepticism to climate change (Cann, 2015; Dunlap, 2013; Hurlbert \& Gupta, 2016; Rademaekers 
\& Johnson-Sheehan, 2014; Singh \& Swanson, 2017). Climate change skeptics span a diverse group of stakeholders ranging from scientific, political, business and public sphere who oppose or undermine the development of sustainable climate change policies (Fletcher, 2009).

The economic frame, on the other hand, emphasizes transformation to renewable energy sources and innovations. The frame provides opportunities for a region's energy dependence as well as social and economic opportunities (Fletcher, 2009).

A scientific frame highlights the different climate change facts, hypotheses, and risks (Fleming et al., 2014; Sarewitz, 2004). Climate change scientists also suggest actions to address identified issues (Sarewitz, 2004). Despite the political nature of climate change, Brand, Bullard, Lander, and Tadzio (2009) explain that climate change is often perceived as scientific. However, the scientific context presents climate change as a problem that can only be targeted through a global approach, using technical knowledge rather than social processes. The frame overlooks the local needs and practical alternatives to climate change (Brand et al., 2009).

Social justice or moral frame views climate change from an equity perspective and emphasizes actions that consider the social and environmental disparities by acknowledging the disproportionate distribution of climate change impacts and burdens across regions and populations (Markandya, 2011; Popke, Curtis, \& Gamble, 2016). The frame evolves from the theory of environmental justice, which provides three forms of justice to those impacted by climate change: distributional, procedural, and substantial justice (Pokpe et al., 2016). Distributional justice focuses on how the impacts and consideration of management strategies are equitably distributed (Pokpe et al., 2016). Procedural justice relates to the fairness and democratic nature of climate change actions; they relate "to the processes that shape environmental outcomes, including the formation of public policy and legal frameworks" (Pokpe et al., 2016). Substantial justice is the legitimate and democratic inclusion of various stakeholder interests in the climate change policy process (Pokpe et al., 2016).

Despite the diversity of frames, the choice applied to portray climate change policy image has a significant impact on influencing attitudes and behaviour change, raising health impact awareness, and gaining consensus towards the climate change actions (Akerlof et al., 2010; Gallagher \& Updegraff, 2012; Maibach et al., 2010). Adopting a frame that supports sustainable interventions capable of enhancing resilience and facilitating sectoral and public's action while also managing climate change risks, calls for collective action from the government, its sectors, and the public.

An emerging consensus among social scientists studying the framing of climate change discourse is that a public health frame provides a normatively superior approach to presenting or 
communicating climate change needs and bridging the multi-stakeholder gap (Akerlof et al., 2010; Maibach et al., 2010; Myers et al., 2012). Such empirically motivated approaches unite the different stakeholders within the climate change dialogue ( Watts et al., 2015a, 2017a; Valles, 2015).

\subsection{LITERATURE EXPLORING THE RELEVANCE OF A PUBLIC HEALTH FRAMED CLIMATE CHANGE POLICY}

The benefits of public health, as highlighted by various research, are summarized in the various subsections below.

\subsubsection{Risk Perceptions}

Impacts and interventions that target climate change are a communicative act that is received and processed by audiences. Like any form of communication, the ability to gain consensus on an action, and the willingness to accept and act on the information received vary across a diverse group of stakeholders (Nisbet, 2009). Climate change risks involve complex scientific concepts that may not be understood by many (Spence \& Pidgeon, 2010). The meaning derived from communication or information influences choices, risk perception, and actions.

Most people apply heuristic approaches when judging the magnitude of risks (Wagner \& Zeckhauser, 2012). Citing Tversky and Kahneman (1974) and Dane and Pratt (2007), Merlo, Lukas, \& Whitwell (2008) defines heuristics as "as cognitive pathways that reduce the complex tasks of assessing probabilities and making predictions to a simplified set of judgmental operations." In other words, the risks are informed by people's biases stimulated by the memorability and imaginability of the risk and its similarity to other risks previously experienced (Slovic, 2010). Some information is perceived as complicated, unfamiliar, involuntary, dreaded, catastrophic or unfair. The approach is referenced as outrage factors to risk perception or outrage model (Slovic, 2010). The model holds that perception and acceptance of risks are determined by characteristics such as dread, involuntary, unfamiliarity, uncertainty, unknown to science or likely to affect children (future generations). In turn, opinions of climate change vary across diverse audiences. Despite some skeptics who deny the presence of climate change, many people believe in the existence of climate change (Valles, 2015). Some deny contributing to the changing climate; others see climate change as a threat to their lives (Valles, 2015). Others believe their actions can reduce climate change impacts while others do not (Rowson, 2013; Valles, 2015). Some do not know what to do while some are engaged and want to be consulted in the actions and processes (Rowson, 2013). Climate change is also viewed as temporary, geographically isolated, or socially distinct (Akerlof, Maibach, Fitzgerald, Cedeno, \& Neuman, 
2013; Dunlap, 2013; Maibach et al., 2010; Wiest et al., 2015). Therefore, climate change communications and policies are not immune to the heuristic approaches to human risk assessment.

Maibach et al. (2010) indicate that the political, economic or environmental focus does not provide a broader audience with relatable risk references. For instance, most stakeholders do not understand carbon pricing mechanisms (Watts et al., 2015; Dervin \& Rudolph, 2015). However, they can relate to the health impact of climate change from floods or extreme heat; air quality and the influence on their respiratory and cardiovascular health; contaminated food and water and the risks of food- and waterborne illnesses (Maibach \& Nisbett, 2011). A public health frame can highlight the various health benefits of action that transcend GHG reduction (WHO, 2011; Watts et al., 2015).

Maibach et al. (2010) also reported that framing climate change as a political issue is less likely to influence or persuade the public to action. The economic or environmental frame narrowly interprets climate change impacts as largely economic or environmentally related. Wang and Horton (2015) argue that framing climate change as a health issue as opposed to an economic, ecological or technological issue puts a face to the somewhat distant threat, resonates with the public, and supports political will. As Dervin and Rudolph (2015) posit, health is a normatively shared value that can bring about the resonance when discussing the health impacts of climate change and the perceptions that may make people distance themselves from climate change. The authors refer to these perceptions as "not here-not-now-not me." Maibach et al. (2010) also found that the public reacts favourably and comprehend climate change needs and issues when a public health frame is used. A public health frame achieves intentions through persuasive messaging that highlights both the gain- and loss-frames (Gallagher \& Updegraff, 2012). That is, the benefits of acting (gain-frame) and the consequences of inaction (loss-frame); this is also referred to as outcome framing (Spence \& Pidgeon, 2010). Furthermore, Watts et al. (2015) assert that the public health concept to climate change is relatable and "far more tangible and visceral than tonnes of atmospheric $\mathrm{CO} 2$ ". Thus, public health communication focuses on presenting the risks and actions in a way that a broader audience relates to and perceive to be important. To illustrate, the broader group of stakeholders are familiar with climate change risks to air quality and can relate such impacts to the health effects such as asthma and allergies as opposed to relating to them to the complicated carbon pricing jargon or the political processes of climate change actions (Valles, 2015; Maibach \& Nisbett, 2011). 


\subsubsection{Creating Trust and Depoliticizing Climate Change}

The topic of climate change is polarized; attitudes towards causes, risks, impacts, and actions are profoundly defined by political ideologies (Nisbet, 2009). Lachapelle, Borick, and Rabe, (2012) conducted a comparative study of the United States and Canada. The study gathered citizens' perceptions and preferences regarding the existence of climate change and the potential policy approaches to address the issue. In both countries, political affiliations and identities shaped the perception of the existence of climate change. The views on the subject heavily drew upon political identities when the citizens in both countries described the acceptance of climate change. Canada's National Democratic Party (NDP) supporters had the highest acceptance of climate change while the Conservative Party had the lowest acceptance rates when the top three political parties in Canada were compared. A similar pattern was evident in the United States, where Democrats were more likely to express acceptance of climate change than Republican party supporters. Partisan divisions lead to the communication of both negative and positive information on climate change actions (Nisbet, 2009). Adverse actions tend to receive the most attention and can have negative impacts on GHG mitigation strategies by delaying rational climate change discourse. Similarly, while communicating risk is likely to raise awareness about the threats, it is less likely to overcome the perceptions of trust in the political nature of the policy-making process (Covello et al., 2001; Jardine, Banfield, Driedger, \& Furgal, 2013).

Trustworthiness is a major factor in overcoming the perception of, or encouraging actions or consensus on, the climate change risk across a political divide (Lundgren \& McMakin, 2013). Lorenzoni, Pidgeon, and O'Connor (2005) state that most people would only oppose climate change actions if they do not trust the effectiveness and fairness of the policies. Quoting the Canada West Foundation (2011), Neville \& Weinthal (2016) posit that "trust is the grease that keeps the machinery of democracy from jamming... if the level of trust falls too low, voter support and community cooperation will fall too low as well and the system will break down." For instance, Ingram and Schneider (2009) reported the lack of trust in the government's ability to deliver policy goals as promised, specifically in the United States. A significant finding forwarded by Sandman and Johnson (1992) on trust stresses that how a government agency behaves or regards the risk and its actions influences the public's perceptions about the risk. Negative behaviours or laxity can lead to public outrage that promotes risk aversion techniques and a lack of consensus on actions to manage the risk (Johnson \& Sandman, 1992). Similarly, the lack of trust intensifies the public's perception of the impacts of a given activity (Neville \& Weinthal, 2016). 
Achieving mutual interests, trust, and collaborations are instrumental and normative to democratic policy processes and deliberation (Fischer, 2012c, 2012a). The government and public health agencies have a role in enhancing this trust. A Canadian survey, cited by Neville and Weinthal (2016) revealed a lack of trust in government and politicians. Frewer et al. (1996) found that the public hardly trusts traditional institutions such as those held by the government ministries or members of parliament. Igram and Schneider (2008) highlight the lack of trust in governments and their motives, indicating that governments value their members and elites instead of the citizen. Conversely, Covello (1996) found that local health departments command a high level of trust within communities. Given the polarized and partisan tendencies of climate change discourse, a public health focus can be a powerful tool for minimizing policy conflicts where partisan divisions or diverse stakeholder beliefs, assumptions, and views arise (Fletcher, 2009). Including a broad range of citizens in policy decisions contributes to democratic policies through conflict resolution, which is likely to increase public trust in the government's decisions and the ability for stakeholders to gain knowledge about the decision processes and the resulting policies (Fischer, 2012c, 2012a). This improved stakeholder-agency relationship enhances support for decisions and intended action. Equally, climate change is a complex problem that spans several issues and requires multi-stakeholder engagement (Head, 2014); it cannot be solved through traditional policy processes (Fletcher, 2009). Lateral public health connects the public health sector with various stakeholders within communities, governments and healthimpacting sectors (Semenza, 2011). Lateral public health advances holistic and democratic climate change discourse in three ways (Semenza, 2011). First, the transdisciplinary nature of public health can address interventions linking social, environmental and political capacities to climate change action and resilience. Second, it advances interventions that address social justice and health equity. Third, it coordinates with multiple sectors to enhance emergency preparedness and reduce risks and vulnerabilities.

Linking GHG emission initiatives to public health depoliticizes the climate change actions by involving public health agencies and new actors, connecting the various interests of stakeholders, negotiating over broad issues, and accounting for behaviours and risk perceptions that can discourage action. Furthermore, Maibach et al. (2010) indicate that a public health focus provides opportunities for inclusion of broader sets of expertise who can provide knowledge or communicate the issues. These can include experts from public health, communities and academics (Neville \& Weinthal, 2016). Including the views and perspectives of a diverse group of citizens in climate change policy processes is useful in developing public trust, achieving political democracy, substantiating public policies, and managing risks (Fischer, 2003; Neville \& Weinthal, 
2016). Fischer (2003) also suggests that broader citizen participation leads to the identification of new knowledge (local knowledge and contexts) and normative interpretations. A public health focus can depoliticize climate change and offer bipartisan solutions by integrating broader citizen participation (Dervin \& Rudolph, 2015; Nisbet, 2009). And, when evidence is uncertain, and the threat is imminent, as, in the case of climate change, the precautionary principle used by public health can guide climate change actions to protect health (CPHA, 2017).

\subsubsection{Moral Justification for Action}

There is an inordinate distribution of climate change hazards and health impacts across societies (Frumkin et al., 2008; Health Canada, 2008; Paavola, 2017; Patz, Grabow, \& Limaye, 2014; PHO, 2014b). There are also the compounding effects of current emissions to future generations. The costs associated with mitigation and adaptation requirements pose ethical and health equity challenges even when some of the benefits from mitigation and adaptation actions are realized (Paavola, 2017; Frumkin et al., 2008). The climate challenges are thus environmental justice and equity issues. Those with limited capacity to cope or already experiencing burdens due to environmental or determinant of health-related issues will also be disproportionately impacted by climate change (Ford, Berrang-Ford, King, \& Furgal, 2010; Frumkin et al., 2008; Paavola, 2017; Patz, Grabow, \& Limaye, 2014)). Environmental justice aims for the inclusion of various stakeholders in policy development, implementation, and enforcement, regardless of the socioeconomic status (Dearden \& Mitchell, 2016).

There is also an intersection between climate change and social justice (Paavola, 2017). The social and institutional powers that shape living conditions and quality of life also dominate climate change discourse (Commission on Social Determinants of Health, 2008; Walpole, Rasanathan, \& Campbell-Lendrum, 2009). Social inequities, institutional settings, and systems not only impact health and well-being, but they also impact climate change policies and vulnerabilities. For instance, carbon reduction mechanisms and innovations through taxations and green energy are likely to increase inequalities, especially to those who cannot afford such strategies; these maybe those who are greatly impacted by climate change (Walpole et al., 2009). Climate change discourse has been dominated by power dynamics which can result in or exacerbate societal inequities (Dervin \& Rudolph, 2015). Adger (2006) posits that vulnerability to changes in the environment is driven by both the intentional and intentional human factors and their interactions with the environment; lack of consideration for the disproportionate distribution of outcomes and power dynamics are likely to exacerbate the current societal inequities. For instance, GHG reduction mechanisms may be costly, hindering adoption by poorer populations 
(Dervin \& Rudolph, 2015). Smart growth, which integrates land use patterns with transportation strategies, may increase redevelopments that favour middle to higher income earners which can displace low-income communities (Dervin \& Rudolph, 2015). Equitable and just climate change actions that support fair and accessible solutions, specifically to those who will be disproportionately impacted by climate change, are necessary. Dervin \& Rudolph (2015) argue that despite the association between climate change and equity, these connections are rarely linked or mainstreamed in climate change deliberations and policies.

Public health practice is founded on the interrelated concepts of social justice, health equity, and SDOH (CPHA, 2017). Public health uses these underpinnings to minimize the geographical, social, economic and demographic disparities that hinder people from achieving good health. Mitigating, adaptation, and building resilience to climate change is a big part of public health (Campbell-Lendrum et al., 2007; Frumkin et al., 2008). In part, the strategies sustain the determinants of health, minimize social, economic, and environmental injustices, and support equity in society (WHO, 2011; Watts et al., 2015). Thus, public health agencies have a moral need to respond to the broader health impacts of climate change. Fundamentally, public health should be the central focus of climate change strategies and policy discussions if positive health outcomes are to be realized. Furthermore, the limited health impact awareness (see The conception of health impacts) provides a moral obligation for public health action.

Climate change is already a public health issue; (Watts et al. 2015, 2017). Public health principles suggest that a health issue must be tackled from a 'public health lens' using a framework that allows for utilization of the five public health tenets: evidence base, risk assessment, policy, program, and evaluation (CPHA, 2017). Therefore, the sector has a moral obligation to act and protect human health.

\subsubsection{Highlighting Health Co-benefits of Actions}

Climate change actions have environmental, social, health, and economic benefits that transcend GHG reduction (WHO, 2011; Watts et al., 2015). The strategies benefit human health to prevent illness and promote healthy environments and lifestyle (Watts et al., 2017).

The public health sector can play two roles in both climate change mitigation and adaptation initiatives (Watts et al., 2015). One, they can assume a leadership role in population health initiatives - such as health promotion and disease prevention competencies - directly related to the public health mandate and expertise. Two, the sector can play a facilitative role in initiatives that go beyond their mandate and expertise, but that have health consequences (e.g. transportation, built environment and energy policies (Watts et al., 2015). Public health leadership 
can enhance the knowledge of the immediate and long-term benefits of actions to both public health and other sectors through a public health narrative, and advance the integration of the benefits of climate change actions. The knowledge of the mutual benefits can then influence stakeholder and political will (WHO, 2011; Watts et al., 2015). In effect, the public health sector has an important role to play in shaping the climate change associated health and wellbeing outcomes by influencing sustainable interventions that connect public health to critical climate change debates (Campbell-Lendrum et al., 2007; Frumkin et al., 2008). Public health facilitation is relevant as health impacts may not be entirely understood by other sectors that lack expertise in public health. Here, their role is to highlight the health co-benefits of actions and coordinate sectors by providing platforms for multiple stakeholder engagements as well as public health evidence necessary for evaluating health implications and integrating health in the policies (Ganesh \& Smith, 2017).

\subsection{LITERATURE ON DISCURSIVE FORMATION, SOCIAL CONSTRUCTION, AND SOCIAL MEANINGS}

The literature above has highlighted the relevance of public health in climate change. The concept of the importance of public health framed climate policy has generated optimism. Optimism has come from those who argue that a public health inclusion in climate change debates provides a compelling vision for supporting holistic approaches to democratic policies and supporting climate change awareness and actions (Gallagher \& Updegraff, 2012; Maibach et al., 2010).

Further, statements that brand climate change as the "greatest global health opportunity of the 21st century," "greatest health opportunity," or "biggest global health threat of the 21st century" (Costello et al., 2009; Howard et al., 2018; Watts et al., 2015) provide optimism for public health inclusion and leadership in climate change policies (Frumkin \& McMichael, 2008; Watts et al., 2015, 2017).

Despite such optimism and the relevance of a public health framed climate change policy, stakeholders working to educate the public and influence climate change actions have often presented biased perspectives on climate change needs (Rowson, 2013; Schäfer \& O'Neill, 2017). Instead, most policy frameworks have focused on economic and technological advancement (Lynch \& Duke, 2004; Spence \& Pidgeon, 2010). Literature also suggests that political and economic focus and interests dominate debates on climate change discourse (Dearden \& Mitchell, 2016; Lynch \& Duke, 2004; Rowson, 2013; Schäfer \& O’Neill, 2017; Spence $\&$ Pidgeon, 2010). Political power has dominated the response to climate change; divergence 
between scientific evidence and economic power continue to define actions (Dearden \& Mitchell, 2016; Rowson, 2013). There are competing interests between various policy stakeholders such as "scientists, industry, policymakers, and non-governmental organizations," each forwarding subjective perspectives on the issue (Schäfer \& O'Neill, 2017).

Overall, supporting public health's capacity in climate change has focused on three areas. Identifying and projecting public health impacts due to climate change, highlighting the relevant policy responses and tools to combat climate change, and ) highlighting the role of public health in climate change (Berry et al., 2014; Watts et al., 2015, 2017, 2018). There has also been an emphasis on, and evidence of, the relevance of a public health policy frame in climate change discourse with lack of consideration of integration needs for the frame (Maibach et al., 2010; Maibach, Nisbet, \& Weathers, 2011; M. Nisbet, 2009; Watts et al., 2015).

While there has been progress in the inclusion of public health in the discourse over the years, the sector historically struggled for a place in the discourse (Lesnikowski et al., 2011; Public Health Agency of Canada, 2013). The role of public health has remained elusive (Workman et al., 2018). There is a lack of coordination and mainstreaming of public health needs (Austin et al., 2016, 2015; Aylett, 2015; Workman et al., 2018). The institutional structures portray a silo approach to climate change governance with public health mainly isolated from such structures (Austin et al., 2016, 2015; Aylett, 2015; Workman et al., 2018). Historically, the public health sector had not prioritized climate change, actively participated in the broader policies and have not been well equipped to target the challenges of climate change (Bell, 2011; Frumkin et al., 2008; Frumkin \& McMichael, 2008; Scheirer \& Dearing, 2011). Altman (2009) revealed that the public health sector is also yet to implement sustainable programs that will allow for intersectoral integration of action areas in the future. Accompanying the lack of inclusion of public health is the limited awareness of climate change health impacts (Akerlof et al., 2010; Berry et al., 2011).

Nilsson, Evengård, Sauerborn and Byass (2012) present climate change actions as complex interactions between the phenomenon, its politics, human behaviour, and health outcomes. Within the interactions, health is the most direct component linking humans to climate change impacts (Nilsson et al., 2012). The limited role of public health in climate change policies, thus, questions the basis of prioritization of the public health framing and relevance in climate change policies and why public health is not the focus of climate change despite its relevance. 


\subsubsection{Discursive Strategies for Understanding the Influence of Language on Public Health Framed Climate Change Policy discourse}

Frames emerge from discourses, and discourse denotes language use in the verbal or written communication or exchange of ideas (Fletcher, 2009; Walter, 2013). Wallner (2008) defines language as a "performative activity encompassing words, texts, and other expressive behaviours." Expressive behaviour is the communication of "emotions or personality"(Colman, 2014) or "acts and declarations that confirm a person's identity" (Hillman, 2010). Gould and Lewis (2009) posit that language provides an avenue for categorizing and understanding things. However, language is an abstract social structure that illuminates certain potentials or possibilities while excluding others (Fairclough, 2003). One way of conceptualizing the prioritization of public health framed policies, then, is to analyze climate change discourse (Fischer, 2012c; Fletcher, 2009; Hajer, 1997; Weedon, 1997).

\subsubsection{Climate change as a discursive construct}

Discourse refers to ways through which knowledge informs human actions and interactions as advanced by social practices, power relations and human subjectivity (Weedon, 1997). Discourse also portrays a shared understanding of the world; "embedded in language, it enables those who subscribe to it to interpret bits of information and translate those into coherent accounts, stories or frames" (Dryzek, 2013). Furthermore, discourse represents the ideologies, language and rhetorics dominant in the discussions of an issue (Fischer, 2012c; Hajer, 1997). It provides avenues for analyzing, debating and agreeing or disagreeing on an issue (Fischer, 2012c; Hajer, 1997; Pettenger, 2007b).

Discourse theory rests on the assumptions that language not only represents social meanings, but it is also a part of the construction of meanings as characterized by structures and functions (Karlberg, 2012). The discourse theory also highlights the importance of framing an issue in a manner that influences perceptions and multiple stakeholder input, and the contextual influences on an issue (Fletcher, 2009). Eventually, we are able to understand why particular environmental issues or actors gain prominence at the expense of others (Fischer, 2012c; Pettenger, 2007b).

Weedon (1997) argues that the complex nature of climate change policies can be conceptualized through the understanding of discourse; ways through which people constitute knowledge and the social practices, subjectivity, and relationships that influence such knowledge.

Moon and Blackman (2014) and Dryzek (2013) assert that humans construct knowledge and meanings, and legitimize knowledge, through discourse. In turn, a researcher can analyze 
how the problem is presented as well as the routine practices and the social influences on the comprehension of, and consensus on, the problem and the actions required (Fairclough, 2003, 2013; Walter, 2013).

Fischer (2012b) indicates that through language, humans constructs, and social meanings, we can relate to intentions, values, or goals of an issue. In other words, meanings are created, evoked, and classified mainly through language (Fischer, 2012c; Gould \& Lewis, 2009). Through language and imagery, a discourse draws upon assumptions, judgements and contentions that provide the contexts to judge the relevance of an issue, stance taken, and the actors needed (Dryzek, 2013; Fischer, 2012c). Over time, some discourses gain prominence as the actors forward a common understanding of the issue or as promoted by powerful actors (Dryzek, 2013; Fischer, 2012c; Pettenger, 2007b). Dryzek (2013) explains that discourses support or hinder communication and coordinates people's and organization's actions. However, the author also notes that discourses are "bound up with political practices and power." As a result, one way of conceptualizing the lack of public health relevance in climate change framing is through an exploration of climate change discourse and how public health is prioritized or integrated into such discourses.

\subsubsection{Discourses of climate change}

Several researchers have identified several discourses guiding environmental issues, in general, and specifically as relevant to climate change as an environmental issue (e.g. Carvalho, 2005; Darrier, 1999; Dayrell, 2019; Fløttum \& Gjerstad, 2017; Hajer \& Versteeg, 2005; HansonEasey, Williams, Hansen, Fogarty, \& Bi, 2015; Koteyko, Thelwall, \& Nerlich, 2010; Nerlich, Koteyko, \& Brown, 2010; Roper, Ganesh, \& Zorn, 2016; Cadman, 2013).

Discursive formations on climate change began within the scientific disciplines, which represented climate change as a change in statistical averages (Taylor, 2013). In turn, the risks and impacts of climate were presented by the scientific communities based on abstract models and calculations from universally constructed observable climate variables, impacts on humans were presented in economic terms; by attaching costs to the current and future impacts. As the issue of climate change became more popular, media, government, and non-government bodies began to forward specific discursive formations that have dominated climate change discussions to date (Cadman, 2013; Dryzek, 2013; Taylor, 2013; Dryzek, Norgaard, \& Schlosberg, 2012).

Taylor (2013) and Dryzek (2013) have detailed the major climate change or environmental discourses. The first discourse that emerged from climate change discussions was the discourse of limits of growth. This discourse emerged in the early 1970s in an effort to stabilize the earth's 
increasing temperatures to an acceptable temperature of below $2^{\circ} \mathrm{C}$ (Dryzek, 2013; Taylor, 2013). While climate change was not the focus, the discourse emerged at the time when several environmental issues (e.g. pollution, climate change, biodiversity, resource depletion and so on) were predicted to collapse (Dryzek, 2013). The discourse thus stressed the human's overexploitation of scarce environmental resources and the push for drastic actions to curb the demand, especially for non-renewable resources. Specific to climate change, the discussions focused on calls for centralized government interventions and the limited use of resources and population growth (Taylor, 2013). Because the actions pushed for the drastic reduction in GHGs, the discourse was viewed as undemocratic and posed economic and political challenges that threatened neo-liberalism and economic development (Dryzek, 2013; Taylor, 2013). The result was the discourse of sustainable development (or the discourse of sustainability), which emerged in the early 1980s and pushed for nesting of environmental protection with economic growth.

The Brundtland Commission, formed in 1983 by the UN to manage the environment and its resources, formally defined sustainable development as "a process of change in which the exploitation of resources, the direction of investments, the orientation of technological development; and institutional change are all in harmony and enhance both current and future potential to meet human needs and aspirations" (World Commission on Environment, 1987). By prioritizing economic growth within the context of environmental protection, the discourse was viewed as a far-sighted, equitable, and holistic approach to environmental governance (Dryzek, 2013). In 1992, during the UN Conference on Environmental Development, the institutionalization of environmental and economic needs was established, leading to a new discursive formation of climate change: liberal environmentalism (Taylor, 2013). As long as sound environmental policies were in place, removing trade barriers between nations was viewed to have a positive impact on the environment through better resource allocation, economic growth and better population wellbeing (Bernstein, 2001; Taylor, 2013).

To this end, the discourses portrayed the governance of climate change as one that should take a specific approach. Taylor (2013) argues that the discourses resulted in the governmentality (domination of state) of climate change ruled by prescribed institutions and procedures, especially at the international level. The results were internationally formalized negotiations and signatories, national inventories for GHG reduction, mitigation strategies, and exercising of power for the sake of collecting GHG emission information. For instance, following a scientific understanding of climate change, economic development, through technological advances, was perceived as powerful policy instruments for decarbonizing economies (Dryzek et al., 2012; Taylor, 2013). Technological and market analytics became embedded in governments, informing many policies 
on climate change. However, the international community echoed that economic growth needed to be sustainable. Climate change was branded as a "failure of the market system" that could be addressed by imposing a price on GHG emissions (Dryzek, 2013; Dryzek et al., 2012; Taylor, 2013). This was the discourse of ecological modernization (Dryzek, 2013; Taylor, 2013).

Dryzek (2013) defines the ecological modernization as "a restructuring of the capitalist political economy along more environmentally sound lines, but not in a way that requires altogether different kinds of the political-economic system". That is, including environmental criteria in the redesign of systems. As a result, economic and technological narratives (frames) dominated climate change governance structures where an authority on climate change policies was defined by elites and technocrats leading to the exclusion of other stakeholders (Dryzek et al., 2012; Taylor, 2013). Decarbonizing the economy - in the form of carbon pricing, government policies, and consumer behaviour change - were promoted through various social movements giving rise to the discourse of "green governmentality" in the hope that individuals would change the consumption patterns (Dryzek, 2013; Dryzek et al., 2012). However, selecting technologies have mainly been based on aggregate rather than discursive democracy (Dryzek, 2013; Dryzek et al., 2012; Taylor, 2013). Equally, attempts to change human behaviour by instilling fear about, and providing information on, the impact of climate change has not resulted in positive impacts (Dryzek, 2013; Dryzek et al., 2012). Although the public cares about climate change and wants action, there seems to be a reluctance to the urgency of the threat of climate change (Dryzek et al., 2012; Jamieson, 2012; M. C. Nisbet, 2012). It is hypothesized that a discourse that supports participation and deliberation on climate change policies is likely to lead to substantive policies and behaviour change (Cadman, 2013; Taylor, 2013). This could be achieved by the environmental discourse of democratic pragmatism, also referred to as environmental pragmatism or civic environmentalism (Dryzek, 2013).

Democratic pragmatism highlights the relevance of legitimizing policy issues through broader public consultation and participation and the involvement of multiple actors (Dryzek, 2013). The discourse recognizes the complexities of climate change issues and forwards the need for practical, rational solutions (Dryzek, 2013). The discourse can be associated with adaptive governance structures that call for the identification of solutions to environmental issues using democratic, deliberative, and polycentric governance platforms (Dietz et al., 2003). The adaptive governance approach focuses on four major areas: provision of information (aggregate and local) and infrastructure (institutional, physical and technological); conflict resolution through resource and user group boundary definition and mix of institutional types. It also includes embracing change as new knowledge is gathered and inducing rule compliance through deliberation, 
enforcements and prohibition of specific actions, financial instruments, monitoring and provisions (Paavola, 2007, 2012).

\subsubsection{Philosophical Paradigms for Exploring Climate Change Discourse}

Climate change has been characterized as a "wicked problem" (Kreuter et al., 2004; Head, 2014; van Woezik et al., 2016). There is no clear definition of a wicked problem (van Woezik et al., 2016). However, Kreuter, De Rosa, Howze, and Baldwin (2004) characterize it as an issue "that is elusive or difficult to pin down and influenced by a constellation of complex social and political factors, some of which change during the process of solving the problem." No single solutions exist (Dearden \& Mitchell, 2016). Thus, climate change presents a contemporary phenomenon, spans several issues, includes multi-stakeholder with different ideas about the nature of the problem and whose outcomes and solutions are influenced by stakeholders, politics, and resources (Kreuter et al., 2004; Head, 2014; van Woezik et al., 2016). However, involving a broad range of citizens in the deliberation of climate change requires an understanding of climate change from the context of social settings (Pettenger, 2007b). Positioning climate change as a wicked problem with competing interests reveals that climate change is a social construction whose processes and actions do not merely rely on availability on the facts about the changing climate change variables such as temperature or rainfall patterns, but also relies on the social construction of meanings within social settings (Pettenger, 2007b). Regardless of effective climate change interventions and instruments, people's understanding of the problem is important (Fischer, 2012b).

Moon and Blackman (2014) advise that exploring and explaining social phenomena require an understanding of two branches of philosophy: ontology and epistemology. Ontology is the study of being or existence of the real world and how a researcher defines that existence (Moon \& Blackman, 2014). Ontology is a philosophical principle that determines the existence of reality, also referred to as the study of being (Moon \& Blackman, 2014; Palys \& Atchison, 2014). Ontology assists a researcher in determining the certainty of the nature of the existence of knowledge and uncovering the multiple existences of reality (Moon \& Blackman, 2014). There are two main forms of the existence of reality: realism and relativism. Realism posits that only a single reality exists independent of human experiences, beliefs or conceptual schemes; it is that single reality that can be studied and experienced (Baghramian \& Carter, 2018; Miller, 2016; Moon \& Blackman, 2014). This singular reality, argues Moon and Blackman (2014), can be understood using a single method (naive realism), described using scientific theories (structural realism) or explored through critical examination (critical realism). As a result, the realists mainly ascribe to 
the epistemological principles of objectivism and positivism, which apply value-free scientific methods (e.g. hypothesis testing and derived logic) to an issue under study (Baghramian \& Carter, 2018; Miller, 2016; Moon \& Blackman, 2014). On the other hand, relativism posits that multiple realities exist; this reality can be explained by a wide variety of ideas and positions and is relatively dependant on individuals' experiences and mental construction (Baghramian \& Carter, 2018; Miller, 2016; Moon \& Blackman, 2014). Relativists thus pay attention to "emotions, cultural backgrounds, social norms, and experiences" that support an individual's construction of reality within social settings (Moon \& Blackman, 2014; Palys \& Atchison, 2014).

Baghramian and Carter (2018) also note that defining relativism requires an understanding of its two scopes: global vs local and strong vs weak relativism. The authors distinguish between the two as follows. Global relativism is a general consideration of reality; it posits that all beliefs in any subject matter are only true but only in relation to a framework or parameter; local relativism limits claim to a specific context. Perhaps, Moon and Blackman's (2014) additional branch of relativism, known as bounded relativism, relates to the scope of local relativism based on the contexts of the definitions. Bounded relativism holds that "mental constructions of reality are equal in space and time within boundaries - e.g. cultural, moral, or cognitive" (Moon \& Blackman, 2014). Strong relativism argues that claims of reality may be true in one context but false in another context; weak relativism is the claims that existence of reality may be true to one framework and not another (Baghramian \& Carter, 2018).

Epistemology, on the other hand, is a philosophical position concerned with knowledge creation, production, acquisition, and structure, and conceptualization as a problem-solving strategy (Goldman, 1983; Moon \& Blackman, 2014; Palys \& Atchison, 2014; Pojman, 2003; Rawnsley, 1998; Scotland, 2012). Knowledge originates from the word "know" (Pojman, 2003). Information and knowledge are sometimes used interchangeably (O'Grady, 2012). However, providing information moves a message from one area to another; knowledge is the collaborative creation of information through processes and contexts constructed by users (O'Grady, 2012). Understanding the meaning and origin of knowledge requires an understanding of the philosophical principles guiding knowledge (Moon \& Blackman, 2014; Palys \& Atchison, 2014). Thus, some of the processes of epistemology include "believing, perceiving, imagining, inferring, remembering, reflecting, constructing, and corroborating" (Rawnsley, 1998). While there are varied definitions of knowledge in philosophical literature and books, there are two common requirements of what knowledge is: truth and belief (Pritchard, 2016). In addition, there is a common psychological approach to what counts as knowledge, what individuals come to know, and the construction and evaluation of language (Pritchard, 2016). In epistemology, knowledge 
is classified into three categories. Knowledge of acquaintance [familiarity with people and objects], competence knowledge [know-how or procedural knowledge], and propositional [knowledge of facts] (Pojman, 2003; Pritchard, 2016). If a person claims to know something, they implicitly claim to possess the truth (Audi, 2010). However, the person may be wrong about their claims, or others may misperceive/misinterpret the information. Thus, the definition of knowledge requires more than a belief in the truth. The knower must have an adequate justification of the truth (Audi, 2010; Pritchard, 2016). While what constitutes justification has been extensively debated by philosophers, three main approaches include foundationalism, coherence, and reliability (Audi, 2010). A significant distinction between knowledge or 'knowing' and mere opinions were first made in the 19th Century by C.S. Pierce, an American philosopher (Palys \& Atchison, 2014; Palys, 1997). In his work, he suggested four major "ways of knowing": authority, intuition, logic, and observation. These principles have been reaffirmed over the years by various epistemologists and others.

There are several epistemological approaches to knowledge acquisition (Moon \& Blackman, 2014). However, constructionism (also known as social constructionism) is the most dominant theory for understanding the policy process (Pierce et al., 2014). The theory has been forwarded as a powerful philosophical approach for exploring discourse, language, and for the understanding of climate change policy issues (see Fischer, 2012a; Gould \& Lewis, 2009; Pettenger, 2007b). Fischer (2012b) defines constructionism as a variety of ways of perceiving and shaping social realities. The theory originates from the sociology of knowledge with a key assumption that humans construct meanings of reality largely based on a shared culture and highlights the role of social settings in defining contexts of actions (Fischer, 2012c; Gould \& Lewis, 2009; Palys \& Atchison, 2014; Pettenger, 2007b). A variety of ways through which people construct climate change meanings will result in multiple ideas, solutions, and perceptions that eventually influence engagement on the issue (Fischer, 2012c; Pettenger, 2007b).

From a constructionist perspective, climate change issues can be understood by exploring how humans are constantly creating meanings within social and cultural contexts (Fischer, 2012c). In turn, the knowledge and meaning of climate change framing and the role of public health can be constructed based on socio-cultural and historical perspectives as individuals interact within their social, political, or cultural settings (Moon \& Blackman, 2014). Ingram and Schneider (2009) also stress the relevance of evaluating the construction of policies and the emerging relationships amongst implementing agencies, and, between the agencies and other stakeholders. This is because policies can have a major influence on discourse (Ingram \& Schneider, 2009). On the other hand, the meaning of political actions - such as climate change 
policy-related actions, events, and activities - are influenced by the meanings and stance taken by political leaders, citizens, and advocacy groups across the world (Fischer, 2012c). Understanding the climate change phenomenon and public health needs, therefore, requires the exploration and understanding of what counts as knowledge and its sources, the social norms, experiences, and the complex contextual yet sometimes predictable ways of climate change discourse and policymaking.

Both ontology and epistemology support theoretical thinking for understanding and examining a research issue (Moon \& Blackman, 2014; Palys \& Atchison, 2014). However, social constructionism ascribes to the ontological position of relativism (Baghramian \& Carter, 2018). Relativists believe that acquiring knowledge is value-laden and inductive; understanding a phenomenon, thus, may require multiple methods that explore unique contexts, human subjectivity and values people assign to a phenomenon under study (Baghramian \& Carter, 2018; Miller, 2016; Moon \& Blackman, 2014; Palys \& Atchison, 2014) Relativist research is a personcentred approach that explores mental models that reveal knowledge, beliefs, and values that individuals use to understand, frame, or view the world around them (Brown, 2003; Kolkman, Veen, \& Geurts, 2007; Moon \& Blackman, 2014). Deductive research approaches provide limited avenues for exploring the research questions and achieving the study objectives (Evely, Fazey, Pinard, \& Lambin, 2008; Moon \& Blackman, 2014). A focus on deductive techniques also minimizes the democratic character of interpretive policy analysis which focuses on legitimizing political processes through the integration of agency and local knowledge (lived experiences) relevant for rational policymaking (Dryzek, 1990; Yanow, 2000, 2007). Thus, uncovering the reality of the social construction of climate change issues can benefit from theoretical perspectives that explore the mental models that people use to understand the problems around them and how people act based on the importance of the issue.

\subsubsection{Theoretical Perspectives of the Social Construction of Climate Change}

Theoretical perspectives are the philosophical orientations guiding the researcher's data collection and result interpretation (Moon \& Blackman, 2014). Within the epistemology of social constructionism, meanings are created as a result of how an individual constructs reality (constructivism) and human perspectives (interpretivism) as humans interact within social settings (symbolic interactionism) (Carter \& Fuller, 2015; Miller, 1973; Moon \& Blackman, 2014). Uncovering such meanings must consider the fundamental relevance of participant perspectives within their social and historical contexts (phenomenology) and how such constructs, 
experiences, and interactions are portrayed in texts (hermeneutics) (Bazeley, 2013; Brinkmann et al., 2015; Moon \& Blackman, 2014; Walter, 2013; Yanow, 2007).

\subsubsection{Constructivism}

Constructivism (social constructivism) relates to how individuals construct reality and how those constructs impact them and their interactions across social settings (Moon \& Blackman, 2014; Pettenger, 2007b). Constructivism and constructionism are terms that have been used interchangeably. However, attempts have been made to differentiate the two terms. The difference between the two can be best described by Moon and Blackman (2014) and Spencer, Pryce and Walsh (2015) definitions. While both are fundamental elements of research and define a social construction of reality, constructionism is an epistemological paradigm - how knowledge is created, produced, or acquired - that views knowledge as a social construct derived from social interactions. Constructivism is a theoretical perspective guiding the researcher's action or the research in identifying such social constructs (Moon \& Blackman, 2014). The study distinguishes how these two terms are applied to this study in Chapter 4 (Theoretical framework).

Constructivism is a theory that recognizes that objective knowledge is a result of the subjective human perspective acquired from interaction with what is around them (Palys \& Atchison, 2014; Yin, 2014). In climate change politics, understanding the social issue relies on understanding the structures and forces that influence its knowledge and language (Pettenger, 2007a). This can be achieved through exploring the inherent social relations embedded in identities and interests and structure that support such relations, including norms and discourses (Pettenger, 2007a). Constructivism also recognizes that humans acquire objective knowledge through social interactions and relations (Baxter \& Jack, 2008; Palys \& Atchison, 2014; Pettenger, 2007a; Yin, 2014). The theory holds that "social facts are real because they always have material consequences, and that material things are real by virtue of social construction...that the material and ideational are complexly interwoven and interdependent...as such, any study of climate change must give value to both" (Pettenger, 2007a). Constructivists argue that the use of deductive reasoning eliminates the researcher's ability to understand human experiences. Instead, understanding individual and group meanings and social constructs rely on inductive reasoning which focuses on human experiences and emphasizes the social and cultural influences (Moon \& Blackman, 2014). Thus, constructivism focuses on norms, discourse, and social structures to uncover how social actors construct their identities and interests (Pettenger, 2007a). 
Social scientists have adopted constructivism as a framework for examining environmental issues, including climate change (Cass, 2010; Pettenger, 2007b). The framework allows a researcher to explore the role of knowledge and power in influencing ideas and actors capacity to independently act on, or make choices about, an issue within a certain structure (agent/structure duality), and the social processes that privilege such ideas and actors (Pettenger, 2007a). As Pettenger (2007b) sums it, through a constructivist approach, climate change can be viewed from a social perspective to identify the "processes, actors, and structures" dominating or undermining the framing of climate change within a specific social context. For instance, through constructivism, we are able to question climate change frame and why is it framed as such; how the role of public health is defined in climate change processes and why it has been defined in such ways; and, how the policy processes and social structures of climate change have privileged or negated specific frames and actors. That is, constructivism allows us to explore the discrepancies between knowledge and power in climate change policy knowledge generation, participation, and engagement (Baxter \& Jack, 2008; Palys \& Atchison, 2014; Pettenger, 2007a; Yin, 2014).

There are two approaches to constructivism: norm centred constructivism and discourseanalytical perspective (Pettenger, 2007a). The norm centred constructivism, also known as soft constructivism, explores the roles of norms in influencing agency (Moon \& Blackman, 2014; Pettenger, 2007a). Discourse analytical perspective examines the emergence of discourses, the

privileging and marginalizing of shared meanings within social settings and the influences of social contexts - such as institutional structures, systems, rules and discursive practices - on power and knowledge (Pettenger, 2007a).

Psychologists say that every individual will internalize meanings; but, despite the creation of reality by individuals and groups across social settings, it is the human interpretation and interactions that recreate, transform, or maintain such realities (Mills et al., 2010).

\subsubsection{Interpretivism}

Interpretivism is a reference to a group of interpretive policy approaches guided by philosophical principles that reveal the social construction of reality, human experiences, and the relevance of meanings in knowledge generation (Brinkmann et al., 2015; Yanow, 2007). Interpretivism focuses on human experiences and claims that natural science methods are not ideal for interpreting realities (Moon \& Blackman, 2014; Thanh, Thi, \& Thanh, 2015). Instead, interpretation of reality is situated in history and culture (Moon \& Blackman, 2014; Thanh et al., 2015). The approach is ideal when the desired information shows people's actions, the issues 
they face, and how they confront them. There are three theories related to interpretivism: hermeneutics, phenomenology, and symbolic interactionism (Brinkmann et al., 2015; Moon \& Blackman, 2014; Yanow, 2007).

\subsection{Hermeneutics}

Hermeneutics is a theoretical perspective for policy interpretation that is connected to social constructionism (Brinkmann et al., 2015). The approach was originally developed to help people interpret bible scriptures; it was later extended as a qualitative approach for the understanding of human life (Brinkmann et al., 2015; Yanow, 2007). Brinkmann et al. (2015) argue that through qualitative research approaches, researchers focus on exploring underlying individual or collective existing human interpretations of a phenomenon. The approach allows for an understanding of why people act in a certain way at a particular time. From hermeneutics perspective, such an understanding is "the very condition of human being"; that is, human behaviour and written or spoken words convey meanings (Brinkmann et al., 2015). Furthermore, these meanings are projected in or drawn from artifacts or documents created by humans (Yanow, 2007). These meanings can be uncovered through the exploration of texts, practices, events, and situations hidden in sociocultural contexts (Moon \& Blackman, 2014; Yanow, 2007). In turn, hermeneutics in policy analysis focuses on policy-related texts (both written and spoken) which can be found in various institutional and agency documents such as legislation, correspondences, reports, and interviews (interviews are considered as texts for interpretation) (Yanow, 2007). While the perspective doesn't endorse a particular method of understanding meanings, spending time with or talking to people who convey their experiences provides avenues for understanding situations.

\subsection{Phenomenology}

Phenomenology is broadly an approach that encompasses nearly all qualitative studies but more specifically, it is a theoretical perspective that focuses on researching personal experiences of any human phenomenon (Bazeley, 2013; Brinkmann et al., 2015; Moon \& Blackman, 2014; Walter, 2013; Yanow, 2007). As a research method, the approach gives primacy to knowledge generated from human experiences because human's past experiences inform

present and future behaviours and a researcher can generate meanings that people make of the phenomenon by involving those experiencing it (Brinkmann et al., 2015; Spencer et al., 2015; Yanow, 2007).

Gathering human experiences and perspectives are supported by research methods such as narrative analysis and ethnography (Spencer et al., 2015). The theory has been applied to the 
study of climate change phenomenon including education on climate change (Howard, 2013), the discourse of climate change (Hanson-Easey et al., 2015; Williams, 2000), agency in climate change (Peeters, De Smet, Diependaele, \& Sterckx, 2015; Wiest et al., 2015), and social features of climate change policies (Hall, 2016).

\subsection{Symbolic Interactionism}

Symbolic interactionism (also referred to as interactionism), is a theoretical perspective for understanding meanings arising from interactions within social settings (Aksan et al., 2009; Brinkmann et al., 2015; Spencer et al., 2015). It symbolizes how communication and interaction between humans are reciprocated and interpreted (Aksan et al., 2009). Every social act "has both a past and a future" (Miller, 1973). As people interact, they develop symbolic meanings that define issues. Carter and Fuller (2015) define symbolic interactionism as "a micro-level theoretical framework and perspective in sociology that addresses how society is created and maintained through repeated interactions among individuals." The central theme lies in how language and symbols define communication between and among individuals (Barkan, 2013; Carter \& Fuller, 2015; Miller, 1973). Symbolic interactionism can be summarized as follows. Human actions are based on meanings. These meanings define interactions within social settings; at the same time, through the social interactions, meanings emerge through interpretations that continuously create and recreate meanings and contexts of interactions (Carter \& Fuller, 2015).

Interactionism has been closely liked with phenomenology (Brinkmann et al., 2015; Spencer et al., 2015). However, Spencer et al. (2015) differentiate between the two as follows. While both illuminate how social interactions in a society influence human worldviews, phenomenology focuses on exploring such human experience while interactionism focuses on how social interactions affect human's meaning-making. These interactions are facilitated through language use (Carter \& Fuller, 2015).

As an environmental issue, climate change can be understood through a symbolic interactionism lens. Environmental problems are socially constructed; however, they only become recognized as social problems when individuals and society (including influential organizations and people) recognize environmental issues as a problem (Barkan, 2013). The way that a political system, economic sectors, and the society at large use and translate climate change language and knowledge influence comprehension of impacts and actions needed (Barkan, 2013; Carter \& Fuller, 2015; Pettenger, 2007b; Shaw, 2017). On the other hand, people have different perceptions about an issue; these perceptions must be considered when influencing outcomes (Barkan, 2013). Shaw (2017) posits that the public's understanding of climate change impacts 
and policy choices is influenced by both the participation in actions and an extended discussion on the issue. Understanding a social issue relies on understanding the structures and forces that influence discourse, identities, and interests (Pettenger, 2007a). As a social construct, climate change discourse must consider the social, psychological, structural, and cultural aspects that promote resilience, actions, and stakeholder inclusion (Barkan, 2013; Wolf, 2011).

Exploring the meaning and social constructs through interactionism does not favour any research method as long as the method is able to capture how human's everyday interactions within social settings support meaning-making (Spencer et al., 2015). Researchers have primarily applied qualitative methods to explore and analyze human interaction processes in various contexts (Spencer et al., 2015). However, Spencer et al. (2015) recommend narrative analysis or ethnography.

Fischer (2012c) forwards the application of approaches broadly associated with the post empirical orientation. These approaches seek to go beyond objectivism to the subjective forms of reality and have been referred to as "discursive, interpretive, narrative, or argumentative-based approaches to policy analysis" (Fischer, 2012c). These approaches will be referred henceforth as discursive or interpretive approach(es). As a result, interpretive and discursive approaches are inherent in explaining social constructs of phenomena as they advance diverse rather than a prescriptive methodology for describing a phenomenon (Fischer, 2012c; Yanow, 2000, 2007).

\subsection{LITERATURE ON DISCURSIVE AND INTERPRETIVE POLICY ANALYSIS}

Discursive policy approaches to research characteristically focus on meaning construction and symbolic language - written or spoken (Dryzek, 2008; Yanow, 2000, 2007). The approaches allow researchers to explore how meanings shape the context of the study and the researcher conducting the study (Yanow, 2000, 2007). Yanow (2007) recommends that the researcher should not only focus on policy-relevant elements and actors conveying such meanings, methodological considerations for accessing, generating, and analyzing meanings are also important.

The discurvise approaches uncover the local contexts, lived experiences, and power relations that are hardly possible with other methodological approaches (van Bommel, van Hulst, \& Yanow, 2015). Such approaches play two roles in supporting a study. They support the identification of people or groups of people with a shared understanding of the policy issue as well as documents where such groups of people express their understanding, interpretation, and construction of the issue (Yanow, 2000). 
There are numerous discurvise policy techniques. While Dryzek (2008) does not specify types of analysis, the author groups interpretive, narrative, and discourse analysis as techniques for explicating meanings in policy setting. However, van Bommel et al. (2015) present four approaches predominantly used in the linguistic- or context-related interpretive analysis. These include discourse analysis, narrative analysis, framing analysis, and category analysis (van Bommel et al., 2015). Framing analysis aims to categorize how a specific feature of a language is used to achieve strategic problem definition or specific goals within social contexts (van Bommel et al., 2015). This approach is a subset of a stage in discourse analysis, where an analysis aims to show the control and regulation of political messages by portraying the information in a specific stance (Walter, 2013). Category analysis is the placing of specific contexts into categories as done in framing or narrative analysis that represents an image, storyline, or account participant's stories (Bochner \& Riggs, 2015; van Bommel et al., 2015; Van Eeten, 2007).

\subsubsection{Narrative Inquiry}

In its basic form, narratives are accounts of stories as narrated by people (Bochner \& Riggs, 2015; Van Eeten, 2007; Walter, 2013). Van Eeten (2007) indicates that narrative analysis has been labelled to imply a research goal, a method or unit of analysis. The author, however, advises that narrative analysis, strictly speaking, is the study of narrated texts. A simpler differentiation can be found in Bochner and Riggs (2015), who summarize the different methods into two forms of narrative inquiry: analysis of narratives (also referred to as narrative-underinquiry) and narrative analysis. Both methods acquire data through narrations, but the difference between them relies on the treatment of data and the final research product. The narrative analysis considers the study data as a whole, and the research product is presented as a story, for example, through a biography. Analysis of narratives treats stories as data that is systematically analyzed for emerging themes and interpreted to form a theoretical judgement (Bochner \& Riggs, 2015). It is the latter that is relevant to this study and will be discussed further.

Analysis of narratives accounts for stories of individuals in their own words, focusing on how these individuals relay their experiences in a policy process (Dryzek, 2008; van Bommel et al., 2015; Walter, 2013). Three characteristics that define a narrative are story (events narrated), text (representing the narrations in writing or speech), and narration of which only texts are available for analysis (Van Eeten, 2007). Van Bommel et al. (2015) advises that narratives do not necessarily represent reality 'as it is'; it is a collection of a series of historical events that a researcher uses to understand the narrator's perspective of a chain of events that have transpired 
or observed. The analysis places people at the centre of the phenomenon under study, viewing people as "social actors and active social agents" representing various human systems, culture, social networks and ideologies (Walter, 2013). The narratives can include an account of stories, personal experiences, or account of events and experiences in response to a specific question (Bazeley, 2013). Such accounts are very relevant in the analysis of the policy process as stories allow for the exploration of how a particular situation came about (Bazeley, 2013; van Bommel et al., 2015). As forwarded by Roe (1994), "stories commonly used in describing and analyzing policy issues are a force in themselves, and must be considered explicitly in assessing policy options." Bazeley (2013) further points that through narrations, experiences are organized into systematic, coherent stories. In a narrative analysis, not only is the content important, but the structure is also imperative(van Bommel et al., 2015). Analyzing the structure presents a chronology of events through the exploration of the individual's portrayal of events, how they organize their thoughts and the relationship between the thought processes (Bazeley, 2013; Walter, 2013).

Narratives are mainly solicited through open-ended, in-depth interviews (Bazeley, 2013; Bochner \& Riggs, 2015; Walter, 2013). The approach is likely to address the what, when or where, who, how, and why questions (Walter, 2013). The analysis can explore the act done; when and where the act was done; who did it and how they/he/she did it (agent and agency); and why the act was done (Walter, 2013). The narrative can also be interpreted and informed by body language and repetition of phrases (Bazeley, 2013). Texts are then transcribed and systematically analyzed. However, the interpretation occurs in five levels. When the researcher attends to the teller, the telling of the story, transcription of the story into text, and the reading of the transcript (Bochner \& Riggs, 2015).

The thematic framework for conducting narrative analysis entails two approaches: sociolinguistic and sociocultural (Walter, 2013). Walter (2013) distinguishes between the two as follows. Sociolinguistic approaches focus on how the teller structures their story while the sociocultural approach connects the teller's story to the broader social and political contexts or processes (Walter, 2013). Relaying such experiences requires retaining the narrative structure by coding both the content and structure of the story while connecting the texts to the context of the study (Bochner \& Riggs, 2015; Walter, 2013).

Bazeley (2013) and Labov and Waletzky (1967) provide six elements primarily applied in narrative analysis. As summarized by Bazeley (2013), they include: abstract - a summary of the sequences of an event in the narrative; orientation - sets up the time, place, situation, participants, and initial behaviour; complicating actions - reports a sequence of events, each given in response 
to a potential question; evaluation - consequences for the needs and desires of the evaluator; resolutions - what finally happened; coda - a final return to the present in a way that precludes the question. As a result, narratives of lived experiences provide an avenue for exploring social meanings, revealing an individual's experiences, interpretation of events, and constructs. However, because narratives also represent accounts of human reasoning and meaning-making, they are seen to represent a specific discourse (Bochner \& Riggs, 2015). In turn, a form of analysis relevant to exploring themes present in narrations is discourse analysis.

\subsubsection{Discourse Analysis}

How people conceptualize reality is based on the discourse that constructs reality. As Phillips and Hardy (2002) define it, social realities and interactions acquire meanings through discourses. Thus, understanding social constructs can be understood by exploring such discourses.

The analysis of spoken or written language is called discourse analysis. Discourse analysis describes approaches for highlighting and analyzing written and spoken language within social and political contexts (Howarth, 2000; Salkind, 2010; Walter, 2013). The approach reveals the influence of language and the social and political contexts that position texts (Walter, 2013). The early work on discourse analysis can be attributed to many philosophers. For example, Martin Heidegger, Maurice Merleau-Ponty, Edmund Husserl, Wilhelm Dilthey, and Alfred Schutz however, it is mainly attributed to works of philosopher Ludwig Wittgenstein, which can be traced back to 1889 (Chouliaraki, 2010; Salkind, 2010; Walter, 2013). Ludwig stressed that language was not a neutral medium, but instead, it is rooted in interactions within social settings (Chouliaraki, 2010; Salkind, 2010; Walter, 2013). This notion has influenced various areas of research, including psychology, sociology, cultural studies, linguistics, and anthropology (Salkind, 2010; Walter, 2013).

According to Walter (2013), the utilization of discourse analysis in social science was influenced by technological advances that have provided avenues for production and consumption of texts, and, the desire to use qualitative inquiry methods. It also fits with public awareness mediums such as media and advertising, such as the frequent use of "sound bites" and "spin" by a journalist to describe the language used by politicians to achieve specific effects (Walter, 2013; Howarth, 2000). In social sciences, discourse analysis can encompass analysis of single utterances, a conversation between two or more people or incorporation of a social and political context (Howarth, 2000). As the concept continues to be applied, it has gained a greater theoretical perspective (Howarth, 2000). 
Proper use of discourse analysis requires an understanding of the theoretical contexts within which the approach is embedded (Howarth, 2000; Salkind, 2010; Walter, 2013). In the social sciences, discourse analysis can take multiple methodological approaches. Howarth (2000) places discourse analysis into two contexts. First, discourses "are best viewed as frames or cognitive schemata", and discourse analysis examines how the frames effectively bring out certain ends. Second, discourse as a theory and an analysis. As a theory, discourse is based on the assumption that human actions and practices are shaped by sociopolitical struggles within specific historical periods (Fischer, 2012c). In essence, discourse relates to constructionism, which emphasizes the interplay between objects in the social world and their influence on social interactions or the creation of meanings by individuals through social interactions (Howarth, 2000; Pettenger, 2007b). Here discourse is regarded as objects with properties and power. Hence, the analysis should focus on the structure of language, and the role of discourse analysis is to expose the power embedded in the language (Howarth, 2000). The approach is grounded on the fact that studying the structure of the text must be located in ways through which such texts are produced and how the underlying discourse influence reality (Howarth, 2000). Clearly, this portrays discourse analysis to be more than just an analysis of texts. Fischer (2012) stresses that meanings of words used in language can be found in social contexts in which they are articulated. As a result, the analysis must consider the ideological system that results in an uneven distribution of power (Fischer, 2012c; Howarth, 2000; Salkind, 2010). It is this second context of thinking that dominates discourse analysis (Howarth, 2000; Salkind, 2010; Walter, 2013). Hence, the consideration of discourse analysis as an interpretive qualitative research method and a social construction under the constructivist paradigm (Salkind, 2010).

\subsubsection{Types of discourse analysis}

There are a variety of discourse analysis approaches (see Fischer, 2012; Howarth, 2000; Salkind, 2010; Walter, 2013). However, the analysis used herein is mainly attributed to two approaches: Foucauldian discourse analysis and non-Foucauldian perspectives (Feindt \& Oels, 2005; Walter, 2013). Common to both forms of discourse is the focus on the influence of language in policies and politics, claims of multiple realities and an acknowledgement of the influence of power in exploring knowledge and language. However, the difference between the two is based on ontological and epistemological perspectives and methodology (Feindt \& Oels, 2005).

According to Feindt and Oels (2005), Foucauldian perspectives are more concerned about power while the non-Foucauldian focuses on language and the pragmatic approaches to the generation of meanings while still integrating power analysis. Foucauldian perspectives were 
inspired by Michael Foucault, a historian, a social theorist, and philosopher whose work focused on the relationship between power and knowledge in discourse (see Foucault, 1972, 1980, 1991). In his work, Foucault does not refer to institutional power, but emphasizes that power is present everywhere, and every meaning-making is associated with some form of power structured by social positions (Chouliaraki, 2010). He situates his discourse and the influence of power to historical contexts, which emerge over time to influence the emergence of a variety of discourses (Blommaert, 2005; Chouliaraki, 2010; Feindt \& Oels, 2005; Foucault, 1972, 1980, 1991). Power is seen to constitute a network of relationships between individuals (Walter, 2013). As a result, discourse can be both an instrument and effect of power; it can be an enabler and constraint to an actor's actions (Feindt \& Oels, 2005). The Foucauldian discourse analysis has been criticized for lack of a systematic approach to discourse analysis (Walter, 2013). Instead, critical discourse analysis (CDA), a non-Foucauldian discourse analysis, which draws on the contexts of Foucauldian discourse analysis, has been forwarded (Fairclough, 2003; Walter, 2013).

\subsubsection{Critical discourse analysis (CDA)}

CDA is the most influential type of discourse analysis in social sciences; the approach is especially relevant due to its outlined framework of discourse analysis that is lacking in the Foucauldian discourse (Fairclough, 2003, 2013; Walter, 2013). CDA is an interdisciplinary approach to studying discourse. It is a type of discourse analysis for analyzing, interpreting, and explaining the influences of language on policies and how power in society is reinforced through language use (Fairclough, 1995; Janks, 1997; Walter, 2013). Bazeley (2013) posits that the central feature of CDA is its focus on uncovering power and power struggles embedded in the contexts of competing discourses. Through CDA, a researcher can explore and explain how dominant groups and institutions use texts (language) to produce and legitimize their position and power (Phillips \& Hardy, 2002)

Some of the main areas of CDA include political discourse, ideology, institutional discourse, and media (Blommaert, 2005). The CDA was developed by Norman Fairclough (Fairclough, 1989, 1995, 2003). The analysis focuses on three-tiered approaches: textual analysis, discursive practices, and social practices (Janks, 1997; Walter, 2013). Textual analysis is a method of analyzing how people make sense of their world through interpretation of words used and their structures (McKee, 2005; Walter, 2013). In CDA, the analysis is not limited to texts but connects the texts to social and political contexts and ideologies. The analysis of discursive and social practices then connects the language in the texts to the broader sociopolitical contexts and ideologies (Fairclough, 2003, 2013; Walter, 2013). Walter (2013) defines discursive practices 
as the analysis of the rhetorical strategies used in the text while social practices expose ideologies and power embedded in sociopolitical processes. The social practices highlight the political contexts that produce such texts. Each stage of the CDA, provide a researcher with a method of analysis and, the three stages of discourse analysis connect policy texts to the social contexts of policies and politics by emphasizing the influence of framing, ideologies and discursive strategies that shape political outcomes and that are embedded in institutions (Fairclough,1989, 1995; Fischer, 2012; Janks, 1997; Walter, 2013).

Discourses are embedded and identifiable in institutions since social actions are generally clustered around institutions, which provide forms of routine interactions, processes, and practices (Dryzek, 2013; Fairclough, 2013; Fischer, 2012c). For example, we can relate a specific social event to a particular institution such as school, family workplace, etc. (Fairclough, 2013). Therefore, it is more sensible to use discourse analysis with some form of institutional analysis approach (Fairclough, 2003). Integrating discourse analysis with institutional analysis can expose the institutions developed to address environmental issues or institutions that play a role in the policymaking and discourse (Cairney, 2015; Fairclough, 2003).

Gould and Lewis (2009) also argue that the visibility of social interactions is sometimes "masked by power relationships." Thus, connecting the world views of climate change knowledge and meaning requires a framework for exploring the political contexts of climate change policies. Social and political contexts such as institutions, policymakers, beliefs, influences of powerful groups, socioeconomic contexts, and political philosophies can support the analysis of power and its influence on climate change framing and public health engagement (Cairney, 2012c; Dryzek, 2013). The legitimacy of institutional relationships and the substantive elements in climate change governance structures applied by different climate change stakeholders to manage climate change have influences on participation and engagement (Cadman, 2013; Wallner, 2008). A framework that exposes the political and social contexts of climate change governance is warranted to uncover institutions influencing discourses.

\subsubsection{Analyzing Institutional Context Shaping Meanings and Discourses}

There is no single definition of institutions (Rhodes, 2006). Gauvin (2014) defines institutions as "the formal and informal rules, norms, precedents, and organizational factors that structure political behaviour." There is a convergence between the definition provided by Gauvin (2014) and those of others in the literature. These include descriptions of institutions as "principles, norms, rules and decision making" (Cadman, 2013), rules and social construction by social actors (Barley \& Tolbert, 1997; McGinnis, 2011; Ostrom, 2010), and the social actors that 
provide opportunities and constraints that shape policy outcomes (McGinnis, 2011). These socially constructed rules, norms, or principles occur at the global, national and local levels (Cadman, 2013). As a social construct, what differentiates institutions with other forms of social construction is power (Lawrence, 2008). Furthermore, institutions can be classified into three forms: rules, policies, and networks (Shearer, Abelson, Kouyaté, Lavis, \& Walt, 2016). Shearer et al. (2016) classification resembles that of Gauvin (2014); it includes "government structures, policy networks, and policy legacies". However, Zucker (1983) classifies organizations as the preeminent forms of institutions. Although, Ostrom (2010) classifies organizations as part of the definition institution. As an organization, the relationship between institutions emerges in their connection to a common issue (Hardy \& Phillips, 1998). Cairney (2012) suggests that organizations, such as "legislature, courts and executives", may have been referred to as institutions in the past, but currently represents the "rules, norms and practices" governing behaviours. These definitions portray the visibility (e.g. organizations) and invisibility (why certain things are done and others not done (e.g. norms, networks etc.) of institutions (Barley \& Tolbert, 1997; Cairney, 2012; McGinnis, 2011; Ostrom, 2010). In turn, analyzing institutions require identification of not only organization but also the norms and the operational strategies that guide the norms.

Several frameworks are relevant for understanding and examining the institutional contexts of policymaking. The approaches can include an analysis of how economic, social, and political institutions influence public policy (Parsons, 1995). Policy analysis can focus on the examination of the different stages of policymaking and implementation and their influence on public policies (Cairney, 2012; Jann \& Weigrich, 2007; Kulaç \& Özgür, 2017). Policy research can consider the impacts of institutional norms and structures, multilevel governance, and distribution of power or policy networks (Cairney, 2011; Moloughney, 2012). Policy study can also analyze the role of ideas (including values and knowledge) or worldview in influencing policies by illuminating the role of frames which elaborates the influence of text on the social construction of an issue, its influence in beliefs and its association to power (Dryzek, 2013; Walter, 2013). Cairney (2012) argues that "there is no single unifying theory" in studying public policies. Instead, perspectives can be based on a single theory or combination of insights from various theories into a framework. John (2012) explains that policymaking is not just about decisions; it also constitute ongoing interactions and conflicts between institutions, networks, actors, decisionmaking approaches, interests, factors external to politics, and ideas.

A framework that has been widely used in exploring influences of institutions, and factors beyond institutions, is the institutional analysis and development (IAD) framework. IAD framework 
is relevant for identifying variables common to all institutional arrangements while accounting for the differences in values across the institutions (McGinnis, 2011; Moloughney, 2012; Ostrom, 2010,2011 ). In the IAD framework, contextual factors (biophysical conditions, attributes of policy communities and rules-in-use) define the problem or set an agenda (action situation). Action situation is the units of analysis or the social spaces for participating and deliberating on the issue (Moloughney, 2012). The agenda is deliberated by participants (interactions), leading to policy outcomes. The interactions and outcomes are evaluated; these produce inputs (external variables) that affect proceeding policies. External variables (inputs) are the contextual factors (social, cultural, institutional, and physical environments) that influence policies (McGinnis, 2011). Thus, within the IAD framework, the first step in examining institutions is to identify action situations and resulting patterns of interaction (McGinnis, 2011; Moloughney, 2012; Ostrom, 2010, 2011).

Each of the frameworks discussed above uniquely targets specific or combined contexts of institutional policymaking and analysis. They also complement one another in several ways. They explore the irrational and political nature of policymaking and how issues set political agendas. They illuminate the role of institutions and policy actors in public policy and patterns of interaction and denote that knowledge, information, attitudes, views, assumptions, and interests influence policies. The frameworks also highlight various components of public policies; some combine the influence of more than one theory on policies (e.g. theories that analyze policies in terms of policy networks and institutions). The policy frameworks discussed also highlight several variables that drive the policy and decisionmaking processes. These include institutions, individual and group values (interests, beliefs, ideologies), and information which influence knowledge within or outside of political systems (Gauvin, 2014; John, 2012; Murphy, 2012; Shearer, Abelson, Kouyaté, Lavis, \& Walt, 2016; Lomas, 2000). A framework that best represents and consolidates these policy contexts is the Lomas Model of Decision Making, also known as the Canadian Health Services Research Foundation (hereafter referred to as Lomas Model).

Lomas model provides broader contextual factors for understanding the interconnection between the three drivers policy (institutions, values, and information) and how they integrate to influence policymaking and decisions within institutions. The model exposes the influence of knowledge or information, institutions, and values on public policies (Brehaut \& Juzwishin, 2005; Lomas, 2000; Rosella et al., 2013). The Lomas Model was created to enable the development of research that was both useful to health and policymakers. The main narratives of the policy frameworks preceding the discussion of Lomas Model are the focus of the Lomas Model. For instance, the framework provided tools for understanding and explaining the contexts of decision 
making using three tenets: the institutional structures for decisionmaking, values, and information (Brehaut \& Juzwishin, 2005; Lomas, 2000; Rosella et al., 2013).

Institutional structures for decision-making include the design of institutions, actors that are legitimized in the process and responsibilities assigned to the actors (Lomas, 2000). The structures can be formal (such as executive, legislative and bureaucracy) or informal structures (e.g. policy brokers, coalitions, stakeholders, and citizens) (Lomas, 2000). Institutions can also include political organizations such as "parliaments, legal systems and bureaucracies" (John, 2012). Demonstrating the influence of institutional power in policymaking requires the portrayal of the powerful versus the powerless (Cairney, 2012c). This can be established either through observable behaviour (behavioralism) that allows the researcher to observe an actor's decisionmaking powers over another or theorized by examining the processes and structures, independent of the actor, that influence decision-making (Cairney, 2012c).

Values affecting the decision comprise of interaction between interests, ideologies, and beliefs (Brehaut \& Juzwishin, 2005; Lomas, 2000; Rosella et al., 2013). Interests are one's personal view of the world; ideologies "declare a person's or an organization's view of how the world ought to work"; beliefs are what one deems to be true based on knowledge (Lomas, 2000).

Information encompasses the sources of evidence that inform decisions (Lomas, 2000). Information can range from research, experiences, anecdotes, propaganda, interest groups, think tanks, and media. The knowledge informs structures for institutional decisionmaking and targets beliefs to persuades the people to make the choices that inform the processes and decisions (Lomas, 2000).

The Lomas model has been utilized by several researchers to connect research to policies. For instance, Rosella et al. (2013) applied the Lomas Model to understand and highlight the processes and challenges of public health decision making following the Influenza pandemic in 2009. The relevance of the framework in healthy public policy has also been cited in various literature (see Brehaut \& Juzwishin, 2005; Conrad, 2008; Lomas, 1997, 2000; Lomas, Culyer, McCutcheon, McAuley, \& Law, 2005; Lomas et al., 2003; Institute of Medicine, Board on Population Health and Public Health Practice, Committee on Valuing Community-Based, 2012). As a result, the Lomas model provides a framework for connecting discourses to institutional influences and assessing the social practices influencing policy and the deliberation and participation processes as well as a framework for connecting language and institutional contexts. 


\subsection{SUMMARY}

Literature has shown that climate change is a complex phenomenon whose responses are defined by competing discourses. Among the many discourses, a public health framed discourse has been identified to support legitimate climate change policies. Despite the relevance, the various stakeholders working to educate the public and influence climate change, political and economic power as well as biased perspectives on the needs dominate. Little attention has been paid to public health. The sector's role has remained elusive in the climate change policy discourse. One may ask why the public health frame and focus do not dominate climate change discourse. While this chapter does not answer those questions, it provides frameworks for understanding the problem (why).

Through the constructionism approach, we can understand the assumptions about the nature and knowledge of climate change and the discursive formations that support its conceptualization. Constructionism can guide the use of techniques that support meaning identification, analysis and interpretation while systematically highlighting the decisions and theoretical thinking taken to arrive at a conclusion. Through social constructivism and interpretivism, this literature review has shown that climate change is a social construct whose comprehension of impacts and consensus or uptake of actions is influenced by the struggle about knowledge, power, and meanings people assign to the phenomenon. An understanding of climate change defines if and how people deal with it. Discourse presents approaches to examining such knowledge and meaning in ways that resonate with the audience. However, discourses also create meanings that define people's understanding of the phenomenon and its needs. Some discourse may not resonate with the audience or may only be relevant to a specific audience. While public health framed climate change supports a broader climate change understanding and action, it competes with other frames. Understanding the influences of a public health frame and engagement can be achieved through analyses that delineate the role of language and the social and political context supporting the domination and legitimization of a frame and actors.

Literature has also suggested that deductive approaches have a limited role in exploring the research problem; also, that no single approach can fully explain the meanings assigned by individuals and their influences on discourse as well as the influence of institutions in shaping meanings within social and political settings. Taking an inductive approach through interpretive policy analysis can expose such influences. Through CDA, we can examine the language applied in written and spoken texts, identify the strategies and processes that produce and emphasize the arguments used in the texts and connect the texts social contexts of policymaking as well as the narration of events, practices, and experiences to the broader sociopolitical and historical 
contexts of climate change debate and actions. Similarly, the chapter highlighted that climate change policy documents and information contain texts (written or verbally spoken and transcribed verbatim). How the information is presented have specific meanings. The meanings they convey cannot be separated from the sociopolitical contexts that produce such texts. However, because discourse and meanings are influenced by, embodied and embedded in, and identifiable with by institutions, we are most likely to understand cyclical influences between language and sociopolitical contexts if we explore institutional contexts of decision-making. The Lomas Model of Decision-Making provides a descriptive framework and key variables for examining and classifying the institutional decision-making features of interest to the study.

The chapter also demonstrated that the arenas where policies are produced and the interactions between the various stakeholders are influenced by different meanings and discourses that arise from political, social and institutional contexts. As such, examining all climate change policies, processes, and institutional influences across the globe would be impractical and time-consuming. In turn, Walter (2013) and Fairclough (2013) advise the need to provide a reader with an overview of the political contexts (social practices) producing the texts under study. In this context, this study focuses on a particular jurisdiction - the province of Ontario context - as an outset for understanding climate change framing and engagement. Such contexts have been described in Chapter 2. Through the various characteristics of the province, the province is an ideal case exploring climate change framing and public health engagement. 


\section{CHAPTER 4: RESEARCH METHODOLOGY}

\section{INTRODUCTION}

The methodology is a comprehensive, conceptual lens for understanding, designing, and conducting research and includes systematic tools for finding, collecting, analyzing, and interpreting research; it is a scientific worldview of generating information that is valid or believable (Rawnsley, 1998; Walter, 2013). The purpose of this chapter is to describe the actions taken to investigate the research problem and rationale for the selection of each technique utilized to identify, collect, analyze, and interpret the study data in a manner that allows for the evaluation of the validity and reliability of the study.

Section 4.1 restates the research problem and questions identified in Chapter 1 and positions them within the methodology. The section also provides a plan on how the research questions are answered, the underlying assumptions and concepts underpinning the study, and the strategy used to implement the research plan.

Section 4.2 discusses the data collection methods, including identification of relevant data, sampling, selection of data, the exclusion and inclusion criteria applied.

Section 4.3 and 4.4 discuss the data analysis methods, focusing on critical discourse analysis and thematic analysis.

\subsection{RESEARCH DESIGN}

Research design is the method and structure used by a researcher to collect and analyze data in a manner that investigates the issue of interest (Salkind, 2015). According to Trochim (2006), most research will have a general structure. The research design can be conceptualized as a linear process where one step informs the next level (Salkind, 2015; Trochim, 2006). However, research is less likely to be a linear process (Berg \& Lune, 2016). For this study, a spiralling research approach, as illustrated in Figure 5: Spiralling research design, was followed (Berg \& Lune, 2016). The study began with a linear process. However, an iterative process was applied in which the research design was informed by theory as a guide to data collection, analysis, and interpretation. The data collection and analysis spiralled back and forth, informed by information acquired in the multiple stages of data collection and analysis. As a result, the research questions and data collection and analysis processes evolved as the research progressed. 


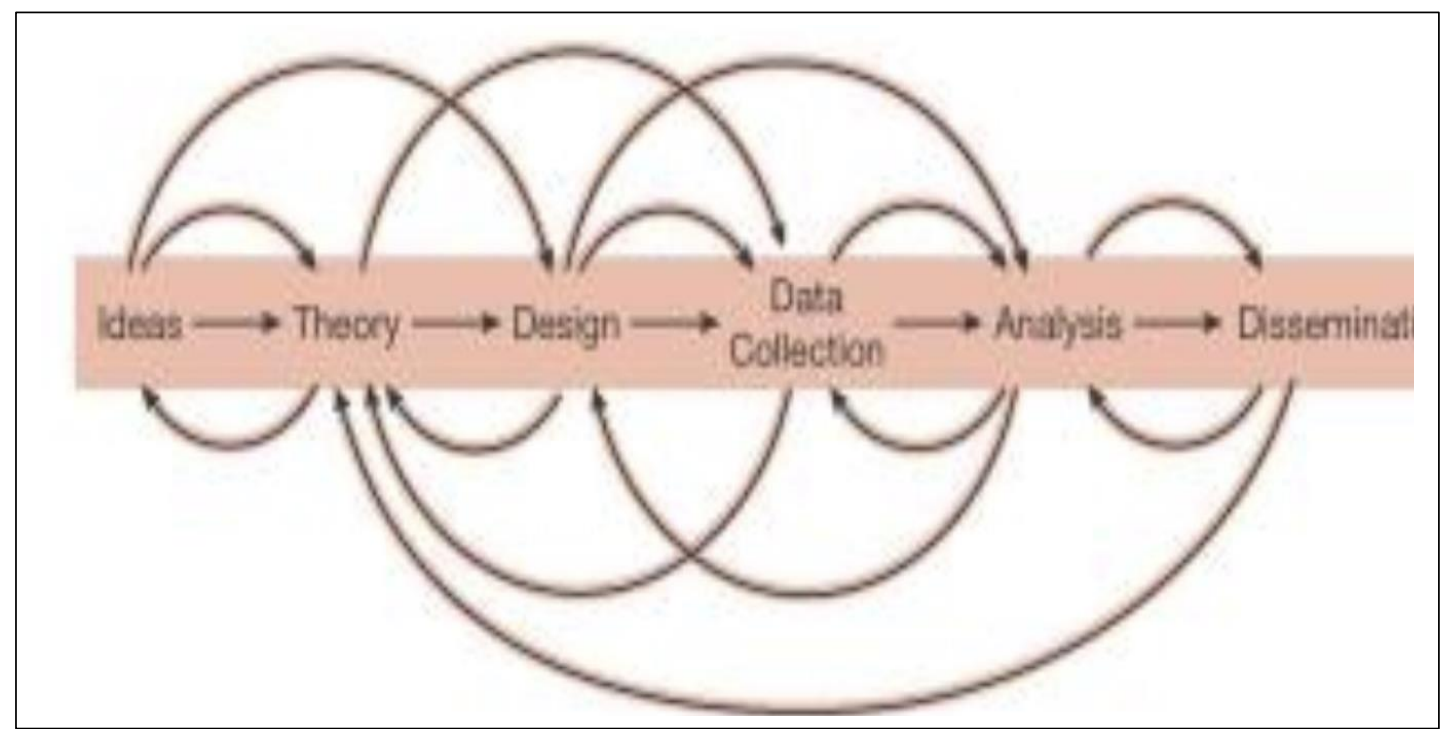

Figure 5: Spiralling research design

Source: Berg and Lune (2016)

\subsubsection{Research Questions}

Research questions were the most important and first step of this research as they guided the direction of research (Salkind, 2015).

The purpose of this research is to use the context of climate change policy discourse in the province of Ontario (Canada) to support the utilization of the frames and encourage public health inclusion in the discourse by examining how public health needs are socially constructed in the discourse, the sociopolitical contexts advancing or impediments the public health framed climate change policy discourse. The specific objectives of the study are three-fold. The study aimed to examine the extent of public health frame application in the province's climate change discourse, the systematic factors influencing the public health frame and needs in the discourse, and, how public health framed climate change policies can be advanced in the climate change language, discourse, and institutions. Exploring the research aims and objectives was facilitated through these three interrelated research questions.

\section{Research Question 1:}

How does the province of Ontario frame its climate change discourse?

\section{Research Question 2:}

What discursive and systematic contexts have influenced the framing of climate change? 


\section{Research Question 1:}

How have the contexts influenced the public health frame and capacity in the climate change discourse?

These questions established the focus of the study and situated the problem and purpose of the study. The questions underpinned the research method, conceptual framework and the techniques of data collection, analysis and interpretation.

\subsubsection{Conceptual Framework}

A conceptual framework is a theoretical map that guides an understanding of an issue, supports answering a research question, and directs data collection and analysis, or supports the mapping of an issue from known to the unknown (Parsons, 1995; Rocco \& Plakhotnik, 2009; Walter, 2013; Yin, 2014). A conceptual framework can be made up of one or several theories, models, and frameworks (Rocco \& Plakhotnik, 2009; Walter, 2013). McGinnis (2011) differentiates between framework, theory, and model. A framework supports our understanding of a phenomenon by portraying factors relevant to the identification, categorization, and organization of thoughts and variables. A theory predicts, explains, and portrays relationships among variables or categories of factors or challenges existing knowledge. A model is a pictorial representation showing relationships between variables or factors (McGinnis, 2011).

\subsubsection{Conceptualizing public health framing in climate change discourse}

Public health's place in the framing of climate change policies was conceptualized as depicted in Figure 6: Logic model of the relevance of public health framing in climate change. The framework has been developed based on research questions and the themes that emerged in the literature review. As shown, climate change results in several risks, impacts, and vulnerabilities. Tackling climate change impacts rely on reducing GHGs (mitigation) and actions to cope with and build resilience to the impacts (adaptation). However, these actions must be communicated in a manner that not only supports the uptake of strategies put forward but also creates awareness of risk and builds consensus on actions needed.

Creating awareness of the impacts, building consensus on actions, and linking the importance of dealing with climate change to a broader audience is a communicative process where ideas are relayed to an audience through verbal and non-verbal means to trigger a response. How the message is relayed to the audience and the audience's interpretation of the message is impacted by how the message is framed. But, within these debates and interactions, 
individual and collective perceptions, knowledge, opinions, ideologies, and power influence the debates, impacts awareness, and the uptake of resulting policies through various frames. While each frame has relevance in the climate change discourse, a public health frame has empirically been identified in the literature to support climate change discourse and disseminating democratically superior communications and engagement platforms that accounts for the broad, varied audience perceptions and needs.

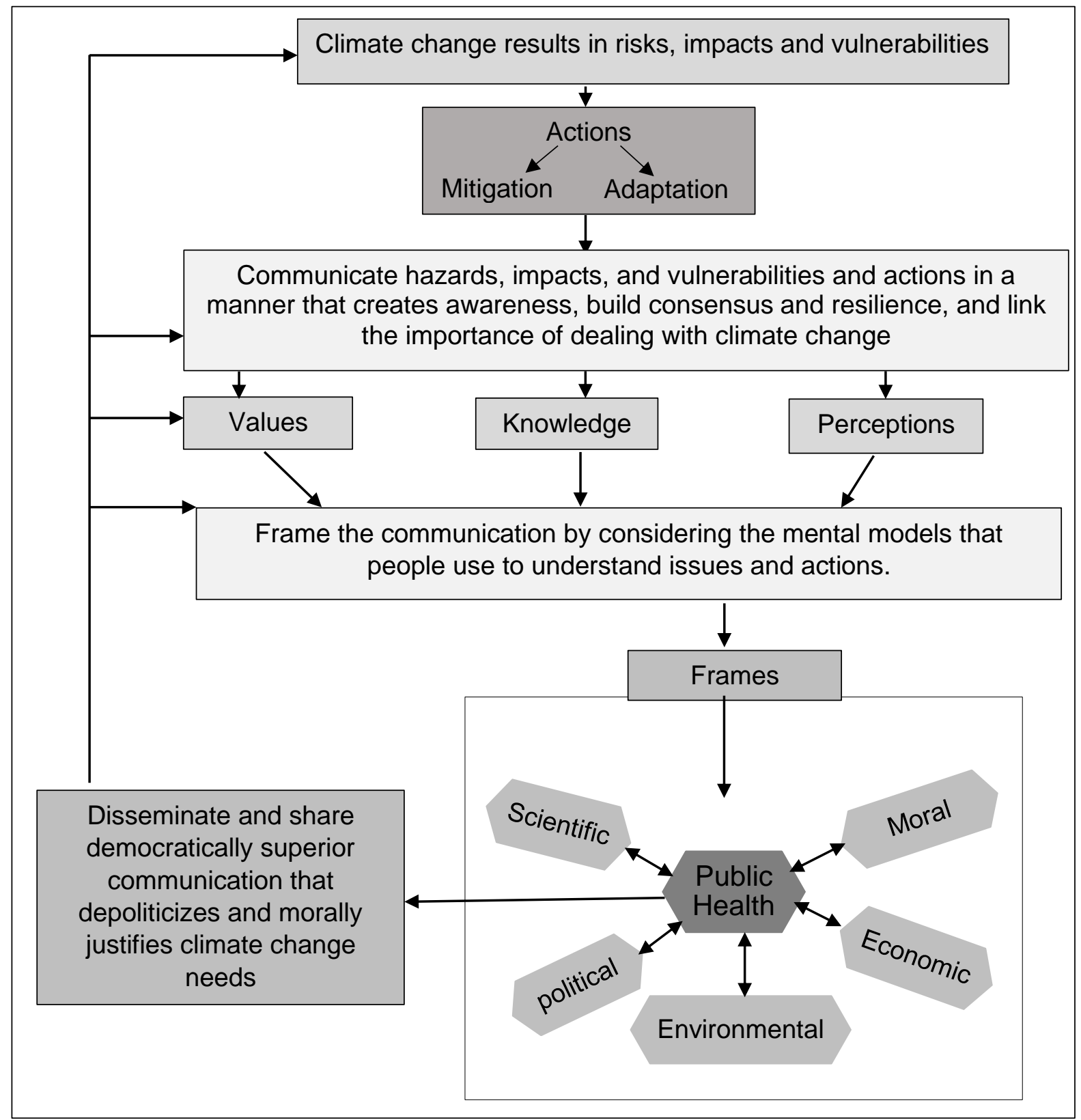

Figure 6: Logic model of the relevance of public health framing in climate change 
In reality, climate change remains socially constructed as a political, economic or environmental problem; partisan division and prioritization of economic policies define actions. However, understanding social issues relies on understanding the structures and forces that influence discourse (Fischer, 2012c; Pettenger, 2007a). And, because discourses are constructed by institutions and actors through historical and social contexts that lead to patterns that shape stakeholder engagement, we can understand the influences of public health framed climate change policies by exploring how institutions work to influence climate change policy discourse and the roles played by social actors.

\subsubsection{Conceptualizing of institutional contexts of a public health framed climate change policy discourse}

Chapter 3 (page 73) introduced the Lomas Model as a framework for conceptualizing contexts of decision making within institutions using three tenets: the institutional structures for decisionmaking, values, and information. These tenets are illustrated in Figure 7: Lomas Model of Decision-Making below.

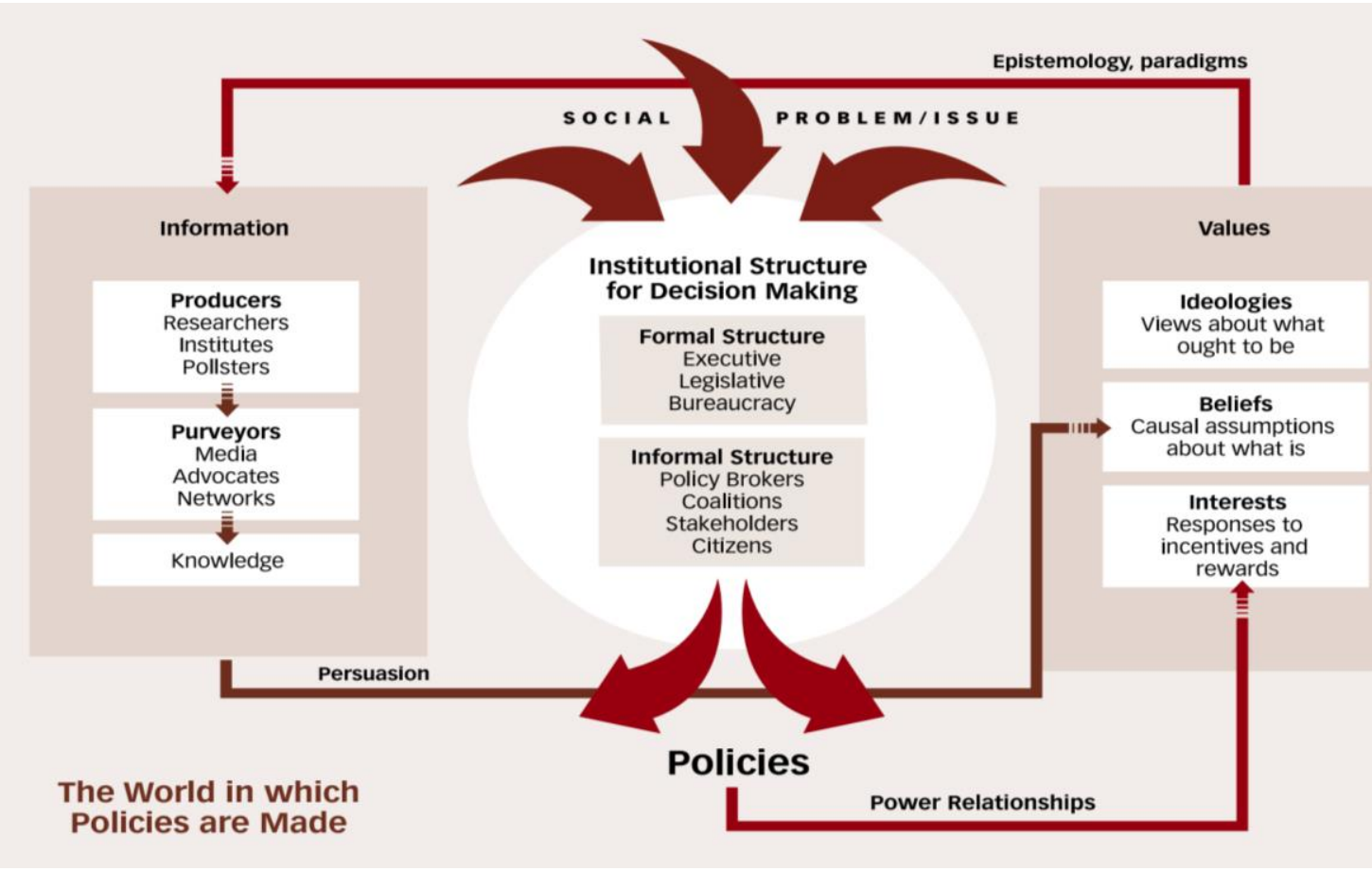

Figure 7: Lomas Model of Decision-Making

Source: (Lomas, 2000) 
The model guided the conceptualization of institutional influences of a public health framed climate change policy discourse. Based on the Lomas Model, the study developed three propositions for a broader conceptualization of institutional influences in a manner that can link language and social contexts.

- Climate change policies (outputs) can be defined by institutional structures of (those who have a voice in) climate change decisionmaking processes.

- The outputs are influenced by values held by the institutions as individuals and organizations integrate their beliefs, interests, and ideologies into the decisionmaking processes.

- Evidence used in decisionmaking will serve as both inputs for institutional decision making and persuasions for beliefs rooted in individual and organizational values.

Because discourses are embodied in institutions, influences of a public health framed climate change policy discourse in Ontario can be understood from a context of social setting (as a social problem) to disclose the constructs and human's meaning-making processes - that is, exploring the "what", and "why" practices and "how" such practices arrange so as to generate an observable outcome - and how the meanings connect to institutional contexts of decisionmaking and public health engagement.

\subsubsection{Theoretical framework}

In viewing climate change as a social construction, the study takes the ontological position of local relativism which argues that multiple realities exist; this reality can be explained by a wide variety of ideas and positions, and it is relative depending on individuals' experiences and mental construction (Baghramian \& Carter, 2018; Miller, 2016; Moon \& Blackman, 2014). Social constructionism was the most appropriate epistemological principle for exploring social meanings embedded in language outcomes and the social contexts that influence climate change outcomes as this study dictates. The epistemological principle of constructionism was underpinned by the theories of constructivism and interpretivism (symbolic interactionism, hermeneutics and phenomenology), as illustrated in Figure 8: Philosophical and theoretical underpinnings and assumptions guiding the study (next page).

\subsubsection{Research Method}

The study applies a qualitative single embedded case study, grounded in the theories presented in the theoretical framework guiding the study. Yin (2014) defines a case study as "an 
empirical inquiry that investigates a contemporary phenomenon within its real-life context, especially when the boundaries between phenomenon and context are not evident."

\begin{tabular}{|c|c|}
\hline \multicolumn{2}{|c|}{$\begin{array}{l}\text { 1. Ontology: Relativism (Scope: Local) } \\
\text { - Multiple realities about climate change framing and role of public health in the discourse exists; these } \\
\text { realities are bound by cultural and social contexts and are relevant in examining the legitimacy of a } \\
\text { public health framed climate change discourse. }\end{array}$} \\
\hline \multicolumn{2}{|c|}{$\begin{array}{l}\text { 2. Epistemology: Constructionism (Social Constructionism) } \\
\text { - Knowledge of meaning of climate change and public health's needs is socially constructed. } \\
\text { - Climate change as a social phenomenon is rooted in instituionalized language, discourse; institutions } \\
\text { also supply individuals with physical arrangements, rules of behaviour and knowledg that supply } \\
\text { individuals with reference points (social contexts). } \\
\text { - Focusing on collective generation of meanings can generate a contextual undertanding of the factors } \\
\text { contributing to, or impeding, a public health framed climate change policy discourse. }\end{array}$} \\
\hline \multicolumn{2}{|r|}{ 3. Theoretical perspectives: } \\
\hline $\begin{array}{l}\text { 3a. Constructivism } \\
\text { - The construction of climate } \\
\text { change within social settings is } \\
\text { value-ladden. } \\
\text { - Exploring meaning and } \\
\text { relevance of public health frame } \\
\text { require focusing on unique } \\
\text { individual constructs; allows for } \\
\text { evaluation of a system to } \\
\text { determine what motivates } \\
\text { individual's (agent's) climate } \\
\text { change policy focus a } \\
\text { - Frames applied to discuss } \\
\text { climate change is connected to } \\
\text { the discourse(s) that dictates } \\
\text { Ontario's actions, and the } \\
\text { processses, norms, actors, and } \\
\text { structures motivating or } \\
\text { obscuring the needs and shared } \\
\text { meanings. The } \\
\text { - Therefore, the meaning of the } \\
\text { relevance of a public health } \\
\text { framed climate change policy } \\
\text { can be understood by exploring } \\
\text { the discourse and social } \\
\text { contexts of Ontario's climate } \\
\text { change actions. }\end{array}$ & $\begin{array}{l}\text { 3b. Interpretivism } \\
\text { - Exploring meanings require focusing on unique individual } \\
\text { experiences using social, inductive human-centred approaches. } \\
\text { - Meanings arise from symbols (language) and social interactions } \\
\text { (shared meanings); that is, the meanings of a public health } \\
\text { framed climate change policies arise from, and is influenced by, } \\
\text { social interactions through language as people interact with and } \\
\text { interpret such meaings - Symbolic Interactionism. } \\
\text { we can explore how the application of public health frame is } \\
\text { impacted by the language of climate change, the social } \\
\text { interactions, and conception of public health's role. } \\
\text { - Hidden meanings are projected in policy texts (written or } \\
\text { spoken), and in events, and practices of social contexts - } \\
\text { Hemeneutics. } \\
\text { we can explore why a public health framed climate change } \\
\text { policy is not dominant in the discourse or why individuals } \\
\text { (agencies) do not utilize public health frame despite its } \\
\text { relevance. } \\
\text { - Meanings can be exposed by participnants accounts and } \\
\text { narratives of events and practices - Phenomenology. } \\
\text { A researcher can complement own intepretations of } \\
\text { meanings with others' narrations of experiences of the } \\
\text { pheonomenon to expose how personal experiences of policy } \\
\text { actors give meanings to a public health framed climate } \\
\text { change policy and the influences of structures, values, norms } \\
\text { and knowledge in the construction of public health needs in } \\
\text { the frame. }\end{array}$ \\
\hline
\end{tabular}

Figure 8: Philosophical and theoretical underpinnings and assumptions guiding the study

The case study method was the most useful approach for understanding the phenomenon of climate change framing within its contexts and most appropriate for answering the research questions and achieving the aims of the study. The method provides a systematic approach with a deeper exploration and explanation necessary for understanding a phenomenon, an event or a 
subject, an organization, a person or people within a specific setting or contexts (Berg \& Lune, 2016; Yin, 2014).

Research questions determined the appropriateness of the case study method (Yin, 2014). Case studies are relevant for examing "how" or "why" research question formats (Baxter \& Jack, 2008; Yin, 2014). These questions are the foundation of this study. The questions supported the explicit exploration of the contexts of the study to outline how and why a public health framed climate change policy discourse is related and the discourse and the social and political contexts justifying framing and engagement of stakeholders (Whetten, 2016; Yin, 2014).

Two additional elements made the method ideal for the study. First, case studies are participant centred and inform the generation of theory for explaining a phenomenon (Baxter \& Jack, 2008; Berg \& Lune, 2016; Yin, 2014). As Berg \& Lune (2016) explain, case studies allow a researcher to study the people and or processes that produce or influence a phenomenon, event, or organization under study. Second, climate change as a social construct means that exploring and exposing meaning-making processes of climate change framing and engagements warrant an application of a theory. Grounding the case study with a theory was relevant for facilitating study design and for comparing the findings to other studies (Berg \& Lune, 2016; Yin, 2014).

\subsubsection{Single, embedded case study}

Types of case studies are diverse and can be classified according to the purpose of the study (Verner \& Abdullah, 2012). The different types are extensively discussed in the literature (e.g. Baxter \& Jack, 2008; Carolan, Forbat, \& Smith, 2015; Crowe et al., 2011; Rowley, 2002; Yin, 2014). This study applied a single, embedded case study approach. A single case study considers a single unit of analysis (Yin, 2014). In embedded case studies, a sub-unit is added to the main unit of analysis (single case) to add significance to the study by providing some insight into the problem under investigation (Yin, 2014). The single, embedded case study was selected because the province of Ontario's climate change decision and processes portray an interaction between the province as a whole (single case) and the interaction between ministries and the premier's office (embedded cases); these interactions may or may not include public health sector (embedded cases). Thus, the Province of Ontario is a single case with embedded units (7 Public Health Regions representing 35 PHUs, the Office of the Premier, and the 10 provincial ministries).

\subsubsection{Unit of analysis (Cases)}

Paramount to the case study method is the selection of the case(s) that illustrate the study (Rowley, 2002; Yin, 2014). A case cannot be an abstract claim, argument, or hypothesis; it must be a real-life phenomenon with a concrete manifestation of an abstract (Yin, 2014). Thus, a case 
can be an individual, a small group, a program, a process or decision, an organization or community, partnerships, an event, or a project (Baxter \& Jack, 2008; Creswell, 2013; Yin, 2014).

The first step in identifying cases was the identification of action situations (i.e. Ontario's climate change institutions and factors likely to set agenda or define the problem) and resulting patterns of interaction. Action situation is the units of analysis or other social spaces where individuals interact and exchange or influence ideas (Moloughney, 2012). Based on Ostrom (2011), the study considered these six components to identity cases.

1. The set of actors - e.g. organizations or ministries mandated with climate change actions in Ontario; the MOHLTC and Public Health Units (PHUs) mandated with advancing public health-related agendas.

2. The positions that exist - e.g. role such as policy advisors (within climate change mandates and public health organizations), ministers and deputy ministers of mandated ministries, Premier etc.

3. The set of allowable actions - e.g. types of mitigation and adaptation strategies applied.

4. Potential outcomes - e.g. those afected and events defining the discourse of climate change.

5. Levels of control over choices - e.g. included in the participation structures and deliberation processes of climate change actions.

6. The information available - e.g. who has information about climate change, its impacts, and related actions.

Therefore, the study specifically considered, as cases, the organizations - the province of Ontario, its ministries, the Premier's office and public health institutions - MOHLTC and PHUs within Ontario. That is, organizations associated with climate change actions whose decisions are likely to influence the climate change decisions in Ontario. These organizations (cases) were represented by documents they have produced and individuals affiliated with the organizations in an attempt to represent the language and discourse of climate change and institutional influences.

\subsubsection{Sample frame}

A sample frame constituted all possible sources where samples (cases) are drawn (DiGaetano, 2013; Palys, 1997). In Ontario, the Office of the Premier provides the overall lead in the province. Ministries also play a significant role in climate change as outlined in mandate letters and strategic plans. The Climate Change Update: 2014 and the Climate Change Action Plan: 2016-2011 identify climate change priority sectors and institutions (Government of Ontario, 2017a; Ontario MOECC, 2014). They include key economic sectors such as transportation, 
electricity, industry, buildings, agriculture and waste, and institutions that support governments, research, and development and Indigenous communities. As a result, the Office of the Premier and ministries with the mandate as identified in the strategic documents were relevant samples for the study. The study sample frame included the Premier's office and 9 non-health affiliated ministries, as identified in Table 2: Study Sample.

Equally important to this study is the role of public health. In Ontario, the MOHLTC and the 35 PHUs develop various policies targeting climate change and health in Ontario. Therefore, the MOHLTC and the 35 PHUs were also relevant samples for the study identified and included 11 provincial ministries and 35 PHUs as possible cases for the study. While all PHUs were considered as samples, the selection of samples was based on the 7 regional aggregates of PHUs as previously illustrated by Figure 4: Public health regions in Ontario and listed in Table 1: Aggregation of 35 Public Health Units into 7 public Health regions. This meant the inclusion of at least one PHU from North West, North East, East, Central East, Toronto, Central West and South West PHU aggregates.

The cases were divided into two groups Public Health (PH) and Non-Public Health (NPH). $\mathrm{NPH}$ group was considered as any case included in the study that is not a part of the MOHLTC and the 35 PHUs. That is, the NPH group consisted of the Office of the Premier and all the sampled government ministries except the MOHLTC while the $\mathrm{PH}$ consisted of the PHUs and the MOHLTC.

\section{Table 2: Study Sample}

\section{Office of the Premier (OP) \\ Ministry of:}

- $\quad$ Agriculture, Food and Rural Affairs (OMAFRA)

- Economic Development, Job Creation and Trade (MEDJCT) *

- $\quad$ Energy, Northern Development and Mines (MENDM) **

- Environment and Conservation and Parks (MECP) ***

- Health and Long-Term Care (MOHLTC)

- Indigenous Affairs (MIA) *****

- $\quad$ Municipal Affairs and Housing (MMAH)

- $\quad$ Natural Resources and Forestry (MNR)

- Research, Innovation and Science (MRIS) ${ }^{\star \star * \star *}$

- Transportation (MOT)

7 Public Health regions representing 35 public health units

- $\quad$ North West

- North East

- East

- $\quad$ Central East

- Toronto 


\begin{tabular}{|c|c|}
\hline$\bullet$ & $\begin{array}{l}\text { Central West } \\
\text { South West }\end{array}$ \\
\hline & $\begin{array}{l}\text { he } 2018 \text {, changes occurred to some of the ministries selecte } \\
\text { e changes occurred post-study sampling and did not have an }\end{array}$ \\
\hline * & Previously - Economic Development and Growth \\
\hline ** & Previously - Ministry of Energy \\
\hline *** & Previously - Ministry of Environment and Climate Change \\
\hline 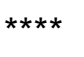 & Indigenous Relations and Reconciliation \\
\hline 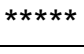 & Eliminated \\
\hline
\end{tabular}

\subsection{DATA COLLECTION METHODS}

The study required the generation of information from written texts as well as from individuals who have knowledge and experience about the research topic as dictated by the case study method (Berg \& Lune, 2016; Yin, 2014). Written (documentation) and verbal (interviews) texts describing climate change policy processes and decisions were considered as relevant data sources.

\subsubsection{Identifying and Collecting Documented Data}

Extended discussion and action on climate change emerged in Ontario's politics around 2007 (MECP, 2016). As a result, numerous policy documents and government websites outline the successes, challenges, policies, programs, interventions, and legislative activities on the issue.

From the selected study sample, numerous policy documents and websites outlining Ontario's climate change information, policies, programs, interventions, and legislative activities on the issue were accessed. Data sources were limited to grey literature published by the government of Ontario from 2007 until December 2018. Identification of climate change policyrelated texts was guided by Cairney's (Cairney, 2012c) and Hogwood and Gunn's (Hogwood \& Gunn, 1984) characterization of public policy. That is, an understanding of public policy as a field of study, an expression of intent, a proposal, decision, a program, legislation, output or outcome, and a process or series of processes. In turn, documents (texts) considered included official, publicly accessible organization's written records on climate change actions and information, specifically, plans, debates, strategies, news releases, legislation, program and process documents or information, reports and websites describing policy processes or outputs as authored by the sampled government agency or by a third party on behalf of the sampled agency.

Identification of documents for the study was also guided by the Preferred Reporting Items for Systematic Review protocol checklist (PRISMA) (Moher, Liberati, Tetzlaff, Altman, \& Group, 2009; Shamseer et al., 2015). To be included in the analysis, the policy texts and captured website 
must have included a description (e.g. impacts, scientific basis, vulnerabilities, risks, etc.) or initiatives, policy processes, discussions, or actions (including mitigation and adaptation strategies). Documents and plans were also included - even if such documents did not include the word climate change - if such documents were specified as relevant in a climate change document (e.g. mentioned in a climate change plan or strategy). Legislation (Acts and Regulations) were only included if they contained a preamble that provided an introductory statement addressing climate change issues. Documents included were only from the government ministries, and not PHUs, as the role was to identify how the government has historically presented climate change discourse in its texts.

A systematic web search was conducted between June 2017 to December 2018. The extended period was used due to the nature of some government websites, specifically, the government's Newsroom website which was periodically updated with relevant climate changerelated policy news updates. Keywords such as "climate", "climate change", and key climate change descriptions such as "impacts", "risks" and "vulnerabilities", "policy", "plan", "strategy", "mitigation" and "adaptation" were used in the search engines. The keywords were searched separately or paired with the relevant sector, ministry, or government institution, depending on the search topic and database. Two search approaches were applied. The first search occurred in government- or ministry-specific websites. Secondly, the Google search engine was utilized using four types of searches depending on the structure of the website: generic search engine, navigation and scanning of website headings and subheadings, scanning through relevant web pages, and reference list examination. Preliminary screening was conducted within the websites. The first 30 results were examined, then every other page until 30 irrelevant consecutive results were observed. This approach has been adapted in various literature (see Austin et al., 2016, 2015; Panic \& Ford, 2013). The search results were screened using titles, abstracts, and full text when deemed necessary (e.g. webpage). Relevant literature and web captures were individually exported to QSR International's NVIVO qualitative data analysis software (Version 12) for further screening for relevance and duplication. Documents excluded either did not conform to the inclusion criteria or were duplicates. The selected documents retained for qualitative analysis.

The intent to examine the frames applied in Ontario's climate change discourse was not only to gather facts and expose the historically dominant frames (output) but also to use that output as a foundation for assessing the influences of public health frame framing in the discourse. Specifically, expositions of individuals and institutions' preferences, values, identities and knowledge on the framing of climate change and public health engagement. Focusing on policy documents was likely to provide clues and expose some knowledge, values, preferences, and 
identities. However, the ambiguity and complexity of written public policies made it difficult to characterize the subjective meanings, preferences, values, and knowledge of climate change framing and public health engagement. Participants' narratives complement the deficiencies of documents by providing a deeper understanding of social contexts.

\subsubsection{Identifying and Collecting Key Informants Data}

The cases were represented by individuals affiliated with the organizations. The study applied purposeful and snowball sampling to recruit study participants. The purposeful sampling focused on identifying the individuals who are likely to have a unique or relevant perspective and rich information about the phenomenon being studied (Voss et al., 2002; Robinson, 2014). The study discriminately identified and selected participants (experts) with critical knowledge that serves the goals of the study (Coyne, 1997; Palinkas et al., 2015). Using quota purposeful sampling, the study set a minimum number of at least one participant per case (Robinson, 2014). Where identified participants were unlikely to participate, snowball (or referral) sampling was used to identify participants through recommendations of qualified individuals (Robinson, 2014).

The individuals needed for study were required to be able to communicate their experiences, opinions, and events effectively and concisely. Categories such as positions and roles served as the starting point of participant selection. Participants were current employees or former employees who had actively taken part in the formulation and/or implementation of climate change policies within Ontario as well as participated inter-agency or stakeholder collaborations and interactions with other institutions on climate change policy-related matters. The individuals needed to be a public health or policy experts holding leading roles in climate-related areas in respective jurisdictions. The level of responsibilities included managerial, directorship, or persons in senior-level positions or directly engaging in climate policy, including policy analysts, Medical Officers of Health, environmental specialists or those holding senior roles over climate change programs, strategies, policy analysis, planning, formulation, implementation or research. The participants were required to be familiar with the legislation, standards, and policies relevant to climate change actions. Those who did not fall within the sampled jurisdictions, employee type or without the nature or level of responsibility defined above were excluded from the study. A participant who either changed jobs, job description, or position but had previously participated in the climate change policy formulation at a senior position was considered.

Provincial ministry participants were identified from the Ontario government website "INFO-GO" (Government of Ontario, n.d.-a). The site provided a directory of government employees and organizations with search options for employees or ministry of interest, including 
contact details (office location, phone numbers, and email addresses). To identify and select relevant participants from the $35 \mathrm{PHUs}$, a research participation request was sent to each $\mathrm{PHU}$ through the Association of Supervisors of Public Health Inspectors of Ontario (ASPHIO). ASPHIO comprises directors and managers serving the 35 PHUs in Ontario (OPHA, 2017). A preliminary search identified potential participants, including managers and senior policy and program advisors, formulating and or implementing climate change in various ministries and PHUs. Each government institution and the PHU aggregates yielded at least one participant. However, sampling was stopped once no new information was learned from the retained participants (theoretical saturation).

Gathering information from humans required ethical approval prior to data collection. To ensure that research participants are protected, ethical approval for the study was obtained from Ryerson University's Research and Ethics Board (Appendix A: REB Approval - Ryerson University) and as well as from one PHU as requested by a participant (Appendix B: REB Approval - Participant Requested Ethics Review). Annual research report requests and renewals for each research ethics board were adhered to as illustrated in Appendix C: Renewal Ryerson University and Appendix D: Renewal - Participant Requested Ethics Review. The ethics requirements were followed throughout the study. This information was highlighted in the consent form (Appendix E: Consent Agreement) provided to participants prior to participation. Prior to ethics approval, a Tri-Council Policy Statement: Ethical Conduct for Research Involving Humans (TCPS) course was completed online as required by Ryerson University (Appendix F: TCPS 2 Certification)

Telephone interviews were conducted between May to December 2018, using semistructured, open-ended questions to capture participant related data. The open-ended questions were utilized with the aim of promoting dialogue between the interviewer and interviewee in a manner that exposed additional factors not considered by the interview themes (Palys \& Atchison, 2014). The interviews lasted approximately one hour. The responses were audio-recorded for verbatim transcription. Interviews were conducted using a semi-structured questionnaire, as outlined in Appendix G: Interview Guide. The development of interview questions was guided by themes, as presented in Appendix H: Interview Questions Guiding Themes. These themes informed questions for the interviews and consisted of those that sought to gain personal perspectives as well as organization-related information (participant acting on behalf of the organization). The themes and the interview script acted as a guide. However, some themes and questions may not be reflected in the script as the interview processes included questions that 
meant to clarify or expand on responses. The interview questions posed to participants varied depending on the types of answers sought and between the cases (PH vs NPH).

As suggested by Walter (2013), several questioning techniques were applied in interviews. These include descriptive questions, contrast questions, opinion questions, knowledge questions, feeling questions hypothetical questions, reflecting questions, devil's advocate questions, posing ideal questions, and summary questions - refer to Walter (2013) for the description of each. Table 3: Interview questioning techniques provide sample questions reflecting each questioning technique. Follow-up questions were also used to encourage clarification, explanation, and expansion of previously provided answer(s). During the interviews, non-verbal cues or behaviour were recorded in memos.

All interviews were audio-recorded and transcribed verbatim. Once the transcription was completed, any personal identifiers collected to facilitate the interview process and those mentioned during the interview, including names, positions, organizational or institutional affiliation, were removed from the transcript. The transcripts were then sent to the interviewee for confirmation of interview content and identification of possible personal identifiers that may have been missed during transcript editing.

Table 3: Interview questioning techniques

\begin{tabular}{|l|l|}
\hline Question technique & Sample interview question \\
\hline Descriptive & $\begin{array}{l}\text { Can you please tell me about your position and the responsibilities you } \\
\text { have in this post? }\end{array}$ \\
\hline Opinion & $\begin{array}{l}\text { What is your view of a public health frame of climate change } \\
\text { discussion? }\end{array}$ \\
\hline Knowledge & $\begin{array}{l}\text { Do your policies have impacts on both climate change and health? } \\
\text { What are some of the evidence that informs your climate change } \\
\text { policies? }\end{array}$ \\
\hline Feeling & $\begin{array}{l}\text { When interviewee presented a statement that reflected emotional } \\
\text { feelings experienced or emotional response, the sample follow-up } \\
\text { question would be: } \\
\text { How did you feel about such statements given your knowledge of } \\
\text { public health's role in climate change? }\end{array}$ \\
\hline Hypothetical & $\begin{array}{l}\text { If public health were to lead climate change, what do you see as their } \\
\text { role in the climate change policy processes or debate? }\end{array}$ \\
\hline Devil's advocate & $\begin{array}{l}\text { Presented the interviewees with opposing statements or perspectives } \\
\text { emerging from previous interviews then followed up with questions } \\
\text { such as: } \\
\text { How would you target such attitudes if public health's role is to be } \\
\text { emphasized? }\end{array}$ \\
\hline Posing ideal & $\begin{array}{l}\text { If you could suggest a role for public health in climate change, what } \\
\text { would that role be? }\end{array}$ \\
\hline
\end{tabular}




\begin{tabular}{|l|l|}
\hline Reflecting & $\begin{array}{l}\text { Questions that reflected back on interviewee's explanation or } \\
\text { clarification: } \\
\text { You mentioned that you have integrated }[. . . . .] \text { in your approaches, } \\
\text { how difficult was the process? }\end{array}$ \\
\hline Summary & $\begin{array}{l}\text { Can you briefly explain how your job responsibilities relate to climate } \\
\text { change adaptation? }\end{array}$ \\
\hline
\end{tabular}

Qualitative data analysis software (QDAS), NVIVO, was used to sort, structure, and analyze both the policy documents and interview transcripts. Managing data included organizing and tracking raw data, documents and other research-related materials such as memos, protocols and interview instruments.

\subsection{DATA ANALYSIS METHODS}

Understanding and interpreting data depend on the method and philosophical approach adopted by the researcher (Berg \& Lune, 2016; Palys \& Atchison, 2014; Walter, 2013; Yin, 2014). CDA, narrative analysis, and institutional analysis were appropriate for analyzing study data. CDA guided the analysis; narrative and institutional analysis were embedded in the CDA as guided by the literature review. However, thematic analysis complemented CDA to support a systematic identification of themes emerging in the texts.

\subsubsection{Critical Discourse Analysis}

CDA was the most appropriate method for analyzing the role of language and its contextual influences (Walter, 2013). The selection of CDA was used based on the assumption that meaning-making is influenced by the language in various forms (written and spoken). It is this language that forms the basis of people's interactions in social settings. And, that discourse analysis emphasizes and shows the sociopolitical contexts of language and provides an approach for analyzing such contexts. Within discourse analysis techniques, CDA provides a structured framework for discourse analysis (Walter, 2013).

Before commencing a CDA, it was imperative to explain the selection of text for the analysis and how and why the text was selected (Walter, 2013). The text selection processes have been highlighted in the data collection methods of this chapter. Further, it was relevant to provide the reader with a contextual background or an overview of social practices (political contexts) under study (Fairclough, 2003; Walter, 2013). The context under study (the province of Ontario context) has already been discussed in Chapter 2 (Climate Change and Policy - Public Health Links). 
The CDA consisted of three stages of analysis: textual analysis, identification of discursive practices producing the texts, and connecting the practices to the social practices. Figure 9: Conceptual framework for critical discourse analysis provides a conceptual framework for CDA, illustrating how the three inter-related approaches were applied in analyzing the study data.

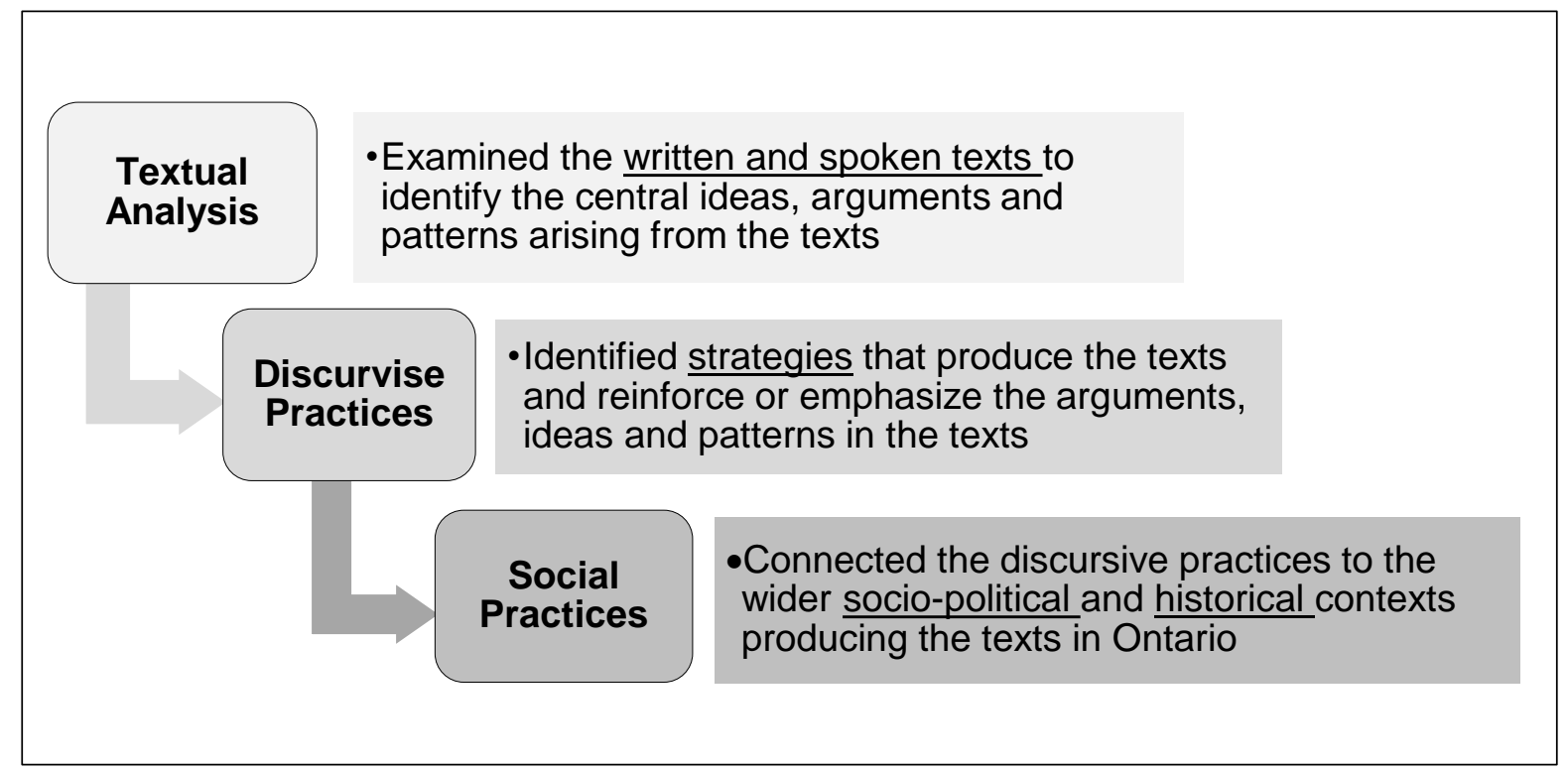

Figure 9: Conceptual framework for critical discourse analysis

Modified from: Fairclough (2003); Janks (1997); Walter (2013)

\subsubsection{Textual analysis and discursive practices}

Textual analysis (first stage) is the study of texts by examining text structure, grammar, vocabulary and cohesion (Walter, 2013). Textual analysis is the most critical part of CDA. In the study, texts were viewed as part of a social event. Texts (written and transcribed texts) constituted the relevant texts for analysis. The conceptual frameworks pointed to the role of texts as relevant variables for describing and explaining the discourses. In other words, texts as relevant variables for describing climate change frames and public health engagement in Ontario's climate change decisions. The analysis involved the identification of the central ideas and patterns arising from the texts and how they were organized. Such ideas were related back to the research questions and the study's aims and objectives.

In the second stage, discursive practices examined the strategies used to produce the texts or to reinforce the arguments in texts (Walter, 2013). Analysis of discursive strategies aided the documentation of the language/linguistic repertoires; that is, the routinely used terms for describing actions events and interactions (Hulme, 2009; Walter, 2013) or tactics for producing 
and understanding texts (Walter, 2013). This stage occurred concurrently and was linked with the first stage (textual analysis).

The final stage involved the processes of connecting the discursive strategies to the political contexts of climate change decisions in Ontario. In this stage, the texts were situated to the wider contexts that expose presence or dominance and power. Interpretation of texts considered both explicit and implicit (assumed) elements of texts (Fairclough, 2003).

The CDA was mainly guided by Fairclough (2003) CDA checklist and supplemented by some descriptions from Walter (2013). The modified checklist is presented in Appendix I: Main Issues Analyzed in Textual Analysis and Discursive Practices. Identification of thematic frames was guided by Appendix J: A Guide for Coding the a Priori Thematic Frames and Sample Text.

Connecting the discursive practices to political contexts or interpreting texts within political contexts require the consideration of the institutional contexts - such as institutions and interests, values, intentions and desires - of producers and how such contexts influence texts at different levels (Fairclough, 2003, 2013; Fischer, 2012; Walter, 2013). Fairclough (2003) advises that textual analysis by itself limiting unless combined with other methods that explore the contexts of power resulting from institutions and actors producing such texts.

\subsubsection{Connecting discursive strategies to the social practices}

Complementing CDA with institutional and narrative analyses can give meaning to the textual analysis by allowing for identification of organizational entities such as structures for including and excluding others, social contexts and power relations (Fairclough, 2003, 2013; Fischer, 2012; Walter, 2013). Such techniques also expose the articulation of a specific language in various events and the history of such events over time; such practices arise from a network of interactions and power of the social agents (Fairclough, 2003). Therefore, institutional and narrative analyses complemented the CDA by revealing not only the social practices (political contexts) but also some of the strategies producing and reinforcing the texts.

\subsection{Integrating institutional analysis into CDA}

The described texts and the strategies forwarding texts were explained by connecting them to the social and political contexts of climate policies in Ontario. Again, the three tenets of the Lomas Model - due to the relevance of the framework in examining sociopolitical contexts were considered as three relevant variables for connecting texts to the strategic and social practices of climate change decision making in Ontario. The three variables included: institutional structures for decisionmaking, values, and information. Also, the three variables not only 
supported the explanation of sociopolitical practices, but they also helped identify the process that produces texts and emphasize the arguments of climate change frames. Through the Lomas Model, an explanation of social practices was guided by the following questions.

1. Which institutional structures and arrangements influence climate change policies?

2. Which individuals, agents, actors, or organizations have a voice in climate change policies?

3. Who is included or excluded from the policy process?

4. What kind of evidence do individuals and organizations access to support climate change decisions, and how is this information accessed? Whose evidence is it? What evidence is privileged or negated? How is the evidence claimed?

5. What values dominate the discourse and inform climate change knowledge or act as input for climate change decisions?

Each of the three components of the Lomas model (institutions, information and values) were perceived to influence framing and public health engagement in unique and interconnected ways, and the analysis and interpretation considered that uniqueness and interconnections.

\subsection{Integrating analysis of narratives into CDA}

In assessing social practices that reinforce discourses, people's statements, stories, experiences, and chronology of events within the various institutions emerging from interviews are relevant for exposing the social and political contexts. Specifically, how the discourses emerge and the process of climate change meaning-making and knowledge that influence the framing of climate change and stakeholder engagements. Analysis of such accounts can complement the CDA. Therefore, the analysis of narratives (narrative-under-analysis) method which places people at the centre of the phenomenon under study and considers people as actors and agents constantly involved in meaning-making was applied (Walter, 2013). A sociocultural approach to the analysis of narratives was used to locate the narratives within the broader sociopolitical contexts of Ontario's climate change actions (Walter, 2013).

Through analysis of narratives, climate change decisionmaking, participation, and deliberation processes were analyzed through participants' lens - that is, those engaged in the processes - to grasp the social relations at play and activities that take place within and between individuals and institutions involved in the decisionmaking environment. The analysis involved the exploration of the content of the participant transcripts, the portrayal of events or experiences, and the participants' language (Bazeley, 2013; Walter, 2013). Narratives included interviewees' accounts of events and experiences relating to climate change framing and engagement. The 
transcripts were also analyzed for structure (exploring how the epistemic community portrayed the events, how they organized their thoughts) and the relationships between the thoughts and processes (Bazeley, 2013; Walter, 2013). The analysis focused on five questions as highlighted by Walter (2013).

- What was done? (act)

- When and where it was done? (scene)

- Who did it (agent)

- How he/she did it? (agency)

- Why? (purpose)

The narratives emerging from the analysis were then used to complement the CDA by connecting the narratives (texts) to the strategic and social practices for explaining the wider social, political, cultural, and historical influences of climate change framing and governance. Where possible, the structure of the narrative was retained as a whole, unlike the fragmentation in the thematic analysis (discussed below).

\subsubsection{Thematic Analysis}

One of the approaches to discourse analysis is the systematic examination of emerging themes and structures in texts (Fairclough, 1995; Janks, 1997). The thematic analysis (or inductive analysis) is a form of qualitative data analysis for "identifying, analyzing and reporting" themes emerging in the data (Vaismoradi, Turunen, \& Bondas, 2013; Walter, 2013). The approach provided a systematic account of data through 5 steps, as illustrated in Figure 10: Thematic analysis.

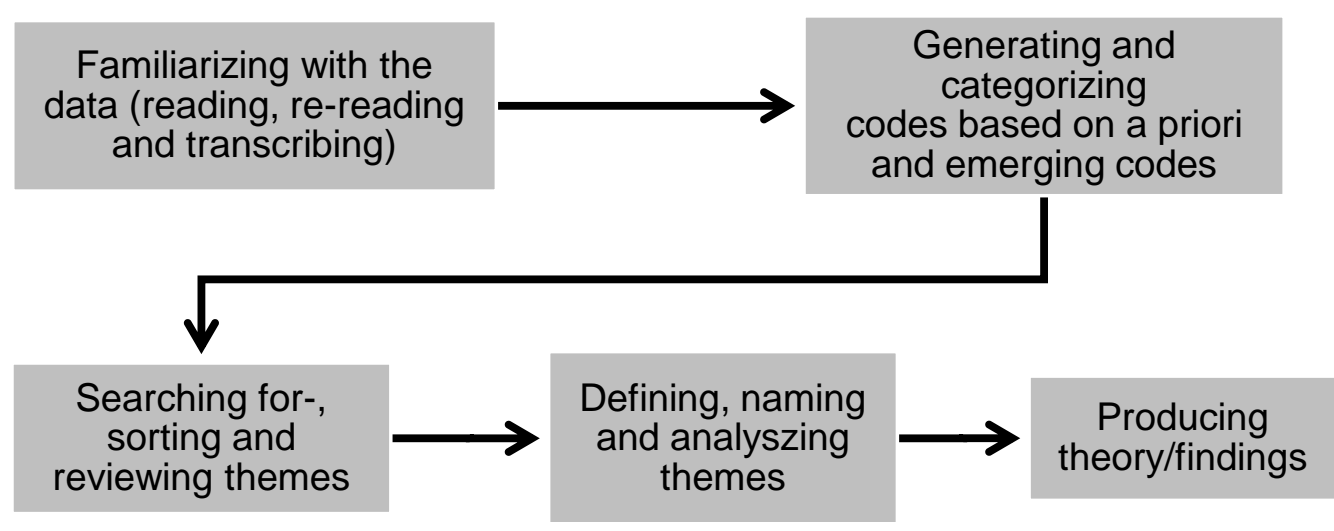

Figure 10: Thematic analysis

Adapted from Vaismoradi et al. (2013) 
Iterative coding was utilized based on deductive and inductive processes. The coding began by using pre-existing (a priori) codes (e.g. thematic climate change frames and themes identified from the systematic review of documents and themes that guided interviews) followed by reading through the data to identify themes emerging from the data.

Each sentence in the texts was studied to identify the themes. The documents (written and interview transcripts) were manually coded between December 2017 to May 2019. Where themes emerged, the text was coded based on sentences, a paragraph, or depending on what best represented the theme. Where several themes emerged in one paragraph, the paragraph was coded for each emerging theme. However, many of the codes relied on the coding of specific sentences. The coding process was then repeated several times, generating codes based on themes defining events, history, values, institutional contexts, verbal interactions, concepts or theories, and signifiers (Neale, 2016). While research questions also supported the generation of a priori themes, the data was not forced to fit into such themes. Instead, emerging themes (not only a priori themes) were considered and used to refine the themes emerging from the data. These represented opinions, issues, concepts, perceptions, values expressed by participants or identified in policy documents.

The coding of data to generate themes was conducted by two coders by setting two user profiles in the NVIVO software. Prior to coding, training and discussions facilitated the provision of a standardized approach to coding in order to achieve accuracy and reproducibility (Belur, Tompson, Thornton, \& Simon, 2018) was provided to the additional coder, nodes were prepopulated that reflected the main themes addressed by the interview questions. Additional codes were created and classified as they emerged. Each node had a descriptor (rule of including a theme in a specific node). Each coder separately coded the same data set, generating themes and sub-themes. The data was then merged into a single file. Inter-rater reliability testing was conducted between the two coders by running a coding comparison query. Kappa coefficient, a statistical measure frequently used to measure interrater reliability (agreement between two or more coders) was applied to compare coding reliability. Coding disagreements were reconciled in two ways. Through discussions between the two coders to ascertain clarity in coding. Also, because each theme was described by the coder and labelled, the labels were inspected to allow for comparison and for merging of similar themes. A benchmark of $75 \%$, a standard established in the literature, was used to measure the agreement of the two coders (Bellieni et al., 2007; Haidet, Tate, Divirgilio-Thomas, Kolanowski, \& Happ, 2009; Kottner \& Dassen, 2008; Laschinger 
\& Healther, 1992). Achieving a $100 \%$ agreement is unlikely due to individual variabilities (Kottner \& Dassen, 2008).

Code and theme clusters were used to assess commonalities, relationships, and differences across cases and to identify narrative accounts and structures embedded in texts that explored the contexts of the study and answered the research questions.

Although each interviewee was assigned a unique identifier in the research process, such identifiers have not been applied in the quoted narratives in order to comply with the ethics approvals and to minimize the reader's ability to connect the various quotes to a specific participant (due to the specific focus of some positions sampled and the political nature of the information provided). As a result, the narratives were only attributed to or reported as $\mathrm{PH}$ or NPH participant without specific identifiers. In addition, where identifiers were present in a selected quote, these were replaced by the word "[reducted]". The reducted information was either based on potential identifiers as identified by the researcher or the participant.

\subsection{SUMMARY}

This chapter has provided an overview of the actions taken to achieve the study objectives, investigate the research problem, and answer research questions. Specifically, it has provided an overview of the frameworks for conceptualizing public health framing and leadership and the roles of the theories of constructionism, constructivism, and interpretivism in underpinning the study and in exploring the exposition of meanings embedded in language and discourse.

A case study method was identified as the appropriate method for the study as it connects to the theoretical frameworks, research questions, and data needs in a manner that supported the identification, collection, and analysis of relevant data. Texts from documents (written) and interviews (verbal) were considered as appropriate data due to their ability to expose the language in texts and to corroborate evidence from a variety of sources. CDA that embedded analysis of narratives and institutional analysis was complemented with thematic analysis to analyze and identify themes for generating theory for answering the research questions and achieving research aims and objectives. The proceeding chapters will present the results of the data collection and analysis in a manner that answers the research questions. 


\section{CHAPTER 5: FEATURES OF THE POLICY DOCUMENT AND KEY INFORMANT INTERVIEWS}

\section{INTRODUCTION}

This chapter provides a brief overview of the characteristics of policy documents and key informants, and the coding features, that accounted for the data informing this study.

Section 5.1 provides the characteristics of policy documents accessed from the Office of the Premier and 10 ministries while Section 5.2 provides the characteristics of key informant interviews accessed from the Office of the Premier, 10 Ministries and 7 public health regions (represented by 10 participants from 10 PHUs).

Section 5.3 provides the results of the cluster analysis assessing the similarities within and between the study groups ( $\mathrm{PH}$ and $\mathrm{NPH}$ ) based on similarities of words used by the participants. which provides an overview of the structure of the data that supplemented the thematic analysis. Section 5.4 describes the results of the agreement between two coders who analyzed the data.

\subsection{POLICY DOCUMENT ANALYSIS}

The systematic search of policy texts yielded 776 records (documents and web captures) across 11 provincial agencies and the google search engine. Records were screened for eligibility and 313 records were included in the analysis, as illustrated in Appendix L: Systematic Search of Records as Guided by PRISMA. The included records represented 9 text sources ( Table 4: Types of documents accessed) and 11 government agencies (Table 4: Types of documents accessed).The documents represented the cases directly affiliated with the government. That is, the Office of the Premier and 10 government ministries. The documents included action and strategic plans, protocols, policy statements and guidelines, reports, discussion papers, news releases, mandate letters, legislation and web pages captures as summarized in Table 4: Types of documents accessed below.

Table 4: Types of documents accessed

\begin{tabular}{|l|l|}
\hline Document Type & $\begin{array}{l}\text { Number } \\
\text { accessed }\end{array}$ \\
\hline News Releases & 180 \\
\hline Web Pages captures & 73 \\
\hline
\end{tabular}




\begin{tabular}{|l|l|}
\hline Discussion Papers & 14 \\
\hline Reports & 12 \\
\hline Action Plans & 12 \\
\hline Strategic Plans & 11 \\
\hline Frameworks & 6 \\
\hline Acts (legislation) & 3 \\
\hline Policy Statements & 2 \\
\hline Total & 313 \\
\hline
\end{tabular}

* Combines 'Protocols, Guidelines and Frameworks' as they all aim to provide direction on intended policies.

Based on the characteristics of the data source (Table 5: Characteristics of data sources by organization), the MECP and the Office of the Premier remained the dominant institutions shaping climate change discourse and actions in Ontario. Despite the lower count of accessed documents from many ministries, search engines within these ministry websites mainly directed searchers to the MECP website for climate change sources. This indicated the relevance of and the reliance on MECP policies to advance other ministries mandate.

Table 5: Characteristics of data sources by organization

\begin{tabular}{|l|c|}
\hline Government Institution & $\begin{array}{c}\text { Number of documents } \\
\text { accessed }\end{array}$ \\
\hline Ministry of Environment, Conservation and Parks (MECP) & 104 \\
\hline Office of the premier & 76 \\
\hline Ministry of Transportation (MOT) & 32 \\
\hline Ministry of Energy, Northern Development and Mines (MENDM) & 23 \\
\hline Ministry of Natural resources (MNR) & 22 \\
\hline Ministry of Municipal Affairs and Housing (MMAH) & 18 \\
\hline Ministry of Health and Long-Term Care (MOHLTC) & 10 \\
\hline Ministry of Agriculture, Food and Rural Affairs (OMAFRA) & 10 \\
\hline Ministry of Research, Innovation and Science (MRIS) & 9 \\
\hline Economic Development, Job Creation and Trade (MEDJCT) & 8 \\
\hline Ministry of Indigenous Affairs (MIA) & 1 \\
\hline Total & $\mathbf{3 1 3}$ \\
\hline
\end{tabular}

Between 2007 to 2018, 180 (58\%) of the documents discussing climate change actions were produced by the two institutions; the rest (9 institutions) accounted for 132 (42\%) combined.

\section{$5.2 \quad$ KEY INFORMANTS}

From the NPH group, a total of 84 potential participants were identified across the $9 \mathrm{NPH}$ ministries and the Premier's office. The experts identified included senior policy advisors, project managers, senior policy analysts, directors, team leads and environmental program specialists whose work directly involved components of climate change policies or who strategically 
collaborated with other partners on policies addressing climate change either directly or indirectly and whose policies. Of the 84 potential participants, 71 (84.5\%) responded, 19 people accepted the invitation to participate, and 13 participants were interviewed; priority was given to those who had previously worked in more than one ministry (in relation to climate change policies). Of the 12 participants interviewed, 5 had previously worked for more than one ministry (between 2 and 3 ministries) on climate change-related actions. Interview questions explored the processes and experiences from those previous ministries as well.

From the public health group, 5 requests were sent to the MOHLTC, 2 accepted to participate: one of the two cancelled participation citing a lack of role or mandate and awareness of climate policies. From PHUs, 18 responses were received, 10 people were interviewed. Although not all PHUs were interviewed, efforts were made to ensure a balanced geographical distribution of the sample. The $10 \mathrm{PHU}$ participants represented all the seven PHU aggregate regions. Within the $10 \mathrm{PHU}$ participants, 2 reported climate change collaborative work with several other PHUs that were not interviewed. Interview questions explored such engagements. Participants included managers, policy experts, policy evaluators, directors, analysts with direct roles on climate change policies within the health units. Many participants were also affiliated with various public health organizations within Ontario and worked together in multiple committees to forward climate change awareness and policy actions. The participant selection and retention breakdown are provided in Table 6: Participation solicitation, response and retention below.

Table 6: Participation solicitation, response and retention

\begin{tabular}{|l|c|c|}
\hline Participation & NPH & PH \\
\hline Total response received & 71 & 18 \\
\hline $\begin{array}{l}\text { Interviewed and retained } \\
\text { (includes 4 referrals from NPH and 3 from public health groups) }\end{array}$ & 13 & 11 \\
\hline Accepted to participate but not interviewed (saturation) & 5 & 6 \\
\hline $\begin{array}{l}\text { Declined: } \\
\text { - Did not see the role of public health in their work }\end{array}$ & 46 & - \\
- Lack of role or mandate on climate change & - & 1 \\
\hline No reasons provided for declining participation & 7 & - \\
\hline
\end{tabular}

\subsection{CLUSTER ANALYSIS}

Cluster analysis compared similarly of words used by both the PH and NPH groups (Bazeley \& Jackson, 2013). The analysis was conducted to gain a preliminary understanding of the similarities and differences between PH and NPH groups in terms of the language used. 
Those similarities and differences are presented by a dendrogram, as illustrated by Figure 11:

\section{Dendrogram comparing word similarities between PH and NPH groups.}

The cluster analysis revealed the similarities and differences across nodes, themes and participants. The cluster analysis revealed compelling similarities within and differences between the two groups. The language and themes coded from $\mathrm{PH}$ and NPH groups transcripts portrayed a $92 \%(10 / 11)$ and $84 \%$ (11/13) similarity within the groups, respectively, while also portraying the difference between the groups. Most PH and NPH groups were clustered within two separate groups except for three participants (1 PH and $2 \mathrm{NPH}$ ), indicating a difference of 88\% (21/24 participants). This portrays the convergence within, and divergence between, the two groups in terms of issues addressed and language used. An indication that each group mostly used similar words to describe interview questions and these words were also reflected in the themes coded.

\section{$5.4 \quad$ CODING OF THEMES}

Overall, the coding agreement surpassed the benchmark of $75 \%$. The two coders agreed $80 \%$ of the time. The range of agreement varied from $63 \%$ to $98 \%$. The themes coded and analysis of themes as they emerged in the policy documents and interview responses are presented in the proceeded chapters (Chapters 6 to 10).

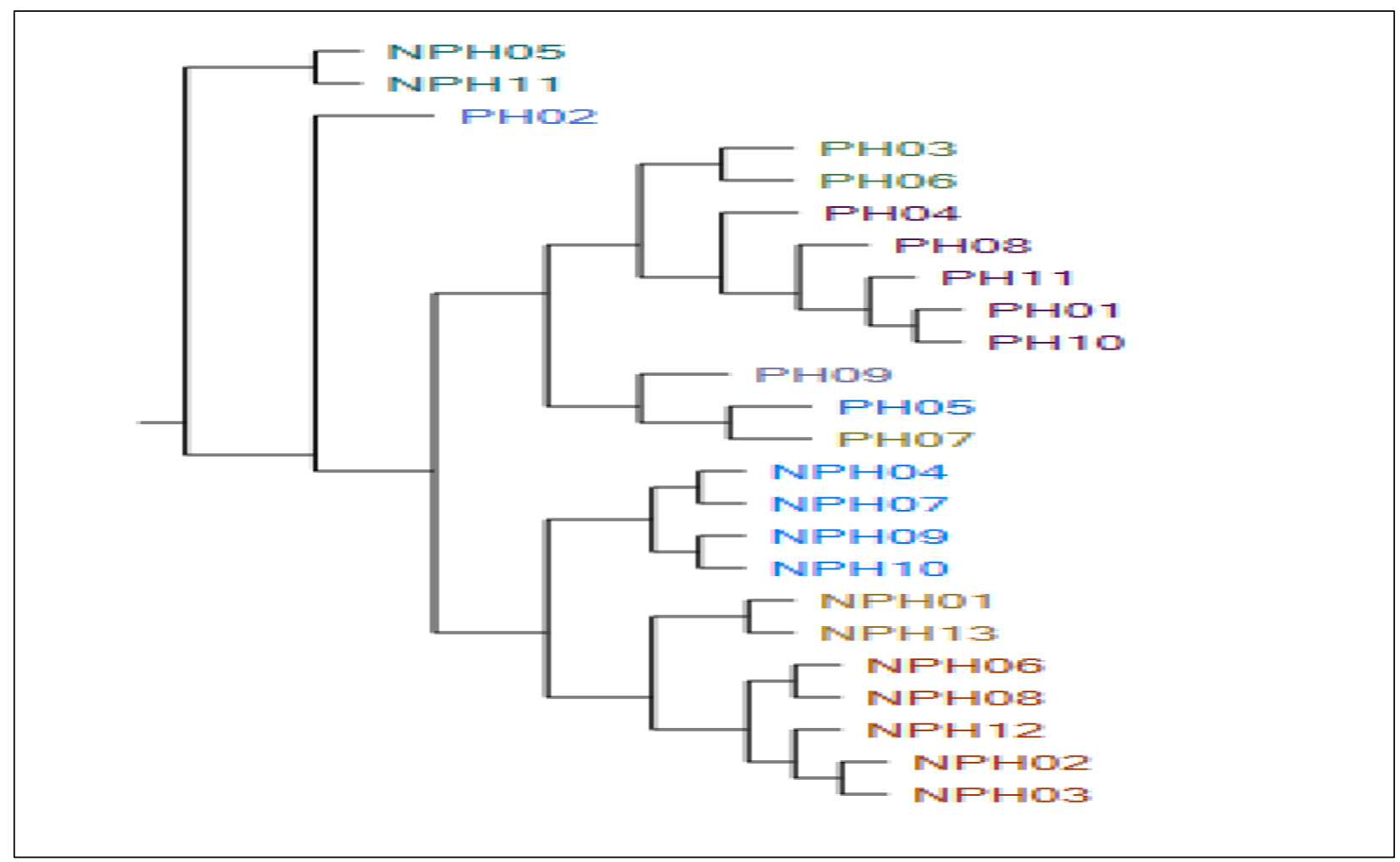

Figure 11: Dendrogram comparing word similarities between PH and NPH groups The cluster analysis is an output from the NVIVO that assessed the similarities within and between the study groups ( $\mathrm{PH}$ and $\mathrm{NPH}$ ), based on similarities of words used by the participants. 


\section{CHAPTER 6: CLIMATE CHANGE FRAMING IN ONTARIO}

\section{INTRODUCTION}

The first two research questions investigated how the province of Ontario frame its climate change discourse and the discursive or systematic factors influencing the framing. This chapter answers these two questions using the results of the thematic frame analysis based on the policy documents accessed from cases representing the government (that is, the Office of the Premier and the 10 ministries).

The identification of frames of focus was guided by literature (see Chapter 3: Climate Change Frames). Thus the a priori thematic codes included: environmental, economic, political, public health, technological, scientific, skeptic and moral frames. The analysis focused on the identification and coding of themes aligning with the eight a priori thematic frames, discursive strategies producing the texts, and historical and social contexts of text production.

Section 6.1 provides an overview of the frames applied to construct and discuss climate change actions in Ontario, between 2007 to 2018.

Section 6.3 discusses the discursive strategies that have been used to advance and/or suppress frames in Ontario.

Section 6.2 details the historical prevalence, trends, and social contexts of climate change framing in Ontario over time.

\subsection{FRAMING OF CLIMATE CHANGE IN ONTARIO}

The thematic analysis of 313 documents across 9 sources and 11 government agencies demonstrated a serious deficiency in the application of the public health frame. As illustrated in Figure 12: Framing of climate change in Ontario, the public health frame remained isolated from the primary focus of climate change policy discourse, only accounting for about $6 \%$ of the discourse in the document texts. Instead, the economic and political frames dominated climate change discourse in Ontario, accounting for $61 \%$ (economic = 34\%; political $=27 \%$ ) of the climate change policy discourse. The two were followed by technological (17\%) and environmental (11\%) frames. The scientific and moral frames were also less utilized ( $3 \%$ and $2 \%$ respectively). The skeptics though modestly evident in the texts, it was embedded in the political narratives in a manner that made it difficult to assess the influence. In its Place, the skeptic narratives were reported as negative political narratives. 


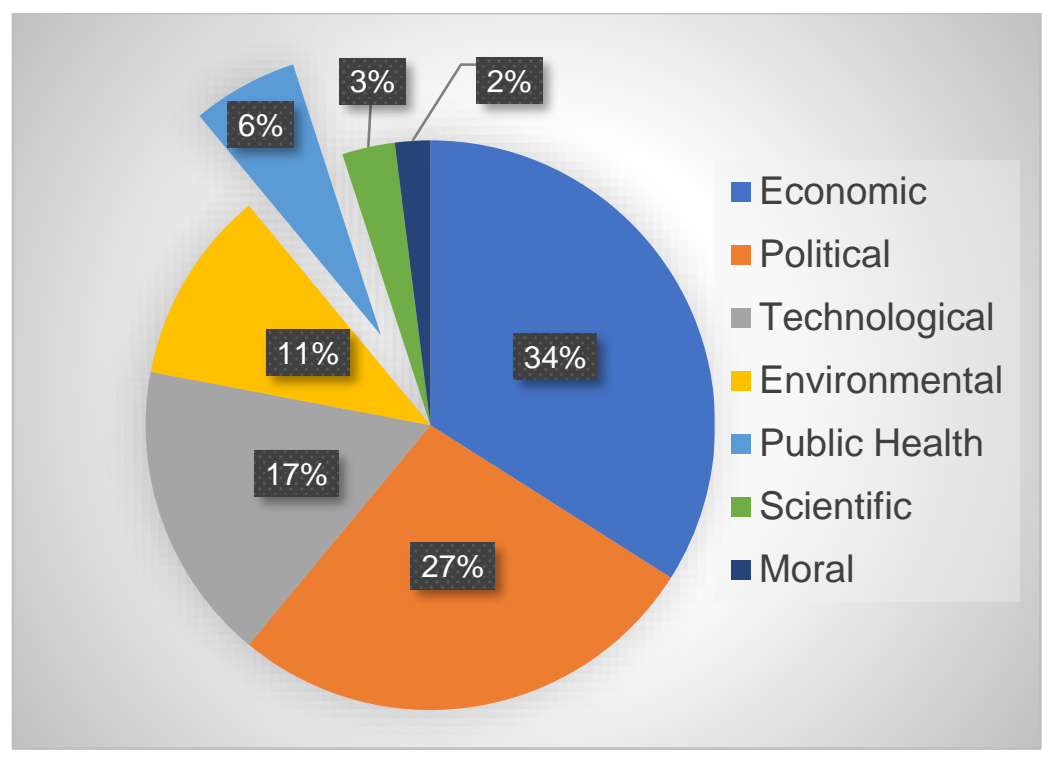

Figure 12: Framing of climate change in Ontario

\subsection{HISTORICAL AND SYSTEMATIC CONTEXT OF CLIMATE CHANGE FRAMES}

Historical prominence of certain frames was the first indicator of the framing and salience of frames of climate change policy discourse in Ontario. The historical dominance or importance of frames between 2007 to 2018 was evident, as illustrated in Figure 13: References to climate change frames between 2007 to 2018.

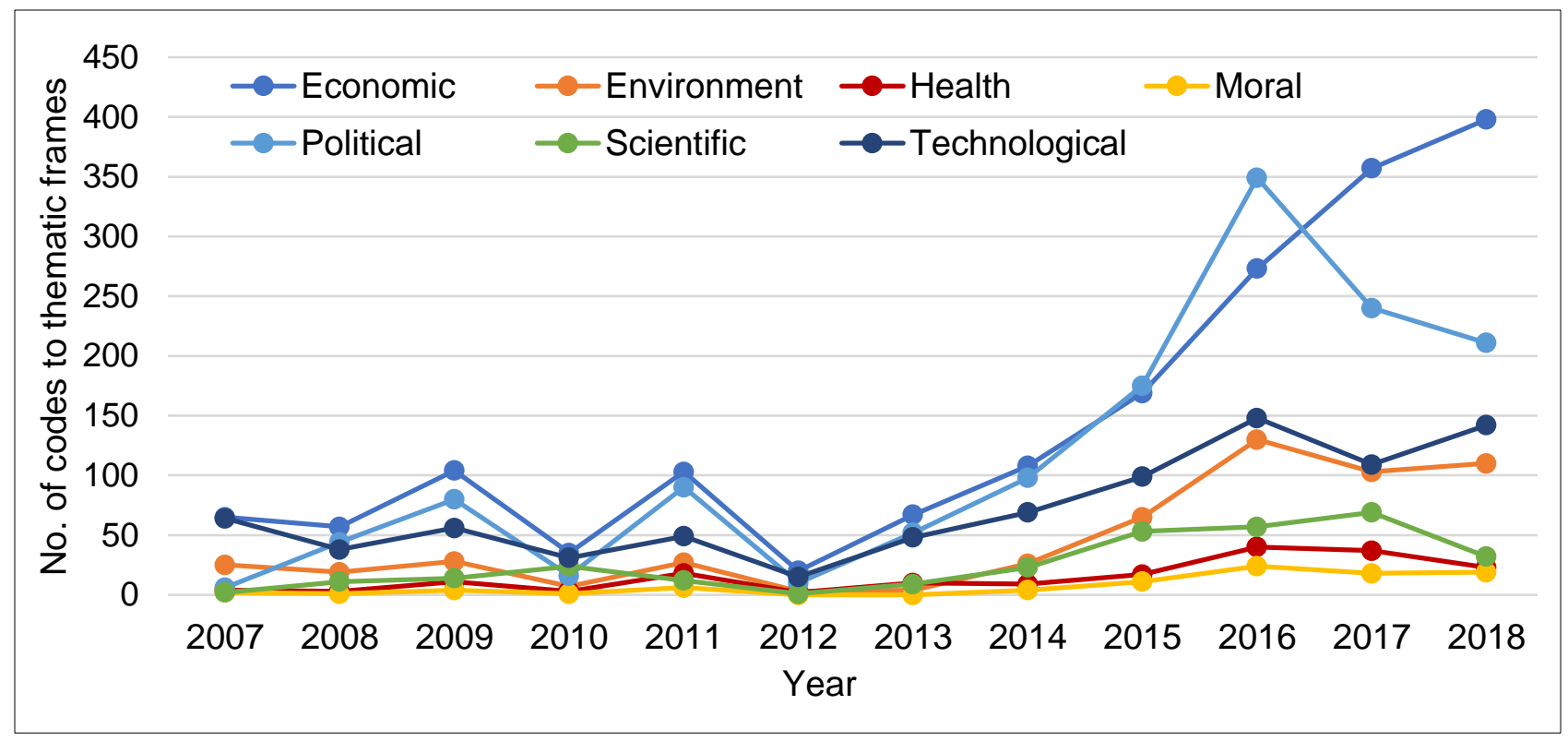

Figure 13: References to climate change frames between 2007 to 2018

Displays the historical trends in the application of frames over a period between 2007 to 2018 . 
Several trends were noted. A stack comparison graph, Figure 14: Prevalence of climate change frames application (2007-2018), illustrates the prevalence of climate change frame application over time. Despite the periodic fluctuations throughout the years of focus, there was an overall increase in the application of the frames over the years with significant post-2013. The utilization of the public health frame consistently lagged throughout the years of analysis with slight attention in 2009, 2011, and 2013 and a moderate increase in 2016 to 2018 . The analysis also portrays three phases: 2007 to 2010; 2010 to 2012; 2013 to 2018. These trends are linked to political activities, as discussed in the next section of this chapter (Political Events and Climate Change Framing).

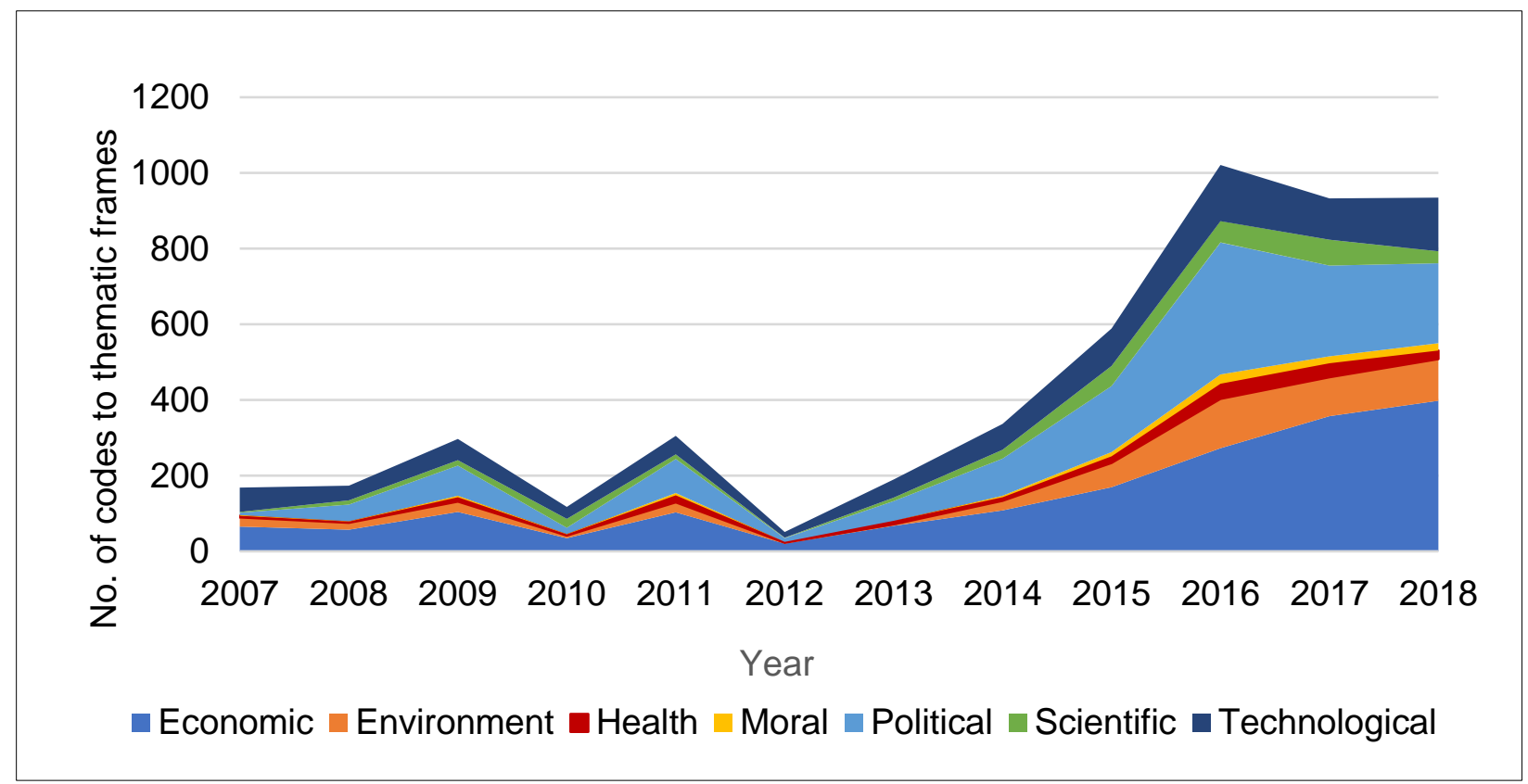

Figure 14: Prevalence of climate change frames application (2007-2018)

The figure displays the evolution of changes in the predominance of each frame through the years.

\subsection{DISCURSIVE STRATEGIES ADVANCING THE CLIMATE CHANGE FRAMES}

The strategic positioning of dominant frames was evident in the climate policy texts. Frames were positioned by organizations, in text sources, and characterized by salience, abstraction, and recontextualization of frames.

\subsubsection{Organizations and Climate Change Framing}

The various organizations propagated frames. A comparison of frame prominence across (Figure 15: A comparison of climate change frame across ministries) and within 
(Figure 16: Salience of frames within ministries) the 11 agencies demonstrated that the MOHLTC dominated in the application of the public health frame while the rest of the agencies lagged behind, mainly dominated by economic, political, and in some cases, technological frames. The economic frame was mainly forwarded by all organizations except the MOHLTC and MNR. There was also less emphasis on political framing within the MOHLTC, MNR and MEDJCT.

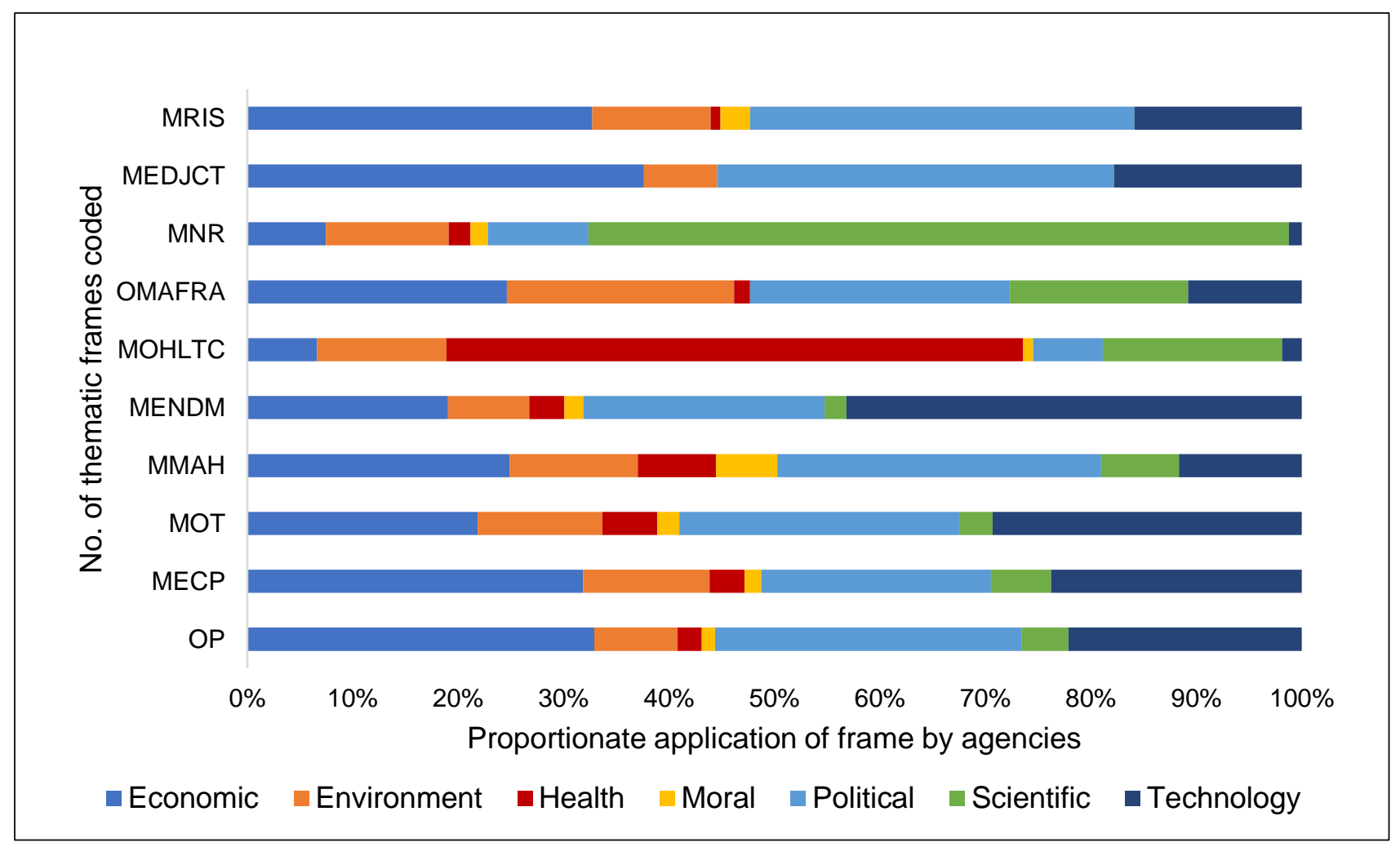

Figure 15: A comparison of climate change frame across ministries

The stack bar graph displays the percentage of frame prevalence for comparative evaluation across the agencies without standardization.

\subsubsection{Text Sources and Climate Change Framing}

Climate change frames were also internalized in policy sources. As a result, the prevalence of frames varied by the source of information. As shown Figure 17: A comparison of climate change frames across sources and Figure 18: A comparison of climate change frames within sources, organizations communicated climate change needs in websites, reports, strategies, discussion papers, action plans, legislation (preamble), news releases, policy statements, and frameworks. Across these sources, there was a varied distribution in the application of frames. However, policy statements and reports relatively highlighted the public 
health frame compared to other sources. The economic and political frames were dominant across and within the sources.

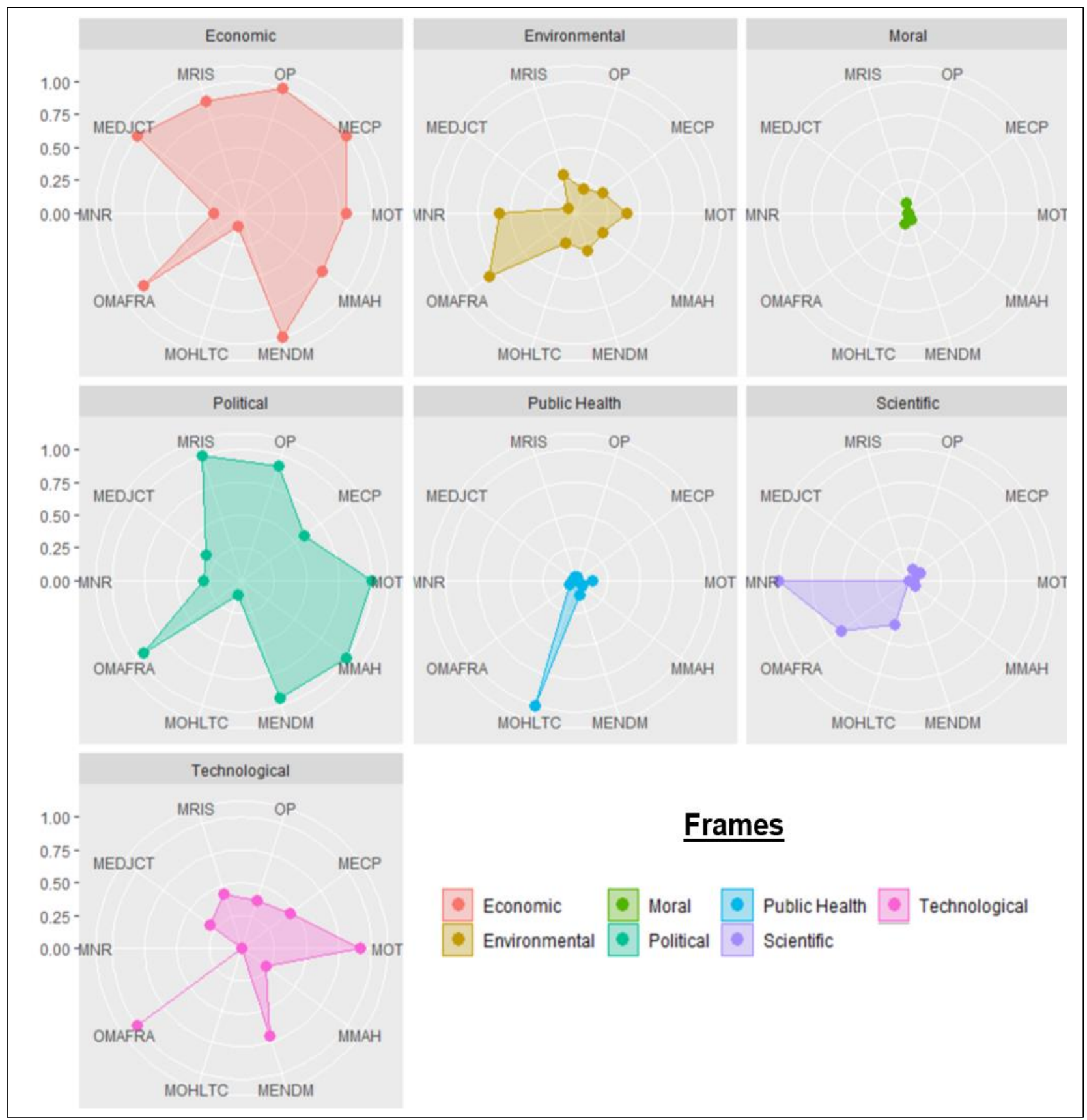

Figure 16: Salience of frames within ministries

The radar chart provides a comparison of climate change frame utilization within ministries. The charts are quantitative measure for visualizing and comparing the performance of ministries on the specific frames using radial display where each frame is displayed on own axis. The furthest away from the centre, the better the performance of the organization on a specific frame. The organizational data were standardized using feature scaling to allow for comparison of performance across the organizations. 


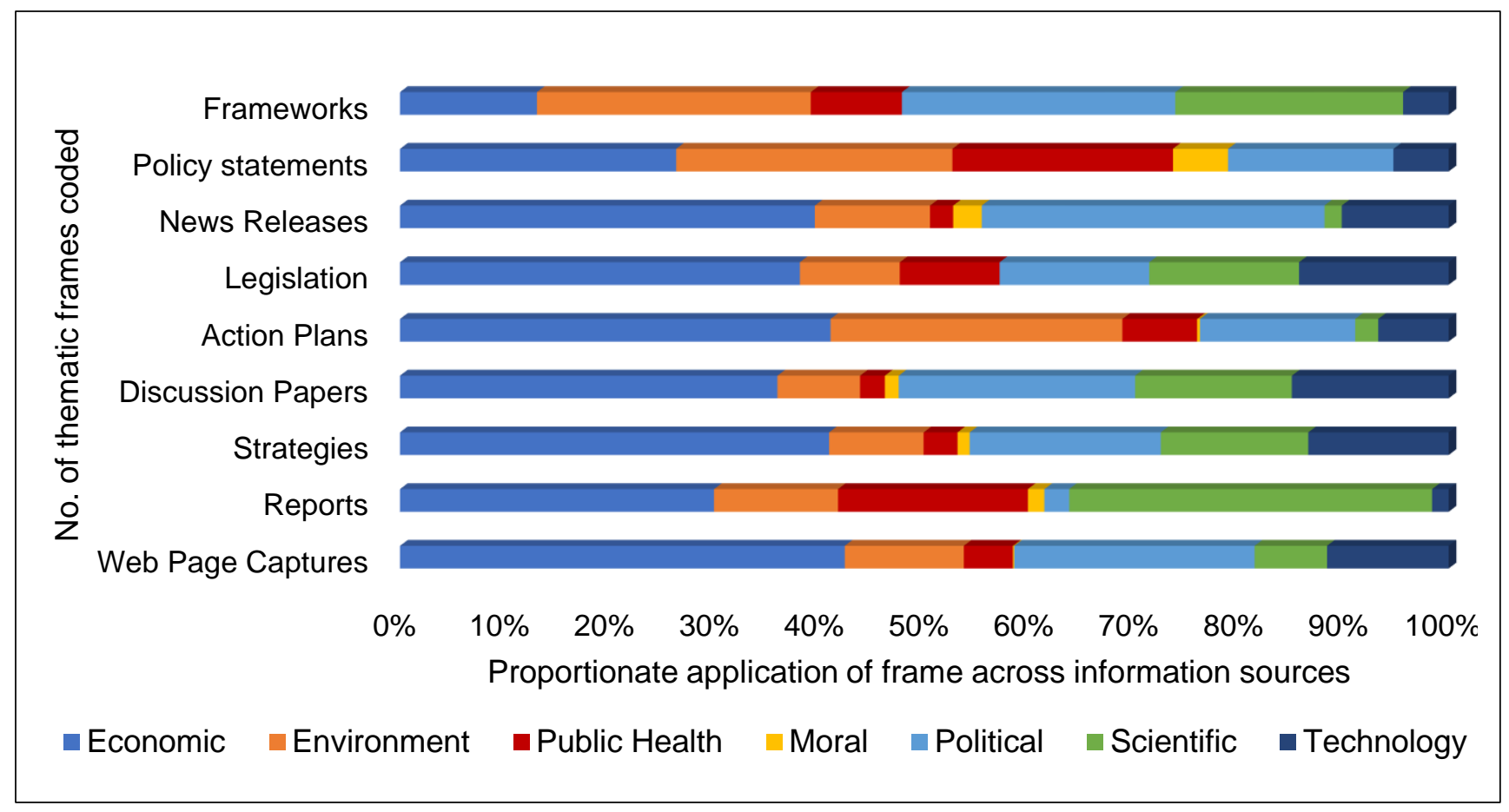

Figure 17: A comparison of climate change frames across sources

The stack bar graph displays the percentage of frame prevalence across sources for comparative evaluation across agencies without standardization.

To advance climate change frames, discussion papers, legislation, and to some extent strategic plans, employed expository or descriptive writing where climate change needs were described, explained, and characteristics listed. Narrative and persuasive writing was mainly utilized in news releases and agency websites, and fairly on strategic plans. Media releases acted as the main source for promoting climate change policies. Text sources were linked together by embedding links directing the reader to additional information detailing policies from other agencies or sources or by integrating information from multiple sources. The texts connected local policies to international policies and commitments on climate change, promoting the role of government locally and internationally and connecting climate change to the existence of global markets and advantage. The texts alternated between direct and indirect reporting and narratives. The texts, especially from news releases, were based on chronologically related social events, as described in Appendix K: Chronology of Ontario's Climate Change Activities and Responses. Such texts either referred to or explained social events.

The policy texts incorporated metaphors, authors and political opinions, commitments, beliefs, positions, and justifications for forwarded policies. The texts also incorporated endorsements of climate policies from industry and corporate leaders. The role of the government 


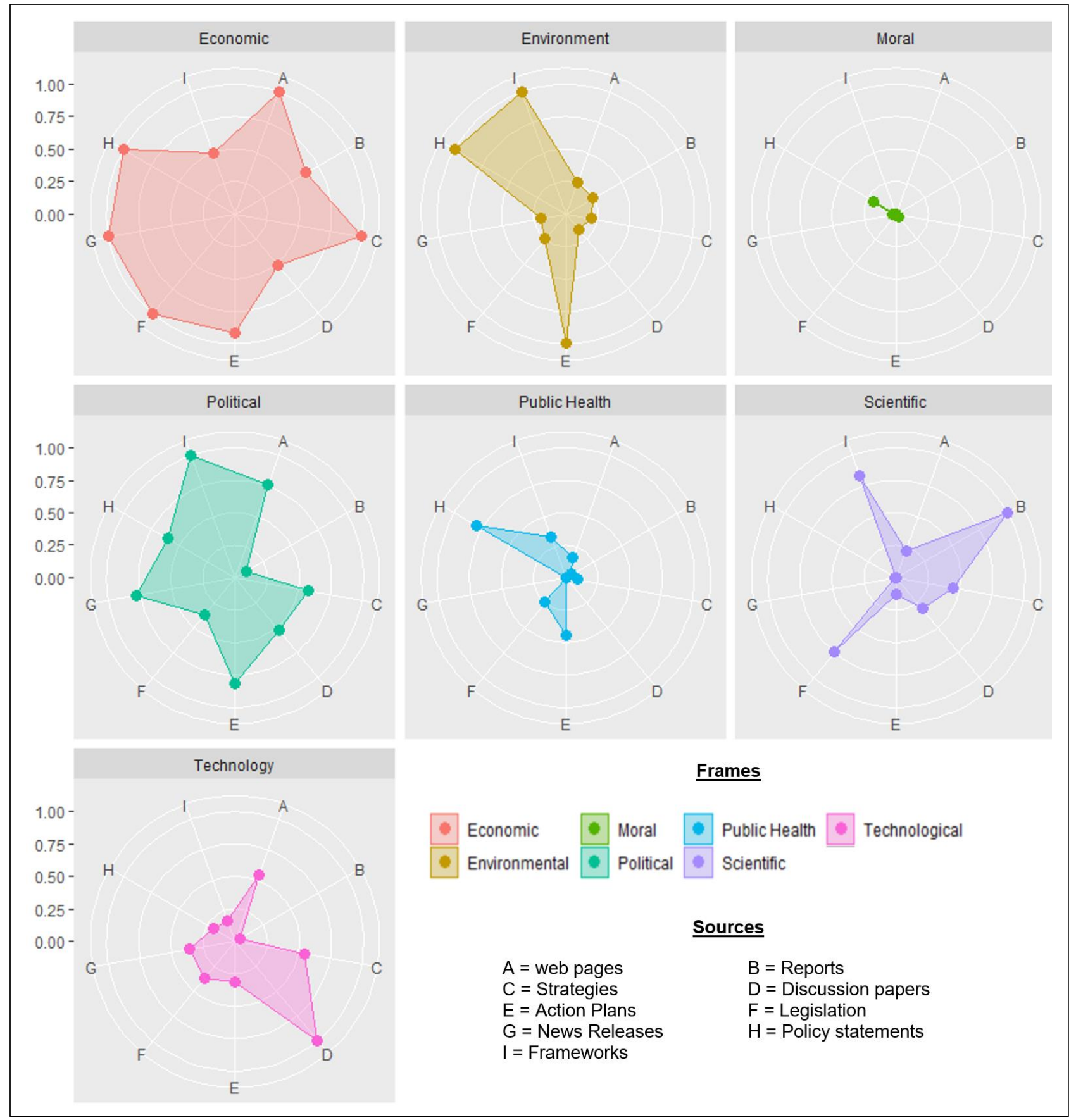

Figure 18: A comparison of climate change frames within sources

The radar plot illustrates the salience of frames within information sources. The charts are quantitative measure for visualizing and comparing the performance of sources on the specific frames using radial display where each frame is displayed on own axis. The furthest away from the centre, the better the performance of the source on a specific frame. The organizational data were standardized using feature scaling to allow for comparison of performance across the organizations. 
and its agencies in the policies were linked through alternate direct and indirect reporting and by embedding quotes, from senior bureaucrats and other prominent actors. These were specific characteristics of news releases and strategic plans. The authors of the texts drew upon texts from other sources or mainly attributed the accounts to those with authority such as senior bureaucrats either through summaries or direct quotes. For instance, the Premier of Ontario and the Minister for the environment were directly quoted 98 (54\%) and 41 (23\%) times respectively, in the 180 news releases. The opinions of corporate leaders were also embedded in many news releases.

Within the sources, policy goals and objectives were also used to advance climate change policies. However, only $8 \%$ of the policy documents highlighted such goals and objectives. Of these, economic $(32 \%)$ and environmental $(31 \%)$ goals of climate change policies dominated. Other goals forwarded targeted technological advancement (13\%), health (8\%), building resilient communities $(5 \%)$, seeking evidence $(4 \%)$ and others $(7 \%)$ related to prioritization of co-benefits of actions, capacity building, and advancing collaborations. Objectives were not specifically defined except for those that focused on GHG reduction targets.

\subsubsection{The Ambiguity of the Public Health Framing}

The public health narrative was largely ambiguously presented in most of the documents analyzed. Climate change or the interventions were presented to impact 'health'; interventions were 'healthy' without elaborating on the anticipated health impacts being addressed. Excluding the MOHLTC documents which extensively used health terms, the term 'health' was used 1525 times across sources. In the instances where 'health' was applied, few described specific health outcomes. The two dominant words preceding health were 'soil health' (341 words) and 'public health' (175 words). The word 'healthy' described both human- and non-human health narratives or interventions and was used 1109 times to describe public health, environmental and economic ideas. The term was also dominantly used in a phrase - "a healthy, clean and prosperous lowcarbon future" - which appeared 73 times, mainly in the Premier's office and MOECP documents. Word proceeding 'healthy' and public health as applied in policy text are listed in Table 7: Ambiguity of terms below.

\section{Table 7: Ambiguity of terms}

\begin{tabular}{|l|l|}
\hline Word & \multicolumn{1}{|c|}{ References } \\
\hline Healthy & $\begin{array}{l}\text { Healthy financial footing; healthy low carbon future; healthy future; healthy } \\
\text { planet; healthy communities; healthy food; healthy discussion; healthy }\end{array}$ \\
\hline
\end{tabular}




\begin{tabular}{|l|l|}
\hline Public health & $\begin{array}{l}\text { ecosystems; healthy forests; healthy world; healthy environments; healthy soils; } \\
\text { healthy habits; healthy individuals; healthy low-carbon economy; healthy } \\
\text { economy; healthy lives; healthy fisheries; healthy greenspaces; healthy Ontario }\end{array}$ \\
& $\begin{array}{l}\text { Public health awareness; public health outcomes; public health risks; public } \\
\text { health effects; public health benefits; public health threat; ensuring public health; } \\
\text { promote public health; protect public health; improve public health }\end{array}$ \\
\hline & $\begin{array}{l}\text { fiscal sustainability; community sustainability; sustainability of energy use; } \\
\text { environmental sustainability; urban sustainability; sustainability features; } \\
\text { region's sustainability; sustainability science; sustainability of deer population; } \\
\text { sustainability goals; forest sustainability; long-term sustainability; long-term } \\
\text { facility sustainability; championing sustainability; industry sustainability; } \\
\text { sustainability practices; sustainability of health and social services; sustainability } \\
\text { of health care systems; future sustainability; sustainability reporting; } \\
\text { sustainability of buildings; economic sustainability; sustainability of great lakes; } \\
\text { sustainability of waste diversion; sustainability of agricultural, agri-food, and agri- } \\
\text { product businesses; self-sustainability; culture of sustainability; ongoing } \\
\text { sustainability; sustainability targets; sustainability for generations to come; } \\
\text { individual sustainability }\end{array}$ \\
\hline
\end{tabular}

Overall, health impacts were mainly presented in general terms without elaborating on the anticipated health impacts being addressed. However, where the health frame was applied, the narratives highlighted the links between climate change and health, the health impacts already occurring or anticipated, vulnerabilities to the impacts and the health co-benefits of actions (adaptation and mitigation). In some instances, the health narrative presented the interconnections between climate change, the environment, health, economic growth and sustainability. These were dominantly the MOHLTC policy documents, including frameworks, tools, standards and guidelines. A few agencies, such as the MOT, highlighted the interconnections between active transportation, greenhouse gas reduction, and health. A review of such documents showed the inclusion of public health professionals in the drafting of the documents. Of all the health impacts highlighted, the impact of coal powerplant closures health supported with specific benefits related to the reduction of smog days and improvement of air quality, specifically to those vulnerable. Furthermore, the impacts were backed by specific evidence highlighting how the interventions impacted health outcomes from a health professional perspective (e.g. Ontario Medical Association). Within the health frames, economic benefits were sometimes emphasized. For instance, the July 2015 news release from the Office of the Premier presented improving air quality due to the closure of coal-fired power plants as part of an economic plan. 


\subsubsection{The Salience and the Recontextualization of Frames}

Presenting climate change as an economic opportunity was the most prevalent strategy used in Ontario to frame climate change. Economic language dominated when the frequency of the first 100 words was analyzed. The top 15 of the top 20 words were economic terms. These included words such as: 'economy', 'growth', 'businesses', 'industry', 'opportunities', 'cost', 'economic', 'goods', 'customer(s)', 'money', 'prosperity', 'income', 'entrepreneur', 'benefits' and 'revenue'.

Embedded in the economic frames were national and international norms highlighting market advantages and globalization. The government agencies, political leaders and senior bureaucrats also framed climate change as a global issue. Institutionalization of international norms and narratives into domestic climate policies were triggered by international agreements, international alliances (e.g. the Western Climate Initiative. To forward the economic and political narratives, Ontario framed climate change as a global issue whose actions require the world's political views and actions that emphasized the gains (both political and economic) that can be achieved through leadership among competing nations. The fight for leadership was forwarded as one that provides opportunities for competitiveness and economic prosperity

The economic narratives were mostly paired with narratives supporting technological innovations. Technological innovation was presented as a solution to climate change as well as a key to economic prosperity and leadership. The innovations were also presented as benefits to both the economy and the innovators through unique business opportunities, high-quality jobs and skills, and global competitiveness. In turn, many economic strategies were linked with technological tools and interventions depicting innovations as powerful tools to target both the economy and climate change. The narrative mainly focused on forwarding climate change issue as an energy issue where the solutions for minimizing GHGs relied on technological innovations and advancement of renewable energy with a significant focus on promoting industry-based technology (e.g. renewable energy technologies) and some consumer-oriented technologies (e.g. home retrofits, smart thermostats, electric vehicles, solar panels). However, the post-June 2018, policy texts reveal that rebates for utilizing such technologies were eliminated.

Economic frames were also paired with those supporting environmental narratives in addition to highlighting the impact of climate change on the environment and ecosystems and the relevance of renewable resources. Although, there were also instances where environmental impacts of policies or the term 'environment' were vague; interventions were presented to have environmental impacts or benefits without further elaboration. 
The economic narrative aligned with, and were embedded in, political narratives on climate change. It is the subsequent framing of the issue in the political arena that largely shaped the discussion of climate policies in Ontario.

\subsubsection{Political Events and Climate Change Framing}

Political activities, legislative mandates, the emphasis of the role of the government and its agencies, provincial elections and partisan preferences heightened the dialogue on climate change and triggered policy decision points. The salience of frames corresponded with trends of major activities, as depicted on the next page in Figure 20: Climate change frames and historical political actions (2007-2018) and reported in Appendix K: Chronology of Ontario's Climate Change Activities and Responses.

The political focus of climate change portrayed two periods with divergent political narratives of climate policies (see Figure 19: Political framing of climate change (2007-2018)). Between 2007 to early 2018, climate change policies were framed as ways to improve economic competitiveness. Largely, in 2018, it was framed as harm to economic competitiveness. Political activities between 2007 to 2018 are illustrated in Appendix K: Chronology of Ontario's Climate

Change Activities and Responses. Such divergence related to political changes in Ontario.

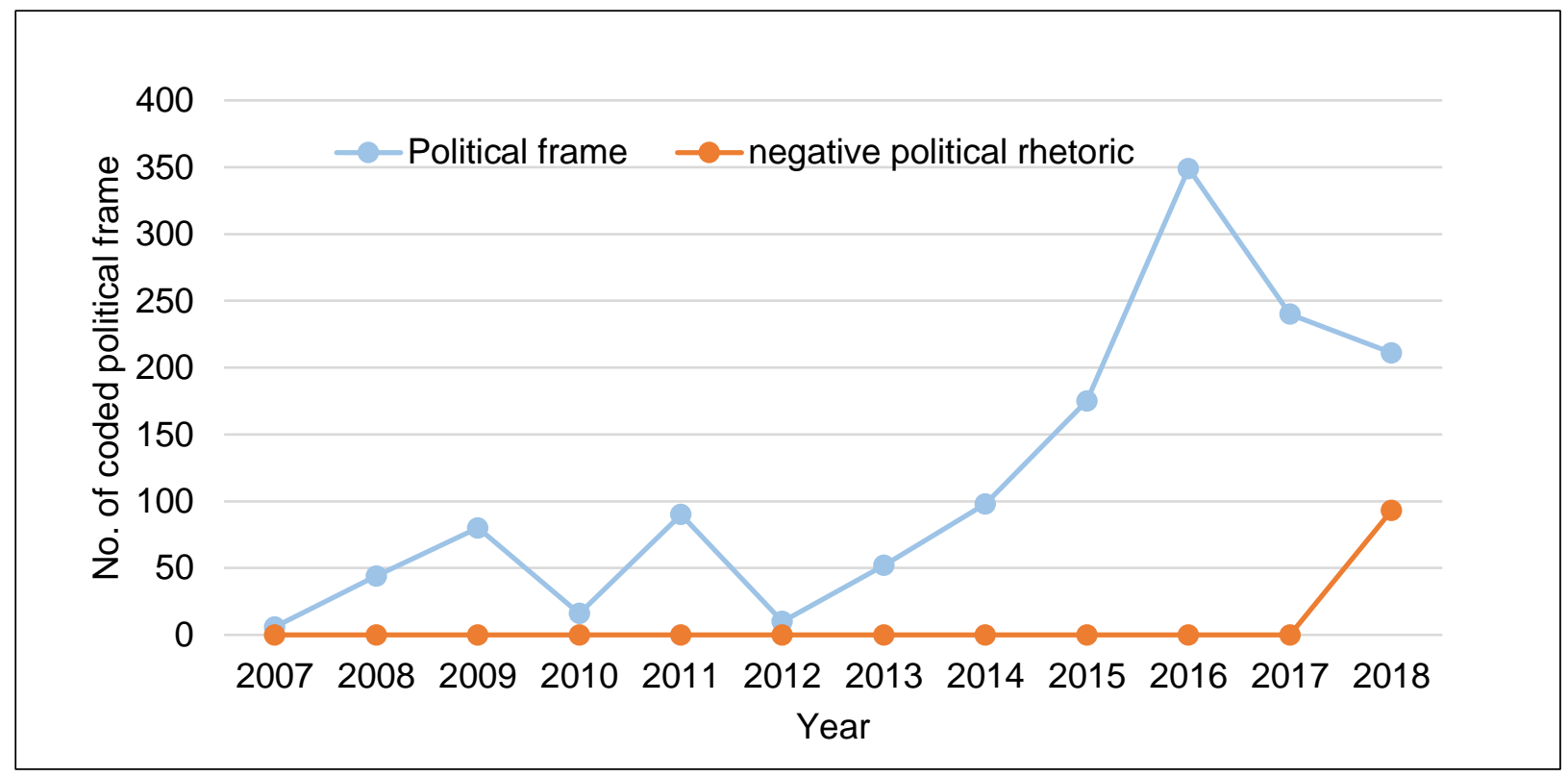

Figure 19: Political framing of climate change (2007-2018)

Demonstrates the decline of political frame between 2017 to 2018 with a subsequent increase in negative political rhetoric within the same period. 


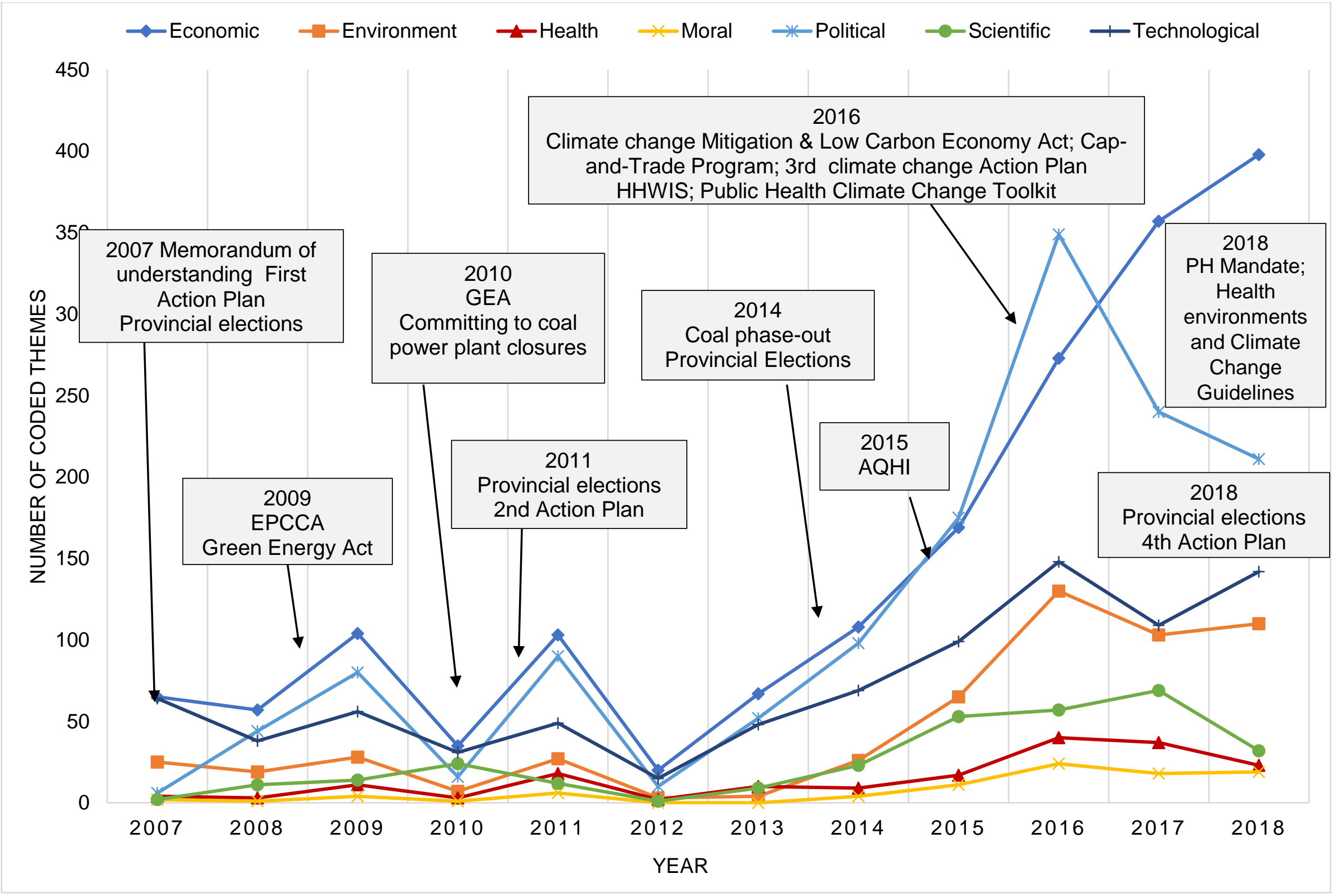

Figure 20: Climate change frames and historical political actions (2007-2018)

Displays how major climate change activities have corresponded with the prevalence of frames through the years. 
Political change - between the Liberal government (2007-June 2018) and Progressive Conservatives (PC) government (post-June 2018) - have shifted the discursive and strategic positioning of climate change in Ontario. As illustrated in the chronology of political activities (Appendix K: Chronology of Ontario's Climate Change Activities and Responses) and the historical trends (Figure 20: Climate change frames and historical political actions (20072018)), these two divergent forms of government did not influence the focus on public health framing. Instead, the dominance of the economic frame was propagated through an economic focus that portrayed two periods of opposing political narratives. That is, framing climate change policies either as ways to improve economic competitiveness (the Liberal narrative) or as harm to economic competitiveness (the PC narrative). The PC's narratives were closely linked to skeptic's framing of climate change as the new government eliminated several climate change initiatives. However, there was no apparent and conclusive evidence of climate change denial as the PC's strategic documents (e.g. the Made-in- Ontario Environmental Plan) acknowledges the phenomenon.

Overall, across the sources, organizations and political platforms, dominant frames were strategically positioned using genres and genre links, intertextuality, modality, orders of discourse, and ideological assumptions as summarized in Table 8: The strategic positioning of climate change frames in policy texts (see definitions in Appendix I: Main Issues Analyzed in Textual Analysis and Discursive Practices).

Table 8: The strategic positioning of climate change frames in policy texts

\begin{tabular}{|l|l|}
\hline \multicolumn{1}{|c|}{ Strategy } & Application \\
\hline Genre and & - Mediation of climate change policies through a variety of sources and \\
genre linking & organizations \\
& - Text arguments presented through expository, descriptive, persuasive \\
& and narrative writing with figurative, declarative and imperative \\
& statements \\
- Linking of the various policy text sources and social events by & embedding them as links \\
& - Promotion of local climate change policies, interventions and \\
& $\begin{array}{l}\text { - } \text { Covernment's local and international roles } \\
\text { - Legitimation of policies by referencing authoritative figures, institutions } \\
\text { and acknowledging specific stakeholders, corporate leaders and } \\
\text { sectors }\end{array}$ \\
\hline Intertextuality & $\begin{array}{l}\text { - Summary of press conference information } \\
\text { Embedding quotes from senior bureaucrats, corporations through } \\
\text { direct and indirect reporting and narratives }\end{array}$ \\
\hline
\end{tabular}




\begin{tabular}{|c|c|}
\hline & $\begin{array}{l}\text { - The prominence of specific government agencies, bureaucrats and } \\
\text { stakeholders with a limited prominence of public health voices } \\
\text { - Presenting or recontextualizing frames within the context of other } \\
\text { frames (e.g. embedding economic, political and technological } \\
\text { narratives) }\end{array}$ \\
\hline Modality & $\begin{array}{l}\text { - Goals and objectives that align with dominant frames } \\
\text { - Statements of commitment from senior bureaucrats such as Premiers } \\
\text { and ministers }\end{array}$ \\
\hline $\begin{array}{l}\text { Order of } \\
\text { discourse }\end{array}$ & $\begin{array}{l}\text { - The lack of recognition of public health's role in mandate letters and } \\
\text { - Domited attention in strategic action plans } \\
\text { - climate policies and the social events } \\
\text { - Forms of social events defining climate change policies mainly align } \\
\text { with dominant frames } \\
\text { - Recontextualizing of frames (also as noted in intertextuality) } \\
\text { - Aligning climate change with government and agency roles and } \\
\text { - international norms } \\
\text { - Abstract presentation and ambiguity of public health terms }\end{array}$ \\
\hline $\begin{array}{l}\text { Ideological } \\
\text { assumptions }\end{array}$ & $\begin{array}{l}\text { - Emphasizing the relevance of global markets and globalization } \\
\text { - Stressing the roles of government and its agencies in climate policies } \\
\text { - Promotion and cancellation of climate policies based on the belief of } \\
\text { the need for Ontarians } \\
\text { - Advancing dominant climate policies as is the norm in international } \\
\text { discourse (e.g. cap and trade, renewable energy innovations etc.) }\end{array}$ \\
\hline
\end{tabular}

\subsection{SUMMARY}

This chapter has presented the results of the thematic analysis of climate change frames and how the government, and its agencies, has historically framed climate change in Ontario. The results have revealed that between 2007 to 2018, Ontario's climate change discourse has been historically and socially constructed as an economic and political issue that can be solved through market strategies and technological innovations forwarded by political elites. As a result, policy texts have marketized and reduced climate change to highlights economic implications of actions or inactions, the institutionalization of national and international norms and political ideologies, and the advancement of market-based solutions through technological innovations. Conversely, a public health frame was ambiguously presented and trivialized through generic narratives that mainly presented public health needs in general terms.

The dominant frames were supported by political commitments and leadership and through historical and rhetorical norms that characterized, recognized, and accentuated the dominant frames. Text sources aimed to educate the public and provide updates on the government's actions mainly established persuasive structures. The voices of senior leaders, 
corporate leaders and experts, through quotes and introductory messages embedded in texts, were used to promote, justify, and legitimize the agencies' policy preferences or to signify the speaker's or author's commitments to the claims being made. The role of politics and partisan inclinations in driving the salience of the dominant frames within the policy texts was clearly evident. The policy texts emphasized the role of the province in climate policies, integrated political leaders and expert opinions and statements of political commitments to promote, justify, and legitimize the policy preferences and directions. 


\section{CHAPTER 7: INSTITUTIONAL ARRANGEMENTS AT THE PROVINCIAL LEVEL}

\section{INTRODUCTION}

Ontario's political context (in Chapter 2) established that policies governing climate change actions in Ontario are typically the responsibility of the provincial government with the aim of reducing GHGs and supporting adaptive capacities. The analysis of thematic frames applied by the government and its agencies in Chapter 6 shows that the government has largely forward economic and political narratives in attempts to advance climate change needs and actions. The focus has resulted in the prioritization of economic and technological narratives with a lack of significance in public health narrative. However, the chapter also revealed the dominant role of government and its institutional structures for climate change decisionmaking. Subsequently, the government's practices have led to the selection of specific structures of climate change governance in Ontario. This chapter aims to answer questions two and three by documenting the institutional contexts within the provincial level influencing both the framing of climate change and public health's capacity in the climate change discourse

This chapter addresses the research questions 2 and 3 by outlining the systematic and contextual factors that have shaped and sustained the dominant frame(s) and influenced the construction of climate change. Mainly, this chapter focuses on the themes that emerged to expose the institutional processes and decisions of the provincial government and its agencies to establish, normalize, and characterize the government's decision structures that have supported the construction of climate change.

Section 7.1 discusses the key provincial strategic actions driving climate change policies in Ontario, while Section 7.2 examines the role of agents and corporates in climate change.

Section 7.3 addresses the integration of knowledge in strategic climate policies, including how public health knowledge is considered and the types of evidence and decision support tools guiding climate change decisions.

Sections 7.4 discusses the policy legacies of the constitution in shaping climate change policies. 
The strategic focus of Ontario's climate policies and frameworks delineates the focused role on mitigation and on specific action areas. Given the economic and technological focus of major climate change strategies, strategic initiatives prioritized certain sectors ,including transportation, energy, industries, housing, transportation, agriculture, and waste. Because the technologies were generally paired with certain sectors/ministries/institutions, the strategic plans also emphasized the leading role that such organizations played. While the approach recognizes the significant role of sectors and ministries in climate change, it was evident that public health is not central to the climate change discourse. Instead, its adaptive role was reinforced, where such roles emerged. Appendix M: Integration of Public Health in the Provincial Climate Change Frameworks highlights the major climate change action plans and strategies that have guided the province's climate change actions and how public health has been positioned in the planning of climate change actions.

Through subsequent strategic action plans, the government has historically outlined priorities for climate change actions, prioritizing areas of focus and inadvertently indicating whose voices matter in the climate change discussion. In Ontario, there is a prioritization of mitigation needs. This is evident in the priorities set in the strategic initiatives, as demonstrated in Appendix M: Integration of Public Health in the Provincial Climate Change Frameworks and in historical climate change actions that mainly favoured mitigation, as illustrated in Appendix K: Chronology of Ontario's Climate Change Activities and Responses. The prioritization was also corroborated by NPH participants' narratives, as shown below.

"... of course, back then [prior to 2018 change in government] the adaptation approach was not really that significant, like it didn't have a lot of expectations directly for people in terms of direct actions, but it did have some intended commitment... I think adaptation is not a wide public interest quite yet ... I think a lot of people just don't think about adaptation as something that they are kind of interested in, right." [NPH participant]

"In Ontario mitigation and adaptation were very different or was handled in two different approaches and it was mainly the mitigation approach that was in focus of the climate change action plan of the previous government [Liberal government]." [NPH participant]

The policy frameworks also portrayed a lack of public health integration. Apart from the EPCCA's recommendations on health adaptions, there were no public health-specific adaptation strategies or plans; health risks, impacts, or vulnerabilities were also not specified in plans and strategies. In the Climate Change Action Plan: 2016-2020, public health is acknowledged twice in an 86page document. One relates to the promotion of cycling and its co-benefits to public health; another refers to accessing experts in public health planning. In the Made-in-Ontario 
Environmental Plan (2018), the role of public health is only acknowledged in actions to improve air quality within communities. However, even with the panel report, only 3 out of the 59 recommendations specifically addressed public health needs.

Also lacking in the climate change initiatives were the procedures for integrating public health needs into existing climate change policies or institutional structures governing climate change. The climate change plans, strategies, and organizational documents did not reveal the role of public health in climate change mitigation strategies. For instance, while the Climate Ready - Adaptation Strategy and Action Plan: 2011 - 2014 provided public health adaptive actions, the plan did not include platforms for intersectoral collaborations and integration of public health needs nor provide for specific roles that public health can play. The Ontario Climate Change Strategy (2015) and the Climate Change Action Plan (2016) both highlight several public health co-benefits associated with climate change action areas. However, public health's role is not defined or provided other than for accessing public health expertise and promotion of cycling in the 2016 action plan. Overall, the roles of public health were not clarified in most of the documents analyzed. Instead, there is an emphasis on climate change mitigation with many initiatives targeting specific ministries and sectors. Where public health's roles were emphasized, the strategic frameworks reinforced the role of public health in climate change adaptation. This is especially salient in areas where public health's roles have been identified (as illustrated in column 4 of Appendix M: Integration of Public Health in the Provincial Climate Change

Frameworks). In turn, many participants from the NPH group did not see a role for public health in climate change mitigation.

"Based on the current structure, I haven't seen a role that public health can play. I mean, greenhouse gas emission reductions will be realized by the industries emitting them. So our focus is primarily on such sectors. I don't know where public health would fall in such setups to be validly considered as players in climate change actions." [NPH participant]

While such response could be due to institutional arrangements that have given other actors authority over climate change (of which public health have not been included), actors inability to see public health's role could also be a result of institutional norms that have defined the roles of other actors, resulting in the lack of clarification of roles public health can play in climate change initiatives.

A review of the policy documents revealed that where health was referenced, public health roles and responsibilities were not clarified. Thus, the actors may not be aware of what roles public health plays in climate change policies. This argument is further supported by the responses received from the NPH group when contacted to participate in the study. Of the total responses received $(n=71), 65 \%(n=46)$ declined to participate because they did not visualize 
public health's role in their climate change processes. That is, the topic of study was not relevant to their policy focus. This was surprising given that those considered for interviews met the inclusion criteria for the study.

Many participants from the $\mathrm{PH}$ group $(\mathrm{n}=9)$ pointed to the lack of emphasis on public health needs in climate change actions. Others also advised that the lack of prioritization has not changed from government to government $(n=5)$. However, some participants $(n=4)$ argued that such ambiguity provides opportunities and openings for health professionals to engage in policies and push for a holistic approach to climate change policies.

\subsection{AGENCY ON CLIMATE}

Narratives from NPH participants revealed that Ontario's institutional functions and authority in climate change policies can be categorized by structures or functions. Some functions sought to design policies and projects targeting climate change; build consensus (through committees or drafting of policy reports and white papers); conduct studies informing policy decisions (although this was a minor function based on the interview responses). Other functions related to increasing the visibility of climate change policies and decisions. Decisionmaking visibility was primarily done by high-level bureaucrats - mainly the Premier, ministers and their assistants, and party-affiliated politicians - whose voices (quotes) were integrated into texts as well as through functions that pursued information sharing and public education on climate change policies (e.g. through Environmental Registry). The use and influences of the Environmental Registry are discussed in detail under institutional engagements in Chapter 9.

$\mathrm{NPH}$ participant narratives also revealed that the issue of climate change in Ontario was monopolized by economic and technocratic elites empowered by the political elites who have sought and forwarded engagement through various political interests. The engagement outcomes are then applied in climate change policies that portray vested interests, expertise, and ideologies that exclude other social actors. The participant narratives confirmed the results of the frame analysis that revealed the proliferation of political and economic rhetorics in climate change policies (see Chapter 9: Political Values and Climate Change Actions). As such, bureaucratic and legislative mandates defined the structure, roles and responsibilities, and prioritized those who have a voice in climate change policy-making and decisions in Ontario. This resulted in privileging of some actors while negating others, the dominance of economic and technological frames, the subjectivity of values, and hierarchical actions that have assigned authority and power and domination of subjective knowledge and expertise. This is specifically prominent in four areas: 
strategic plans as already discussed and through the agency mandates and roles of agents, especially the MECP.

\subsubsection{Mandate on Climate Change}

Bureaucracy influenced the authority and responsibility for climate change policies in Ontario. The policies and initiatives were mainly planned and implemented by the various Ontario ministries, in collaboration with specific sectors identified to influence climate change. There was a focus on a top-down approach. The Office of the Premier is the primary agency; the ministries assigned by the government as secondary agencies. Organizational document analysis portrayed the Office of the Premier to heavily define climate change actions, determining the design and influence of institutions, setting priorities, determining relevant focus areas, the relevant ministries, policy actors or experts, their roles, and types of legislation and policy instruments that guide actions and interventions on climate change.

Climate change policies and discourses also aligned with institutional contexts that prioritized sectors and actors relevant to climate change actions. The result is a division of responsibilities based on ministries and sectors perceived to play a role in climate change action and the accompanying areas of specialization. The government, through climate change plans and strategies, hierarchically placed specific organizations and expertise above others, mainly favouring market-based mechanisms and technological innovations as an efficient approach to addressing climate change. However, all mandated organizations do not have equal capacities to impact climate change policies. For instance, the MECP was identified as the lead agency on climate change actions. This lead is acknowledged in both policy documents (e.g. plans and discussion papers) and participant interviews. For instance, this participant not only points out the dominant role of MECP, but also the unequal distribution of authority between the mandated agencies.

"This ministry does not have much of a role in formulating the plans; it will be the Ministry of Environment [MECP]. So we are just really, like a commenting agency, almost. And so you are not going to probably get a lot more from anyone else in here upfront, because the content or the framework has already been set out and we may provide our input, and it could be extensive, it could be minor, right? It depends on what the content is. But at the end of the day, that decision and all decisions about where that final product is, which I have in my hand right now, it's coming out of the Ministry of Environment [MECP]. So, we are not really able to tell you what you are looking for? What was the process that they underwent? We wouldn't be able to tell you that." [NPH participant]

The MECP builds Ontario's capacity in climate change (both mitigation and adaptation) through various legislative, procedural and administrative policy instruments and coordinates 
actions with various actors they view to have a mandate on climate change. Each ministry's mandate on climate change mainly corresponded with the action areas identified by the various plans; these roles were also linked with sectoral or organizational specialization. The various ministries identified included: The ministries include the MECP, OMAFRA, MNR, MOT, MEDJCT, MENDM and MMAH; MRIS and MIA were hardly mentioned by NPH participants.

To ensure coherence in climate change policy in a manner that supports the government's polities, cabinets ministers and/or their assistants work with select cross-government ministries. However, as this participant illustrates, some ministries had minor roles despite highlighted mandate on climate change documents.

"Well, the role that we would have, for example, with the climate change plan, comes out of a certain ministry [MECP], right? So, what we normally do, and I haven't seen this change much, is that they would send us to other ministries who would have an interest and we would review and provide our comments. That has always been the case and it is my understanding that we have a role in providing comments. That has continued, so mechanically, I don't think that has changed". [NPH participant]

Even where the mandate was provided, there was a clear separation of bureaucratic power between the formulators and implementors of climate change policies. The formulation was mainly dominated by the mandated ministries. The implementation of climate change policies was tasked not only to some branches within the mandated ministries but also to organizations outside of the government. The agents (mandated ministries and respective actors), thus, acted as a result of legislative orders or cooperations that require them to address the climate change issues (i.e. draft, implement and enforce policies or partner with others).

The authority of the select organizations is prominent in mandate letters sent by the Premier of Ontario to the various mandated ministries in 2014 and 2016. The letters not only outline ministerial roles, but they also define climate change mandate, focus, and priorities. The letters also highlighted the cross-sectoral collaborations and coordination needs between the prioritized ministries. The mandate letter contents portrayed an embodiment of a hierarchy of positions for action that assigns power or authority over climate change actions to certain ministries while excluding others. To illustrate, the lack of inclusion of public health mandate, roles, and collaborative needs in the mandate letters (2014 and 2016) to the MOHLTC minister is apparent in both years the letters were issued compared to other ministries (mandated). Simultaneously, the health minister's response to Premier's mandate letters does not acknowledge any need for public health inclusion or responsibility on climate change issues. Equally, public health needs were not included or mentioned in any mandate letter to the various 
ministers. The influence of mandate letters on public health capacities was acknowledged by some members of the $\mathrm{PH}$ group $(\mathrm{n}=3)$, as highlighted by this participant.

"So when the liberal government was in power in Ontario, Kathleen Wayne [Former Premier of Ontario] issued mandate letters for all of her ministers, just like Justin Trudeau [Prime Minister of Canada] did, and maybe, they did at provincial level first. So those mandate letters were really interesting because she [Kathleen Wayne - Former Premier of Ontario] was telling each of her ministers - here is what you have to accomplish in the next four years, and maybe about 12 of the ministries had something about climate change in their mandate letter. So, of course, the ministry of environment was named, so they certainly had a mandate on how they have to address climate change, so did the ministry of natural resources. I can't even think of all the ministries that were to address climate change, but the ministry of health's one wasn't. "[PH participant]

"That was one thing that we noticed from a few years ago with the provincial mandate letters that were put out by the Premier, that there was a connection from the ministry of environment and climate change [MECP] to essentially work with every single ministry on climate change but health wasn't listed and that's an unfortunate missed opportunity, I think. But I think with the new standards that have come out from public health this year, that have higher emphasis on climate change and the recognition of health impacts due to climate change, that will, hopefully, expand in the future and that the Ministry of Health will be able to engage with their other ministry colleagues to expand the knowledge of why public health, and health generally, needs to be included in the conversation, and we are also trying to do that here on a local perspective and letting our municipalities know that, yes, we want to be engaged in climate change with you, and this is why - because a lot of the adaptation pieces are the responsibilities of municipalities. When we look at infrastructure and making sure that stormwater sewers are built to a capacity that can deal with new storm events, that's nothing that we have control over but it will impact greatly on our population from a flooding perspective, from a mental health perspective. It impacts indoor air quality if people's basements flood and they are not remediated properly. It also impacts from a social determinants of health perspective if people are not able to be resilient because they do not have the funds to be able to deal with this changing environments, so I think there is still a lot of education that needs to happen of why public health needs to be involved but I think it has expanded from where it was even 5 years ago when we started this process." [PH participant]

The interviews reveal that the mandated ministries have been granted broader powers to determine regulations and other policy instruments guiding climate change issues. As a result, many participants from the NPH group viewed their roles to include the development of legislative frameworks guiding climate change, advising ministers and/ ministry, recommending policies, supporting legislative mandate, and as points of contact between management, directors, and policy team members. Others claimed ownership of some climate change legislation, as demonstrated below.

"We own certain regulations under the [Redacted]. There are also other regulations that we own that deal with the industrial, commercial and institutional sectors and its actions to try and [Redacted]. So those are sort of the regulatory pieces." [PH participant]

To make their voices heard, the public health sector has recognized various arenas for policy actions in Ontario. For instance, participants reported taking the opportunities to comment 
on various climate change actions posted on the Environmental Registry. Individuals public health professionals, and through their various associations such as Ontario Public Health Association (OPHA), Clean Air Partnership, Canadian Association of Physicians for the Environment, Registered Nurses of Ontario and so on, have encouraged their colleagues and partner organizations to provide technical comments based on expertise and experiences; they have also sent letters to ministries. Public health has also commended agencies on areas that have positively addressed health either directly or indirectly. And, in collaboration with public health NGOs, they have testified at public hearings. Specifically, public health professionals worked with OPHA to raise awareness about the impacts of coal; they testified and provided evidence that supported the banning of coal in Ontario. Public health further pushed for legislation to ensure that coal prohibition was legislated to avoid future reversal of the ban. Giving such evidence to legislators was met by resistance from politicians, but public health's evidence prevailed as this participant narrates.

" [Redacted] appeared before the legislative committee and conservatives said, this is a waste of time, we don't need a legislation, we have already stopped burning coal for electricity...We said that we want to be there a legislation so that anybody who tries to reverse it, it's going to be harder to do that. And everyone was kind of like, we will never go back, and then what happened two years later? You know, you had a president [referring to U.S politics] who was now calling for burning of coal. So, I would say that was our role. So l'll just say, we have had this tradition of speaking out about the links between the environment and health and we are going to continue to do that." [PH participant]

A review of policy documents revealed the relevance and inclusion of public health voices in policy texts addressing coal powerplant closures. Also, when opportunities arise, public health professionals have also spoken to the ministries directly to address their concerns. Some of the advocacy work by public health is leading to the inclusion of public health in some of the climate change plans.

"We met with the new minister at the time, of Environment and Climate change [now referred as Environment, Conservation and Parks], and we had a chance to talk to that minister about how important addressing climate change is for health, all the links between health and the environment and the things that our members were seeing in terms of vector-borne diseases and extreme heat, and we indicated our interest in wanting to work with government to help both with mitigation efforts and adaptation...that ministry put out a number of action plans for consultation, and we had the opportunity to provide input, and we were pleased to see in those action plans, some of the ideas that we were putting forward were reflected in their documents. So the ministry started to demonstrate those links between climate change and health. So we were pleased about that because our feeling was that the Ministry of Health and the Ministry of Environment and Climate Change [MECP] were not talking enough together, but, you know now, of course, we have got a new government, and we are curious to see what their approach is going to be since they have already indicated they do not want to support what the last government was doing around climate change." [PH participant] 


\subsubsection{Corporatism and Climate Change Actions}

Climate change decision-making processes in Ontario were also characterized by both formal and informal domination of corporate elites who enjoyed privileges to define policies as reported by $11 \mathrm{NPH}$ participants. Based on NPH participants $(n=4)$, the privileges stem from affiliation with political leaders, the overlap of economic interests, technological expertise, and interdependence of governments on corporations for economic growth. Corporatism was also embraced in order to gain consensus on the actions which generally impact corporations. Over time, such interest groups become institutionalized in the government's climate change political processes, as argued by these participants.

"The government has a number of people from industries that they consult and over time. These people are always considered as new policies, or changes...or even amendments to policies are considered...they are consulted to ensure that that line of communication is maintained and each party is aware of what is going on...it's like protecting your neighbour by always checking on them and providing them with updates on what is going on so that you are always on the same page." [NPH participant]

Climate change policies are greatly contested and the government often tries to appeal to certain groups. I would say such groups include major corporations whom they have probably dealt with or whom they know their policies will impact greatly. I believe this is relatively justified as the government always wants to make sure that the proposed policies do not impact industries economically. Of course, if the sector is impacted, the GDP is also impacted. So there is always some sort of, informal negotiations, sometimes with corporate leads. [NPH participant]

As a result, the corporate elites and agencies negotiate the types of policies, technological advances that forward their mutual interests (i.e. between the corporations and governments). These interests were mainly defined by economic and technological interests, or sometimes as a result of previous work areas, as pointed below.

"There are several sectors and corporations that are impacted by the climate change decisions we make. So, sometimes, you find that, for example, the politicians may have held a senior corporate position prior to venturing in politics, quit politics to hold a position in a powerful corporation or own a company. So sometimes there are vested interests at play which may dominate the agenda or decision processes, maybe, due to promises made to the corporation, I don't know! But I can tell you that sometimes there are efforts to advance personal interests or the interest of their corporate contacts." [NPH participant]

A review of policy documents also highlighted the significant role played by corporations in Ontario's climate change politics. Many of the climate change policies, especially as presented in news releases, were accompanied by embedded quotes of corporate elites endorsing government policies. Examples included quotes from energy corporations - e.g. Gas Supply and Business Development, Enbridge Gas Distribution Inc. and Union gas - endorsing energy-related climate change policies. Investment in renewable energy was endorsed by quotes from Enbridge, 
Canadian Biogas Association, and Ontario Waste Management Association. The cancellation of the cap and trade program was endorsed by seven different corporations or associations representing major corporations. These included: Ontario Trucking Association, Ontario Greenhouse Vegetable Growers, Coalition of Concerned Manufacturers and Businesses of Canada, Canadian Taxpayer Federation, Canadian Manufacturers \& Exporters, Ontario Waste Management Association and Canadian Independent Petroleum Marketers Association. Opinions contrary to the government's climate change politics were not present in such texts.

Also, in 2015, the government of Ontario created a 16-member action group whose role was to provide strategic advice to the minister of MECP. The members included bureaucrats, environmental specialists but predominantly consisted of members who are or have worked in various corporations in areas such as building, energy, automotive, agriculture, and industries, and those engaged in capital and investor relations. The 2007 EPCCA membership was slightly different from the 2015 action group as it included a policy expert and health professional. However, the panel was still dominated by experts drawn from economic and technologically focused corporations. The action groups, thus, align with the direction set in climate change strategic plans.

\subsection{INTEGRATION OF PUBLIC PEALTH RISKS AND EVIDENCE}

\subsubsection{Health Impacts Identified}

Nearly all plans and strategies did not include specifically targeted health risks. Instead, health was broadly presented, as already shown in the thematic frame analysis. Where health risks were considered, extreme events, followed by air quality, were the most frequently cited as demonstrated by Figure 21: Health risks reported in climate change policy documents . Within the extreme events, extreme heat was the most reported (Figure 22: Health related extreme events reported in documents). These impacts were mainly reported by three institutions: the OP, MECP and MOHLTC (Figure 23: Institutions documenting health risks).

However, during the interviews, the most frequently mentioned health risk (by both $\mathrm{PH}$ and NPH participants) was heatwave implications $(n=18)$. This response could be attributed to the high number of heatwaves and the associated significant morbidity and mortality in the various provinces in Canadian 2018, especially in Quebec and Ontario. The interviews were conducted during or after the occurrence of extreme heat events. Of the health impacts of climate change, psycho-social impacts, specifically mental health, received minimal attention or were lacking. 


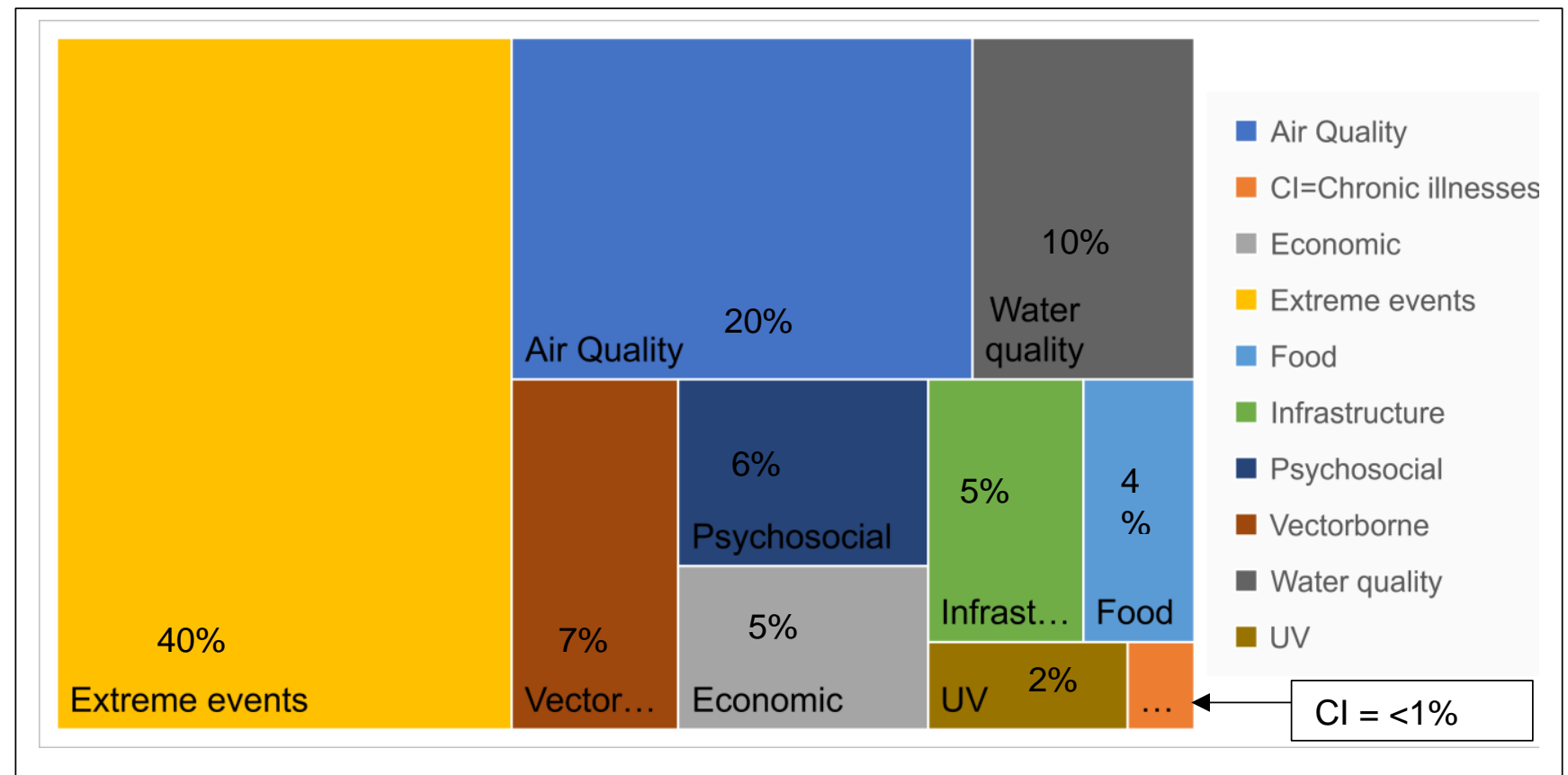

Figure 21: Health risks reported in climate change policy documents

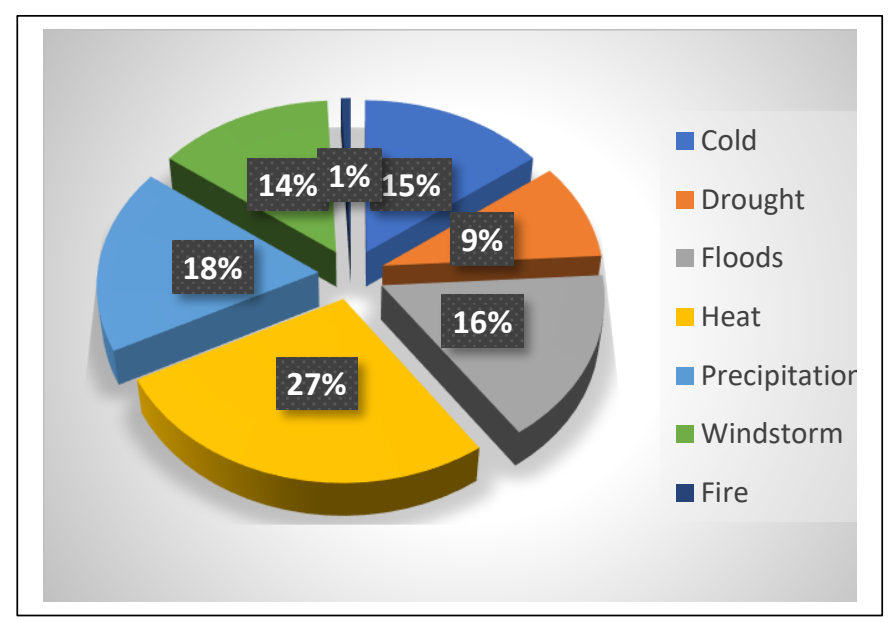

Figure 22: Health related extreme events reported in documents

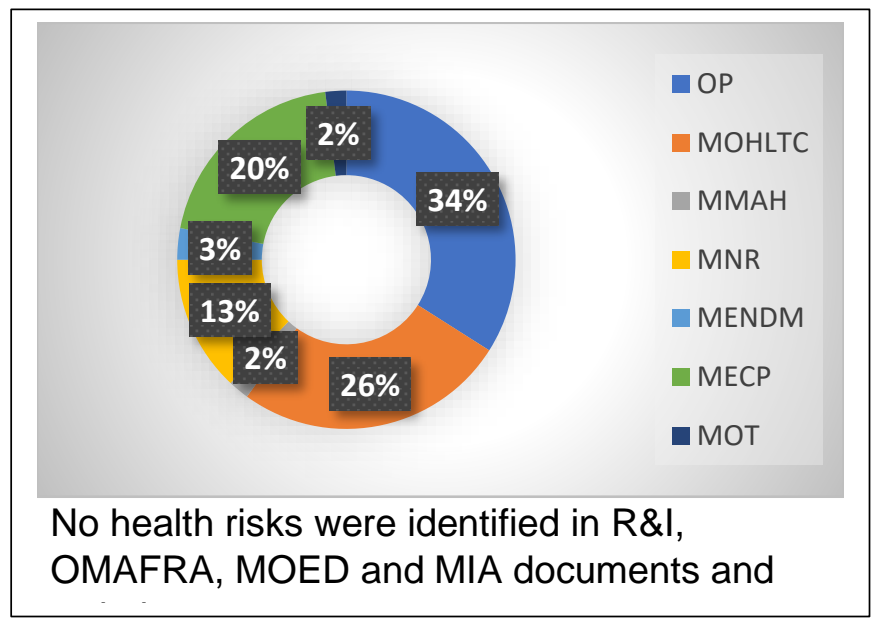

Figure 23: Institutions documenting health risks

\subsubsection{Agencies' Consideration of Public Health Evidence}

In Ontario, agencies have applied several avenues to integrate evidence in the various stages of climate change decision making. Sources of evidence that were cited by NPH participants during the interviews are summarized in Table 9: Sources of evidence informing climate change decisions at the provincial level below. 
Table 9: Sources of evidence informing climate change decisions at the provincial level

\begin{tabular}{|l|l|l|}
\hline Source of information & $\begin{array}{l}\text { NPH group } \\
\text { responses }(\mathbf{n}=\mathbf{1 3})\end{array}$ & $\begin{array}{l}\text { PH group } \\
\text { responses }(n=11)\end{array}$ \\
\hline Best practices and toolkits & 0 & $55 \%(n=6)$ \\
\hline Brainstorming with colleagues & $23 \%(n=3)$ & $46 \%(n=5)$ \\
\hline Expert consultation & $69 \%(n=9)$ & $9 \%(n=1)$ \\
\hline Public consultation & $62 \%(n=8)$ & $73 \%(n=8)$ \\
\hline Data and research & $23 \%(n=3)$ & $64 \%(n=7)$ \\
\hline Defined by bureaucracy & $77 \%(n=10)$ & 0 \\
\hline Health Canada & 0 & $27 \%(n=3)$ \\
\hline Insurance Bureau of Canada & $8 \%(n=1)$ & 0 \\
\hline Interviews & 0 & $18 \%(n=2)$ \\
\hline UN/IPCC & $31 \%(n=4)$ & 0 \\
\hline Jurisdictional scan & $15 \%(n=2)$ & $82 \%(n=9)$ \\
\hline MOHLTC & 0 & $9 \%(n=1)$ \\
\hline Needs assessment & $8 \%(n=1)$ & $27 \%(n=3)$ \\
\hline Talking to stakeholders informally & $23 \%(n=3)$ & 0 \\
\hline Tools: Cost-benefit analysis & $23 \%(n=3)$ & 0 \\
\hline EPA/US & $15 \%(n=2)$ & 0 \\
\hline Internal documents & $23 \%(n=3)$ & 0 \\
\hline Ontario Public Health Convention & 0 & $9 \%(n=1)$ \\
\hline
\end{tabular}

Based on the table above, evidence informing agencies' climate change policies was mainly defined by bureaucracies (77\%), expert consultants (69\%), and public consultation (62\%). The agencies also reviewed evidence from international bodies such as the UN, IPCC, and United States' EPA (31\%), utilized some research (23\%), and informally spoke to stakeholders (23\%); none of these stakeholders were from public health settings.

On the other hand, a lack of scientific and technical information was identified as a barrier to the design of climate change policies by several NPH participants $(n=8)$. It is not surprising that research and data use was only reported by $23 \%$ of those interviewed. The difficulty in acquiring research on climate change was highlighted by a few participants $(n=2)$, as illustrated below.

"Sometimes it is hard...it's a challenge in climate change policies compared to more set policy areas. You don't always understand what are the needs in your area because you don't have that much research on the public need available...so you have to do a lot of work yourself like there isn't... it's not like there are like five researchers sitting out there writing about Ontario climate change options, policy options." [NPH participant]

Similarly, the lack of utilization of public health evidence was evident, as portrayed by this quote.

"We don't do a lot of primary research ourselves, we use the [redacted] for some of the more technical, like the mapping and understand how projections will impact heat days in 
the future, that sort of things. But in terms of what that means for health impacts, that is not something that we ...it's not...we are not on top of the research." [NPH participant]

\subsubsection{Dominant evidence sources}

\section{Based on Table 9: Sources of evidence informing climate change decisions at the}

provincial level above, the three leading sources of evidence included bureaucracy-related evidence, knowledge from consultants, and public consultation. In other words, climate policy decisions in Ontario were mainly defined by two forms of evidence: bureaucratic and fiduciary knowledge.

\subsection{Bureaucratic knowledge}

Bureaucratic knowledge is knowledge created and constructed by civil servants (Hunt \& Shackley, 1999). In turn, the knowledge that shaped and set policy agendas in Ontario were mainly constructed through bureaucratic channels and from formal and informal interactions of the public servant.

"We often incorporate political requirements...like... as you know, each government will want a certain direction in their policies, right? So we incorporate those requirements because that's what they want." [NPH participant]

"Government has its direction and priorities and frequently will state that this is what's happening. That's their role. So, it's our role to make sure that a certain outcome, certain pieces, are included because that's the direction we have been provided." [NPH participant]

According to many participants $(n=6)$, the government or the Premier's office ensures coherence of policies across ministries through committees and advice through cabinet ministers to support political agenda. The requirements are generally rehearsed to ensure that a coordinated response across ministries. On other occasions, consultants and experts advise on courses of action, as illustrated by participants below.

"The committees we have play a big role in formulating climate change policies. Most of the time, the decisions are already made and all we do is just to deliberate on them on the best ways to translate them into policies. [NPH participant]

"So the way it works in the Ontario's government is we would develop policy working with partner ministries, and then all ministries will comment on the new proposals, the new policies, and, further, these policies would go to cabinet committee for discussion between the different cabinet members and their representatives. We also have various interministry committees before we reach the cabinet. So, you will have committees at the director level and at the assistant deputy minister level and then again at the deputy and then eventually, at the minister level. So ministries work together to keep each other informed so that when a new proposal goes to the political level, their minister is not surprised. Staff director, assistant deputy ministers, and the deputy has briefed their respective ministers, and the other ministries, that this is what they are coming forward 
with, and hence, what we have told him and he has read our input, our considerations and support for the proposal. So it basically works up across the ministry and ideally, right?" [NPH participant]

"Sometimes we have to deal with conflicting requests or interests from different sections and ministers...this is mostly in committees that are formed to support the discussions or formulation of policies. And because these are authoritative figures, we have to consider such requirements. That is just the nature of bureaucracy." (NPH participant)

"You have to realize that climate change policies are very contentious...at the end of the day, the policies that prevail is determined by the cabinet committees or the Premier's office" (NPH participant)

The presence of such committees was acknowledged by the $\mathrm{PH}$ group as well.

"I understand that the ministries do have some committees, or they did anyway in the previous government. There were climate change committee that were cross-ministerial, but I don't even know if the ministry of health was part of that committee." [PH participant]

The agencies' utilization of public consultation platforms can also be credited to bureaucratic knowledge. Ontario has embedded environmental rights into law through the Environmental Bill of Rights, 1993. As a result, nearly all NPH participants $(n=11)$ acknowledge the Environmental Registry platform as the government's form of consulting with the public on environmental issues and specifically climate change policies.

"In Ontario, it really is the Environmental Registry that is used to identify number of stakeholders and to understand the public need and the challenges and gaps that might be important when designing a new environmental policy." [NPH participant]

The information is posted for a specified number of days, and once comments are received, there is no communication between the agency and the commenters. Feedback is not provided directly to those who have provided the comment. Instead, all the comments are summarized to define how they were integrated into the decision process. In most cases, very few people participate in providing comments.

"The environmental registry posting that was posted for I think 60 days or so, 90 days may be in [redacted]" [NPH participant]

"Under the environmental bill of rights, it is the obligation of the government to respond and summarize the comments. That's why you will see that on the info, and you will see how typically comments will be summarized and responded to." [NPH participant]

Further discussion on the use of Environmental Registry as a form of communication is provided in Chapter 9 (Influences on Institutional Engagements). Apart from the use of Environmental Registry, only a few NPH participants $(n=3)$ mentioned utilizing face-face consultations (meetings) in informal settings. However, inquiry of the processes that guided such consultation revealed a mere information provision and answering of questions rather than meaningful dialogue on the 
issues. As another participant reported, how the province has utilized such laws in climate change policy is questionable. The consultation processes were mainly procedural and not substantive, as portrayed by the one-way public consultation processes.

\subsection{Fiduciary knowledge}

Fiduciary science is a policy-driven and oriented knowledge where evidence is a result of externally outsourced service for the benefit of the user and not the producer; in other, words knowledge produced through external consultancy (Hunt \& Shackley, 1999). The use of consultancy was prevalent in interviews of the NPH group $(n=8)$. An emerging theme was that in several instances, the ministries hired consultants to conduct some of the policy decisions (expert policy designers):

"We do hire consultants with expertise in the area that targets the action. They have the expertise in that area and will provide us with the evidence and advice we need to make the decisions." [NPH participant]

"Sometimes we do not have internal experts in the areas that we are dealing with....we are forced to hire a private consultant to provide expert advice, information, and policy options...I have spoken to my colleagues in other departments or ministries and they have done the same too... I believe it's a pretty common thing going on in governments nowadays." [NPH participant]

"...we consulted a technical expert when [redacted]..it took a bit of our resources but in the end that information was not utilized at all. I think at the end of the day, political power outweighs some of the scientific evidence we seek." [NPH participant]

"Sometimes the cabinet ministers lack expertise on the subject area of ministries or branch, or we may also lack such expertise. So, we will, or other, the government will hire external consultants or experts who provide advice mainly in form of written reports or so, advising or giving direction on course of action." [NPH participant]

The resulting knowledge was then applied to the various policy deliberations to inform policy outcomes at various ministries mandated with climate change actions.

\subsubsection{Decision support tools and evidence}

Decision support is defined as "organized efforts to produce, disseminate and facilitate the use of data and information to improve decision-making" (Moss et al., 2014; National Research Council [NRC], 2009). Policymakers can have access to several decision support tools. These can include those used to asses policy alternatives or trade-offs - such as cost-benefit analysis (CBA), life-cycle assessment and multicriteria analysis. Others can be specific for assessing risks and vulnerabilities such as health impact assessment or risk assessment; these can also inform trade-offs (Hattis \& Goble, 2003; Moss et al., 2014). Others can also include tools for visualizing 
and modelling data (Moss et al., 2014; Palutikof, Street, \& Gardiner, 2019). Surprisingly, there was not a significant utilization of decision support tools by the various agencies. An emerging theme as reported by most NPH participants $(n=9)$ was that many agencies do not use the tools at all, minimally used them, indicated that they were not relevant to their work, or that they were not simple to use. Such examples are highlighted in Table 10: Ministries' use of decision support tools, as described by NPH participants below.

Table 10: Ministries' use of decision support tools, as described by NPH participants

\begin{tabular}{|l|l|}
\hline Reason & Sample quote \\
\hline Not used at all & $\begin{array}{l}\text { "I have been involved in several climate change policies, but I } \\
\text { don't remember ever using any of those tools...like, no one ever } \\
\text { said, that policy is not adequate because it lacks, say, backing } \\
\text { from a specific research tool" [NPH participant] }\end{array}$ \\
\hline Minimally used & $\begin{array}{l}\text { "I have used cost-benefit at [redacted], where I worked formally. } \\
\text { the time." [NPH participant] }\end{array}$ \\
\hline Not relevant & $\begin{array}{l}\text { There wasn't really that kind of analysis. It's more of a strategic } \\
\text { plan for [redacted] and so, I mean some of those tools are used } \\
\text { more in whatever that context lends itself to but not globally for } \\
\text { the [redacted]." [NPH participant] }\end{array}$ \\
\hline complex & $\begin{array}{l}\text { "Like there is a lot of debate, as well, about the best tools that } \\
\text { you can use here in Ontario. It's not always that simple." [NPH } \\
\text { participant] }\end{array}$ \\
\hline $\begin{array}{l}\text { The tools do not advance } \\
\text { the agency's mandate }\end{array}$ & $\begin{array}{l}\text { "Again, we have to remember the focus of our ministry is more } \\
\text { to our mandated items." [NPH participant] }\end{array}$ \\
\hline
\end{tabular}

The only tool that emerged during the analysis was the Cost-Benefit Analysis (CBA), as reported by 3 NPH participants. CBA is a tool for quantifying costs and benefits associated with a proposed policy (Boardman, Greenberg, Vining, \& Weimer, 2006; D. Pearce, Atkinson, \& Mourato, 2006; Puig \& Aparcana Robles, 2016). While such themes did not emerge in policy documents, they were evident in interviews. Unfortunately, Health Impact Assessment (HIA) was also not integrated into Ontario's climate change policies as none of the NPH participants reported using the tool and many $(n=6)$ were not even aware of the tool. This omission was not only recognized but also intriguing to $\mathrm{PH}$ participants.

"That is interesting ... with a health impact assessment, you could be looking at how public health could review a project, whether it is transportation project, and they could ..using the health impact assessment tool, they could say, ok, here is what the air quality impacts would be if you go ahead, but they could also say, here is what the impacts to the community in terms of the social impacts or physical activity impacts or just like dividing the community examples, but we don't see a whole lot of those. [PH participant] 
Another evidence tool that would be relevant in supporting public health inclusion is risk assessment. However, based on NPH participant responses $(n=3)$, the government of Ontario has not conducted a risk assessment to determine the risks, impacts, and vulnerabilities posed by climate change. However, as this participant indicates, such activities had been planned but not executed by the former (Liberal) government.

"Another piece was the intention to undertake a province-wide climate change risk assessment. That was something [redacted]..., and then the main piece was developing a governmentwide kind of government framework to help coordinate better how government responded to climate change so that we weren't just ministries working in silos, that we kind of had a unified front and that we were all working towards same goals." [NPH participant]

While the lack of inclusion of risk assessments could be attributed to lack of information as reported by $4 \mathrm{NPH}$ and $8 \mathrm{PH}$ participants, a $\mathrm{PH}$ participant suggested that the lack of utilization of HIA could be due perceptions that integrating health in policies may imply superiority of health in other sectors policies or due to resource constraints.

"Some [redacted] are nervous about that [HIA] because it could be anything, and it's not like an environmental assessment because they know exactly what studies have to be done... maybe it's [environmental assessment] a little more clear cut. But for the health impact assessment, I think, some people fear that that's going to cost so much money and people are... plus quantifiable... how are you going to see if there is going to be a health impact... it might not just be that the air standards are going to be exceeded in this area if you go ahead with those projects. You might say the community is going to be impacted because seniors in these areas will no longer be able to get to grocery stores across the street or something like that. But we cannot quantify it. So that could be why they are not done as much, but I think you see them more in Europe and other countries than you do in Canada. But hopefully, that is changing, and people will see the benefits and even just to get that information out and to consult with the community, I think that's the true benefit of the health impact assessment." [PH participant]

Another participant pointed out that it could be due to policymakers' attitudes on health (see more discussion on attitudes in Chapter 10 (Perspectives on the Climate Change-Public Health Nexus). However, the participant argues that including a health perspective is beneficial as it provides evidence for the public's support of the support project or policy.

"That is really interesting that you bring that up because [redacted], this conservation that I was having related to transportation. We talked about health impact assessment and their role in transportation planning and related to environmental assessment. So I kind of think that when it comes to decision-making, it's almost like things like health impact assessment is just one more thing, you know. Like there are so many pieces of legislation and guidance already in place and it's like... what! Now you want us to think about health! The health perspective actually, in some cases strengthens a case for a particular project or policy, so if for example, there is a public pushback about some kind of street design, let's say it's a complete street and there is pushback from people who do not want bike lanes or something like that, then having the health perspective included can actually help to strengthen the case for a design. So I think sometimes the transportation professionals 
appreciate having that because, you know, this is going to be evidence-based and presents the health benefits which, I think, can be helpful so that there is opportunity using a health impact assessment framework or something to add health into the mix to help sell the polices or projects to the municipal council or public." [PH participant]

\subsubsection{Evidence and boundary organizations}

Boundary organizations are organizations set up to support translation and utilization of technical, scientific information in a manner that is accessible and usable to decision-makers (Moss et al., 2014). A number of NPH participants $(n=4)$ reported that while the government has access to some relevant climate change information that can support climate change actions, the information is quite technical. Prior to 2018, the government of Ontario did have a research ministry. This ministry was eliminated in 2018 when the new government (PC) came to power. A document review did not identify any documented research relating to the public health-climate change connections. Also, according to three NPH participants, the former government had planned on implementing a boundary organization that would support technical information translation and accessibility to various stakeholders. Such plans were eliminated when the new government came to power.

"One of them [goals] was the development of a new climate change organization that would help both in capacity and consolidate information on climate change impacts in Ontario and help local governments, industries and organizations, conservation authorities, public health units, anyone, build the capacity and help implement climate change adaptation and resilience work in their own local jurisdictions." [NPH participant]

Such an organization would have supported access to evidence, including those that support public health actions and capacities.

"So, I think the idea was for the government at that time, that Ontario would do something similar to Quebec, where you provide topic information to municipalities and institutions, public institutions or public health institutions, for example, so that they have climate change modelling, specifically for Ontario, because what is happening is that a lot of the climate change modelling is global and we actually have quite a bit of information in Ontario that our ministry has paid for. But it is difficult to understand the modelling data unless you are an expert. So, there is a big translation job in making this information tangible to decisionmakers in public sector and even in private sector because not every company will go out and assess their infrastructures, like their buildings, for climate change risks. They might need a helping hand because it is a smaller company, right, and especially for communities, and indigenous communities in particular. It's hard to have the capacity and expertise. So I think the idea at that time was that, maybe, the government can provide climate change information to other levels of governments, because as a government, the province, we already invested in the modelling and we have the climate change data on a public website. It is available to the public, but it is just that it's not that easy to use it. So the idea at the time was that the government would provide the modelling data in a way so that it would be easier for others to put it to use. For example, for municipalities, as they make decisions on updating their sewage infrastructure in a 
changing climate. At the moment, we are dealing with a new government, so we will see what the next step will be in terms of climate change data and information." [NPH participant]

\subsection{INFLUENCE OF THE CONSTITUTION POWERS}

The use of constitutional powers on provincial lands was evident in how the new government (PC) handled the former government's climate change plans by eliminating environmental policies relating to climate change actions in 2018 (see Appendix K: Chronology of Ontario's Climate Change Activities and Responses). Given constitutional powers over provincial lands, it was not surprising that Ontario has eliminated the climate change in the portfolio of the MECP and cut millions of funding from the various environmental programs run by the various ministries mandated with climate change.

"The government cut nearly [redacted], and this is mainly on programs targeting climate change. This includes the cuts to programs that supported reduction of electricity bills, among others....the cap and trade program has been eliminated...it's interesting to see what they have place...but again, they have the right to do what they want. But we'll see how it works out with the federal government's actions to impose carbon tax." [NPH participant]

Document analysis revealed the recent conflict between the federal government and the province of Ontario court battle to block a federally-proposed carbon tax imposed on provinces that did not have GHG reduction mechanisms in place. The result has been a court battle over the jurisdiction of the carbon tax. On the other hand, the most significant influence of the constitution on public health engagement has been the lack of recognition of rights to a healthy environment in the Canadian constitution. As one participant echoes:

"Canada has had a poor environmental record...being ranked poorly among other industrialized countries. I think I read one article indicating it was ranked second last. Unfortunately, poor environments such as air pollution present public health hazard, yet they are voluntarily regulated. I think one of the reasons is because our constitution does not recognize a right to a healthy environment. If it was recognized, maybe that would give public health stronger leverage and regulatory options to protect populations from health hazards associated with environmental impacts climate change such as pollutions...right now, we don't have that. When we have environmental issues, the ministry of environment takes the lead; it's like public health does not have a mandate on that. There is so much ambiguity in what we do and what the ministries do." [PH participant]

There was also a proposal underway to remove environmental protection in protected areas (water, greenbelts, habitats, etc.) and to give municipalities greater powers to overrides certain legal requirements and plans and develop such protected areas. At the time of the interviews, the Bill had not been enacted into law. And, as this participant illustrates, many interviewed were not sure of the outcome. 
"Based on what they are proposing, municipal bylaws will take precedence over the various plans, some of which are meant to target climate change such as the greenbelts and various ecological areas...I think the Great Lakes... Lake Simcoe... not sure if I got most them....but what will happen is that developers will bypass various environmental plans and develop in such areas. It's very interesting...so many people are against it." [NPH participant]

"I think that at the end of the day, because we are just starting to see from the newspapers and from the reaction, etcetera, that you know, it is one of those things of policy planning where you sit back...this is the democratic process, and it is working. Other than that, if you are asking me to predict what the outcome of all of this is going to be, I can't, I don't know, it is hard to say. You know, we are the policy people, we provide advise, but at the end of the day, it is the decisions, and of course, the reactions have just begun so that's hard to say to... how that will unfold." [NPH participant]

\subsection{SUMMARY}

Climate change is an issue that impacts several areas of governance at the international, national, regional and local levels. Given the breadth and complexity of the issue, guidance is necessary to ensure the adequacy and sustainability of proposed actions. The government undertook such initiatives by establishing necessary sets of organizations and enabling various sectors, ministries, political actions, programs, policy instruments such as enabling legislations and rules, mobilizing specific sectors and ministries, availing multiple forms of resources such as financial, technological, physical and human resources and taking specific stances to climate change actions. However, Ontario's focus has been on mitigation of GHG with an insignificant focus on adaptation, including the assessment of adaptive needs across the province. Such actions took a negative turn with the emergence of the new government in 2018 , leading to extensive changes to climate change policies and decisions. However, each government committed to and communicated its climate change strategy and actions needed. The strategic initiatives displayed a disconnected and fragmented sectoral approach. Given the type of priorities set, the climate change action plans focused on supporting the identified action areas to achieve GHG reduction and access economically viable low carbon solutions. Each area of the focus required different solutions and expertise, most of which did not directly align with public health. The focus has led to the selection of specific governance structures that have privileged actors, sectors, resources, and knowledge, marginalizing public health's role through defined roles and responsibilities, positions, authority, power, specialized knowledge that assign relevance of social actors or institutions. Each area of the focus required different solutions and expertise, most of which did not directly align with public health.

The government has identified some areas for public health engagement in climate change. Yet, there is a lack of integration of public health in the various mitigation and adaptation 
approaches broadly addressing Ontario's climate change needs. Public health needs are not the focus of Ontario's climate change strategies. Like the economically and technologically focused narratives identified in Chapter 6, Ontario's climate change discourse has highlighted that economic and technological ideals are defining the mandate of climate change policies. Overall, there have been some attempts to integrate public health knowledge in agency climate change policies. However, public health is a neglected knowledge producer. Decisions are made by a small group of actors without accounting for the knowledge of those impacted by the decisions. The result is a significant focus on economic and technological discourse, with little attention to public health and the connection between action areas and public health. 


\section{CHAPTER 8: PUBLIC HEALTH-SPECIFIC INSTITUTIONAL ARRANGEMENTS}

\section{INTRODUCTION}

Like Chapter 7, this chapter addresses the research questions 2 and 3 by outlining the systematic and contextual factors that have shaped and sustained the dominant frame(s), influenced public health engagement in advancing the climate change discourse, and the construction of climate change. However, unlike Chapter 7 that focused on the broader provincial government contexts, this chapter focuses on public health-specific contexts that emerged in texts to demonstrate the institutional influences and barriers to public health engagement in climate change policy discourse and subsequent construction of climate change as a public health issue.

Section 8.1 presents the public health-specific strategic initiatives that have guided the sector's climate change decisions and action.

Section $\mathbf{8 . 2}$ and $\mathbf{8 . 3}$ focuses on the institutional structures and resources that public health has leveraged to advance the climate change agenda and the various impediments to public health capacities.

\subsection{PUBLIC HEALTH STRATEGIC APPROACH TO CLIMATE CHANGE}

Within public health, adaptation emerged as a critical context defining public health's role in climate change as reported by all public health participants. The focus on adaptive capacity was divergent from the provincial focus on mitigation with a minimal focus on adaptation.

\subsubsection{A Focus on Adaptation}

The adaptation-focused public health role was evident in public health climate change strategic frameworks, as illustrated in Appendix N: Public Health Climate Change Initiatives. And, like the provincial-wide climate change initiatives, the public health-specific frameworks reinforced the adaptive role of public health in climate change. A point that was also confirmed by several $\mathrm{PH}$ participants $(n=5)$. Many $\mathrm{PH}$ participants $(n=9)$ also reported that a focus on the adaptive role of public health was justified as climate change impacts are likely to lead to significant health consequences regardless of current mitigation measures. As this participant advises:

"So at this point, what we are doing is focusing on adaption partly because of the resources that we have available, and so the first question for us is not really about mitigation but 
focusing on adaptation because it is going to need to happen. Like if we stop climate change now, it is still going to happen. So, the issue for us is, what are the health issues that we need to start thinking about and how do we need to change our programs? Who we need to be working within the community, specifically around potential health impacts, and how we adapt to the impacts." [PH participant]

Where public health's role in mitigation was identified, $\mathrm{PH}$ participants $(\mathrm{n}=9)$ affiliated such roles with built environments, as pointed out below.

“...proportionally speaking, I think we fall more on the adaptation side. With respect to mitigation, public health units are getting more and more heavily involved in issues around built form. And as we advocate for things like compact built, mixed-use environment, all of those, in many ways, are climate change mitigators because if you can walk to work, if you don't have to drive 20 kilometres to a grocery store or whatever, those all reduce emissions, and so we do have a role in advocating for the built form and what society... what our communities are going to look like in the future, and so we have got the mitigation hat on at that point. We also have the mitigation hat on when we deal with issues like air quality, which, of course, is impacted by climate change and, you know, having discussions around the development for a transportation network, supporting active transportation, supporting public transport, all those kinds of things. So there is absolutely a role for us in the mitigation part, but I think we are real leaders in the adaptation component of it." [PH participant]

In terms of mitigating own emissions, some health professionals $(n=4)$ referred to the general municipal GHG reduction initiatives. However, one PHU specifically identified measures they have adopted to reduce specific public health activity emissions.

"So from a mitigation standpoint, our health unit has been implementing...we call it the [redacted] and that has come of work since [redacted], that is looking to decrease our carbon footprint. So we had indicators and identified actions surrounding things like our mileage uses because we have a lot of staff that are out on the road on a regular basis. So how can we reduce the impact from vehicle travel as well as our paper usage and enhanced waste streams? And we are also in the process of implementing an [redacted] for the agency to help to transition over into lower carbon work within our own [redacted]." [PH participant]

The PH participants also revealed the significant focus of public health in health-related climate change adaptions within the local levels of government. For instance, several participants $(n=5)$ reported engaging in local municipal committees on climate change or contributing to municipal adaptation plans. However, the $\mathrm{PH}$ participants $(n=9)$ reported that there is still a significant gap in public health's engagement in the national mitigation and adaptation strategies. Many $(n=7)$ admitted that public health engagements at the provincial level were influenced by provincial institutional arrangements that have historically denied public health the legal mandate on climate change policies. For instance, the lack of recognition of public health's role in mitigation and the framing of climate change in economic terms was blamed for the lack of prioritization of climate change at the local $\mathrm{BOH}$ agenda and the resulting allocation of resources to tackle climate 
change. The lack of public health need prioritization was also linked to the perceptions of the role of public health. For further discussion on perceptions, refer to Chapter 10 (Perspectives on the Climate Change-Public Health Nexus).

\subsubsection{Divergent, Silo Approach}

The provincial institutional arrangements for climate decision-making in Ontario have focused on mitigation structures, unlike public health's focus on adaptation actions involving the promotion of adaptive capacity and community resilience. The divergence of focus between provincial strategic frameworks and public health frameworks was acknowledged by both the NPH group, as already discussed in Chapter 7 (Provincial Strategic Planning and Actions) and by the $\mathrm{PH}$ group, as illustrated below.

"The Ministry of Environment is doing a lot of work around mitigation. Proportionally speaking, they are less about adaptation." [PH participant]

It may not be that the government completely lacks a focus on adaptation. As this participant mentions, adaptation is a new area of focus for the government, and such initiatives may also be referenced in different terms or may not be linked to climate change actions.

"Adaptation is such a nascent field. Decision-makers might make decisions relating to climate change planning and resiliency, but they might not even call it adaptation or resilience. It will just be their infrastructure-related decisions." [NPH participant]

Participants from both groups, but mostly from the PH group, highlighted the 'silo' approach to climate change governance in Ontario. According to $7 \mathrm{PH}$ and $5 \mathrm{NPH}$ professionals, the current provincial and public health climate change frameworks project a 'silo' approach of governance and the 'supposedly' insignificant role public health plays in the climate change discourse.

"For example, work that has been done related to active transportation. There is the ministry of transportation, and, do they connect with the ministry of health-related to health impacts of transportation? No! So, I would say, in any topic, there's a lead ministry, and one of the things that I am also involved with is the [redacted], and so one of the things that we do is try to advocate for communication between ministries. So, yes, climate change primarily sits with the ministry of environment and climate change [now known as MECP]. Well, it did anyway, but because there is this health connection, there needs to be communication. They shouldn't be in silos, right? Ideally, there is overlap in all sorts of different topic areas. So I think public health has a really important role advocating to ministries, to connect with each other and work with each other and you know as you say, one of our strengths is social marketing, so that's part of what we do, is get the message out." [PH participant]

“We do focus a lot in our areas of mandate. I haven't really connected with public health in any work that we do, neither have I been approached by public health on any of their actions. If anything, I really don't know what they are up to there. So, I guess it's relevant to say that we are really a very fragmented system." [NPH participant] 
The lack of integration is evident in the province's strategic climate change and the public healthspecific frameworks. For instance, the role of public health is not specified in the core provincial policy frameworks and vice Versa. Overall, public health participants argued that the lack of public health inclusion hinders the development of actions that target the public health needs and minimizes the understanding of actions by other sectors that may benefit from public health expertise.

\subsection{PUBLIC HEALTH ORGANIZATIONAL STRUCTURES}

In an effort to enhance public health capacity in climate change, both at the provincial (MOHLTC) and local levels (PHUs), various organizational structures were evident in Ontario. Themes that emerged included jurisdictional influences, the modernization of the public health system to support a public health mandate in climate change, provision of various resources including information, standards, and guidelines, staff training, and expertise. While these structures were relevant to public health capacity, several barriers and constraints existed.

\subsubsection{Leadership and BOH Jurisdictions}

The public health's governance structures emerged as a major influence of the sector's engagements in climate change. Within public health organizations, the MOHLTC was viewed as a leader in climate change decisions and policies. As a result, participants $(n=9)$ advised that engagements and capacities across and between PHUs, and with other non-PHU stakeholders in general, and especially at the provincial level, would have been advanced by the MOHLTC. Unfortunately, many PH participants $(n=9)$ faulted the MOHLTC for lack of leadership or inability to steer the sector's inclusion in climate change policies.

“....back to the Ministry of Health... you weren't finding someone there who is being the champion and leading the way and inspiring others. So this makes it hard." [PH participant]

"I also think that there needs to be leadership from the ministry [MOHLTC] to be able to say, we recognize that this is within the mandate of environment, but it is also within the mandate of health." [PH participant]

"So this is something that I have struggled with over the last 20 years trying to explain to the ministry [MOHLTC] what the role of the environmental public health professions are in public health. Because even when they [MOHLTC] speak about chronic disease and they [MOHLTC] release their report on chronic disease and they [MOHLTC] list the four top risk factors - they talk about obesity, physical activity, healthy eating, healthy weight, smoking - and there is no mention about air quality. And even when we were working on public health standards, we really wanted them to reference environmental exposures in the chronic risk prevention standards because all the things we are doing in environmental 
health, or the majority of them anyway, I mean there are acute illnesses, but the majority is chronic disease prevention. So air quality or any of those other pieces. But, you know, we did have a challenge to have the ministry [MOHLTC] understand that. But then when you talk to the Ministry of Environment - if we are talking about human health - they would say we don't do that; that's the Ministry of Health. But at the same time, if you are the lead for climate change, then you should be talking to the ministry of health. So, I definitely think that that has to be something that has to be strengthened." [PH participant]

The MOHLTC was criticized for its laxity to mainstream climate change into the various climate change policies across the various sectors whose actions provided health co-benefits.

"What we also lack is the integration of public health needs in major climate change policies and plans brought forward by different sectors. There are so many health benefits of such actions. Yet, most of the time, public health needs are not integrated. I have seen some public health needs mentioned, but that's really as far as it goes. It's always about the obvious public health connections - what about those that only public health experts can point out to policymakers? The ministry of health has a role in doing that, but so far, I have not seen any leadership or tangible evidence that I can point to and say, yes, the ministry has done this and that... I haven't seen that kind of leadership. As a PHU, we mainly work with municipal partners, and I believe we have done our best to integrate health impacts into municipal plans. But these are always isolated incidences, and we struggle to bring our points across sometimes. Fully integrating public health into policy proposals would really give us some leverage." [PH participant]

Despite the criticism of MOHLTC leadership, some health units stood out as leaders in climate change policies as complemented by participants from other PHUs. These PHUs were characterized by resource availability and the willingness of directorates to take on climate change policies. As a result, they were ahead of other PHUs in terms of collaborative work as well as identification of vulnerabilities to climate change within their specific jurisdictions. Such health units collaborated with the MOHLTC and other PHUs, offering resources (training and information) that were supporting vulnerability and adaptation assessment across several other health units. The leaderships of various specific public health professionals within PHUs and NGOs were recognized by several participants $(n=6)$. While such individuals cannot be disclosed in this report due to ethics and confidentiality agreements, the participants recognized how such leaderships had advanced public health's role in climate change decisions and capacities across Ontario. This can be broadly summarized by this participant's response.

"Well, I know for ourselves, within the region, if our senior leadership had not bought into this [integration of climate change needs in local PHU's policies], we wouldn't be where we are at. And so, without that leadership and the allocation of resources that that leadership can bring to the table, we are not going to go anywhere. And so it's getting that level of ...in Ontario... you know, the medical officers of health across the board, public health Ontario, the Ministry of Health and Long-Term Care... it's getting those folks on board to allow the 
front line staff to do the work that they need to do in order to address climate change in their communities." [PH participant]

Geographical structures were also highlighted to influence public health's capacity in climate change. As already highlighted in Chapter 2 (Structure of the public health system), the geographical sizes and jurisdictions of PHU vary considerably. Such variations were identified to impact public health's role in climate change and have led to a focus on other mandated programs that were considered significant. Despite such constraints, the well-resourced PHUs were identified to support other health units.

"Well, I think a lot of it was capacity. You know, we are a relatively small health unit. We cover quite a large geographic area." [PH participant]

"There are currently 35 public health units in Ontario and across the board. There is a variety of capacities. Some of the bigger health units are much more resourced than some of the smaller ones and, in some cases, for the northern ones, because of the size of the geography, you have to [redacted] every time you [redacted]. And so the issues are different across the health units. So the health units that have the capacity and resource to do it [vulnerability and adaptation assessments], they have been long involved in it. With the Ontario public health standards changing, there is more of recognition, and we are seeing new partners, new health units coming into the discussion. So I think it is encouraging to see and certainly, the big health units do everything they can to help and assist the smaller health units because, you know, training capacities, brainstorming, all those different kind...sharing of documents, sharing of resources to help across the board." [PH participant]

\subsubsection{Public Health Mandate in Climate Change}

Based on public health frameworks (see Appendix N: Public Health Climate Change Initiatives), public health has had a role in climate change since 2008. However, the sector did not have a mandate. This lack of mandate has resulted in a vague consideration of public health, as illustrated below.

So, I think we are just starting to think about climate change in a structured and more rigorous way in public health. Public health has, for a long time, had climate change vaguely on our radar. So, public health has not really dipped into it, and we have not really had the mandate to do public education around climate change and resources to do that. So I don't know that it is a failure of public health, in that we have never actually been given the task." [PH participant]

It was not until mid-2018 that the sector had an official mandate and responsibility in climate change. This mandate was a result of the public health modernization or reorganization process in the previous year (2017) that provided a foundation for public health engagement and inclusion in current climate change policies. Based on the $\mathrm{PH}$ participant responses, the specific 
requirements for the mandate includes the identification of health risks and vulnerabilities within each jurisdiction with efforts to connect public health needs with the various policies across various institutions, including governments and communities. However, completion of the vulnerability and adaptation assessments (or the $\mathrm{V}$ and $\mathrm{A}$ as referenced by most of the $\mathrm{PH}$ participants) within specific PHU jurisdictions was the most cited mandate. This participant's response can broadly sum the role of the $V$ and $A$ assessment.

"The role is in identifying the health risk, in our district, associated with climate change and who the most vulnerable populations are. So it's sort of identifying the projected climate changes...you know, if the average temperature continues to increase...and these are the health hazards associated with that. Therefore, in our district, these are the health outcomes that we could anticipate coming about, and then the health unit, for us to look at what our contribution to adaptation is or how our programs can help to make our populations more adaptive and more resilient. And I think the other part of it is how do we connect with the broader community to increase awareness about the health link and the health risks associated with climate change? Because I think that most of the conversation about climate change is about environmental impacts and not so much about health. I mean really, when you talk about the environment there is always going to be a health impact, right? But that connection is not necessarily clear, nor is it very commonly made. And so I think part of our role also is to put the message out there about the fact that climate change affects us all, because this has the potential to impact our health in these kinds of ways, and also to make it really local and I think that is part of the role of the vulnerability assessment too. Is to say, yeah, climate change is a global issue. It affects populations around the world, but here is how it's going to affect us locally. And I think that will help to... I hope... to bring that message home and make it a little bit more local and personalized so that not just the health units but other organizations, municipalities, etcetera, can see that it's really important to put in place strategies for adaptations but also more strategies to mitigate our own impacts on climate change. You know, so to put efforts to reduce greenhouse gas emissions." [PH participant]

As a result, Ontario's public health sector is now (since mid-2018) taking the necessary steps to integrate climate change into its policies and programs. For instance, the MOHLTC now requires all PHUs in Ontario to conduct and report on their V and A assessments. However, across the various health units, the assessments were at various stages. Some health units had completed their assessment; some completed the assessment several years prior to the MOHLTC's guidance documents or requirements. Other health units were still in the process of completing their $V$ and $A$ assessments, while others had not begun working on the assessments at the time of the data collection process. Other health units were not applying the ministry's guidelines but instead using their own guidelines.

Those PHUs currently conducting the assessments hope such tools will enhance public health capacity in climate change through various initiatives - such as supporting the 
development of new policies and programs, guiding future engagements, and mainstreaming public health needs into broader provincial policies - as illustrated by the responses below.

"So the $V$ and $A$ assessment, we expect, will identify new policies and programs that the health units need to do but will also identify climate change adaptations that community stakeholders need to consider and we might then work with them to either encourage them or facilitate the development of those policies." [PH participant]

"My understanding of $V$ and $A$ assessment process is that it's going to pull us in into all kinds of future work. And at this point, we don't know what future work looks like. And then some pieces of that will pull us into having new partners to talk to about things and... well, how does health connect to infrastructure? How does health connect to economic viability? How does health connect to food systems? Which actually, food systems then connect to economic viability. So, I think that the $V$ and $A$ process is actually just the starting point for us to begin to think about how climate change is impacting health. How it is likely to impact health in the future, and then based on the work that we typically do around healthy public policy, that work ripples out to all over the place. So I don't even know today who those new partners will be or what the particular topics will be because really what we are going to do is that we are doing our $V$ and $A$ assessment and now we are actually going to do it across the [redacted], do a draft of that which then becomes a consultation draft so we can go out and talk to these other potential partners and say here are what we think ... what have we missed from your perspective? What are the linkages to the work that you are doing? What are the linkages to climate change issues that you have already addressed, and where do we need to work together as we move forward, right? So that's just part of the lid of like a million things that we haven't even thought of. So the issue for me is... why I think my answers are fuzzy for some of these...and like, I don't know if public health should be a leader for some of these because we don't know where this is going to take." [PH participant]

Such forecasted benefits are already being experienced by PHUs who have completed their initial assessments. These health units reported that the completed assessments have informed identification of vulnerabilities, mitigation and adaptation needs and plans, and built public health capacity within their jurisdictions as well as across various PHUs in Ontario and other provinces (Quebec and British Columbia). Others who had completed such assessments had also begun working on a second assessment, informed by the information from the first assessment. The second round of assessments is now considering and integrating changes in demographics and vulnerabilities to climate change within their jurisdictions, a point illustrated by this participant.

"These documents [V and A assessment] cannot be static. Communities grow, they shrink, you know. Different demographic factors come into play, or populations are ageing, and with all these changes that happen, the vulnerabilities to climate change shift as well. And so you really need to be watching your communities and be aware of what the issues are in it if you are going to be effective in planning adaptation and these other things. So we are just in the final stages of updating our vulnerability assessment, and again, it is a guidance document for us as we move forward. " [PH participant] 
The PHUs who completed the $\mathrm{V}$ and $\mathrm{A}$ assessments have also supported the MOHLTC in developing two toolkits for conducting the $\mathrm{V}$ and $\mathrm{A}$ assessment. That is, the vulnerability and Adaptation Assessment Guideline and Workbook. In addition to supporting the development of the toolkits, such initiatives have supported capacity building initiatives (e.g. workshops and seminars on lessons learned) between the MOHLTC and the various PHUs as highlighted by this participant.

"Yes, so it [V and A assessment toolkit] provides a technical background as well as how to do a vulnerability assessment. And so, we provided input in that document, reviewed it, talked about lessons learned, what we would have done differently. And there are things in that toolkit that were lessons learned [redacted]. So with the Ministry, we have done a series of workshops [redacted] worked closely with the Ministry." [PH participant]

The completion of some assessments allowed for the integration of public health needs into municipal climate change initiatives and partnerships that would have otherwise not been possible. Despite the recognition of the relevance of $V$ and $A$ assessments and the MOHLTC's attempts to mainstream climate change into public health policies, several concerns were raised by participants. These included the lack of clear or formal guidelines from the MOHLTC on the vulnerability and adaptation assessments $(n=5)$, inconsistencies in the approach to the assessments $(n=7)$, duplication of evidence generation due to independent assessments $(n=3)$, and a lack of coordination between the PHUs $(n=7)$. The standards guiding the process was also criticized by several public health professionals $(n=4)$ for the lenient approach to $V$ and $A$ assessment.

"it's not a strong wording as we wanted from the public health standards, but it does say public health is to take action on climate change. So we are assuming most of them [PHUs] are doing their vulnerability assessment. Some may be more rigorous than others, but all depends on all resources that they [PHUs] have." [PH participant]

On the other hand, the MOHLTC indicated that the laxity was due to the lack of additional resources provided to health units for the assessment. When the $\mathrm{V}$ and $\mathrm{A}$ assessments were proposed by the MOHLTC, it was a neutral exercise, and the ministry did not intend to pose new requirements that would have potential physical and resource impacts on PHUs. As a result, the laxity in approach to the $\mathrm{V}$ and $\mathrm{A}$ assessment was meant to balance between the requirements of the assessment and the promotion of healthy environments.

"At the time, it was a resource neutral exercise, so we wanted to make sure that while we are not going to be posing new requirements that could have potential physical impacts on public health units, we still wanted to promote some of the work under healthy environments. So we had to really find a balance in doing that and think we were able to, sort of, strike that. I think healthy environments and climate guideline is one of the first 
documents that sort of enables the work on climate change adaptation. We also have the Ontario climate change and health tool kit, but that is very specific. It helps with the vulnerability assessment and developing adaptation plans, but the overarching guidance document was the guideline itself." [PH participant]

By the time of the interviews, there was no evidence suggesting that the new public health mandate in climate change had significantly influenced public health inclusion in provincial strategic policies. Many NPH participants $(n=8)$ were not aware of this mandate. Public health was majorly regarded as not having a mandate in the climate change decision-, policy-making processes. In some instances, the provincial policies were viewed as superior to those at the local level (e.g. local public health agencies or municipalities). Those within the lower levels were, therefore, to use such policies as templates for designing their own policies as this participant highlights:

"I don't think we necessarily need to work with public health directly. The policies that we produce within our organizations are guided by the overall mandate of climate change and should guide interventions at local levels. So, because public health units are considered local levels because they are attached to municipalities...they do not have a direct jurisdiction on making such policies but should use our policies to guide some of their programs. Or if they [PHUs] do work on some policies, then ours [agency/ministry policies] should act as a guideline for them to follow. You know, I believe we shouldn't create additional policies when the province already has policies in place that we have worked on in collaboration with other ministries." [NPH participant]

\subsection{PUBLIC HEALTH RESOURCES}

The themes that emerged on public health resource influences related to the financial, evidence, expertise and other capacity-building resources such as surveillance and public health's capability as a boundary organization.

\subsubsection{Funding}

Financial constraint was the most significantly cited challenge to public health engagement in climate change policies and an apparent resource constraint. All the public health participants expressed concerns about the impact of the lack of funding of public health policies, in general, and specific to climate change. These constraints were further exacerbated by jurisdictional structures where smaller health units with larger jurisdictional areas were poorly resourced compared to larger, urbanized PHUs.

Prior to the modernization of Ontario's public health standard in 2018, public health did not have a mandate explicitly requiring them to offer or participate in climate change programs. As a result, the financial resources were only geared towards those programs that were mandated 
by the ministry. This point is clearly illustrated by these two participants demonstrating the financial influence on the lack of engagement in climate change policies.

Our health unit also had its budget frozen [redacted] ago. So there was basically no new hire, no new hiring of staff; people left for retirement purposes and often, their positions didn't get filled. So I would say that was one reason. And so the focus, particularly of our environmental health staff, was on the legislated programs, on inspections and those kinds of things and we had, you know, that was their focus, and that's all we had the staff capacity to do until the new OPHS came out with a really clear mandate for public health to look at climate change and health. As part of that, our health unit went through a big reorganization, and as part of that, my position in environmental health was created, and so that added some capacity in that department to take on this work." [PH participant]

Even after the mandate was provided to public health, no additional financing was given to the PHUs to support the $V$ and $A$ assessments.

"Given that public health units were given the mandate to do a vulnerability and adaptation assessment, but we are given no new resources to do any of this. We are doing the best that we can, and our focus is going to start with just what we are required to do and focus on adaptation." [PH participant]

Further, financial constraints were associated with the limited engagements of the MOHLTC in public health-related climate change initiatives.

"The challenge is that getting the attention and support and involvement of the Ministry of Health is very hard because of their, sort of, you know, $\$ 60$ billion budget. Most of that money and attention is being sent on the healthcare system and care and treatment issues, and they have about $2 \%$ of their budget looking at issues of health prevention and promotion..., so it is very hard to get the Minister of Health, it's hard to get senior officials to want to speak out, spend time and be champions for these issues." [PH participant]

\subsubsection{Public Health Sector Evidence and Skills}

\section{According to Table 11: Sources of evidence for climate change decisions within}

public health below, public health decision-making was mainly informed by scientific knowledge such as jurisdictional scans (82\%) and research (64\%). Public consultation was also a significant component of public health evidence (73\%). The public health sector consulted communities and community partners within PHU jurisdictions, other PHUs within Ontario and other provinces in Canada, colleagues, health agencies at the federal and provincial level, MOHLTC, municipalities, regions or counties, and non-governmental organizations.

Table 11: Sources of evidence for climate change decisions within public health

\begin{tabular}{|l|l|l|}
\hline Source of information & $\begin{array}{l}\text { NPH group } \\
\text { responses }(n=13)\end{array}$ & $\begin{array}{l}\text { PH group } \\
\text { responses }(\mathbf{n}=11)\end{array}$ \\
\hline Best practices and toolkits & 0 & $55 \%(n=6)$ \\
\hline
\end{tabular}




\begin{tabular}{|l|l|l|}
\hline Brainstorming with colleagues & $23 \%(n=3)$ & $46 \%(n=5)$ \\
\hline Expert consultation & $69 \%(n=9)$ & $9 \%(n=1)$ \\
\hline Public consultation & $62 \%(n=8)$ & $73 \%(n=8)$ \\
\hline Data and research & $23 \%(n=3)$ & $64 \%(n=7)$ \\
\hline Defined by bureaucracy & $77 \%(n=10)$ & 0 \\
\hline Health Canada & 0 & $27 \%(n=3)$ \\
\hline Insurance Bureau of Canada & $8 \%(n=1)$ & 0 \\
\hline Interviews & 0 & $18 \%(n=2)$ \\
\hline UN/IPCC & $31 \%(n=4)$ & 0 \\
\hline Jurisdictional scan & $15 \%(n=2)$ & $82 \%(n=9)$ \\
\hline MOHLTC & 0 & $9 \%(n=1)$ \\
\hline Needs assessment & $8 \%(n=1)$ & $27 \%(n=3)$ \\
\hline Talking to stakeholders informally & $23 \%(n=3)$ & 0 \\
\hline Tools: Cost-benefit analysis & $23 \%(n=3)$ & 0 \\
\hline EPA/US & $15 \%(n=2)$ & 0 \\
\hline Internal documents & $23 \%(n=3)$ & 0 \\
\hline Ontario Public Health Convention & 0 & $9 \%(n=1)$ \\
\hline
\end{tabular}

Despite the broad range of evidence for supporting public health's capacity in climate change, several impediments to public health evidence generation were evident. The challenges included the lack of adequate information, training, and expertise in the area of climate change. Specific challenges identified by $\mathrm{PH}$ participants and sample quotes are summarized in Table 12: Barriers to public health evidence generation below.

Table 12: Barriers to public health evidence generation

\begin{tabular}{|l|l|}
\hline Factor & Sample quote [PH participants] \\
\hline $\begin{array}{l}\text { Lack of information, } \\
\text { data and knowledge }\end{array}$ & $\begin{array}{l}\text { "There is a bit of a knowledge gap because there is uncertainty and } \\
\text { it's become a political issue. There is a gap in putting into practice the } \\
\text { things that need to be put into practice. And even amongst those who } \\
\text { believe in climate change - that humans are causing it and that there } \\
\text { is going to be implications - understanding what to plan for in the } \\
\text { future and how much to plan is a challenge. And what information is } \\
\text { valid? What information should we use to underpin policies or } \\
\text { infrastructures or program efforts? Those are things that there is no } \\
\text { one answer. And I think because of that, people are, maybe, a bit } \\
\text { unsure of what to do and how to properly address these issues. So } \\
\text { it's a governance issue; it's a perception issue, and I think it is a } \\
\text { knowledge and information and data issue and all those together } \\
\text { mean that the work isn't necessarily done at the speed that it should } \\
\text { be done." [PH participant] } \\
\text { "As well as the potential increase for tornados, and there wasn't a lot } \\
\text { of data on that, but we do recognize that with the changing weather } \\
\text { patterns, there is a potential increase of thunderstorms, and severe } \\
\text { thunderstorms make tornados, and we have had tornados in our }\end{array}$ \\
\hline
\end{tabular}




\begin{tabular}{|c|c|}
\hline & $\begin{array}{l}\text { region in the past." [PH participant] } \\
\text { "We also looked at vector-borne disease ... that was specific to West } \\
\text { Nile and Lyme diseases. We didn't look at any other potential future } \\
\text { issues like dengue or Malaria because there wasn't any data for that." } \\
\text { [PH participant] }\end{array}$ \\
\hline $\begin{array}{l}\text { A new area of public } \\
\text { health }\end{array}$ & $\begin{array}{l}\text { "So for me, it's just that this is a new issue and a new field for public } \\
\text { health as a program that we need to address and it will take us a while } \\
\text { to learn within the organization and then with partners and across } \\
\text { health units generally." [PH participant] } \\
\text { "One of the big challenges was really not knowing how to even begin } \\
\text { some of this work, so it is a really a novel aspect of public health, at } \\
\text { least within Ontario, to be doing climate change." [PH participant] } \\
\text { "I think part of is just that it's a new area for me, it's a new are for our } \\
\text { health unit and it's new for public health. So there is a pretty big } \\
\text { learning curve for sure but, that's ok, I enjoy that." [PH participant] }\end{array}$ \\
\hline $\begin{array}{l}\text { Climate change is } \\
\text { complex }\end{array}$ & $\begin{array}{l}\text { "The biggest challenge is that it is [climate change] a massively } \\
\text { complex topic." [PH participant] } \\
\text { "It's such a big issue." [PH participant] }\end{array}$ \\
\hline Overwhelming & $\begin{array}{l}\text { "We didn't have the data to do that (vulnerability assessment), we } \\
\text { didn't do a health modelling study, so getting my brain around that } \\
\text { was a big shift for me, and as well, just with the breadth of the data } \\
\text { and the breadth of the topics that we were looking at, it was really } \\
\text { overwhelming." [PH participant] }\end{array}$ \\
\hline Competing interests & $\begin{array}{l}\text { "There are so many other issues that people are concerned about, } \\
\text { whether it is the economy or health care that trying to get the climate } \\
\text { message...to get it to resonate with the audience so that they see it } \\
\text { as a really important issue is challenges because they don't see it } \\
\text { necessarily happening now and when we see extreme heat events, } \\
\text { they think, oh, we have always had extreme events. But, they } \\
\text { [extreme heat events] are happening more often and more intense } \\
\text { and for a longer duration. So the challenge is getting buy in from } \\
\text { stakeholders knowing it's going to cost them money to do some of } \\
\text { these actions that need to protect human health." [PH participant] }\end{array}$ \\
\hline $\begin{array}{l}\text { Lack of expertise or } \\
\text { training }\end{array}$ & $\begin{array}{l}\text { "The other difficulty that we had or a challenge was understanding } \\
\text { some of the climate data, and that's because we have no } \\
\text { climatologists or meteorologists here, and there is just a wealth of } \\
\text { information out there in terms of the actual climate data that we were } \\
\text { able to download." [PH participant] } \\
\text { "It [vulnerability assessment] was really a struggle for me in, sort of, } \\
\text { looking at climate change and saying, how the heck are we going to } \\
\text { actually complete a vulnerability assessment, and how do you } \\
\text { complete a vulnerability assessment?" [PH participant] } \\
\text { "When I started working on the vulnerability assessment, I didn't even }\end{array}$ \\
\hline
\end{tabular}




\begin{tabular}{|c|c|}
\hline & $\begin{array}{l}\text { know where to start. Other than the toolkit, there is nothing else. I } \\
\text { didn't have the training on how to do it. I was so confused and I didn't } \\
\text { even know what I am suppose to be doing." [PH participant] } \\
\text { "Former director-general of the World Health Organization, she is } \\
\text { quoted as saying that climate change is the public health opportunity } \\
\text { of the } 21 \text { st century. So you have those in public health that are saying } \\
\text { now this is the biggest issue and should be our biggest priority but we } \\
\text { have got this lack of knowledge, training, and leadership that is } \\
\text { happening." [PH participant] }\end{array}$ \\
\hline $\begin{array}{l}\text { Training needs not } \\
\text { covered in curriculum }\end{array}$ & $\begin{array}{l}\text { "For example, if our [redacted] produces data that describe Lyme } \\
\text { disease incidences, most of the time all we do is identify potential risk } \\
\text { areas using such data. But if we had training or expertise in modelling } \\
\text { such data, we can combine them with, let say, weather patterns to } \\
\text { inform future risks. But at the moment, we don't have those skills and } \\
\text { our curriculum in public health does not include such because these } \\
\text { are mainly covered by those taking environmental or geography } \\
\text { studies." [PH participant] }\end{array}$ \\
\hline Lack of technology & $\begin{array}{l}\text { "For us to advance the various public health research, you know, I } \\
\text { can tell you that we have epidemiologists who can produce really } \\
\text { good population data but sometimes to understand those data within } \\
\text { a specific geographical context, you know, you have to use certain } \\
\text { technologies or data modelling techniques, for example, through } \\
\text { remote sensing or geographical information systems, also known as } \\
\text { GIS. But we just don't have training or experts in those areas within } \\
\text { our staff. Sometimes I see these really cool studies where they have } \\
\text { produced models that combine so many different aspects of a } \\
\text { population and I am like, wow, I wish we had that because it would } \\
\text { really make our vulnerability assessment easier and more accurate." } \\
\text { [PH participant] }\end{array}$ \\
\hline
\end{tabular}

Amongst the factors presented in the table above, lack of information and evidence to advance public health agenda on climate change was an overwhelming challenge as reported by nearly all public health participants $(n=10)$. Currently, PHUs have access to some capacitybuilding resources. As illustrated in Appendix N: Public Health Climate Change Initiatives, the MOHLTC has availed a range of resources relevant to advancing public health in the climate change agenda. These resources are predominantly frameworks, guidelines, standards and protocols. But, despite the ministry's provision of frameworks and guidelines for public health engagement in climate change, training was a neglected area of public health capacity building. For instance, while the PHUs are required to conduct climate change $\mathrm{V}$ and $\mathrm{A}$ assessments for their specific jurisdictions, several public health professionals $(n=5)$ indicated the lack of adequate training and sometimes incomprehension of how the assessment would be completed. Also, while many public health professionals interviewed had a clear knowledge of climate change issues, 
incomprehension of some climate terms was evident in a few instances $(n=3)$. These included requests for clarification on the differences between mitigation and adaptation and the interchangeable use of mitigation when referring to adaptation needs and vice versa. Also, as highlighted by this participant, climate change issues may not also be well understood by public health professionals who are not engaged in environmental health areas or by other decisionmakers and the general public.

"I think within the community of public health, people who work on environmental health issues, the impacts of climate change on health are very well understood. So for people who are part of that public health community, I think that is very clear, I am not sure that is clear for others in public health, or the public, for example, and sometimes for the decision-makers. And so, I think there is a real need to communicate some of that. And I know the OPHA has been working on developing some material that might help do some of that communication." [PH participant]

Although it would be reasonable to say that climate change is a new area of public health (as the mandate only began in 2018), information on climate change can also be accessed through other ministries. Unfortunately, these needs are never identified due to a lack of institutional engagements (as discussed in Chapter 9: Institutional Engagements). However, it was surprising to hear that other Ministries (mandated ministries) may have access to data relevant to public health. And, as this participant highlights, such data are never shared or sought.

"Because our ministry... and our applied research nature, we have been taking climate change into consideration, probably since as early as the 80s. We may have some long-term data set that we might be able to provide more of a service to public health institutions than they realize. Unfortunately, they don't reach out to us." [NPH participant]

Overall, the resource constraint was not only limited to PHUs. As a participant pointed out, the MOHLTC is also impacted.

"So in the new standard, they have a much clear mandate of what is expected around climate change. So you are going to see more about local action. But sadly, at the provincial level, within the Ministry of Health, you don't have a climate change office there like you have a climate change office in the Ministry of Environment. But you don't have one in the Ministry of Health. You do have someone who is at the manager level but has very little staff to work on this topic. So, whether it is the local level or provincial level, you don't have a lot of resources that are being dedicated to this." [PH participant]

In spite of the challenges, the public health professionals have sought to increase their visibility in climate change policies through information sharing and translation initiatives (boundary processes) and advocacy to support the uptake of public health information in a manner that is relevant to both policymakers and public. The initiatives have included research, simplifying health needs to stakeholders, education and awareness, and building and integrating 
public health evidence into municipal plans. These initiatives are highlighted in Table 13: Public health capacities and boundary processes below.

Table 13: Public health capacities and boundary processes

\begin{tabular}{|c|c|}
\hline Activity & Sample quote \\
\hline Research & $\begin{array}{l}\text { "Our team researched the climate change implications related to health, and } \\
\text { we also did environmental scans of other policies...we looked at other } \\
\text { official plans and how they had worded climate change actions. So, for } \\
\text { example, one of the policies, that is, in [redacted] official plan is that the } \\
\text { community should be designed to reduce vehicle emissions, both for the air } \\
\text { quality benefits and for the GHG reduction benefits. So, researching and } \\
\text { developing policy, certainly, was one of the roles of public health." [PH } \\
\text { participant] }\end{array}$ \\
\hline $\begin{array}{l}\text { Communicating } \\
\text { in a manner that } \\
\text { resonates with } \\
\text { stakeholders }\end{array}$ & $\begin{array}{l}\text { "Well, I have been working on this file long enough that there have been } \\
\text { times when we can't use the term climate change. And so we have used all } \\
\text { kinds of euphemisms to get around it. We have also moved back and forth } \\
\text { between climate change and air quality, depending on the government at } \\
\text { the time because nobody is going to argue that breathing in poor air is not } \\
\text { good for our health. And so, as I said early on that, there is win-win with air } \\
\text { quality and climate change and so, if we are not resonating with the } \\
\text { audience on the topic of climate change then we can move to air quality and } \\
\text { achieve the same goal but using different terminology and, I mean, I am not } \\
\text { so tied to the ideology. To me, as long as we get to where we want to get } \\
\text { to, I don't care if I am talking about climate change or if I am talking air } \\
\text { quality. So there is that opportunity. We have also marketed or packaged- } \\
\text { and we being the [redacted] have packaged climate change initiatives } \\
\text { around sustainability, and greening, and those kinds of things. And so, if you } \\
\text { get too tied to global warming or climate change or those kinds of terms, you } \\
\text { can actually do yourself a de-service. It's having an end goal in mind and } \\
\text { then taking different channels to get there is what is really needed." [PH } \\
\text { participant] }\end{array}$ \\
\hline $\begin{array}{l}\text { Educating and } \\
\text { raising } \\
\text { awareness }\end{array}$ & $\begin{array}{l}\text { "There is a general consensus that the public doesn't see the urgency of } \\
\text { climate change action because they are not seeing how it's linked to human } \\
\text { health. So this campaign is about getting people to understand the link - } \\
\text { whether it's Lyme disease and climate change, extreme heat...those may } \\
\text { be the easier ones, but even things like asthma - understand that there could } \\
\text { be more into symptoms of asthma because of poor air quality, maybe } \\
\text { because of forest fires or because of climate change or more pollen } \\
\text { production....I think it is so important to raise awareness...because if the } \\
\text { provincial government is not going to address climate change, then no one } \\
\text { is going to hear about it because the public is going to think it's something } \\
\text { we don't have to act on or act on so urgently." [PH participant] }\end{array}$ \\
\hline $\begin{array}{l}\text { Information } \\
\text { provision }\end{array}$ & $\begin{array}{l}\text { "We just had some information for them [MOHLTC] because the ministry } \\
\text { [MOHLTC] was working on that when we were starting our assessment as } \\
\text { well because we had identified climate change as an urgent public health } \\
\text { issue back in [redacted]." [PH participant] }\end{array}$ \\
\hline $\begin{array}{l}\text { Integrating } \\
\text { public health- }\end{array}$ & $\begin{array}{l}\text { "We are fortunate to be part of a regional government. We have had the } \\
\text { opportunity to work with our planning department. So we have actually }\end{array}$ \\
\hline
\end{tabular}




\begin{tabular}{|l|l|}
\hline $\begin{array}{l}\text { related evidence } \\
\text { into regional } \\
\text { plans }\end{array}$ & $\begin{array}{l}\text { drafted policies that are in the official regional plan around climate change } \\
\text { and not only linked them to air quality but many health impacts. And we have } \\
\text { also had an opportunity to comment on other regional documents like } \\
\text { [redacted] plans, and our team would look at the environmental health } \\
\text { benefits of climate actions and would work with our public health partners } \\
\text { that work in chronic disease prevention, and maybe a focus of increasing } \\
\text { physical activity......I mentioned that transportation master plans at } \\
\text { [redacted], and there is a section in there on climate change, so we worked } \\
\text { with them on it." [PH participant] }\end{array}$ \\
\hline
\end{tabular}

In addition to the dominant role in adaptation, advocacy emerged as a major role of public health capacity in climate change. Public health has publicly supported or recommended policies and built consensus through committees and working groups within their jurisdictions, across other PHUs, and with other NGOs. A prominent NGO being the OPHA climate change workgroup and others, as discussed in Chapter 9 (Institutional Engagements). Various areas of advocacy roles included health promotion $(n=10)$, highlighting health co-benefits $(n=6)$, and emergency management and preparedness $(n=6)$. Some participants $(n=3)$ also acknowledged that while public health has engaged in various climate change policies, these programs have not been recognized as climate change policies. For instance, this participant provided examples where health programs have targeted climate change impacts even though they have not been labelled as such.

"So, climate change has been on the radar of public health for quite a while. And we have done, you know, shade and sunscreen programs that are about cancer prevention that are also connected to climate change. But they are really about cancer prevention. We have also done some work around food security and acknowledge climate change role, but we have never in the past, that I know of, really been given the lens of climate change as a way to organize the thinking of health program delivery." [PH participant]

As the participant mentions, this could be due to the lack of the historical acknowledgement of public health's role and mandate in climate change by other sectors or the lack of the health sector's ability to embrace its role in climate change.

\subsubsection{Surveillance as an Approach to Gathering and Disseminating Evidence}

Surveillance emerged as a major component of public health's population assessment initiative (as reported by all $\mathrm{PH}$ participants). To respond to public health needs, health units conducted surveillance to understand the needs, trends, risks within their jurisdictions, and priority populations. The dominant surveillance activities by PHUs related to those defined in Ontario's toolkit as many of the reported surveillance activities were mainly in line with those defined in the toolkit. The three most reported surveillance activities were actively conducting vectorborne 
disease surveillance (Lyme disease and WNV) $(n=10)$ and population assessments associated with extreme heat $(n=11)$ and UV $(n=5)$ exposure.

Through surveillance systems, the health units integrated some climate data, when present, to support population health assessments of vectorborne diseases, air quality, and extreme events impacts, as illustrated below.

"Under the Ontario public health standards, surveillance is one of the foundational standards, and so every 10 years our health unit does a snapshot, if you will, of the state of the health of the region...there is a whole big section in it around climate change, and so we have gone into the data and ... we went back retrospectively and looked and certainly, we see a signal that the climate is changing in [name of PHU removed]. We see our temperature has gone up. We see the differences in the mean and the maximum and minimum temperatures. We see changes over time in precipitation and so forth, all those sorts of things. We also looked... at our health data and so you can see trends in things like Lyme disease and you know, in 2006, we did not have Lyme disease in (name of PHU removed) and now [redacted] will be declared a Lyme disease risk area next year and we seeing a Lyme activity in [redacted]. So you can see the trend or the change over time for diseases like that. But we also looked at things like emergency room visits and hospital admissions and those kinds of stuff. And you can see it varies from year to year for things like extreme weather events and so on, but there is an upward trend. More people are going to hospitals...the mortality still remains slow, but morbidity, there is a small signal going on there. And so with that comprehensive status report, it covers all aspects that the health unit is responsible for - so things like mental health, infectious diseases, communicable diseases, and all those kind of stuff, but all that data is put together, and then it informs our strategic plan - what we are going to put resources forward for to tackle in the next ten years." [PH participant]

"We were able to look at things like, not only the temperature increases but also looking at things like icing days and frost days and tropical nights. So it gave us the ability to really see what some of the health impacts could be as our climate is changing. So, for example, tropical nights are nights where the temperature does not go below $20^{\circ} \mathrm{C}$. So we know that there can be increased health impacts when the temperature doesn't get lower during the evenings. So we saw a major increase of that for our region, and so, it was a challenge but also an opportunity for us because once we were able to have a bit of orientation and get our minds wrapped around what this data meant, it really helped us to give a full picture of what potential health impacts could be from a heat-health perspective all the way down to an injury prevention perspective, of you know, the amount of icing days, whether it could be ice on the roads or sidewalks or those sought of things." [PH participant]

The recent extreme heat events in the summer of 2018 was a good example of the need for better information capture to support the surveillance and reporting of climate-related health impacts. Several participants $(n=6)$ reported that Ontario and Quebec experienced some of the worst episodes of extreme heat events in the summer of 2018 that lead to over 100 deaths, mostly elderly. Although such deaths relatively occurred at the same time, Quebec reported its mortalities as they happened while Ontario's data were reported several months after the incidences. 
"I remember in the news they were talking about the number of people that had died in Montreal because of that extreme event, and I thought, how come they are not mentioning anybody that has died in Ontario? Later on, I heard, and I knew this already because there are lots of webinars about what they are doing in Quebec. But it is because Quebec has such a great surveillance system. They were monitoring, and I guess for surveillance, maybe it's hospitalization, but they track so much more information about deaths and the syndromic surveillance that they do. So we could have many more than they had in Quebec, but you did not hear about that in the news because it is not being tracked. So, all people are hearing about is that so many people died in Montreal. Well, is it hotter there? A lot of them were a man living alone, or it could have been homeless or others. But, is it because of that or that we are not tracking it that well? I think it is so important to raise awareness about the work that we are doing because if the provincial government is not going to address climate change, then no one is going to hear about it because the public is going to think it's something we don't have to act on or act on so urgently." [PH participant]

The discrepancies in reporting extreme heat-related deaths could be attributed to Ontario's current surveillance system for extreme heat events, as explained by this participant.

"So I think there were two key things. One, I think there were more deaths in Quebec, but still, in Ontario, the number was zero. We knew that people were dying, but why are the numbers zero? So, it is the way data is captured in Ontario. And the way the data is captured is that heat in vulnerable groups would lead to other health issues. So, it would lead to cardiac arrest and so on. So when that death was captured, it was captured as a cardiac arrest, but heat was not captured. So that is one of the challenges. It is how we are getting data, and that is a gap. So I think we will try to address that and public health units have a key role in doing that. For example, in-home and community care, when they go and do an assessment for elderly folks who are living in the home or staying in the home, that data set captures them as a vulnerable group and then identifies them as vulnerable to heat, for example. May be public health units, if they are able to get better access to data, we can sort of make those connections early on and identify those groups and do more outreach and awareness initiatives and preventative measures. Maybe have more cooling centres and work along with the landlords and buildings and areas where vulnerable groups are living. You know, just really finding ways to raise awareness and address that earlier on before the impacts come into play." [PH participant]

Currently, public health initiatives for addressing extreme events included information provision, public education, ensuring the provision of cooling centres during extreme heat events, and coordinating with the MECP to call for heat warning advisories.

Surveillance of food security and water safety and security influences were not reported. Climate change-specific social and equity-related impacts also were minimally reported by public health participants or considered by PHUs and the MOHLTC. For example, the response received, while reaching out to respondents within the MOHLTC affiliated with the health equity policies, indicated a lack of mandate on equity and climate change (that is, the work conducted by the section was not related to climate change) and a lack of awareness of climate change policies (as a reason for declining interview participation). However, a $\mathrm{PH}$ participant pointed out 
that socio-economic and equity impacts have emerged on vulnerability assessments and have been flagged, but policies addressing such impacts have not been identified (yet). The minimal application of socioeconomic and equity lenses within public health does not necessarily mean that public health does not consider equity in their programs. As this participant suggests, these lenses are widely applied in various public health programs, but not prominently in climate change issues.

"I will be honest with you; in this area [Climate change decisions], we are on a learning curve. And so with our vulnerability assessment, it came through that climate change is a threat multiplier. And so if you are already in a low socio-economic status, have an underlying health issue, and so on and so forth, you are much more at risk for climate change than for someone who is, let's say, is healthy and has a higher socioeconomic status or have a stronger social network. And so we have flagged this, and we are still trying to wrap our head around what it is going to look like. It is something that we have had discussions around the table about how do we handle this? What do we do with it? And I am not sure we have the full answer at this stage of the game. And certainly, with the health equity pieces, I know within our own health department, we have people who are tasked with looking at equity and what does applying health equity lens across all their programs look like. And we have had several discussions about climate change back and forth, but to say that we have got a solution at this point, we are not there yet. We are still very much in the discussion phase." [PH participant]

To support future surveillance activities, a participant reported that a comprehensive population assessment is currently underway by $\mathrm{PHO}$ in collaboration with other NGOs such as the Canadian Urban Environmental Health Research Consortium (CANUE). This collaborative assessment is likely to provide a better picture of the burden of environmental factors, including climate change.

"I know PHO released a report on the environmental burden of cancer, two or three years ago,....that was great, and now they are working on the environmental burden of everything else. So anything that is not cancer endpoint. But that will take them so many years to do because there are so many different contaminants in the environment that they have to consider. And there are also so many health points that they have to consider... I don't know if it is going to be released this year or next year, but I think if we really looked at all the burden of illness in total and all the risk factors, I think that's all we need... but they are looking at pulling data together on environmental exposures, health outcomes, the built environment, and about five different layers that they are looking at and it might take 5 to 10 years to come up with this detailed map. I think it is going to be an eye-opener for a lot of people to show, oh, this is really a significant burden. So, I think about some of the infectious diseases that people get alarmed about, and rightly so, but that's not where the burden of illness is. If there is meningitis that people are up and arm and very nervous about it because they are not used to that or like the cases of Lyme diseases. It's important that we address Lyme disease, but that isn't the top burden of illness. Look at how many people died from extreme heat events that we had in July." [PH participant] 


\subsection{SUMMARY}

Overall, the government has developed tools, protocols, guidelines and frameworks guiding public health capacity in climate change. However, there is a divergent focus between public health and the provincial government. The focus on adaptation has led to the selection of climate change decision-making structures focused on-, and salience of, identities associated with building adaptive capacities. The public health's focus has led to the lack of public health engagement in provincial climate change policies and the lack of accompanying resources (financial, skills and information) necessary for facilitating such roles. Furthermore, the underlying assumption that public health does not have a role in climate change mitigation has resulted in several three influences. The misalignment of policy initiatives. The social differences on how each group identify with climate change policies; and, the influence of the historical representation of climate change decisions which have predominantly been associated with NPH sector. As a result, there are assumptions on the meanings and roles of public health, meaning that public health is less likely to be included in most climate change decisionmaking and the participatory and deliberative processes. This not only has a huge impact on the underlying focus of climate change policies - i.e. domination of economic and technological frames that advance mitigation to climate change - and the experts, it has huge implication of public health capacity in climate change discourse. As a result, the chapter portrays the various challenges arising from public health's institutional arrangements, structures, and style of governance in climate change including the impacts of lack of leadership at the provincial level of public health, structures for public health program implementation, and resources targeting public health decisions such as funding, information and skills. However, public health has committed to addressing climate change through surveillance activities, vulnerability and adaptation assessments, advocating for healthy climate change policies and boundary processes that have supported the mainstreaming of public health needs in municipal policies, and the provision of information and evidence. 


\section{CHAPTER 9: INSTITUTIONAL ENGAGEMENTS}

\section{INTRODUCTION}

Based on Lomas Model, institutional engagement is a significant component of building institutional capacities, exchanging knowledge and deliberating on climate change policies (Lomas, 2000; Lomas et al., 2005). The purpose of this chapter to answer research questions 2 and 3 by exploring the influences of institutional engagements in the participation and deliberation and forwarding public health needs in the climate change policy discourse.

Section 9.1 reports on the engagement activities between the provincial and public health agencies.

Section 9.2 presents the contexts of institutional engagements and elaborates on the various influences and opportunities for public health participation, cohesion, inclusion, and integration, including identification of predominant influences, means for promoting mutual understanding, and ways of acquiring resources for building relationships across organizations. Themes reported included the influences of collaborative settings, impacts of processes and structures within and across organizations and the establishment of communication channels for advancing engagement needs

Section 9.3 discusses the impacts that such inter-organizational engagements have presented to the advancement of public health capacity in climate change.

\section{$9.1 \quad$ FOSTERING INSTITUTIONAL ENGAGEMENTS}

Partnerships on climate change policies occurred within and across institutions. Institutional engagements, although divergent between the two groups, were supported by clear goals and objectives. Within the NPH group, the participants $(n=11)$ reported a shared goal to advance institutional mandates and interests. Such engagements were also uneven and paid very little to no attention to public health stakeholders.

$\mathrm{PH}$ group reported collaborating with those within and outside the area (or sector) of public health. Within the mandated agents, partnerships were fostered between ministries mandated with climate change actions with little to no involvement of other stakeholders. On the other hand, within the public health agencies, there were partnerships between PHUs, as well as with federal and provincial ministries and agencies, NGOs and communities. 
Within the NPH agencies, there was an emphasis on engagement with stakeholders within similar areas or sectors. No direct collaborations were reported between the agencies and the Premier's office. However, participants $(n=8)$ indicated that such office was represented by the cabinet ministers in their roles within the specific ministries. Table 14: Summary of stakeholder collaboration reported provides an overview of stakeholder as reported by both groups.

\section{Table 14: Summary of stakeholder collaboration reported}

\begin{tabular}{|l|l|l|}
\hline Collaborated with & NPH (n=13) & PH (n=11) \\
\hline Mandated ministries & 13 & 4 \\
\hline Non-mandated ministries (excluding MOHLTC) & 3 & 0 \\
\hline MOHLTC & 2 & 6 \\
\hline PHUs & 0 & 9 \\
\hline Federal Government & 3 & 8 \\
\hline Municipal Government & 2 & 7 \\
\hline Communities & 0 & 4 \\
\hline Non-Governmental Organizations & 3 & 5 \\
\hline Health Agencies (other than PHU) & 0 & 6 \\
\hline Academia & 2 & 4 \\
\hline Corporations & 11 & 0 \\
\hline
\end{tabular}

The NPH group reported having collaborated extensively with each other at the provincial level. The agencies always connected and deliberated with the MECP, which was referenced as the lead agency on climate change issues. The nature of these engagements was mostly formal, arising from the legal obligations and mandates to consult between the ministries on the various climate change initiatives. Corporations were also significantly engaged in climate change policies. Other stakeholders were largely not included in the climate change engagements.

Unlike the NPH participants, the PH participants reported extensive engagements within and across public health systems, programs, and professional groups. At the local public health level, agencies focused on networking and building relationships within communities, with other health agencies and NGOs, and with municipal partners. Partnerships were also reported across PHUs, with the MOHLTC and NGOs, federal government, and municipalities. There were also some efforts of reaching out or consulting with the ministries mandated on climate change actions. Engagements between PHUs and the MOHLTC were mainly associated with the modernization of the public health standards which led to the inclusion of climate change needs in the protocols, the $V$ and $A$ assessment and harmonized heat alert guidelines. The role of the federal government in public health capacities was very prominent. The PHU participants and the MOHLTC both reported engaging the federal government and/or receiving funding to support public healthrelated climate change initiatives. Three federal government institutions named included Health 
Canada $(n=7)$, Environment and Climate Change Canada $(n=3)$, and Natural Resources Canada $(n=1)$. There was also reported engagement with communities within PHU jurisdiction and public health as well as non-public health affiliated environmental organizations. Some of the NGOs mentioned included organizations such Ontario Public Health Association (OPHA), Canadian Institute of Public Health Inspectors (CIPHI), Registered Nurse Association of Ontario, health groups supporting asthma and lung diseases, Canadian Association of Physicians for the Environment (CAPE), Association of Public Health Epidemiologists in Ontario (APHEO), ASPHIO, Canadian Environmental Law Association, Environmental Defense, Canadian Partnership for Children's health and the Environment, Ecohealth, Transportation Association Canada, CANUE, Alliance for the Clean Economy, Ontario Professional Planners Institute, Conservation Ontario, Forest Ontario and Clean Air Partnership, and Centre for Urban Health Solutions. About 36\% (4 of 11) of the PH participants reported working with mandated ministries. However, such efforts did not seem reciprocal as many NPH organizations did not report engaging with public health.

While there was a significant engagement between the PHUs, some participants noted that there should be a need to reach out to smaller health units as well.

"I think there also needs to be more collaborations amongst health units. I see that within the GTA [Greater Toronto Area] health units, they work very closely together: Peel, York, Halton, Toronto. I think they work really close together. But I think health units need to sort of reach out to other smaller health units and collaborate a little bit more. I think that would help as well." [PH participant]

\section{$9.2 \quad$ INFLUENCES ON INSTITUTIONAL ENGAGEMENTS}

Institutional impacts included influences of collaborative settings, impacts of processes and structures within and across organizations and the establishment of communication channels for advancing engagement needs.

\subsubsection{Influences of Collaborative Settings}

\subsubsection{Accessing stakeholders and historical contexts}

The structures for identifying stakeholders varied between the two groups. Some participants reported having strategic frameworks for stakeholder identification, while others did not. However, only public health actors $(n=8)$ provided detailed strategic frameworks for stakeholder identification; these included utilization of laid out protocols, guidelines, and workgroups, whose role includes identifying stakeholders for engagement.

The NPH actors mainly referenced bureaucratic structures $(n=9)$, the use of the environmental registry as the main tool for stakeholder identification $(n=11)$, and using 
institutionalized stakeholders $(n=5)$. NPH actors also reported identifying stakeholders based on previous projects or deliberations $(n=8)$ and political directions $(n=6)$. Structures reported by NPH are presented in Table 15: Structures for stakeholder identification below, as reported by NPH group.

Table 15: Structures for stakeholder identification

\begin{tabular}{|c|c|}
\hline $\begin{array}{l}\text { How } \\
\text { stakeholders are } \\
\text { identified }\end{array}$ & Sample quote \\
\hline $\begin{array}{l}\text { Strategic } \\
\text { frameworks }\end{array}$ & $\begin{array}{l}\text { "In our organization, we have a policy development framework that we apply } \\
\text { more broadly, I guess, it's not specific to climate change but we would look } \\
\text { to that for basically any issue that we tackle. So the framework suggests } \\
\text { broad categories of stakeholders that one would look to, and then, I think } \\
\text { the other thing is that because we have been working in this area for a long } \\
\text { time, we also have familiarity with a lot of the stakeholders who are routinely } \\
\text { or actively engaged on this, so then what we have to do is kind of take a } \\
\text { step back and think whether there are stakeholders who are kind of not the } \\
\text { usual suspects that we need to think about." [PH participant] }\end{array}$ \\
\hline Bur & $\begin{array}{l}\text { "More specific issue is the bureaucracy itself. And ministry always has, sort } \\
\text { of, known stakeholders. Like people or specific organizations that they have } \\
\text { reached to before, that would typically be .... anyone who would write to the } \\
\text { minister. Generally, there is a tradition in Ontario that people who contact } \\
\text { the Minister might have an opportunity to talk directly to the political level } \\
\text { about a topic. So, in theory, there are people and organizations who have } \\
\text { the opportunity to meet with the politicians to talk about climate change, for } \\
\text { example. And then there are also organizations with whom the } \\
\text { administration might need informally to understand more about what actors } \\
\text { are working on out there, and how the government policy design might } \\
\text { leverage and work with what's already happening. For example, on climate } \\
\text { change information, we were very aware of not getting in the way of } \\
\text { organization that makes it their business to translate climate change data, } \\
\text { and instead, designing a government program that would build on the } \\
\text { activities already taking place in municipalities and private sector." [NPH } \\
\text { participant] }\end{array}$ \\
\hline $\begin{array}{l}\text { Environn } \\
\text { registry }\end{array}$ & $\begin{array}{l}\text { "In terms of structure to identify stakeholders in Ontario, it really is the } \\
\text { Environmental Registry that is used to identify number of stakeholders and } \\
\text { to understand the public need and the challenges and gaps that might be } \\
\text { important when designing a new environmental policy." [NPH participant] }\end{array}$ \\
\hline $\begin{array}{l}\text { Internalized } \\
\text { stakeholders }\end{array}$ & $\begin{array}{l}\text { "I mean some of them (stakeholders) just become internalized, and people } \\
\text { go on" [NPH participant] } \\
\text { "At the end of the day, every ministry has their share of stakeholders who } \\
\text { they put at the forefront." [NPH participant] } \\
\text { "We have those stakeholders that we have worked with on other climate } \\
\text { change decision processes, and we turn to them when similar platforms } \\
\text { arise." [NPH participant] }\end{array}$ \\
\hline
\end{tabular}




\begin{tabular}{|l|l|}
\hline $\begin{array}{l}\text { Political } \\
\text { direction }\end{array}$ & $\begin{array}{l}\text { "They [the government] would give the political level some direction, } \\
\text { always." [NPH participant] }\end{array}$ \\
\hline $\begin{array}{l}\text { Approach the } \\
\text { MOHLTC }\end{array}$ & $\begin{array}{l}\text { "I think if we were looking for specific public health stakeholders or health } \\
\text { stakeholders, we would go to the Ministry of Health for their thoughts. " [NPH } \\
\text { participant] }\end{array}$ \\
\hline $\begin{array}{l}\text { Historical } \\
\text { contexts }\end{array}$ & $\begin{array}{l}\text { "The ministry has demonstrated long-term collaborative work with partners } \\
\text { across ministries who engage in climate change. These collaborations did } \\
\text { not begin with climate change, but we have also engaged in other projects } \\
\text { that impact the environment in general. And so whenever something new } \\
\text { comes up, like climate change, for example, we have these people, from } \\
\text { ministries, that we are already working with and who we know their } \\
\text { expertise... I think it makes it easier that way, rather than finding new } \\
\text { partners to work with." [NPH participant] }\end{array}$ \\
\hline
\end{tabular}

The history of collaboration was a major determinant of future collaborations. This was most evident within the $\mathrm{PH}$ group, where most participants $(n=7)$ referred to historical contexts as ways of identifying stakeholders, as narrated by this participant.

"We engage the stakeholders that we have historically worked with in the past. We have built these relationships across various communities because we tend to work a lot with community partners. So we will have a list of people that we know would support certain pieces of work we do. So we would historically connect with them." [NPH participant]

However, some NPH participants $(n=4)$ also reported the influence of historical contexts in determining future collaborations.

"The ministry has demonstrated long-term collaborative work with partners across ministries who engage in climate change. These collaborations did not begin with climate change, but we have also engaged in other projects that impact the environment in general. And so whenever something new comes up, like climate change, for example, we have these people, from ministries, that we are already working with and who we know their expertise... I think it makes it easier that way, rather than finding new partners to work with." [NPH participant]

Where historical influences were presented by participants emphasized the influence of mutual goals in such engagements. On the other hand, the $\mathrm{PH}$ group highlighted inter-PHU and NGO collaborations that have led to opportunities for advocating for, engaging in, and funding of, some climate change initiatives at the local PHU levels. Although, several PH participants $(n=4)$ reported the need to address funding issues with collaborators as financial resource was reported as a deterrent or limit to public health collaborations.

\subsubsection{Leadership in collaborations.}

The MECP played a key role in climate change initiatives and was seen as a leading organization in climate change frameworks in Ontario, especially in the NPH sector. The ministry also led the planning for collaborations and coordination across various sectors and stakeholders. 
"The Ministry of Environment leads climate change policies. We generally collaborate with them on our policies and seek their advice on the formulation and implementation of our policies. But, sometimes, the ministry [MECP] would request that certain specific ideas be incorporated in what we are doing." [NPH participant]

Because of the ministry's leadership, the $\mathrm{PH}$ participants reported some levels of engagement with the MECP despite the limited engagements between the public health sector and climate change agencies. However, some NPH participants $(n=5)$ mentioned that the lack of collaborations between the public health sector and other ministries was because the lead ministry (MECP) has not steered such collaborative efforts or that it was the role of the MOHLTC to advance such engagement needs.

"Those we work with are mainly determined by the MOECC [MECP]. So far, I have not received an indication. I think if you believe that public health needs to be included in [redacted] then maybe that has to come from the ministry [MECP] or even the mandate letters that give directions to the top bureaucrats." [NPH participant]

Even though some NPH participants mention including the ministry of health when public health issues arise, only one concrete example was provided across 13 participants. This related to the inclusion of public health stakeholders in an advisory committee for a disease outbreak to support the management of the outbreak. Such inclusion only occurred after a health impact had been realized instead of collaborating with public health for upstream preventative strategies. However, another example provided portrayed a transfer of responsibilities to public health for modifications instead of working together on the issue to gain consensus. In some instances, hypothetical scenarios of partnerships that would occur should a public health issue arise were provided, as demonstrated below.

"No, I don't think there is like a specific topic health perspective. It is like...that's really the responsibility of the ministry of health. Public health is their mandate. So it's up to them to ask other ministries to consider public health. Public health considerations, in general, is affected by other ministries or other areas of policy. Like as I said before, bigger policies are worked through with other ministries, so if we were to propose something and there could be a public health implication, then we would loop in the ministry of health." [NPH participant]

Within public health, the lack of MOHLTC's leadership in advancing public health engagements, as has previously emerged in the lack of leadership in mainstreaming public health needs (see Chapter 8 Leadership and BOH Jurisdictions) was evident it also emerged and discussed

They [MOHLTC] really look to the Ministry of Environment to take that leadership. And then within the Ministry of Environment, you know, they didn't see health people as their main stakeholders. Amongst the community organizations, the non-profit organizations, there is a lot of openness and interests and willingness to collaborate." [PH participant] 


\subsubsection{Political influences.}

Political interests influenced how and who collaborated. While collaboration was high in the government's agenda, these focused on specific structures, outcomes, and expertise. The document analysis revealed government funding to support collaborations within technological companies that supported technical climate change solutions. The prominence of political influences on organizational collaboration practices was also evident during the interviews as well. The political and administrative systems minimized the inclusion of other actors by enabling committees made up of mandated organizations only. Further, climate change policy processes were reported by the NPH group $(n=9)$ to rely heavily on political influences that both facilitated and constrained institutional engagements. The structures and processes mainly facilitated the engagement of mandated organizations $(n=8)$, positioning them with authority and control $(n=3)$, and determining who is included or excluded from participating in climate change frameworks $(n=6)$. As this participant explains, even when public health's role is acknowledged, the influence of politics determines who takes part in the policy processes.

"I know that public health can play a role in climate change policies. But as much as I recognize that, the work that we do, and the people that we collaborate with are sometimes determined by political structures, to some degree. We really don't have an influence on who we collaborate with in climate change policies. Our mandate, for example, and these are mandates that generally come from the Premier's office, specifies that we work with certain ministries and sectors and so we generally make a point to either directly or indirectly connect with such organizations. So, again, it is politics. Yes, I may have an area where I would like to work with public health in our policies, but our resources and actions are tied to certain actors and not necessarily to public health. Politics basically dictate the direction." [NPH participant]

The political influences and preferences may have acted as barriers to public health inclusion as the organizations set goals that aligned with political requirements and preferences as further supported by this quote.

"When you are in policy development, unlike program delivery and operations in government, you very much are waiting to see the mandate of the incoming government so that you can define a policy that responds to, or at least provide options that align with, their approach to things...to their political preferences." [NPH participant]

Political influences impacting collaborations also aligned with the framing of climate change discourse.

"Sometimes it [collaboration] depends on the political direction and based on my observations over time, what the government emphasizes, be it an election promise or directives to incoming ministers or a new climate change plan, those kind of determine who they want to be included in the policy deliberations and we have always tried to do that". Although I would say it depends on the scope of the policy." [NPH participant] 
Stakeholder engagement initiatives were also directed by political figures. While explaining why the Environmental Registry postings occurred, this participant points to the political and committee influence.

"We would do normal due diligence where we would get a request from the policy committees, political leaders, that you go out and do public consultation or some form of public engagement on your proposal." [NPH participant]

While this participant alludes public consultation, such consultations were limited to postings and not any face to face or two-way consultations techniques where members of the public and agency discussed the policies and got clarification on concerns or clarity on issues. The use of Environmental Registry is discussed further in several sections in this chapter.

\subsubsection{Impact of Organizational Process and Structure}

In Ontario, institutional engagements were influenced by layers of decision-making structures and alignment with policy mandates or objectives.

\subsubsection{Fragmented engagements}

Within and across the PH and NPH agencies, policy silos existed, as already explained in Chapters 7 and 8. Thus, each group worked separately, guided by different policy objectives. Fragmented engagement approach was also blamed on the status quo ("this is how we have always done it"). Participants also linked the piecemeal engagement approaches to historical relationships and organizational structures or cultures that limited broader stakeholder engagements and partnerships. Despite the extent of cross-ministerial collaborations, a dominant silo approach to policy engagements between NPH and PH organizations was reported by nearly all participants from both groups $(n=21)$. For instance, within the NPH group, the topic of inclusion of a public health agency or the MOHLTC did not come up in the conversations unless prompted. It was surprising that only two participants acknowledged engaging with a public health organization. However, as already identified in an earlier example where public health was included (that is after a disease outbreak), this second citation of collaboration follows a similar pattern. The public health engagement was not initiated by the agency but rather a suggestion from other non-policy stakeholders when an issue impeding a proposed policy was identified.

"[Redacted].... we ended up contacting the Ministry of Health to find the area that dealt with that topic. We had talked to them and said, what can happen? How can this be adjusted? So that was the discussion. And with health, it was more making the connections and seeing what the interest is in moving forward. So we didn't have the knowledge or mandate to address that topic. So we wouldn't necessarily be involved in the development of their [MOHLTC] new guideline. What we have done is made the connection and shown there is a concern and got their buy-in as a ministry. We have offered, and it looks like it's 
something that I'll still be involved in to review material to say, from our ministry's perspective, here is where things work or there may need to be a couple of modifications." [NPH participant]

However, this quote also highlights the lack of public health engagement in areas that are clearly part of their mandate, as identified by the participant. But it also highlights two other influences on public health engagement in climate change decisions. One, even when public health's role is identified, this role is instead trivialized, and public health's compromise is sought instead of working collaboratively to achieve solutions to climate change (e.g. "buy-in" and need for public health to make modifications to a framework because it does not suit the ministries action). Two, while this participant identifies the role that public health plays in their climate change framework, they did not seek public health collaborating to develop the said framework, but instead, they offer to review the framework for modifications. This highlights the disconnect and influence of silos in Ontario's government policies, as has already been identified in the previous chapter, and their subsequent impact on institutional engagements. This was also evident in other interviews with the NPH group. For instance, when asked if they have included public health in their policy frameworks, $69 \%(n=9)$ of the NPH responses suggested a transfer of responsibilities to public health instead of collaboration if a potential public health issue is identified.

During the interview with the NPH group, the topic of public health as a stakeholder only emerged with additional probes. That is, the participants failed to mention public health as one of the stakeholders or collaborators, resulting in follow-up questions that specifically asked if they had worked with public agency or body in any of the climate change decisions. It is in such probes that few NPH participants $(n=8)$ acknowledged public health implications and the relevance of public health in their policies or having worked with public health agencies prior to their current role. Still, such acknowledgements did not result in information suggesting substantive collaborations with public health. In turn, collaborations were mainly confined within the organizational sections and across ministries mandated with climate change actions with less inclusion of public health organizations. The lack of public health inclusion by mandated ministries is acknowledged by $\mathrm{PH}$ participants $(n=6)$. A concrete example is illustrated by the quote below.

"For example, there is work that has been done relating to active transportation. There is the ministry of transportation. And, do they connect with the ministry of health related to the health impacts of transportation? No!" [PH participant]

When inquiring about the reason for lack of collaboration, several responses were identified from NPH participants. Many participants believed it was the role of public health agencies to reach out to other ministries for collaboration. Others suggested that the agency's area of focus did not have a public health perspective or align with public health needs. Still, others did not see the role 
of public health in their policies. Alternatively, when a public health issue is identified, the NPH participants reported that such issues would instead be transferred to public health instead of collaborations. These attributes, responses, and sample quotes are summarized in Table 16: Contexts of collaboration.

Table 16: Contexts of collaboration

\begin{tabular}{|c|c|c|}
\hline Attribute & $\begin{array}{l}\text { No. of } \\
\text { Responses }\end{array}$ & Sample quotes \\
\hline $\begin{array}{l}\text { Would } \\
\text { collaborate only } \\
\text { when public } \\
\text { health reached } \\
\text { out }\end{array}$ & $\mathrm{n}=7$ & $\begin{array}{l}\text { "I think if public health approached us for inclusion in one of } \\
\text { our processes for climate change, we would consider such } \\
\text { partnerships. Maybe they just need to explain to us a little bit } \\
\text { more of how their involvement will benefit or complement } \\
\text { what we are currently doing." [NPH participant] }\end{array}$ \\
\hline $\begin{array}{l}\text { Would } \\
\text { collaborate only } \\
\text { on known areas } \\
\text { of public health } \\
\text { or a public health } \\
\text { issue is identified }\end{array}$ & $\mathrm{n}=8$ & $\begin{array}{l}\text { "I believe we would collaborate with public health if what we } \\
\text { are working on issues directly touched public health } \\
\text { mandates... such as those related to climate change and its } \\
\text { impact on diseases. But again, those are not the focus of our } \\
\text { policies. So it may be hard to say that, yes, I will include } \\
\text { public health." [NPH participant] }\end{array}$ \\
\hline $\begin{array}{l}\text { When } \mathrm{PH} \text { focus } \\
\text { is identified, the } \\
\text { issue is } \\
\text { transferred to } \mathrm{PH} \\
\text { instead of } \\
\text { collaborating }\end{array}$ & $\mathrm{n}=9$ & $\begin{array}{l}\text { "If there is a public health implication in this policy proposal, } \\
\text { we are going to move it to the public health people. Like I } \\
\text { think they have a public health division there." [NPH } \\
\text { participant] }\end{array}$ \\
\hline $\begin{array}{l}\text { Do not } \\
\text { collaborate with } \\
\text { PH at all }\end{array}$ & $\mathrm{n}=10$ & $\begin{array}{l}\text { "No, no involvement of public health agencies." [NPH } \\
\text { participant] }\end{array}$ \\
\hline $\begin{array}{l}\text { Public health is } \\
\text { responsible for } \\
\text { initiating } \\
\text { collaboration }\end{array}$ & $\mathrm{n}=8$ & $\begin{array}{l}\text { "No, I don't think there is like a specific topic health } \\
\text { perspective. It is like ..that's really the responsibility of the } \\
\text { ministry of health, public health is their mandate,...so it's up } \\
\text { to them to ask other ministries to consider public health." } \\
\text { [NPH participant] }\end{array}$ \\
\hline $\begin{array}{l}\text { Acknowledge } \\
\text { public health } \\
\text { relevance but do } \\
\text { not collaborate }\end{array}$ & $\mathrm{n}=6$ & $\begin{array}{l}\text { "I would say I've been asked what the public health } \\
\text { ramifications of some of our findings might be but to say that } \\
\text { I'm being inclusive, or including public health, I can't say that } \\
\text { we do that definitively, no." [NPH participant] }\end{array}$ \\
\hline $\begin{array}{l}\text { Do not see the } \\
\text { role of public } \\
\text { health in their } \\
\text { work }\end{array}$ & $\mathrm{N}=6$ & $\begin{array}{l}\text { "No, I don't think there is like a specific ... health } \\
\text { perspective." [NPH participant] } \\
\text { "I have not worked with public health or consulted public } \\
\text { health in any of the policies we developed. I don't think there } \\
\text { was any role that public health could have played in our } \\
\text { policies." [NPH participant] }\end{array}$ \\
\hline $\begin{array}{l}\text { Public health is } \\
\text { only a small } \\
\text { consideration of }\end{array}$ & $\mathrm{N}=6$ & $\begin{array}{l}\text { "We deal with broad climate change issues and when you } \\
\text { consider public health issues, it is only a small proportion of } \\
\text { what the climate change policies target. I think at this stage }\end{array}$ \\
\hline
\end{tabular}




\begin{tabular}{|l|l|l|}
\hline $\begin{array}{l}\text { the overall } \\
\text { policies }\end{array}$ & $\begin{array}{l}\text { in climate change policies, we can't target every little impact } \\
\text { that climate change poses...I mean, I don't think we are there } \\
\text { yet...I think that what current policies and decisions are } \\
\text { targeting are more broadly defined." [NPH participant] }\end{array}$ \\
\hline
\end{tabular}

Many members of the $\mathrm{PH}$ group did not understand why public health connections are not made.

"I actually find it difficult to understand why people have difficulty making these connections. But we have a role to play to help make them clear, and in particular, situations where there are multiple health benefits to taking action." [PH participant]

However, many in the $\mathrm{PH}$ group blamed the lack of elaborate engagement of public health on mandated agencies' decisions on institutional structures that have alienated public health $(n=9)$ and the lack of leadership from the MOHLTC $(n=9)$. The lack of public health engagement was also associated with the fact climate change was a new area of public health practice.

"So with respect to climate change, it has been minimal because, again, this is all new for us." [PH participant]

Conversely, a PH participants' responses also alluded to the lack of relevance of NPH actors in public health policies.

"For us, the sector is the public health sector. We also worked very closely with our key stakeholders. So, our key stakeholders would be the public health units, some of our key public health organizations like CIPHI APHEO, ASPHIO. We also work very closely with OPHA and members from the OPHA." [PH participant]

Even within the public health sector, fragmentation existed despite many reporting worked together. Some participants $(n=3)$ in the $\mathrm{PH}$ group reported experiencing isolation and lack of ability to connect with professionals who could help them meet their climate change policy needs (that is, the $V$ and $A$ assessment). A review of collaboration links revealed that such participants hardly collaborated with other health units or ministries in their climate change work.

\subsubsection{Strategic structures and processes}

Institutional engagements in climate change decisions relied heavily on processes and structures. Strategies existed at provincial and local levels for encouraging stakeholder engagements, mainly within and across institutions (especially for mandated ministries). The structures mentioned included committees (both within PH and NPH levels), professional groups (only mentioned by $\mathrm{PH}$ participants), internal and collaborative workgroups, and environmental registry (only used by NPH group).

The NPH group heavily relied on committees that comprised of the various ministries mandated with climate change with no representation from public health. 
"So we have a closer connection with the ministry of [redacted] and [redacted], we have close connection with [redacted], we have a close connection with [redacted] and with [redacted], but that is also just because there are government committees that have kind of, naturally, have slotted us together." [NPH participant]

Such committees facilitated deliberative and participative approaches to climate change decisionmaking resulting in collaborations between the ministries. Through the committees, the $\mathrm{NPH}$ participants acknowledged the considerable impacts such platforms made in shaping climate change policies and in consideration of relevant stakeholders engaged in decision-making processes. In turn, climate change institutional engagements were monopolized by politicians and bureaucrats. Policy stakeholders who did not belong to such mandated organizations and committees were not considered to play a meaningful role in climate change decision-making. The awareness of committee structures for collaboration within the ministries was acknowledged by the $\mathrm{Ph}$ group. For instance, these participants noted that climate change action committees in Ontario did not have representation from public health and that the presence of such committees presents hurdles to public health engagement in climate change.

"I know that the Ontario government had set up an advisory committee, but they did not have any health representative in their advisory committee to the minister. And I assume, you know, I don't know with this new government what is going to happen." [PH participant]

"Now I understand that the ministries do have some committees, or they did anyway in the previous government, the climate change committee that were cross-ministerial. But I don't even know if the ministry of health was part of that committee." [PH participant]

"We have been told that there are certain committees within the ministries who have a role in climate change. I believe the Ministry of Health is not a part of so it is really hard to know what they discuss there and whether there is a role we can play since we are never included in such discussions. I don't think we can ever move forward if our ministry [MOHLTC] does not engage in climate change. We expect directions from the ministry [MOHLTC] and if those engagements are not present, the role of public health is also very vague." [PH participant]

The committee structures have provided directions and focus or limited engagement. The participants highlighted how the mandated structures across the province had impacted levels of engagement in climate change policies, influencing relationships and requiring more efforts to reach out to non-mandated organizations.

"Yeah, we don't have those direct relationships necessarily with health organizations or with the organization's outside of governments." [NPH participant]

"We kind of have to make more of an effort to reach out to the kind of the health side or the community safety, those kinds of ministries. We are not necessarily on top of what they are doing all the time and vice versa because those regular channels of communication are not as built in as the ones we have with natural resources and 


\section{infrastructure side of things." [NPH participant]}

Within public health, the availability of structures and processes for engaging in climate change decisions were also evident. These included structures for engagements within the PHUs and between PHUs and MOHLTC, PHUs and municipalities, and PHUs and the various healthor environmentally-affiliated NGOs. For instance, the MOHLTC utilized committees, workgroups, and personal sessions to prepare PHUs for the new requirement of conducting $\mathrm{V}$ and $\mathrm{A}$ assessment. However, the formation of committees is the most predominant form of multistakeholder engagement structure in public health. Some forms of committees reported included advisory, steering, work-group, and technical committees. For instance, there were steering committees formed to lead and guide the development of climate change policy guidelines across the province. Internal committees within PHU were formed to address the $\mathrm{V}$ and $\mathrm{A}$ assessment processes. Technical committees were created to support the preparation of OPHS that also integrated the mandate of public health in climate change. Committees within the broader local contexts (i.e. within municipalities, regions or counties) were, in some instances, formed to integrate public health's role in climate change and facilitate PHUs work with other departments within the local governments such as planning, water, transportation, and emergency management departments. Within such committees, the main role of public health, as cited by the public health group, was around active and sustainable transportation systems. The types of committees applied by PHUs varied, with some engaging in numerous committees than others. However, such committees did not include a representation of the mandated ministries. Within the municipal committees, a few members of public health practitioners $(n=3)$ raised concerns on the gender composition of platforms for public health engagement at the municipal level. Such compositions were reported to cause anxiety and a feeling of inferiority.

"Some of the meetings I have attended barely have women in them. I think, ...may be... this could be just the nature of issues being addressed because I find that many built environment areas are dealing with energy, transportation, or other infrastructure that are dominated by male, especially engineers. But it really makes you so nervous and anxious when I'm putting my points across. Are they even going to consider what I say, or I am even relevant here?" [PH participant]

The influence of gender in climate policies was an emergent theme that was not explored in the study. However, a review of the composition of study participants identified disparities in the gender-balanced composition, mainly at the local public health level. To illustrate, the PH participants that that met the criteria for inclusion in the study, and that were interviewed, consisted mostly of females (82\%). Within the NPH group, female participants comprised of only $32 \%$. 
Other than committees, the public health sector's engagement in climate change policies was supported by workgroups. The two most cited $(n=9)$ workgroups within public health settings were affiliated with OPHA. The Environmental Health Workgroup directly focused on climate change issues and other related issues such as air quality, water quality, and energy. The Built Environments Workgroup focused on issues related to the planning and implementation of various built environment components and their links to health. The OPHA workgroups portrayed a multistakeholder approach to climate change issues with representation from various areas such as public health, environmental health, policy, law, private sector, health care, other NGOs and academics. Through such structures, the OPHA has aimed to advance climate change-related policies. At the time of the interviews, the group was working on climate change messaging to support the comprehension of climate change impacts in Ontario.

"There is a general consensus that the public doesn't see the urgency of climate change action because they are not seeing how it's linked to human health, so this campaign is about getting people to understand the link between, whether it's Lyme disease and climate change, extreme heat,...those may be the easier ones, but even things like asthma - understand that there could be more into symptoms of asthma because of poor air quality, maybe because of forest fires or because of climate change or more pollen production......because of this project that OPHA is doing on messaging around climate change and health, there is an advisory committee and a few of us are public health people on that advisory committee. But a few are people from other health organizations or environmental organizations. So, for example, the Canadian Association of Physicians for the Environment, and the other organization is the Registered Nurse Association of Ontario, the Canadian Environmental Law Association, Environmental Defense, so the usual environmental organizations but also others that represent the health sector." $[\mathrm{PH}$ participant]

Other forms of processes or structures for supporting public health engagement needs were the utilization of forums, conferences, and webinars facilitated by $\mathrm{PHO}$.

"So Public Health Ontario has been instrumental in creating forums that have allowed us to, either through conferences or through webinars or various things, to have those discussions with other health units, and it is iterative." [PH participant]

\subsubsection{Mandate}

Partnerships in climate change policies mainly occurred between those who the actors viewed to have a mandate on climate change or with mutual interests. Specific to NPH organizations, these mandates and interests were associated with specific ministries assigned to climate change and the subsequent committees formed to debate and formulate such policies. This can be illustrated by this participant's narrative as the participant explained how interests determine who the ministries partnered with. 
"We work with ministries across governments where there is intersecting kind of interests... I think given the weight that the government is structured a little bit." [NPH participant]

In turn, the lack of public health partnerships with ministries was seen as a result of a lack of public health's role or mandate in the policies that were being formulated or debated. In some instances, public health was viewed as belonging to the 'humanities' or social ministries as opposed to the applied nature of policies implying their lack of role in ministries policies. For instance, this NPH participants expressed the lack of engagement with 'social-' oriented ministries leading to the exclusion of such ministries in climate change frameworks.

"We tend to work with the natural resources and the kind of, the infrastructure ministries a bit more than social ministries... so we have a closer connection with the ministry of natural resources and forestry, we have a close connection with agriculture, we have a close connection with infrastructure and with municipal affairs." [NPH participant]

Public health agencies were also sometimes referred to as "other" agencies or as not being part of the government, signifying the structural features that NPH actors draw upon to identify the relevance of actors in climate change decisions. Equally, some participants $(n=5)$ revealed that no direct relationships exist between the mandated ministries and organizations "outside of the government." While these narratives point to the lack of understanding of the role of public health, they also unmask the influences of perceptions and meanings assigned to actors in Ontario's climate change policies, as will be discussed in Chapter 10 (Perspectives on the Climate Change-Public Health Nexus).

Overall, at the local public health level, agencies focused on networking and building relationships. In turn, there was a representation from a varied segment of stakeholders, including communities, other health agencies and NGOs, and municipal partners, as already illustrated earlier in Table 14: Summary of stakeholder collaboration reported.

\subsubsection{Communication}

Communication was a significant determinant of institutional engagements. Engagements between PH and NPH groups was influenced by a lack of connection between the two groups, specifically, a lack of contact, a lack of awareness of what others were doing, a lack of direct relationships, and a lack of structures for communication.

\subsubsection{Regular communication}

There was frequent and extensive communication reported within each group, but these communications were fragmented. Communication between the two groups was minimal. Within 
the two groups, there was regular communication. NPH groups mainly utilized committees as sources of communication while the $\mathrm{PH}$ groups mainly relied on platforms from MOHLTC, NGOs, internal committees, and indirect communication among colleagues. The MOHLTC's platform was specifically utilized for knowledge exchange on $V$ and $A$ assessment. However, public health agencies' engagement with NGOs was extensive. Many professionals were members of the various NGOs affiliated with public health. The NGO representatives met regularly, discussing and advocating for healthy public policies targeting climate change. Through these NGOs, most health professionals reported interacting with and sharing or receiving knowledge for advancing climate change decisions, formally and informally. However, the public health group portrayed a disconnect with the NPH group. For instance, while each group reported communications within the groups, there was a lack of contact between them. This is illustrated by the quotes below:

"It's [public health] not something that comes up a lot." [NPH participant]

"They [public health] are not the one that we have, kind of, the most regular contact with." [NPH participant]

"I have never really worked directly with them [public health] ... no, it's not something that typically comes up." [NPH participant]

"No, I don't remember ever working with the ministries on our projects. And this is not only specific to climate change, but in general." [PH participant]

"Perhaps the ministry [MOHLTC] has worked with them [NPH ministries], but we haven't on our side." [PH participant]

\subsubsection{Established formal and informal communication channels}

A cohesive and collaborative network was observed within each group, supported by both formal and informal communication links. Within each specific group, there were laid down formal and informal channels of communication that supported partnerships and contacts among the groups and their interaction with their various stakeholders. However, participants suggested a divergence in the awareness of what each group was doing (i.e. PH vs NPH), suggesting a lack of contact and established communications channels between the two groups.

For the NPH sectors, in addition to the already discussed role of committee settings, informal communication (i.e. consulting with colleagues) across ministries was prevalent. However, communication between the ministries and other non-policy actors were mainly through Environmental Registry postings. As this participant reveals, the Environmental Registry was the government's way of communicating and engaging stakeholders. In this registry, documents were 
posted for a specific period, allowing for the public to comment and opinions on the policy proposals.

"The environmental registry posting ...., I mean, that's the government's way of consulting and engaging on issues. Almost anything that is kind of going to be consulted on in some way will be posted there as kind of a formal consultation, and anyone is able to make a response to that posting. I know we definitely did receive some health responses to that posting, so health organizations are aware of the environmental registry and will comment where they feel there is a necessity to comment." [NPH participant]

The postings were accompanied by additional documents, such as discussion papers and other technical documents, that provided an overview of the proposed policy. The document analysis, though limited in its scope to analyze collaboration, revealed some level of consultation. However, as this participant indicates, consultations are rarely applied in NPH settings.

"Yeah, so whenever a policy is proposed, we are required to post it in the registry for public comment. We don't necessarily have a roundtable discussion with many stakeholders unless they are among the ministries that we work with, especially on the various committees we have. But to say that we do have a face-to-face consultation with the public, including public health people, no! But we always receive a lot of comments from many other organizations, including public health." [NPH participant]

During the interviews, 11 of the $13 \mathrm{NPH}$ participants reported using Environmental Registry as a form of public consultation. However, participants' descriptions of the application of Environmental Registry as a form of public engagement platform show that such platforms present a communicative rather than collaborative platform. The platform does not allow for dialogue between the policymakers and other stakeholders. These engagements were likely forms of communication or information provision rather than consultation, a point reinforced by this participant narrative.

"Generally the way things go is that we will consolidate all the responses that we have received and we will incorporate, kind of, work to incorporate the major concerns and comments for them and then there will be a response posted on that posting to say how the broader set of comments and concerns were addressed in the final proposal or in the final piece of work, whether it's via policy development or regulation or piece of legislation, how these comments were addressed. It's generally not something that would....it isn't the most two-way of engagement. It's kind of is a one-way engagement, but it's something that we do follow-up with them, you know. We had the opportunity to do so specifically with one organization, but I am not sure how often that does happen. We...I don't believe that happens with public health, yeah! " [NPH participant]

The interviews revealed that public health had utilized the Environmental Registry for communicating with mandated ministries and provided evidence relevant to climate change policies $(\mathrm{n}=8)$.

"Through the formal commenting process, we have brought issues related to climate change to make sure that those plans consider and reflect the issues related to climate 
change - whether it is the infrastructure of a road and making sure that it is resilient to climate change and that, you know, making sure that we understand...that the concerns that we have been understood by those ministries." [PH participant]

"We have also had an opportunity to comment on other regional documents like the [redacted]." [PH participant]

However, as these participants illustrate, responses to comments provided are broadly summarized, and no feedback is provided on how comments were integrated, unlike the feedback provided in environmental impact assessment by project proponents. But, public health has had some successes in seeing their comments integrated into the policies.

"I have never seen the postings that the ministry post in response to how our comments were integrated." [PH participant]

“Well, they don't usually provide a rationale for why they considered something or not but when we look at the legislation, we can see which of our comments were included, so that's good, I mean.. but that's just a bit of work. They don't reply back to say... it's different than if we submitted comments to environmental assessment, then they would have to. It is not the ministry that would get back to us on that. It is whoever the proponent is. So let's say there is an environmental assessment for a road-widening project, and one region is the proponent for that environmental assessment. If we submitted a comment, it is a requirement that that region or that municipality would have to respond to say, yes, we accept your comment and we will make that adjustment or, no we are not for whatever reason." [PH participant]

"It depends on the comment. For some of them, we are pretty deeply involved and have regular dialogue with the ministry, and for others much less so. It depends on how strong the relationship is with the person to whom the comments are going and how familiar they are with us, and it also depends on how attuned the government is with us. But, with other ones, less so! You win some, you lose some!" [PH participant]

Given that the main form of engaging with the stakeholders was the registry posting, the policy experts within the mandated ministries draft and deliberate on the various climate change policies then posted them to the registry for other stakeholders to provide comments. However, two participants explained that, by the time such policies are posted, several decisions have already been made. This was also demonstrated by the supporting documents embedded in such posts. For instance, the discussion papers were not meant to provide the different policy options or alternatives being considered or proposed, but instead, the documents provided information on the specific policy decisions presented as proposals.

Specific to the public health institutions, there were extensive formal and informal communications between the various public health organizations as well as communication between PHU and municipalities, communities, NGOs and the MOHLTC. There were also some efforts to connect with the various ministries mandated, although such communications were very 
limited. Various structures utilized for communicating and networking on climate change including focus group, internal policy consultation, consulting with other PHUs who had completed their vulnerability and adaptation assessments, engagements through webinars and conferences and through interactive membership activities from the various public health NGOs, many of whom have formed working groups on areas related to climate change and built environment. For instance, many public health professionals are affiliated and work with the OPHA Built Environment or Climate Change Workgroups.

The lack of established communication channels across the two groups was obvious to participants as well and was evident in the interview. In turn, many participants emphasized the need for better communication to minimize the fragmented policy work currently being done in Ontario.

"I think that there needs to be better communication in governments and between the ministries. I mean, we do operate in silos often, and I think we might not get...we might miss ... we might not be able to advance as soon as we can because we are kind of not talking to each other." [NPH participant]

To leverage communication and engagements between the two groups, several participants $(n=18)$ from both groups made several suggestions as summarized below.

- Presence of framework for learning about each other's roles, responsibilities and leadership areas

- Development of communication channels that facilitate open, two-way communication between the two groups unlike the currently used Environmental Registry

- Integration of needs of public health in the mandates, with clear goals, and objectives and clarifications of points of engagement

- Involving each group in respective climate change initiatives from the initial stages of policy development, implementation and evaluation.

\subsection{EFFECTS OF INTERORGANIZATIONAL ENGAGEMENTS ON INSTITUTIONAL CAPACITIES}

Where institutional engagements were reported - whether across organizations or within the organizations - such engagement resulted in strategic and knowledge impacts on organizational capacities. Participants reported that where engagements were effective, they resulted in beneficial opportunities and set relationships for future engagements. Specifically, $\mathrm{PH}$ group found engagements as helpful avenues for forwarding public health needs or making their needs understood by other stakeholders within the various collaborative settings. 
Resources, including access to skills, funds and knowledge, were linked to the support for and the outcomes of institutional engagements in climate change frameworks. Two emerging sets of resources systemically linked to institutional engagements broadly related to funding and skills (expertise). Participants reported that partnering with others supported capacities for addressing climate change within their jurisdictions and added value to the engagement in climate change policy processes through knowledge sharing and access to expertise and skills from fellow health professionals. These resources were reported to add value to the engagement processes by motivating organizations to collaborate and acquire skills that were not possessed internally or to share the knowledge that had been acquired internally and externally through partnerships with institutions within and outside of their organizations.

Collaborations within the NPH groups were mainly viewed as efforts to improve strategic roles (i.e. advance the mandate on climate change actions). In turn, resources (knowledge, funds, and technologies) were shared to advance the mandated climate change roles through the pooling of funds, transfer of knowledge, and application of technologies relevant to the institutionally designated climate change actions. Within this group, impacts of government defunding various climate change actions were blamed for the lack of engagement by such institutions.

For the $\mathrm{PH}$ group, the participants pointed out that, where collaborations were utilized, the engagement expanded their capacities, competencies and involvement, and supported access to funds. The collaborations created relationships and opportunities for future engagements while also revealing the role of public health in climate change policies. These engagements also impacted knowledge transfer and sharing and creation of new forms of knowledge. The importance or strategic impact of institutional engagement was particularly noted by $\mathrm{PH}$ participants who extensively collaborated with municipal and community partners on the $V$ and $A$ assessments and other jurisdictionally specific climate change policies. Equally, representation of public health in various platforms within health units, across other health units, with municipalities and with the MOHLTC resulted in new partnerships as the organizations and departments (in cases of internal engagements) gained more awareness of each others' roles; such engagements also resulted in changes in attitudes towards individual's roles in partnerships. For example, targeting the skepticism that would arise at the beginning of partnerships; such feelings were overcome as individuals interacted and clearly identified the roles within the broader partnerships.

However, as public health organizations acquire this new knowledge, it did not only impact the capacities within the collaborator institutions. The knowledge diffused into other collaborations 
across jurisdictions, between different PHUs and other provinces, including collaborations with the health agencies in two Canadian provinces. As several participants also mentioned, the development of the specific PHU's $\mathrm{V}$ and $\mathrm{A}$ assessments have been sustained by collaborations across PHUs

Public health engagements were also not only viewed as sources of the capacity building but rather as mechanisms for gaining funds to support climate change actions. Equally, the lack of funding by PHUs was mentioned as a major impediment to engagement in climate change actions. For instance, while NGOs affiliated with public health supported public health professionals' engagement in climate change, the sustainability of such NGOs was threatened by the lack of additional funds to advocate for public health needs. Through collaborations, public health has gained access to new funds supported by partnerships with NGOs and federal government public health agencies. For instance, the collaboration between the PHUs and OPHA have brought about direct access to funds and political platforms, and collaborative research across the various public health jurisdictions.

A summary of the key impacts of public health engagements on its capacities and sample quotes is presented in Table 17: Impacts of engagements on public health's capacities below.

Table 17: Impacts of engagements on public health's capacities

\begin{tabular}{|l|l|}
\hline Impact & Sample quotes \\
\hline exchange & $\begin{array}{l}\text { "[collaboration] provided us with a forum to do a lot of knowledge translation } \\
\text { and a lot of knowledge exchange, and ... I have worked with other health } \\
\text { units that are now in the process of doing it N and A assessment]. So I have } \\
\text { worked with [redacted], I have worked closely with [redacted]. Each } \\
\text { community has to do a vulnerability assessment in their own way, but there } \\
\text { are lessons that can be learned, and so I have met with them. I have had } \\
\text { discussions with a number of other health units, [redacted] in [redacted]. Just } \\
\text { this past week, I have had some discussions with [redacted] in [redacted]. } \\
\text { So they are looking at doing vulnerability assessment similar to what we did } \\
\text { and so, you know, lessons learned, those kinds of thing." [PH participant] }\end{array}$ \\
\hline $\begin{array}{l}\text { "It was an enormous learning curve for me, but it was really interesting } \\
\text { and skills } \\
\text { development } \\
\text { because I brought perspectives for it that perhaps we wouldn't have thought } \\
\text { of, and it was really interesting dialogue, and we all collectively learned a lot } \\
\text { from each other." [PH participant] } \\
\text { "I am learning from my colleagues as much as they are learning from me, and } \\
\text { so you know, you take the lessons learned back, and you incorporate it into } \\
\text { the work that you are doing. So it is a lot of capacity building; it's a lot of } \\
\text { knowledge translation, those kinds of things." [PH participant] }\end{array}$ \\
$\begin{array}{l}\text { "One piece that we identified within our key informant interviews was the need } \\
\text { for a regional network that could help to bring different stakeholders together } \\
\text { to support climate change mitigation and adaptation, and that's because most } \\
\text { of our municipalities are quite small and they are resource-strapped, and they }\end{array}$ \\
\hline $\begin{array}{l}\text { Access to } \\
\text { resources }\end{array}$
\end{tabular}




\begin{tabular}{|c|c|}
\hline & $\begin{array}{l}\text { don't have either the money or the knowledge to be able to start some of the } \\
\text { climate change adaptations. And so they wanted a way that they could have } \\
\text { a community of practice or a sharing network or a way that they could } \\
\text { collaborate to create regional actions. So the health unit has been working to } \\
\text { pull that group together, and it is something that we are going to be continuing } \\
\text { to lead over the next couple of years. We are calling it a [redacted], where we } \\
\text { have conservation authorities, school boards, municipalities, and ourselves } \\
\text { as health unit partners working together to identify what others are doing, } \\
\text { where there could be collaborations and partnerships and what funding } \\
\text { opportunities could be done collaboratively. And so it was one of those pieces } \\
\text { that everyone sort of said we need this, but no one was able or had the } \\
\text { resources to step up and lead. And so, we were able to put those resources } \\
\text { into that program, and we will continue to do so." [PH participant] }\end{array}$ \\
\hline $\begin{array}{l}\text { Building } \\
\text { capacities } \\
\text { beyond } \\
\text { climate } \\
\text { change } \\
\text { needs }\end{array}$ & $\begin{array}{l}\text { "So I think it is an opportunity [collaborating with others] that other health units } \\
\text { hopefully can take up as well, and we have done it for other program areas, } \\
\text { for social determinants of health, for healthy built environment. Public health } \\
\text { has been engaged in community development and engagement for many } \\
\text { years, and so I think this is just another area that public health can lead in." } \\
\text { [PH participant] }\end{array}$ \\
\hline $\begin{array}{l}\text { Change in } \\
\text { attitude }\end{array}$ & $\begin{array}{l}\text { "So I think before I got in my current role, when I thought of climate change, } \\
\text { it was just like big picture which was the...like global warming which is, you } \\
\text { know, the essence and core of climate change, you know, melting ice caps, } \\
\text { also increasing temperature of the planet. And when you think about all those } \\
\text { things, sometimes it is hard to remember the smaller pieces, the incremental } \\
\text { pieces that can support... adaptation measures, and, sometimes when I } \\
\text { thought about that, it was hard for me to think of the public health role because } \\
\text { I thought of it as this great big science that needs to be tackled by } \\
\text { climatologists. When I got into this role, I think what was very inspiring to see } \\
\text { was the work that public health units were already doing to address health } \\
\text { impacts of climate change." [PH participant] }\end{array}$ \\
\hline Advocacy & $\begin{array}{l}\text { "As well, I sat on the vulnerability assessments from [redacted], so as I } \\
\text { mentioned - water, wastewater, infrastructure and so on - and brought forth } \\
\text { a public health lens to those vulnerability assessments." [PH participant] }\end{array}$ \\
\hline Strategic & $\begin{array}{l}\text { "That work [that is, a vulnerability assessment that the participant did in } \\
\text { collaboration with other stakeholders] has driven much of the work that we } \\
\text { have done since". [PH participant] }\end{array}$ \\
\hline $\begin{array}{l}\text { Platforms } \\
\text { for potential } \\
\text { and future } \\
\text { partnerships }\end{array}$ & $\begin{array}{l}\text { "What that [a previous collaboration] also did was set stage for further } \\
\text { partnership work, and we have done a couple of interesting projects with } \\
\text { partners that perhaps we wouldn't have worked with as closely in the past. } \\
\text { For example, we developed a tool to look at [redacted] and brought in a } \\
\text { social-economic lens, brought in a health protection lens. Looking at things } \\
\text { like urban heat island. Looking at equity, all those kind of issues, ... we are } \\
\text { now doing a pilot project applying that tool in [redacted] and looking at } \\
\text { communities that are disadvantaged for one reason or another and looking to } \\
\text { see if we can try and impact things like the urban heat island. So there has } \\
\text { been a lot of involvement in a lot of different projects and people have been, } \\
\text { in my mind, very welcoming of the public health lens to the discussion. The } \\
\text { engineers welcomed us; the planners have welcomed us. There has been } \\
\text { learning of each other's languages and needs, and that takes time, but } \\
\text { certainly, there has been no hesitation, whatsoever, to have public health }\end{array}$ \\
\hline
\end{tabular}


sitting at the table." [PH participant]

There were two tangible impacts of public health engagement reported by the $\mathrm{PH}$ group. One conveyed the role that a committee played in the inclusion of public health's mandate on climate change during the modernization of OPHS. As this participant echoes, there was a public health committee:

"... that promoted or pushed to have more information or more requirements in the public health standards related to public health action on climate change, and I do know that a lot of the health units are doing that work." [PH participant]

The second was related to the accessibility of hard-to-reach communities, which was made possible through communication channels and platforms for public health engagement (i.e. conference).

"We did try to engage with our First Nation and Metis communities within the region. We were unsuccessful in engaging in that for the vulnerability assessment key informant process. I think we just didn't have the right contact. We weren't connecting with the right people. I personally didn't have any connections with any of our first nations partners from previous work, and like, I think we weren't just connecting with the right people, but we have since been able to work with some of our local communities, and we are involved in some projects that are supporting adaptation planning within First Nations communities within our region, and so, that was really great, having some conversations with an individual at First Nations who was doing some climate change adaptation, and I was wanting to see what they were doing and then meeting her at other conferences, and that allowed us to build a relationship, and she then brought us into her projects that she's doing. So that has been really great because we saw a gap in our vulnerability assessment ....we didn't have any Indigenous views throughout the vulnerability assessment.... and so, now that we have those connections, it has been great, and there has been a real collaborative approach to being able to support them when we can with our vulnerability assessment and they are using traditional ecological knowledge as well to further adaptation planning, so it has been really great to be able to start to build those relationships." [PH participant]

\section{$9.4 \quad$ SUMMARY}

An overarching theme identified from the analysis was the lack of holistic interorganizational engagement approaches. Indeed, the biggest issue minimizing the public health capacity in climate change discourse is the fragmentation of work across climate change stakeholders - specifically, fragmentation between public health and non-public health sector and social differences arising from these two groups. Policy development reflected organizational structures and cultures mainly focused on functional areas with a lack of clear commitment to engaging public health in climate change. There was mostly a one-way communication between public health and nonpublic health institution, and in some cases, how people identified with climate change determined the level of engagement in climate change policy processes. As a 
result, engagements in general - and between ministries, public health- and non-public health professionals, and between national and local levels of agencies - was influenced by the alignment of policies. In turn, the selection of stakeholders also aligned with the organization's policy objectives and mandate drawn upon climate change decision-making structures of the institutions. However, where engagements were realized, such engagement resulted in strategic, financial and knowledge impacts that were relevant in supporting institutional capacities in climate change decisionmaking. 


\section{CHAPTER 10: PERSPECTIVES ON THE CLIMATE CHANGE- PUBLIC HEALTH NEXUS}

\section{INTRODUCTION}

Chapters 7 to 9 have exposed the various structures, arrangements, and practices that have defined climate change discourse, enabling actors to focus on specific decision processes and policies. However, what has also been prominent is the influence of interests, beliefs and ideologies embedded in the various themes discussed. This chapter complements chapters 7 to 9 by exposing the values and perspectives influencing the construction of climate change in Ontario and the needs of public health in the discourse.

Chapter 10 focuses on the themes defining values, from both groups, and from policy documents that portrayed specific interests, ideologies, beliefs, and assumptions held by policy actors and politicians to construct the direction of climate change policies and the role of public health in the actions. The various themes that emerged related to the influence of political values on climate change decisions (Section 10.1) as well as participants' perspectives and opinions on the various public health engagements in climate change, including roles, leadership, framing and inclusion (Sections 10.2).

\subsection{POLITICAL VALUES AND CLIMATE CHANGE ACTIONS}

In Ontario, the culture of climate change policies is characterized by political and partisan values mainly propagated by political elites or leaders. Such values have defined political will and directed the discourse of climate change in the province.

\subsubsection{Convergence and Divergence of Political and Partisan Norms}

In Ontario, several NPH participants $(n=6)$ acknowledged the influence of political norms in determining climate change policies. The participants indicated that many policies are influenced either directly or indirectly by the premier's office, political interests, cabinet interests, interests of ministers and their assistants. The influences emerge in climate change discussions within committees formed to deliberate on climate change policies. Such insights are supported by various participant's narratives.

"When we craft the policies, most consideration is given to the government bodies...or like politicians, especially the cabinet...they mainly have a say on most of the policies...I believe we generally integrate their interests, mostly." [NPH participant] 
"I am not sure if the political support comes entirely from the Premier's office, although, I would say most of the time it does, but mainly indirectly through the ministers and other bureaucrats aligned with the government...but I would definitely say that political party interests have mainly defined our policies...I would say at least $80 \%$ of our policies are weighted on politics". [NPH participant]

"I would definitely say that the cabinet has a lot of power in influencing the policies that are proposed." [NPH participant]

While the above responses demonstrate the influence of politics on climate change policies, these narratives are supported by the analysis of the documents (and as outlined in

Appendix K: Chronology of Ontario's Climate Change Activities and Responses). For instance, the influence of political contexts was evident in the divergence of climate change policy approaches between the Liberal government (who governed Ontario for most of the document analysis reference years until June 2018) and the incoming PC government who had just accessed power after the June 2018 provincial elections. Thus, regardless of the consensus on climate change impacts and the need for actions, the divergence on political convictions and partisan division defined the relevant climate change policies in Ontario. As this participant sums it:

"We now have a new government, and we will wait to see what their direction is. At the moment, we don't know what sets of policies they want to implement, but we do know for sure that they are going to toss most, if not all, climate change policies initiated by the Liberals. As of now, I know that our funding has been discontinued. So that's a clear sign." [NPH participant]

There eminence of values (interests, ideologies, and beliefs) affirming political influence on Ontario's climate change policies was especially evident from the policy documents. Values held by political parties towards climate change policies are evident in news release quotes (narratives) where the messages and narratives from various ministers (and or assistants) portrayed shared or collective agreements and support on released climate change actions and interventions. The quotes highlighted the ideologies of the politicians and organizational views on appropriate climate change actions and intended outcomes as well as interests of how they would like the policies to work or to be formulated. These included interests in how political or bureaucratic elites (Premier, ministers or those quoted) would like the climate change action or intervention to work (i.e. interest). For example, the Premier's message on the climate change plan that broadly defines the interests of the government as to what the plan is to achieve.

"When my grandchildren ask me what we did to help our planet, I want to be proud of what we accomplished. Together, we will build a greener, more prosperous future for them, and for generations to come." [Premier's message, Ontario Climate Change 
Action Plan, 2016]

Embedding such texts portrayed the propositional assertions that climate change policies aim to build greener (technological) and financial viability for future generations.

Values were also projected in the declarations that expressed the ministers' or assistant ministers', and their ministries' views of how the climate change action or intervention ought to work (i.e. ideology). To illustrate, in order to create an idea that there is a greater role for Green Commercial program in the province's economy, the Assistant Minister of Transportation's news release began by illustrating the importance of low carbon economy:

"Creating a low-carbon economy is vital to the province's continued economic success. The Green Commercial Vehicle Program will help businesses invest in fuel-saving technologies that will reduce greenhouse gas emissions. We're committed to working with our partners and local businesses to modernize the way we do business and keep Ontario Dan attractive and sustainable place to work." [Assistant Minister of Transportation, News Release, September 6, 2017]

Furthermore, political values were used to acknowledge that proposed actions or interventions work to target climate change based specific information (i.e. belief). For instance, the Minister for Environment's ideology of the relevance of the Food and Organic Waste Framework in boosting a low carbon and circular economy is based on the existential assumptions of Ontario residents' food disposal behaviours.

"Ontario residents and businesses send a staggering amount of food waste to landfills every year - up to 125 kilograms per household per year. That food waste breaks down into methane, a potent greenhouse gas. This framework will help shift how we think of food and organic waste to viewing it as a valuable resource we should recover. It's a bold, transformative plan that will help Ontario build a strong, low-carbon and circular economy where nothing is wasted." [ Minister of the Environment, News release, April 30, 2018]

Political beliefs were also manifested in politicians' beliefs of knowing what Ontarians want. This is demonstrated by the Premier's support for renewable energy and Act supporting the initiative and the Minister for Environment's support for cancellation of the cap-and-trade program, through presenting opposite values of climate change actions.

"Because of our Green Energy Act, our province would be greener, stronger, and in a better position to compete and win against the rest of the world. We're going to seize this opportunity to build a better Ontario — better for jobs, better for our children, better for our planet." [Premier, News Release - Office of the Premier, February 3, 2009]

"We heard from people across Ontario that natural gas expansion is important in order to grow businesses, create jobs and compete.... by cancelling the cap-and-trade carbon tax, we have already acted to bring natural gas prices down for Ontario families and businesses. Now we are taking the next step to ensure that the benefits of natural gas expansion are shared throughout the entire province." [Premier, News Release - Office of the Premier, September 18, 2018] 
In other instances, technological advancement was justified by statements that pointed out that advancement was the will of the people of Ontario.

"Everywhere I go in Ontario, people tell me they want us to build a greener province. I'll be introducing legislation soon that would make Ontario a world-leading jurisdiction for renewable energy, with best-in class programs designed to yield best-in-class progress to attract investment and create 21st century job opportunities for Ontarians." [Deputy Premier and Minister of Energy and Infrastructure, News Release - Office of the Premier, February 3, 2009]

The above-mentioned political values present only a few of the many quotes that emerged from the documents. However, the predominance of political interests in influencing climate change policy was evident between the two governments (incoming and outgoing). Still, both parties acknowledge the threat posed by climate change and depicted interests that reflect the political determination to influence policies that promote economic growth and innovation. In contrast, ideological differences emerged on the views of how the policies ought to work. The incoming government challenges the outgoing government policies on the grounds that the former's policies (specifically cap and trade) do not benefit Ontarians economically, calling for alternative forms of policies that enhance economic growth. Through the various news releases and documents, the values held by various politicians and ministers (both current and former) assert the relevance of the economic frame in climate change discourse, paying no attention to public health. The prominence of such values and political approaches to climate change decisions were also reported by NPH participants $(n=9)$.

\subsubsection{Participant's Perspectives on Ontario's Political Approaches to Climate Change and Public Health Prioritization}

The influence of politics and the lack of political or organizational will emerged as the two defining perceptions of the current climate change discourse in Ontario. These themes mainly emerged from the NPH group. For instance, 9 of the $13 \mathrm{NPH}$ participants highlighted that the ruling political parties, past and present, have not made firm decisions or provided appropriate structures for steering climate change policies in the right direction. A lack of political oversight was blamed for climate change decisions that broadly target various issues of climate change in Ontario.

"Until governments can get on board and start to make firm decisions on prevention, mitigation and adaptation policies, I think advancing the climate change agenda is going to continue to stall... I think the other reason why climate change policy is so long in being developed is because of political will, and, I think it takes incredible foresight for politicians to look past the end of their term to make decisions for the future, and too many politicians 
can't look past that. They can't look past the end of their term, and that is a real problem." [NPH participant]

"I don't think there are good structures, but multiple groups have come together to try and tackle these issues. But there is not one, kind of, an overarching structure that facilitates communication and coordination of action, and we haven't seen government leadership to make that happen, especially now. I think the Liberals tried a bit to streamline the policies, but again, most of the time their policies focused more on the economy than climate change. Even when you look back at the McGuinty government [served as Ontario Premier - 2003 to 2013], his climate change platforms were prioritizing economy." [NPH participant]

A convergence in attitudes was evident when participants compared the climate change policy discourses of the two political parties, that is, the current (PC) and former (Liberals). Participants $(n=8)$ viewed the former's policies favourably compared to the latter. For instance, while the liberals' climate change policies were considered to be inadequate and narrowly focused (mainly focused on mitigation), the policies were viewed to prioritize climate change actions.

"When I compare the two governments, and sort of different ministries, what I will note as a good example was the former government. They had climate change action plan, and as part of that, there were a number of different actions and some of them affected different ministries, some of them were largely one industry. There were like transportation-based kind of initiatives, innovation-based, ministry of research... the former ministry of innovation and science." [NPH participant]

On the other hand, PC's policies were viewed by many participants $(n=10)$ to portray uncertainties in climate change actions and lacked prioritization on climate change. The new government's rhetoric was viewed to stall some of the progress strategic plans and actions made, including plans that would have influenced the availability of evidence (e.g. the proposed risk assessment for Ontario and the new climate change organization that was proposed by the former government.

"The current government does not prioritize climate change. If you look at the new plan, there is barely anything about climate change. The government even removed the word 'climate change' from the ministry's name. What does that tell you about this government? Sometimes I think that as much as we value and support democracy, changes may not always be for the interest of the public. For example, look at all the investments made on climate change...all that is gutted, and we start a fresh...that is public fund that has been wasted. There were other proposals to follow... a climate change organization, I believe. I think that was a really good idea, but it's not gonna happen. So again, as much as we need change, that change sometimes can derail the progress made. The liberals... they did not have the best policies on climate change, but I think, it was something that could be improved..." [NPH participant]

"Well I think the reality is that we have the government doing it [climate policies], that's that the nature of the beast. They are the policymakers, and they want to make policy. And then it's also too early to say what the new government will be doing. But as per 
regulatory approach, I think it's too early to know, and we don't have a detailed agenda in that part. We know what they [new PC government] don't like but we don't know what they might come up with." [NPH participant]

The frustrations about the political climate were seen to impact climate change broadly. Some participants expressed frustration on the influence of politics in their work as climate change policy formulators. Political forces were viewed as setbacks to progress on, and rational evidence for, climate change policies.

"I think the challenge also is the institutional setup. When you ask for something, often, it has to be packaged up and documented and researched very correctly. And we try to be ahead of our politicians by having facts and some analysis available. But it is not always... we don't always quite get to what they might want. So, a lot of our time gets focused on responding to political level questions. It would be really helpful to have more wellresearched policy facts. For example, surveying the specific decision needs of municipalities in regards to them making decisions around climate change adaptation." [NPH participant]

While the $\mathrm{PH}$ group did not express perceptions regarding the current political climate in Ontario, several in the group $(n=7)$ felt that despite the changes in government, none had prioritized public health needs. However, there was optimism that having a new government from a different political party after the Liberal's 15-year rule provided opportunities for public health integration -specifically given that the new government had not restricted the role of public health in general.

"I feel like it is still the same [that it, how governments have failed to integrate public health]. You know what, honestly...I am going to be very honest with you. I think public health was always in that position where they were trying to find the spot where they fit in. Overall speaking, the environmental plan [the new Made in Ontario Environmental Plan] is very different. Climate change is not a huge part of it. And you know, there are things that are sort of taking a back seat. But, the role of public health, in my honest opinion, was not always very huge even in the previous climate change and adaptation plan. [Redacted] had a role to play in more specific things .. but it was always an area where we were exploring and where we were saying that health units can do this, and health units can do that. And not just health units, but public health in general, can be promoted through these initiatives. So I think we are still sort of, ... nothing has really changed for public health. I think I would say that although the new environmental plan can be viewed as a setback for some folks, I don't think it should be viewed as a set back for public health because even the previous role of public health was not very obvious, which has led to those kinds of notions that, you know, where does public health fit into climate change and so on? It's always been a little bit ambiguous, even with the new plan. I think it's up to us to use the modernized Ontario public health standards as the opportunity to promote the public health role." [PH participant]

Equally, the uncertainties within the current political climate were viewed to influence the

MOHLTC's climate change initiatives negatively.

"So the ministry [MOHLTC] right now is in a state of flux because the manager who led 
this work [climate change-related policy work] has just retired. So there is a vacancy there, and the Ford government [incoming PC government] came in and the rearranging of the structure within the ministry. And at this point in time, there is no word in terms of that position, who will be in that position, and when it will be. So...there is a vacuum that remains to be seen how it is going to be filled. With public health Ontario, they are engaged, but public health Ontario's role is scientific advisory, it is not policy. So it is up to the local area and municipalities or the local area public health units to do policy with their municipalities around these stuff." [PH participant]

Instead, the $\mathrm{PH}$ group $(\mathrm{n}=8)$ mentioned that they strive for proactivity, suggesting that public health policymakers should be proactive with climate change policies and provide opportunities for public health engagements.

"I think for policymakers, like myself, we need to be more proactive and sort of push this in the agenda of policymakers and say, this is actually very important work that needs to be done. But personally speaking, I think it's something that is still very important and if I see that there is a dilution of some sort, it's unfortunately happening, but I think, ...having a new government is also new opportunities." [PH participant]

\subsection{PERCEPTIONS ON PUBLIC HEALTH'S ROLE, LEADERSHIP AND INCLUSION}

Participants, manly from the $\mathrm{PH}$ group, highlighted what was considered as relevant and key roles for public health engagement in climate change. The emerging themes included a dominant role in supporting adaptation strategies and communicating climate change health risks through information provision, advocacy, and public education in a manner that resonated with broader audiences.

\subsubsection{PH Group}

Among the 11 public health professionals interviewed, all agreed that public health had a role in climate change adaptation. 7 of the 11 believed public health's role in climate change is more affiliated with adaptation than mitigation. Conversely, only 4 of 11 linked or saw some role for public health in climate change mitigation. Others perceived public health's role to be associated with mitigation. However, where mitigation links were made, the links mainly related to actions around the built environments.

"I do think that public health has a role in mitigation, and I think a lot of it leads back to our mandate to support healthy built environments. So the way our communities are built has such an impact on the way that people can get around. So while some of the rationales for building communities and specific ways for public health perspective may not be to support climate change mitigation, in the end, it is a major factor in decreasing GHG emissions. If we have walkable communities that are transit-supportive and have active transportation infrastructures, we can greatly reduce the amount of emissions, especially because in Ontario, transportation is one of the leading causes of GHG emissions. So I think from that perspective, although it is not necessarily the main rationale for completing that work, it is a really big part of creating supportive and healthy communities. But as 
well, having a lot of infrastructure within our communities, like for ourselves, we have [redacted]. We have staff that are constantly on the road; that are driving around to be able to complete their work. We have team members that are, you know, really spanning about a four-hour drive from the southern portion of our region up into the most northern sections. And so, we, I think, have a responsibility to ensure that they are being respectful of the communities that we are supporting and making sure that if we can have teleconference meetings or if we can carpool, it helps to decrease the impacts on the health of our communities. So I think we have a responsibility to do that, and we are very lucky that [redacted] at the health unit is very supportive of including mitigation into this work ...[redacted]..., and so that has sort of been instilled into this climate change work that while adaptation is a really key piece for public health, we need to have that integrated into our programing not only here at [redacted] but across the province. Mitigation, it still needs to happen as well, and we can decrease impacts moving forward by supporting mitigation, both internally from a sustainable business practise perspective but also by making sure our communities are built in such a way that helps to decrease the need for GHG emissions." [PH participant]

"I think adaptation is the most obvious link. I think mitigation is a little more challenging because as an agency, we can mitigate our impacts. So, you know, put in place policies that have to do with reducing driving and conservation of electricity and those kind of things. But I think where we connect to mitigation is in our work as it pertains to, say, the partnership that we have with, so let's say, with municipalities who actually have more direct control around mitigation. So things like.. you know, we do a lot of work around the built environment and active transportation and working with our municipalities to encourage them to promote active transportation and make investment in infrastructure which in turn encourages people to drive less, walk and bike more. So, it's kind of... I think for mitigation, its kind of a stage removed because we don't build roads. We don't build sidewalks. That kind of thing." [PH participant]

Some public health professionals did not see their role in climate change mitigation. The lack of role was linked to several factors, mainly associated with structural or resource constraints, as summarized in Table 18: Why public health does not have a role in mitigation below.

Table 18: Why public health does not have a role in mitigation

\begin{tabular}{|l|l|}
\hline Reason & Sample quote \\
\hline $\begin{array}{l}\text { Municipal } \\
\text { government } \\
\text { jurisdiction }\end{array}$ & $\begin{array}{l}\text { "We do a lot on the adaptation side, but in terms of mitigation, I believe } \\
\text { public health does not have a role in it. As far as I know, it is the } \\
\text { municipalities that will have a role in it within the local government's } \\
\text { jurisdictions." [PH participant] }\end{array}$ \\
\hline Lack of capacity & $\begin{array}{l}\text { "Everybody has a little bit of a role in mitigation but public health or at } \\
\text { least this health unit, and I think most health units, don't have the } \\
\text { capacity to also be providing leadership on climate change mitigation } \\
\text { strategies in the broader community...mitigation strategies are not } \\
\text { directly related to potential health impacts." [PH participant] }\end{array}$ \\
\hline $\begin{array}{l}\text { Mandate not } \\
\text { provided by the } \\
\text { MOHLTC }\end{array}$ & $\begin{array}{l}\text { "I don't think we have a role in climate change mitigation in the future or } \\
\text { not. I have had those conversations, but we have certainly not been } \\
\text { given any mandate by the ministry [MOHLTC] to do that. So we are not }\end{array}$ \\
\hline
\end{tabular}




\begin{tabular}{|l|l|}
\hline & $\begin{array}{l}\text { doing any mitigation work, including public health education around } \\
\text { mitigation." [PH participant] }\end{array}$ \\
\hline No directives from & $\begin{array}{l}\text { "To be honest, public health should not have a role in mitigation, and as } \\
\text { far as I know, the ministry [MOHLTC] has not given us directives that } \\
\text { would support such roles. But I do know that we are actively engaged } \\
\text { in adaptation...our current activities on conducting the vulnerability } \\
\text { assessments stem directly from such needs... I don't know how we can } \\
\text { integrate mitigation in such an assessment." [PH participant] }\end{array}$ \\
\hline
\end{tabular}

Follow-up questions with other members of the $\mathrm{PH}$ group on public health's role in mitigation revealed that the results of not seeing a role in mitigation could also be due to a lack of resources or that such narratives could be justified based on public health's prominent role in adaptation. However, some $(n=2)$ also characterize the lack of the group's ability to identify with climate mitigation role potentially due to presentation of the climate change as a social event (given that framing was blamed for lack of prioritization of public health). But the lack of identification was also blamed on the structures that have failed to integrate public health into broader climate change initiatives. This was especially because the MOHLTC was quoted to have not provided 'directives' and 'mandates' for public health engagements

Other roles for public health, as mentioned by the participants, included advocating for healthy climate change policies $(n=10)$, coordinating climate change work $(n=6)$, developing policies $(n=9)$, health promotion $(n=9)$. Unfortunately, perspectives revealing public health's role in climate change were predominantly identified by the PH group and not the NPH group.

\subsubsection{NPH Group}

Within the NPH group, only 4 of the 13 participants identified roles that public health could play in climate change discourse. All of the responses were a result of additional probes during the interview process and such roles related to risk communication, building health-related adaptation and resiliency in communities, and advocacy. However, whenever the role of public health in climate change was questioned, relevance was mainly connected with the impacts of the recent extreme heat events that occurred in Quebec and Ontario in the summer of $2018(n=5)$, as demonstrated below.

"I mean in general, public health is certainly related to climate change, right, like I don't know... I see all the articles in the grey literature, at least, on public health and extreme heat and what it means and this...you know, looking at what has happened recently in Quebec and Ontario during the summer. So climate change considerations definitely have a place in public health." [NPH participant]

"I think it is interesting that climate change, from my perspective, there seems to be more interest in climate change after there have been kind of documented and reported 
casualties and health concerns as a result of an extreme weather event. In this past summer, people in Quebec died due to extreme heat, I think 17 or 20 or something like that. I think that brings the issue home because health is one of those things that you can... you might not necessarily feel the economic loses as a result of roads being washed out and basements being flooded, but I think health is one of those things where, you know, when you start saying people are dying because of the heat or this many people died or, got sick because of ....you know, asthma rates ...things like that. I think people understand that, and they can see a difference a bit more. In a way, they can see that, oh, well, you feel it on your body before you feel it on your pocket. How the weather is changing, I think public health definitely should play a role and needs to play a big role in advancing the conversation. I am not saying that they don't do a very good job now, I don't have an opinion on that, to be honest. I don't know how well they are doing but I think there is a role for them to play in pointing out the impacts of climate change but also advocating for change and also helping people adapt and helping people make choices that will improve their health as a result or in response to climate change...it's one of those things that speaks to people in terms of how climate is changing and what we need to do to adapt to it. I think the human health costs speak to people more than actual financial." [NPH participant]

Still, some did not vision what role public health would play in such instances or in general.

That is something I haven't looked into as much [ when asked about the roles of public health in the agency's policies]. I see that there can be a role for public health in the overall impact. Particularly if you look at this heatwave and the number of fatalities in Quebec. This is an unusual degree of heat that extended for a period of time. Where public health may sit in that is something that will be challenging because the traditional role is to say... public health in this piece... [response not completed by interviewee]." [NPH participant]

Apart from the few that related specific public health roles, the responses from the NPH group to public health-related questions portrayed a widespread lack of familiarity with the role of public health in climate change or in general. Although many from the NPH group support public health efforts, most participants $(n=9)$ neither recognized the efforts as public health activities in climate change nor understood the role of public health. Where public health-specific questions were raised, many paused for several seconds, passed on the question or provided incoherent or incomplete responses with several pauses in between the words and sentences. Specifically, when the NPH group was asked what they perceived as the roles of public health in climate change, the common theme that emerged was their inability to identify the roles. Many $(n=5)$ indicated that this was an area they haven't considered. Other participants identified hypothetical instances where public health may be included. In these instances, public health consequences were sometimes considered without public health inclusion or after such consequences are already impacting populations. Other NPH participants $(n=3)$ also felt that public health did not have a role in climate change or that it would be challenging for the public health sector to play a significant role in climate change.

'It's something that may be valuable for the ministry of health to look into, but I can't see 
what their particular role might be." [NPH participant]

Even So, others had specific roles that they see public health playing $(n=3)$; these roles did not relate to climate change but to other public health competencies as highlighted below.

"I see the roles of public health in ... as restaurant inspections, taking care of inspections like SARS and so on and not in climate change. I mean,...I don't see how they can influence the mitigation of greenhouse gases." [NPH participant]

"You know what, most of the time when I see public health in media, it usually relates to some sort of a ... disease outbreak...something like the flu that happened a few years ago. Currently, or at least in Canada, climate change isn't impacting us in such a way that we'd see some kind of infectious diseases creeping in...or at least not yet. So I guess, public health... will have a limited role in climate change for now. But I am not sure what that role can be at the moment." [NPH participant]

One participant indicated that public health might have a role in adaptation but not mitigation.

"I don't believe public health has any role in climate change mitigation; maybe, if we are talking about adaptation...maybe, they may have some limited roles...like for example, I have seen their campaigns on limiting mosquito bites because of warmer temperatures, for example." [NPH participant]

However, mostly guided by their mandate on climate change, some NPH trivialized public health's role. Public health was considered as "the other" or a "social ministry" or "humanities", "not part of the government", or not as relevant to climate change, meaning that public health was not part of the broader climate change action group typical of the ministries work. Furthermore, public health was not considered an immediate level of government as this participant notes.

"So we wouldn't typically work with public health because it's an external or not immediate government. So we would work across ministries, and there's always consultation across ministries and anything that has impact on ministry's mandate..., we will often bring in the Ministry of Health specifically on new policies if they seem related to their mandate because they are not part of the resource ministries with whom we regularly consult with on new policy proposals. Resource ministries are, for example, Forestry, Mining and Agricultural ministries. Like health wasn't a part that [part of committees and mandates], so if we had anything related to health, we would just reach out to them separately, so that's how it specifically works in Ontario." [NPH participant]

Sometimes, climate change was not viewed as an eminent public health issue.

To be honest I never thought of it like that. I don't think it's the biggest public health issue. When I think of public health, I think more emissions, like when you breathe stuff in. Personally, I think the big issue is if it is heating up. Like we see deaths in Quebec, because there are people that already have health problems, and the heat only makes it worse. But climate change wouldn't bring acute impacts; it's not like a spill or a toxic gas or something where, you know, you have trouble breathing because of asthma. It's more like the heat. I mean there are incidences that could happen like forest fires, that I guess people die too, so then there is like a health aspect, as in you are dead, you know what I mean. But I don't see it as much a direct thing. With the economic development standpoint, 
health is more like... there are economic opportunities for Ontario business to gain market share worldwide..." [NPH participant]

The $\mathrm{PH}$ group was not surprised and sometimes disheartened by such opinions and perspectives. This was especially evident in participants' responses, which were sometimes accompanied by silence, gasps, disbelief, anger, frustration or change of tone. Many of the $\mathrm{PH}$ participants $(n=6)$ linked ideologies about a lack of a role for public health in climate change to several factors. These included Ontario's narrow-focused climate change policies, the economic focus of Ontario's policies, both at the provincial and local levels, committees that have excluded public health participation, and the ministries' inability to vision public health's role in different projects across various levels of government. These ideologies were also linked to the lack of media attention and laxity in recognizing public health's implications of climate change globally and locally.

"I think our biggest concern is that most people are not making that link between what we are seeing now with extreme heat, fires, flooding, Lyme disease. It's been only recently that the media is actually starting to hint at... oh, maybe this links to climate change. So that is really been in the last several months, I would argue. Because after that point, a lot of these events were not being linked, you know. The health impacts were not being linked to climate change." [PH participant]

"I mean it just could be that it's a newer issue on health and public health radar, not just in Ontario but globally. I know that the World Health Organization, for example, now has a climate change and health panel, but that probably hasn't been around for that long. I can remember, I was reading about it, so I think it takes global, national, and local organizations to sort of put that frame of things then. If that hasn't happened, then nobody else is going to pick up on it either. Because historically, climate change has been about environment, about the environmental impacts, and there has been nobody to sort of take that next step to say, well, if there are these environmental impacts then there are also these health impacts. I was just in a meeting yesterday where we were talking about environments and environmental assessment, and you know someone said, really, when you talk about environmental assessment, you are talking about impacts on human health, that's why they are done. And so I think it's sort of taking the messaging to that next step where you say that there is changes to the climate, it's affecting the environment in these ways...temperature, water levels, floods... and then these are the health impacts of those things. And I think that that's the next kind of piece, is that, you know, whatever happens to the environment affects us and affects the environment." [PH participant]

Public health participants further revealed that attitudes that deprecate public health's role are very prevalent in their work, and not only in climate change competencies. Such resentments are present and have been experienced at the local and provincial levels or at forums with NPH participants. In turn, some public health participants $(n=6)$ reported feeling devalued in various platforms they have engaged in both at the provincial and local levels.

"That is something we have come across as well. You know, sort of the question of why 
is public health here. And I think again it is that traditional recognition of climate change as an environmental issue, which it is. But it is also a people issue, and you know, we at public health are not responsible for clinical health, but we are responsible for the wellbeing of our population, and so I think climate change really does fit," [PH participant]

"I am not surprised because again, I have seen that locally in the work that I have done related to built environment. That it takes a lot of work and really constant messaging and constant communication with our municipalities, for example, to really connect those dots because their focus might be on economic development, for example. So they want to bring in new business, that kind of thing. But they are not thinking about what in the community is going to make it attractive for a business and a family to relocate here. So what our role is, I think, is to connect those dots and say, ok, you want to bring more business in the community, that means people are going to move here with their family, and that means they are looking for a good quality of life, but what does that look like in our community? They want it to be healthy, they want opportunities for recreation, they don't want to always get into their cars, they want their children to be able to play in safe places.. you know, and so a lot of the work that we do in public health attributes to that, but we need to point those things out, and I have had some interactions with different ministries as well, and I think communication with provincial ministries is the same thing." [PH participant]

"It's pretty much the same conversation that we have been having related to public health and the built environment. You know, because really the lead ministries related to the built environment are the Municipal Affairs and Housing and Transportation and so through the [redacted] we have spent a lot and doing a lot of work on how do we engage the municipal planning sector. And now, how do we engage the transportation sector? And they say the same exact things. Like, you know, why would we invite public health? What interest would they have on a road plan? Same thing, we have talked to transportation engineers, we have talked to transportation planners about if they engage with public health and if so how or where the input would best be and, yeah, the same conversation, different topics." [PH participant]

Given such results, many from the $\mathrm{PH}$ group $(\mathrm{n}=9)$ agreed that it is imperative for the public health sector to educate policymakers and the general public on the broad roles of public health in climate change, a point that is stressed by this participant.

"I think it is more a challenge that is broader than climate change and ...understanding what public health is about, and understanding the determinants of health, and how our social and physical environments affect health. I think there is a limited understanding of that in the general population. And, anybody who is outside the public health field, I don't think, has a real sense of those determinants of health and how equity issues and the physical environment can affect your wellbeing so much. And also, with the role of public health, it can be very typical to think of vaccination, but I think that's a very limited view of the scope of what public health is. And so, maybe, it is up to the public health agencies to be doing some education and communication about what it is as our role, because I think understanding that broadly would naturally lead to a better understanding of how public health fits into the climate change conversation because it's mediated through all these determinants of health in terms of what are the impacts on our physical environments. You know, extreme heat...you know, what does that mean for public health or impacts of air quality or vector-borne diseases. I think once people understand, it is very clear to them, 
but it is not something that comes to mind unless it has been explained." [PH participant]

One public health participant suggested health in all policy approach to support the identification of public health's role in climate change by ensuring that stakeholders are made aware of the various areas that public health impact within communities.

"There needs to be constant messages and effort to raise awareness about why health should be at the table. And it's the whole, kind of, health in all policies approach which makes sense to us, but for somebody whose world is business or whose world is roads, that's what they think about. They don't think about, oh, well, you know, roads are also part of community health and have the potential to impact health in different ways. And I think that a constant... that is something that we in public health always have to be thinking about. All these things make sense to us, but they necessarily do not make sense to people who work in other sectors, other ministries, etcetera. And so, I think we have to think about how does what we are doing connect to those other ministries, those other professionals, and the work that they do? And how do we show the value that a health perspective brings to the work in terms of the goals that they are working towards? So related to economic development, what do we contribute to that? Well, to me, what contribute is that people want to live in a healthy community that has a good quality of life. And so here are the health-related things that contribute to that, and that's going to be good for the economy because more people will come and live here, more people will visit, more people will shop, etc. I think in public health, it is important. Like sometimes we get really caught up in our own objectives, but we exist in a large system and have to think about how what we do connects to those other pieces and be able to communicate regularly those messages to those other stakeholders because they are not necessarily looking up for public health and saying...oh, I wonder what public health thinks about this? Or I wonder what the health impacts is of that? Because the other thing is that people think about health and they think about health care. They think about hospitals, doctors, wait times, all that kind of stuff. Like that's the catchy bit about health, when there is so much more to health than that and so much that public health contributes to the health system beyond only healthcare and treatment. They think of the easy things like immunization and water safety, safe water; those are the really easy public health things that people try to identify. The things that are less obvious are the health promotion things, like doing the vulnerability assessments, like advocating for policy. All that kind of health promotion work is harder to define, is harder to see and is longer-term. The outcomes are longer term. You know, when you talk about reducing chronic diseases and those kinds of things. And so they are not at the top of mind for people because they are not visible and so to me, part of the work of health promotion is not just, the health promotion itself, its's also communicating with stakeholders at all levels what the value is in health promotion initiatives and how that benefits in many different ways aside from health, because if you don't have a healthy population, what have you got? That is going to impact your economy" [PH participant]

Equally, the health professionals hope that the 2018 public health modernization initiative that led to the inclusion of public health mandate in climate change provides opportunities for addressing such attitudes and further developing the guidelines in a manner that highlights the role of public health within the broader climate change framework.

"We also encounter such [i.e. attitudes of lack public health relevance], and we really 
hope that this guideline [that provides a mandate to public health] that we came up with will address some of those attitudes. Because when you look at the guideline, it doesn't say "address climate change", it talks about the work that public health can do to address climate change impacts. Some of that work is the work they [PHUs] are already doing. That's what I mean, like recognizing that climate change, although it sounds like a big issue or role, there are still some parts that public health can tackle. So as I was saying, those kinds of attitudes that challenge the notion that public health doesn't have a role to play in climate change - I think that's a challenge for sure - but I think for us, we want to talk about the work that public health is already doing. There are opportunities within that work. Before we even get to other work that they [PHUs] can do, there are opportunities within the current work that they [PHUs] are doing. And even maybe...that could be the next step of even highlighting further because this guideline is just a first step." [PH participant]

However, there were also suggestions from the NPH participants on how public health can be included if the sector identifies common interests in agencies mandates. Suggestions included considering the policymakers' interests, values, objectives, priorities, and clearly explaining how public health fits into the current decision-making process. Many $(n=6)$ suggested economically focused narratives for overcoming the silos and supporting public health inclusion. As illustrated below, many decisions are rated based on economic savings or gains, and public health narratives should highlight such economic narratives when characterizing their relevance in climate change decision processes.

"Anyone you try to convince, stakeholder groups, municipalities, and any kind of individual, you have to make it like, why do you care? Usually, it's like something is expensive, it costs me money, or like, this is really burdensome, it's hard to do. I don't want to do it because it's going to cost me time or effort. Or how can you make it easy? How can you make it cheaper? How can you make it, like, this is important to you? They [policy actors] will hear. I know you find these things important, so it actually sells your problems or get problems that are important to you. They will be like you are trying to sell somebody something ...because you need this. Because, you know, this will actually help you or you have committed to this to help you reduce the goal or improve in this aspect that you said you needed to improve. It's building a story around that person or route-specific problem or opportunities or, you know, to help them make money or something. You really have to put it in the context of what their values or objectives or priorities are." [NPH participant]

"I think if you are a public health professional, the best way to approach it is to try to identify linkages to existing government commitments. Whether it's like - how can we create jobs? How can we, maybe, help? So maybe it's like a social policy for lower income? How can we help those individuals linkages to poverty reduction; link benefits. Like climate change stuff you know, like coal phaseout, for example. Just try to find where you can link it to other existing ministries instead so that you can come up with ideas that would benefit both of us. That's the best way forward to get the momentum. Otherwise, you work in silos. But I wouldn't really think about it unless someone came to me and said - you know, there is a big opportunity for Ontario companies if you create jobs because there is a big issue in public health. We feel like this is a big issue in China as well. So if we can figure out how to get these companies to both commercialize technologies that could solve a problem in china too, I think we can benefit because we can actually raise our GDP and 
export technology and patents or whatever." [NPH participant]

The above quotes demonstrated the economic focused priorities that public health needs to consider when reaching out to government agencies for inclusion in the discourse. The PH group $(n=4)$ also brought up the issue of the economic-focused framing of climate change as a barrier to public health inclusion and engagement. Document analysis of the thematic frames (Chapter 6) also revealed the dominance of the economic narratives and ideologies in Ontario's climate change discourse. Further analysis of these themes from participant interviews exposed the perspectives of participant's framing of climate change and will be discussed in subsection 10.2.4 (Meaning of Climate Change).

\subsubsection{Perspectives on Public Health Leadership}

When the two groups were prompted on whether public health had the capacity or potential to lead climate change policies in Ontario, there was largely a consensus between the $\mathrm{PH}$ group as more than $70 \%(n=8)$ of the participants acknowledged the need for public health leadership in climate change. However, there was a lack of consensus within the NPH groups with blurred differentiation between leadership versus the role of public health.

Within the PH group, many who supported a public health leadership in climate change indicated that such leadership is relevant as it brings in different stakeholders and pool resources that are needed to develop legitimate climate change policies. Public health leadership was viewed as a means of advancing knowledge on the direct and indirect health impacts of climate change and connecting such impacts to the needed mitigation and adaptation strategies in a manner that resonates with many communities. Equally, the participants indicated that public health is well-integrated in, portrays great relationships with, and is trusted in, various communities. The sector directly engages in a wide range of health-related initiatives and with a wide range of populations that support advancing climate change needs at the local levels. Such views are summarized by this participant's response

"I do think leadership from public health is important, and I think that it's because of the way that we are integrated into our communities. We understand environmental impacts. We understand the social impacts, and we also already have really great relationships built-up with multiple community stakeholders, and climate change is something that cannot be dealt with by one group alone. It really needs to have a community response. So I think public health can lend a really great hand and provide that leadership to bring different organizations together to come up with solutions, and we have seen that already here in our region." [PH participant]

As this participant points out, public health personnel are already showing leadership in climate change initiatives. 
"There are many in the public health community that are showing leadership. And so again, when you hear [name redacted], all the different forums I have been to, [name redacted] is always talking about climate change. And people like [names redacted] and [redacted] network of people. They are doing a lot of innovative things" [PH participant]

This leadership, from a variety of stakeholders, as these two participants point out, is collaborative leadership. However, it can also be through public health advocacy.

"So we don't know everything. We are not experts. So what does that mean when you say take leadership? So, we shouldn't be the source of everything, and know everything, and be the ones asked to do everything. I think we have a role to play, and others have a role to play too. So I don't think it's about like, oh you should be a leader, and you shouldn't be a leader. I think leadership needs to come from many places. It's collaborative leadership. That's very much the philosophy of how we do work. It's collaborative leadership. It's not about one group being the lead. It's more about - how do we help bring people together, and then when we bring people together, are we providing a facilitative role?" [PH participant]

"I think another way we try to provide leadership is to say, if there is an opportunity to speak out, whether that is through responding in the media, whether that's meeting with the government officials, whether that's appearing before legislative committee...so there is different ways you can play a leadership role. But I think public health isn't the lead, but public health needs to show leadership. So, I think that's what's unique that we can bring, is talking about the health impacts of climate change and what we can do to mitigate it." [PH participant]

Similarly, many who supported a public health leadership reinforced the notion of public health's unique position to lead climate change.

"There are great health impacts of climate change. Some that are currently happening and some that are projected. But already, we are seeing some of these effects. We have increased vector-borne diseases; we have seen an increase in the Lyme vector, for example. So how do we address that? Public health is very uniquely positioned to address some of that because public health units work directly with some of those vulnerable groups and populations in Ontario and they do a lot of great work on public awareness, raising public awareness, and ensuring development and mitigation efforts. So, I think, now in my role, I see climate change as something that public health is uniquely positioned to address and it starts from smaller initiatives that address the specific geographical location that health units are in right now. So an example would be like the vulnerability assessment. For example, the [redacted] did the vulnerability assessment, and they are a smaller health unit. So, when we talk about vulnerability assessment which is a very huge task, I think they are a great example and a leading example of doing the assessment and identifying the vulnerabilities and eventually helping in the development of adaptation plans. So for me, now, being in this role, I see a huge role for public health." [PH participant]

While some agreed that public health leadership is needed, they point out that for public health to lead climate change policy discourse, the leadership role must be clearly defined. Other $\mathrm{PH}$ participants $(n=3)$ also indicated that other sectors have a leadership role to play as well. 
Furthermore, $\mathrm{PH}$ participants $(n=4)$ suggest that such leadership roles must be accompanied by the leadership from the MOHLTC and Medical officers of Health. Some public health participants $(n=7)$ also pointed out that there are systemic barriers to be overcome for that leadership to be successful. For public health to lead climate change discourse, the leadership roles must be clearly defined and be accompanied by authority and resources to support such responsibilities.

"Well, I mean, my starting point would be that I am trying to understand what do they mean by a leading role? What do they see public health doing? Authority that they are going to give us to actually do that work. And what resources are they going to give us to do that work? Climate change is certainly an important issue, and I am not opposed to doing the work, I just need to understand the framework in which I am working, right." [PH participant]

"And again, I mean, it's not actually work that public health is going to have lots of authority to get other people to do the thing differently. But I mean public health may have an opportunity or role in the public education around mitigation." [PH participant]

"I am not necessarily saying that public health shouldn't say anything or whatever. I am saying that you need to recognize - and not just like you need to recognize - but you need to recognize that there are systemic barriers and there is a difference for me between saying that public health can advocate if there is some legitimacy to advocating than actually saying public health has the responsibility to solve this issue. It's not an issue that public health can solve on its own. So I think it's a balance about framing and how do we say... how do critics say then... wow, public health is behind on this or should be doing $x y z$ or is responsible to solve it. Public health is a very small part of a giant system. And absolutely, we do all kinds of work around healthy public policy, and we add this one item and one topic to the list of healthy public policy topics that we want to do, that we want to influence the broader environment because they all impact health but that doesn't actually mean that we have the authority or responsibility to fix this or the power to fix this. So, I think that we are saying the same things slightly differently. Like, I am completely on board, we need to be included, think about it, play a role and that kind of stuff but... we have premiers and prime ministers and cabinets that give conflicting things, and public health is not going to have the resources or the authority or the ability to make anybody else do anything." [PH participant]

A participant mentioned that providing a public health leadership (at the moment) - specifically, those relating to mitigation - is not reasonable, as public health neither has the capacity to lead climate change nor the bureaucratic function on climate change.

"For health units, it's not about which ministry is the lead. It's not about whether it's the ministry of environment or whether it's the ministry of health. It is hard because they (PHUs) are closely tied to the ministry of health. I know that there are a number of health units that work very closely with our partners at the ministry of environment. So it's not necessarily about which ministry is taking the leading role because that is a bureaucratic function. But with health units, their roles are very different. They are to serve populations and certain groups and understanding their own geographical needs... and you know those kind of things. And then finding opportunities within their existing work and not sort 
of tying their work to what the ministry of health is saying. Well, they are not saying that... may be, we shouldn't do it [i.e. take leadership role]. I don't think that needs to be an understanding of that sort. I think it needs to be an understanding of what can we do to address the needs of our public health? Of the health of the public in the population in our jurisdiction. And what are some of the best measures? What are our partner health units doing?" [PH participant]

Following a similar pattern on the roles of public health in climate change, many NPH participants $(n=7)$ did not support a public health-led climate change discourse. Few were certain of public health leadership. As this participant specified, the relevance can be due to the public health independence of government, highlighting public health's collaborative and facilitative role.

"I mean, I think the civil society and public health officials can certainly... I mean public health officials probably have a pretty good chance [of leading climate change actions]. They are relatively independent of the senior levels of government. I think a lot of local public health officials can play a pretty important role in raising awareness in the population. I think the thing is that if public health can forward a discourse and consensus around society that is not a result of what the government does, that is a result of what civil society and population have reached as a consensus, I think that discussion can certainly enhance climate change actions. But there could also be roles for a lot of people in academia, environmental groups, and health professionals as well. So, I believe everyone has a role to play in the discourse. That's leadership in civil society and sometimes that's the leadership that is needed before government follows along." [NPH participant]

Few $(n=3)$ also suggested that there was a role for public health or need for consideration of public health's role and not leadership in climate change. However, such reasons were rarely associated with public health competencies. For instance, a participant suggested that public health leadership is warranted given the sector's elaborate budget.

"Public health system is quite amazing in Ontario. It is very big, like financially, like if you can work it of, it's... about $60 \%$ to $70 \%$ of total spending in Ontario is related to ministry of health directly or indirectly. They are always such a big part of public spending for a number of reasons. That ministry is very much... it is a government on its own. It is a big ministry. The Ministry of [redacted] is a much smaller organization in the big bureaucracy." [NPH participant]

Those who did vision the role of public health in leading climate change suggested that it would be difficult for public health to lead climate change as such engagements require sectors directly associated with GHG emissions. The public health would also have to overcome the political dominance of Ontario's climate change decisions. For instance, a participant gives an example of the cancelled Cap and Trade program to highlight that such decisions cannot be overcome by public health leadership, although there is a chance for leadership in the future.

"In terms of cancelling of the cap and trade program, I don't think that public health could have swayed anything on that front. I think that was a move made. It was a promise made 
in the election and it was a political move that the government would have followed through regardless. But I think, moving forward, public health can play a role in helping shape whatever comes next." [NPH participant]

On the contrary, a member of the $\mathrm{PH}$ group advised that public health is likely to provide healthrelated evidence that would be used in policy processes to dissuade such cancellations or public education that enables the public to see the relevance of such programs if the sector is meaningfully included in the policy discourse.

NPH participants also argued that it was harder to sell the need for public health leadership in Ontario because the health impacts were not as pronounced as in other parts of the world. However, public health may become relevant in the future as these impacts become more severe. "But I think, I mean, in a way I think, in Ontario we are generally, this is a very general statement, but we are pretty insulated from the worst of the climate change impacts. They are here. We are feeling them. But in terms of, kind of, the worst that we are starting to see or having seen around the world in terms of drought, in terms of extreme heat, in terms of sea level rising that directly impacts a large number of people, we are pretty ok in Ontario. And I think it's a harder sell, as a result, to have people focus on climate change because if they are not sick, if they are not dying because of these things like a lot of people are, then it is a harder sell to make a public health argument. But, as the years go on, it's going to become easier and easier because of the nature of the changing climate. The changes are going to happen faster and more intensely moving forward. So at this point, it is human nature that people don't necessarily see decades into the future. They see immediately. So they may be swayed by the fact that they may have more money in their pockets now because they don't perceive themselves as being at risk from a health point of view of climate change. I think that is generally how I feel, and it's something we have a bit of a harder sell here to make, but we are trying. I think public health does have a role for sure." [NPH participant]

According one NPH participant, public health leadership is warranted because climate change adaptation was not an environmental issue that should be dealt with by the MECP and instead should be under public health among other ministries.

“Adapting to climate change cannot...isn't really an environmental issue because it's the consequences of an environmental issue. But it is not environmental issue in itself. It's not necessarily protecting air or land or water in the way the [redacted] thinks of, of what it's work and role is. It's an infrastructure issue, it is a public health issue, it's a community health and safety issue, it's an economic issue, but [redacted]...So I think, as I said before... you know, on the adaptation side of climate change - again it is not an environmental issue. Maybe, we can play a coordinating role but in terms of actually putting into practice the actual policies and programs that will have a real effect on Ontario's broader response to climate change. I mean, it's probably not going to be us. I think it will probably be ministry of health, and infrastructure and community safety, those kind of ministries that kind of, you know, they are a bit more directly involved in the things that will be impacted by climate change." [NPH participant] 


\subsubsection{Meaning of Climate Change}

During the interview process, one of the questions explored the perceptions of participants on climate change framing. This question explored what climate change meant to the participants. Based on the responses, while some provided a general definition of climate change, there was a divergence on the climate change meaning with many NPH professionals focusing on environmental $(n=9)$, economic $(n=7)$, or technological $(n=6)$ frames when discussing what climate change meant to them or how it should be framed. Two NPH participants included a public health narrative.

On the other hand, the $\mathrm{PH}$ group was dominated by health $(\mathrm{n}=9)$ and environmental focus $(n=8)$. However, there was also an inclusion of economic $(n=4)$ and equity or moral $(n=2)$ frames. Climate change frames and sample quotes are illustrated in Table 19: Frames used by participants to describe climate change below. However, unlike the document analysis, political frames were not evident.

Table 19: Frames used by participants to describe climate change

\begin{tabular}{|c|c|}
\hline Frame & Sample Quote \\
\hline $\begin{array}{l}\text { Economic and } \\
\text { technological } \\
\text { frame }\end{array}$ & $\begin{array}{l}\text { "So, I mean, climate change is an interesting one because its an externality, } \\
\text { right, it's not priced in so it's almost like in some ways it's a market failure, } \\
\text { like I took public economics I looked at specifically cap and trade, you know } \\
\text { globally emissions are rising, and there are impacts globally and the reasons } \\
\text { there are emissions you know it's cheap to bring coal. The prices for example } \\
\text { of renewables have come down quite a lot, but they needed incentivizing } \\
\text { from government so some sorts are the government needed to incentivize } \\
\text { new technologies they won't get because they are expensive so we need to } \\
\text { be supportive about research and innovation and commercialization and so } \\
\text { because the price of carbon was not priced in people would just emit but if } \\
\text { you put a price in carbon other technologies are more likely to be used } \\
\text { because the real cost of burning coal or petroleum-based product would be } \\
\text { added to the market so the market would be like, ooh, its more expensive to } \\
\text { burn coal because this is a real cost of it. Otherwise, if it is not included } \\
\text { people just cope up their ways. [NPH participant] }\end{array}$ \\
\hline $\begin{array}{l}\text { Public health } \\
\text { and economic } \\
\text { frame }\end{array}$ & $\begin{array}{l}\text { "And there is that human cost. The human cost to health and livelihood, it's } \\
\text { something that I think about, you know, kind of the acute losses that might } \\
\text { happen as a result of more extreme weather, but also kind of the longer-term } \\
\text { health implications of being exposed to hotter weather, the mental health } \\
\text { concerns as people's livelihood might be affected as people have a lower } \\
\text { ability to cope with the changes that are happening, you know, that is } \\
\text { something that I think we are all going to face in some way or another and } \\
\text { it's the people's capacity to withstand those changes, you know, very much } \\
\text { depends on their...you know, I think inequality plays a big role, income, all } \\
\text { that sort of things.. you know, socioeconomic issues play a role in broader }\end{array}$ \\
\hline
\end{tabular}




\begin{tabular}{|c|c|}
\hline & health implications of climate change." [NPH participant] \\
\hline $\begin{array}{l}\text { Environmental } \\
\text { frame }\end{array}$ & $\begin{array}{l}\text { "I go back to the basic concept of it. It's human-induced changing climate } \\
\text { which has many consequences globally and locally, and some of it is } \\
\text { temperature related, some of it weather changes, weather patterns and then } \\
\text { the subsequent change in ecosystem." [NPH participant] }\end{array}$ \\
\hline $\begin{array}{l}\text { Scientific, } \\
\text { Environmental, } \\
\text { Health and } \\
\text { equity }\end{array}$ & $\begin{array}{l}\text { "Wow, ok, I didn't expect this question...but I would say I see climate change } \\
\text { as changes in the climate factors such as temperature, over an extended } \\
\text { period of time. These changes lead to various impacts, including health } \\
\text { impacts, impacts to the environment. Some people will be more affected than } \\
\text { others and like we have seen across the world, there are different health } \\
\text { outcomes both in health and environment...I think, here in Canada, the } \\
\text { northern areas are greatly impacted with the less snow and thawing of } \\
\text { ground while here in Ontario we are experiencing more extreme heat and so } \\
\text { on." [PH participant] }\end{array}$ \\
\hline Healt & $\begin{array}{l}\text { "The meaning and relevance of climate change to me relate to its impacts on } \\
\text { human health, and that is what we try to integrate into our policies...by } \\
\text { ensuring that such health impacts are proactively identified, and that } \\
\text { adaptation measures are in place to minimize or prevent the impacts." [PH } \\
\text { participant] }\end{array}$ \\
\hline
\end{tabular}

Overall, to create effective messaging or framing for climate change, many participants from both groups $(n=17)$ suggested a need to create messages that resonate with a broader audience. The recommendations for such messages broadly covered health, economic and environmental narratives. However, as this participant mentions, instead of abstract impacts, the message should be personified to illustrate impacts on an individual's health or economic status.

"I think we have to be creative, looking at different types of messaging. So you know, we've spoken a bit about public health, and I think where people might be able to see a threat or see where they can take preventive measures to make their own life healthier, that might be more effective messaging. From an economic standpoint, maybe you know, demonstrating what the actual hit on your pocketbook is. The result of insurance rates going up due to extreme weather events or an increase in wildland fires, or you know, those type of things where you're making that messaging more personable for people. Because I think to say to them that in 2050 we are going to have an average temperature that is $2^{\circ} \mathrm{C}$ greater than what we have now, that doesn't mean too much to people. So we have to go with deeper messaging." [NPH participant]

To illustrate how to personalize climate change frames, one participant provided a comparison between Ontario's framing and that applied in Europe indicating that there is not enough public discussions on climate change and frames that resonate with individuals

"Science on climate change has been on the sky is falling' for so long, and now it's kind of falling. But I still think the general public doesn't understand what does that means to me in terms of mitigation and adaptation? Like, I read a newspaper from European countries. There is a lot of debate about personal individual climate substance. Like what can I do... I can, maybe, go on a flight not every year but every second year. Like with airplanes, because there are carbon footprints when taking airplanes. I can buy less clothes because the clothing industry has a big carbon footprint. So I think in other 
countries, like in Europe, there is more debate about what climate change means for the general public or for the individual. The public discourse on climate change is more active because they have experienced climate change more directly. I mean if you are in Europe worrying about the stability of economy, well there is a public discourse focusing on

that...it's focused on that.... and the public discourse changes all the time, even in North America, right? So we don't have a lot of open conversations, like.... yeah, like there is extreme weather and people are getting impacted, but do we have enough public discourse or discourse? Not really, right!" [NPH participant]

\section{$10.3 \quad$ SUMMARY}

This chapter analyzed attitudes and perceptions that have defined climate change actions in Ontario and perspectives on public health roles, leadership, framing, and inclusion. The analysis revealed that perceptions and attitudes towards public health and climate change connections are influenced by individual perceptions and the broad factors and tendencies rooted in both political and decision-makers' beliefs, interests and ideologies. These outcomes are critical for understanding the values that support or minimize public health capacities in climate change discourse.

Both assumptions and ideologies guide the political parties, leaders, and elites about the appropriate climate change policies and that climate change issues are worth considering in the political agenda. Each government ensured its policy narratives dominate Ontario's climate change discussions and decisions. However, their assumptions diverge as one set of policies that are viewed as economically viable also threatens the economic progress of another political party. Equally, those with the mandate on climate change have limited public health's engagement through attitudes that have denied, distorted or misperceived the role of public health by simply denying that public health has a role in climate change decisions at the provincial levels. Some have failed to recognize their responsibilities (e.g. perceptions) in creating barriers for public health inclusion, instead of blaming their lack of authority and control over climate change decisions and processes. The contradictory responses - e.g. where NPH participants see no role for public health in climate change yet provide recommendations on potential areas of engagement - reveal the policymakers state of cognitive dissonance reduction in Ontario's climate change and public health nexus.

Within the climate change policy networks, the public health community is mainly aware and willing to advance their capacities in climate change. The community is already making strides in facilitating or leading climate change actions. The sector has mainly sought leadership roles that directly relate to their mandate and fall within their realm of expertise. The public health community has also sought to facilitate actions that fall outside of their mandate by supporting 
actions, providing expertise or identifying the relevant resources for supporting climate changehealth promotion-related actions. On the other hand, public health's facilitative and leadership roles have been challenged or limited by the lack of inclusion of public health, inadequate resources, and mandate, and the trivialization of public health needs by political and bureaucratic values. The PH group believes that the NPH perceptions on public health's role and leadership attribute to institutional arrangements, the lack of authority and awareness public health impacts and roles, and the province's frame of climate change as an economic issue.

Above all, political values have provided channels and tools - e.g. mandates and climate change frames - for non-public health policy actors to rationalize public health exclusion and trivialization. The bureaucratic administrators view their task as advancing the government's agenda; they direct their interests in climate change decisions as informed by the values of the political elites that have mainly sprung from economic and technocratic-informed vision of climate change policies. In turn, the mandated agents have developed the view of their roles and those of others in the climate change debates and selectively identify information and actors that they perceive to be relevant in the decision processes based on mandates, norms, and political structures. While values from political and individual values guide this interpretation, such perceptions on public health are not always a reality, especially after the literature review clearly highlights significant roles for public health in climate change.

The psychological impacts of such barriers on the public health community are apparent, as demonstrated by the participant's narration exemplifying how they have experienced devaluation in decision-making platforms. Nonetheless, the community has continued to identify avenues for public health engagement and health promotion. To support the public health-focused frame and public health inclusion, public health communities must highlight the relevance of public health in different forums. Public health also needs to work with different stakeholders and decision-makers to influence political support of public health needs. They also need to forward a health-in-climate-change-policy approach to influence the current perceptions held mandated agents, and link the need for public health in terms relatable to policymakers (e.g. economic terms). 


\section{CHAPTER 11: INTERPRETATION OF FINDINGS}

\section{INTRODUCTION}

Chapters 6 to 10 have reported on the findings of the study based on the thematic description to support the understanding of the research problem from various perspectives. The purpose of this chapter is to make sense of these findings by interpreting and discussing the significance of the study findings based on logical sequence and by highlighting how the findings related to those from previous studies or literature.

Section 11. 1 addresses and connects study findings with the first and second research question by explaining the framing of climate change in Ontario and the strategic or systematic influences. The section explains the effects and roles of discourses, strategic and communicative actions, and identities in the construction of climate change.

Section 11.2 address the third research question by connecting the influence of climate change framing in Ontario to the governance structures and processes, and institutional arrangements, within and without public health, which either facilitated or impeded the public health frame and capacity in climate change policy discourse. There is a particular focus on the impediments of knowledge integration, institutional engagements, and contexts of power.

Section $\mathbf{1 1 . 3}$ addresses the characteristics of the methodology or study design likely to impact the interpretation of the study findings and how such limitations were overcome or addressed.

\subsection{ONTARIO'S CLIMATE CHANGE FRAMING, STRATEGIC INFLUENCES, AND SOCIAL CONTEXTS}

The analysis revealed that between 2007 to 2018, the government of Ontario recognized the various impacts of climate change and that solutions to climate change are needed. Regardless of such acknowledgements, a significant influencer of climate change policy discourse was the economic frame, which was embodied in major strategic plans, media releases, and other government texts. There was a focus on presenting climate change as an economic opportunity in which political and technocratic elites favoured technological innovations to advance market-based solutions.

The economic frame was mainly presented by highlighting the economic opportunities of action. "Good climate policy" was considered a "good economic policy" (Government of Ontario, 2015a). The frame highlighted how the province's economy, industries, business and the public 
can benefit from the actions and that such actions provide economic leadership and investment opportunities for both individuals and the government. Economic consequences - such as those of extreme weather - on business were highlighted, awareness of the impacts by business emphasized and needs for effective future planning to minimize such economic impacts encouraged. The economic-focused climate change policies were not only viewed as a trade-off but as a complement to environmental protection and the recognition of global and local economic opportunities for businesses, technological innovators and to the province (Government of Ontario, 2017). The appropriateness of policies was largely presented in monetary terms with predictable and calculable costs without a focus on risks and uncertainties. For example, Climate Ready - Adaptation Strategy and Action Plan 2011-2014 only presented impacts of rainstorms and floods in monetary terms while the Made-in-Ontario Environmental Plan (2018), mentioned "costs and impacts" separately, even though the cost is an impact of climate change. The narrative depicted norms of economic competitiveness, opportunities (such as investments), access to global markets, economic growth, economic leadership and job creation, trade-off, economic consequences of action inactions. The policies were portrayed to present economic opportunities for businesses, families and the province. However, it was the subsequent framing of the issue in the political arena that has shaped the economic narrative and focus of climate policies in Ontario.

The political influences on climate policies have been heavily influenced by both local politics and norms. At the local level, legislative mandates, provincial elections and partisan preferences heightened the dialogue on climate change and triggered policy decision points (Elections Ontario, 2019). In the election years, parties (through their leaders) defined their climate policy platforms and positions. The politicization and inclination of climate change policies along party lines were very apparent in Ontario. For most of the years of this study's focus, Ontario was ruled by the Liberal government (i.e. 2007 to June 2018) with the PC government taking over thereafter (Elections Ontario, 2019). Within the periods, there was a significant rise in both economic and political narratives at the beginning of each election year. These two political periods displayed divergent politics and narratives of climate policies. The political narratives focused on framing climate change policies either as ways to improve economic competitiveness (the liberal narrative) or as harm to economic competitiveness (the PC narrative).

Functioning concurrently along domestic political narratives were the national and international norms. International agreements triggered institutionalization of international norms into domestic climate policies, international alliances (e.g. the Western Climate Initiative), privileging mitigation and specific sectors (e.g. energy, industries, transportation). To forward the economic and political narratives, Ontario framed climate change as a global issue whose actions 
required the world's political views and actions. These views emphasized the gains (both political and economic) that can be achieved through leadership among competing nations. Ontario's global leadership was emphasized and presented as an opportunity for economic competitiveness and prosperity (Government of Ontario, 2015d, 2015c, 2016d). As a result, political frames also mirror the patterns of international activities such as the 4th IPCC report (2007), COP 15 (2009), Canada's withdrawal from the Kyoto protocol (2011), and COP21 (2015). National leaders used international norms to justify their policies. This was prevalent in the forwarding of carbon market mechanisms, partnerships nationally (e.g. Quebec) and internationally (e.g. California), technological innovations and legislative mandates. There was a focus on specific sectors such as energy, transportation, industry, and waste. National influences, such as pushback on climate policies by Western provinces in Canada (e.g. Saskatchewan, New Brunswick), were used by political leaders, through alliances, to justify the elimination of cap-andtrade. These alliances were also used to oppose federal carbon tax impositions (Government of Ontario, 2018; Government of Ontario, 2018e, 2018f, 2018d).

To advance the economic narratives, political elites favoured technological innovations that were presented to benefits both the economy and the innovators through unique business opportunities and global competitiveness. In turn, most economic strategies were linked with technological, innovations, tools, and interventions depicting technology as powerful solutions for targeting both the economy and climate change. Such benefits presented to derive from the use of renewable energy sources and energy efficiency. The narrative reduced climate change to an energy issue where the solutions for minimizing GHGs relied on technological innovations and the advancement of renewable energy. The technological narrative was mostly nested with its relevance to economic growth, competitiveness and innovative leadership. Investing in clean technologies was also presented as an economic opportunity for creating and maintaining highquality jobs and skills and growing new sectors. By claiming technocratic rationality, Ontario prioritized addressing climate change using technological advances and innovations from expert knowledge (Pettenger, 2007b). Fighting climate change was presented as an opportunity for innovation due to the global demand for low-carbon products and technologies.

Textual elements of social events are likely to influence knowledge, values, and attitudes; texts as social events also shape identities and institutional relationships (Fairclough, 2003). The results of the analysis revealed that such textual influences were prevalent in influencing the framing of climate change. Three elements of social practices emerged as the influences of climate change framing. First, how the issue was presented and connected to wider social contexts (discourse). Second, interactions between climate change stakeholders (Actions). Third, 
governance styles and how those involved in the policy process identified, legitimized, and normalized climate change actions (identities). These elements controlled the course of climate change decision processes and policies by forwarding a narrative with specific climate change needs that led to the inclusion and exclusion of others.

\subsubsection{Discourse}

Frames align with specific discourses (Fairclough, 2003, 2013; Walter, 2013). As illustrated in the literature review, several researchers have identified several discourses guiding environmental issues, in general, and specifically as relevant to climate change as an environmental issue (Carvalho, 2005; Darrier, 1999; Dayrell, 2019; Hajer \& Versteeg, 2005; Hanson-Easey et al., 2015; Koteyko et al., 2010; Nerlich et al., 2010; Roper et al., 2016).

In Ontario, just like many parts of the world, climate change debates have focused on economic and technological frames (Spence \& Pidgeon, 2010). The political (social) contexts of Ontario's climate change framing and the resulting discourse mirrors four global climate change discourses: liberal environmentalism, ecological modernization, green governmentality, and administrative rationalism. Between 2007 and early 2018, climate change policies were guided by the discourse of liberal environmentalism and ecological modernization. The discourses were portrayed through the internationally formalized negotiations and signatories, national inventories for GHG reduction and mitigation strategies and exercising of power for the sake of collecting GHG emission information (e.g. national inventories of GHG emissions). As a result, Ontario's climate change policies prioritized economic growth within the context of environmental protection while also institutionalizing environmental protection into the various economic norms that defined climate change policies. The two discourses were especially relevant during the 2007-8 economic crisis, which led to the incorporation of economic narratives in climate change policies with an effort to improve the economy. Some of the notable climate change policies that emerged included the promotion of renewable energy sources such as solar and wind power. Within the liberal environmentalism discourse, economic development and technological advances were viewed as efficient and powerful policy instruments for decarbonizing economies (Dryzek et al., 2012; Taylor, 2013). And as evident in Ontario, a technologically focused economy increasingly became embedded in climate change decisions, informing many policies and actions on climate change. Technologically framed climate change centrally assigns knowledge and power at the apex, assuming that agents at this level have greater knowledge than their subordinates (Cadman, 2013). In Ontario, expert positions (e.g. expert consultations) were used to justify climate policies. In turn, specific institutions actively engaged and dominated climate change 
discourse. The solutions were then privileged and forwarded by political elites as solutions to climate change. Further, proposed technologies - which were mainly hard technologies such as renewable energies - require specific expertise and specialized knowledge (Sovacool, 2011; Zhouying, 2005). Such tactics distance other actors and institutions, minimizing dialogues and alternative viewpoints (Cadman, 2013). Consideration of area of expertise to legitimize participation in policies would favour expert-linked solutions that lead to knowledge asymmetry (Eden, 1999). In turn, the neo-liberal focus of climate change may have minimized opportunities for the emergence of other frames. Particularly, the ambiguity of other frames can lead to a lack of collaborative efforts as those who do not possess such knowledge are considered non-experts. However, ecological modernization discourse was mostly signified in Ontario's climate change policies that emerged between 2016 and early 2018, which were guided by policies meant to decarbonize the economy in the form of carbon pricing, government policies supporting pricing mechanisms, and the role of industries and consumers behaviour change.

While there was little focus on consumer behaviour, highlighting consumer behaviour and providing consumer technologies such as electric vehicle and energy efficiency rebates showed that Ontario's discourse of ecological modernization was embedded with the discourse of green governmentality. That is, the hope that individuals would change their consumption patterns through policies that promoted uptake of renewable energy sources and means of reducing individuals' carbon footprints (Dryzek, 2013; Dryzek et al., 2012). This was promoted through rebate programs and technologies for GHG reduction strategies. However, there was a focus on industries, mainly funded by the revenue resulting from carbon pricing mechanisms.

Currently, given the time frame that the new government was in power (post-June 2018 to December 2018), it would have been premature to place the current government approach to a specific discourse within the various neo-liberal approaches. However, despite a short time in office, the PC government's discourse on climate change broadly focused on economic and political discourse, in general, with a predominant focus on economic growth and a lack of consideration of technological innovation and consumer behaviour changes. For instance, prior to 2018, there was a consensus on globally defined economic action (e.g. cap and trade). PostJune 2018, negative political narratives dominated after the change of government. Here, the inaction on GHG reductions is attributed to economic losses and blamed on previous government and assertion of Ontario's trivial contribution to Canada's and global GHG emissions, as highlighted in the Made in Ontario Environmental Plan (2019). Also, while texts did not identify explicit utilization of the skeptic's frame, the climate policy politics post-June 2018 exposed the negative political rhetoric and partisan inclination that could be associated with the promotion of 
skepticism to climate change. Within this period, some climate policies portrayed as harmful than beneficial to Ontarians (Roper et al., 2016), leading to the cancellation of several initiatives as described in Appendix K: Chronology of Ontario's Climate Change Activities and

\section{Responses.}

The three discourses discussed were complemented by the discourse of administrative rationalism. Throughout the study years $(2007$ - 2018), the government of Ontario (state) recognized the problem of climate change and the need for policies; it established plans, strategies, targets, and means to solve the problem. However, there was an emphasis on the role of government and its agencies in climate change decisions. The approach resulted in decisions based on government assigned institutional arrangements and powers that define how policy actors and stakeholders act based on the legal structures, rules, authority, norms, beliefs, interests, expertise, and ideologies as well as roles and mandates that were connected to the neoliberal narrative (Fairclough, 2003; Fischer, 2012c; Lawrence, 2008; Pettenger, 2007b). By focusing on expert and bureaucratic knowledge, Ontario's climate change impacts and actions were defined by those producing the texts, mainly elites such as political bureaucrats, agency actors, and select experts. The discourse emphasized the government's role in climate change, where the government and its mandated ministries were active participants in the discourse, influencing policy outcomes. Also emphasized was the role of elites and technocrats (especially from corporations) with little consideration of the role of the general public and public health among other stakeholders.

Studies have shown that climate change discourses, at national and international levels, have been dominated with discourses that emphasize market-oriented approaches as solutions and efficient approaches to target climate change (DeCanio, 2009; Lockwood, 2015; Lohmann, 2016; Stilwell, 2012; Vlachou \& Pantelias, 2019; Workman et al., 2018). The focus on neoliberal frames and discourses has been advanced by several works of literature that have focused on Canada's discourse. Although analysis of frames (discourses) have focused on news coverage as opposed to policy documents (including government media releases), a study by Stoddart, Haluza-DeLay and Tindall (2016) and Young \& Dugas (2012) found Canada's focus on neoliberal discourses with a dominant focus on economic frames and the emphasis of or the dominant role of the state (government) in climate change policies (e.g. Stoddart et al., 2016; Young \& Dugas, 2012). Also, changes in the magnitude of the application of rhetoric and thematic frames have been found to correspond with global climate change events and discourse (Stoddart et al., 2016).

Discourses are also embedded, identifiable, clustered, and embodied in institutions that provide forms of routine interactions, processes, norms, and practices (Dryzek, 2013; Fairclough, 
2013; Fischer, 2012c; Gould \& Lewis, 2009). The discourse applied on an issue not only defines how the issue is presented, but it is also a part of political agenda that defines how the issue is understood, the tenable actors, views and options, and the structures and policy-making processes addressing the issue (Dryzek, 2013; Fairclough, 2003; Ingram, Schneider, Igram, \& Schneider, 2008; Miljan \& Brooks, 2018).

Fischer, 2012, argued that it is not the institutions that caused political actions. Rather, it is their discursive practices that shaped the behaviours of actors, supplying institutions with meanings and structures, norms, and rules of practice. Dominance and stability of discourses are achieved by institutions through two approaches: coordinative and communicative discourses (Cairney, 2012a; Fischer, 2012c; Schmidt, 2008). Coordinative discourse highlights the role of ideas forming the basis of collective action as generated by "individuals, groups, and networks" (Cairney, 2012a; Schmidt, 2008). In contrast, communicative discourse underscores the application of such concepts in interactions, discussions and communications in the public and political spaces (Cairney, 2012a; Schmidt, 2008).

\subsubsection{Strategic and Communicative Discourses}

Institutional and actor discursive influences were prominent. Specifically, Ontario's institutional arrangements have shaped the behaviour of actors, influenced the social and political interpretation of climate change needs, limited the choices of solutions to be pursued and impacted actor perspectives and preferences. The two types of discourses were prominent in Ontario. The coordinative discourse focused on the policy sphere where policy actors (mostly from government ministries and select epistemic communities) engaged each other in the construction of climate change policies (Fischer, 2012c; Schmidt, 2008). Communicative discourse, on the other hand, focused on the political sphere, which emphasized the role of political actors in communicating the necessity and usefulness of climate change policies (Fischer, 2012c; Schmidt, 2008). Such influences are discussed further below.

\subsubsection{Strategic actions}

Specifying the aims and objectives that the climate change policies aim to achieve is a crucial first step of climate change decision- and policy-making (Keeney \& McDaniels, 2001). In Ontario, it was evident that the purpose of the climate change policies aligned with the discourses forwarded, reinforcing the association between economic growth and climate change. This created narratives that linked climate change actions with economic integrity or prosperity, and that inaction may result in being left behind in the global market. The outcomes were institutional 
structures and decisions that resulted in a variety of decision processes and administrative procedures which legitimized certain agencies in the climate change discourse and limited the consideration of other stakeholder views in the discourse. These included a focus on agency, mandates, top-down decisionmaking, rigid hierarchical relationships, formalized and centralized decisionmaking, bureaucratic decisionmaking processes, fragmented decisionmaking, and limited coordination and information sharing. This also resulted in a network of practices and formalized governance (deliberation processes and participation structures) that aligned with the narrative and excluded others and assigned resources based on agency. There was the domination of political power (including political interests, the party system, and corporatism) and formal bureaucratic structures that defined deliberation and participation in climate change policy processes. The structures and agency for climate change actions provided resources that determined climate change deliberations, the domination of actors, and courses of action. Within such institutional structures, the reported lack of leadership from the MOHLTC and divergent focus between provincial and local PHU strategies resulted in inconsistencies in the prioritization of climate change, the lack of standards for public health focus and for mainstreaming of public health needs in strategic plans and processes, and assessment requirements, and a lack of coordination within the public health sector.

Participation structures and deliberation processes were also determined by policy legacies. That is, the influence of past policies, policy directions, and the Constitution that shaped the political actions, institutional capacities, and incentives for collective actions on climate change (Gauvin, 2014). Overall, authority and power on the policies were governed by rules and strategic instruments (including the Constitution, legislation, mandate letters, and plans prioritizing specific agents, sectors, and corporations). Such structures institutionalized deliberation and participation processes over time.

Deliberations occurred through committees that drew upon the economic, technocratic, bureaucratic, and fiduciary knowledge to guide economically viable solutions. There was also a portrayal of the relevance of corporate leadership; this highlighted constructions of climate change policies in line with corporate elites who must or should be consulted if the government hoped to enhance the uptake of climate change initiatives while still remaining economically competitive. The rationale for the extensive inclusion of corporates could be because corporates, whose profits are likely to be impacted by the mitigation policies are necessary for the government to achieve its objectives (Maeseele \& Pepermans, 2017). It could also be a result of vested interests as the results revealed the influence of bureaucrats whose careers have changed from corporate to politics and vice versa. 
As supported by Barley and Tolbert (1997) argument, the institutions governing climate change in Ontario were socially constructed by actors through historical and political negotiations that led to patterns that shaped successive interactions and actions. The resulting dominant discourse marginalized other actors who did not belong to the group of actors identified to be relevant to the government's political narratives. The role of experts, hierarchy, and agency defined engagement in climate change decisions and policies. The agency assigned to the policy elites led to decision outcomes strategically motivated by dominant frames and discourse. Assigning leadership roles and the subsequent prioritization of specific ministries, sectors or experts concentrated the power of policymaking within specific institutions. These justified the types of knowledge, stakeholders, roles, and interventions selected. The actions privileged some actors over others, rendered participation in climate change debates and policy decisions accessible to elites who participated in, and interpreted, climate change policies through the government's lens. In turn, the discourse of climate change was dominated by elites and bureaucrats, specifically those forwarding the government's agenda on economic focus. These processes led to a focus of deployment (or revocation) of policy instruments (e.g. cap and trade system of GHG reduction), the formation of expert commissions and consultation. The experts or elite-led policies guided responses to climate change, reducing climate change responses to those that promote economic prosperity, competitiveness, state leadership (globally and locally), innovation, and job creation. Such narratives were forwarded to be mainly possible through the specific deployment of mitigation policy instruments. And, as the analysis demonstrates, mitigation policies dominated climate change policy outputs, outcomes and discourse. Within such policies, experts played several roles ranging from providing technical knowledge to civil servants merely advancing a politically given mandate or political interests. The result was limited use of frames that expose the health consequences of climate change, the role of humans in accelerating the changes, and the subsequent need for holistic approaches that integrate both mitigation and adaptation needs.

\subsubsection{Communicative actions}

The discourse was also influenced by social relations between the agents and knowledge that was considered in, and that validated climate change policies.

A rational policy is grounded on evidence and what has been proven to work (Alaszewski \& Brown, 2012; CPHA, 2016; Hess, Eidson, Tlumak, Raab, \& Luber, 2014). There is a significant emphasis on evidence, specifically scientific evidence, in informing healthy public policies. However, policymaking is not always a rational process (Dale \& Hill, 2001). As highlighted in the 
study results, policy decisions were often influenced by politics and vested interests that challenge the balanced role of science in policymaking. Climate change policies were internalized by public servants, policy analysts, policy advisors, ministers and assistant ministers, managers, directors, and politicians, among others, through their daily activities and interactions. Where there were interactions with other social actors who did not have a mandate on climate change, such interactions were defined by inequality in power, which reduced evidence-gathering exercises to information provision rather than substantive and interactive participation. These interactions were mainly through a one-way communication channel (the Environmental Registry) and, in a few instances, through meetings. Where public meetings were held, such meetings only provided information or addressed questions instead of consultations. In both mediums of consultation, (Environmental Registry postings and face-to-face consultations), the government's policy directions were already set. Such procedures limited participation and collaborative initiatives since the agency only involved the external stakeholders late in the decision-making process. The processes were reduced to the provision of information and to address questions. Genuine partnerships are those where stakeholders are actively and directly involved in decision making and that such decisions are based on consensus (Ansell \& Gash, 2008).

Sources of evidence in Ontario, thus recognized three positions of consulting situations: technocracy, servants of power, and limited mandates. Howlett and Migone (2013) define these three terms. Technocracy refers to sources of policymaking using technical and complex evidence primarily derived from experts. Servants of power relate to the idea that the government or an institution would only have experts merely for symbolic purposes to claim that expert knowledge was used to advance a policy; the author refers to this as 'window dressing'. Limited mandates relate to the domination of experts or the utilization of expert knowledge in a specific area of policymaking. Consultancy can be viewed as a way for the government to compensate for the resources not available within the civil servants or bring change in an organization (Howlett \& Migone, 2013; Kippin \& Engwall, 2003). However, others argue that it is a way of government bypassing certain bureaucratic principles of decision-making (Howlett \& Migone, 2013). Howlett \& Migone (2013) posit that consultancy can be viewed as tactics used by politicians to bypass reluctant civil servants or provide superficial or trending advice (Howlett \& Migone, 2013; Kippin \& Engwall, 2003; Saint-Martin, 2005). Consultancy minimizes the democratic processes of policymaking as it hinders the government from seeking and using evidence from multiple stakeholders. It is not surprising that the climate change framing in Ontario was dominated by technocratic frames that emphasize and portray trends and norms of neoliberal policies seen across other governments' actions on climate change. 
In short, Ontario's historical and social construction of climate change as an economic and political issue solved through market strategies and technological innovations supplied actors with coordinative and communicative ideas for substantiating the types of structures and processes of policies and decisions, the relevant actors and knowledge. However, literature also argues that discourses also inform identities and interests supporting the discussion and communication of ideas (Fairclough, 2003; Fischer, 2012c; Hajer, 1997; Pettenger, 2007b). This is because discourses influence attitudes, desires, and values (Fairclough, 2003). In other words, ideas act as roadmaps guiding the policy agents' behaviours and their choices; they clarify the goals of policies and shape beliefs and interests (Cairney, 2012b; Fischer, 2012c).

\subsubsection{Identities and Vested Interests}

In Ontario, the actions of the government, its agencies, bureaucrats, and mandated actors and experts were defined by ideological assumptions, beliefs, and identities mainly affiliated with the province's dominant climate change policy discourse and political values. The social and institutional relations guiding climate change were defined by political and partisan ideologies; these also included interests and beliefs of political leaders and other sets of policy actors (bureaucrats, policy actors from mandated ministries, and select corporations and sectors). Their ideologies contributed to the status quo of the economic and political focus of climate change policies. Both political parties that governed Ontario within the study reference period emphasized the neoliberal narratives. Although there was a significant focus on the economy than the environment, this focus can be translated as a portrayal of economic focus at the expense of environmental protection. The result was a business-like approach to climate change policies where climate change was reduced to economic gains and losses mainly solved by technological advances (mainly energy-related) or a perceived inadequacy of technological progress. This resulted in a narrative of technological innovations as enablers and solutions for achieving this economic growth, global parity where lack of such technologies were linked to the economic disadvantage to Ontario, and minimize global leadership and competitiveness as Ontario attempted to lead technological innovations and global economy through climate change actions.

Political ideologies and assumptions were validated by political commitments and leadership and through historical and rhetorical norms that characterized, recognized, and accentuated the dominant frames. Such tactics included the provision of concrete evidence for supporting the narratives, intertextuality (integration of political and expert voices), and modality (statements of commitment). The voices of senior leaders, corporate leaders, and experts through quotes and introductory messages embedded in texts, were used to promote, justify, and 
legitimize the agencies' policy preferences or to signify the speaker's or author's commitments to the decisions or claims being made (Government of Ontario, 2009, 2016a, 2016c, 2016b, 2017, 2018a, 2018b, 2018h; MECP, 2012). The role of local, national, and international norms, partisan inclinations, and elections in driving the salience of the dominant frames was evident. Values were presented through promotional genres in websites and documents in a manner that persuaded the uptake of proposed policies while also aiming to attract investments both locally and internationally. Mainly missing from the embedded voices were the views of opposition parties and many stakeholders (such as public health professionals) whose voice would validate the need for the uptake of policies proposed. The few instances where public health voices were integrated into policy documents were those that addressed the closure of coal power plants and active transportation initiatives. The ideologies were, thus, constructed by political discourse where politicians, political parties (and leaders), and senior bureaucrats shaped political engagements, interests, decisions, and the way climate change has been viewed historically. Ideologies defined the social structures and group interests where elites propagated and legitimized their ideas. Different sources were linked by embedding links directing readers to other sources.

Text sources for public educating and awareness on the government's actions mainly established persuasive structures. Persuasion was complemented with narrative writing that highlighted quotes from seniors, bureaucrats. The major sources, such as news releases, aimed to frame and convince readers of the current position and the relevance of the current framing of climate change in Ontario. Persuasive tactics have been applied in international climate policies across various countries, including United States, Germany and Britain, in accepting climate change as a political issue requiring specific position or stance in action (Cass, 2010; Loren, 2006). In Ontario, persuasion was complemented with narrative writing that incorporated the voices of senior bureaucrats in the major sources, such as news releases, aimed to convince readers, promote and justify policy preferences or to signify the speaker's or author's commitments to the claims being made (Government of Ontario, 2009a, 2016a, 2016c, 2016b, 2017, 2018b, 2018c, 2018I; Ontario Ministry of Environment Conservation and Parks, 2012)

The basis for most of the policy actions mainly assumed two types of objectives: economic and environmental outcomes. These cohesively aligned with, and were linked to, the economic focus of the province's policies. As a result, the textual analysis demonstrated a serious deficiency in the application of the public health frame. The frame remained isolated from the primary focus of Ontario's climate change discourse. Apart from isolated instances such as those highlighting coal powerplant closures and transportation or built environment health needs (Government of 
Ontario, 2011, 2014), the public health frame was largely trivialized through generic narratives that presented public health needs in ambiguous terms.

The dominant discourses also supplied the agents with symbolic meanings and language that shaped how they objectively advance climate change decisions and the construction of roles of other actors (Fischer, 2012c). For instance, there was a clear causal role of descriptive ideologies (e.g. perspectives of policy actors from mandated ministries and public health) as was explored in the study. Based on study findings, apart from the public health group, the ideological perspectives portrayed narratives of economic or an integration of economic and environmental inclination with a few providing health narratives. There was also a lack of recognition of public health's role and leadership. Based on the responses, such perspectives relate to ideological norms influenced by Ontario's current frames and the influence of structures that have hindered interactions, collaborations, and the generation of knowledge that can inform public health frames and that perpetuate stereotypes of roles of public health, in general, and in climate change discourse.

While the ideas contribute to the status quo of the economic and political focus, an emerging influence, both in Ontario and across literature, is the role of political and vested interests in influencing policies. Austin et al. (2016) found that policy integration needs were identified based on what suited the political contexts and governance system. Workman et al. (2018) found the dominance and influence of vested interests in climate policies. Such interests are embedded in power relations exerted by international climate change agreements, political leaders, sectors relevant to climate change mitigation (such as renewable energy sectors), corporations, business and industry stakeholders (Aaheim, Wei, \& Romstad, 2017; Schrefler, 2014; Workman et al., 2018; Workman, Blashki, Karoly, \& Wiseman, 2016).

Furthermore, the influence of conservative ideologies in advancing negative political narratives of climate change policy output and advancing skepticism to climate change, such as those observed in Ontario in 2018, are well documented in the literature (Boussalis \& Coan, 2016; Riley E Dunlap \& Jacques, 2013; Jacques, Dunlap, \& Freeman, 2008; Schlosser, 2018; Workman et al., 2018). The skepticism has been mainly linked to US climate change politics (R E Dunlap \& McCright, 2011; Riley E Dunlap \& Jacques, 2013; Workman et al., 2018). In Ontario, the decline in the political emphasis of climate change and the infiltration of negative rhetoric about climate change are seen to follow similar trends of negative rhetoric in the United States just before and after the Conservative government in the country. The influence of ideological perspectives and identities from groups, networks and individuals was reflected in Ontario's political and partisan activities. Literature highlights the influence of groups, networks and individuals as drivers for 
policy change, policy windows and entrepreneurs which not only shape the construction of an issue, but also the political actions and policy solutions (Cairney, 2012b; John, 2006; Michaelowa, 1998; Mu, 2018). Policymaking has been argued to be an irrational and incomprehensive process where ideas can influence the direction of policies. Individuals and groups (e.g. interest groups, civil servants, politicians and senior bureaucrats) can play a significant role in problem identification, political attention to the problem and the resulting policy proposals or outcomes (Cairney, 2012b; Mu, 2018). For instance, the dominance of frames aligned with the historical events and political changes, which either minimized or enhanced attention to frames. As demonstrated in Figure 20: Climate change frames and historical political actions (20072018) - which displays periods and activities that characterized climate policies in Ontario. The figure demonstrated the various influences of framing and policy changes, including strategic plans, provincial elections, partisan shifts, legislative and political activities, and in a few instances, public health ideas.

The politically, economically and technocratically centred frames of Ontario's climate change are associated with the various forms of neoliberal discourses which emphasize economically centred actions, technological innovations and the role of the state in climate change policies. Conversely, the public health framed climate change can be associated with the discourse of democratic pragmatism, which emphasizes the legitimacy of policy actors through substantive participation and deliberation processes (Dryzek, 2013). Public health framing and democratic pragmatism share common characteristics. They both aim to achieve adaptative governance approaches to climate change by promoting democratic approaches to legitimize climate change policies and target the complexities of climate change (Dietz et al., 2003; Dryzek, 2013; Paavola, 2007, 2012). However, given that the democratic pragmatism discourse did not emerge in Ontario, it was not surprising that a public health frame did not dominate the province's climate change discourse. But most significantly, the misalignment of the discourses forwarded in Ontario and those that support public health integration presented barriers to the integration of public health frame and capacities relevant for advancing the frame in the climate change policy discourse.

\subsection{SYSTEMIC FACTORS INFLUENCING PUBLIC HEALTH CAPACITIES IN THE DISCOURSE}

The discourse applied on an issue not only defines how the issue is presented, but it is also a part of political agenda that defines how the issue is understood, the tenable actors, views 
and options, and the structures and policy-making processes addressing the issue (Dryzek, 2013; Fairclough, 2003; Ingram et al., 2008; Miljan \& Brooks, 2018).

The study results revealed that the current discourses of climate change did not only have an impact on the framing of climate change as a health issue, it also led to the construction of climate change roles and the types of actors supporting climate change actions. That is, the framing defined the types of institutions (norms, organizations, rules) for guiding climate change policies. Because the supporting discourse did not consider public health as a significant factor in the policy processes, there were contextual barriers to public health inclusion and engagement in climate change policy discourse. These barriers were associated with social contexts of policymaking, including the power relations, the type of information informing decision processes, and institutional structures for engagement in climate policy decisions.

\subsubsection{Contexts of Political Power and its Impediments on Public Health Framing}

Although widely used, the meaning of power varies. Various studies have conceptualized power (e.g. Gaventa, 2006; Hardy \& Phillips, 1998; Hendriks, 2009). Power may be held by one or a few actors or embedded in relationships or social norms. However, power is often defined in descriptive terms (Gaventa, 2006). Such as power-over and power-with (Hendriks, 2009). Power over occurs when those that are considered powerful exert their dominance over the powerless in order to achieve their desired outcomes; this is also referred to as coercion (Hendriks, 2009). Power-with refers to democratically acquired power associated with community-based approaches to citizen participation and empowerment in government policies (Gaventa, 2006; Hendriks, 2009). Hardy and Phillips (1998) provide three dynamics to understanding power and its influence on organizations: formal authority, scarce or critical resources, and discursive legitimacy. The authors define formal authority as the power provided to people in order to make specific, legitimate decisions. The authority can be dispersed or can rest with certain actors, a specific person, an organization (e.g. government), or among organizations. Critical resources are those related to money and those that influence the capacity to act on an issue (such as expertise, equipment, and information). Discursive legitimacy refers to the ability to speak on an issue in a manner that influences an understanding of, or actions on, an issue. These forms of power determine the extent of participation (representation of interests and responsibilities) and deliberation on an issue (decision making and implementation) (Cadman, 2013; Hardy \& Phillips, 1998). Gaventa (2006) posits that understanding how power in political spaces influences deliberation and participation in policies requires exposing three domains: opportunities for 
participation (spaces), arenas or platforms for actions on decisions (places or levels), and forms of power manifested in places and spaces of decision-making.

The first approach to changing or balancing power relations is to understand how power works to influence policy outcomes (Gaventa, 2006, 2011; Hardy \& Phillips, 1998). Institutions can exercise power in several ways; these forms of power may be visible, invisible or hidden; they may be legitimate or illegitimate, concentrated or diffuse (Cairney, 2012c; John Gaventa, 2006). Power may also be concentrated (elitism) or diffused (pluralism) across institutional settings (Cairney, 2012c). In the context of Ontario, despite public health's ability to create some spaces for engagement, their participation was constrained by resources, exclusion from deliberation platforms, and the lack of equal opportunities for participation. This participation opportunity was offered to select actors (mandated agencies) who dominated the decision making processes. The spaces for participation were defined by mandates, legislative rights, and formal invitation (e.g. to committees), of which public health was not included. These spaces were influenced by normative dynamics both at the local, provincial and global levels that aimed to legitimize and justify climate change policies through neoliberal narratives. The power was manifested in political structures (visible), political influence (hidden) or ideological boundaries (invisible) that defined and shaped perceptions on participation and deliberation. The influence of these three domains (place, space, and power) on public health needs has occurred over time. In reference to this analysis, the occurrence of 11 years (between 2007 to 2018).

To illustrate the influence of power in limiting public heath's role and framing of climate change as a public health issue, Table 20: influences of power on public health role and framing summarize the three domains, as were manifested in the themes coded from the data, discussed in the preceding sections of this chapter, and supported by literature.

Table 20: influences of power on public health role and framing

\begin{tabular}{|l|l|l|}
\hline $\begin{array}{l}\text { Domains of } \\
\text { power }\end{array}$ & $\begin{array}{l}\text { Strategic } \\
\text { influences }\end{array}$ & Manifestation \\
\hline $\begin{array}{l}\text { Spaces for } \\
\text { participation }\end{array}$ & $\begin{array}{l}\text { Economic } \\
\text { and political } \\
\text { discourse } \\
\text { constructed } \\
\text { the meaning } \\
\text { of climate } \\
\text { change }\end{array}$ & $\begin{array}{l}\text { Linking and shaping climate change decisions to neoliberal } \\
\text { discourse, framed in economic and political narratives. The } \\
\text { discourse does not conform to the public health role in } \\
\text { climate change, as highlighted by the discourse of } \\
\text { democratic pragmatism. }\end{array}$ \\
& $\begin{array}{l}\text { The dominant frames set the foundation and direction of } \\
\text { climate change policies and supporting institutional } \\
\text { arrangements and governance structures. } \\
\text { Neoliberal narratives served as ideas and reference points } \\
\text { for framing the discussion on climate change across }\end{array}$ \\
\hline
\end{tabular}




\begin{tabular}{|c|c|c|}
\hline & & $\begin{array}{l}\text { political or partisan platforms, organizations, and text } \\
\text { sources. }\end{array}$ \\
\hline & $\begin{array}{l}\text { Institutional } \\
\text { channels for } \\
\text { effecting and } \\
\text { shaping } \\
\text { climate } \\
\text { change } \\
\text { decisions }\end{array}$ & $\begin{array}{l}\text { - Cabinet and inter-ministry committees for discussing } \\
\text { climate change between agencies and representatives; } \\
\text { excluded public health in the climate change deliberations } \\
\text { - Platforms for engagement, such as the environmental } \\
\text { registry, offered one-way communication approaches to } \\
\text { policy deliberations and limited meaningful participation. }\end{array}$ \\
\hline & $\begin{array}{l}\text { Social and } \\
\text { political } \\
\text { practices that } \\
\text { influenced } \\
\text { the politics of } \\
\text { climate } \\
\text { change and } \\
\text { access to } \\
\text { climate } \\
\text { change } \\
\text { political } \\
\text { processes }\end{array}$ & 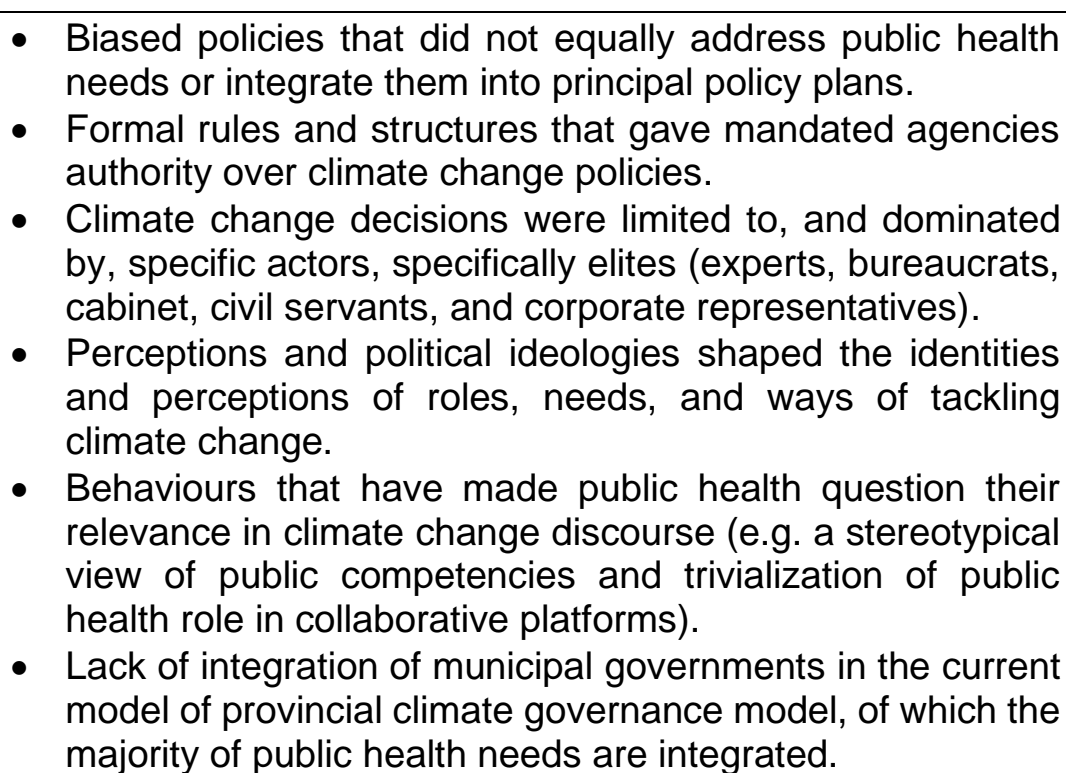 \\
\hline $\begin{array}{l}\text { Levels and } \\
\text { Places }\end{array}$ & $\begin{array}{l}\text { Arenas where } \\
\text { the political } \\
\text { power } \\
\text { resided }\end{array}$ & $\begin{array}{l}\text { - The policies were mainly influenced by the provincial level } \\
\text { of government, specifically the Office of the Premier and the } \\
\text { mandated ministries. There was an emphasized norm of the } \\
\text { role of the state (provincial government) in climate policies. } \\
\text { As a result, state-mediated forums supported deliberation } \\
\text { by elites. } \\
\text { - The influence of the state also intersected with global norms } \\
\text { that forward capitalist narratives of globalization and the } \\
\text { accompanying neoliberal and technocratic discourses that } \\
\text { have reduced climate change to economic opportunities } \\
\text { and leadership. In turn, the state's policies were mainly } \\
\text { influenced by international discourses, which have largely } \\
\text { favoured neoliberal policies. At the same time, international } \\
\text { forums and instruments were used to deliberate on and } \\
\text { justify the province's climate change policies. } \\
\text { At the local level, the municipalities had some power to } \\
\text { impact climate change. It is here that public health has } \\
\text { realized some success in influencing climate change } \\
\text { policies. However, these forums were hardly connected to } \\
\text { the forums typically used by state agents. }\end{array}$ \\
\hline Power & Visible power & $\begin{array}{l}\text { - Domination of formal institutions (e.g. Premier, cabinets } \\
\text { ministers and assistants), sectors (e.g. energy, } \\
\text { transportation, industry) in the discourse. }\end{array}$ \\
\hline
\end{tabular}




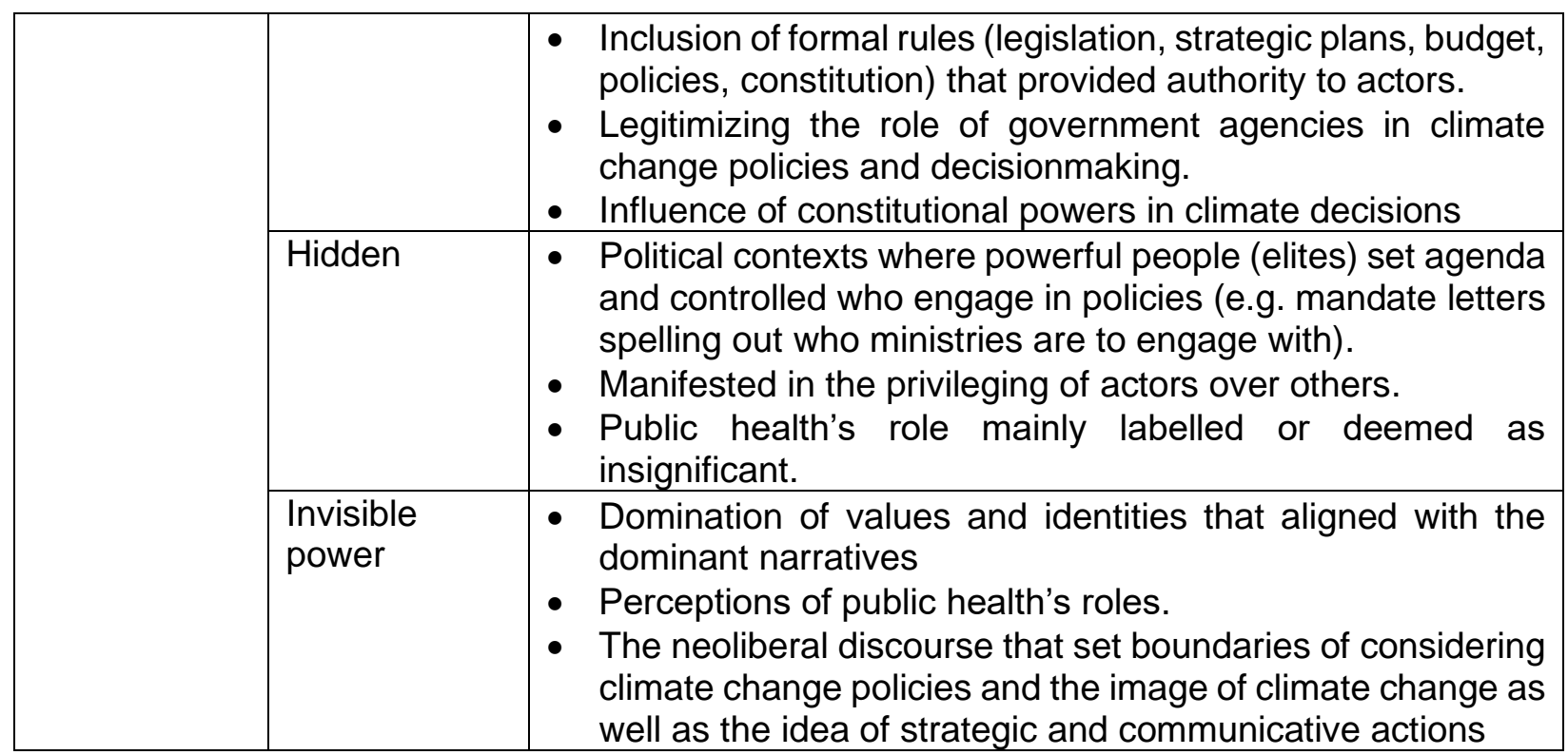

Guided by: (Gaventa, 2006, 2011; Webster \& Engber-Pedersen, 2002)

\subsubsection{Lack of Integration of Public Health Needs and Knowledge in Climate Change Decisionmaking Processes}

Inclusion of public health in the climate change political agendas are likely to be leveraged in two instances. First, when public health needs are integrated into climate change policy processes (mainstreaming) (Ganesh \& Smith, 2017; Kemm, 2001; Wellstead \& Stedman, 2015). Second, where climate change policies and processes consider the health consequences of climate change policies (healthy public policy) (Ganesh \& Smith, 2017; Kemm, 2001; Wellstead \& Stedman, 2015). However, the results reveal that Ontario's mitigation and adaption policies are not linked and operate in two separate domains. The various population health needs and tools were also not considered. As a result, public health needs were not well integrated into climate change policies in Ontario. There was a disconnect between the adaptation-focus role of public health and the province's focus on mitigation.

Assessing information that informs decisionmaking processes allows for the exploration of how health issues are identified and their contexts (Government of Canada, Health Canada, 2000; Moss et al., 2014). Such allows for the integration of health information and collaborative efforts, health risk assessment and management process and justification of choices of management, evaluation of trade-offs, stakeholders and their values, and the various strategies for implementing, monitoring and evaluating the decisions (Government of Canada, Health Canada, 2000; Moss et al., 2014). Public health participants also frequently cited the importance 
of integrating health in climate change agendas. Yet, there was also minimal consideration of public health evidence, limited use of tools for integrating public health evidence, and inadequate collaborative efforts between public health and non-public health actors in Ontario's climate change policies. Instead, there was a focus on bureaucratic and fiduciary knowledge. For the integration to occur, agencies must understand the various health impacts of climate change and have access to critical public health expertise, evidence and capacities necessary for integrating public health needs into climate change policies (Kemm, 2001; Wellstead \& Stedman, 2015).

Managing climate change and identifying policies require the integration of evidence at the various stages of decisionmaking. Typically, evidence can inform various stages of decisionmaking because the evidence is conceptually linked to all stages (Government of Canada, Health Canada, Health Products and Food Branch, 2000; Moss et al., 2014). The stages can range from issue definition, establishing decision criteria, accessing decision-support information, assessing, perceiving and managing risk, and implementing, monitoring, and evaluating decisions (Government of Canada et al., 2000; Moss et al., 2014). And, climate change decision-making, like any other policy decision process, is likely to go through such defined stages. To achieve public health needs, all the stages of decision-making would require consideration of public health evidence, if mainstreaming of public health needs and the development of healthy climate change policies is expected. Decision support can aid the identification and integration of public health evidence required for sound decisions (Moss et al., 2014; National Research Council, 2009). On the contrary, bureaucratic and fiduciary knowledge prevailed in Ontario's climate change policies. There was evidence of a lack of integration of public health knowledge, and broadly, scientific knowledge, in the climate change policies. Also, where decision-making tools were used to guide the agency policies, tools such as CBA were forwarded. While such tools can integrate analysis of health benefits and costs, including unintended consequences of the policy, health was not integrated into such tools. Instead, there was a focus on evaluating economic impacts where the CBA was used. The use of CBA tool portrays the economically focused framing in Ontario as such tools are used to calculate the costs and benefits and provide monetary equivalences associated with policies (Moss et al., 2014). Health associated tools such as HIA and risk assessment tools were not used or discredited as irrelevant to the policy contexts within the ministries. Integration of CBA to advance climate change needs or inform climate change policy outputs have been widely discussed in the literature, for example (Ackerman, DeCanio, Howarth, \& Sheeran, 2009; Admiraal, Hof, den Elzen, \& van Vuuren, 2016; Agrawala et al., 2011; Aldy et al., 2003; Bosello, Carraro, \& De Cian, 2013; Den Elzen et al., 2011; Stern, 2007; Workman et al., 2018). 
However, health assessments are relevant to climate policies since all policies have some impact on human health (Kemm, 2001). And, a healthy public policy enhances the lives or health of the target population by targeting the various social, economic, cultural, environmental and equity factors that hinder people from achieving good health (Awuor \& Melles, 2019; Buse, Lai, Cornish, \& Parkes, 2019; Kemm, 2001). HIA is an approach that is widely acknowledged for advancing healthy public policies. The tool was also highly regarded by the $\mathrm{PH}$ group. The assessment - typically carried out in non-health sector polices - can identify the various pathways a policy can impact health and provide evidence for analyzing policy alternatives and trade-offs (Kemm, 2001). Yet, HIA lacked in Ontario's climate change policy processes. Kemm (2001) posits that there is the notion that HIA may be equated to health imperialism, that is, efforts to make health superior in all areas of public policy. However, HIA is distinct from health imperialism in that it attempts to appraise policies just like how policies are assessed for economic impacts.

Moss et al. (2014) emphasize that decision making is more than just acquiring evidence; the process must integrate the views of the impacted stakeholders. That is, there is a need for participatory approaches from a variety of stakeholders, and in this case, public health stakeholders (Crisp, Swerissen, \& Duckett, 2000; Wellstead \& Stedman, 2015).

\subsubsection{Institutional Engagement Practices and Barriers to Public Health Capacity in Advancing Public Health Framed Policy Discourse}

The analysis revealed a flawed engagement and inclusion of public health in broader climate change policies in the province.

Up until this point, this report has loosely referred to institutional engagement (interaction between and within the two study groups) as partnerships, collaborations, engagements, or coordination. This was strategical to analyze how the groups interacted or worked together (between and within the groups), related to one another, and accessed stakeholders as well as the contexts that defined or negated those relationships or interactions. Through the interpretation of results, the report (or this section) now focuses on situating the dominant form of institutional engagement in Ontario.

Public engagement can include public communication and public participation (Luís et al., 2018; Rowe \& Frewer, 2005). Public communication can occur in two forms (Rowe \& Frewer, 2005b). Communication relates to one-way information transmission either from an agency to the public (public communication) or from the public to an agency (public consultation). On the other hand, public participation relates to "the practice of involving members of the public in the agendasetting, decision-making, and policy-forming activities of organizations/ institutions responsible for 
policy development" (Rowe \& Frewer, 2005). Public participation is also synonymous with collaboration. Mattessich, Murray-Close, and Monsey, (2001) define collaboration as "a mutually beneficial and well-defined relationship entered into by two or more organizations with a commitment to a set of common goals....includes a commitment to mutual relationships and goals; a jointly developed structure and shared responsibility; mutual authority and accountability for success; and sharing of resources and rewards."

Within institutional engagement domains, collaboration ideally connects stakeholders, supports relationship building, and helps to work towards mutually beneficial actions (PHAC, 2016; Schell et al., 2013; Gray, 1989). Collaborations sometimes take the form of, and is synonymously associated with, cooperation, coordination, partnerships, or networking (Miller \& Pellen, 2006; PHAC, 2016a; Schöttle, Haghsheno, \& Gehbauer, 2014). However, each represents a specific form of institutional engagement. Schöttle et al. (2014) define cooperation as "an interorganizational relationship among participants of a project, which are not commonly related by vision or mission, resulting in separated project organization with an independent structures, where the project culture is based on control and coordination to solve problems independently in order to maximize the value of the own organization." Coordination, on the other hand, is "characterized by more formal relationships and understanding compatible missions (Miller \& Pellen, 2006; Schöttle et al., 2014). Some planning and division of roles are required, and communication channels are established. Authority still rests with individual organizations, and resources are mutually acknowledged (Miller \& Pellen, 2006; Schöttle et al., 2014). Networking only relates to the provision of information (Miller \& Pellen, 2006; Schöttle et al., 2014).

The PHAC (2015) differentiates between collaboration and partnership in that partnerships include both formal or informal forms of "collaboration between individuals, groups, organizations, governments or sectors for the purpose of joint action to achieve a common goal". Meaning that partnerships describe any of these forms of engagement: networking, cooperation, coordination or collaboration. As a result, the study conceptualized four tiers of interorganizational engagement: networking and communication, cooperation, coordination, and collaboration. Each level of engagement builds on the other, with collaboration as the most critical tier of engagement (Miller \& Pellen, 2006).

Analysis of institutional engagements revealed very low levels of interaction between the two groups ( $\mathrm{PH}$ and NPH). Engagements were dominated by networking and cooperation, with collaborations existing within each group. Between the two groups, a few informal relationships existed without commonly defined missions, structures or goals, and information was only shared as needed. The information-sharing was mainly from public health to the government agencies 
(public consultation). This cooperation was sometimes seen as collaboration by public health agencies. On the other hand, some coordination or collaboration existed within each group. Such engagements were defined by both formal and informal structures for accessing information, some resource sharing, and mutual problem-solving. Within each group, evidence was gathered through collaborative networks and communicative platforms. For instance, communication within each group was facilitated by two-way information sharing and facilitation of dialogue. These engagement practices, as analyzed in the data, are highlighted in Figure 24: Achieving collaborative governance in Ontario.

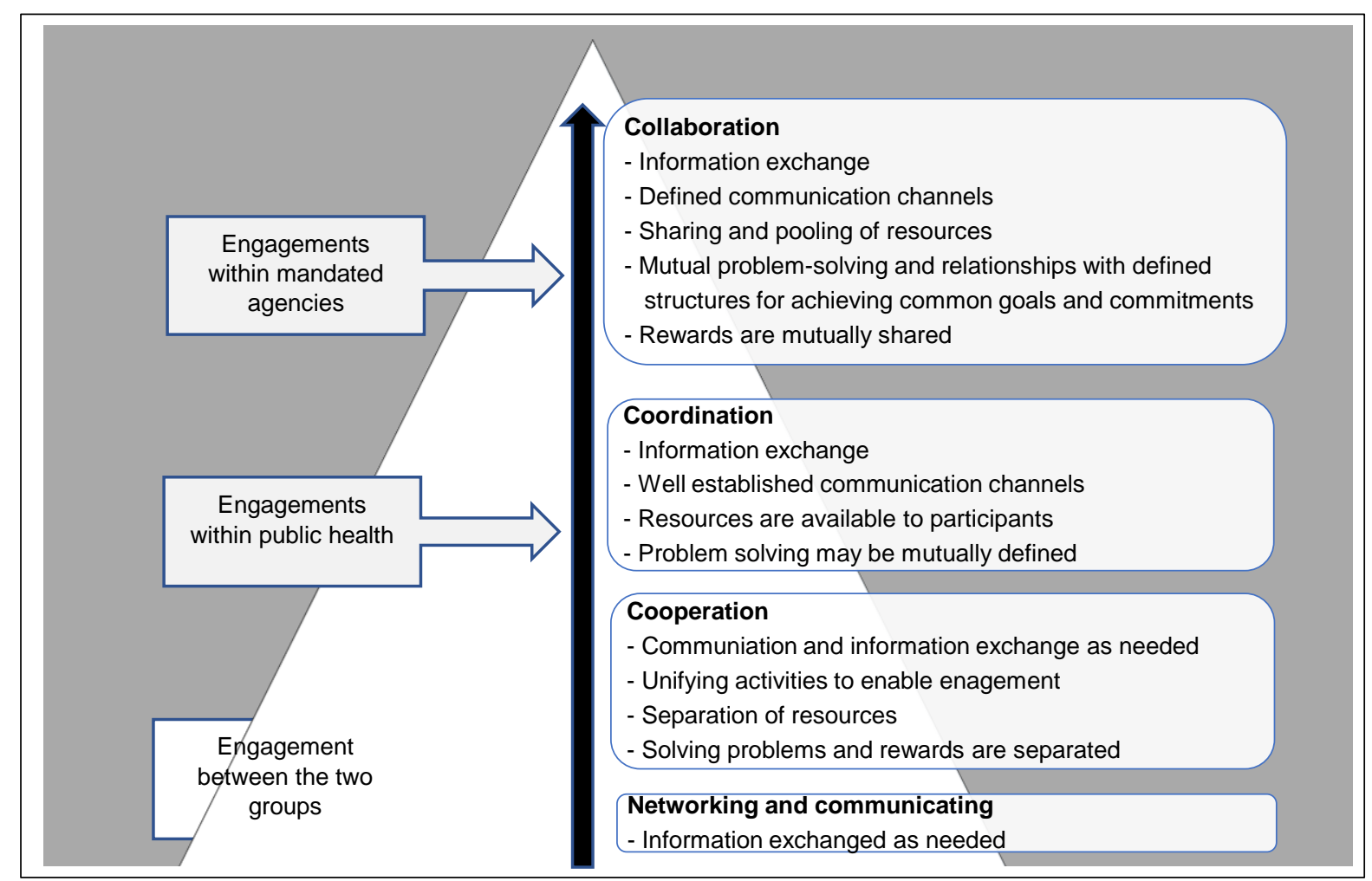

Figure 24: Achieving collaborative governance in Ontario

Guided by: (Crisp et al., 2000; Luís et al., 2018; Mattessich \& Monsey, 1992; Mattessich et al., 2001; Public Health Agency of Canada, 2015a; Rowe \& Frewer, 2005b)

Collaborations and partnerships connected decisions, outputs and structures to stakeholders and allowed for the development of relationships that enhance action to identified issues (PHAC, 2015a; Schell et al., 2013). Unlike public health agencies that lacked resources (funding stability, information, training, and expertise) for advancing climate change needs, the interactions of the mandated agencies were accompanied by resources. In turn, as the analysis reveals, the limited engagement of public health in the climate change policy discourse constrained the sector's ability or capacity to forward a public health framed climate change policy 
discourse in Ontario. The structures of Ontario's institutional arrangements and the resulting governance approach exposes the influence of legitimacy in climate change policies, where authority given to agencies through formal and informal institutional structures, norms, values, resources, and discourse resulted in who is considered legitimate actor; the actors then had the rights and justifications of power over climate change decisions. Such power was supported by resources (human, financial, technological and information) and through the domination of bureaucratic agencies and elites and normative ideas. This power has influenced the opportunities and arenas for engagement.

The results described in this section (Systemic Factors Influencing Public Health Capacities in the Discourse) correspond with other research findings done in Canada and in other parts of the world.

Aylett (2015) surveyed 350 cities distributed across five continents to investigate governance structures created for advancing climate change. Many cities acknowledged integrating mitigation and adaptation strategies. However, the structures portrayed a silo approach to climate change governance, and public health remained isolated from such structures.

Austin et al. (2016) reviewed the national strategies on the occurrence of public health adaptations, roles and government dimensions in the Organization for Economic Cooperation and Development countries (OECD). Some of the countries cited by the authors include Canada, United States, Switzerland, France, UK, Belgium, Australia, Luxembourg, New Zealand, and Ireland. The study revealed that while some countries prioritized public health adaptation, many portrayed low prioritization of public health needs in other sectors. The health needs of climate change were solely initiated, planned and implemented in by the health sector. There was low prioritization, conflicting mandate and silo approach to climate change adaptations. Lack of coordination was prominent in Canada and the United States. While the study reported intersectoral collaboration included public health in countries such as the UK and France, such was not reported in Canada. Specifically, strategic frameworks for Canadian climate change policies did not include sector-specific needs. Adaptation plans in Canada also focused on addressing infections and heat-related health impacts. Furthermore, the dominant public health capacity building initiatives included frameworks and toolkits.

A similar study focusing on the public health adaptation in the Canadian context by Austin et al. (2015) found that apart from Quebec, all provinces in Canada were lagging in integrating public health needs into climate change adaptation frameworks. Both studies (Austin et al. 2015 and 2016) found the prominence of horizontal collaboration (collaboration with similar sectors or 
areas) with some vertical collaborations (a collaboration between sectors) and a limited streamlining of public health needs into the broader climate change policies.

A focus on Ontario's public health adaptation needs by Paterson et al. (2012) revealed that public health needs were enabled by federal government support (information and financial), local public health leadership, local municipalities' political will and inter-agency collaborations (between municipal departments and public health). However, the authors also noted the influence of resource constraints, a lack of communication, perceptions in undermining the generation of evidence and public health role in climate change discourse.

While reviewing the literature on the politics of climate change and health Workman, Blashki, Bowen, Karoly, and Wiseman (2018) identified that the role of public health has been elusive in climate change mitigation. The study showed that the influence of public health in mitigation was embedded in four factors: discourse, efficiency, vested interests, and structural challenges. National and international discourses embedded in economic frames have been presented as both the problem and solution in economic narratives. To pursue such narratives, the national governments have focused on neoliberal policy decisions, including resource allocation and a central focus on optimizing GHG reduction using efficient options. Such efficiencies have mainly been assessed using CBA, which are based on economic and political rationality rather than environmental needs. In turn, the policies have been dominated by vested interests and power dynamics that alight with the discourse and the political economy principles. The structural impediments relate to the influence of political, socioeconomic and cultural factors $(\mathrm{SDOH})$ that lie out of public health practice. These limited public health capacity to act. While such a structural impediment can be addressed through scientific knowledge, scientific evidence is rarely utilized. The role of expert knowledge in regulatory policies has ranged from instrumental, to strategic (to forward predefined position), to symbolic (Ambrus, Arts, Hey, \& Raulus, 2014; Haas, 2014; Schrefler, 2014). The influence of power dynamics in limiting actors' spaces and places for participation and deliberation on a variety of policies has been evidenced in a variety of literature. These have included climate change (Few, Brown, \& Tompkins, 2007; Romsdahl et al., 2018) the environment (De Francisco \& Boelens, 2014), health (Kaim, 2013), economic inequality (Gaventa \& Martorano, 2016), mental health (Brosnan, 2013), participation and governance (Rabe \& Kamanzi, 2012), policy processes (Swedish International Development Cooperation Agency, 2013) and water management (Whaley \& Weatherhead, 2015).

Furthermore, the capacity influences identified in this study have been identified in several literature. According to Ostrom (2011), four sets of factors influence the actor's ability to analyze a problem: resources available to participants; values actors bring into the policy process; 
knowledge and information that define the problem and outcomes; and processes for selecting the course of action. For public health, this lack of inclusion has resulted in the lack of resources, including access to information and funding, human resources, and technology for advancing public health needs in climate change policy processes. Political, institutional, and individual values trivialized the role of public health. The lack of consideration knowledge in climate change needs and processes neglected the roles of public health in climate change decisions. What was clear in the analysis was the lack of integration of public health knowledge and the influence of structures and processes of engagement. It was the agencies that had the power to control the legitimacy, uses, and producers of knowledge guiding climate change decisions. While there has been some integration of public health through the recent mandate and the advocacy work that has been done by the community, such platforms are yet to lead to meaningful engagements in broader climate change policies in Ontario. This is because the neoliberal discourse and institutional structures were used to set boundaries and limit who has authority in climate decisions; these also set identities of who should be included, whose knowledge counted, and ideologies, interests, and beliefs influencing the structures of decisionmaking.

According to Scheirer and Dearin (2011), public health capacities are also influenced by the social, policy and financial environments, and the degree to which these factors are embedded in the policy framework for action. Schell et al. (2013) also identify nine domains that influence public health engagement in sustainable programs. These include political support, funding, partnerships, capacity and flexibility to changes, program evaluation, communications, public health impacts, and strategic planning. Similarly, Crisp (2000) and Huang et al. (2011) identify various approaches and constraints to public health capacities in general (i.e. Crisp, 2000) and specific to climate change engagements (i.e. Huang et al., 2011). These include organizational approaches (top-down and bottom-up), the availability of resources for fostering public health engagement - information, skills, technological and financial, and collaborative approaches and community engagement platforms for highlighting and strengthening public health roles and those of the communities and other agencies.

The lack of local public health inclusion in the provincial structures also shows that the province has not meaningfully included local municipalities in climate change policies, which may also imply that municipalities do not fit in the current model of provincial climate governance. The lack of inclusion of local governments in the broader climate change governance structures has been documented. The lack of inclusion has been accompanied by limited public support and resources, competing priorities and inability to provide the local governments with opportunities for policy development, inadequate climate change discussions (Bulkeley \& Betsill, 2013; 
Rickards, Wiseman, \& Kashima, 2014; Romsdahl et al., 2018; Wood, Hultquist, \& Romsdahl, 2014).

\subsection{ADDRESSING CRITICISMS AND LIMITATIONS OF THE STUDY}

\subsubsection{Case Study and CDA Approach}

The study applies a case study approach and discourse analysis. Case studies have been criticized for lack of consistency, robustness in design, and subjectivity (Yin, 2014; Zainal, 2007). Case studies have also been criticized for lack of generalizability and inability to generate hypothesis when compared to other forms of research approaches (Thomas, 2011; Yin, 2014). On the other hand, discourse analysis has been portrayed by critics to lack a specifically outlined approach that can lead to reliability and validity issues (Walter, 2013).

The quality of research design can be judged using a set of logical tests grounded on two criteria: reliability and validity (Palys \& Atchison, 2014; Salkind, 2015; Trochim, 2006; Yin, 2014). These concepts have been indirectly addressed throughout the study design. However, this section provides an overview of their application to address this criticism.

Palys and Atchison (2014) define reliability as "the degree to which repeated observation"

yields similar results when the same phenomenon is repeated at different times or explored by different observers. In short, the ability to reproduce the same results through a repeated procedure outlined in a study (Palys \& Atchison, 2014; Salkind, 2015 Yin, 2014). Validity relates to whether the study actually measures what it is supposed to measure (Palys \& Atchison, 2014; Trochim, 2006; Salkind, 2015 Yin, 2014). To differentiate, reliability is synonymous with consistency while validity with accuracy (Palys \& Atchison, 201; Salkind, 2015).

There were four forms of validity that were relevant to the study: construct, internal and external, and content validity (Salkind, 2015; Trochim, 2006; Yin, 2014). Construct validity relates to the identification of sound research measures (Trochim, 2006; Yin, 2014). In qualitative studies, this validity bases research on operation measures instead of subjectivity (Trochim, 2006; Yin, 2014). Construct validity can ascertain whether the study presents constructs or conceptual elements grounded in some reality, such as theoretical similarities (Trochim, 2006; Yin, 2014). Internal validity "seeks to establish a causal relationship" (Yin, 2014). While it is largely applied to quantitative research, internal validity applies to explanatory case studies, such as this study, where a researcher explores how and why specific events lead to specific outcomes, and where the researcher infers that particular events have resulted from historical or past occurrence based on case study document and interview evidence (Yin, 2014). External validity address the 
generalizability of the study beyond the sample taken, regardless of the research method applied; this can either be through analytical generalization in qualitative research or statistical generalization in quantitative research (Yin, 2014). The former is applied in this study. Analytical generalizability relates to researcher's ability to conceptualize a research problem through theoretical underpinnings, shows how the results of a study align with patterns from theoretical constructs or theories and then using the same theoretical ideas also to implicate other study results and compare or connect the findings of the research to those done by others (Yin, 2010, 2014).

A summary of the criteria applied to achieve reliable and valid research outcomes of the study is summarized in Table 21: Summary of the application of reliability and validity in the research process.

Table 21: Summary of the application of reliability and validity in the research process

\begin{tabular}{|c|c|c|}
\hline Test & Approach applied & $\begin{array}{l}\text { Phase of } \\
\text { application }\end{array}$ \\
\hline $\begin{array}{l}\text { Construct } \\
\text { validity }\end{array}$ & $\begin{array}{l}\text { - The literature review: identified key and specific concepts } \\
\text { (e.g. theories and contextual influences such as language, } \\
\text { discourse, and institutions) known to influence climate } \\
\text { change framing. Connected the concepts to study } \\
\text { objectives, data collection, analysis and interpretation. } \\
\text { - Expert consultation: sought expert opinions on the } \\
\text { contents of the study, including approach, appropriateness } \\
\text { of interview questions and identification of participants. } \\
\text { - Triangulation: use of multiple sources of evidence: } \\
\text { documents and key informant interviews for corroboration. } \\
\text { Participant validation: determined the accuracy of key } \\
\text { informants reviewing interview transcripts through } \\
\text { participant validation of interview transcription. }\end{array}$ & $\begin{array}{ll}\text { - } & \text { All phases } \\
\text { - } & \text { Data } \\
\text { collection } \\
\text { - } \\
\text { Data } \\
\text { collection }\end{array}$ \\
\hline $\begin{array}{l}\text { Internal } \\
\text { validity }\end{array}$ & $\begin{array}{l}\text { - Pattern matching: matching of the results of the study } \\
\text { with empirical studies to support causal inference } \\
\text { (analytical generalization) to similar results outside of } \\
\text { Ontario. } \\
\text { - Time Series: chronology of events and tracing events over } \\
\text { time (2007 to 2018) to support the explanation of } \\
\text { relationships between identified results and historical } \\
\text { trends or comparison to other empirically significant trends. } \\
\text { - Logic models: as a framework for understanding the } \\
\text { needs of the study and informed theoretical frameworks for } \\
\text { accessing and analyzing data. Eventually, as a framework } \\
\text { for legitimizing public health in the climate change } \\
\text { discourse. } \\
\text { Cross-case analysis: aggregated the findings of } \\
\text { individual and groups (public health and NPH) to examine }\end{array}$ & $\begin{array}{ll}\text { Data } \\
\text { analysis } \\
\text { - } \begin{array}{l}\text { Data } \\
\text { analysis }\end{array} \\
\text { - } \begin{array}{l}\text { Research } \\
\text { design }\end{array}\end{array}$ \\
\hline
\end{tabular}




\begin{tabular}{|c|c|c|}
\hline & $\begin{array}{l}\text { the convergence and divergence between the individuals } \\
\text { and groups. }\end{array}$ & \\
\hline $\begin{array}{l}\text { External } \\
\text { validity }\end{array}$ & $\begin{array}{l}\text { - Grounding the study on theory: guided data collection, } \\
\text { analysis, and situated the issue within broader contexts } \\
\text { beyond the sample being studied (interpretation). } \\
\text { - Representative sampling: by sampling cases through } \\
\text { inclusion and exclusion criteria to respond to the needs of } \\
\text { the study, and purposeful and snowball sampling to } \\
\text { identify those with relevant information for the study. } \\
\text { - Using explanatory research questions (e.g. how): these } \\
\text { questions not only aimed to achieve a description of the } \\
\text { phenomenon under study, they support the explanation of } \\
\text { the phenomenon in a manner that can be generalizable. }\end{array}$ & $\begin{array}{ll}\text { - } & \begin{array}{l}\text { Research } \\
\text { design }\end{array} \\
\text { - } & \begin{array}{l}\text { Date } \\
\text { collection }\end{array} \\
\text { - } & \begin{array}{l}\text { Research } \\
\text { design }\end{array}\end{array}$ \\
\hline Reliability & $\begin{array}{l}\text { - } \text { Clarifying the research question and the purpose of the } \\
\text { study. } \\
\text { - } \\
\text { - } \text { Cocumentation of research procedures. } \\
\text { boundaries, including what will and will not be included in } \\
\text { the study. Protocols and databases developed to enhance } \\
\text { replication and minimize data loss. } \\
\text { - } \text { Appropriate sampling and analysis strategies. } \\
\text { - Standardized data collection and analysis procedures and } \\
\text { standardized instructions and conditions for key informants } \\
\text { participation - e.g. all participants were interviewed via } \\
\text { telephone to maintain consistency. } \\
\text { - Interrater reliability: consistency in data collection by more } \\
\text { than one person. }\end{array}$ & $\begin{array}{l}\text { Data } \\
\text { collection } \\
\text { and } \\
\text { analysis }\end{array}$ \\
\hline
\end{tabular}

Sources: (Baxter \& Jack, 2008; Bazeley \& Jackson, 2013; Belur, Tompson, Thornton, \& Simon, 2018; Kitto, Chesters, \& Grbich, 2008; McHugh, 2012; Rowley, 2009; Salkind, 2015; Scheel, Mecham, Zuccarello, \& Mattes, 2018; Viera \& Garrett, 2005; Trochim, 2006; Verner \& Abdullah, 2012; Yin, 2014).

Additionally, to enhance the reliability and validity of the case study approach, the researcher must adequately describe methodological foundations (Hyett, Kenny, \& Dickson-Swift, 2014). As a result, the study followed the DECARTE Model (Design of Case Research In Healthcare Model) developed by Carolan et al. (2015). The model provides three stages to case studies and twelve guiding questions to sequentially conduct a case study research. The three stages allow the researcher to situate their research using philosophical and ethical considerations, determine research design components, and coherently analyze data while considering the overlap between the philosophical, strategic and integrative stances. The philosophical stance means that the method used to analyze the data must be in agreement with the philosophical perspectives guiding the study. A strategic stance means that the researcher needs to explicitly describe the strategy used to analyze the study data (Carolan et al., 2015). An integrative stance means outlining how the data analyzed will be integrated (Carolan et al., 2015). 
The twelve guiding questions guide a researcher through questions aimed at satisfying the requirements of the three stances. The questions include philosophical approach, situating the research, ethical dimensions of the research, case and context definition, the purpose of the case study, conceptual or theoretical framework, sampling approach, rationale for data sources, and congruence of the analysis to the three stances (Carolan et al., 2015).

To illustrate, researchers have used case studies to examine and understand complex real-life issues and contexts of phenomena including organizational influences on public health initiatives (Peirson, Ciliska, Dobbins, \& Mowat, 2012), policy barriers on minorities (Sheikh et al., 2009), health inequities and SDOH (PHAC, 2011), decisionmaking processes (Baxter \& Boblin, 2006), bus pollution, industrial hog production, moving from nursing homes to communities, school conditions, making healthy choices, and youth empowerment (O'Toole, Aaron, Chin, Horowitz, \& Tyson, 2003). Through case studies, the authors demonstrated how listening to informants provide perspective, information, and experiences that enrich an understanding of a research problem with real-life contexts rather than relying on information generated from the outside of the organization or institution under study (Palys, 1997).

\subsubsection{Publicly Accessible Documents}

A literature search for documents was restricted to publicly available information from government websites. The ambiguity of written public policies makes it difficult to characterize subjective meanings, values (ideologies, interests, and beliefs), privately reported political and institutional activities, and power relations of climate change discourse and policymaking. However, the document analysis was complemented with key informant interviews for the corroboration of evidence and for the exploration of additional themes for answering the research question.

Furthermore, while this is a proxy measure of the discourse, the systematic review that included a review of all relevant documents from the government-affiliated cases allowed for a comprehensive assessment of the documents in a manner that supported answering the study questions. Government actions and interventions are subject to queries from the public and those that represent the public in different forums. In turn, proactive disclosure of government actions and strategies is a common practice in the public service sector, in an attempt to maintain accountability and transparency. The availability or lack of information from these publicly available literature sources, possibly reflects the extent, the lack of, or prioritization of climate change actions. Also to access the relevant documents, systematic procedures were followed as identified in the data collection (Chapter 4). 


\subsubsection{Research Participation}

The reliability and success of a study rely on identifying and retaining relevant participants (Newington \& Metcalfe, 2014). Because this research heavily relied on study informants to answer the research questions, attempts were made to optimize recruitment and retention of the participants. As suggested by Cerasoli, Nicklin, and Ford (2014), participant identification and retention were achieved by appealing to the intrinsic motivation of participants. The authors argue that a participant is likely to take part in a study if they are made aware that their participation will likely make a difference. To attract participants, the benefits and impacts of the study were clearly identified and relayed in the study invitations and consent; these were also reinforced prior to and during the interviews.

Newington and Metcalfe (2014) also suggest using a large sample frame and directing information to a specific audience. To support the study, the samples were drawn from all the relevant ministries and PHUs, with each agency and PHU aggregates yielding at least one participant each. Equally, the participation was directed to those with relevant knowledge of the study area. These included those who have worked or work on climate change policies and had the knowledge that is beneficial to improving climate change actions. Kaiser (2009) indicates that respondents may be discouraged from participating in a study where they provide confidential information. The author discusses two approaches that are relevant for maintaining participant confidentiality in this study. First, participant confidentiality was maintained during research planning, data collection, cleaning, and dissemination. Second, an alternative approach where respondents were made aware of how the data will be used, the audience for the study findings, and how the findings will be disseminated. These approaches were included in the consent forms.

\subsubsection{Challenges of Discourse Analysis}

Discourse analysis has been criticized for selectivity and lack of clarity on how texts have been selected to support the study or excluded (Fairclough, 2003; Fischer, 2012c; Phillips \& Hardy, 2002; Walter, 2013). Because only a small number of texts can be analyzed, improper selection can lead to partial consideration of texts and biases (Walter, 2013). To overcome the challenge, the study boundaries were selected by including cases that were relevant for the study, specific frameworks for considering the relevant texts were outlined through sample frames, the definition of boundaries for text consideration (inclusion and exclusion criteria) and systematic identification of policy documents; key informant participants informed the production texts informing research areas. In textual analysis, identification of texts for exploring and explaining 
the research topic was guided by a specifically designed framework incorporating issues relevant for analyzing in textual analysis and discursive practices (Appendix I: Main Issues Analyzed in Textual Analysis and Discursive Practices) and the incorporation of social contexts for explaining the practices (Lomas Model and narrative analysis). Specifically, the relevance of texts was considered based on their ability to connect to the research questions and conceptual frameworks. In analyzing themes, consideration of who produced such texts, how such texts are produced, the channels for communicating the texts, how such texts can be sampled and the effective ways of understanding and interpreting the texts were used.

Discourse analysis is based on the assumption that language defines social life (Fairclough, 2003; Walter, 2013). As a result, the method has been criticized for focusing on language while favouring subjectivity and privileging opinions of individuals (Fairclough, 2003; Fischer, 2012c; Walter, 2013). However, Weedon (1997) advises that despite the influence of discourse on perceptions and how people deal with an issue, discourses are invisible. Fischer (2012b) also posits that the characteristics that define discourse are clear. For example, exploring language is considered the first step to understanding politics and its realities (Fischer, 2012c; Moon \& Blackman, 2014). Exploring language within its social contexts, therefore, requires the exploration of texts (verbal or written). Fairclough (2003) suggests three analytical elements in the meaning-making process. First is the production of texts which focus on the role played by authors, speakers or those producing the texts in meaning-making; this author was considered to be anyone who put together the words in the document or website or one whose position was reflected in the texts. Second is the interpretation of the text which focuses on how the person receiving or reading the texts makes meanings of the text; last is the text itself

In addition, overcoming the limitations associated with subjectivity and focus on language can be overcome by integrating other forms of analysis (Fairclough, 2003). The study integrated institutional and narrative analysis that not only support the identification of relevant texts but also connect the texts to the social contexts producing the texts.

\subsubsection{Structure of Public Health in Ontario and Analytical Generalizability}

In Canada, most provinces have an integrated public health system where public health is regionalized (Moloughney, 2007, 2016). This means that the delivery of public health programs and services are provincially and centrally with a single governance board known as a Regional Health Authority (RHA). The services and programs are comprehensive (includes elements of public health and healthcare services) and are funded by the provincial governments. However, Ontario's public health structure is unique and different from the rest of the provinces. As already 
discussed in Chapter 2 (Structure of the public health system), the governance structures of $\mathrm{BOH}$ vary considerably (Ontario Public Health Capacity Review Committee, 2006a). The governing structures vary between autonomous and integrated structures (Association of Local Public Health Agencies - ALPHA, 2010; Lyons, 2017). Some operate independently from the municipal structures (autonomous); others are administered by the regional/single-tier governments while some are operated under local governing structures (ALPHA, 2010; EPPH, 2017). $\mathrm{MOH}$ of health affiliated with the autonomous structures have autonomy over PHU administration, while those on the integrated structures report some of the PHU administrative duties to the respective municipality. Besides, unlike the rest of the provinces, PHUs funding in Ontario is covered by both the province and municipalities. Ontario's unique governance and funding system are likely to result in distinct public health activities and challenges compared to other forms of public health governance across Canada or other countries. The study applied two approaches to overcome this limitation and generalize the findings across Canda or other jurisdictions internationally.

First, by using a case study grounded on theories for examining and explaining the meaning-making processes of climate change construction. The literature review showed that the processes of the social construction of ideas and how information is received, perceived, interpreted, and acted upon are guided by various philosophical and theoretical paradigm (see Theoretical Perspectives of the Social Construction of Climate Change and Theoretical framework). Application of the theories for the exploration and evaluation of meaning-making constructs, experiences, and processes guiding the construction of climate change as well as the language that defines symbolic interactions and conception of climate change. Therefore, grounding the case study with a theory played two roles in the study. Theory facilitated the study design, where the theory acted as a blueprint for data collection, analysis, and interpretation, as has been applied in other research. Theory supported the generalization of lessons learned from the case study (Berg \& Lune, 2016; Yin, 2014). Yin (2014) characterizes this generalization as analytical generalization and not statistical generalization applied to empirical studies. This means that a theory-guided case study offered grounds or theory for explaining the construction of the public health framed climate change policy discourse and facilitated the comparison of the research findings to others in the literature and the potential transferability of findings to other settings other than the cases studied.

Second, the study not only assessed the activities of public health agencies but also integrated public health's holistic approaches for advancing population health. Therefore the study was guided by the definition of public health (see Defining Public Health in the Context of this 
Study). Based on the definition, it was critical to analyze the problem from the broader principles and perspectives public health utilizes to minimize the socioeconomic, demographic, geographical and environmental disparities that hinder people from achieving good health. That is the consideration of public health principles of $\mathrm{SDOH}$, equity and justice and how those apply in the public health's approach to climate change governance and the interactions across health units and with other stakeholders across Ontario and beyond.

\subsection{SUMMARY}

This chapter has interpreted and discussed the significance of the study findings using the study results and literature to explain how Ontario's construction of climate change was influenced by economic approaches that framed the phenomenon as an economic and political issue that can be solved through market strategies and technological innovations advanced through political and partisan platforms forwarded by elites. The chapter explained how the historical and strategic framing was advanced by the roles of discourses, strategic and communicative actions, and identities and political interests in the construction of climate change. In essence, the discourse impacts issue framing and the policymaking structures and processes for addressing the issue. Ontario's discourse had two influences on climate change framing and institutional engagements. The discourses provided arguments for substantiating climate policies and decisions as well as the relevant actors and knowledge; they also supported discursive, normative, and strategic practices within institutions. The discourses guided how climate change issues are framed, action identified, as well as structures, knowledge and values considered in the decision making. The practices, identities and structures limited the role and relevance of, and resources for, advancing public health frame and capacity in climate change policies and discourse. This focus did not align with a discourse that can be associated with public health framing. A public health framed climate change policy can be situated with the discourse of democratic pragmatism, which emphasizes the legitimacy of policy actors through substantive participation and deliberation processes. As a result, the chapter connects the discoursal influence to Ontario's governance structures and processes, and institutional arrangements, within and without public health, which either facilitated or impeded the public health frame and capacity in climate change policy discourse. Here the chapter focused on elaborating the impediments of knowledge integration, institutional engagements and supporting capacities, and contexts of power as they emerged in the findings and as has been forwarded by various researchers. 


\section{CHAPTER 12: CONCLUSION, SIGNIFICANCE, AND RECOMMENDATIONS}

Climate change poses a diverse collection of risks and impacts. It is projected to impact environmental, social, political, cultural, and economic structures that humans depend on for survival and wellbeing. These impacts have adverse direct and indirect health outcomes. Minimizing the health impacts, now and in the future, relies on broader health impact awareness and the availability of sound mitigation and adaptation strategies. Regrettably, the health impacts are poorly understood, and, a consensus on greenhouse gas reduction strategies and sustainable adaptation initiatives are lagging.

A public health framed climate change policy discourse has been forwarded as a solution to increasing climate change impact awareness and consensus on actions needed. Public health can achieve this role through three strategies. First, a public health framed climate change can support the awareness and consensus on measures by providing climate change communication techniques that resonate with broader audiences as opposed to the complicated jargon of climate change or distant environmental impacts. Second, public health leadership can advance population health initiatives - such as health promotion and disease prevention competencies directly related to the public health mandate and expertise. Third, a facilitative role can highlight the health co-benefits of actions, provide evidence for communicating and integrating health needs in policies and coordinate sectors by offering multi-stakeholder engagement platforms for democratizing and depoliticizing climate change needs. Despite such relevance, there has been a limited utilization of the frame in the discourse.

Using the context of climate change policy discourse in the province of Ontario (Canada), this research examined examine how public health needs are socially constructed in the discourse and the sociopolitical contexts advancing or impeding the public health framed climate change policy discourse. Specifically, the study examined three interrelated questions. How does the province of Ontario frame its climate change discourse? What discursive and systematic contexts have influenced the framing of climate change? How have the contexts influenced the public health frame and capacity in the climate change discourse?

This chapter concludes the study by providing 1) a summary of key research findings that answered the research questions, 2) the significance and implications, and future directions of the study, and 3) recommendations for advancing public health needs in the discourse, including the feasibility and limitations of the recommendations. 


\section{$12.1 \quad$ KEY FINDINGS}

The study has revealed how Ontario's climate change policy discourse has been historically and socially constructed as an economic and political issue that can be solved through market strategies and technological innovations forwarded by political elites. Consequently, policy texts marketized and reduced climate change to economic implications of actions or inactions, the institutionalization of national and international norms, and the advancement of market-based solutions through technological innovations. Politics and partisan inclinations drove the salience of the dominant frames. The policy texts revealed Ontario's emphasis on the role of the government in climate policies. The texts also exposed the values and influences of political leaders, experts, and corporations whose voices and values were integrated through statements of political commitments to promote, justify, and legitimize the policy preferences. Conversely, a public health frame was ambiguously presented and trivialized through generic narratives that mainly presented public health needs in general terms. Such frames aligned with international discourses and norms and were propagated by strategic and communicative actions and identities.

The historical and social approach of framing shaped the institutional structures and responses, values, and knowledge guiding climate change policy discourse. As a result, Ontario's discourses were embedded and identifiable in the governance and institutional structures, exposing how the different government agents, text sources, as well as individual narrations of events and practices, assumptions and accounts have supported the dominant frame or negated the public health needs in the discourse. Specifically, the approach exposed the interplay between discourses and institutions in influencing the public health framing and needs by impacting the actors' understanding of the problem, influencing the types of actions, goals, and objectives that guided such actions, and delineating the types of institutional arrangements, actors, and relationships relevant in the climate change discourse. The dominant discourses were embedded in institutions, supplying them with forms of interaction, processes, and practices. As a result, the Province of Ontario's construction of climate change influenced climate change governance by guiding and translating the government's political visions into policy outcomes, actions and programs and the participation from stakeholders that support such visions. On the other hand, the dominant frames provided institutions with the discursive legitimacy that limited public health's engagement in climate change policies.

The strategic forces within the provincial structures and the public health-specific structures enabled and constrained the construction of climate change and the construction of knowledge and actors relevant to climate change policies in Ontario. The structures impacted 
how the marginalized (public health) attempted to engage in and challenge the dominant discourses, norms, and processes. This is because the focus substantiated the types of structures and processes of policies and decisions, the relevant actors and knowledge, and the values supporting the discursive, normative and strategic practices. The focus also limited the utilization of the public health frame and the supporting capacities through the misalignment between public health and the provincial strategic actions, the lack of recognition and integration of public health roles, mandate and structures, and limited public health capacity building initiatives.

The study also exposed who the critical actors in the discourse are and the role that each group (public and non-public health group), as social beings, took to shape and advance the construction of climate change in the province. The study exposed that social interaction and relationships directed the governance of climate change, affecting the perspectives of actors, the understanding of public health needs and inclusion, and limiting public health deliberation processes and participation structures in the discourse. The study has also revealed the influence of political and individual attitudes, beliefs, interests, and perspectives, which defined climate change actions and constructed the roles and relevance of public health in climate change policies. As a result, the study has clarified that the construction of climate change policies using a public health lens is impacted by the dominant discourse, identities, value, and ways through which governance structures, processes, and institutional arrangements (both within and external to public health) facilitate or impede public health leadership and the deliberative and participative roles. The dominant discourses and the resulting governance structures and institutional arrangements do not conform to those that support the integration of public health frames - such as the discourse of democratic pragmatism and collaborative governance.

Challenging the dominant frames and incorporating the public health framing as an endpoint of climate change policy discourse requires the institutional outcomes that legitimize the role of public health through governance structures and outcomes that supports the sector's agency and authority. Against this backdrop, the study presents a framework, recommendations and future directions for advancing public health's needs in the climate change discourse.

\subsection{SIGNIFICANCE, CONTRIBUTIONS, AND FUTURE DIRECTIONS}

\subsubsection{A Framework for Public Health Framed Climate Change Policy Discourse}

The study results, interpretation, and conclusion, as well as literature, postulate that advancing the public health frame in the discourse requires legitimation of public health into the various institutional structures and governance of climate change. 
The failure and lack of inclusion of relevant actors in climate change decisions have been blamed on the legitimacy of the process, conceived as an outcome resulting from an institution's activity (Cadman, 2013; Taylor, 2013). Creating new institutional arrangements will not lead to the utilization of a public health frame in climate change policies or inclusion of public health in the climate change discourse. What is needed is the consideration of the legitimacy of public health in the climate change discourse.

As a complex social process, climate change, and its management, is influenced by governance at various levels, from global to national to local (Kreuter et al., 2004; Head, 2014; van Woezik et al., 2016). It is this governance structure that has an influence on, and that has been blamed for, issue framing, prioritization, and stakeholders engagements in climate change decision processes and policies (Cadman, 2013). Governance quality is determined by gaps in two forms of legitimacy: input and output-oriented legitimacy (Cadman, 2013). The former relates to the government's (state's) need for consent from the people they are ruling - that is, decisions of the state is pinned by democracy; the latter relates to the efficiency and competency of the state in achieving public interest - that is good governance (Cadman, 2013; DeRouen \& Goldfinch, 2012). Achieving legitimacy is based on two governance arrangements: participatory structures and deliberative processes that support meaningful engagements and productive outcomes. Meaning that actors can only meaningfully participate in decision processes if the participatory structures are inclusive and not selective, where there is equal access to the resource to support their capacity needs in the decision process, and where the processes are guided by transparency and accountability (Cadman, 2013). The quality of the discussions and dialogue should be fruitful, resulting in outputs that actually impact policies. Achieving such outcomes rely on significant interactions between stakeholders from local to international levels (Cadman, 2013).

Therefore, public health framing as an endpoint of climate change discourse will be influenced by the legitimacy accorded to the public health sector through institutional and governance arrangements that support participation, deliberation, and collaboration, resulting in meaningful and productive engagements. This approach must be supported by collaborative interactions. It is this legitimacy that is likely to propel the recognition of the relevance of public health framed and led climate change policy discourse, resulting in behavioural outcomes (e.g. climate change awareness and the consensus on, and uptake of, climate change actions).

Public health already has discursive legitimacy on climate change through the relevance of a public health frame on issue framing (Akerlof et al., 2010; Maibach et al., 2010; Myers et al., 2012; Watts et al., 2015a, 2017a; Valles, 2015). As studies have suggested, the sector already 
owns the power to speak on, or justify, climate change issues in a manner that is likely to influence consensus on the issue and actions. However, achieving legitimacy to use such powers in a manner that influences policies requires institutional arrangements and governance structures that provide public health with the authority and resources necessary for support deliberation and participation. In other words, availability of places and spaces for engagement. It requires systemic attempts to integrate public health in decision processes, the trust in the ability to lead the discourse, and political commitments - including policies that highlight clear objectives and measurable targets for evaluating outcomes, achievement, and policy processes.

This new institution calls for a collaborative governance approach, a multi-stakeholder engagement approach, where governing institutions or agencies support participation by collectively working with and integrating values from a variety of stakeholders (Ansell \& Gash, 2008; Hamburger \& Weller, 2012; Koliba \& Gajda, 2009; Luís et al., 2018; Rowe \& Frewer, 2005, Wellstead \& Stedman, 2015). The approach stresses the creation of partnerships where the need for a two-way communication and knowledge exchange is paramount (Crisp et al., 2000). As a result, the engagement processes initiated by either an agency or public health institution should bring stakeholders together through deliberative forums. Within such institutional engagement domains, collaboration (including public participation) is identified as an ideal form of public engagement that connects stakeholders, builds collaborative relationships and supports working towards mutually beneficial actions (PHAC, 2016; Schell et al., 2013; Gray, 1989). On the other hand, communication and consultation should complement participation by providing information that necessitates collaboration (PHAC, 2016a; Rowe \& Frewer, 2005a).

Watts et al. (2015) advise that a silo approach to addressing climate change-induced health impacts is detrimental. Through its reports, the Lancet Commission on Climate Change and Public Health primarily advocated for a collaborative approach to climate change by emphasizing the cross-sectoral drivers of health impacts and public health needs (Watts et al., 2015). Specifically, the commission emphasizes the need for governments to facilitate collaborations between health ministries and other agencies of government in a manner that supports the empowerment of health professionals and support integration of health needs in the climate policies (Watts et al., 2015).

Collaborative governance focused on deliberation and consensus-building implies that meaningful institutional engagements are not merely one-way information provision or consultation but rather a process where both the agencies and the public health organizations are participating and engaged in the decision-making process. Participation is situated as a form of public engagement where diverse stakeholders are included in the process as opposed to the 
'traditional models of governance' that only include mandated policymakers and select experts (Luís et al., 2018; Rowe \& Frewer, 2005a).

In the new institution, access to decision making information is not only considered a prerequisite for a successful democracy, but it also enhances public participation (Odparlik \& Köppel, 2013). For instance, enabled access from mandated agencies can support public health actors' access to relevant information and technology that guides their policies. In another stance, public health stakeholders are more likely to understand relevant health impacts and consequences posed by proposed policies and, provide various alternatives to the responsible authorities. Based on Arnstein's Ladder of public participation, an effective public participation tool informs, consults, involves, collaborates, and empowers participants (Odparlik \& Köppel, 2013). Further, participation must incorporate two-way communication processes where participants - whether commenter (in Environmental Registry) or participants in dialogue and consultative meetings know how their information is integrated into the policy process. However, the mere provision of information does not equate to public participation; it only translates to the degree of tokenism in which information is provided to stakeholders, but their inputs are not always acted on or where information is provided after decisions are already made (Cadman, 2013). Instead, participatory democracy should create opportunities for public health to make meaningful contributions to the outcomes of climate change policy decisions through discursive levels of engagement.

This new institution for supporting public health framing and leadership or inclusion in climate change discourse can be conceptualized through the framework in Figure 25: Governance and institutional approaches for legitimizing the public health frame: a conceptual framework (see next page). The framework is developed by modifying Cadman's (2013) model of global governance and conceptualized through the study findings, and the various literature (see Sources: DeRouen \& Goldfinch, 2012; Gaventa, 2006; Hardy \& Phillips, 1998; Ingram \& Schneider, 2009; Luís et al., 2018; Rowe \& Frewer, 2005b; Watts et al., 2017).

\subsubsection{Implications for Practice and Policy}

The study is of interest to the broader priorities of addressing public health implications of climate change and the health implications. Climate change is a defining issue across our society, and, reducing GHG emissions and protecting human health are both priorities for policymakers and public health practitioners. While a public health framed climate change has been empirically linked to a broader understanding of climate change impacts and building consensus on actions, the study has shown that it is competing with other frames. The limited application of the public 


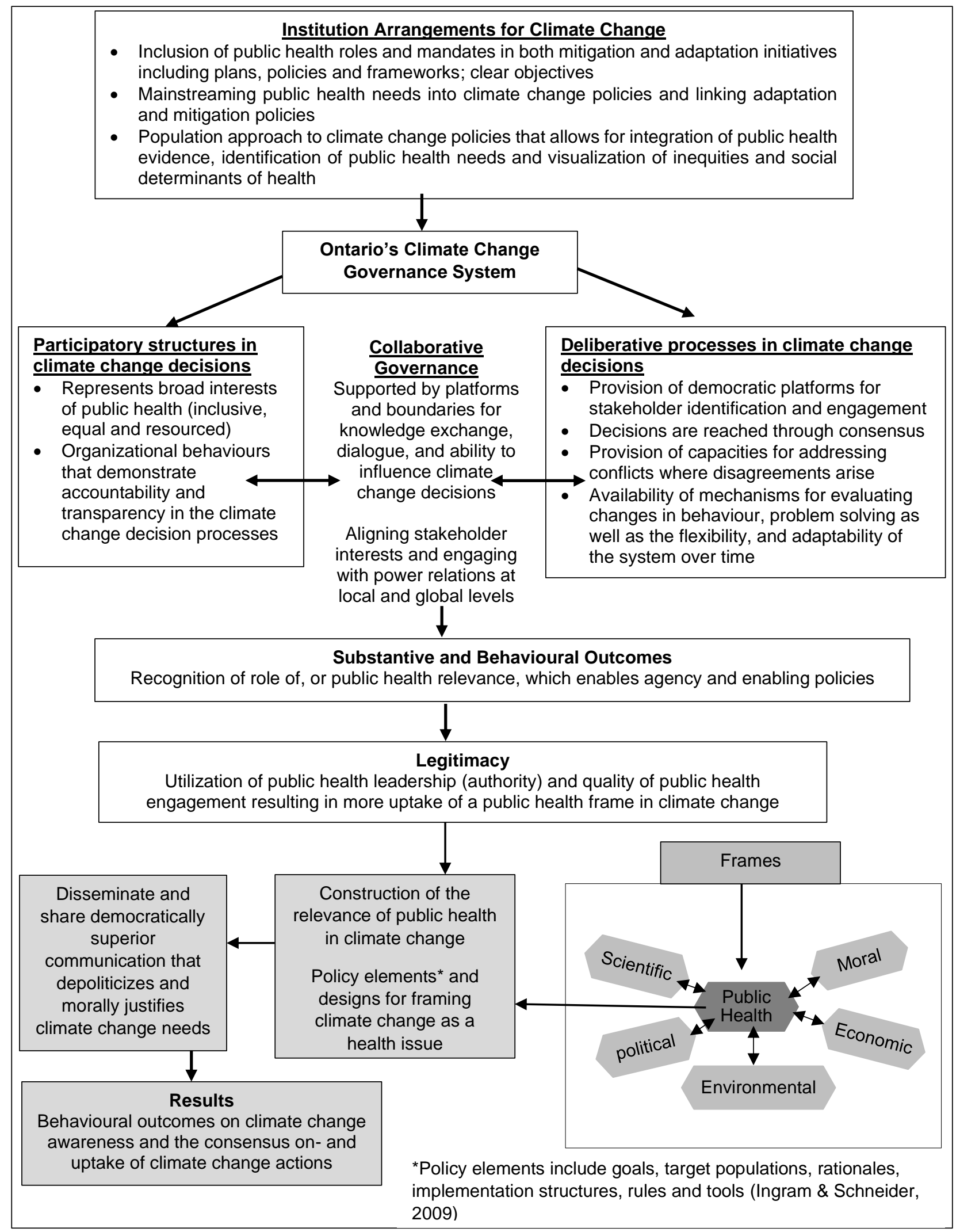

Figure 25: Governance and institutional approaches for legitimizing the public health frame: a conceptual framework 
awareness and consensus on actions required. The dominance of economic and political narratives of climate change discourse means other competing and important frames, such as a public health frame will remain vague if not supported by climate change institutions. The lack of focus on public health is also likely to minimize public health's leadership and facilitative roles in climate change policy processes, integrative institutional arrangements, collaborative efforts, and the accompanying resources for building public health capacity in the discourse.

The knowledge from this study is relevant as it demonstrates how society and governments approach the climate change phenomenon. Specifically, this study provides the public health policymakers and non-public health policymakers, as well as researchers concerned with the elusive role of public health in the discourse, with knowledge on or of:

- The climate change policy image (frame) and the strategic and contextual factors that have supported and legitimized that image, including the role of institutional structures, values and knowledge in generating that image.

- How the image impedes the public health frame, including the factors impeding the frame and the reference points and strategies for integrating the public health frame.

- A framework for supporting the growing need for public health inclusion in the climate change discourse while accounting for the power relations of the political processes of policymaking.

- The impact networks and political activities in setting the agenda for climate change discussions and policy outputs as demonstrated by influences of activities before or during the development of strategic plans, provincial elections, partisan shifts, legislative and political activities, and in few instances, public health concerns. These agenda-setting initiatives can help public health policymakers and practitioners to:

- Analyze action situations and identify opportune moments and strategies for matching public health interests in politically beneficial settings.

- Understand how government priorities change and how events force new ideas into the government's agenda; the practitioners can then use such platforms to sell their ideas to the political leaders or promote the ideas to media, which can then prompt agenda setting as a result of public opinions.

- Understand how certain situations provide a window of opportunity for including a public health issue into the political agenda.

- Priorities and gaps for mainstreaming of public health needs and for developing healthy public policies. 
- Factors to consider when evaluating the relevance of stakeholders and platforms for stakeholder engagements in climate change policies, including:

- The role of ideas in influencing issue framing, relevant actors, and knowledge.

- Impacts of multilevel governance when some actors are not well integrated and supported by capacity building resources.

\subsubsection{Implications for Future Research}

The study has developed a framework for supporting the integration of public health needs in climate change discourse (see Figure 25: Governance and institutional approaches for legitimizing the public health frame: a conceptual framework). The framework underscores potential possibilities for future research. Future studies can validate the framework through case studies that demonstrate the successes and/or modification needs of the framework. Such case studies can arise from public health institutions or other institutions engaged in climate change actions or other complex social problems that require integration of actors into the governance and institutional structures for solving the problem.

The province of Ontario did not stand out as a case for exposing approaches to how public health has been integrated into the climate change discourse. However, it revealed the many impediments of inclusion. The study also provided a theoretical framework on how research on discourse can benefit from the integration of institutional and narrative analyses to expose reciprocal interactions between discourses and institutions in influencing policy discussions and outcomes. Future exploration of other case studies is warranted to show how a public health framed climate change policy has been integrated and legitimized in climate change policies. Such explorations can also support the strengthening of the developed framework by providing additional variables for public health inclusion in the climate change discourse.

\subsection{RECOMMENDATIONS}

\subsubsection{Recommendation 1: Incorporate democratic climate change policy approaches engagements that support the inclusion of public health inclusion}

When economic and technological narratives dominate, climate change governance structures generally will be defined by elites, the processes become exclusionary, and experts are institutionalized and given authority over climate change policies (Dryzek et al., 2012; Taylor, 2013). Taylor (2013) argues that such discourse results in the domination of state of climate change leading to dominance by prescribed institutions and procedures. Climate change should not only be viewed as an economic or political issue. It may distinctively and collectively affect the 
political, economic, environmental, and social systems. But, as these structures are impacted, long-term public health consequences are anticipated. Therefore, climate change is also a public health threat. Moreover, studies have shown that framing climate change as an economic or environmental issue is less likely to influence or persuade the public to action compared to framing climate change as a public health issue. Framing climate change as a non-health issue can result in oblivescence and lack of engagement by other actors who do not see their role in climate change. Democratic principles command wide support across political parties and the nonpolitical stakeholders. This can only be achieved through a pragmatic discourse.

\subsubsection{Recommendation 2: Advance public health leadership and advocacy in climate change policy discourse}

Many climate change health impacts transcend the public health into other sectors due to the multiple pathways through which climate change and sectoral actions impact health (Gosselin, Bélanger, Lapaige, \& Labbé, 2011; Watts et al., 2015, 2017). Climate change decisionmakers may need the help of public health professionals to identify information and processes for integrating health needs into climate change decisions. Also, supporting positive health and environmental outcomes and highlighting the co-benefits of action in non-health sectors requires an understanding of the various health components of climate change and SDOH (Health Canada, 2008). These include an understanding of health impacts at regional and local scales, the vulnerabilities and disparities within the various populations, the risk perceptions and individual risk assessment approaches, and the complex pathways within which climate change and its related actions impact health. While this is true, health impacts may not be entirely understood by other sectors who lack expertise in public health. Rather than applying the sectoral approach to climate change mitigation, public health leadership can enhance the knowledge of the immediate and long-term benefits of actions to both public health and other sectors, and advance the integration of the benefits of the climate change actions. The knowledge of the mutual benefits can then influence stakeholder and political will (WHO, 2011; Watts et al., 2015). In effect, the public health sector has an important role to play in shaping the climate change associated health and wellbeing outcomes by influencing sustainable interventions that connect public health to critical climate change debates (Campbell-Lendrum et al., 2007; Frumkin et al., 2008).

To support this leadership, the public health community must reinforce the relevance of public health interventions in the climate change policy agendas by outlining the shared goals between public health and other climate change strategies and highlighting the public health cobenefits of climate change strategies (Dale \& Hill, 2001). The relevance can be reinforced by 
supporting and participating in multijurisdictional collaborative approaches to tackle climate change such as research, climate risk surveillance and communication, public health surveillance, and advocacy. This will allow for the integration of skills and capacity to better understand public health adaptation needs and co-benefits of climate change strategies. Public health communities must also work with other sectors to stress the importance of GHG reduction policies on reducing future human health impacts, and advocate for low carbon policy options that will contribute to GHG reductions and public health co-benefits (Frumkin et al., 2008).

\subsubsection{Recommendation 3: Advance a health-in-all-policy approach}

Tonelli, Tang, and Forest (2020) define Health in All Policies (HiAP) as "an approach that systematically considers the health and social implications of policies contemplated by all sectors of government - aiming for synergistic benefits and to minimize social and health-related harms."

Public health's overall aim is to reduce the health inequities and disparities that hinder people from achieving good health. Public health achieves this by targeting three key areas: $\mathrm{SDOH}$, equity and justice. Specific to climate change, public health relies on primary, secondary and tertiary prevention strategies to respond to population health needs of climate change (Frumkin et al., 2008). Primary strategies slow, reduce or stagnate climate change by decreasing GHG emissions. Secondary and tertiary strategies relate to public health adaptation strategies, also referred to as preparedness (Frumkin et al., 2008). While primary prevention is the most critical climate change response, mitigation strategies fall outside the public health sector and practice (Frumkin et al., 2008). Instead, preparedness has a longstanding association with public health practice and is used by health agencies to reduce the population's vulnerability to the health impacts of climate change. Advancing a HiAP approach to climate change policies can permit the integration of public health evidence and the visualization of social determinants of health, inequities, and injustices of climate change policies.

Population health assessment is also one of the foundational standards of public health practice. Population health assessment includes "the measurement, monitoring, analysis, and interpretation of population health data and knowledge and intelligence about the health status of populations and subpopulations, including social determinants of health and health inequities" (MOHLTC, 2018). Such a framework underscores not only the relevance of evidence-informed policies and programs but also the consideration of the health implications of policies through the inclusion of public health expertise. Supporting positive population health outcomes and health, sustainable environmental outcomes, and highlighting the co-benefits of action require an understanding of the various health components of climate change (Health Canada, 2008). These 
include an understanding of health impacts at regional and local scales, the vulnerabilities and disparities within the various populations, the risk perceptions and individual risk assessment approaches, and the complex pathways within which climate change and its related actions impact health. While this is true, health impacts may not be entirely understood by other sectors that lack expertise in public health.

The HiAP approach can also support the mainstreaming of public health needs in climate change, linking adaptation and mitigation policies, and inclusion of include public health roles and mandates in both mitigation and adaptation policies.

Empirical evidence has delineated the significant role that public health plays in advancing both mitigation and adaptation to climate change. In short, public health's role in climate change can be summarized into three parts (Watts et al., 2015). First, they engage in mitigation strategies by reducing their own carbon footprints (i.e. reducing sector's emission) and through collaborations with other sectors to identify means of reducing GHGs while also promoting health (health co-benefits of actions). Second, they develop interventions for responding to and preparing for the health impacts of climate change and build resilience within the public health sector and communities to cope with the direct and indirect climate change health impacts. Third, the health sector can connect the various sectors addressing climate change to support a broader understanding of impacts of climate change on health and wellbeing, and the opportunities for promoting health and reducing inequalities and injustices resulting from climate change

Public health organizations also have goals to achieve in fighting climate change. They hope to minimize the health impacts of climate change and support the development of healthy climate change policies capable of reducing GHG emissions while also protecting populations and advancing coping mechanisms to climate change impacts. The inclusion of mandates will provide the agency and the accompanying resources for achieving public health competencies and for intersectoral collaborations. While public health has been given a mandate (since 2018), this mandate is very abstract, mainly focused on vulnerability and adaptation assessments.

The current chaotic and the lack of prioritization of climate change policy in Ontario can reverse the gains and progress made in addressing climate change in the province. Public health advocacy is likely to support the continuation of public health's role in climate change policies in the absence of provincial leadership. Public health advocacy is achieved through expression of views or concerns that promote public health needs and actions (PHAC, 2015a). When supported by a clear mandate and resources, public health's advocacy can influence policy processes and political commitment on climate change by effecting changes that target the sociopolitical contexts 
of policymaking, exposing flows of policy outcomes such as laws and regulations and institutional practices and by making policymakers cognizant of policy needs on health (Johnson, 2009).

\subsubsection{Recommendation 4: Support public health capacity and mandates with access to resources}

Money is an essential resource in the policy process; when resources are not available, the policy outcomes are merely symbolic and contrived (Alaszewski \& Brown, 2012). Funding was the most significantly cited challenge to public health participation in climate change policies. However, some PHUs were more constrained than others, especially the smaller health units and those that covered large geographical areas. The lack of financial resources also impacts various areas of public health operation, including access to information and technology guiding climate change leading to differences in data collection and human resources available to advance public health climate change actions and procedures across the 35 PHUs. Financial constraints meant that public health only focused on- or strived to achieve the minimum requirements for the mandated public health programs, often neglecting climate change needs. This was more dominant in public health activities before the 2018 mandate on climate change. The mandate has also not been supported by resources.

Capacity constraints can hinder data integration and health needs assessment or management and lead to substandard interventions that compromise the efforts to mitigate and adapt to climate change not only within the public health settings but across various sectors. Resource constraint also minimizes the understanding of climate change health needs, hindering the integration of public health requirements in the climate change agenda.

To deliberate and develop a public health funding model, a Funding Review Working Group representing various public health communities was set up in 2010 (MOHLTC, 2013). The group made three recommendations. The recommendations related to the provision of funding in proportion to PHU's population, infrastructure and administrative costs, and, "equity-adjusted population model." The 'equity-adjusted population model' bases service costs on cost drivers (geography, living costs, and language), which impact the delivery of interventions and drivers for public health needs that reflect the demand and utilization of public health interventions. This approach is still not fully equitable as funding is still a responsibility of municipalities with reimbursement by the province. Still, sustaining public health interventions require clear provincial legislative mandate and commitment to funding provision.

Impacts of climate change are uncertain (IPCC, 2013b; NRC, 2010). Building capacity in the public health sector will support new challenges posed by the changing weather patterns. 
Enhanced public health capacity through collaborations and development of common objectives towards sustainable climate change actions and health initiatives will support a variety of mechanisms and infrastructure that the public health sector uses in supporting and protecting the health of a population (CPHA, 2016). As a result, building public health capacity relies on three fundamental concepts: advocating, enabling and mediating (PHAC, 2012). The concepts recognize the benefits of social capital in achieving health outcomes. The three pillars advocate for favourable health outcomes for all, permitting full health potentials through equal opportunities and resources and coordinating actions by various stakeholders and not only by the public health community (PHAC, 2012). However, such capacities will require inter-sectoral policy collaborations and partnerships at local and national levels targeting legislation, funding and institutional arrangements for influencing the SDOH and social policies (PHAC, 2012; Frumkin et al., 2008).

Assuring the Health of the Public in the 21st Century, a committee tasked with drafting a population health framework in the United States proposes an inclusive approach to public health systems capacity where public health systems and other sectors work together to influence health and address health issues (Institute of Medicine, 2002, 2003). The approach has been applied by the Finnish European Union, referred to as Health in All Policies, to promote healthy public policies across diverse settings other than public health (Ståhl, Wismar, Ollila, Lahtinen, \& Leppo, 2006). This means that to achieve sustainability and support climate change actions, the various sectors working on managing climate change must consider health components of their policy by likely integrating the public health essential operations, broadly considered as health protection and, disease prevention (WHO, 2014; Hess, McDowell, \& Luber, 2012; Portier et al., 2010b; Frumkin et al., 2008). A broader public health capacity in climate change actions will enhance the understanding of resources, gaps, opportunities, and coordinated actions for communicating risks and gaining consensus on actions; it will also provide public health expertise on public health needs and address multiple influences to health. Working with other stakeholders provides opportunities for action at the individual, organizational and system-level and enhances cooperation, trust and mutuality while promoting economic development (Crisp et al., 2000; Heller et al., 2007). 


\subsubsection{Recommendation 5: Create public health governance structures that promote equitable access to resources and capacity to act on climate change}

The influence of the governance structures and MOHLTC's leadership in climate change was evident. The theme also emerged where participants emphasized the need to work together across PHUs.

Over the years, the structure of public health governance has been scrutinized and criticized. Various public health inquiry commissions have advocated for autonomous $\mathrm{BOH}$. Municipalities also advocate for some control of the $\mathrm{BOH}$. An assessment of the District of Algoma Public Health Unit following a reported misuse of public health funds suggested appointing skilled board members instead of municipal politicians (Graham, 2015). Following the SARS outbreak in 2003, the Honourable Mr. Justice Archie Campbell was critical of the integrated governance model, indicating that the lack of full administrative control by the BOH limits the MOH's ability to deliver the necessary public health programs (Campbell, 2004). The Ontario Public Health Capacity Review Committee (2006a) recommended an autonomous skill-based $\mathrm{BOH}$. Governance plays a major role in public health policies and interventions (Love et al., 2005).

Equally, the jurisdictional separation (both within the governance of PHUs and between provincial approaches to health) promotes decentralized policymaking at the different levels of the government (Balme \& Ye, 2014). Decentralization can allow for climate change actions at the various levels of government and provide opportunities to cater to the needs of local needs (Balme \& Ye, 2014). But, it can lead to a lack of political will due to vested and conflicting interests within the different political systems (Dale and Hill, 2001; Love et al., 2005). Fragmented actions can paralyze the policy processes due to the ambiguity of roles, reduced funding, overlaps, gaps, duplication, and the divergence of information that result in the provision of incomplete or inaccurate information (Dale and Hill, 2001; Wilson, 2004; Baggott, 2011). Currently, the province has neither aligned PHUs with the LHINs nor included PHUs in their vision; the public health has no role in these agencies but continues to engage in various LHIN programs and committees (ALPHA, 2010; EPPH, 2017). The EPPH report identified that the lack of alignments hinders collaboration, resources and enhancing the effectiveness of the public health and the health system in the province ( EPPH, 2017).

Achieving parity across governments require institutional and structural changes by redesigning them to understand the risks better and promote actions to manage the risks (Dale and Hill, 2001). Moloughney $(2007,2016)$ portrayed the advantages and limitations of RHA in advancing public health mandate. An RHA is likely to further the integration of population health 
needs through leadership, collaboration and inclusion of public health needs in other services. However, such integration must also consider risks which can be overcome by limiting changes to the current critical components of Ontario's public health structure, accompanying public health involvement with resources, and balancing public health's role in the broader system to minimize the riks of overburdening the public health system (Moloughney, 2016). Balme and Ye (2014) recommends transforming policies and gaining political support through multi-governance approaches that include various stakeholders and mix of both centralized and decentralized forms of governance. The centralized governance can promote consistent actions or legislative frameworks to climate change that link $\mathrm{PH}$ needs to the most important political ideologies (Balme \& Ye, 2014). Complementing the centralized approach is the decentralized framework that targets the local requirements of each PHU. The process clarifies gaps in agenda setting at the national and provincial levels, and implementation needs at the local level (Balme \& Ye, 2014). While recommending ways to strengthen and integrate public health with Ontario's healthcare system, the OPHA and OPHCRC recommended maintaining the autonomy of public health but linking it with LHINs (OPHA, 2005; OPHCRC, 2006a, 2006b).

\subsubsection{Recommendation 6: Develop communication resources for advancing public health's role in climate change awareness and education}

Key informants highlighted the relevance of public health in creating awareness and communicating climate change needs. Effective communication is an essential and principal component of public health practice (Akerlof et al., 2010; Dervin \& Rudolph, 2015; Maibach et al., 2011). Furthermore, public health should communicate climate change risks, impacts and needs as climate change threatens population health and well being (Frumkin et al., 2008; Maibach et al., 2011; Watts et al., 2017, 2018). These impacts are already being experienced are likely to be exacerbated in the future (Maibach et al., 2011; Watts et al., 2017). The public health community are aware of the many health impacts and needs and have a moral obligation to act (CPHA, 2016; Maibach et al., 2011; Watts et al., 2017)

Frumkin and McMichael (2008) outline three frameworks currently used by public health to target risk perceptions and behaviour change. These include social marketing, risk communication, and health communication. Social marketing relates to the use of market principles to communicate to and influence the behaviours of the target audience (Cheng, Kotler, \& Lee, 2009). Public health's social marketing can support climate change in four major areas: health promotion, injury prevention, environmental protection, and community mobilization (Cheng et al., 2009). Risk communication emphasizes "two-way communication, aiming to build 
credibility, trust, knowledge, and cooperation in addressing a problem" (Frumkin \& McMichael, 2008). There are three forms of effective risk communicating (Lundgren \& McMakin, 2013). Care communication relays risks that are familiar to the audience or backed by scientific evidence. Consensus communication informs and encourages an audience to work together towards a common goal. Crisis communication supports actions in the face of imminent or extreme danger. In short, climate change risks and actions can be conveyed to an audience to create awareness on its impacts (care); encourage action towards climate change or cope with the climate-related natural disasters (care or crisis); support a course of action or unanimity on GHG reduction or adaptation needs (consensus). Health communication informs about the health risks and means of minimizing or preventing such impacts (Frumkin \& McMichael, 2008). Given the effectiveness of such communication strategies in the public health sector, climate change discussions can benefit from a public health focus to influence perceptions of climate change impacts and actions.

Maibach et al. (2011) forward two broad frameworks for climate change-related public health communications. The first strategy advises the public health community to get the message right by framing climate change as a health issue with geographically specific or local needs. There needs to be an emphasis on the immediate health co-benefits of actions, and the message must be conveyed using appropriate communication techniques. For techniques, see Cho, 2012; Finn \& O'Fallon, 2019; Health Canada, 2011; Maibach \& Parrott, 1995. The second strategy requires "getting the message out." Here, the authors provide several options for achieving the strategy. These include strengthening the knowledge of public health staff and partnerships, which then act as a conduit for creating awareness and providing education. Posting climate change information on websites and social media and advancing stories through media. Advancing platforms for bringing experts, communities, and various stakeholders together, such as expert panel discussions, regional meetings or through the writing of reports, opinion-editorials, guest columns and coalition statements; these can trigger coverage of public health needs with a wider audience or through mass media.

\subsubsection{Feasibility and Limitations of Recommendations}

Ontario's Climate change action plans describe the province's mitigation and adaptation strategies to tackle climate change. The presence of such plans provides PHU in Ontario with platforms for linking local public health issues to the provincial mandate. The integration of the local and provincial governments provides opportunities for the formulation of equitable and sustainable environmental and health policies across the province. In essence, framing a problem determines the perception and amount of attention it receives (Bardwell, 1991). On the contrary, 
there are significant climate change uncertainties, such as the magnitude of future climate changes and health impacts. In addition, the projected changes are based on modelled environmental and biological assumptions that also carry levels of uncertainties. Such uncertainties complicate the policy consideration and decision-making act as barriers to the predictability of outcomes and measurable policy outcomes (Head, 2014).

Highlighting climate change through a health lens means public health problems must be explored using the five foundations of public health, as already shown in recommendation 5 . Although this monograph allows for a feasible implementation of the recommendations, it can be influenced by several limitations.

One, policymaking is not always a rational process. It is often influenced by politics, making it a challenge to balance the role of science in policymaking. Tedesco, Ruiz and McLafferty (2010) revealed that politics play a major in decision-making. It influences the levels of funding and attitudes towards preparedness needs. Similarly, Baggot (2011. Pg. 20) asserts that the emergence of an issue in a political agenda is determined by the public health attention it attracts. Dale and Hill (2001) reveal that pluralism and competing vested interests define the political will. On the contrary, some public health impacts are generally long-term and not clearly understood or highlighted; this influences how they shape a policy agenda.

Two, integrating science into policymaking may be hindered by a lack of engagements between scientists and decisionmakers, and a lack of collaborations and communications due to skepticism that hinders the democratic relevance of science to policies (Choi et al., 2005). Climate change uncertainties such as the magnitude of future anthropogenic GHG emissions, weather changes, and other climate feedbacks minimize the knowledge for effective policy outcomes (IPCC, 2013b; NRC, 2010; Stocker et al., 2013). The result is the ambiguity of projected socioeconomic, political and environmental influences, and the likelihood of risk aversion techniques that limit climate change-related forecasting and interventions (Wardekker, De Jong, Van Bree, Turkenburg, \& Van Der Sluijs, 2012; Webster, 2003).

Three, in Canada, public health initiatives are fragmented between federal, provincial and governments. Each level of government has different values, perceptions and perspectives on a health issue. At the same time, the public health regions, at the municipal level, have autonomy over the delivery of public health programs but not automony over the direction of public health programming. The direction of public health programming is driven at the provincial level through the OPHS and the HPPA. Also, while the decentralized approach provides an opportunity to cater to the needs of the local jurisdictions, they can lead to divergence of information and result in the provision of inaccurate information that may paralyze the policy decision-making processes (Dale 
and Hill, 2001). Such levels of a disconnect also minimize the funding needs for the development of superior public health interventions. As already identified in limitations (Structure of Public Health in Ontario and Analytical Generalizability) and Recommendation 5, the current governenace structure in Ontario is also likely to minimize the feasiblity of the recommedations, if the governance structure does not account for the funding disparities and benefits of working across geographical regions.

Despite such limitations, case studies exploring the integration of public health in climate change initiatives have been identified in various cities and countries. Prominent examples emerge from California. Here, the Public Health Institute and the Centre for Climate change and Health public health has collaborated with various institutions to advance climate change-related social and environmental justice (Public Health Institute, 2017f; Rudolph, Gould, \& Berko, 2015). Specific areas have included addressing of food security and food systems in the Central Coast (Public Health Institute, 2017a) health equity in San Francisco (Public Health Institute, 2017d), energy use and access to air pollution-related information in San Diego (Public Health Institute, 2017h; Rudolph et al., 2015), development of local plans for addressing air, water and food pollution, zoning and land use, transportation, energy use, and waste (Public Health Institute, 2017b; Rudolph et al., 2015) and targeting respiratory-related morbidity and mortality in Wilmington and Gilroy (Public Health Institute, 2017c, 2017g, 2017e).

Sawin, McCauley, Edberg, Mwaura, and Gutierrez (2018) identified several case studies. In London, cases included the Healthy Streets of London explicitly uses public health consultant to modernize and improve the transportation system in the city (City of London, 2017; Sawin et al., 2018), England's Walk to School Outreach Project (Durham County Council, 2016; Sawin et al., 2018). These programs have been supported by government funding (Government of the United Kingdom, 2020). The Warm Up New Zealand project has supported healthy homes and health outcomes (Government of New Zealand, n.d.; Ministry of Economic Development, 2011; Sawin et al., 2018). Mexico's ProAire program has systematically improved local air quality and reduced $\mathrm{CO}^{2}$ emissions while achieving some measurable health outcomes (OECD, 2015; Sawin et al., 2018).

These cases highlight the feasibility of advancing public health needs in climate change despite limitations. These examples not only reduced GHG emissions and poor health outcomes, but they also contributed to the integration of public health in the broader discourse and generated positive economic outcomes through the provision of jobs and provided engagements relevant to promoting positive health outcomes and wellbeing (Sawin et al., 2018). The projects overcome the challenges such as funding, resistance to the program, collaborative needs, accessing 
information needed to support evaluation, and ways of influencing positive attitudes and behaviours (Sawin et al., 2018). 


\section{APPENDICES}

\section{Appendix A: REB Approval - Ryerson University}

\section{$\begin{array}{ll}\text { Research } \\ \text { Ryerson } & \text { Ethics Board }\end{array}$}

To: Luckrezia Awuor

Environmental Applied Science and Management

Re: REB 2017-390: Climate Change Discourse and Policies: Depoliticizing and humanizing climate change in Ontario through a public health frame

Date: March 2, 2018

Dear Luckrezia Awuor,

The review of your protocol REB File REB 2017-390 is now complete. The project has been approved for a one year period. Please note that before proceeding with your project, compliance with other required University approvals/certifications, institutional requirements, or governmental authorizations may be required.

This approval may be extended after one year upon request. Please be advised that if the project is not renewed, approval will expire and no more research involving humans may take place. If this is a funded project, access to research funds may also be affected.

Please note that REB approval policies require that you adhere strictly to the protocol as last reviewed by the REB and that any modifications must be approved by the Board before they can be implemented. Adverse or unexpected events must be reported to the REB as soon as possible with an indication from the Principal Investigator as to how, in the view of the Principal Investigator, these events affect the continuation of the protocol.

Finally, if research subjects are in the care of a health facility, at a school, or other institution or community organization, it is the responsibility of the Principal Investigator to ensure that the ethical guidelines and approvals of those facilities or institutions are obtained and filed with the REB prior to the initiation of any research.

Please quote your REB file number (REB 2017-390) on future correspondence.

Congratulations and best of luck in conducting your research.

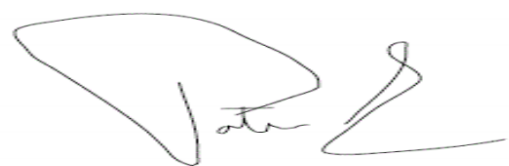

Dr. Patrizia Albanese, PhD

Chair, Ryerson University Research Ethics Board 


\section{Appendix B: REB Approval - Participant Requested Ethics Review}

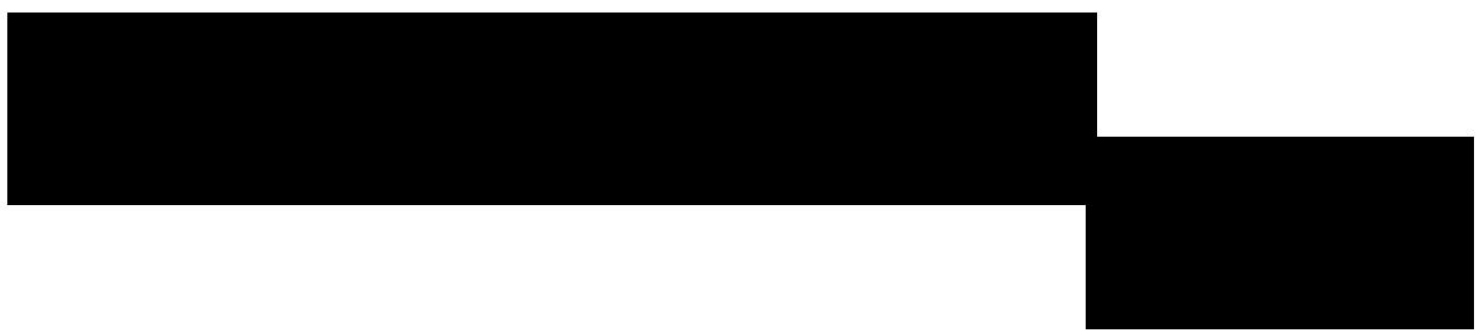

October 5, 2018

Ms. Luckrezia Awuor

School of Occupational and Public Health

Ryerson University

350 Victoria St.

Toronto, ON M5B 2K3

Dear Ms. Awuor,

Re: New Study Submission Climate Change Discourse and Policies: Depoliticizing and humanizing climate change in Ontario through a public health frame - [File Number

\section{Principal Investigator: Ms. Luckrezia Awuor}

I am writing to advise you that the

has reviewed and approved the research proposal referenced above for a period of one year, until October 5, 2019. If the study is expected to continue beyond this date you will need to complete a Continuing Research Renewal Form by September 5, 2019 and forward it to the REB or your ethics approval will expire

If changes are made to the approved research proposal, implementation protocols, and/or consent materials an amendment form will need to be submitted to the REB for review and approval prior to implementation. Any adverse or unanticipated issues or events that occur during the course of the study that may increase the level of participants' risk or have other ethical implications that may affect participants' welfare (e.g., unexpected reactions by participants, unavoidable single incidents, inappropriate/unauthorized use of information, privacy breaches) must be reported to the REB immediately.

Upon completion of the project an End of Research Project Reporting Form and a final report must be submitted to the REB. 
Best wishes for the successful completion of your project.

Yours sincerely,

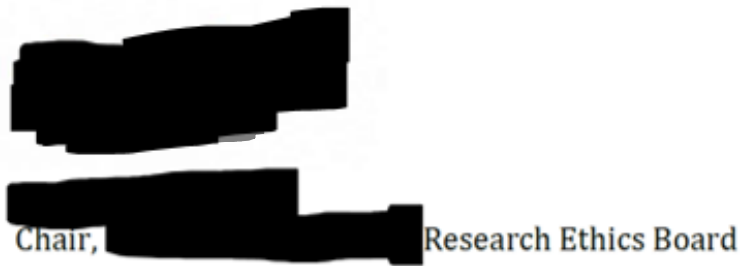

Enclosure: Approved Consent Agreement Form

cc

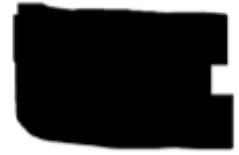




\section{Appendix C: Renewal Ryerson University}

\section{$\begin{array}{ll}\text { Research } \\ \text { Ryerson } & \text { Ethics Board }\end{array}$ University}

To: Luckrezia Awuor

Environmental Applied Science and Management

Re: REB 2017-390: Climate Change Discourse and Policies: Depoliticizing and humanizing climate change in Ontario through a public health frame

Date: February 11, 2019

Dear Luckrezia Awuor,

The annual review of your protocol REB File REB 2017-390 is now complete. Ethics approval has been renewed for an additional year and will now expire on March 2, 2020. Please note that before proceeding with your project, compliance with other required University approvals/certifications, institutional requirements, or governmental authorizations may be required.

This approval may be extended after one year upon request. Please be advised that if the project is not renewed, approval will expire and no more research involving humans may take place. If this is a funded project, access to research funds may also be affected.

Please note that REB approval policies require that you adhere strictly to the protocol as last reviewed by the REB and that any modifications must be approved by the Board before they can be implemented. Adverse or unexpected events must be reported to the REB as soon as possible with an indication from the Principal Investigator as to how, in the view of the Principal Investigator, these events affect the continuation of the protocol.

Finally, if research subjects are in the care of a health facility, at a school, or other institution or community organization, it is the responsibility of the Principal Investigator to ensure that the ethical guidelines and approvals of those facilities or institutions are obtained and filed with the REB prior to the initiation of any research.

Please quote your REB file number (REB 2017-390) on future correspondence.

Congratulations and best of luck in conducting your research.

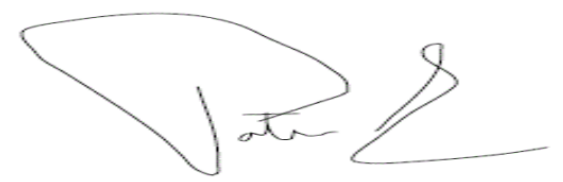

Dr. Patrizia Albanese, $\mathrm{PhD}$

Chair, Ryerson University Research Ethics Board 


\section{Appendix D: Renewal - Participant Requested Ethics Review}

October 25, 2019

Ms. Luckrezia Awuor

School of Occupational and Public Health

Ryerson University

350 Victoria St.

Toronto, ON M5B 2K3

Dear Ms. Awuor,

Re: Continuing Research Renewal Submitted October 23, 2019 Climate Change Discourse and Policies: Depoliticizing and humanizing climate change in Ontario through a public health frame - File Number

\section{Principal Investigator: Ms. Luckrezia Awuor}

I am writing to advise you that the

has reviewed and approved the continuation of the research proposal referenced above for a period of one year, until October 25, 2020. If the study is expected to continue beyond this date, you will need to complete a Continuing Research Renewal Form and forward it for receipt by the REB by September 25, 2020, or your ethics approval will expire.

If you make changes to the approved research proposal, implementation protocols, and/or consent materials, you must submit an amendment form to the REB for review and approval prior to implementation. You must report the following to the REB immediately: any adverse or unanticipated issues or events that occur during the course of the study that may increase the level of participants' risk or have other ethical implications that may affect participants' welfare (e.g., unexpected reactions by participants, unavoidable single incidents, inappropriate/unauthorized use of information, privacy breaches).

Upon completion of the project, please submit an End of Research Project Reporting Form and a final report about study findings to the REB.

Best wishes for the successful completion of your project. 
Yours sincerely,

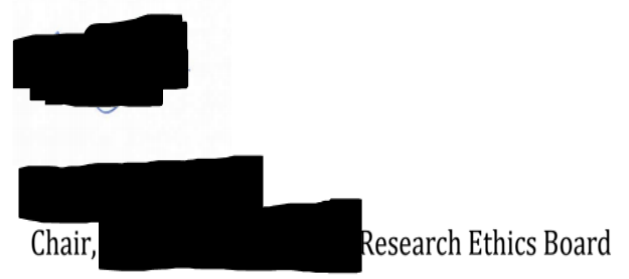

CC

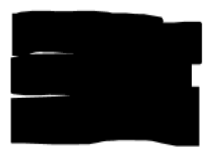




\section{Consent Agreement}

You are being invited to participate in a research study. Please read this consent form so that you understand what your participation will involve. Before you consent to participate, please ask any questions to be sure you understand what your participation will involve.

STUDY TITLE: Climate Change Discourse and Policies: Depoliticizing and humanizing climate change in Ontario through a public health frame.

INVESTIGATOR: This research study is being conducted by Luckrezia Awuor - Environmental Applied Science and Management, Yeates School of Graduate Studies, Ryerson University. The study is under the supervision of Dr. Richard Meldrum and Dr. Eric Liberda both from the School of Occupational and Public Health and the Environmental Applied Science and Management Departments.

PURPOSE OF THE STUDY: My proposed research aims to increase public health capacity in climate change policy frameworks and supports a socially integrative frame for climate change. Specifically, the study is designed to explore two areas. 1) how the various areas mentioned in the Ontario Climate Change Action Plan enhance climate change action by integrating opportunities for social participation, cohesion, inclusion, and integration in their climate change policies; 2) how those within and outside of the public health profession perceive the current framing of climate change in Ontario the relevance of a public health frame. I anticipate recruiting approximately 44 participants for the study. To be eligible for the study, the participants must be policy experts in senior level positions within the organization and holds senior or managerial role over programs, strategies, policy analysis, planning, formulation, implementation or research of climate change policies. The participants must also be familiar with the legislation, standards, and policies relevant to climate change actions. The results of this study will contribute to a dissertation, research articles and discussions on different climate change-related platforms.

WHAT PARTICIPATION MEANS: If you volunteer to participate in this study, you will be asked to participate in an interview session for approximately 1 hour. The interview questions have been designed to gather perceptions to climate change framing in Ontario and how the various areas mentioned in the Ontario Climate Change Action Plan can integrate opportunities for social participation, cohesion, inclusion, and integration in their climate change policies. The interviews will take place at the participants office, or via phone. The research findings will be availed to participants all participants, who wish to access the findings, at the end of the study.

POTENTIAL BENEFITS: Knowledge and information generated from this study may help researchers, policy makers and practitioners in four distinct ways. One, support the understanding of impediments to public health framing, the various perceptions to climate change framing in Ontario and the opportunities for incorporating other frames in the current climate change discourse. Two, mobilize public health professionals to ensure that opportunities for socially inclusive health programs and actions are considered and protected in climate change policies. Three, explore how the role of public health can extend beyond adapting to actively 
participating in the climate change discourse. Four, enhance climate change risk communication likely to create awareness of impacts, encourage action, cope with natural disasters, support a course of action or reach consensus on greenhouse gas (GHG) reduction or adaptation needs. Although I have listed many benefits of being a part of this study, I cannot guarantee that participants will receive any benefits.

WHAT ARE THE POTENTIAL RISKS TO YOU AS A PARTICIPANT: potential risks of participation is very low. However, possible risk may include anxiety and/or loss of reputation for speaking for or against the climate change policies. Such risks will be minimized by ensuring that the respondent answers are never linked to allow for identification; neither will the name of the organization be disclosed.

CONFIDENTIALITY: Any information that is obtained in connection with this study will remain confidential. Names personal information about the participants will not appear in the dissertation, on any report or article resulting from this study. Participants will not be identifiable as information received will be coded. All field notes and records will be retained locked in a secure office and cabinet in the school of Occupational and Public Health Department at Ryerson University. All paper notes will be confidentially destroyed at the end of the study. Further, all electronic data will be stored indefinitely with no personal identifiers. The data collected will be kept in a secure location and disposed of at the end of the study, in approximately 3 years from the time of the interview. This will also include deletion of electronic and audio records. Finally, only myself and my advisors, Dr. Meldrum and Dr. Liberda at the school of Occupational and Public Health Department at Ryerson University will have access to these materials.

INCENTIVES FOR PARTICIPATION: No incentives will be offered for participation.

COSTS TO PARTICIPATION: There are no direct costs associated with study apart from time allocation for interview.

VOLUNTARY PARTICIPATION AND WITHDRAWAL: Participation in this study is completely voluntary. You can choose whether to be in this study or not. If any question makes you uncomfortable, you can skip that question. You may stop participating at any time. If you choose to stop participating, you may also choose to not have your data included in the study. Your choice of whether or not to participate will not influence your future relations with Ryerson University or the investigators (Luckrezia Awuor, Richard Meldrum and Eric Liberda) involved in the research, and any Ryerson institutional partners

QUESTIONS ABOUT THE STUDY: If you have any questions about the research, please feel free to contact any of the following:

Principal Investigator: Luckrezia Awuor; lawour@ryerson.ca

Supervisors: Dr. Meldrum, 416-979-5000, ext. 4621; meldrum@ryerson.ca

Dr. Liberda: 416-979-5000, ext. 3020; eric.liberda@ryerson.ca

This study has been reviewed by the Ryerson University Research Ethics Board. If you have questions regarding your rights as a participant in this study please contact: Research Ethics Board c/o Office of the Vice President, Research and Innovation

Ryerson University

350 Victoria Street

Toronto, ON M5B 2K3 416-979-

5042 rebchair@ryerson.ca 


\section{CLIMATE CHANGE DISCOURSE AND POLICIES: DEPOLITICIZING AND HUMANIZING CLIMATE CHANGE IN ONTARIO THROUGH A PUBLIC HEALTH FRAME}

\section{CONFIRMATION OF AGREEMENT:}

Your signature below indicates that you have read the information in this agreement and have had a chance to ask any questions you have about the study. Your signature also indicates that you agree to participate in the study and have been told that you can change your mind and withdraw your consent to participate at any time. You have been given a copy of this agreement. You have been told that by signing this consent agreement you are not giving up any of your legal rights.

I agree to participate in this study.

Name of Participant (please print)

Signature of Participant Date

I agree to be audio-recorded for the purposes of this study. I understand how these recordings will be stored and destroyed. 
Appendix F: TCPS 2 Certification

PANEL ON

RESEARCH ETHICS

\section{TCPS 2: CORE}

\section{Certificate of Completion}

This document certifies that

\section{Luckrezia Awuor}

has completed the Tri-Council Policy Statement:

Ethical Conduct for Research Involving Humans

Course on Research Ethics (TCPS 2: CORE)

Date of Issue: 16 May, 2017 


\section{Appendix G: Interview Guide}

\section{Introduction}

My name is Luckrezia Awuor. I am a Ph.D. Candidate in the ENCIMAN program, Yeates School of Graduate Studies, Ryerson University.

My dissertation explores the perceptions, attitudes, support for-, and the inclusion of public health sector in the climate change discourse using a case study of climate change actions, organizational opinions, and policy drivers in Ontario. Findings from this project may help researchers, policymakers, and public health practitioners enhance climate change risk communication, increase public health capacity in climate change policy frameworks, and support a socially integrative frame of climate change.

Your participation in this study is completely voluntary. You may withdraw from this study at any point during or after this interview. You may also choose not to answer some of the questions I ask.

Any information obtained from you will be confidential. Your answers will be kept anonymous, but I may quote some of the information you tell me in some of my reports, without attributing them to you. Please let me know if you want more details about this project or have any other doubts which I might not have addressed.

May I also request your permission to record the interview?

\section{Interview}

\begin{tabular}{|l|l|l|}
\hline $\begin{array}{l}\text { Overarching } \\
\text { Themes }\end{array}$ & Questions & $\begin{array}{l}\text { Possible or additional } \\
\text { Probes }\end{array}$ \\
\hline $\begin{array}{l}\text { Policy } \\
\text { Background }\end{array}$ & $\begin{array}{l}\text { Can you please tell me a little about your } \\
\text { position and the responsibilities you have in } \\
\text { this post? }\end{array}$ & $\begin{array}{l}\text { What roles do you play in } \\
\text { [insert organization]? }\end{array}$ \\
\cline { 2 - 3 } & $\begin{array}{l}\text { Please tell me how you have addressed } \\
\text { issues about climate change in [insert the } \\
\text { sector/organization] policies }\end{array}$ & $\begin{array}{l}\text { When did that happen? } \\
\text { Who else was involved? } \\
\text { How does your role relate } \\
\text { to the broader climate } \\
\text { change strategies in } \\
\text { Ontario? } \\
\text { What are some of the } \\
\text { reasons for engaging in } \\
\text { such policies? } \\
\text { What are some of the } \\
\text { accomplishments you have } \\
\text { achieved in your } \\
\text { engagements? }\end{array}$ \\
& $\begin{array}{l}\text { Priorities and focus } \\
\text { Policy influences } \\
\text { Is public health } \\
\text { integrated/relevant in the } \\
\text { decision-making structures, } \\
\text { and processes? }\end{array}$ \\
\hline $\begin{array}{l}\text { Policy } \\
\text { processes }\end{array}$ & $\begin{array}{l}\text { What is the mandate of your organization in } \\
\text { climate change? } \\
\text { How are climate change decisions made? } \\
\text { Are there policies that have/have not } \\
\text { worked? What were the reasons for the } \\
\text { successes and challenges? }\end{array}$ &
\end{tabular}




\begin{tabular}{|c|c|c|}
\hline & & Policy evaluations \\
\hline $\begin{array}{l}\text { Meaning of } \\
\text { climate } \\
\text { change }\end{array}$ & $\begin{array}{l}\text { What does climate change mean to you? } \\
\text { Are such definitions shared amongst the } \\
\text { actors in the organization? }\end{array}$ & $\begin{array}{l}\text { When you think about } \\
\text { climate change what } \\
\text { comes to mind and how } \\
\text { does that inform the } \\
\text { policies that you develop? }\end{array}$ \\
\hline \multirow[t]{4}{*}{ Collaborations } & $\begin{array}{l}\text { Have you worked with other } \\
\text { institutions/sectors/ministries to support } \\
\text { climate change actions? }\end{array}$ & $\begin{array}{l}\text { Who were they? } \\
\text { When did this happen? } \\
\text { What was your role? } \\
\text { How did that come about? } \\
\text { How did you feel about } \\
\text { your role? }\end{array}$ \\
\hline & $\begin{array}{l}\text { Are you aware of any climate change action } \\
\text { plan/document/policy that your } \\
\text { office/organization has been a part of? If } \\
\text { none, are there any plans for future policies } \\
\text { or actions? } \\
\text { OR } \\
\text { Has your organization collaborated with other } \\
\text { ministries/organizations to support climate } \\
\text { change actions? } \\
\text { OR } \\
\text { How does your [insert organization] work } \\
\text { with other institutions/sectors/ministries on } \\
\text { climate change issues? }\end{array}$ & $\begin{array}{l}\text { Would you elaborate on } \\
\text { that? } \\
\text { When did this happen? } \\
\text { Did you have a role that } \\
\text { you would like to elaborate } \\
\text { on? } \\
\text { Could you mention other } \\
\text { sectors included in this } \\
\text { (these) policy process(es)? }\end{array}$ \\
\hline & $\begin{array}{l}\text { Given the number of sectors that influence } \\
\text { climate change policies, is there ever any } \\
\text { overlap or conflicts? If yes, how are } \\
\text { disagreements resolved? } \\
\text { Have you tried to include pH professionals } \\
\text { into your climate change strategies to } \\
\text { minimize such conflicts? }\end{array}$ & $\begin{array}{l}\text { What challenges have you } \\
\text { experienced given the } \\
\text { intersectoral nature of } \\
\text { climate change policies? } \\
\text { (this question presents an } \\
\text { opportunity for asking } \\
\text { questions relating to } \\
\text { consideration of public } \\
\text { health when challenges } \\
\text { emerge) }\end{array}$ \\
\hline & $\begin{array}{l}\text { Have you tried to integrate public into your } \\
\text { health climate change policies? If yes, how } \\
\text { so? If not, why not? }\end{array}$ & $\begin{array}{l}\text { Has public health played } \\
\text { any role in your climate } \\
\text { change policy processes? }\end{array}$ \\
\hline \multirow[t]{2}{*}{ Evidence } & $\begin{array}{l}\text { What type of evidence do you consider when } \\
\text { developing and deliberating on climate } \\
\text { change policies? }\end{array}$ & $\begin{array}{l}\text { How are such evidence } \\
\text { accessed? } \\
\text { How are the needs } \\
\text { determined? } \\
\text { How is the evidence } \\
\text { integrated into climate } \\
\text { change policies? }\end{array}$ \\
\hline & Are public health evidence considered? & $\begin{array}{l}\text { How are such evidence } \\
\text { accessed? }\end{array}$ \\
\hline
\end{tabular}




\begin{tabular}{|c|c|c|}
\hline & & $\begin{array}{l}\text { How are the needs } \\
\text { determined? } \\
\text { How is the evidence } \\
\text { integrated into climate } \\
\text { change policies? }\end{array}$ \\
\hline & Do you utilize decision support tools? & $\begin{array}{l}\text { What types are utilized and } \\
\text { why? }\end{array}$ \\
\hline \multirow[t]{4}{*}{$\begin{array}{l}\text { Perception of } \\
\text { public health } \\
\text { inclusion } \\
\text { Public health's } \\
\text { role/leadership }\end{array}$} & $\begin{array}{l}\text { What is your view of health professionals } \\
\text { advocating for the inclusion of public health } \\
\text { the climate change frameworks? } \\
\text { Do you believe that public health has a role } \\
\text { in leading role in climate change actions? } \\
\text { What is your view of health professionals } \\
\text { advocating for a public health frame of } \\
\text { climate change? }\end{array}$ & $\begin{array}{l}\text { Are climate change and } \\
\text { public health connected? }\end{array}$ \\
\hline & $\begin{array}{l}\text { Do you think the inclusion of public health in } \\
\text { the core climate change frameworks is } \\
\text { essential for sustainable climate change } \\
\text { actions? If yes, how so? }\end{array}$ & $\begin{array}{l}\text { Could you tell me more } \\
\text { about that? }\end{array}$ \\
\hline & $\begin{array}{l}\text { In the long-term, do you think public health } \\
\text { has a place in the climate change discourse? } \\
\text { Do you think a public health frame is relevant } \\
\text { to your organizational policies? } \\
\text { Can a public health leadership be } \\
\text { emphasized when others (such as the } \\
\text { MOECC) are leading climate change } \\
\text { discourse? }\end{array}$ & $\begin{array}{l}\text { If yes, how so? If no, why } \\
\text { not? }\end{array}$ \\
\hline & $\begin{array}{l}\text { Has anyone ever asked your views on the } \\
\text { inclusion of public health on climate change } \\
\text { policy processes? If yes, how often? }\end{array}$ & $\begin{array}{l}\text { If yes, what impact did this } \\
\text { have on your policies? } \\
\text { If not, why do you think } \\
\text { public health has not been } \\
\text { considered in your policy } \\
\text { discussions? }\end{array}$ \\
\hline \multirow[t]{2}{*}{ Closing } & $\begin{array}{l}\text { Is there anything else you would like to add } \\
\text { to what we have covered? }\end{array}$ & \\
\hline & $\begin{array}{l}\text { Can I contact you later in case I have any } \\
\text { questions? }\end{array}$ & \\
\hline
\end{tabular}

\section{Conclusion}

Thank you for speaking with me today. Your insights were constructive and will be very relevant to my study. I will follow-up with you in the near future to provide progress of the res 
Appendix H: Interview Questions Guiding Themes

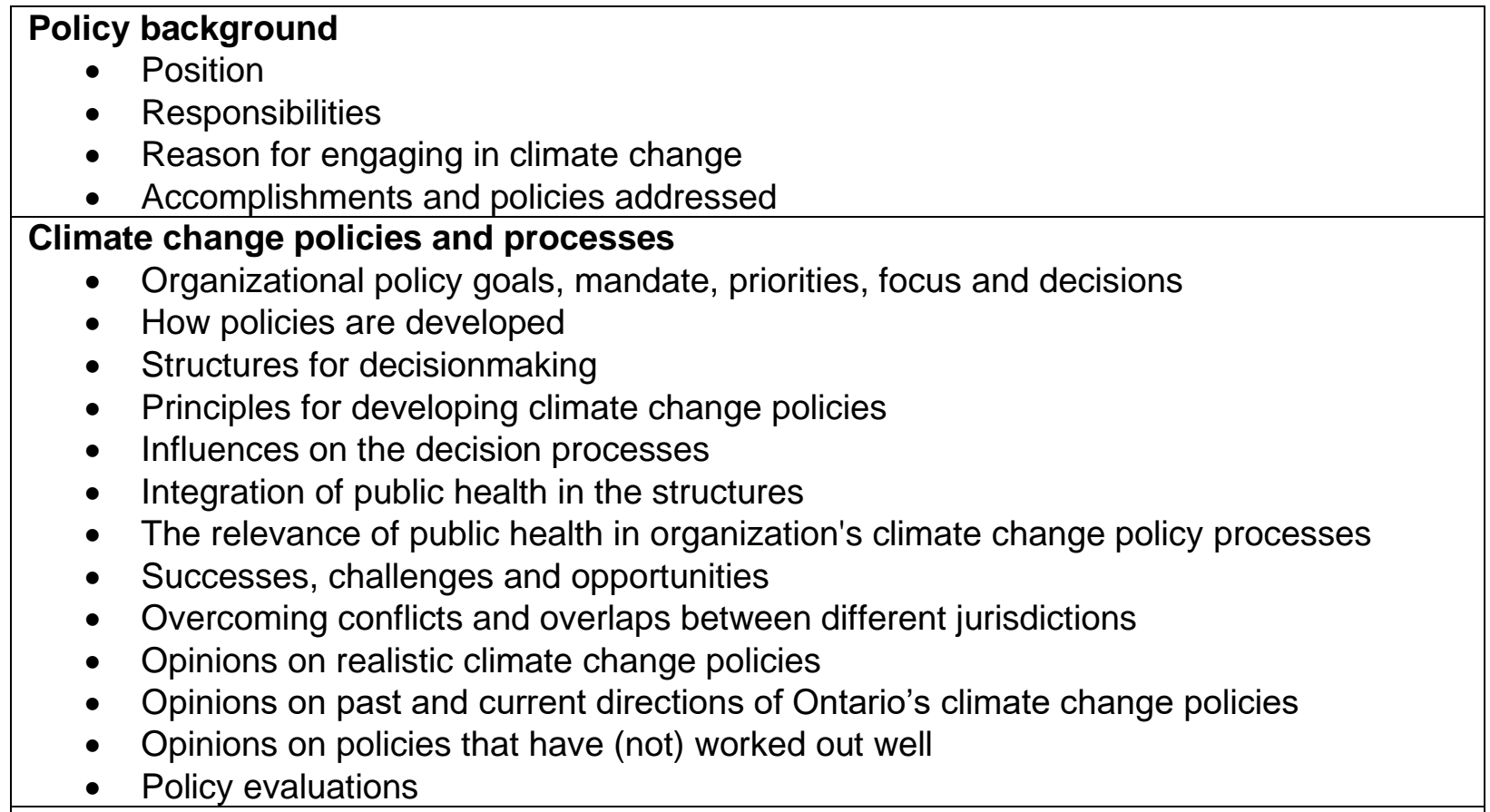

Meanings of climate change and public health needs (personal and professional opinions)

- Definition and understanding of climate change

- Climate change framing

- Public health framing

- whether meanings of definition and frame of climate change are shared the organization

\section{Stakeholders and collaborations}

- Types of stakeholders

- Roles that stakeholders identified played

- Types of climate change policies influenced by stakeholders

- How stakeholders are identified and consulted

- How the organization works with stakeholders

- Current structures for stakeholder engagements and participation

- Opinions on current structures on stakeholder engagements and participation

- Impacts of stakeholder engagements

\section{Evidence}

- How evidence needs are determined

- Types of evidence considered

- How evidence is accessed

- How evidence is integrated into climate change policies

- How public health evidence and needs are considered, accessed and integrated

- Types of decision support tools used

- Evidence associated challenges

- How evidence or information is shared

- Evidence or information gaps

\section{Perspectives}


- The connection between public health and climate change

- Public health's role in climate change

- Public health's leadership Public health framed climate change

- Ideal roles for public health in climate change

- Inclusion of public health in climate change

- Whether perceptions are shared by others in the organization or stakeholders worked with 


\section{Appendix I: Main Issues Analyzed in Textual Analysis and Discursive Practices}

\section{Thematic frames (climate change framing in Ontario) \\ - Involved analyzing the historical presentation (framing) of the climate change issue. \\ - The theme only focused on preexisting documents (from government websites) to establish how climate change has been historically presented in Ontario (between 2007 -2018) \\ - Apriori themes guiding frame analysis; the} themes included economic, environmental, health, moral and scientific frames.

- Analyzed how the frames were ordered and the narratives (rhetorics) that guided the framing.

Intertextuality

- Involves the processes of embedding other texts within a text - that is integrating other voices into the texts other than the voice of the author (Fairclough, 2003; Walter, 2013). E.g. references or embedding direct quotations within a document or providing links]

- Analyzed texts for links, quotations or any form of embedded in texts other than those of authors.

\section{Style (identificational meanings)}

- Relates to how people identify themselves and are identified by others within a social setting (Fairclough, 2003).

- Analyzed social (e.g. structure and agency) and personal identities and features that characterize the styles drawn upon by actors (including body language).

\section{Social events}

- Are practices within institutions that lead to the selection of specific structures and exclusion of others (Fairclough, 2003; Walter, 2013).

- Texts were coded for the emergence of themes related to social events and chains of social events (e.g. how the dominant frame is

\section{Genre}

- Represents ways of acting or interacting [e.g. meeting] or style used in the text [e.g. a persuasive or descriptive text] (Fairclough, 2003; Walter, 2013).

- Analyzed the types of genres and their characteristics; activities regulating and managing climate change decision processes within institutions (e.g. types of options for participating in climate change decisions).

- Analyzed genre mixing (e.g. activities for promoting climate change decisions locally or internationally or alternating reporting structures using a mix of quotations and facts in a single report).

\section{Discourse}

- The type of discourse drawn.

- Analyzing the discourse guiding Ontario's climate change actions was guided by Dryzek (2013) and included analyzing the types of entities whose existence is recognized or constructed; the presence of assumptions, metaphors and features characterizing climate change discourse (s); characterization of agents and their motives

- Identification of orders of discourse; that is the power relation between the writer or speaker and the reader or listener if interviewing (Fairclough, 2003).

\section{Social differences}

- The salience of identities (e.g. identifying to belong to a particular group).

- Analyzed scenarios that characterize, recognize, accentuate or explore differences; how the differences are claimed (e.g. consensus over or normalization of, attempts to solve or suppression of the differences).

\section{Representation of social events}

- Analysis of how the social events were presented (e.g. abstract vs concrete); the elements of social events represented; how the processes of the social events were presented and the predominant process types; metaphors applied; how social actors are represented (e.g. named, generic). 
embedded in the networks of structures within institutions).

- Whether the text was part of or network of texts.

\section{Assumptions}

- Refers to the implicitness of texts and based on three types of assumptions: existential ("assumption about what exists"), propositional ("assumptions about what is or can be or will be the case") and value ("assumption about what is desirable") (Fairclough, 2003).

- Fairclough (2003) uses globalization as an illustrative example. That it is assumed that globalization exists (existential) and that it is a process (propositional) which can 'help' achieve economic progress (value).

- Analyzed the various assumptions, perceptions and ideologies present in texts.

\section{Actional Meanings (exchanges, speech} functions and grammatical mood)

- Exchange: relates to exchange in dialogue (Fairclough, 2003; Walter, 2013). Analysis of exchanges focused on two types of exchanges: knowledge and activity exchange. In knowledge exchange, analysis focused on the exchange of information, how information is given and elicited and how facts are stated. Activity exchange focused on the analysis of activities that people do or get others to do.

- Speech functions: relate to acts of dialogue (Fairclough, 2003; Walter, 2013). That is, is an analysis of whether the knowledge exchanges are initiated by actor or by others through, for example, offers or demands; and whether activity exchanges are initiated by the knower(s) or others through, for example, questions and statements).

- Grammatical mood: analyzed how exchanges and speech functions (dialogues) are portrayed in sentences (e.g. declaratory, interrogative or imperative sentences)
- Analysis of presentation of historical events or milestones.

\section{Modality}

- Defined by Walter (2013) as a term for signifying "author's or speaker's commitment to the claim being made."

- Related to speech functions in that modality supports the analysis of "what people commit themselves to when they make statements, ask questions, make demands or offers" because each signals a different commitment (Fairclough, 2003).

- Analyzed text for commitments, attitudes, judgements and stances of actors.

\section{Meaning relations}

- Semantic relations are presented in grammatical structures of sentences; that is relations between sentences and clauses (or simple sentences) within sentences in a manner that legitimize the issue or creates classes of differences (e.g. power).

- Example by Fairclough (2003). "We are late because train was delayed." Conveys a causal meaning relation. The underlined word acts as a grammatical connector to elaborate a causal relationship indicating that the reason for the delay is due to train arriving late.

- Involved analysis of word connectors which mark relationships and their relationships (e.g. causal, conditional, temporal, additive, elaborative). 
Appendix J: A Guide for Coding the a Priori Thematic Frames and Sample Text

\begin{tabular}{|c|c|c|}
\hline $\begin{array}{l}\text { Thematic } \\
\text { frames }\end{array}$ & Definition & Sample text \\
\hline Public Health & $\begin{array}{l}\text { A public health } \\
\text { framing stresses the } \\
\text { impacts of climate } \\
\text { change on human } \\
\text { health and well-being } \\
\text { by highlighting the } \\
\text { impacts of climate } \\
\text { change on the various } \\
\text { social determinants of } \\
\text { health (Akerlof et al., } \\
\text { 2010; Maibach et al., } \\
\text { 2010; Myers et al., } \\
\text { 2012; Petrovic et al., } \\
\text { 2014; Watts et al., } \\
\text { 2015). }\end{array}$ & $\begin{array}{l}\text { "Climate change presents many risks to health and } \\
\text { well-being in Ontario. The V\&A assessment is } \\
\text { designed to increase understanding of how climate } \\
\text { change may affect the health of people in Ontario's } \\
\text { communities. Assessment results facilitate community- } \\
\text { driven change that builds and maintains healthy } \\
\text { communities and environments, while taking the } \\
\text { economic implications of these changes into account, } \\
\text { including the costs associated with reducing the } \\
\text { burden of climate-sensitive health outcomes and } \\
\text { reducing the strains on health care systems." } \\
\text { [MOHLTC, 2016; Ontario Climate Change and Health } \\
\text { Vulnerability and Adaptation Assessment Guideline] } \\
\text { "Cycling is a core part of Ontario's transportation } \\
\text { system and is integral to fostering healthier and more } \\
\text { prosperous communities. Increasing cycling } \\
\text { opportunities in Ontario offers many benefits, including } \\
\text { improved well-being, lower rates of chronic conditions } \\
\text { and reduced health care costs as a result of active } \\
\text { living, reduced traffic congestion in urban areas, a } \\
\text { cleaner environment and increased tourism } \\
\text { opportunities across the province."[Ministry of } \\
\text { Transportation, 2018; Cycle-On Action Plan 2.0] }\end{array}$ \\
\hline Environmental & $\begin{array}{l}\text { The environmental } \\
\text { frame emphasizes the } \\
\text { climate impacts on } \\
\text { the environmental } \\
\text { components and } \\
\text { ecosystems (Fletcher, } \\
\text { 2009; Maibach et al., } \\
\text { 2010) }\end{array}$ & $\begin{array}{l}\text { "The development of a separate, quality, branded } \\
\text { voluntary offset class provides a unique opportunity to } \\
\text { mitigate climate change by leveraging land-use } \\
\text { activities in the Province. By focusing on land-use to } \\
\text { fight climate change, many environmental co-benefits } \\
\text { such as flood management, are incorporated into the } \\
\text { design of the program. As we consider the role of land- } \\
\text { use in mitigating climate change in our province, we } \\
\text { must also think of the complex interactions of natural } \\
\text { systems and other important services they provide to } \\
\text { Ontarians. Ecosystems provide many basic services } \\
\text { that make human life possible such as flood } \\
\text { management and erosion control provided by trees; air } \\
\text { and water purification and natural cooling on hot days } \\
\text { provided by forests and wetlands; and pollination by } \\
\text { bees of plants and flowers that provide us with food." } \\
\text { [MECP, 2017; Developing a Voluntary Carbon Offsets } \\
\text { Program for Ontario - Discussion Paper] }\end{array}$ \\
\hline Economic & $\begin{array}{l}\text { The economic frame } \\
\text { highlights or } \\
\text { emphasizes the } \\
\text { economic costs, }\end{array}$ & $\begin{array}{l}\text { "Ontario is a world leader in the fight against climate } \\
\text { change. We are committed to creating a low-carbon } \\
\text { economy that will drive innovation, create more } \\
\text { opportunities for business and industry, and generate }\end{array}$ \\
\hline
\end{tabular}




\begin{tabular}{|c|c|c|}
\hline & $\begin{array}{l}\text { benefits, harm, } \\
\text { opportunities of } \\
\text { climate change } \\
\text { actions (Fletcher, } \\
\text { 2009; Maibach et al., } \\
\text { 2011; Rademaekers } \\
\text { \& Johnson-Sheehan, } \\
\text { 2014; Stecula \& } \\
\text { Merkley, 2019) }\end{array}$ & $\begin{array}{l}\text { high-value jobs. Our government's Climate Change } \\
\text { Action Plan is laying the foundation for cleaner air, a } \\
\text { healthier environment, a stronger economy and a } \\
\text { better future for our children and grandchildren." } \\
\text { "Ontario's Climate Change Action Plan will create } \\
\text { good jobs, help people and businesses reduce their } \\
\text { carbon footprint, save money and accelerate a shift to } \\
\text { a more sustainable society. Through the plan, } \\
\text { Ontarians and the government are doing their part in } \\
\text { the global effort to fight climate change." [Office of the } \\
\text { Premier, News Release, June 8, 2016] }\end{array}$ \\
\hline Political & $\begin{array}{l}\text { Political frames focus } \\
\text { on political narratives, } \\
\text { with persuading or } \\
\text { dissuading ideologies } \\
\text { (sometimes through } \\
\text { progressive, } \\
\text { conservative } \\
\text { inclinations, or } \\
\text { partisan ideologies)on } \\
\text { specific climate } \\
\text { change policy } \\
\text { interventions or } \\
\text { actions; they also } \\
\text { highlight the impacts } \\
\text { of climate change on } \\
\text { political systems } \\
\text { (Fletcher, 2009; } \\
\text { Lakoff, 2010) }\end{array}$ & $\begin{array}{l}\text { "Today, Ontario's Government for the People } \\
\text { announced the cancellation of the outdated Drive } \\
\text { Clean program, saving money for Ontario taxpayers } \\
\text { and reducing the regulatory burden on Ontario families } \\
\text { while enhancing regulations for the biggest polluters on } \\
\text { Ontario's roads. Effective April 1, 2019, drivers will no } \\
\text { longer be required to get Drive Clean emissions tests } \\
\text { for their passenger vehicles. By ending Drive Clean } \\
\text { tests and repairs for passenger vehicles, this } \\
\text { government is reducing the burden on residents and } \\
\text { families who own a car, so they no longer need to take } \\
\text { time out of their days to take their vehicles in for } \\
\text { unnecessary tests," said Premier Doug Ford. "We're } \\
\text { saving taxpayers over \$40 million every year. And } \\
\text { we're better targeting the biggest polluters to protect } \\
\text { Ontario's air." } \\
\text { "When first introduced by a previous Progressive } \\
\text { Conservative government in 1999, Drive Clean was } \\
\text { effective. It provided a way to target emissions related } \\
\text { to smog and other environmental problems," said Rod } \\
\text { Phillips, Minister of the Environment, Conservation and } \\
\text { Parks. "This has resulted in a steady decrease in the } \\
\text { number of cars that fail the emissions test. Drive Clean } \\
\text { was intended to be a time-limited program, and as the } \\
\text { years passed, so did its usefulness. It has provided } \\
\text { less and less value for taxpayer dollars." [Office of the } \\
\text { Premier, News Release, September } 28,2018]\end{array}$ \\
\hline Tech & $\begin{array}{l}\text { The technological } \\
\text { frame advances the } \\
\text { relevance and } \\
\text { consumption of green } \\
\text { technologies, } \\
\text { innovations, and } \\
\text { solutions and their } \\
\text { relevance in } \\
\text { greenhouse gas } \\
\text { reduction and } \\
\text { infrastructures for } \\
\text { adapting to climate } \\
\text { change and achieving }\end{array}$ & $\begin{array}{l}\text { "Worldwide, it is estimated that \$6 trillion dollars per } \\
\text { year will be spent to meet infrastructure needs over } 15 \\
\text { years. Making these investments both low-carbon and } \\
\text { climate-resilient will require a massive scaling-up of } \\
\text { new green technologies, goods and services. The } \\
\text { growing population presents another opportunity. The } \\
\text { Organization for Economic Co-operation and } \\
\text { Development (OECD) projects that, if current trends } \\
\text { continue, per capita consumption will more than triple } \\
\text { and the global gross domestic product will almost } \\
\text { quadruple as the global population grows, requiring } \\
80 \% \text { more energy by } 2050 \text {. Supporting this growth } \\
\text { while reducing emissions will only be possible by }\end{array}$ \\
\hline
\end{tabular}




\begin{tabular}{|c|c|c|}
\hline & $\begin{array}{l}\text { competitive economy } \\
\text { (Grant, 2011; } \\
\text { Mazzanti, 2018; } \\
\text { Schäfer \& O’Neill, } \\
\text { 2017; Teelucksingh, } \\
\text { 2019; Teelucksingh \& } \\
\text { Poland, 2011). }\end{array}$ & $\begin{array}{l}\text { developing new methods, innovative new products, } \\
\text { and a low-carbon, high-productivity global economy. } \\
\text { Ontario is working with the business and science } \\
\text { communities to develop and bring to market unique, } \\
\text { made-in-Ontario ideas, technologies and solutions." } \\
\text { [Ontario's Climate Change Strategy, 2015] }\end{array}$ \\
\hline Scientific & $\begin{array}{l}\text { A scientific frame } \\
\text { highlights the different } \\
\text { climate change facts, } \\
\text { hypotheses, and risks } \\
\text { and suggest actions } \\
\text { to address identified } \\
\text { issues (Fleming et } \\
\text { al., 2014; Sarewitz, } \\
\text { 2004). }\end{array}$ & $\begin{array}{l}\text { "Scientists firmly believe a gradual increase in the } \\
\text { amount of the sun's heat being captured by the } \\
\text { atmosphere is the main reason for the change in } \\
\text { weather events and seasonal weather patterns. The } \\
\text { changes have developed over at least } 40 \text { years and } \\
\text { clearly amount to a change in climate. The Ontario } \\
\text { government agrees that an increase in the quantity of } \\
\text { heat-trapping gases in the atmosphere has been } \\
\text { largely responsible for contributing to climate change } \\
\text { and is working to reduce Ontario's emissions of those } \\
\text { gases." [Government of Ontario, 2011; Climate } \\
\text { Change Ready: Ontario's Adaptation Strategy and } \\
\text { Action Plan 2011-2014] }\end{array}$ \\
\hline Moral & $\begin{array}{l}\text { Moral frame (which } \\
\text { can also be } \\
\text { conceptualized as } \\
\text { social justice or equity } \\
\text { frame) views climate } \\
\text { change from an } \\
\text { equity perspective } \\
\text { and and emphasizes } \\
\text { actions that consider } \\
\text { the social and } \\
\text { environmental } \\
\text { disparities by } \\
\text { acknowledging the } \\
\text { disproportionate } \\
\text { distribution of climate } \\
\text { change impacts and } \\
\text { burdens across } \\
\text { regions and } \\
\text { populations (Buse et } \\
\text { al., 2019). }\end{array}$ & $\begin{array}{l}\text { "Like you, I know how beautiful Ontario's environment } \\
\text { and communities are. They are worth protecting. This } \\
\text { is why we all have a role to play in fighting climate } \\
\text { change. The Climate Change Action Plan is already } \\
\text { giving people and businesses more ways to cut } \\
\text { greenhouse gas pollution while saving money on } \\
\text { energy costs. Whether you live in Mississauga, } \\
\text { Nepean, Timmins or Fort Erie, we are making it easier } \\
\text { for you to protect the environment and our way of life } \\
\text { for generations to come." [Minister of Environment and } \\
\text { Climate Change; Fighting Climate Change: Better } \\
\text { Communities, 2018] } \\
\text { "Climate change is a crisis we caused together, and a } \\
\text { responsibility we all share, together. So it's important } \\
\text { we act, not only because we can't ignore the science, } \\
\text { not only because we bear the responsibility, and not } \\
\text { only because we have an obligation to our children." } \\
\text { [Go Green: Ontario's Action Plan on Climate Change, } \\
2007 \text { ] }\end{array}$ \\
\hline Skeptics & $\begin{array}{l}\text { Skeptics frame } \\
\text { challenges the } \\
\text { presence or science } \\
\text { of climate change or } \\
\text { relevance of } \\
\text { proposed actions } \\
\text { (Cann, 2015; R. E. } \\
\text { Dunlap, 2013; } \\
\text { Fletcher, 2009; } \\
\text { Hurlbert \& Gupta, } \\
\text { 2016; Rademaekers }\end{array}$ & - $\quad$ None identified in text. \\
\hline
\end{tabular}




\begin{tabular}{|l|l|l|}
\hline & \& Johnson-Sheehan, & \\
2014; Roper et al., & \\
2016; Singh \& & & \\
Swanson, 2017) & \\
\hline
\end{tabular}


Appendix K: Chronology of Ontario's Climate Change Activities and Responses

\begin{tabular}{|c|c|}
\hline Year & Strategic Activity \\
\hline May 2007 & $\begin{array}{l}\text { Province of Ontario signs a memorandum of understanding with the State of } \\
\text { California for market-based mechanisms to GHG reduction and energy } \\
\text { efficiency collaborations (Government of Ontario, 2007a; Ontario Ministry of } \\
\text { Environment Conservation and Parks, 2016) }\end{array}$ \\
\hline May 2007 & $\begin{array}{l}\text { MOE introduces the Go Green: Ontario's Action Plan that also sets out the GHG } \\
\text { reduction target for 2014, } 2020 \text { and } 2050 \text { (Ontario Ministry of Environment } \\
\text { Conservation and Parks, 2015, 2016) }\end{array}$ \\
\hline $\begin{array}{l}\text { December } \\
2007\end{array}$ & $\begin{array}{l}\text { The government forms the Expert Panel on Climate Change Adaptation } \\
\text { (EPCCA) for consideration of climate change risks (Government of Ontario, n.d.- } \\
\text { b; Ontario Ministry of Environment Conservation and Parks, 2016). }\end{array}$ \\
\hline May 2008 & $\begin{array}{l}\text { Ontario government establishes the Climate Change Secretariat, reporting to the } \\
\text { Premier. Roles are to coordinate and implement Ontario's climate change } \\
\text { actions (Ontario Ministry of Environment Conservation and Parks, 2016) }\end{array}$ \\
\hline June 2008 & $\begin{array}{l}\text { The government of Ontario signs a memorandum of understanding with Quebec } \\
\text { with intentions of joining the cap-and-trade system with other North American } \\
\text { jurisdictions (Government of Ontario, 2008b; Ontario Ministry of Environment } \\
\text { Conservation and Parks, 2016). }\end{array}$ \\
\hline July 2008 & $\begin{array}{l}\text { Ontario joins Western Climate Change Initiative, an NGO that provides } \\
\text { administrative and technical expertise programs governing GHG emission } \\
\text { trading (Ontario Ministry of Environment Conservation and Parks, 2016) }\end{array}$ \\
\hline $\begin{array}{l}\text { November } \\
2008\end{array}$ & $\begin{array}{l}\text { Reporting structure for the Climate Change Secretariat changed, reporting } \\
\text { directly to the minister of the environment (Ontario Ministry of Environment } \\
\text { Conservation and Parks, 2016). }\end{array}$ \\
\hline $\begin{array}{l}\text { December } \\
2008\end{array}$ & $\begin{array}{l}\text { Ontario releases the first discussion paper on cap and trade: A Greenhouse Cap } \\
\text { and Trade System for Ontario Discussion Paper, discussing options for GHG } \\
\text { reduction, including WCI partnerships (Government of Ontario, 2008a; Ontario } \\
\text { Ministry of Environment Conservation and Parks, 2016). }\end{array}$ \\
\hline 2008 & $\begin{array}{l}\text { nal transportation plan: the Big Move Transportation } \\
\text { io, 2015e) }\end{array}$ \\
\hline $\begin{array}{l}\text { February } \\
2009\end{array}$ & $\begin{array}{l}\text { Ontario introduces the Green Energy and Economy Act (2009) meant to expand } \\
\text { the province's green energy sources and jobs and support energy conservation. } \\
\text { in response to the economic impact resulting from the global economic downturn } \\
\text { (Ontario Ministry of Environment Conservation and Parks, 2015, 2016). }\end{array}$ \\
\hline May 2009 & $\begin{array}{l}\text { Ontario amends the Environmental Bill of Rights } 1993 \text { to include monitoring and } \\
\text { reporting of GHG requirements by the Environmental Commissioner (Ontario } \\
\text { Ministry of Environment Conservation and Parks, 2016) }\end{array}$ \\
\hline June 2009 & $\begin{array}{l}\text { Ontario releases the second discussion paper: Moving Forward: A GHG Cap- } \\
\text { and-Trade for Ontario. Discussing the designing of a cap-and-trade program that } \\
\text { meets the province's GHG reduction targets (Ontario Ministry of Environment } \\
\text { Conservation and Parks, 2016). }\end{array}$ \\
\hline $\begin{array}{l}\text { November } \\
2009\end{array}$ & $\begin{array}{l}\text { Expert Panel on Climate Change Adaptation releases report on Ontario's climate } \\
\text { change adaptation needs. The pannel also made three public health-specific } \\
\text { recommendations actions for integrating public health in the climate change } \\
\text { discourses (Ontario Ministry of Environment Conservation and Parks, 2016; The } \\
\text { Expert Panel on Climate Change Adaptation, 2009) }\end{array}$ \\
\hline $\begin{array}{l}\text { December } \\
2009\end{array}$ & Ontario passes the Lake Simcoe Protection Act, for minimizing environ \\
\hline
\end{tabular}




\begin{tabular}{|c|c|}
\hline 2010 & $\begin{array}{l}\text { Ontario's Long-Term Energy Plan (2010) commits to closing all coal-powered } \\
\text { plant by } 2014 \text { (Government of Ontario, 2019) }\end{array}$ \\
\hline March 2011 & $\begin{array}{l}\text { The province releases Growth Plan for Northern Ontario which guides the } \\
\text { alignment of the government's decision-making with investments in Northern } \\
\text { Ontario }\end{array}$ \\
\hline April 2011 & $\begin{array}{l}\text { MOE releases Climate Ready: Ontario's Adaptation Strategy and Action Plan } \\
\text { with } 37 \text { actions to be completed between } 2011 \text { to } 2014 \text { (Ontario Ministry of } \\
\text { Environment Conservation and Parks, 2016) }\end{array}$ \\
\hline May 2011 & $\begin{array}{l}\text { Ontario eliminates Climate Change Secretariat (Ontario Ministry of Environment } \\
\text { Conservation and Parks, 2016). }\end{array}$ \\
\hline $\begin{array}{l}\text { January } \\
2013\end{array}$ & $\begin{array}{l}\text { Ontario releases a discussion paper on cap-and-trade: GHG Emission } \\
\text { Reductions in Ontario; it discusses the key elements to be included in the } \\
\text { province's cap-and-trade program (Ontario Ministry of Environment } \\
\text { Conservation and Parks, 2016) }\end{array}$ \\
\hline 2013 & $\begin{array}{l}\text { The MOHLTC introduces the Make No Little Plan which laid out the vision, } \\
\text { mission, strategic goals, and the public health focus areas and provided a } \\
\text { foundation for the Environmental Health Climate Change Framework for Action } \\
\text { (Ebi et al., 2016; Government of Ontario, 2013). }\end{array}$ \\
\hline April 2014 & $\begin{array}{l}\text { Ontario releases Ontario Climate Change Update } 2014 \text { which provides an } \\
\text { update on GHG reduction targets set out in } 2007 \text { Climate Change Action Plan } \\
\text { (Ontario Ministry of Environment Conservation and Parks, 2014b, 2016) }\end{array}$ \\
\hline April 2014 & $\begin{array}{l}\text { Ontario's last coal power plant, the Thunder Bay GS Closes coal, closes } \\
\text { (Ontario Ministry of Environment Conservation and Parks, 2015) }\end{array}$ \\
\hline April 2014 & $\begin{array}{l}\text { Ontario releases the Provincial Policy Statement that direct land use planning } \\
\text { policies (Ontario Ministry of Environment Conservation and Parks, 2015). }\end{array}$ \\
\hline $\begin{array}{l}\text { February } \\
2015\end{array}$ & $\begin{array}{l}\text { Ontario releases Ontario Climate Change Discussion Paper } 2015 \text { that discusses } \\
\text { and seeks public opinion different options of carbon pricing and transition to low } \\
\text { carbon economy (Ontario Ministry of Environment Conservation and Parks, } \\
\text { 2016) }\end{array}$ \\
\hline March 2015 & $\begin{array}{l}\text { Ontario creates a 16-member action group consisting of academics, civic and } \\
\text { business leaders to advise the Minister of Environment on climate change } \\
\text { actions. }\end{array}$ \\
\hline April 2015 & $\begin{array}{l}\text { MOHLTC in Collaboration with the Ministry of Environment introduces the Air } \\
\text { Quality Health Index (AQHI) for understanding and measuring air quality in } \\
\text { relation to health (MECP, n.d.; Ontario Ministry of Health and Long-term Care, } \\
2017 a) \text {. }\end{array}$ \\
\hline $\begin{array}{l}\text { November } \\
2015\end{array}$ & $\begin{array}{l}\text { MOE releases the Climate Change Strategy indicating the province's intended } \\
\text { fresh approach in GHG reduction by recognizing opportunities for low carbon } \\
\text { economy (Ontario Ministry of Environment Conservation and Parks, 2016) }\end{array}$ \\
\hline $\begin{array}{l}\text { November } \\
\text { and } \\
\text { December } \\
2015\end{array}$ & $\begin{array}{l}\text { Ontario engages in COP } 21 \text { to advance provincial leadership in climate change } \\
\text { (Government of Ontario, } 2015 c, 2015 d \text { ) }\end{array}$ \\
\hline July 2015 & $\begin{array}{l}\text { countries to sign the } \\
\text { climate change (Govern }\end{array}$ \\
\hline May 2016 & $\begin{array}{l}\text { The government passes the Climate Change Mitigation and Low-Carbon } \\
\text { Economy Act. Two regulations guide the Act: The Cap-and-Trade Program } \\
\text { Regulations (Cap-and-Trade Regulations), and the Reporting and Verification of } \\
\text { Greenhouse Gas Emissions Regulations (Emissions Regulations) (Ontario } \\
\text { Ministry of Environment Conservation and Parks, 2016) }\end{array}$ \\
\hline
\end{tabular}




\begin{tabular}{|c|c|}
\hline July 2016 & $\begin{array}{l}\text { רe MOHLTC introduces the Harmonized Heat Warning Information System } \\
\text { IWIS) for guiding public health actions on extreme heat events (Ontario } \\
\text { inistry of Health and Long-term Care, 2016, 2017b). }\end{array}$ \\
\hline July 2016 & $\begin{array}{l}\text { The MOHLTC develops the Ontario Climate Change and Health Toolkits which } \\
\text { includes two complementary tools for addressing the health-related climate } \\
\text { change challenges in Ontario. The Climate Change and Health Vulnerability and } \\
\text { Adaptation Assessment Guidelines and the Climate Change and Health } \\
\text { Modelling Study (Ebi et al., 2016; Gough, Anderson, \& Herod, 2016b; Ministry of } \\
\text { Health and Long-term Care, 2016). }\end{array}$ \\
\hline June 2016 & $\begin{array}{l}\text { OE releases the Climate Change Action Plan 2016-2020 that outlines the } \\
\text { arious areas the province's targets to reduce GHG emissions (Ontario Ministry } \\
\text { Environment Conservation and Parks, 2016) }\end{array}$ \\
\hline $\begin{array}{l}\text { December } \\
2017\end{array}$ & $\begin{array}{l}\text { overnment passes bill to amend building code intended to support energy } \\
\text { ficiency in houses and large buildings (Government of Ontario, 2018k) }\end{array}$ \\
\hline 2018 & $\begin{array}{l}\text { Modernization of public health to include public health mandate in climate } \\
\text { change and the subsequent update of Ontario Public Health Standards, and } \\
\text { introduction of the Healthy Environments and Climate Change Guideline } \\
\text { (Government of Ontario, 2018m; Ministry of Health and Long Term Care, 2018). }\end{array}$ \\
\hline May 2018 & $\begin{array}{l}\text { tario signs an agreement of understanding with Quebec and Oregon to work } \\
\text { gether on GHG reduction solutions (Government of Ontario, 2018d) }\end{array}$ \\
\hline July & $\begin{array}{l}\text { Ontario introduces legislation to eliminate the Cap and Trade program } \\
\text { (Government of Ontario, 2018j; MECP, 2019c) }\end{array}$ \\
\hline July 2018 & $\begin{array}{l}\text { Ontario ends Electric and Hydrogen vehicle incentives (Ministry of Transport, } \\
\text { 2018) }\end{array}$ \\
\hline July 2018 & $\begin{array}{l}\text { tario cancels } 758 \text { renewable energy projects that were meant to advance the } \\
\text { ovince's renewable energy initiatives (Government of Ontario, 2018n) }\end{array}$ \\
\hline $\begin{array}{l}\text { August } \\
2018\end{array}$ & $\begin{array}{l}\text { tario, under the new government (PC) announces intention to challenge the } \\
\text { deral government's push for a carbon tax in Ontario citing constitutional } \\
\text { ounds (MECP, 2019a, 2019b) }\end{array}$ \\
\hline $\begin{array}{l}\text { September } \\
2018\end{array}$ & $\begin{array}{l}\text { Ontario government files a statement to the Courts of Appeal to challenge the } \\
\text { Federal Government's carbon tax. The province challenges the federal } \\
\text { government on constitutional grounds (MECP, 2019a, 2019b) }\end{array}$ \\
\hline $\begin{array}{l}\text { September } \\
2018\end{array}$ & $\begin{array}{l}\text { Ontario introduces legislation to repeal the Green Energy Act (Government of } \\
\text { Ontario, } 2018 \mathrm{e}, 2018 \mathrm{f}) \text {. }\end{array}$ \\
\hline $\begin{array}{l}\text { October } \\
2018\end{array}$ & $\begin{array}{l}\text { Ontario's new Premier joins premiers of Western Canada in fighting the } \\
\text { proposed federal carbon tax (Govenment of Ontario, 2018; Government of } \\
\text { Ontario, 2018h, 2018i, 2018g) }\end{array}$ \\
\hline $\begin{array}{l}\text { October } \\
2018\end{array}$ & $\begin{array}{l}\text { Ontario government passes legislation to end cap and trade program } \\
\text { (Government of Ontario, 2018j; Legislative Assembly of Ontario, 2018; MECP, } \\
\text { 2019c) }\end{array}$ \\
\hline $\begin{array}{l}\text { October } \\
2018\end{array}$ & $\begin{array}{l}\text { Ontario eliminates the Green Ontario Fund, a rebate program that incentivized } \\
\text { carbon footprint reduction in homes and businesses (Government of Ontario, } \\
2018 \text { a). }\end{array}$ \\
\hline $\begin{array}{l}\text { November } \\
2018\end{array}$ & $\begin{array}{l}\text { Ontario releases the Made in Ontario Environmental Plan with a significantly } \\
\text { reduced focus on climate change and citing a need to balance between } \\
\text { environment and economy (Ontario Ministry of Environment Conservation and } \\
\text { Parks, 2018). }\end{array}$ \\
\hline November & $\begin{array}{l}\text { ario proposes to eliminate the office of the Environmental Commissioner an } \\
\text { ironmental watchdog whose jurisdiction had the authority to report, audit and }\end{array}$ \\
\hline
\end{tabular}


review environmental issues including climate change (Office of the Auditor General of Ontario, 2019) 


\section{Appendix L: Systematic Search of Records as Guided by PRISMA}
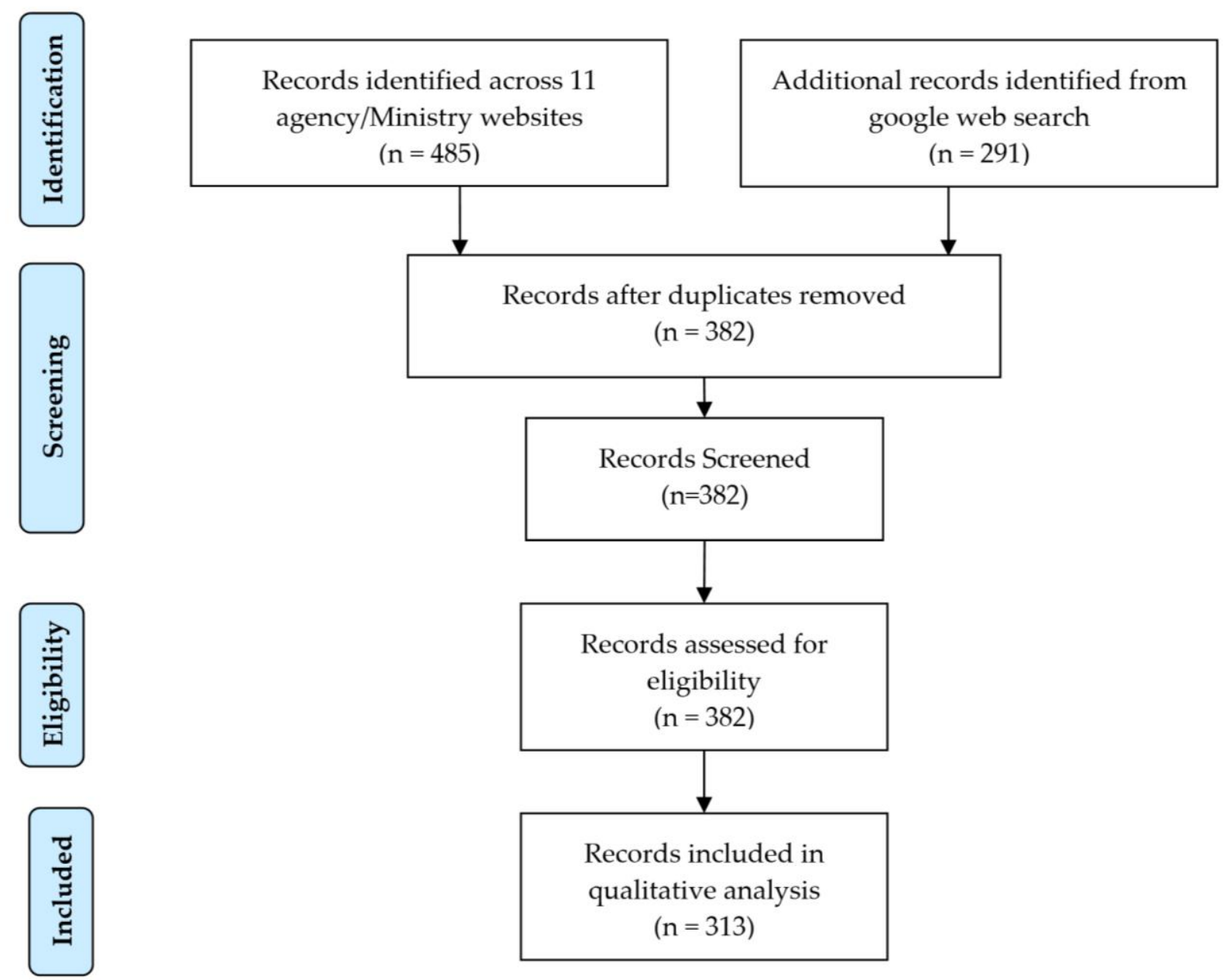

Guided by Shamseer et al. (2015) and Moher et al. (2009) 
Appendix M: Integration of Public Health in the Provincial Climate Change Frameworks

\begin{tabular}{|c|c|c|c|}
\hline Year & Plan & Priority & Public health role specified \\
\hline 2009 & $\begin{array}{l}\text { Expert Panel's } \\
\text { report on climate } \\
\text { change adaptation }\end{array}$ & $\begin{array}{l}\text { - 11-panel members identified six broad action } \\
\text { areas: public health, infrastructure, economy, } \\
\text { environment, potential climate change impacts } \\
\text { (to government, municipalities and the public), } \\
\text { and areas of scientific needs. } \\
\text { - } 59 \text { recommendations forwarded }\end{array}$ & $\begin{array}{l}\text { - The panel met with MOHLTC (senior-level } \\
\text { government managers) in order to assess } \\
\text { climate change adaptation needs } \\
\text { - Three specific recommendations addressed } \\
\text { public health needs (rec. 16, } 17 \text { \& 18) } \\
\text { Assessment and expansion of public } \\
\text { health capacity to respond to climate } \\
\text { change health risks } \\
\text { Assessment of tools and resources for } \\
\text { PHUs response to climate change } \\
\text { health risks } \\
\text { A need for the completion of health } \\
\text { vulnerability assessments and } \\
\text { identification of priority areas. } \\
\text { Role of public health is also highlighted in } \\
\text { the need to integrate adaptation action } \\
\text { plans by community partners such as PHUs } \\
\text { (rec. } 36 \text { ) }\end{array}$ \\
\hline 2011 & $\begin{array}{l}\text { Climate Ready: } \\
\text { Adaptation and } \\
\text { Strategy and } \\
\text { Action Plan }\end{array}$ & $\begin{array}{l}\text { - } 37 \text { action areas to be taken by } 10 \text { ministries. } \\
\text { - These actions focused on four areas: water } \\
\text { management, infrastructure (transportation, built } \\
\text { environment, energy and water), agriculture and } \\
\text { tourism. }\end{array}$ & $\begin{array}{l}\text { - Provides public health adaptive actions to } \\
\text { climate change but does not include } \\
\text { platforms for intersectoral collaborations } \\
\text { and integration of public health needs }\end{array}$ \\
\hline 2015 & $\begin{array}{l}\text { Ontario Climate } \\
\text { Change Strategy }\end{array}$ & $\begin{array}{l}\text { - highlighted } 5 \text { areas of transformation that were } \\
\text { to be by a series of five action plans. }\end{array}$ & - No direct role of public health identified \\
\hline
\end{tabular}




\begin{tabular}{|c|c|c|c|}
\hline & & $\begin{array}{l}\text { These areas included the promotion of green } \\
\text { economy, collaboration and leadership, } \\
\text { reducing GHG emission in key sectors } \\
\text { (transportation, industry, building, electricity, } \\
\text { agriculture, and waste), productive use of } \\
\text { resources, and the consideration of } \\
\text { vulnerabilities, costs and adaptive needs. }\end{array}$ & \\
\hline 2016 & $\begin{array}{l}\text { Climate Change } \\
\text { Action Plan: 2016- } \\
2020\end{array}$ & $\begin{array}{l}\text { - Identified } 8 \text { key priority areas for emission } \\
\text { reduction: transportation; building and homes; } \\
\text { land use planning; industry and business; } \\
\text { collaboration with Indigenous communities; } \\
\text { research and development; emission reduction } \\
\text { in government; agriculture, forest and lands } \\
\text { - Called on the ministries assigned to the } \\
\text { identified areas to identify and commit to GHG } \\
\text { reduction strategies that support international } \\
\text { GHG commitments }\end{array}$ & $\begin{array}{l}\text { Public health topic is raised twice in an 86- } \\
\text { page document; one relates to the } \\
\text { promotion of cycling and its co-benefits to } \\
\text { public health (pg. 22); another refers to the } \\
\text { need of accessing experts in public health } \\
\text { planning (pg. 55). }\end{array}$ \\
\hline 2018 & $\begin{array}{l}\text { Made-in-Ontario } \\
\text { Environment Plan }\end{array}$ & $\begin{array}{l}\text { - Climate change actions addressed separately } \\
\text { from actions meant to maintain clean air, water, } \\
\text { land and soil and the conservation of land and } \\
\text { green space. } \\
\text { - Prioritizes } \\
\circ \text { Helping families and communities prepare } \\
\text { Setting achievable GHG reduction targets } \\
\text { that correspond with Ontario's share of } \\
\text { GHG emissions relative to other provinces } \\
\text { and global emissions } \\
\text { Ensuring polluters pay fair share while } \\
\text { advancing industries role in GHG reduction } \\
\text { - Government Leadership } \\
\text { Prioritized sectors: industry, building, waste, } \\
\text { agriculture, electricity and transportation }\end{array}$ & $\begin{array}{l}\text { - This requirement is not directly associated } \\
\text { with climate change actions but is listed } \\
\text { under clean air protection actions } \\
\text { Recognizes the role of PHUs in air } \\
\text { quality improvements. Here the } \\
\text { government proposes to improve air } \\
\text { quality through partnerships with public } \\
\text { health units. No elaboration is provided } \\
\text { as to how such partnerships are to be } \\
\text { supported. }\end{array}$ \\
\hline
\end{tabular}

* This document was not publicly accessible. However, a summary from news releases and its reference in the Climate Change Strategy (2015) highlights the priorities set in the document. 
Appendix N: Public Health Climate Change Initiatives

\begin{tabular}{|c|c|c|c|}
\hline Year & $\begin{array}{l}\text { Plans and } \\
\text { frameworks }\end{array}$ & Priority & $\begin{array}{l}\text { The action specified (mitigation } \\
\text { and/or adaptation) }\end{array}$ \\
\hline 2008 & $\begin{array}{l}\text { Ontario Public } \\
\text { Health } \\
\text { Standards } \\
\text { 2008- The } \\
\text { Health Hazard } \\
\text { Prevention and } \\
\text { Management } \\
\text { Standard }\end{array}$ & $\begin{array}{l}\text { Increase public awareness of } \\
\text { health hazards, including: } \\
\text { - climate change } \\
\text { - extreme weather } \\
\text { - } \text { air quality } \\
\text { - exposure to radiation } \\
\text { Help community partners in } \\
\text { developing healthy policies } \\
\text { related to } \\
\text { - Air quality } \\
\text { - Built environments } \\
\text { - Extreme weather }\end{array}$ & $\begin{array}{l}\text { No directives on climate change } \\
\text { but the role in developing a } \\
\text { healthy built environment and air } \\
\text { quality policies can also be } \\
\text { ascribed to both mitigation and } \\
\text { adaptation (though ambiguously } \\
\text { presented). }\end{array}$ \\
\hline 2013 & $\begin{array}{l}\text { Make No Little } \\
\text { Plans }\end{array}$ & $\begin{array}{l}\text { Ontario's first public health } \\
\text { strategic plan } \\
\text { No specific inclusion of climate } \\
\text { change needs but has been } \\
\text { identified in public health } \\
\text { frameworks as a strategy for } \\
\text { public health actions on health }\end{array}$ & $\begin{array}{l}\text { No directives on climate change; } \\
\text { but addresses one goal (goal \#4) } \\
\text { associated with climate change } \\
\text { mitigation and adaptation. } \\
\text { - Promoting healthy built } \\
\text { environments permit active } \\
\text { transportation, walkable } \\
\text { neighbourhoods and better air } \\
\text { quality. }\end{array}$ \\
\hline 2016 & $\begin{array}{l}\text { Environmental } \\
\text { Health } \\
\text { Framework for } \\
\text { Action }\end{array}$ & $\begin{array}{l}\text { Reducing vulnerability to climate } \\
\text { change impacts Ontario air quality } \\
\text { index } \\
\text { - Ontario Heat Warning and } \\
\text { Information System } \\
\text { - Proposed Cold Warning and } \\
\text { Information System } \\
\text { Public health adaptive capacity } \\
\text { enhancing tools } \\
\text { - Vulnerability and Adaptation } \\
\text { Assessment Guideline and } \\
\text { Workbook } \\
\text { - Climate Modelling Study (5 } \\
\text { areas of focus: heat, UV } \\
\text { exposure, air pollution, VBDs, } \\
\text { extreme precipitation) } \\
\text { Building partnerships and } \\
\text { linkages at the local levels } \\
\text { - Reducing public health } \\
\text { vulnerability through healthy } \\
\text { resilient communities }\end{array}$ & Focus on adaptation \\
\hline
\end{tabular}




\begin{tabular}{|c|c|c|c|}
\hline 2018 & $\begin{array}{l}\text { Ontario Public } \\
\text { Health } \\
\text { Standards } \\
2018 \text { - Healthy } \\
\text { Environments } \\
\text { Standard }\end{array}$ & $\begin{array}{l}\text { Aims to reduce health hazards } \\
\text { and develop healthy built and } \\
\text { natural environments to minimize } \\
\text { risks and impacts of climate } \\
\text { change }\end{array}$ & $\begin{array}{l}\text { Focus on adaptation (based on } \\
\text { the outlined expected program } \\
\text { outcomes and requirements) } \\
\text { - The ambiguous role of } \\
\text { public health in mitigation } \\
\text { (e.g. PHUs requirements } \\
\text { to collaborate with } \\
\text { partners in promoting } \\
\text { healthy build and natural } \\
\text { environments could be } \\
\text { related to participation in } \\
\text { both mitigation and } \\
\text { adaptation actions) }\end{array}$ \\
\hline 2018 & $\begin{array}{l}\text { Healthy } \\
\text { Environments } \\
\text { and Climate } \\
\text { Change } \\
\text { Guideline }\end{array}$ & $\begin{array}{l}\text { Guideline to assist PHUs work } \\
\text { with provincial ministries and local } \\
\text { partners in: } \\
\text { - assessing climate change } \\
\text { risks (e.g. vulnerability and } \\
\text { adaptation assessments), and } \\
\text { - mitigation of risk factors } \\
\text { identified within their specific } \\
\text { jurisdictions. }\end{array}$ & $\begin{array}{l}\text { Focus on adaptation with an } \\
\text { vague role in mitigation (e.g. } \\
\text { participating in healthy build and } \\
\text { natural environments policies). }\end{array}$ \\
\hline
\end{tabular}




\section{REFERENCES}

Aaheim, A., Wei, T., \& Romstad, B. (2017). Conflicts of economic interests by limiting global warming to $+3^{\circ} \mathrm{C}$. Mitigation and Adaptation Strategies for Global Change, 22(8), 11311148. https://doi.org/10.1007/s11027-016-9718-8

Abelsohn, A., Rachilis, V., Rosen, D., \& Kasperski, J. (2008). Addressing the Health Effects of Climate Change: Family Physicians Are Key. Retrieved from http://www.deslibris.ca/ID/225371

Ackerman, F., DeCanio, S. J., Howarth, R. B., \& Sheeran, K. (2009). Limitations of integrated assessment models of climate change. Climatic Change, 95(3-4), 297-315. https://doi.org/10.1007/s10584-009-9570-x

Adger, W. N. (2006). Vulnerability. Global Environmental Change, 16(3), 268-281. https://doi.org/10.1016/j.gloenvcha.2006.02.006

Admiraal, A. K., Hof, A. F., den Elzen, M. G. J., \& van Vuuren, D. P. (2016). Costs and benefits of differences in the timing of greenhouse gas emission reductions. Mitigation and Adaptation Strategies for Global Change, 21(8), 1165-1179. https://doi.org/10.1007/s11027-015-9641-4

Agrawala, S., Bosello, F., Carraro, C., De Bruin, K., De Cian, E., Dellink, R. O. B., \& Lanzi, E. (2011). Plan or React? Analysis of Adaptation Costs and Benefits Using Integrated Assessment Models. Climate Change Economics, 2(3), 175-208. https://doi.org/10.1142/S2010007811000267

Akerlof, K., Debono, R., Berry, P., Leiserowitz, A., Roser-Renouf, C., Clarke, K. L., ... Maibach, E. (2010). Public Perceptions of Climate Change as a Human Health Risk: Surveys of the United States, Canada and Malta. International Journal of Environmental Research and Public Health, 7(6), 2559-2606. https://doi.org/10.3390/ijerph7062559

Akerlof, K., Maibach, E. W., Fitzgerald, D., Cedeno, A. Y., \& Neuman, A. (2013). Do people "personally experience" global warming, and if so how, and does it matter? Global Environmental Change, 23(1), 81-91. https://doi.org/10.1016/j.gloenvcha.2012.07.006

Aksan, N., Kısac, B., Aydın, M., \& Demirbuken, S. (2009). Symbolic interaction theory. Procedia Social and Behavioral Sciences, 1, 902-904. https://doi.org/10.1016/j.sbspro.2009.01.160

Alaszewski, A., \& Brown, P. (2012). Making Health Policy: A Critical Introduction. Retrieved from https://catalogue.library.ryerson.ca/record=b2117710

Aldy, J. E., Ashton, J., Baron, R., Bodansky, D., Charnovitz, S., Diringer, E., ... Wang, X. (2003). Beyond Kyoto: Advancing the International Effort against Climate Change. Pew Center on Global Climate Change Arlington VA. https://doi.org/10.1787/9789264171022-en

Altman, D. G. (2009). Challenges in Sustaining Public Health Interventions. Health Education \& Behavior, 36(1), 24-28. https://doi.org/10.1177/1090198107299788

Ambrus, M., Arts, K., Hey, E., \& Raulus, H. (2014). The Role of 'Experts' in International and European Decision-Making Processes: Advisors, Decison Makers or Irrelevant Actors.' (M. Ambrus, K. Arts, E. Hey, \& H. Raulus, Eds.). United Kingdom.

Ansell, C., \& Gash, A. (2008). Collaborative governance in theory and practice. Journal of Public Administration Research and Theory, 18(4), 543-571. https://doi.org/10.1093/jopart/mum032

Anthony J. Viera, \& Joanne M. Garrett. (2005). Understanding Interobserver Agreement: The Kappa Statistic. Family Medicine, 37(5), 360-363.

Association of Local Public Health Agencies. (2010). Orientation Manual for Board of Health Members. Retrieved from http://www.simcoemuskokahealth.org/docs/default-source/huaboutus/bohorientationmanual2010 
Association of Local Public Health Agencies. (2018). 2018 Orientation Manual for Boards of Health. Retrieved from www.alphaweb.org

Association of Local Public Health Agencies. (2019). Public Health Units. Retrieved September 6, 2019, from https://www.alphaweb.org/page/PHU

Audi, R. (2010). Epistemology: A Contemprary Introduction to the Theory of Knowledge (Third Edit). New York and London: Routledge.

Austin, S. E., Biesbroek, R., Berrang-Ford, L., Ford, J. D., Parker, S., \& Fleury, M. D. (2016). Public health adaptation to climate change in OECD countries. International Journal of Environmental Research and Public Health, 13(9). https://doi.org/10.3390/ijerph13090889

Austin, S. E., Ford, J. D., Berrang-Ford, L., Araos, M., Parker, S., \& Fleury, M. D. (2015). Public Health Adaptation to Climate Change in Canadian Jurisdictions. Int. J. Environ. Res. Public Health International Journal of Environmental Research and Public Health, 123390(10), 623-651. https://doi.org/10.3390/ijerph120100623

Awuor, L., \& Melles, S. (2019). The influence of environmental and health indicators on premature mortality: An empirical analysis of the City of Toronto's 140 neighborhoods. Health and Place, 58. https://doi.org/10.1016/j.healthplace.2019.102155

Aylett, A. (2015). Institutionalizing the urban governance of climate change adaptation: Results of an international survey. Urban Climate, 14, 4-16. https://doi.org/10.1016/j.uclim.2015.06.005

Baghramian, M., \& Carter, A. J. (2018). Stanford encyclopedia of philosophy: Relativism. (N. Zalta, Edward, Ed.), Stanford encyclopedia of philosophy. Stanford University. Center for the Study of Language and Information (U.S.). Retrieved from https://plato.stanford.edu/archives/win2018/entries/relativism/

Barkan, S. E. (2013). Social problems: Continuity and change. Retrieved from https://catalog.flatworldknowledge.com/bookhub/reader/3064?e=barkansoc_1.0-ch15_s01

Barley, S. R., \& Tolbert, P. S. (1997). Institutionalization and Structuration: Studying the Links between Action and Institution. Organization Studies, 18(1), 93-117. https://doi.org/doi:10.1177/017084069701800106

Baxter, Pamela, \& Jack, S. (2008). Qualitative Case Study Methodology : Study Design and Implementation for Novice Researchers Qualitative Case Study Methodology : Study Design and Implementation. The Qualitative Report, 13(4), 544-559. Retrieved from http://nsuworks.nova.edu/tqr/vol13/iss4/2

Baxter, PE, \& Boblin, S. (2006). Decision making by baccalaureate nursing students in the clinical setting. Journal of Nursing Education, 45(4), 345-350. Retrieved from http://nsuworks.nova.edu/tqr/vol13/iss4/2

Bazeley, Pat, \& Jackson, K. (2013). Qualitative Data Analysis with NVIVO. (J. Seaman \& A. Horvai, Eds.) (Second). Sage Publications Ltd.

Bazeley, Patricia. (2013). Qualitative Data Analysis: Practical Strategies. .. Sage Publications Ltd.

Bell, E. (2011). Readying health services for climate change: A policy framework for regional development. American Journal of Public Health, 101(5), 804-813. https://doi.org/10.2105/AJPH.2010.202820

Bellieni, C. V, Cordelli, D. M., Caliani, C., Palazzi, C., Franci, N., Perrone, S., ... Buonocore, G. (2007). Inter-observer reliability of two pain scales for newborns. Early Human Development, 83(8), 549-552. https://doi.org/10.1016/j.earlhumdev.2006.10.006

Belur, J., Tompson, L., Thornton, A., \& Simon, M. (2018). Interrater Reliability in Systematic Review Methodology: Exploring Variation in Coder Decision-Making. Sociological Methods and Research. https://doi.org/10.1177/0049124118799372

Benford, R. D., \& Snow, D. A. (2000). Framing Processes and Social Movements : An Overview and Assessment Authors ( s ): Robert D. Benford and David A. Snow Source: Annual 
Review of Sociology, Vol . 26 ( 2000 ), pp . 611-639 Published by: Annual Reviews Stable URL : http://www.jstor.org/. Reviews, Annual, 26(2000), 611-639.

Berg, B. L., \& Lune, H. (2016). Qualitative research methods for the social sciences. Retrieved from http://catalogue. library.ryerson.ca/record=b2697649

Bernstein, S. (2001). The Composite of Liberal Environmentalism. New York, US: Columbia University Press.

Berrang-Ford, L., MacLean, J. D., Gyorkos, T. W., Ford, J. D., \& Ogden, N. H. (2009). Climate Change and Malaria in Canada: A Systems Approach. Interdisciplinary Perspectives on Infectious Diseases, 2009(14), 1-13. https://doi.org/10.1155/2009/385487

Berry, P. (2008). Vulnerabilities, adaptation and adaptive capacity in Canada. Human health in a changing climate: A Canadian assessment of vulnerabillities and adaptive capacity.

Berry, P., Clarke, K.-L., Fleury, M. D., \& Parker, S. (2014). Chapter 7- Canada in a Changing Climate: Sector Perspectives on Impacts and Adaptation. Health Canada; Environment Canada)Public Health Agency of Canada)Health Canada)Environment Canada) Human Health, 191-232. Retrieved from https://www.nrcan.gc.ca/sites/www.nrcan.gc.ca/files/earthsciences/pdf/assess/2014/pdf/Ch apter7-Human-Health_Eng.pdf

Berry, P., Clarke, K.-L., Pajot, M., \& Hutton, D. (2011). Risk Perception, Health Communication, and Adaptation to the Health Impacts of Climate Change in Canada. Climate Change Adaptation in Developed Nations: From Theory To Practice (Vol. 42). Springer, Dordrecht. https://doi.org/10.1007/978-94-007-0567-8_14

Blommaert, J. (2005). Critical Discourse Analysis. In Discourse: a critical introduction (pp. 2138). Cambridge University Press.

Boardman, A. ., Greenberg, D. ., Vining, A. ., \& Weimer, D. . (2006). Cost-benefit analysis: concepts and practice. Upper Saddle River, New Jersey, United States of America: Prentice-Hall.

Bochner, A. P., \& Riggs, N. A. (2015). Practicing Narrative Inquiry. In P. Leavy (Ed.), he Oxford Handbook of Qualitative Research (pp. 195-222). New York, US: Oxford University Press.

Bolotin, S., Feld, J. J., Garber, G., Wong, W. W. L., Guerra, F. M., \& Mazzulli, T. (2018). Population-based estimate of hepatitis $\mathrm{C}$ virus prevalence in Ontario, Canada. PLoS ONE, 13(1), 1-10. https://doi.org/10.1371/journal.pone.0191184

Bosello, F., Carraro, C., \& De Cian, E. (2013). Adaptation can help mitigation: An integrated approach to post-2012 climate policy. Environment and Development Economics, 18(3), 270-290. https://doi.org/10.1017/S1355770X13000132

Boussalis, C., \& Coan, T. G. (2016). Text-mining the signals of climate change doubt. Global Environmental Change, 36, 89-100. https://doi.org/10.1016/j.gloenvcha.2015.12.001

Brand, U., Bullard, N., Lander, E., \& Tadzio, M. (2009). Contours of Climate Justice: Ideas for shaping new climate and energy politics. Critical Currents, 6(7). Retrieved from https://www.tni.org/files/download/contoursofclimatejustice.pdf

Brehaut, J., \& Juzwishin, D. (2005). Bridging the Gap: The Use of Research Evidence in Policy Development.

Brinkmann, S., Jacobsen, M. H., \& Kristiansen, S. (2015). Historical Overview of Qualitative Research in the Social Sciences. In P. Leavy (Ed.), The Oxford Handbook of Qualitative Research (pp. 17-42). New York, US: Oxford University Press.

Brosnan, L. (2013). Power and participation: An examination of the dynamics of mental health service-user involvement in Ireland. Studies in Social Justice, 6(1), 45-66. https://doi.org/10.26522/ssj.v6i1.1068

Brown, H. E., Young, A., Lega, J., Andreadis, T. G., Schurich, J., \& Comrie, A. (2015). Projection of climate change influences on U.S. West nile virus vectors. Earth Interactions, 19(18), 1-19. https://doi.org/10.1175/El-D-15-0008.1 
Brown, K. (2003). Three challenges for a real people-centred conservation. Global Ecology and Biogeography, 12(2), 89-92. https://doi.org/10.1046/j.1466-822X.2003.00327.x

Brugman, B. C., \& Burgers, C. (2018). Political framing across disciplines: Evidence from 21stcentury experiments. Research and Politics, 5(2). https://doi.org/10.1177/2053168018783370

Bulkeley, H., \& Betsill, M. M. (2013). Revisiting the urban politics of climate change. Environmental Politics, 22(1), 136-154. https://doi.org/10.1080/09644016.2013.755797

Buse, C. G., Lai, V., Cornish, K., \& Parkes, M. W. (2019). Towards environmental health equity in health impact assessment: innovations and opportunities. International Journal of Public Health. https://doi.org/10.1007/s00038-018-1135-1

Cadman, T. (2013). Climate change and global policy regimes: Towards institutional legitimacy. Palgrave Macmillan. Retrieved from http://catalogue.library.ryerson.ca/record=b2442109

Cairney, P. (2011). Punctuated Equilibrium. In Understanding Public Policy: Theories and Issues (Vol. 1, pp. 175-199). https://doi.org/10.1017/CBO9781107415324.004

Cairney, P. (2012a). Institutions and New Instititonalism. In Understanding Public Policy: Theories and Issues (pp. 69-93). Palgrave Macmillan. https://doi.org/10.1007/987-0-23035699-3

Cairney, P. (2012b). The Role of Ideas. In Understanding Public Policy: Theories and Issues (pp. 220-243). Palgrave Macmillan. https://doi.org/10.1007/987-0-230-35699-3

Cairney, P. (2012c). Understanding Public Policy: Theories and issues. Palgrave Macmillan. https://doi.org/10.1007/987-0-230-35699-3

Cairney, P. (2015). Policy and policy making in the UK. In Policy and Policymaking in the UK (pp. 1-22). Retrieved from https://paulcairney.wordpress.com/policymaking-in-the-uk/

Campbell-Lendrum, D., Corvalán, C., \& Neira, M. (2007). Global climate change: implications for international public health policy. Bulletin of the World Health Organization, 85(3), 161244. Retrieved from http://www.who.int/bulletin/volumes/85/3/06-039503/en/

Campbell, A. (2004). The SARS Commission Interim Report: SARS and Public Health in Ontario- The Honourable Mr. Justice Archie Campbell-Commissioner - Ministry Reports Publications - Public Information - MOHLTC. Retrieved from http://www.health.gov.on.ca/en/common/ministry/publications/reports/campbell04/campbell 04_2.aspx

Canadiān Public Health Association. (2016). Public Health: A Conceptual Framework FIRST EDITION. Retrieved from http://www.who.int/trade/glossary/story076/en/\#

Canadian Public Health Association. (2017). Canadian Public Health Association Working Paper. Retrieved from https://www.cpha.ca/sites/default/files/uploads/policy/phframework/phcf_e.pdf

Cann, H. W. (2015). Climate Change, Still Challenged: Conservative Think Tanks and Skeptic Frames. Western Political Science Association, 1-19. Retrieved from https://wpsa.research.pdx.edu/papers/docs/wpsa15 - cann.pdf

Carolan, C. M., Forbat, L., \& Smith, A. (2015). Developing the DESCARTE Model: The Design of Case Study Research in Health Care. Qualitative Health Research, 1-14. https://doi.org/10.1177/1049732315602488

Carter, M. J., \& Fuller, C. (2015). Sympolic interactionism. Sociopedia.Isa, (1), 1-17. https://doi.org/10.1177/205684601561

Carvalho, A. (2005). Representing the politics of the greenhouse effect: Critical Discourse Studies, 2(1), 1-29. https://doi.org/10.1080/17405900500052143

Cass, L. R. (2010). The Politics of Climate Change. The Politics of Climate Change Oxford Research Encyclopedia of International Studies. https://doi.org/10.1093/acrefore/9780190846626.013.112 
Cerasoli, C. P., Nicklin, J. M., \& Ford, M. T. (2014). Intrinsic motivation and extrinsic incentives jointly predict performance: A 40-year meta-analysis. Psychological Bulletin, 140(4), 980 1008. https://doi.org/10.1037/a0035661

Chen, C. C., Jenkins, E., Epp, T., Waldner, C., Curry, P. S., \& Soos, C. (2013). Climate change and West Nile virus in a highly endemic region of North America. International Journal of Environmental Research and Public Health, 10(7), 3052-3071. https://doi.org/10.3390/ijerph10073052

Cheng, C. S., Auld, H., Li, Q., \& Li, G. (2012). Possible impacts of climate change on extreme weather events at local scale in south-central Canada. Climatic Change, 112(3-4), 963979. https://doi.org/10.1007/s10584-011-0252-0

Cheng, H., Kotler, P., \& Lee, N. (2009). Social Marketing for Public Health: An Introduction. In Social Marketing for Public Health Global Trends and Success Stories (pp. 1-28). Kotler \& Lee. Retrieved from http://samples.jbpub.com/9780763757977/57977_ch01_final.pdf

Cho, H. (2012). Health communication message design : theory and practice. Thousand Oaks, Calif: SAGE Publications. Retrieved from https://catalyst.library.jhu.edu/catalog/bib_4174276

Chong, D., \& Druckman, J. N. (2007a). A theory of framing and opinion formation in competitive elite environments. Journal of Communication, 57(1), 99-118. https://doi.org/10.1111/j.1460-2466.2006.00331.x

Chong, D., \& Druckman, J. N. (2007b). Framing Theory. Annual Review of Political Science, 10(1), 103-126. https://doi.org/10.1146/annurev.polisci.10.072805.103054

Chouliaraki, L. (2010). Discourse analysis. In T. Bennett \& J. Frow (Eds.), The SAGE Handbook of Cultural Analysis (pp. 674-698). London: Sage Publications.

City of London. (2017). Healthy Streets for London. Retrieved from http://content.tfl.gov.uk/healthy-streets-for-london.pdf

Colman, A. M. (2014). DICTIONARY OF PSYCHOLOGY (3rd ed.). Oxford University Press. Retrieved from http://www.oxfordreference.com/view/10.1093/acref/9780199534067.001.0001/acref9780199534067

Colombo, S. J., McKenney, D. W., Lawrence, K. M., \& Gray, P. a. (2007). Climate Change Projections for Ontario: Practical Information for Policymakers and Planners. https://doi.org/CCRR-05

Commission on Social Determinants of Health. (2008). Closing the gap in a generation: Health equity through action on the social determinants of health. Retrieved from ttp://apps.who.int/iris/bitstream/handle/10665/43943/9789241563703_eng.pdf;jsessionid=D CE118473C094E39725CEF29562ABF9E?sequence $=1$

Conrad, P. (2008). To Boldly Go: A Partnership Enterprise to Produce Applied Health and Nursing Services Researchers in Canada. Healthcare Policy, 3(Special Issue), 13-30. https://doi.org/19810 [pii]

Costello, A., Abbas, M., Allen, A., Ball, S., Bell, S., Bellamy, R., ... Patterson, C. (2009). Managing the health effects of climate change. Lancet and University College London Institute for Global Health Commission. The Lancet, 373(9676), 1693-1733. https://doi.org/10.1016/S0140-6736(09)60935-1

Covello, V. T., Peters, R. G., Wojtecki, J. G., \& Hyde, R. C. (2001). Risk communication, the West Nile virus epidemic, and bioterrorism: Responding to the communication challenges posed by the intentional or unintentional release of a pathogen in an urban setting. In Journal of Urban Health (Vol. 78, pp. 382-391). https://doi.org/10.1093/jurban/78.2.382

Coyne, I. (1997). Sampling in qualitative research. Purposeful and theoretical sampling; merging or clear boundaries? Journal of Advanced Nursing, 26(3), 623-630. https://doi.org/10.1046/j.1365-2648.1997.t01-25-00999.x 
Crabbé, P., \& Robin, M. (2006). Institutional adaptation of water resource infrastructures to climate change in Eastern Ontario. Climatic Change, 78(1), 103-133.

https://doi.org/10.1007/s10584-006-9087-5

Creswell, J. W. (2013). Qualitative Inquiry and Research Design, 472. https://doi.org/10.1017/CBO9781107415324.004

Crisp, B. R., Swerissen, H., \& Duckett, S. (2000). Four approaches to capacity building in health: consequences for measurement and accountability. Health Promotion International, 15(2), 99-107. https://doi.org/10.1093/heapro/15.2.99

Crowe, S., Cresswell, K., Robertson, A., Huby, G., Avery, A., \& Sheikh, A. (2011). The case study approach. BMC Medical Research Methodology, 11, 100. https://doi.org/10.1186/1471-2288-11-100

Dale, A., \& Hill, S. B. (2001). At the edge: sustainable development in the 21st century. UBC Press. Retrieved from http://catalogue.library.ryerson.ca/record=b1377530

Darrier, E. (1999). Discourses of the Environment. Blackwell, Oxford.

Dayrell, C. (2019). Discourses around climate change in Brazilian newspapers: 2003-2013. Discourse and Communication, 13(2), 149-171. https://doi.org/10.1177/1750481318817620

De Francisco, J. C. R., \& Boelens, R. (2014). Payment for environmental services and power in the Chamachán Watershed, Ecuador. Human Organization, 73(4), 351-362. https://doi.org/10.17730/humo.73.4.b680w75u27527061

Dearden, P., \& Mitchell, B. (2016). Environmental Change and Challenge (Fifth Edit). Oxford University Press.

Debono, R., Vincenti, K., \& Calleja, N. (2012). Risk communication: Climate change as a human-health threat, a survey of public perceptions in Malta. European Journal of Public Health, 22(1), 144-149. https://doi.org/10.1093/eurpub/ckq181

DeCanio, S. J. (2009). The political economy of global carbon emissions reductions. Ecological Economics, 68(3), 915-924. https://doi.org/10.1016/j.ecolecon.2008.10.003

Den Elzen, M. G. J., Hof, A. F., Mendoza Beltran, A., Grassi, G., Roelfsema, M., van Ruijven, B., ... van Vuuren, D. P. (2011). The Copenhagen Accord: Abatement costs and carbon prices resulting from the submissions. Environmental Science and Policy, 14(1), 28-39. https://doi.org/10.1016/j.envsci.2010.10.010

Dennis R. O'Connor. (2002a). PART TWO REPORT OF THE WALKERTON INQUIRY: A STRATEGY FOR SAFE DRINKING WATER. Queen's Printer for Ontario . Retrieved from http://www.ontla.on.ca/library/repository/mon/3000/10300881.pdf

Dennis R. O'Connor. (2002b). Report of the Walkerton Inquiry (part one): The Events of May 2000 and Related Issues. Retrieved December 20, 2017, from http://www.archives.gov.on.ca/en/e_records/walkerton/report1/index.html

DeRouen, K., \& Goldfinch, S. (2012). What Makes a State Stable and Peaceful? Good Governance, Legitimacy and Legal-Rationality Matter Even More for Low-Income Countries. Civil Wars, 14(4), 499-520. https://doi.org/10.1080/13698249.2012.740201

Dervin, K., \& Rudolph, L. (2015). Climate Change and Health Communications. Retrieved from http://usclimateandhealthalliance.org/wpcontent/uploads/2016/06/ClimateChangeHealthCommunication2016.pdf

Dickinson, J. L., Crain, R., Yalowitz, S., \& Cherry, T. M. (2013). How Framing Climate Change Influences Citizen Scientists' Intentions to Do Something About It. Journal of Environmental Education, 44(3), 145-158. https://doi.org/10.1080/00958964.2012.742032

Dietz, T., Ostrom, E., \& Stern, P. C. (2003). Struggle to Govern the Commons. Science, 302(5652), 1907-1912. https://doi.org/10.1126/science.1091015

DiGaetano, R. (2013). Sample Frame and Related Sample Design Issues for Surveys of Physicians and Physician Practices. Evaluation and the Health Professions, 36(3), 296- 
329. https://doi.org/10.1177/0163278713496566

Dora, C., Fletcher, E., Pfeiffer, M., \& Adair-Rohan, H. (2014). Promoting Health While Mitigating Climate Change a new report on Access to Modern Energy Services for Health Facilities in Resource-Constrained Settings. Health Care); and Noah Scovronick (SLCPs \& Health. Retrieved from http://www.who.int/hia/green_economy/en/

Dora, C., Haines, A., Balbus, J., Fletcher, E., Adair-Rohani, H., Alabaster, G., ... Neira, M. (2015). Indicators linking health and sustainability in the post-2015 development agenda. The Lancet, 385(9965), 380-391. https://doi.org/10.1016/S0140-6736(14)60605-X

Dryzek, J. S. (1990). Discursive democracy: politics, policy, and political science. Cambridge University Press.

Dryzek, J. S. (2008). Policy Analysis as a Critique. In M. Moran, M. Rein, \& R. E. Goodin (Eds.), The Oxford handbook of public policy. Oxford University Press.

Dryzek, J. S. (2013). The politics of the Earth (Third). Oxford University Press.

Dryzek, J. S., Norgaard, R. B., \& Schlosberg, D. (2012). Climate Change and Society: Approaches and Responses. In The Oxford Handbook of Climate Change and Society. Oxford University Press. https://doi.org/10.1093/oxfordhb/9780199566600.003.0001

Dunlap, R. E. (2013). Climate Change Skepticism and Denial: An Introduction. American Behavioral Scientist, 57(6). https://doi.org/10.1177/0002764213477097

Dunlap, R E, \& McCright, A. M. (2011). The Oxford Handbook of Climate Change and Society Google Books. In J.S. Dryzek, R. B. Norgaard, \& D. Schlosberg (Eds.), ... Oxford Handbook of Climate Change ... (pp. 144-160). Oxford University Press.

Dunlap, Riley E, \& Jacques, P. J. (2013). Climate Change Denial Books and Conservative Think Tanks: Exploring the Connection. American Behavioral Scientist, 57(6), 699-731. https://doi.org/10.1177/0002764213477096

Durham County Council. (2016). How to get more children walking to school. Retrieved from https://www.livingstreets.org.uk/media/1393/walk-to-school-outreach-best-practice-reportweb.pdf

Ebi, K., Anderson, V., Berry, P., Paterson, J., \& Anna Yusa, A. (2016). Ontario Climate Change and Health Toolkit. Ministry of Health and Long-Term Care. Retrieved from http://www.health.gov.on.ca/en/common/ministry/publications/reports/climate_change_tool kit/climate_change_toolkit.pdf

Eden, S. (1999). Business claims of legitimacy in the environmental debate. Environment and Planning A, 31, 1295-1310. https://doi.org/10.1068/a311295

Elections Ontario. (2019). Dates of General Elections, Dates of Opening and Dissolution of Legislatures. Retrieved from https://results.elections.on.ca/en/publications

EPA. (2019). Strategies for Climate Change Adaptation. Retrieved September 3, 2019, from https://www.epa.gov/arc-x/strategies-climate-change-adaptation

Evely, A. C., Fazey, I., Pinard, M., \& Lambin, X. (2008). The Influence of Philosophical Perspectives in Integrative Research: a Conservation Case Study in the Cairngorms National Park. Ecology and Society, 13(12).

Expert Panel on Public Health. (2017). Public Health within an Integrated Health System Report of the Minister's Expert Panel on Public Health. Retrieved from http://www.health.gov.on.ca/en/common/ministry/publications/reports/public_health_panel_ 17/expert_panel_report.pdf

Fairclough, N. (1989). Language and power. London, Longman.

Fairclough, N. (1995). Critical Discourse Analysis. London, Longman.

Fairclough, Norman. (2003). Textual Analysis for Social Research. New York, US: Routledge.

Fairclough, Norman. (2013). Critical Discourse Analysis: The Critical Study of Language

(Second). London and New York: Routledge. Retrieved from

https://books.google.ca/books?id=3djbAAAAQBAJ\&printsec=frontcover\&redir_esc=y\#v=on 
epage \&q\&f=false

Febriani, Y., Levallois, P., Gingras, S., Gosselin, P., Majowicz, S. E., \& Fleury, M. D. (2010).

The association between farming activities, precipitation, and the risk of acute gastrointestinal illness in rural municipalities of Quebec, Canada: A cross-sectional study. BMC Public Health, 10. https://doi.org/10.1186/1471-2458-10-48

Feindt, P. H., \& Oels, A. (2005). Does discourse matter? Discourse analysis in environmental policy making. Journal of Environmental Policy and Planning, 7(3), 161-173. https://doi.org/10.1080/15239080500339638

Few, R., Brown, K., \& Tompkins, E. L. (2007). Public participation and climate change adaptation: Avoiding the illusion of inclusion. Climate Policy, 7(1), 46-59. https://doi.org/10.1080/14693062.2007.9685637

Field, B. C., \& Olewiler, N. D. (2011). Environmental Policy and Institutions in Canada: An Overview. In Environmental economics. McGraw-Hill Ryerson. Retrieved from http://catalogue.library.ryerson.ca/record=b2454105

Finn, S., \& O'Fallon, L. (2019). Environmental health literacy. (S. Finn \& L. O’Fallon, Eds.). Springer.

Fischer, F. (2012a). Citizens and experts:democratizing policy deliberation. In Reframing Public Policy (pp. 1-25). https://doi.org/10.1093/019924264x.001.0001

Fischer, F. (2012b). Making Social Science Relevant: Policy Inquiry in Critical Perspective. In Reframing Public Policy: Discursive Politics and Deliberative Practices (pp. 1-278). https://doi.org/10.1093/019924264X.001.0001

Fischer, F. (2012c). Reframing Public Policy: Discursive Politics and Deliberative Practices. Retrieved from www.oxfordscholarship.com

Fleming, A., Vanclay, F., Hiller, C., \& Wilson, S. (2014). Challenging dominant discourses of climate change. Climatic Change, 127(3-4), 407-418. https://doi.org/10.1007/s10584-0141268-z

Fletcher, A. L. (2009). Clearing the air : the contribution of frame analysis to understanding climate policy in the United States. Environmental Politics, 18(5), 800-816. https://doi.org/10.1080/09644010903157123

Fleury, M., Charron, D. F., Holt, J. D., Allen, O. B., \& Maarouf, A. R. (2006). A time series analysis of the relationship of ambient temperature and common bacterial enteric infections in two Canadian provinces. International Journal of Biometeorology, 50(6), 385-391. https://doi.org/10.1007/s00484-006-0028-9

Fløttum, K., \& Gjerstad, Ø. (2017). Narratives in climate change discourse. Wiley Interdisciplinary Reviews: Climate Change, 8(1), e429. https://doi.org/10.1002/wcc.429

Flowerdew, R., Manley, D. J., \& Sabel, C. E. (2008). Neighbourhood effects on health: Does it matter where you draw the boundaries? Social Science and Medicine, 66(6), 1241-1255. https://doi.org/10.1016/j.socscimed.2007.11.042

Ford, J. D., Berrang-Ford, L., King, M., \& Furgal, C. (2010). Vulnerability of Aboriginal health systems in Canada to climate change. Global Environmental Change, 20(4), 668-680. https://doi.org/10.1016/j.gloenvcha.2010.05.003

Foucault, M. (1972). The Archaeology of Knowledge and the Discourse of Language. New York: Pantheon Books.

Foucault, M. (1980). Power/Knowledge: Selected Interviews \&amp; Other Writings 1972-1977.

Foucault, M. (1991). Governmental Rationality: An Introduction. (B. Graham, C. Gordon, \& P. Miller, Eds.), The Foucault Effect: Studies in Governmentality. The University of Chicago Press. https://doi.org/10.1146/annurev-micro-090110-102957

Frumkin, H., Hess, J., Luber, G., Malilay, J., \& McGeehin, M. (2008). Climate change: The public health response. American Journal of Public Health, 98(3), 435-445. https://doi.org/10.2105/AJPH.2007.119362 
Frumkin, H., \& McMichael, A. J. (2008). Climate Change and Public Health. Thinking, Communicating, Acting. American Journal of Preventive Medicine.

https://doi.org/10.1016/j.amepre.2008.08.019

Funari, E., \& Testai, E. (2008, January 10). Human health risk assessment related to cyanotoxins exposure. Critical Reviews in Toxicology. https://doi.org/10.1080/10408440701749454

Gall, G. L., \& McLellan, A. A. (2017). Peace, Order and Good Government. Retrieved September 5, 2019, from https://www.thecanadianencyclopedia.ca/en/article/peace-orderand-good-government

Gallagher, K. M., \& Updegraff, J. A. (2012). Health message framing effects on attitudes, intentions, and behavior: A meta-analytic review. Annals of Behavioral Medicine, 43(1), 101-116. https://doi.org/10.1007/s12160-011-9308-7

Ganesh, C., \& Smith, J. A. (2017). Climate Change, Public Health, and Policy: A California Case Study. American Journal of Public Health, 108(S2), S114-S119. https://doi.org/10.2105/ajph.2017.304047

Gauvin, F.-P. (2014). Understanding Policy Developments and Choices Through the "3-i" Framework: Interests, Ideas and Institutions. National Collaborating Centre for Healthy Public Policy. Retrieved from www.ncchpp.ca

Gaventa, J. (2011). Power Pack: Understanding Power for Social Change. Retrieved from www.powercube.net/analyse-power/levels-of-power/

Gaventa, J, \& Martorano, B. (2016). Inequality, Power and Participation - Revisiting the Links. IDS Bulletin, 47(5), 11-30. https://doi.org/doi:10.19088/1968-2016.164

Gaventa, John. (2006). Finding Space for Change: A power analysis. Institute of Development Studies Bulletin, 37(6), 23-33.

Githeko, A. K., Lindsay, S. W., Confalonieri, U. E., \& Patz, J. (2000). Climate change and vector-borne diseases: A regional analysis. Bulletin of the World Health Organization, 78(9), 1136-1147. Retrieved from www.who.int/about/licensing/copyright_form/en/

Goldman, A. I. . (1983). Epistemology and the Theory of Problem Solving. Synthese, 55(1), 2148. https://doi.org/doi:10.1007/BF00485372

Goodin, R. E., Rein, M., \& Moran, M. (2008). The public and its policies. In The Oxford handbook of public policy (pp. 3-35). Oxford University Press.

Gosselin, P., Bélanger, D., Lapaige, V., \& Labbé, Y. (2011). The burgeoning field of transdisciplinary adaptation research in Quebec (1998-): A climate change-related public health narrative. Journal of Multidisciplinary Healthcare, 4, 337-348. https://doi.org/10.2147/JMDH.S14294

Gough, W., Anderson, V., \& Herod, K. (2016a). Ontario Climate Change and Health Modelling Study. Ministry of Health and Long-Term Care. Retrieved from http://www.health.gov.on.ca/en/common/ministry/publications/reports/climate_change_tool kit/climate_change_health_modelling_study.pdf

Gould, K. A., \& Lewis, T. L. (2009). Twenty lessons in environmental sociology. Oxford University Press.

Govenment of Ontario. (2018). Newsroom : Ontario Leads Growing Opposition to the Federal Carbon Tax. Retrieved January 17, 2020, from https://news.ontario.ca/opo/en/2018/12/ontario-leads-growing-opposition-to-the-federalcarbon-tax.html

Government of Canada, Health Canada, Health Products and Food Branch, A. D. M. O. (2000). Health Canada Decision-Making Framework for Identifying, Assessing and Managing Health Risks [Health Canada, 2000]. Retrieved from https://www.canada.ca/content/dam/hc-sc/migration/hc-sc/ahc-asc/alt_formats/hpfbdgpsa/pdf/pubs/risk-risques-eng.pdf 
Government of Canada. (2010). Canadian Vehicle Survey 2008 Update Report. Retrieved September 4, 2019, from http://oee.nrcan.gc.ca/publications/statistics/cvs08/chapter2.cfm?attr=0

Government of Canada. (2013). What Makes Canadians Healthy or Unhealthy? - Population Health Approach - Public Health Agency of Canada. Retrieved May 25, 2017, from http://www.phac-aspc.gc.ca/ph-sp/determinants/determinants-eng.php\#status

Government of Canada. (2019a). Changes in precipitation - Canada.ca. Retrieved September 2, 2019, from https://www.canada.ca/en/environment-climate-change/services/climatechange/canadian-centre-climate-services/basics/trends-projections/changesprecipitation.html

Government of Canada. (2019b). Constitution Acts, 1867. Retrieved September 5, 2019, from https://laws-lois.justice.gc.ca/eng/const/

Government of Canada. (2019c). NEB - Provincial and Territorial Energy Profiles - Ontario. Retrieved September 4, 2019, from https://www.cerrec.gc.ca/nrg/ntgrtd/mrkt/nrgsstmprfls/on-eng.html

Government of Canada, H. C. and the P. H. A. of C. (2015). Surveillance of Lyme disease. Retrieved December 21, 2017, from https://www.canada.ca/en/publichealth/services/diseases/lyme-disease/surveillance-lyme-disease.html\#a2

Government of New Zealand. (n.d.). Warm-up New Zealand.

Government of Ontario. (n.d.-a). INFO-GO - Government of Ontario Employee Directory. Retrieved January 21, 2018, from http://www.infogo.gov.on.ca/infogo/home.html

Government of Ontario. (n.d.-b). Newsroom : Report From The Expert Panel On Climate Change Adaptation. Retrieved June 9, 2017, from https://news.ontario.ca/ene/en/2009/12/report-from-the-expert-panel-on-climate-changeadaptation.html

Government of Ontario. (2007a). Newsroom : McGuinty And Schwarzenegger Team Up To Curb Climate Change, Boost Stem Cell Research. Retrieved January 20, 2020, from https://news.ontario.ca/archive/en/2007/05/30/McGuinty-And-Schwarzenegger-Team-UpTo-Curb-Climate-Change-Boost-Stem-Cell-Resea.html

Government of Ontario. (2007b). Ontario Facts - Overview. Retrieved September 4, 2019, from https://web.archive.org/web/20070129072416/http://www.2ontario.com/facts/fact01.asp

Government of Ontario. (2008a). Discussion Paper A Greenhouse Gas Cap-and-Trade System for Ontario. Retrieved from www.premier.gov.on.ca/news/Product.asp?ProductID=2281.

Government of Ontario. (2008b). Newsroom : Memorandum of understanding between the Government of Ontario and the Government of Québec. Retrieved January 20, 2020, from https://news.ontario.ca/opo/en/2008/6/memorandum-of-understanding-between-thegovernment-of-ontario-and-the-government-of-quebec.html

Government of Ontario. (2009a). Newsroom : Greener Technology Helps Create Auto Sector Jobs In Kitchener. Retrieved January 17, 2020, from https://news.ontario.ca/archive/en/2009/01/29/Greener-Technology-Helps-Create-AutoSector-Jobs-In-Kitchener.html

Government of Ontario. (2009b). Newsroom : Lake Simcoe Protection Act. Retrieved January 19, 2020, from https://news.ontario.ca/ene/en/2008/12/lake-simcoe-protection-act.html

Government of Ontario. (2011). Newsroom : Ontario Shutting Down Two More Coal Units. Retrieved January 17, 2020, from https://news.ontario.ca/mndmf/en/2011/12/ontarioshutting-down-two-more-coal-units.html

Government of Ontario. (2013). Make no little plan.pdf.

Government of Ontario. (2014). Newsroom : Taking Steps to Fight Climate Change, Protect Health. Retrieved January 17, 2020, from https://news.ontario.ca/opo/en/2014/07/takingsteps-to-fight-climate-change-protect-health.html 
Government of Ontario. (2015a). Archived - Climate change consultation. Retrieved January 17, 2020, from https://www.ontario.ca/page/climate-change-consultation

Government of Ontario. (2015b). Newsroom : Landmark Climate Statement Signed in Ontario. Retrieved January 17, 2020, from https://news.ontario.ca/opo/en/2015/07/landmarkclimate-statement-signed-in-ontario.html

Government of Ontario. (2015c). Newsroom : Ontario Supports New Global Climate Change Agreement. Retrieved January 17, 2020, from https://news.ontario.ca/opo/en/2015/12/ontario-supports-new-global-climate-changeagreement.html

Government of Ontario. (2015d). Newsroom : Premier Wynne Represents Ontario at COP21. Retrieved January 17, 2020, from https://news.ontario.ca/opo/en/2015/11/premier-wynnerepresents-ontario-at-cop21.html

Government of Ontario. (2015e). Ontario's Climate Change Discussion Paper.

Government of Ontario. (2016a). Newsroom : Helping Homeowners Cut Energy Bills with Retrofits and Renovations. Retrieved January 17, 2020, from https://news.ontario.ca/opo/en/2016/10/helping-homeowners-cut-energy-bills-with-retrofitsand-renovations.html

Government of Ontario. (2016b). Newsroom : Helping Small- and Medium-Sized Businesses With Energy Efficient Upgrades. Retrieved January 17, 2020, from https://news.ontario.ca/medg/en/2016/11/helping-small--and-medium-sized-businesseswith-energy-efficient-upgrades.html

Government of Ontario. (2016c). Newsroom : Ontario Invests in New Electric and Hybrid Vehicle Parts Manufacturing. Retrieved January 17, 2020, from https://news.ontario.ca/medg/en/2016/03/ontario-invests-in-new-electric-and-hybridvehicle-parts-manufacturing.html

Government of Ontario. (2016d). Newsroom : Ontario Leads on Climate Change at COP22. Retrieved January 17, 2020, from https://news.ontario.ca/ene/en/2016/11/ontario-leads-onclimate-change-at-cop22.html

Government of Ontario. (2017). Climate Change Action Plan:2016-2020. Retrieved December 30, 2017, from https://www.ontario.ca/page/climate-change-action-plan\#section-4

Government of Ontario. (2018a). Green Deal: energy saving for your home or business. Retrieved March 8, 2020, from http://archive.is/EgmKX

Government of Ontario. (2018b). Newsroom : Ford Government to Help Expand Access to Natural Gas. Retrieved January 17, 2020, from https://news.ontario.ca/opo/en/2018/09/ford-government-to-help-expand-access-to-naturalgas.html

Government of Ontario. (2018c). Newsroom : Helping Businesses Respond to Climate Change. Retrieved January 17, 2020, from https://news.ontario.ca/opo/en/2018/04/helpingbusinesses-respond-to-climate-change.html

Government of Ontario. (2018d). Newsroom : Ontario, Québec and Oregon Partner to Fight Climate Change. Retrieved January 20, 2020, from https://news.ontario.ca/opo/en/2018/05/ontario-quebec-and-oregon-partner-to-fight-climatechange.html

Government of Ontario. (2018e). Newsroom : Ontario's Government for the People Introduces Legislation to Repeal the Green Energy Act. Retrieved March 8, 2020, from https://news.ontario.ca/mndmf/en/2018/09/ontarios-government-for-the-people-introduceslegislation-to-repeal-the-green-energy-act.html

Government of Ontario. (2018f). Newsroom : Ontario Repeals the Green Energy Act. Retrieved March 8, 2020, from https://news.ontario.ca/mndmf/en/2018/12/ontario-scraps-the-greenenergy-act.html 
Government of Ontario. (2018g). Newsroom : Premier Doug Ford and Premier Scott Moe Agree to Fight Federal Carbon Tax. Retrieved January 17, 2020, from

https://news.ontario.ca/opo/en/2018/07/premier-doug-ford-and-premier-scott-moe-agree-tofight-federal-carbon-tax.html

Government of Ontario. (2018h). Newsroom : Premier Doug Ford and Premier Scott Moe Pledge to Continue the Fight Against the Federal Carbon Tax. Retrieved January 17, 2020, from https://news.ontario.ca/opo/en/2018/10/premier-doug-ford-and-premier-scott-moepledge-to-continue-the-fight-against-the-federal-carbon-tax.html

Government of Ontario. (2018i). Newsroom : Premier Doug Ford and Saskatchewan Premier Scott Moe to Work Together to Fight Carbon Tax and Encourage Interprovincial Trade. Retrieved January 17, 2020, from https://news.ontario.ca/opo/en/2018/10/premier-dougford-and-saskatchewan-premier-scott-moe-to-work-together-to-fight-carbon-tax-andencour.html

Government of Ontario. (2018j). Newsroom : Premier Doug Ford Announces the End of the Cap-and-Trade Carbon Tax Era in Ontario. Retrieved March 8, 2020, from https://news.ontario.ca/opo/en/2018/07/premier-doug-ford-announces-the-end-of-the-capand-trade-carbon-tax-era-in-ontario.html

Government of Ontario. (2018k). Newsroom : Regulations and Statutes Coming Into Force January 1, 2019. Retrieved January 20, 2020, from https://news.ontario.ca/opo/en/2018/12/regulations-and-statutes-coming-into-force-january1-2019.html

Government of Ontario. (2018I). Newsroom : Relief on the Way: Ontario Passes Legislation to End Cap and Trade Carbon Tax. Retrieved January 17, 2020, from https://news.ontario.ca/ene/en/2018/10/relief-on-the-way-ontario-passes-legislation-to-endcap-and-trade-carbon-tax.html

Government of Ontario. (2018m). Ontario Public Health Standards: Requirements for Programs, Services, and Accountability. Retrieved from

http://www.health.gov.on.ca/en/pro/programs/publichealth/oph_standards/docs/protocols_g uidelines/Ontario_Public_Health_Standards_2018_en.pdf

Government of Ontario. (2018n). Ontario to cancel energy contracts to bring hydro bills down. Retrieved March 8, 2020, from https://news.ontario.ca/mndmf/en/2018/07/ontario-tocancel-energy-contracts-to-bring-hydro-bills-down.html

Government of Ontario. (2019). Archived - The End of Coal. https://doi.org/10.1201/9781439818930-c4

Government of Ontario. (2020). Forest fires / Ontario.ca. Retrieved from https://www.ontario.ca/page/forest-fires

Government of United Kingdom. (2020). Promoting walking in primary schools - Case study. Retrieved February 8, 2020, from https://www.gov.uk/government/case-studies/promotingwalking-in-primary-schools

Graham, W. S. . (2015). Assessors Report on Algoma Public Health Unit.

Grant, L. K. (2011). Can we consume our way out of climate change? a call for analysis. Behavior Analyst, 34(2), 245-266. https://doi.org/10.1007/BF03392256

Gray, B. (1989). Collaborating : finding common ground for multiparty problems (First Edit). Jossey-Bass. Retrieved from https://ryerson.summon.serialssolutions.com/search?fvf=ContentType\%2CBook+\%2F+eB ook\&input=Collaborating $\% 3 \mathrm{~A}+$ Finding + Common+Ground+for+Multiparty+Problems\&q=Titl e\%3A\%28Collaborating\%3A+Finding+Common+Ground+for+Multiparty+Problems\%29\&sp ellcheck=true\#!/searc

Greenough, G., McGeehin, M., Bernard, S. M., Trtanj, J., Riad, J., \& Engelberg, D. (2001). The potential impacts of climate variability and change on health impacts of extreme weather 
events in the United States. Environ Health Perspect, 109 Supp/(2), 191-198.

https://doi.org/10.2307/3435009

Haas, P. M. (2014). Ideas, experts and governance. In M. Ambrus, K. Arts, E. Hey, \& H. Raulus (Eds.), The Role of 'Experts" in International and European Decision-Making Processes: Advisors, Decison Makers or Irrelevant Actors' (pp. 19-43). United Kingdom: Cambridge University Press.

Habegger, S. (2014). Lyme Disease in Canada: An Update on the Epidemiology. Retrieved from https://nccid.ca/wp-content/uploads/sites/2/2015/03/PP_43_EN1.pdf

Haidet, K. K., Tate, J., Divirgilio-Thomas, D., Kolanowski, A., \& Happ, M. B. (2009). Methods to improve reliability of video-recorded behavioral data. Research in Nursing and Health, 32(4), 465-474. https://doi.org/10.1002/nur.20334

Haines, A., Kovats, R. S., Campbell-Lendrum, D., \& Corvalan, C. (2006a). Climate change and human health: Impacts, vulnerability and public health. Public Health, 120(7), 585-596. https://doi.org/10.1016/j.puhe.2006.01.002

Hajer, M. A. (1997). The Politics of Environmental Discourse. Oxford University Press. https://doi.org/10.1093/019829333X.001.0001

Hajer, M., \& Versteeg, W. (2005). A decade of discourse analysis of environmental politics. Journal of Environmental Policy and Planning, 7(3), 175-184. https://doi.org/10.1080/15239080500339646

Hall, J. R. (2016). Social futures of global climate change: A structural phenomenology. American Journal of Cultural Sociology, 4(1), 1-45. https://doi.org/10.1057/ajcs.2015.12

Hamburger, P., \& Weller, P. (2012). Policy Advice and a Central Agency: The Department of the Prime Minister and Cabinet. Australian Journal of Political Science, 47(3), 363-376. https://doi.org/10.1080/10361146.2012.704005

Hamlet, A. F., Lee, S.-Y., Mickelson, K. E. B., \& Elsner, M. M. (2010). Effects of projected climate change on energy supply and demand in the Pacific Northwest and Washington State. Climatic Change, 102(1-2), 103-128. https://doi.org/10.1007/s10584-010-9857-y

Hanson-Easey, S., Williams, S., Hansen, A., Fogarty, K., \& Bi, P. (2015). Speaking of climate change: A discursive analysis of lay understandings. Science Communication, 37(2), 217239. https://doi.org/10.1177/1075547014568418

Hardy, C., \& Phillips, N. (1998). Strategies of Engagement: Lessons from the Critical Examination of Collaboration and Conflict in an Interorganizational Domain. Organization Science, 9(2), 217-230. https://doi.org/10.1287/orsc.9.2.217

Hassan, N. A., Hashim, Z., \& Hashim, J. H. (2016). Impact of Climate Change on Air Quality and Public Health in Urban Areas. Asia Pacific Journal of Public Health, 28(2_suppl), 38S48S. https://doi.org/10.1177/1010539515592951

Hattis, D., \& Goble, R. (2003). The Red Book, Risk Assessment, and Policy Analysis: The Road Not Taken. Human and Ecological Risk Assessment: An International Journal, 9(5), 12971306. https://doi.org/doi: 10.1080/10807030390240319

Head, B. W. (2014). Evidence, uncertainty, and wicked problems in climate change decision making in Australia. Environment and Planning C: Government and Policy, 32(4), 663-679. https://doi.org/10.1068/c1240

Health Canada. (2008). Human Health in a Changing Climate: A Canadian Assessment of Vulnerabilities and Adaptive Capacity. Retrieved from http://publications.gc.ca/collections/collection_2008/hc-sc/H128-1-08-528E.pdf

Health Canada. (2011). Communicating the Health Risks of Extreme Heat Events: Toolkit for Public Health and Emergency Management Officials. Ottawa, Ontario. Retrieved from www.healthcanada.gc.ca

Health Canada. (2016). Cyanobacterial Toxins in Drinking Water Cyanobacterial Toxins in Drinking Water Document for Public Consultations. Retrieved from 
https://www.canada.ca/content/dam/canada/health-canada/migration/healthycanadians/health-system-systeme-sante/consultations/cyanobacteria-

cyanobacterie/alt/cyanobacteria-cyanobacterie-eng.pdf

Health Canada and Public Health Agency of Canada. (2010). Evaluation of the Public Health

Agency of Canada's Non-Enteric Zoonotic Infectious Disease Activities List of Acronyms.

Retrieved from https://www.canada.ca/content/dam/canada/health-

canada/migration/healthy-canadians/department-ministere/public-health-sante-

publique/transparency-transparence/corporate-reporting-rapports-gestion/evaluation/2016-

2017/zoonotic-zoonoses/alt/pub-eng.pdf

Heller, R. F., Chongsuvivatwong, V., Hailegeorgios, S., Dada, J., Torun, P., Madhok, R., \& Sandars, J. (2007, December). Capacity-building for public health: Http://peoples-uni.org. Bulletin of the World Health Organization. World Health Organization. https://doi.org/10.2471/BLT.07.044388

Hendriks, C. M. (2009). Deliberative governance in the context of power. Policy and Society, 28(3), 173-184. https://doi.org/10.1016/j.polsoc.2009.08.004

Hess, J. J., Eidson, M., Tlumak, J. E., Raab, K. K., \& Luber, G. (2014). Review An EvidenceBased Public Health Approach to Climate Change Adaptation, 122(11), 1177-1186.

Hess, J. J., McDowell, J. Z., \& Luber, G. (2012). Integrating climate change adaptation into public health practice: Using adaptive management to increase adaptive capacity and build resilience. Environmental Health Perspectives. https://doi.org/10.1289/ehp.1103515

Hillman, A. L. (2010). Expressive behavior in economics and politics. European Journal of Political Economy, 26(4), 403-418. https://doi.org/10.1016/j.ejpoleco.2010.06.004

Historica Canada. (2019). Public Policy. Retrieved February 25, 2019, from https://www.thecanadianencyclopedia.ca/en/article/public-policy

Hogwood, B., \& Gunn, L. (1984). Policy analysis for the real world. Oxford University Press.

Hongoh, V., Berrang-Ford, L., Scott, M. E., \& Lindsay, L. R. (2012). Expanding geographical distribution of the mosquito, Culex pipiens, in Canada under climate change. Applied Geography, 33(1), 53-62. https://doi.org/10.1016/j.apgeog.2011.05.015

Howard, C., Rose, C., \& Rivers, N. (2018). Briefing for Canadian Policymakers. Retrieved from http://www.lancetcountdown.org/media/1418/2018-lancet-countdown-policy-briefcanada.pdf

Howard, P. (2013). "Everywhere you go always take the weather with you": Phenomenology and the pedagogy of climate change education. Phenomenology \& Practice, 7(2), 3. https://doi.org/10.29173/pandpr21165

Howarth, D. R. 1963-. (2000). Discourse. Open Univ. Press.

Howe, P. D., Mildenberger, M., Marlon, J. R., \& Leiserowitz, A. (2015). Geographic variation in opinions on climate change at state and local scales in the USA. Nature Climate Change, 5(6), 596-603. https://doi.org/10.1038/nclimate2583

Howlett, M., \& Migone, A. (2013). Policy advice through the market: The role of external consultants in contemporary policy advisory systems. Policy and Society, 32(3), 241-254. https://doi.org/10.1016/j.polsoc.2013.07.005

Huang, C., Vaneckova, P., Wang, X., Fitzgerald, G., Guo, Y., \& Tong, S. (2011). Constraints and barriers to public health adaptation to climate change: A review of the literature. American Journal of Preventive Medicine. https://doi.org/10.1016/j.amepre.2010.10.025

Hulme, M. (2009). Why We Disagree About Climate Change. Understanding controversy, inaction and opportunity. Cambridge University Press.

Hunt, J., \& Shackley, S. (1999). Hunt \& Shackley (1999).pdf. Minerva, 37, 141-164.

Hurlbert, M., \& Gupta, J. (2016). Adaptive Governance, Uncertainty, and Risk: Policy Framing and Responses to Climate Change, Drought, and Flood. Risk Analysis, 36(2), 339-356. https://doi.org/10.1111/risa.12510 
Hyett, N., Kenny, A., \& Dickson-Swift, V. (2014). Methodology or method a critical review of qualitative case study reports. International Journal of Qualitative Studies on Health and Well-Being, 9(1). https://doi.org/10.3402/qhw.v9.23606

Ingram, H., \& Schneider, A. L. (2008). Policy analysis for democracy. In M. Moran, M. Rein, \& R. E. Goodin (Eds.), The Oxford handbook of public policy (pp. 169-189). Oxford University Press. https://doi.org/10.1093/oxfordhb/9780199548453.003.0008

Institute of Medicine. (2002). The Future of the Public's Health in the 21st Century. Institute of Medicine, (November 2002), 509. https://doi.org/10.17226/10548

Institute of Medicine. (2003). The Future of the Public's Health in the 21st Century. Washington, D.C.: National Academies Press. https://doi.org/10.17226/10548

IPCC. (2007a). Climate Change 2007: The Physical Science Basis. Journal of Chemical Information and ModelingContribution of Working Group I to the Fourth Assessment Report of the Intergovernmental Panel on Climate Change. (K. B. A. Solomon, S., D. Qin, M. Manning, Z. Chen, M. Marquis \& M. T. and H. L. Miller, Eds.). Cambridge University Press, Cambridge, United Kingdom and New York, NY, USA.

https://doi.org/10.1017/CBO9781107415324.004

IPCC. (2007b). Climate Change 2007. Mitigation. Contribution of Working Group III to the Fourth Assessment Report of the Intergovernmental Panel on Climate Change. (B. Metz, O. Davidson, P. Bosch, Dave R, \& Meyer L, Eds.). Cambridge University Press. Retrieved from http://www.ipcc.ch/pdf/assessment-report/ar4/wg3/ar4_wg3_full_report.pdf

IPCC. (2007c). Climate Change 2007. Synthesis Report. Intergovernmental Panel on Climate Change [Core Writing Team IPCC. Retrieved from https://www.ipcc.ch/pdf/assessmentreport/ar4/syr/ar4_syr_full_report.pdf

IPCC. (2013a). CLIMATTE CHAN̄GE 2013: The Physical Science Basis. Retrieved from https://www.ipcc.ch/pdf/assessment-report/ar5/wg1/WGIAR5_SPM_brochure_en.pdf

IPCC. (2013b). Summary for Policymakers. Climate Change 2013: The Physical Science Basis. Contribution of Working Group I to the Fifth Assessment Report of the Intergovernmental Panel on Climate Change, 33. https://doi.org/10.1017/CBO9781107415324

IPCC. (2014a). Climate Change 2014: Impacts, Adaptation, and Vulnerability. Summaries, Frequently Asked Questions, and Cross-Chapter Boxes. Climate Change 2014: Impacts, Adaptation, and vulnerability. Contribution of Working Group II to the Fifth Assessment Report of the Intergovernmental Panel on Climate Change. https://doi.org/10.1016/j.renene.2009.11.012

IPCC. (2014b). Climate Change 2014: Mitigation of Climate Change. Working Group III Contribution to the Fifth Assessment Report of the Intergovernmental Panel on Climate Change. https://doi.org/10.1017/CBO9781107415416

IPCC. (2014c). Climate Change 2014 Synthesis Report. Contribution of Working Groups I, II and III to the Fifth Assessment Report of the Intergovernmental Panel on Climate Change. (Core Writing Team, R. K. Pachauri, \& L. A. Meyer, Eds.), Kristin Seyboth (USA). Geneva, Switzerland: Gian-Kasper Plattner. Retrieved from https://archive.ipcc.ch/pdf/assessmentreport/ar5/syr/SYR_AR5_FINAL_full_wcover.pdf

IPCC. (2014d). Climate Change $201 \overline{4}$ Sysnthesis Report: Summary for Policymakers. Retrieved from https://www.ipcc.ch/site/assets/uploads/2018/02/AR5_SYR_FINAL_SPM.pdf

Jackson, R., \& Jackson, D. (2006). Politics in Canada: Culture, Institutions, Behaviour and Public Policy (6th Editio). Toronto: Pearson Education Canada Inc.

Jacques, P. J., Dunlap, R. E., \& Freeman, M. (2008). The organisation of denial: Conservative think tanks and environmental scepticism. Environmental Politics, 17(3), 349-385. https://doi.org/10.1080/09644010802055576

Jamieson, D. (2012). The Nature of the Problem. In The Oxford Handbook of Climate Change and Society. Oxford University Press. 
https://doi.org/10.1093/oxfordhb/9780199566600.003.0003

Jang, S. M., \& Hart, P. S. (2015). Polarized frames on "climate change" and "global warming" across countries and states: Evidence from Twitter big data. Global Environmental Change, 32, 11-17. https://doi.org/10.1016/j.gloenvcha.2015.02.010

Janks, H. (1997). Critical Discourse Analysis as a Research Tool. Discourse: Studies in the Cultural Politics of Education, 18(3), 329-342. https://doi.org/10.1080/0159630970180302

Jann, W., \& Weigrich, K. (2007). Theories of the Policy Cycle.

Jardine, C. G., Banfield, L., Driedger, S. M., \& Furgal, C. M. (2013). Risk communication and trust in decision-maker action: A case study of the Giant Mine Remediation Plan. International Journal of Circumpolar Health, 72(SUPPL.1), 21184. https://doi.org/10.3402/ijch.v72i0.21184

John, P. (2006). Explaining policy change: The impact of the media, public opinion and political violence on urban budgets in England. Journal of European Public Policy, 13(7), 10531068. https://doi.org/10.1080/13501760600924118

John, P. (2012). Analyzing Public Policy.

Johnson, B., \& Sandman, P. (1992). Outrage and Technical Detail : The Impact of Agency Behavior on Community Risk Perception. Retrieved from http://docplayer.net/36883381Outrage-and-technical-detail-the-impact-of-agency-behavior-on-community-riskperception.html

Johnson, S. A. (2009). Healthy Public Policy: Public health advocacy. Edmonton, Alberta. Retrieved from https://phabc.org/wp-content/uploads/2015/07/Public-Health-Advocacy.pdf

Kaim, B. (2013). who are we to care? exploring the relationship between participation, knowledge and powere in health system. Retrieved from www.copasah.net.

Kaiser, K. (2009). Protecting respondent confidentiality in qualitative research. Qualitative Health Research, 19(11), 1632-1641. https://doi.org/10.1177/1049732309350879

Karlberg, M. (2012). Discourse Theory and Peace. The Encyclopedia of Peace Psychology, 15.

Keeney, R. L., \& McDaniels, T. L. (2001). A framework to guide thinking and analysis regarding climate change policies. Risk Analysis. https://doi.org/10.1111/0272-4332.216168

Kelly, J., Makar, P. A., \& Plummer, D. A. (2012). Projections of mid-century summer air-quality for North America: Effects of changes in climate and precursor emissions. Atmospheric Chemistry and Physics, 12(12), 5367-5390. https://doi.org/10.5194/acp-12-5367-2012

Kemm, J. (2001). Health Impact Assessment: a tool for Healthy Public Policy. HEALTH PROMOTION INTERNATIONAL (Vol. 16). Retrieved from https://watermark.silverchair.com/160079.pdf?token=AQECAHi208BE49Ooan9kkhW_Ercy 7Dm3ZL_9Cf3qfKAc485ysgAAAklwggl-

BgkqhkiG9w0BBwaggglvMIICKwIBADCCAiQGCSqGSIb3DQEHATAeBglghkgBZQMEAS4 wEQQMI7F6BcUHpeOY-

IfkAgEQgIIB9Xo2XtL1uyBJEEn4iFobwwTYjujYUIYI0yJQ0D1TJrD-ka6G

Kippin, M., \& Engwall, L. (2003). Management consulting: Emergence and dynamics of a knowledge industry. USA: Oxford University Press.

Kitto, S., Chesters, J., \& Grbich, C. (2008). Quality in Qualitative Studies. Medical Journal of Australia, 188(4), 243-246. Retrieved from http://onlineqda.hud.ac.uk/intro QDA/qualitative analysis.php

Koliba, C., \& Gajda, R. (2009). "Communities of practice" as an analytical construct: Implications for theory and practice. International Journal of Public Administration, 32(2), 97-135. https://doi.org/10.1080/01900690802385192

Kolkman, M. J., Veen, A. van der, \& Geurts, P. A. T. M. (2007). Controversies in water management: Frames and mental models. Environmental Impact Assessment Review, 27(7), 685-706. https://doi.org/10.1016/j.eiar.2007.05.005 
Koteyko, N., Thelwall, M., \& Nerlich, B. (2010). From carbon markets to carbon morality: Creative compounds as framing devices in online discourses on climate change mitigation. Science Communication, 32(1), 25-54. https://doi.org/10.1177/1075547009340421

Kottner, J., \& Dassen, T. (2008). Interpreting interrater reliability coefficients of the Braden scale: A discussion paper. International Journal of Nursing Studies. https://doi.org/10.1016/j.ijnurstu.2007.08.001

Kreuter, M. W., De Rosa, C., Howze, E. H., \& Baldwin, G. T. (2004). Understanding Wicked Problems: A Key to Advancing Environmental Health Promotion. Health Education \& Behavior, 31(4), 441-454. https://doi.org/10.1177/1090198104265597

Kulaç, O., \& Özgür, H. (2017). An Overview of the Stages (Heuristics) Model as a Public Policy Analysis Framework. European Scientific Journal, 1857-7881. Retrieved from https://eujournal.org/index.php/esj/article/viewFile/9250/8789

Labov, W., \& Waletzky, J. (1967). Narrative Analysis. In D. Tannen (Ed.), Essays on the verbal and visual arts (pp. 22-44). University of Washington Press.

Lachapelle, E., Borick, C. P., \& Rabe, B. (2012). Public Attitudes toward Climate Science and Climate Policy in Federal Systems: Canada and the United States Compared. Review of Policy Research, 29(3), 334-357. https://doi.org/10.1111/j.1541-1338.2012.00563.x

Lakoff, G. (2010). Why it Matters How We Frame the Environment. Environmental Communication, 4(1), 70-81. https://doi.org/10.1080/17524030903529749

Laschinger, S., \& Healther, K. (1992). Interclass Correlation as Estimates of Interater Reliability in Nursing Research. Western Journal of Nursing Research, 14(2), 246-251. https://doi.org/doi:10.1177/019394599201400213

Lawrence, T. B. (2008). Power, Institutions and Organizations. In Handbook of Organizational Institutionalism (pp. 170-197). Sage Publications.

Legislative Assembly of Ontario. Bill 4, Cap and Trade Cancellation Act (2018). Retrieved from https://www.ola.org/en/legislative-business/bills/parliament-42/session-1/bill-4

Legislative Assembly of Ontario. (2019). About us. Retrieved September 6, 2019, from https://www.ola.org/en/offices-divisions-branches/about-us

Lesnikowski, A. C., Ford, J. D., Berrang-Ford, L., Paterson, J. A., Barrera, M., \& Heymann, S. J. (2011). Adapting to health impacts of climate change: A study of UNFCCC Annex i parties. Environmental Research Letters, 6(4). https://doi.org/10.1088/1748-9326/6/4/044009

Levitus, S., Antonov, J. I., Boyer, T. P., Baranova, O. K., Garcia, H. E., Locarnini, R. A., ... Zweng, M. M. (2012). World ocean heat content and thermosteric sea level change (02000m), 1955-2010. Geophysical Research Letters, 39(10), 1-5. https://doi.org/10.1029/2012GL051106

Liu, J., Folberth, C., Yang, H., Röckström, J., Abbaspour, K., \& Zehnder, A. J. B. (2013). A Global and Spatially Explicit Assessment of Climate Change Impacts on Crop Production and Consumptive Water Use. PLoS ONE, 8(2). https://doi.org/10.1371/journal.pone.0057750

Lockwood, M. (2015). Stern review 2.0? The report of the global commission on the economy and climate. Political Quarterly, 86(1), 146-151. https://doi.org/10.1111/1467-923X.12136

Lohmann, L. (2016). Neoliberalism's Climate. In S. Springer, K. Birch, \& J. MacLeavy (Eds.), The Handbook of Neoliberalism (pp. 480-492). London, UK: Routledge.

Lomas, J. (1997). Improving research dissemination and uptake in the health sector: beyond the sound of one hand clapping. McMaster University Centre for Health Economics and Policy Analysis Policy Commenattry, C 97-1.

Lomas, J. (2000). Connecting research and policy. Isuma Canadian Journal of Policy Research, 1(1), 140-144. https://doi.org/10.1177/1473095213499216

Lomas, J., Culyer, T., McCutcheon, C., McAuley, L., \& Law, S. (2005). Conceptualizing and Combining Evidence for Health System Guidance. Health (San Francisco). Retrieved from 
http://www.cfhi-fcass.ca/Migrated/PDF/insightAction/evidence_e.pdf

Lomas, J., Fulop, N., Gagnon, D., \& Allen, P. (2003). On being a good listener: Setting priorities for applied health services research. Milbank Quarterly, 81(3), 363-388.

https://doi.org/10.1111/1468-0009.t01-1-00060

Loren, C. R. (2006). The Failure of American and European Climate Policy. State University of New York Press.

Lorenzoni, I., Pidgeon, N. F., \& O'Connor, R. E. (2005). Dangerous climate change: The role for risk research. Risk Analysis. https://doi.org/10.1111/j.1539-6924.2005.00686.x

Luís, S., Lima, M. L., Roseta-Palma, C., Rodrigues, N., P. Sousa, L., Freitas, F., ... Poulos, S. (2018). Psychosocial drivers for change: Understanding and promoting stakeholder engagement in local adaptation to climate change in three European Mediterranean case studies. Journal of Environmental Management, 223, 165-174. https://doi.org/10.1016/j.jenvman.2018.06.020

Lundgren, R., \& McMakin, A. (2013). Risk communication: a handbook for communicating environmental, safety, and health risks.

Lynch, P., \& Duke, S. (2004). Climate Change. Change, 1(BSc 1987), 1987-1987. https://doi.org/10.1080/03071847.2013.807583

Lyons, J. (2017). The Independence of Ontario 's Public Health Units : Does Governing Structure Matter? Autonomie des bureaux de santé publique en Ontario : la structure de gouvernance a-t-elle une importance? Healthcare Policy, 12(1), 71-84.

https://doi.org/doi:10.12927/hcpol.2016.24777

Maeseele, P., \& Pepermans, Y. (2017). Ideology in Climate Change Communication. Oxford Research Encyclopedia of Climate Science, 1(September), 1-19. https://doi.org/10.1093/acrefore/9780190228620.013.578

Maibach, E., Nisbet, M., Baldwin, P., Akerlof, K., \& Diao, G. (2010). Reframing climate change as a public health issue: an exploratory study of public reactions. BMC Public Health, 10(1), 299. https://doi.org/10.1186/1471-2458-10-299

Maibach, E., Nisbet, M., \& Weathers, M. (2011). Conveying the Human Implications of Climate Change: : A Climate Change Communication Primer for Public Health Professionals. Climatechangecommunication.Org, 52. Retrieved from https://publichealth.yale.edu/alumni/benefits/events/4C Communication Primer - Conveying the Human Implications of Climate Change_86971_1095_31769_v1.pdf

Maibach, E., \& Parrott, R. (1995). Designing health messages: approaches from communication theory and public health practice. Sage Publications.

Markandya, A. (2011). Equity and Distributional Implications of Climate Change. World Development, 39(6), 1051-1060. https://doi.org/10.1016/j.worlddev.2010.01.005

Marmot, M. G., \& Wilkinson, R. G. (2006). Social Determinants of the Health. (Second Edi). Oxford University Press. https://doi.org/DOI:10.1093/acprof:oso/9780198565895.001.0001

Masters, G. ., \& Ela, W. . (2008). Introduction to Environmental Engineering and Science (3rd Editio). Prentice-Hall.

Mattessich, P. W., \& Monsey, B. R. (1992). What Makes It Work A Review of Research Literature on Factors Influencing Successful Collaboration \&quot; $r$ U S DEPARTMENT OF EDUCATION Once or Educahonai Research and Imptovernent EDUCATIONAL RESOURCES INFORMATION. https://doi.org/10.1073/pnas.0707369105

Mattessich, P. W., Murray-Close, M., \& Monsey, B. R. (2001). Collaboration--what makes it work. Amherst $\mathrm{H}$. Wilder Foundation.

Matthes, J. (2011). Frames in Political Communication: Towards Clarification of a Research Program. In S. Allan (Ed.), Rethinking Communication: Keywords in Communication Research (pp. 123-136). New York: Hampton Press.

Mazzanti, M. (2018). Eco-innovation and sustainability: dynamic trends, geography and policies. 
Journal of Environmental Planning and Management, 61(11), 1851-1860.

https://doi.org/10.1080/09640568.2018.1486290

McDermid, J., Fera, S., \& Hogg, A. (2015). Climate change projections for Ontario: An updated synthesis for policymakers and planners. Climate Change Research Report 44. Retrieved from http://www.climateontario.ca/MNR_Publications/CCRR-44.pdf

McFarland, V., \& Huffman, S. (2017). Analysis of data from the Rapid Risk Factor Surveillance System. Retrieved from https://www.publichealthgreybruce.on.ca/Portals/1/Documents/Our Environment/Climate Change Awareness in Grey Bruce.pdf

McGinnis, M. D. (2011). An Introduction to IAD and the Language of the Ostrom Workshop: A Simple Guide to a Complex Framework. Policy Studies Journal, 39(1), 169-183. https://doi.org/10.1111/j.1541-0072.2010.00401.x

McKee, A. (2005). Textual Analysis: A Beginner's Guide. In Textual Analysis (pp. 2-33). Sage Publications Ltd.

McKenzie, J. I. (2001). The governmental role in environmental policy. In Environmental Politics in Canada: managing the commons into the twenty first century (pp. 105-127). Oxford University Press.

MECP. (n.d.). What is the Air Quality Health Index? Retrieved April 7, 2020, from http://www.airqualityontario.com/science/aqhi_description.php

MECP. (2019a). Newsroom : Ontario Takes The Federal Carbon Tax to Court. Retrieved March 8, 2020, from https://news.ontario.ca/ene/en/2019/04/ontario-takes-the-federal-carbon-taxto-court.html

MECP. (2019b). Newsroom : Statement from Minister Yurek on Appealing the Federal Carbon Tax Decision to the Supreme Court of Canada. Retrieved March 8, 2020, from https://news.ontario.ca/ene/en/2019/08/statement-from-minister-yurek-on-appealing-thefederal-carbon-tax-decision-to-the-supreme-court-of-c.html

MECP. (2019c). Ontario Introduces Legislation to End Cap and Trade Carbon Tax Era in Ontario. Retrieved March 8, 2020, from https://news.ontario.ca/ene/en/2018/07/ontariointroduces-legislation-to-end-cap-and-trade-carbon-tax-era-in-ontario.html

Merlo, O., Lukas, B. A., \& Whitwell, G. J. (2008). Heuristics revisited: Implications for marketing research and practice. Marketing Theory, 8(2), 189-204. https://doi.org/10.1177/1470593108089204

Michaelowa, A. (1998). Climate policy and interest Groups-A Public choice analysis. Intereconomics, 33(6), 251-259. https://doi.org/10.1007/BF02929886

Mikkonen, J., \& Raphael, D. (2010). Social Determinants of Health: The Canadian Facts Juha Mikkonen. Retrieved from http://www.thecanadianfacts.org/

Miljan, L. A. (Lydia A., \& Brooks, S. (2018). Public policy in Canada : an introduction (Seventh Ed). Don Mills, Ontario: Oxford University Press.

Miller, A. (2016). Stanford encyclopedia of philosophy: Realism. (N. Zalta, Edward, Ed.). Stanford University. Center for the Study of Language and Information. Retrieved from https://plato.stanford.edu/entries/realism/

Miller, D. (1973). George Herbert Mead: Symbolic Interaction and Social Change. Psychological Record, 23, 294-304.

Miller, W., \& Pellen, R. M. (2006). Libraries beyond their Institutions; Partnerships that Work. The Haworth Press. Retrieved from https://books.google.ca/books?id=AMm3AwAAQBAJ\&pg=PA37\&lpg=PA37\&dq=\%22chara cterized+by+informal+relationships+that+exist+without+any+commonly+defined+mission,+ structure,+or+planning+effort.+Information+is+shared+as+needed,+and+authority+is+retai ned+by+each

Mills, J. A., Durepos, G., \& Wiebe, E. (2010). Symbolic Interactionism. In Encyclopedia of Case Study Research. 2455 Teller Road, Thousand Oaks California 91320 United States: SAGE 
Publications, Inc. https://doi.org/10.4135/9781412957397.n336

Mimura, N. (2013). Sea-level rise caused by climate change and its implications for society. Proceedings of the Japan Academy Series B: Physical and Biological Sciences, 89(7), 281-301. https://doi.org/10.2183/pjab.89.281

Ministry of Economic Development. (2011). Impacts of the NZ Insulation Fund on Industry \& Employment, (October). Retrieved from http://www.healthyhousing.org.nz/wpcontent/uploads/2012/03/NZIF_Producers_report-Final.pdf

Ministry of Health and Long-term Care. (2016). The Ontario Climate Change and Health Toolkit. Retrieved from http://www.health.gov.on.ca/en/common/ministry/publications/reports/climate_change_tool kit/climate change toolkit.aspx

Ministry of Health and Long-term Care. (2018). Ontario Public Health Standards: Requirements for Programs, Services, and Accountability. Retrieved from https://www.simcoemuskokahealth.org/docs/default-source/huaboutus/standards_2018.pdf?sfvrsn=0

Ministry of Health and Long-Term Care. (2012). Public Health Funding. In Presentation to the alPHa Board of Health Section (p. 14). Retrieved from https://www.healthunit.com/uploads/129-12-appendix-a.pdf

Ministry of Health and Long-Term Care. (2013). Public Health Funding Model for Mandatory Programs, (December), 1-65.

Ministry of Health and Long-Term Care. (2014). Health Services in Your Community. Retrieved January 27, 2018, from http://www.health.gov.on.ca/en/common/system/services/phu/

Ministry of Health and Long-Term Care. (2008). Identification, Investigation and Management of Health Hazards Protocol, 2008, 1-4. Retrieved from

http://www.health.gov.on.ca/en/pro/programs/publichealth/oph_standards/docs/identificatio n_health_hazards.pdf

Ministry of Health and Long-Term Care. (2010). The Health Hazard Prevention and Management Standard. Retrieved from http://www.health.gov.on.ca/en/pro/programs/publichealth/oph_standards/healthhazard.asp $\mathrm{x}$

Ministry of Health and Long Term Care. (2018). Healthy Environments and Climate Change Guideline, 2018. Retrieved from

http://www.health.gov.on.ca/en/pro/programs/publichealth/oph_standards/docs/protocols_g uidelines/Healthy_Environments_and_Climate_Change_Guideline_2018_en.pdf

Ministry of Transport. (2018). Electric vehicles incentive program. Retrieved March 8, 2020, from http://archive.is/HPceM

Minns, C. K. (2009). The potential future impact of climate warming and other human activities on the productive capacity of Canada's lake fisheries: A meta-model. Aquatic Ecosystem Health and Management, 12(2), 152-167. https://doi.org/10.1080/14634980902905775

Moher, D., Liberati, A., Tetzlaff, J., Altman, D. G., \& Group, T. P. (2009). Preferred Reporting Items for Systematic Reviews and Meta-Analyses: The PRISMA Statement (Reprinted from Annals of Internal Medicine). Physical Therapy, 89(9), 873-880. https://doi.org/10.1371/journal.pmed.1000097

Moloughney, B. (2007b). A Discussion Paper on Public Health, Local Health Integration Networks, and Regional Health Authorities. Retrieved from https://opha.on.ca/getmedia/d7eb60bb-063c-421e-b107-f89067966ad0/OPHADiscussionPaper-PH-LHINs-Oct07.pdf.aspx?ext=.pdf

Moloughney, B. (2012). The Use of Policy Frameworks to Understand Public Health-Related Public Policy Processes: A Literature Review Final Report. Peel Public Health. Retrieved from https://www.peelregion.ca/health/library/pdf/Policy_Frameworks.PDF 
Moloughney, B. (2016). The Impacts on the Public Health Function with Integration with Regionalized Healthcare Systems. Retrieved from http://www.toronto.ca/legdocs/mmis/2016/hl/bgrd/backgroundfile-88527.pdf

Moon, K., \& Blackman, D. (2014). A Guide to Understanding Social Science Research for Natural Scientists. Conservation Biology. https://doi.org/10.1111/cobi.12326

Moss, R., Scarlett, P. L., Kenney, M. A., Kunreuther, H. C., Lempert, R., Manning, J., ... Patton, L. (2014). Ch. 26: Decision Support. In J. M. Melillo, T. Raymond, \& G. W. Yohe (Eds.), Climate Change Impacts in the United States: The Third National Climate Assessment (pp. 620-647). U.S. Global Change Research Program. https://doi.org/10.7930/J0H12ZXG.On

Mu, R. (2018). Coupling of problems, political attention, policies and institutional conditions: Explaining the performance of environmental targets in the national five-year plans in China. Sustainability (Switzerland), 10(5). https://doi.org/10.3390/su10051477

Murphy, M. (2012). Interests, institutions and ideas: Explaining irish social security policy. Policy and Politics, 40(3), 347-365. https://doi.org/10.1332/030557312X626640

Myers, T. A., Nisbet, M. C., Maibach, E. W., \& Leiserowitz, A. A. (2012). A public health frame arouses hopeful emotions about climate change: A Letter. Climatic Change, 113(3-4), 1105-1112. https://doi.org/10.1007/s10584-012-0513-6

NASA. (2017). How does climate change affect precipitation? | Precipitation Measurement Missions. Retrieved September 2, 2019, from https://pmm.nasa.gov/resources/faq/howdoes-climate-change-affect-precipitation

NASA. (2019). Graphic: The relentless rise of carbon dioxide - Climate Change: Vital Signs of the Planet. National Oceanic and Atmospheric Administration. Some Description Adapted from the Scripps CO2 Program Website, "Keeling Curve Lessons." Retrieved from https://climate.nasa.gov/climate_resources/24/graphic-the-relentless-rise-of-carbondioxide/

NASA, \& NOAA. (2019). Carbon Dioxide | Vital Signs - Climate Change: Vital Signs of the Planet. Retrieved September 2, 2019, from https://climate.nasa.gov/vital-signs/carbondioxide/

National Collaboration Centre for Healthy Public Policies, \& National Institute of Public Health of Quebec. (2013). Public Policy Models and Their Usefulness in Public Health: The Stages Model, (October), 1-11. Retrieved from http://www.ncchpp.ca/docs/ModeleEtapesPolPubliques_EN.pdf

National Research Council. (2009). Informing decisions in a changing climate. Washington, D.C.: National Academies Press. https://doi.org/10.5860/choice.47-4101

National Research Council. (2010). Advancing the Science of Climate Change. Advancing science of climate change. https://doi.org/https://doi.org/10.17226/12782

Natural Resources Canada. (2015a). Climate and Climate-related Trends and Projections. Retrieved October 24, 2017, from http://www.nrcan.gc.ca/environment/resources/publications/impactsadaptation/reports/assessments/2008/10261

Natural Resources Canada. (2015b). Overview of Climate Change in Canada | Natural Resources Canada. Retrieved October 24, 2017, from http://www.nrcan.gc.ca/environment/resources/publications/impactsadaptation/reports/assessments/2008/ch2/10321

Neale, J. (2016). Iterative categorization (IC): A systematic technique for analysing qualitative data. Addiction, 111(6), 1096-1106. https://doi.org/10.1111/add.13314

Nerlich, B., Koteyko, N., \& Brown, B. (2010, January). Theory and language of climate change communication. Wiley Interdisciplinary Reviews: Climate Change. https://doi.org/10.1002/wcc.2

Neville, K. J., \& Weinthal, E. (2016). Mitigating Mistrust? Participation and Expertise in Hydraulic 
Fracturing Governance. Review of Policy Research, 33(6), 578-602. https://doi.org/10.1111/ropr.12201

Newington, L., \& Metcalfe, A. (2014). Factors influencing recruitment to research: Qualitative study of the experiences and perceptions of research teams. BMC Medical Research Methodology, 14(1). https://doi.org/10.1186/1471-2288-14-10

Nilsson, M., Evengård, B., Sauerborn, R., \& Byass, P. (2012). Connecting the global climate change and public health agendas. PLoS Medicine, 9(6), 5. https://doi.org/10.1371/journal.pmed.1001227

Nisbet, M. (2009). Communicating climate change: Why frames matter for public engagement. Environment, 51(2), 12-25. https://doi.org/10.3200/ENVT.51.2.12-23

Nisbet, M. C. (2012). Public Opinion and Participation. In The Oxford Handbook of Climate Change and Society. Oxford University Press. https://doi.org/10.1093/oxfordhb/9780199566600.003.0024

NOAA. (2014). ESRL Global Monitoring Division - Global Greenhouse Gas Reference Network. Journal of Geophysical Research. https://doi.org/10.1029/95JD03410.

Nuccitelli, D., Way, R., Painting, R., Church, J., \& Cook, J. (2012). Comment on Ocean heat content and Earth's radiation imbalance. II. Relation to climate shifts. Physics Letters, Section A: General, Atomic and Solid State Physics, 376(45), 3466-3468. https://doi.org/10.1016/j.physleta.2012.10.010

O'Grady, L. (2012). What is knowledge and when should it be implemented? Journal of Evaluation in Clinical Practice, 18(5), 951-953. https://doi.org/10.1111/j.13652753.2012.01899.x

O'Toole, T. P., Aaron, K. F., Chin, M. H., Horowitz, C., \& Tyson, F. (2003). Community-based Participatory Research. Journal of General Internal Medicine, 18(7), 592-594. https://doi.org/10.1046/j.1525-1497.2003.30416.x

O'Campo, P., Wheaton, B., Nisenbaum, R., Glazier, R. H., Dunn, J. R., \& Chambers, C. (2015). The Neighbourhood Effects on Health and Well-being (NEHW) study. Health \& Place, 31, 65-74. https://doi.org/10.1016/j.healthplace.2014.11.001

Odparlik, L. F., \& Köppel, J. (2013). Access to information and the role of environmental assessment registries for public participation. Impact Assessment and Project Appraisal, 31(4), 324-331. https://doi.org/10.1080/14615517.2013.841028

OECD. (2015). OECD Territorial Reviews: Valle de México, Mexico. https://doi.org/10.1787/9789264245174-en

Office for State Tribal Local and Territorial Support. (2014, January 15). The 10 Essential Public Health Services: An Overview. Centers for Disease Control and Prevention. World Health Organization. Retrieved from http://www.euro.who.int/en/health-topics/Healthsystems/public-health-services/policy/the-10-essential-public-health-operations

Office of the Auditor General of Ontario. (2019). Annual Report 2019: Report on the Environment. Retrieved March 8, 2020, from http://www.auditor.on.ca/en/content/annualreports/arbyyear/ar2009.html

Ogden, N. (2016). Vector-borne disease, climate change and urban design. Canada Communicable Disease Report, 42(10), 202. Retrieved from https://www.canada.ca/content/dam/phac-aspc/migration/phac-aspc/publicat/ccdrrmtc/16vol42/dr-rm42-10/assets/pdf/16vol42_10-ar-04-eng.pdf

Ogden, N. H., St-Onge, L., Barker, I. K., Brazeau, S., Bigras-Poulin, M., Charron, D. F., ... Thompson, Ra. (2008). Risk maps for range expansion of the Lyme disease vector, Ixodes scapularis, in Canada now and with climate change. International Journal of Health Geographics, 7(1), 24. https://doi.org/10.1186/1476-072X-7-24

Olsson, E. K., \& Paglia, E. (2008). Global problem: National accountability: Framing accountability in the Australian context of climate change. Journal of Contingencies and 
Crisis Management, 16(2), 70-79. https://doi.org/10.1111/j.1468-5973.2008.00535.x

Ontaio College of Family Physicians. (n.d.). HEALTH EFFECTS OF CLIMATE CHANGE: AN

INFORMATION BROCHURE FOR FAMILY PHYSICIANS FROM THE ONTARIO

COLLEGE OF FAMILY PHYSICIANS. CLIMATE CHANGE, 1. Retrieved from

www.ocfp.on.ca

Ontario Centre for climate Change Impacts and Adaptation Resources. (2015). Overview of

Climate Change Risks to Human Health in Ontario. Retrieved from

http://www.climateontario.ca/doc/RACII/National_Assessment_Syntheses/SummarySheets

/Chapter7-Human_Health.pdf

Ontario Centre for Climate Impacts and Adaptation Resources. (n.d.). OVERVIEW OF

CLIMATE CHANGE IMPACTS ON, 70-80. Retrieved from

http://www.climateontario.ca/doc/RACII/National_Assessment_Syntheses/SummarySheets

/Chapter5-Industry.pdf

Ontario Medical Association. (2005). The Illness Costs of Air Pollution: 2005-2026 Health and

Economic Damage Estimates, 11. Retrieved from http://www.incineratorfree.com/wpcontent/uploads/2010/01/cost-of-Air-pollution.pdf

Ontario Ministry of Agriculture and Rural Affairs. (2017). Developing Ontario 's Agricultural Soil Health and Conservation Strategy, (January).

Ontario Ministry of Environment Conservation and Parks. (2011). Climate Ready: Adaptation Strategy and Action Plan 2011-2014 | Ontario.ca. Retrieved December 16, 2017, from https://www.ontario.ca/document/climate-ready-adaptation-strategy-and-action-plan-20112014-0

Ontario Ministry of Environment Conservation and Parks. (2012). Climate Ready: Ontario's Adaptation Strategy and Action Plan. Retrieved from https://www.nvca.on.ca/Shared Documents/Ont.AdaptationStrategicAction Plan.pdf

Ontario Ministry of Environment Conservation and Parks. (2014a). Ontario's climate Change Update 2014. Retrieved from https://dr6j45jk9xcmk.cloudfront.net/documents/3618/climatechange-report-2014.pdf

Ontario Ministry of Environment Conservation and Parks. (2014b). Ontario's Climate Change Update 2014. Retrieved from https://dr6j45jk9xcmk.cloudfront.net/documents/3618/climatechange-report-2014.pdf

Ontario Ministry of Environment Conservation and Parks. (2015). Ontario's Climate Change Discussion Paper 2015, 38. Retrieved from http://www.downloads.ene.gov.on.ca/envision/env_reg/er/documents/2015/012-3452.pdf

Ontario Ministry of Environment Conservation and Parks. (2016). 2016 Annual Report of the Office of the Auditor General of Ontario. Retrieved from http://www.auditor.on.ca/en/content/annualreports/arreports/en16/v1_302en16.pdf

Ontario Ministry of Environment Conservation and Parks. (2018). Preserving and Protecting our Environment for Future Generations: A Made-in-Ontario Environment Plan. Retrieved from https://prod-environmental-registry.s3.amazonaws.com/2018-11/EnvironmentPlan.pdf

Ontario Ministry of Finance. (2010). 2006 CENSUS HIGHLIGHTS: Factsheet 2. Retrieved September 5, 2019, from

https://www.fin.gov.on.ca/en/economy/demographics/census/cenhi06-2.html

Ontario Ministry of Health and Long-term Care. (2016). A Harmonized Heat Warning and Information System for Ontario. Retrieved April 7, 2020, from http://www.health.gov.on.ca/en/common/ministry/publications/reports/heat_warning_inform ation_system/heat_warning_information_system.aspx

Ontario Ministry of Health and Long-term Care. (2017a). Health Vulnerability Assessment: MOHLTC Guidance and Resources. Retrieved from https://cleanairpartnership.org/cac/wpcontent/uploads/2017/11/Noor_CAP-Presentation-20171106.pdf 
Ontario Ministry of Health and Long-term Care. (2017b). Health Vulnerability Assessment: MOHLTC Guidance and Resources.

Ontario Public Health Association. (2005). Enhancing our Capacity: A consultative report from the OPHA and its constituent societies to the Capacity Review Committee. Retrieved from http://www.opha.on.ca/getmedia/f2d20044-763b-41fe-b5df-349c5f581d45/OPHACRCinput-Report.pdf.aspx?ext=.pdf

Ontario Public Health Capacity Review Committee. (2006a). Revitalizing Ontario's Public Health Capacity: The Final Report of the Review Committee. Retrieved from http://neltoolkit.rnao.ca/sites/default/files/1._Capacity_Review_Committee_Full_Report_20 06 (1).pdf

Ontario Public Health Capacity Review Committee. (2006b). SUMMARY OF THE INTERIM REPORT OF THE CAPACITY REVIEW COMMITTEE REVITALIZING ONTARIO'S PUBLIC HEALTH CAPACITY: A DISCUSSION ON ISSUES AND OPTIONS. Retrieved from https://www.grandsudbury.ca/content/div_councilagendas/documents/Report_REVITALIZI NG_ONTARIO_April_19_06_.pdf

OPHA. (2017). CIPHI Ontario Partners - Canadian Institute Of Public Health Inspectors. Retrieved January 21, 2018, from http://www.ciphi.on.ca/partners

Orihel, D. M., Bird, D. F., Brylinsky, M., Chen, H., Donald, D. B., Huang, D. Y., ... Smith, R. E. $H$. (2012). High microcystin concentrations occur only at low nitrogen-to-phosphorus ratios in nutrient-rich Canadian lakes. Canadian Journal of Fisheries and Aquatic Sciences, 69(9), 1457-1462. https://doi.org/10.1139/f2012-088

Ostrom, E. (2010). Intitutional Analysis and Development: Elements of the Framework in Historical Perspective. Historical Developments and Theoretical Approaches in Sociology, II. Retrieved from http://www.eolss.net/sample-chapters/c04/e6-99a-34.pdf

Ostrom, E. (2011). Background on the Institutional Analysis and Development Framework. The Policy Studies Journal, 39(1), 7-27. Retrieved from https://onlinelibrary-wileycom.ezproxy.lib.ryerson.ca/doi/pdf/10.1111/j.1541-0072.2010.00394.x

Oulo (2015). Climate Change Governance: Emerging Legal and Institutional Frameworks for Developing Countries. In L. Filho (Ed.), Handbook of Climate Change Adaptation (pp. 227250). Springer, Berlin, Heidelberg. https://doi.org/https://doi.org/10.1007/978-3-642-386701_9

Paavola, J. (2007). Institutions and environmental governance: A reconceptualization. Ecological Economics, 63(1), 93-103. https://doi.org/10.1016/j.ecolecon.2006.09.026

Paavola, J. (2012). Climate change : the ultimate tragedy of the commons? In Property in land and other resources / Lincoln Institute of Land Policy. Ed. by Daniel $\mathrm{H}$. Cole and Elinor Ostrom (pp. 417-433). Retrieved from https://www.lincolninst.edu/sites/default/files/pubfiles/climate-change_0.pdf

Paavola, J. (2017). Health impacts of climate change and health and social inequalities in the UK. Environmental Health: A Global Access Science Source. https://doi.org/10.1186/s12940-017-0328-z

Palinkas, L. A., Horwitz, S. M., Green, C. A., Wisdom, J. P., Duan, N., \& Hoagwood, K. (2015). Purposeful Sampling for Qualitative Data Collection and Analysis in Mixed Method Implementation Research. Administration and Policy in Mental Health and Mental Health Services Research, 42(5), 533-544. https://doi.org/10.1007/s10488-013-0528-y

Palutikof, J. P., Street, R. B., \& Gardiner, E. P. (2019). Decision support platforms for climate change adaptation: an overview and introduction. Climatic Change. https://doi.org/10.1007/s10584-019-02445-2

Palys, T., \& Atchison, C. (2014). Research Decisions: Quantitative and qualitative perspective. Nelson Education. https://doi.org/10.1177/1524838015588502 
Palys, T. S. (1997). Research decisions : quantitative and qualitative perspectives / Ted Palys (Second Edi). Toronto: Harcourt Brace \& Company Canada, c1997.

Panic, M., \& Ford, J. D. (2013). A review of national-level adaptation planning with regards to the risks posed by climate change on infectious diseases in 14 OECD nations. International Journal of Environmental Research and Public Health, 10(12), 7083-7109. https://doi.org/10.3390/ijerph10127083

Parrish, R. G. (2010). Measuring Population Health Outcomes. Preventing Chronic Diseases, 7(4), A71. Retrieved from http://www.cdc.gov/pcd/issues/2010/jul/10_0005.htm.Accessed[date].

Parry, M. L., Rosenzweig, C., Iglesias, A., Livermore, M., \& Fischer, G. (2004). Effects of climate change on global food production under SRES emissions and socio-economic scenarios. Global Environmental Change, 14, 53-67. https://doi.org/10.1016/j.gloenvcha.2003.10.008

Parsons, W. (1995). Public policy: an introduction to the theory and practice of policy analysis. Edward Elgar Publishing company.

Paterson, J. A., Ford, J. D., Ford, L. B., Lesnikowski, A., Berry, P., Henderson, J., \& Heymann, J. (2012). Adaptation to climate change in the Ontario public health sector. BMC Public Health, 12(1), 452. https://doi.org/10.1186/1471-2458-12-452

Patz, J. A., Campbell-Lendrum, D., Foley, J. A., \& Holloway, T. (2005). Impact of regional climate change on human health. Nature, 438(7066), 310-317. https://doi.org/10.1038/nature04188

Patz, J. A., Grabow, M. L., \& Limaye, V. S. (2014). When it rains, it pours: Future climate extremes and health. Annals of Global Health. https://doi.org/10.1016/j.aogh.2014.09.007

Pearce, D., Atkinson, G., \& Mourato, S. (2006). Cost-Benefit Analysis And The Environment. Recent Developments. Paris France. Retrieved from http://www.sourceoecd.org/environment/9264010041http://www.sourceoecd.org/92640100 41

Pearce, J., Witten, K., Hiscock, R., \& Blakely, T. (2007). Are socially disadvantaged neighbourhoods deprived of health-related community resources? International Journal of Epidemiology, 36(2), 348-355. https://doi.org/10.1093/ije/dyl267

Peeters, W., De Smet, A., Diependaele, L., \& Sterckx, S. (2015). The Phenomenology of Agency in Climate Change. In W. Peeters, A. De Smet, L. Diependaele, \& S. Sterckx (Eds.), Climate Change and Individual Responsibility: Agency, Moral Disengagement and the Motivational Gap (pp. 47-93). London: Palgrave Macmillan. https://doi.org/10.1057/9781137464507.0008

Peirson, L., Ciliska, D., Dobbins, M., \& Mowat, D. (2012). Building capacity for evidence informed decision making in public health: A case study of organizational change. BMC Public Health, 12(1), 137. https://doi.org/10.1186/1471-2458-12-137

Petersen, L. R., Nasci, R. S., Beard, C. B., \& Massung, R. F. (2016). Emerging Vector-Borne Diseases in the United States: What is next, and are we prepared? Global Health Impacts of Vector-Borne Diseases. https://doi.org/10.17226/21792

Petrovic, N., Madrigano, J., \& Zaval, L. (2014). Motivating mitigation: when health matters more than climate change. Climatic Change, 1-10. https://doi.org/10.1007/s10584-014-1192-2

Pettenger, M. E. (2007a). Introduction: Power, Knowledge and the Social Construction of Climate Change. In The Social Construction of Climate Change: Power, Knowledge, Norms, Discourses (pp. 1-22). Retrieved from http://books.google.com/books?id=8c7Bcat_b9oC\&pgis=1

Pettenger, M. E. (2007b). The Social Construction of Climate Change Power, Knowledge, Norms, Discourses. International Journal of Sustainability in Higher Education, 9(1), 9-25. https://doi.org/10.1108/ijshe.2008.24909aae.001 
Phillips, N., \& Hardy, C. (2002). What Is Discourse Analysis? In Discourse Analysis. Thousand Oaks: SAGE Publications, Inc. https://doi.org/10.4135/9781412983921

Pierce, J. J., Siddiki, S., Jones, M. D., Schumacher, K., Pattison, A., \& Peterson, H. (2014). Social construction and policy design: A review of past applications. Policy Studies Journal, 42(1), 1-29. https://doi.org/10.1111/psj.12040

Pilotto, L. S., Douglas, R. M., Burch, M. D., Cameron, S., Beers, M., Rouch, G. J., ... Attewell, R. G. (1997). Health effects of exposure to cyanobacteria (blue-green algae) during recreational water-related activities. Australian and New Zealand Journal of Public Health, 21(6), 562-566. https://doi.org/10.1111/j.1467-842X.1997.tb01755.x

Pojman, L. P. (2003). The theory of knowledge : classical and contemporary readings. Wadsworth/Thomson Learning.

Polese, M. (2018). Regional Economics in Canada. Retrieved September 4, 2019, from https://www.thecanadianencyclopedia.ca/en/article/regional-economics

Popke, J., Curtis, S., \& Gamble, D. W. (2016). A social justice framing of climate change discourse and policy: Adaptation, resilience and vulnerability in a Jamaican agricultural landscape. Geoforum, 73, 70-80. https://doi.org/10.1016/j.geoforum.2014.11.003

Portier CJ, Thigpen Tart K, Carter SR, Dilworth CH, Grambsch AE, Gohlke J, Hess J, Howard SN, Luber G, Lutz JT, Maslak T, Prudent N, Radtke M, Rosenthal JP, Rowles T, Sandifer PA, Scheraga J, Schramm PJ, Strickman D, Trtanj JM, W. P.-Y. (2010a). A Human Health Perspective On Climate Change. Environmental Health, 5, 80. https://doi.org/10.1017/CBO9780511803826

Portier CJ, Thigpen Tart K, Carter SR, Dilworth CH, Grambsch AE, Gohlke J, Hess J, Howard SN, Luber G, Lutz JT, Maslak T, Prudent N, Radtke M, Rosenthal JP, Rowles T, Sandifer PA, Scheraga J, Schramm PJ, Strickman D, Trtanj JM, W. P.-Y. (2010b). On Climate Change On Climate Change A Report Outlining the Research Needs on the Human Health Effects of Climate Change. The Interagency Working Group on Climate Change. https://doi.org/10.1289/ehp.1002272

Pralle, S., \& Boscarino, J. (2011). Framing Trade-offs: The Politics of Nuclear Power and Wind Energy in the Age of Global Climate Changer opr_500 323..346. Retrieved from https://journals-scholarsportalinfo.ezproxy.lib.ryerson.ca/pdf/1541132x/v28i0004/323_fttpontaogcc.xml

Pritchard, D. (2016). What is this thing called Knowledge? Memory and Cognition (Third Edit, Vol. 28). Routledge.

Public Health Agency of Canada. (2008). Core competencies for public health in Canada. https://doi.org/10.1136/jech.2003.019141

Public Health Agency of Canada. (2011). Canadian Reference Group on social determinants of health. World Health Organization.

Public Health Agency of Canada. (2012). Ottawa Charter for Health Promotion: An International Conference on Health Promotion. Retrieved January 15, 2018, from https://www.canada.ca/en/public-health/services/health-promotion/populationhealth/ottawa-charter-health-promotion-international-conference-on-health-promotion.html

Public Health Agency of Canada. (2013). Pilot Infectious Disease Impact and Response Systems - Public Health Agency of Canada. Retrieved from http://www.phacaspc.gc.ca/chn-rcs/e-pidirs-eng.php

Public Health Agency of Canada. (2015a). Canadian Best Practice Portal: Partnerships, Collaboration and Advocacy. Retrieved August 6, 2019, from https://cbpp-pcpe.phacaspc.gc.ca/resources/public-health-competencies-information-tools/partnershipscollaboration-advocacy/

Public Health Agency of Canada. (2015b). Climate Change and Public Health Factsheets Canada.ca. Retrieved November 26, 2017, from https://www.canada.ca/en/public- 
health/services/health-promotion/environmental-public-health-climate-change/climatechange-public-health-factsheets.html

Public Health Agency of Canada. (2016a). Key Element 6: Collaborate Across Sectors and Levels | Canadian Best Practices Portal - CBPP. Retrieved February 12, 2019, from http://cbpp-pcpe.phac-aspc.gc.ca/population-health-approach-organizing-framework/keyelement-6-collaborate-sectors-levels/

Public Health Agency of Canada. (2016b). Surveillance of West Nile virus. Retrieved September 10, 2017, from https://www.canada.ca/en/public-health/services/diseases/west-nilevirus/surveillance-west-nile-virus.html\#s1

Public Health Agency of Canada, \& Public Health Agency of Canada. (2008). Core competencies for public health in Canada, 1-25. https://doi.org/10.1136/jech.2003.019141

Public Health Institute. (2017a). Central Coast Youth Highlight Connections Among Climate Change, Food Systems and Health - Center for Climate Change and Health. Retrieved April 28, 2018, from http://climatehealthconnect.org/stories/central-coast-youth-highlightconnections-among-climate-change-food-systems-and-health/

Public Health Institute. (2017b). Climate Change is a Social Justice Issue in Inglewood, California - Center for Climate Change and Health. Retrieved April 28, 2018, from http://climatehealthconnect.org/stories/climate-change-is-a-social-justice-issue-ininglewood-california/

Public Health Institute. (2017c). Fighting for Environmental Justice in the Diesel Death Zone Center for Climate Change and Health. Retrieved April 28, 2018, from http://climatehealthconnect.org/stories/fighting-for-environmental-justice-in-the-dieseldeath-zone/

Public Health Institute. (2017d). Health Department Brings Health and Equity Lens to Contra Costa County Climate Action Plan - Center for Climate Change and Health. Retrieved April 28, 2018, from http://climatehealthconnect.org/stories/health-department-brings-healthand-equity-lens-to-contra-costa-county-climate-action-plan/

Public Health Institute. (2017e). Solar School Buses a "Disruptive Innovation" to Reduce Emissions, Protect Lungs - Center for Climate Change and Health. Retrieved April 28, 2018, from http://climatehealthconnect.org/stories/solar-school-buses-a-disruptiveinnovation-to-reduce-emissions-protect-lungs/

Public Health Institute. (2017f). Stories from the Field - Center for Climate Change and Health. Retrieved April 28, 2018, from http://climatehealthconnect.org/solutions/stories-from-thefield/

Public Health Institute. (2017g). Valley Improvement Projects, "Working with the community to improve the community" - Center for Climate Change and Health. Retrieved April 28, 2018, from http://climatehealthconnect.org/stories/valley-improvement-projects-working-with-thecommunity-to-improve-the-community/

Public Health Institute. (2017h). Working with Community Clinics to Link Climate and Health in San Diego - Center for Climate Change and Health. Retrieved April 28, 2018, from http://climatehealthconnect.org/stories/working-with-community-clinics-to-link-climate-andhealth-in-san-diego/

Public Health Ontario. (2008). Ministry of Health and Long-Term Care Population and Public Health Divison, Ministry of Health and Long-Term Care. Retrieved from http://www.health.gov.on.ca/en/pro/programs/publichealth/oph_standards/docs/ophs_2008. pdf

Public Health Ontario. (2014a). Eastern Equine Encephalitis Virus History and Enhanced Surveillance in Ontario. Retrieved from http://www.publichealthontario.ca/en/eRepository/Eastern_Equine_Encephalitis_Virus_Rep ort_2014.pdf 
Public Health Ontario. (2014b). Extreme Weather: The Fallout after the storm. Retrieved from http://www.publichealthontario.ca/en/eRepository/OHP_infog_ExtremeWeather_2014.pdf

Public Health Ontario. (2014c). Vector-Borne Diseases $201 \overline{3}$ summary report. Retrieved from https://www.publichealthontario.ca/en/eRepository/Vector_Borne_Diseases_Summary_Re port_2013.pdf

Public Health Ontario. (2015a). Vector-borne diseases: 2014 Summary Report. Retrieved from https://www.publichealthontario.ca/en/eRepository/Vector_Borne_Diseases_Summary_Re port_2014.pdf

Public Health Ontario. (2015b). Vector-Borne Diseases 2014 Summary Report. Retrieved from https://www.publichealthontario.ca/en/eRepository/Vector_Borne_Diseases_Summary_Re port_2014.pdf

Public Health Ontario. (2016a). Vector-borne Diseases: 2015 Summary Report. Retrieved from https://www.publichealthontario.ca/en/eRepository/Vector_borne_diseases_Summary_repo rt_2015.pdf

Public Health Ontario. (2016b). Vector-borne diseases - 2015 Summary report. Retrieved from https://www.publichealthontario.ca/en/eRepository/Vector_borne_diseases_Summary_repo rt_2015.pdf

Puig, D., \& Aparcana Robles, S. R. (2016). Decision-support tools for climate change mitigation planning. UNEP DTU Partnership Publication (Vol. 1). Retrieved from https://pdfs.semanticscholar.org/fb09/d8474b7537265d608c2da2890014334bd3de.pdf?_g $\mathrm{a}=2.268810356 .425067870 .1565234040-1957345185.1560192256$

Rabe, P., \& Kamanzi, A. (2012). Power analysis : A study of participation at the local level in Tanzania. ASC Working Paper 105. Retrieved from www.ascleiden.nl

Rademaekers, J. K., \& Johnson-Sheehan, R. (2014). FRAMING AND RE-FRAMING IN ENVIRONMENTAL SCIENCE: EXPLAINING CLIMATE CHANGE TO THE PUBLIC. Technical Writing and Communication, 44(3-21). https://doi.org/10.2190/TW.44.1.b

Raftery, A. E., Zimmer, A., Frierson, D. M. W., Startz, R., \& Liu, P. (2017). Less than $2{ }^{\circ} \mathrm{C}$ warming by 2100 unlikely. Nature Climate Change, 7(9), 637-641. https://doi.org/10.1038/nclimate3352

Ravel, A., Smolina, E., Sargeant, J. M., Cook, A., Marshall, B., Fleury, M. D., \& Pollari, F. (2010). Seasonality in Human Salmonellosis: Assessment of Human Activities and Chicken Contamination as Driving Factors. Foodborne Pathogens and Disease, 7(7), 785-794. https://doi.org/10.1089/fpd.2009.0460

Rawnsley, M. M. (1998). Ontology, Epistemology, and Methodology: A Clarification. Nursing Science Quarterly, 11(1), 2-4. https://doi.org/doi:10.1177/089431849801100102

Region of Waterloo. (2019). Organization of Public Health In Ontario. Retrieved from www.regionofwaterloo.ca/ph

Reisen, W. K. (2013). Ecology of West Nile virus in North America. Viruses, 5(9), 2079-2105. https://doi.org/10.3390/v5092079

Rhodes, R. A. . (2006). Rhodes, R. A. W. (2006). Policy network analysis. In M. Moran, M. Rein \& R. E. Goodin (Eds.), (pp. 425-447). In The Oxford handbook of public policy (pp. 425447). Oxford University Press.

Rickards, L. (2013). Climate change adaptation and scenario planning: framing issues and tools. Proceedings of the Royal Society of Victoria, 125(1/2), 34-44.

Rickards, L., Wiseman, J., \& Kashima, Y. (2014). Barriers to effective climate change mitigation: The case of senior government and business decision makers. Wiley Interdisciplinary Reviews: Climate Change, 5(6), 753-773. https://doi.org/10.1002/wcc.305

Rijsberman, F. R., \& Swart, R. (1990). Targets and Indicators of Climatic Change. The Stockholm Environment Institute. Stockholm : Stockholm Environment Institute. Retrieved from https://searchworks.stanford.edu/view/9450740 
Robinson, O. C. (2014). Sampling in Interview-Based Qualitative Research: A Theoretical and Practical Guide. Qualitative Research in Psychology, 11(1), 25-41.

https://doi.org/10.1080/14780887.2013.801543

Rocco, S. T., \& Plakhotnik, S. M. (2009). Literature reviews, conceptual frameworks, and theoretical frameworks: Terms, functions, and distinctions. Human Resource Development Review. https://doi.org/10.1177/1534484309332617

Roe, E. M. (1994). Narrative Policy Analysis: Theory and Practice. Durham, London: Duke University Press.

Romsdahl, R., Blue, G., \& Kirilenko, A. (2018). Action on climate change requires deliberative framing at local governance level. Climatic Change, 1-11. https://doi.org/10.1007/s10584018-2240-0

Roper, J., Ganesh, S., \& Zorn, T. E. (2016). Doubt, Delay, and Discourse: Skeptics' Strategies to Politicize Climate Change. Science Communication, 38(6), 776-799. https://doi.org/10.1177/1075547016677043

Rosella, L. C., Wilson, K., Crowcroft, N. S., Chu, A., Upshur, R., Willison, D., ... Goel, V. (2013). Pandemic H1N1 in Canada and the use of evidence in developing public health policies--a policy analysis. Social Science \& Medicine (1982), 83, 1-9. https://doi.org/10.1016/j.socscimed.2013.02.009

Roux, D. A. V, \& Mair, C. (2010). Neighborhoods and Health. ANNALS OF THE NEW YORK ACADEMY OF SCIENCES, 1186(1), 125-145. https://doi.org/10.1093/acprof:oso/9780195138382.001.0001

Rowe, G., \& Frewer, L. J. (2005a). A typology of public engagement mechanisms. Science Technology and Human Values, 30(2), 251-290. https://doi.org/10.1177/0162243904271724

Rowe, G., \& Frewer, L. J. (2005b). A typology of public engagement mechanisms. Science Technology and Human Values, 30(2), 251-290. https://doi.org/10.1177/0162243904271724

Rowley, J. (2002). Using case studies in research. Management Research News, 25(1), 16-27. https://doi.org/10.1108/01409170210782990

Rowley, J. (2009). Using case studies in research. Management Research News, 25(1), 16-27. https://doi.org/10.1108/01409170210782990

Rowson, J. (2013). a New Agenda on Climate Change. Action and Research Centre (RSA), (December). Retrieved from https://www.thersa.org/discover/publications-andarticles/reports/a-new-agenda-on-climate-change

Rudolph, L., Gould, S., \& Berko, J. (2015). Climate Change, Healh and Equity: Opportunities for Action. Public Health Institute, (March). Retrieved from https://www.phi.org/uploads/application/files/h7fjouo1i38v3tu427p9s9kcmhs3oxsi7tsg1 fovh 3yesd5hxu.pdf

Ruff, N. J. (2015). Provincial Government. Retrieved September 6, 2019, from https://www.thecanadianencyclopedia.ca/en/article/provincial-government

Saint-Martin, D. (2005). The politics of management consulting in public sector reform. In P. Christopher \& L. Lawerence (Eds.), Handbook of public management (pp. 84-106). Oxford University Press.

Salkind, N. . (2010). Discourse Analysis. In Encyclopedia of Research Design. 2455 Teller Road, Thousand Oaks California 91320 United States: SAGE Publications, Inc. https://doi.org/10.4135/9781412961288.n115

Salkind, N. . (2015). Exploring Research (9th Editio). Upper Saddle River, New Jersey: Pearson Prentice Hall.

Sarewitz, D. (2004). How science makes environmental controversies worse. Environmental Science and Policy, 7(5), 385-403. https://doi.org/10.1016/j.envsci.2004.06.001 
Sathaye, J., Lucon, O., Rahman, A., Christensen, J. M., Denton, F., Fujino, J., ... Shmakin, A. (2011). Renewable energy in the context of sustainable development. In E. Edenhofer O \& Al (Eds.), IPCC Special Report on Renewable Energy Sources and Climate Change Mitigation (Vol. Chapter 9). Cambridge University Press. Retrieved from http://www.mccberlin.net/ creutzig/SRREN_Ch09.pdf

Sawin, E., McCauley, S., Edberg, S., Mwaura, G., \& Gutierrez, M. J. (2018). Multisolving at the intersection of health and climate: lessons from success stories. Retrieved from https://img.climateinteractive.org/wp-content/uploads/2018/02/Multisolving-at-theIntersection-of-Health-and-Climate-1.pdf

Schäfer, M. S., \& O'Neill, S. (2017). Frame Analysis in Climate Change Communication. Oxford Research Encyclopedia of Climate Science (Vol. 1). https://doi.org/10.1093/acrefore/9780190228620.013.487

Scheirer, M. A., \& Dearing, J. W. (2011). An agenda for research on the sustainability of Public Health Programs. American Journal of Public Health, 101(11), 2059-2067. https://doi.org/10.2105/AJPH.2011.300193

Schell, S. F., Luke, D. A., Schooley, M. W., Elliott, M. B., Herbers, S. H., Mueller, N. B., \& Bunger, A. C. (2013). Public health program capacity for sustainability: a new framework. Implementation Science, 8(1), 15. https://doi.org/10.1186/1748-5908-8-15

Schenck, P., Ahmed, M. A. K., Bracker, A., Debernardo, R., \& Cih, M. (2010). CLIMATE CHANGE, INDOOR AIR QUALITY A N D HEALTH Climate Change, Indoor Air Quality and Health. U.S. Environmental Protection Agency. Retrieved from https://www.epa.gov/sites/production/files/2014-08/documents/uconn_climate_health.pdf

Schlosser, K. (2018). Geohumanities and climate change skepticism. Geography Compass, 12(10). https://doi.org/10.1111/gec3.12402

Schmidt, V. A. (2008). Discursive Institutionalism: The Explanatory Power of Ideas and Discourse. Annual Review of Political Science, 11(1), 303-326. https://doi.org/10.1146/annurev.polisci.11.060606.135342

Schöttle, A., Haghsheno, S., \& Gehbauer, F. (2014). DEFINING COOPERATION AND COLLABORATION IN THE CONTEXT OF LEAN CONSTRUCTION. Proceedings IGLC22, 1269-1280. https://doi.org/10.1136/bmj.1.14.375

Schrefler, L. (2014). Reflections on the Different Roles of Expertise in Regulatory Policy Making. In M. Ambrus, K. Arts, E. Hey, \& H. Raulus (Eds.), The Role of 'Experts" in International and European Decision-Making Processes: Advisors, Decison Makers or Irrelevant Actors' (pp. 63-81). United Kingdom: Cambridge University Press.

Scotland, J. (2012). Exploring the philosophical underpinnings of research: Relating ontology and epistemology to the methodology and methods of the scientific, interpretive, and critical research paradigms. English Language Teaching, 5(9), 9-16. https://doi.org/10.5539/elt.v5n9p9

Semenza, J. C. (2011). Lateral Public Health: A Comprehensive Approach to Adaptation in Urban Environments. Climate Change Adaptation in Developed Nations (Vol. 42). Springer, Dordrecht. https://doi.org/10.1007/978-94-007-0567-8

Shamseer, L., Moher, D., Clarke, M., Ghersi, D., Liberati, A., Petticrew, M., ... Stewart, L. A. (2015). PRISMA-P ( Preferred Reporting Items for Systematic review and Meta-Analysis Protocols ) 2015 checklist : recommended items to address in a systematic review protocol *. Bmj, 349(jan02 1), g7647-g7647. https://doi.org/10.1136/bmj.g7647

Shaw, C. (2017). The Two Degrees Celsius Target. Oxford Research Encyclopedia of Climate Science. https://doi.org/10.1093/acrefore/9780190228620.013.15

Shearer, J. C., Abelson, J., Kouyaté, B., Lavis, J. N., \& Walt, G. (2016). Why do policies change? Institutions, interests, ideas and networks in three cases of policy reform. Health Policy and Planning, 31(9), 1200-1211. https://doi.org/10.1093/heapol/czw052 
Sheikh, A., Halani, L., Bhopal, R., Netuveli, G., Partridge, M. R., Car, J., ... Levy, M. (2009).

Facilitating the recruitment of minority ethnic people into research: qualitative case study of South Asians and asthma. PLoS Med, 6(10), e1000148. https://doi.org/10.1371/journal.pmed.1000148

Singh, S. P., \& Swanson, M. (2017). How issue frames shape beliefs about the importance of climate change policy across ideological and partisan groups. PLoS ONE, 12(7). https://doi.org/10.1371/journal.pone.0181401

Slovic, P. (2010). The feeling of risk: new perspectives on risk perception. London ; Washington, DC : Earthscan, 2010. Retrieved from https://books.google.ca/books?id=HsgsIFdevlcC\&pg=PA26\&lpg=PA26\&dq=sandman+heur istic\&source=bl\&ots=32BAkcWMe9\&sig=sK9gFEEbq4O9-

qsGSfZq5fwNmcA\&hl=en\&sa=X\&ved=0ahUKEwi7jva6NXYAhUS0IMKHXJID5EQ6AEILDAB\#v=onepage\&q=sandman heuristic\&f=false

Smoyer, K. E., Rainham, D. G. C., \& Hewko, J. N. (2000). Heat-stress-related mortality in five cities in Southern Ontario: 1980-1996. International Journal of Biometeorology, 44(4), 190197. https://doi.org/10.1007/s004840000070

Sovacool, B. K. (2011). Hard and soft paths for climate change adaptation. Climate Policy, 11(4), 1177-1183. https://doi.org/10.1080/14693062.2011.579315

Spence, A., \& Pidgeon, N. (2010). Framing and communicating climate change: The effects of distance and outcome frame manipulations. Global Environmental Change, 20(4), 656667. https://doi.org/10.1016/j.gloenvcha.2010.07.002

Spencer, R., Pryce, J. M., \& Walsh, J. (2015). Philosophical Approaches to Qualitative Research. In P. Leavy (Ed.), The Oxford Handbook of Qualitative Research (pp. 81-98). New York, US: Oxford University Press.

Ståhl, T., Wismar, M., Ollila, E., Lahtinen, E., \& Leppo, K. (2006). Health in All Policies. Medizinische Universität Graz. Retrieved from http://ec.europa.eu/health/ph_projects/2005/action1/docs/2005_1_18_frep_a3_en.pdf

Statistics Canada. (2016). Census Profile, 2016 Census: Ontario [Provincē] and Canada [Country]. Retrieved from https://www12.statcan.gc.ca/census-recensement/2016/dp$\mathrm{pd} / \mathrm{prof} /$ details/Page.cfm?Lang=E\&Geo1=PR\&Code1=35\&Geo2=\&Code2=\&Data=Count\& SearchText=Ontario\&SearchType $=$ Begins $\&$ SearchPR=01\&B1=All\&GeoLevel $=P R \& G e o C o$ de $=35$

Statistics Canada. (2018). Cropland in Ontario grows despite fewer farms. Retrieved September 4, 2019, from https://www150.statcan.gc.ca/n1/pub/95-640-x/2016001/article/14805eng.htm

Stecula, D. A., \& Merkley, E. (2019). Framing Climate Change: Economics, Ideology, and Uncertainty in American News Media Content From 1988 to 2014. Frontiers in Communication, 4(February), 1-15. https://doi.org/10.3389/fcomm.2019.00006

Stern, N. H. (2007). he Economics of Climate Change: The Stern Review. Cambridge, UK: Cambridge University Press.

Stilwell, F. (2012). Economy and the Environment. In Political Economy: The Contest of Economic Ideas (3rd Editio, pp. 325-337). South melbourne, Victoria: Oxford University Press.

Stocker, T. F., Dahe, Q., Plattner, G.-K., Alexander, L. V., Allen, S. K., Bindoff, N. L., ... Xie, S.P. (2013). Technical Summary. Climate Change 2013: The Physical Science Basis. Contribution of Working Group I to the Fifth Assessment Report of the Intergovernmental Panel on Climate Change, 33-115. https://doi.org/10.1017/ CBO9781107415324.005

Stoddart, M. C. J., Haluza-DeLay, R., \& Tindall, D. B. (2016). Canadian News Media Coverage of Climate Change: Historical Trajectories, Dominant Frames, and International Comparisons. Society and Natural Resources, 29(2), 218-232. 
https://doi.org/10.1080/08941920.2015.1054569

Sutherst, R. W. (2004). Global Change and Human Vulnerability to Vector-Borne Diseases Global Change and Human Vulnerability to Vector-Borne Diseases. Clinical Microbiology Reviews, 17(1), 136-173. https://doi.org/10.1128/CMR.17.1.136

Swedish International Development Cooperation Agency. (2013). Support to Civil Society Engagement in Policy Dialogue. Retrieved from www.danida-publikationer.dk.

Taylor, C. (2013). The Discourses of Climate Change. In T. Cadman (Ed.), Climate Change and Global Policy Regimes (pp. 17-31). London: Palgrave Macmillan UK.

Teelucksingh, C. (2019). Diverse environmentalism and inclusivity in Toronto's Green Economy. Environmental Sociology, 5(1), 47-58. https://doi.org/10.1080/23251042.2018.1507246

Teelucksingh, C., \& Poland, B. (2011). Energy solutions, neo-liberalism, and social diversity in Toronto, Canada. International Journal of Environmental Research and Public Health, 8(1), 185-202. https://doi.org/10.3390/ijerph8010185

Thanh, N. C., Thi, T., \& Thanh, L. (2015). The Interconnection Between Interpretivist Paradigm and Qualitative Methods in Education. American Journal of Educational Science, 1(2), 2427. Retrieved from http://www.aiscience.org/journal/ajes

The Expert Panel on Climate Change Adaptation. (2009). Adapting to Climate Change in Ontario: Towards the Design and Implementation of a Strategy and Action Plan. Retrieved from http://www.climateontario.ca/doc/publications/ExpertPanel-AdaptingInOntario.pdf

Thomas, G. (2011). A Typology for the Case Study in Social Science Following a Review of Definition, Discourse, and Structure. Qualitative Inquiry, 17(6), 511-521. https://doi.org/10.1177/1077800411409884

Thomas, K. M., Charron, D. F., Waltner-Toews, D., Schuster, C., Maarouf, A. R., \& Holt, J. D. (2006). A role of high impact weather events in waterborne disease outbreaks in Canada, 1975 - 2001. International Journal of Environmental Health Research, 16(3), 167-180. https://doi.org/10.1080/09603120600641326

Thompson, L. G. (2010). Climate change: The evidence and our options. Behavior Analyst, 33(2), 153-170. https://doi.org/10.1007/BF03392211

Thorsten, M., \& Pincus, R. (2017). Committed warming inferred from observations. Nature Climate Change, 7(9), 652-655.

Tonelli, M., Tang, K. C., \& Forest, P. G. (2020). Canada needs a "Health in All Policies" action plan now. Canadian Medical Association Journal, 192(3), E61-E67. https://doi.org/10.1503/cmaj.190517

Toronto Public Health. (2015). A Climate of Concern: Climate Change and Health Strategy for Toronto. Retrieved from https://www.toronto.ca/legdocs/mmis/2015/hl/bgrd/backgroundfile81509.pdf

Trochim, W. M. K. (2006). Social Research Methods - Knowledge Base. Retrieved January 22, 2018, from http://www.socialresearchmethods.net/kb/contents.php

UNFCCC. (2016). The Paris Agreement - main page. Retrieved January 18, 2018, from http://unfccc.int/paris_agreement/items/9485.php

UNFCCC. (2017). Essential Background. Retrieved January 18, 2018, from http://unfccc.int/essential_background/items/6031.php

US EPA, O. (n.d.). Climate Change Indicators: Atmospheric Concentrations of Greenhouse Gases. Retrieved from https://www.epa.gov/climate-indicators/climate-change-indicatorsatmospheric-concentrations-greenhouse-gases\#ref2

Vaismoradi, M., Turunen, H., \& Bondas, T. (2013). Content analysis and thematic analysis: Implications for conducting a qualitative descriptive study. Nursing and Health Sciences. https://doi.org/10.1111/nhs.12048

Valles, S. A. (2015). Bioethics and the Framing of Climate Change's Health Risks. Bioethics, 29(5), 334-341. https://doi.org/10.1111/bioe.12110 
van Bommel, S., van Hulst, M., \& Yanow, D. (2015). Intepretive policy analysis in the Netherlands. In F. van Nispen \& P. Scholten (Eds.), Policy Analysis In the Netherlands. Great Britain.

Van Eeten, M. J. G. (2007). Narrative Policy Analysis. In F Fischer, G. Miller, \& M. Sidney (Eds.), Public Policy Handbook of Analysis: Theory, politics and Methods. CRC Press.

van Woezik, A. F., Braakman-Jansen, L. M., Kulyk, O., Siemons, L., \& van Gemert-Pijnen, J. E. (2016). Tackling wicked problems in infection prevention and control: a guideline for cocreation with stakeholders. Antimicrobial Resistance and Infection Control, 5, 20-016-01192. eCollection 2016. https://doi.org/10.1186/s13756-016-0119-2 [doi]

Vermeer, M., \& Rahmstorf, S. (2009). Global sea level linked to global temperature. PNAS, 106(51). https://doi.org/10.1007/978-3-319-65558-1_20

Verner, J. M., \& Abdullah, L. M. (2012). Exploratory case study research: Outsourced project failure. Information and Software Technology, 54(8), 866-886. https://doi.org/10.1016/j.infsof.2011.11.001

Vincent, L. A., Wang, X. L., Milewska, E. J., Wan, H., Yang, F., \& Swail, V. (2012). A second generation of homogenized Canadian monthly surface air temperature for climate trend analysis. Journal of Geophysical Research Atmospheres, 117(17), 1-13. https://doi.org/10.1029/2012JD017859

Vlachou, A., \& Pantelias, G. (2019). CLIMATE UNDER NEOLIBERALISM: THE EU EMISSIONS TRADING SYSTEM IN CRISIS-RIDDEN GREECE Climate under Neoliberalism: The EU Emissions Trading System in crisis-ridden Greece Climate under Neoliberalism: The EU Emissions Trading System in crisis-ridden Greece.

Wagner, G., \& Zeckhauser, R. J. (2012). Climate policy: Hard problem, soft thinking. Climatic Change, 110(3-4), 507-521. https://doi.org/10.1007/s10584-011-0067-z

Wallner, J. (2008). Legitimacy and Public Policy: Seeing Beyond Effctiveness, Efficiancy and Performance. Policy Studies Journal, 36(3), 421-443. https://doi.org/10.1111/j.15410072.2008.00275.x

Walpole, S. C., Rasanathan, K., \& Campbell-Lendrum, D. (2009, October 1). Natural and unnatural synergies: Climate change policy and health equity. Bulletin of the World Health Organization. https://doi.org/10.2471/BLT.09.067116

Walter, M. (2013). Social Research Methods. (M. Walter, Ed.) (Third). Oxford University Press.

Wang, H., \& Horton, R. (2015, November). Tackling climate change: The greatest opportunity for global health. The Lancet. https://doi.org/10.1016/S0140-6736(15)60931-X

Wardekker, J. A., De Jong, A., Van Bree, L., Turkenburg, W. C., \& Van Der Sluijs, J. P. (2012). Health risks of climate change: An assessment of uncertainties and its implications for adaptation policies. Environmental Health: A Global Access Science Source, 11(1), 1. https://doi.org/10.1186/1476-069X-11-67

Warren, F. J., \& Lemmen, d. . (2014). Canada in a Changing Climate: Sector Perspectives on Impacts and Adaptation.

Watts, N., Adger, N., Ayeb-Karlsson, S., Bai, Y., Byass, P., Campbell-Lendrum, D., ... Costello, A. The Lancet Countdown: tracking progress on health and climate change, 389 The Lancet $\S(2017)$. https://doi.org/10.1016/S0140-6736(16)32124-9

Watts, N., Adger, N., Ayeb-Karlsson, S., Bai, Y., Byass, P., Campbell-Lendrum, D., ... Costello, A. (2017). The Lancet Countdown: tracking progress on health and climate change. Www. Thelancet.Com, 389. https://doi.org/10.1016/S0140-6736(16)32124-9

Watts, N., Adger, W. N., Agnolucci, P., Blackstock, J., Byass, P., Cai, W., ... Costello, A. (2015). Health and climate change: Policy responses to protect public health. The Lancet, 386(10006), 1861-1914. https://doi.org/10.1016/S0140-6736(15)60854-6

Watts, N., Amann, M., Arnell, N., Ayeb-Karlsson, S., Belesova, K., Berry, H., ... Costello, A. (2018). The 2018 report of the Lancet Countdown on health and climate change: shaping 
the health of nations for centuries to come. Www. Thelancet.Com, 392.

https://doi.org/10.1016/S0140-6736(18)32594-7

Watts, N., Amann, M., Ayeb-Karlsson, S., Belesova, K., Bouley, T., Boykoff, M., ... Costello, A. (2017). The Lancet Countdown on health and climate change: From 25 years of inaction to a global transformation for public health. The Lancet, pp. 581-630.

https://doi.org/10.1016/S0140-6736(17)32464-9

Watts, N., Amann, M., Ayeb-Karlsson, S., Belesova, K., Bouley, T., Boykoff, M., ... Costello, A. (2018). The Lancet Countdown on health and climate change: from 25 years of inaction to a global transformation for public health. The Lancet. https://doi.org/10.1016/S01406736(17)32464-9

Webster, M. (2003). Communicating Climate Change Uncertainty to Policy-Makers and the Public. Climatic Change, 61(1/2), 1-8. https://doi.org/10.1023/A:1026351131038

Webster, N., \& Engber-Pedersen, L. (2002). Introduction to Political Space. In N. Webster \& L. Engber-Pedersen (Eds.), In the Name of the Poor: Contesting Political Space for Poverty Reduction. Zed Books. Retrieved from https://books.google.ca/books/about/In_the_Name_of_the_Poor.html?id=DPw_t3PEwZsC \&printsec $=$ frontcover\&source $=k p$ read button\&redir_esc $=y \# v=0$ onepage \& $q \& f=f$ alse

Weedon, C. (1997). Feminist practice \& poststructuralist theory (Second Edi). Blackwell Publishing Ltd.

Wellstead, A., \& Stedman, R. (2015). Mainstreaming and Beyond: Policy Capacity and Climate Change Decision-Making. Michigan Journal of Sustainability, 3(20181221). https://doi.org/10.3998/mjs.12333712.0003.003

Whaley, L., \& Weatherhead, E. K. (2015). Power-sharing in the english lowlands? The political economy of farmer participation and cooperation in water governance. Water Alternatives, $8(1), 820-843$.

Whetten, D. A. (2016). What Constitutes a Theoretical Contribution ? Published by : Academy of Management Linked references are available on JSTOR for this article: What Constitutes a Theoretical Contribution?, 14(4), 490-495.

WHO, \& WMO. (2012). Atlas of health and climate change. Health and Environment Series.

Wiest, S. L., Raymond, L., Clawson, R. A., van der Linden, S., Unsworth, K. L., Fielding, K. S., ... Settanni, M. (2015). Personal experience with climate change predicts intentions to act. Journal of Environmental Psychology, 41(3), 104-115. https://doi.org/10.1016/j.jenvp.2014.12.004

Willems, S., \& Baumert, K. (2003). INSTITUTIONAL CAPACITY AND CLIMATE ACTIONS. Retrieved from http://www.oecd.org/env/cc/

Williams, J. (2000). The phenomenology of global warming: The role of proposed solutions as competitive factors in the public arenas of discourse. Human Ecology Review, 7(2), 63-72.

Wilson, K. (2004). The complexities of multi-level governance in public health. Canadian Journal of Public Health.

Windsor-Essex Country health Unit. (2016). Aedes albopictus mosquito | The Windsor-Essex County Health Unit. Retrieved October 15, 2017, from https://www.wechu.org/z-healthtopics/aedes-albopictus-mosquito

Windsor-Essex County Health Unit. (2016). Mosquito Surveillance Reveals the Aedes aegypti Species in the Area | The Windsor-Essex County Health Unit. Retrieved October 15, 2017, from https://www.wechu.org/newsroom/mosquito-surveillance-reveals-aedes-aegyptispecies-area

Winter, J. G., Desellas, A. M., Fletcher, R., Heintsch, L., Morley, A., Nakamoto, L., \& Utsumi, K. (2011). Algal blooms in Ontario, Canada: Increases in reports since 1994. Lake and Reservoir Management, 27(2), 105-112. https://doi.org/10.1080/07438141.2011.557765

WMO. (2009). A History of Climate Activities |. Retrieved January 18, 2018, from 
https://public.wmo.int/en/bulletin/history-climate-activities

Wolf, J. (2011). Climate Change Adaptation in Developed Nations. Change, 42(October), 2132. https://doi.org/10.1007/978-94-007-0567-8

Wood, R. S., Hultquist, A., \& Romsdahl, R. J. (2014). An examination of local climate change policies in the great plains. Review of Policy Research, 31(6), 529-554. https://doi.org/10.1111/ropr.12103

Workman, A., Blashki, G., Bowen, K. J., Karoly, D. J., \& Wiseman, J. (2018). The political economy of health co-benefits: Embedding health in the climate change agenda. International Journal of Environmental Research and Public Health, 15(4). https://doi.org/10.3390/ijerph15040674

Workman, A., Blashki, G., Karoly, D., \& Wiseman, J. (2016). The role of health co-benefits in the development of Australian climate change mitigation policiesx. International Journal of Environmental Research and Public Health, 13(9). https://doi.org/10.3390/ijerph13090927

World Commission on Environment. (1987). Report of the World Commission on Environment and Development: Our Common Future Towards Sustainable Development 2. Part II. Common Challenges Population and Human Resources 4. Retrieved from https://sustainabledevelopment.un.org/content/documents/5987our-common-future.pdf

World Health Organization. (1946). Constitution of the World Health Organization. Retrieved from http://apps.who.int/gb/bd/PDF/bd47/EN/constitution-en.pdf?ua=1

World Health Organization. (2011). Health In the Green Economy: Health co-benefi ts of climate change mitigation - Transport sector. https://doi.org/978 9241502917

World Health Organization. (2014a). A global brief on vector-borne diseases. World Health Organization, 9. https://doi.org/WHO/DCO/WHD/2014.1

World Health Organization. (2014b). Media centre 7 million premature deaths annually linked to air pollution. World Health Organization, 1-4. https://doi.org//entity/mediacentre/news/releases/2014/air-pollution/en/index.html

World Health Organization. (2014c). Promoting Health While Mitigating Climate Change. Technical Briefing for the World Health Organization Conference on Health and Climate Discussion Draft. Retrieved from http://www.who.int/hia/green_economy/en/

World Health Organization. (2014d). Strengthening Health Resilience to Climate Change. Andy Haines Jonathan Patz. Retrieved from http://www.who.int/phe/climate/conference_briefing_1_healthresilience_27aug.pdf

World Health Organization. (2018). Climate change and health. Retrieved October 8, 2018, from http://www.who.int/news-room/fact-sheets/detail/climate-change-and-health

World Health Organization. (2019, August 29). Public health services. Retrieved August 29, 2019, from http://www.euro.who.int/en/health-topics/Health-systems/public-health-services

World Meteriological Organization. (2018). WMO Greenhouse Gas Bulletin (GHG Bulletin) - No. 14: The State of Greenhouse Gases in the Atmosphere Based on Global Observations through 2017. Retrieved from http://www.wmo.int/gaw

Wu, X., Lu, Y., Zhou, S., Chen, L., \& Xu, B. (2016). Impact of climate change on human infectious diseases: Empirical evidence and human adaptation. Environment International, 86, 14-23. https://doi.org/10.1016/j.envint.2015.09.007

Yanow, D. (2000). Conducting Interpretive Policy Analysis. Thousand Oaks California, USA: SAGE Publications, Inc.

Yanow, D. (2007). Interpretation in policy analysis: On methods and practice. Critical Policy Studies, 1(1), 110-122. https://doi.org/10.1080/19460171.2007.9518511

Yin, R. (2010). Analytic Generalization. In J. Albert, G. Mills, G. Durepos, \& E. Wiebe (Eds.), Encyclopedia of Case Study Research (pp. 21-23). Thousand Oaks California, USA: SAGE Publications Inc.

Yin, R. K. (2014). Case Study Research: Design and methods (5th Edicti). Sage Publications. 
Young, N., \& Dugas, E. (2012). Comparing Climate Change Coverage in Canadian English- and French-Language Print Media: Environmental Values, Media Cultures, and the Narration of Global Warming. Canadian Journal of Socialogy, 37(1), 25-54.

Zainal, Z. (2007). Case study as a research method. Jurnal Kemanusiaan Bil.9, 9, 1-6. https://doi.org/10.1177/15222302004003007

Zhang, X., Brown, R., Vincent, L., Skinner, W., Feng, Y., \& Mekis, E. (2010). Canadian Climate Trends, 1950 - 2007. The Canadian Councils of Resource Ministers. Technical Thematic Report Series No. 5.

Zheng, H., Drebot, M., \& Coulthart, M. (2014). West Nile virus in Canada: ever-changing, but here to stay. Canada Communicable Disease Report: CCDR., 40(10). Retrieved from https://www.canada.ca/en/public-health/services/reports-publications/canadacommunicable-disease-report-ccdr/monthly-issue/2014-40/ccdr-volume-40-10-may-152014/ccdr-volume-40-10-may-15-2014.html

Zhouying, J. (2005). Global Technological Change: From hard technology to soft technology. Techné: Research in Philosophy and Technology. https://doi.org/10.5840/techne201115217

Zucker, L. G. (1983). Organizations as institutions. Research in the Sociology of Organizations, 2(1), 1-47. Retrieved from https://www.sabin.org/sites/sabin.org/files/restricted/Zucker_Orgs_as_Insts_83.pdf 